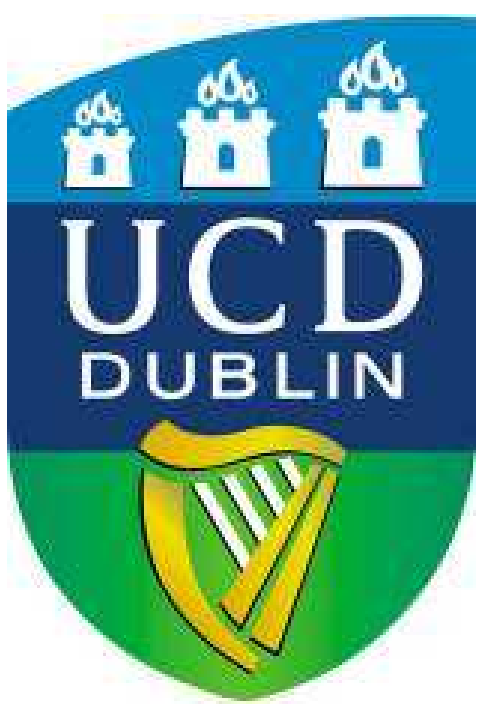

\title{
Apoplast acidification in growing barley (Hordeum vulgare L.) leaves
}

\section{Tamás Visnovitz ('Okleveles Biológus'; MSc)}

The thesis is submitted to University College Dublin in fulfilment of the requirements for the degree of Doctor of Philosophy

School of Biology and Environmental Science

Head of School: Prof. Thomas Bolger

Principal Supervisor: Dr Wieland Fricke

Members of the Doctoral Studies Panel: Dr Paul McCabe \& Prof. Bruce Osborne 


\section{Contents}

Contents _ $i i$

List of figures__ v $v$

List of tables___viii

Abstract _ $x$

Statement of Original Authorship ___

Collaborations __ xii

Acknowledgements __ xiii

1 General Introduction __ 1 -

1.1 Plant growth 1 -

1.1.1 Plant cell expansion __ -1 -

1.1.1.1 Cell wall

1.1.1.2 Solutes — 3 -

1.1.1.3 Water -4 -

1.1.2 $\mathrm{pH}$ conditions in the apoplast

1.1.3 'Acid growth' theory _- 5 -

1.1.3.1 'Acid growth' and effect of auxin and fusiccoccin on growth

1.1.3.2 Experimental systems using coleoptiles__ - 6 -

1.1.3.3 Acid growth of coleoptiles___ -6 -

1.1.3.4 Acid growth of dicotyledonous leaves___ -8 -

1.1.3.5 Acid growth of roots -9 -

1.1.4 Potassium uptake and 'acid growth'___ 10 -

1.2 Plasma membrane $\mathrm{H}^{+}$-ATPase ___

1.2.1 Isoforms of PM- $\mathrm{H}^{+}$-ATPase____ -12 -

1.2.2 Structure of PM- $\mathrm{H}^{+}$-ATPase -14 -

1.2.3 Catalytic cycle of P-type ATPase and $\mathrm{H}^{+}$transport mechanism ___ 15 -

1.2.4 Control of PM- $\mathrm{H}^{+}$-ATPase _ 15 -

1.2.5 Fusicoccin-dependent PM- $\mathrm{H}^{+}$-ATPase activation ___ 17 -

1.3 Barley _ 18 -

1.3.1 The two weeks old barley seedlings and their advantage ___ -18 -

1.3.1.1 Morphology of developing barley leaves___ 19 -

1.3.1.2 Anatomy of developing barley leaf -20 -

1.3.2 Growth and potassium uptake of barley _ 21 -

\subsection{Technical approaches _ 22 -}

1.5 Objectives of the present study _ 23 -

2 Materials and Methods _ 24 -

2.1 Plant material ___ 24 -

2.1.1 Plant growth for study of leaves ___ 24 -

2.1.2 Plant growth for study of coleoptiles __ 25 -

2.2 Apoplast pH measurements ___ 25 -

2.2.1 In-vitro gel system_- 26 -

2.2.2 Microelectrode measurements __ 27 -

2.3 Confocal microscopy ___ 29 -

2.3 LVDT measurements ___ 30 -

2.3.1 Leaf growth measurements ___ -30 -

2.3.2 Analysis of cell wall properties ___ -31 - 
2.4 Expression analyses ___ 32 -

2.4.1 Plant harvest - 32 -

2.4.2 RNA extraction and cDNA synthesis ___ 33 -

2.4.3 PCR -34 -

2.4.4 qPCR_- 36 -

2.4.5 Analysis of qPCR data___ 37 -

2.5 Cell size and tissue ratio measurements____ 38 -

2.5.1 Mesophyll and epidermis cell size __ - 38 -

2.5.2 Tissue ratio calculation in elongation zone and emerged blade ___ 38 -

2.5.3 Cell size and plasma membrane surface estimation for qPCR analysis ___ 38 -

2.6 Plasma membrane isolation ___ 39 -

2.6.1 Plant harvest -39 -

2.6.2 Preparation of microsomal fraction___ 39 -

2.6.3 Purification of plasma membrane vesicles___ -40 -

2.7 Determination of the total protein content of plasma membrane vesicles - 41 -

2.7.1 Bradford method__ - 41 -

2.7.2 Densitometric analysis of Laemmli gels ___ -41 -

2.8 Polyacrylamide gel electrophoresis (PAGE) __

2.8.1 Gradient polyacrylamide gel electrophoresis (PAGE)___ -42 -

2.8.1.1 Solubilisation of membrane protein __ -42 -

2.8.1.2 Gradient PAGE gel system _ 43 -

2.8.2 Linear (12\%) PAGE___ - 45 -

2.9 ATPase assay ____ 45 -

2.10 Approach for light microscopy ___ 46 -

2.10.1 Fixation of leaf tissue ___ -46 -

2.10.2 Dehydration and embedding __ -46 -

2.10.3 Staining with toluidine blue __- 47 -

2.11 Immunological methods for $\mathrm{PM}-\mathrm{H}^{+}$-ATPase detection ___ 48 -

2.11.1 Qualitative Western blot analysis___ -48 -

2.11.2 Quantitative Western blot analysis__ - 49 -

2.11.3 Immunostaining of paraffin-embedded sections ___ -50 -

2.11.4 Densitometric analysis of Western blots ___ 51 -

2.12 Protoplast experiments ___ _ 51 -

2.12.1 Protoplast isolation___ -51 -

2.12.2 Purification of protoplasts _ -52 -

2.12.3 Calculation of size and surface of the protoplast___ -52 -

2.13 Statistical analysis____ 52 -

3 Results _ 53 -

3.1 Apoplastic pH measurements ___

3.1.1 In-vitro agarose gel system ___ - 53 -

3.1.2 Microelectrode measurements _ -57 -

3.1.1 Confocal microscopy ___ - 60 -

3.2 LVDT analyses of growth responses to treatments ___ 65 -

3.2.1 Leaf elongation under different treatments_____ -65 -

3.2.2 Cell wall changes in response to treatments ___ 69 -

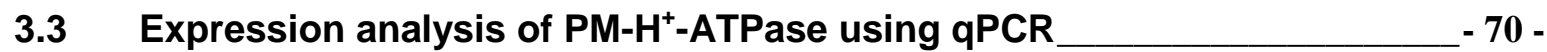

3.3.1 Quality control of the standard required for absolute qPCR

3.3.2 Calculation of cell number and membrane surface _- 72 -

3.3.3 Gene expression data based on absolute qPCR method___

3.4 PM- $\mathrm{H}^{+}$-ATPase activity and expression at protein level ___ 77 -

3.4.1 Optimization of membrane isolation and ATPase assay _____ -78 -

3.4.1.1 Plasma membrane isolation__ -78 -

3.4.1.2 Determination of total protein content in plasma membrane vesicles ___ -79 - 
3.4.1.3 ATPase assay ___ 79 -

3.4.2 Quality of plasma membrane fractions -81 -

3.4.3 Quantitative analysis of PM- $\mathrm{H}^{+}$-ATPase protein __ -82 -

3.4.4 Activity of PM- $\mathrm{H}^{+}$-ATPase _ 83 -

3.4.5 Immunolocalisation of PM- $\mathrm{H}^{+}-\mathrm{ATPase} \_-83$ -

4 Discussion _ 85 -

4.1 Growth-associated apoplast acidification ___ 85 -

4.1.1 Apoplast $\mathrm{pH}$ difference between growing and non-growing leaf tissue ___ -85 -

4.1.2 Reliability of $\mathrm{pH}$ values measured in elongation zone and emerged blade ___ -85 -

4.1.3 Relation between apoplast acidification and leaf growth __ 86 -

4.2 $\mathrm{K}^{+}$and apoplast acidification ___ 87 -

4.2.1 Potassium uptake and leaf growth ___ 87 -

4.2.2 High affinity potassium transporters and leaf growth___ -88 -

4.3 PM- $\mathrm{H}^{+}$-ATPase expression and leaf elongation _ 89 -

4.3.1 PM- $\mathrm{H}^{+}$-ATPase density in plasma membrane and leaf growth ___ -90 -

4.3.2 $\mathrm{gPCR}$ data__ -91 -

4.3.4 Immunolocalisation of PM- $\mathrm{H}^{+}$-ATPase _ 92 -

4.4 Leaf growth and changes in cell wall properties___ 92 -

4.5 'Acid growth' in barley leaves? ___ 93 -

4.6 Model of leaf growth in barley ___ 93 -

5 Conclusions and future work

5.1 Conclusions ___ 97 -

5.2 Future works ___ 98 -

6 Literature _ 99

7 Appendix _ 109 -

7.1 Processing of qPCR data___ 109 -

7.2 List of chemicals ___ 115 - 


\section{List of figures}

Figure 1.1 Model how expansins might interact with other wall components ......... - 3 -

Figure 1.2 Fusicoccin and auxin effect on maize coleoptiles............................ 7 -

Figure 1.3 Root elongation growth rate (REGR) and apoplast pH changes .......... - 9 -

Figure 1.4 Trajectory of a root element .................................................. 10

Figure 1.5 Potassium transport dependency of abraded maize coleoptiles ......... - 11 -

Figure 1.6 Structure of AHA2 without auto-inhibitory domain ........................... - 14 -

Figure 1.7 Catalytic cycle and $\mathrm{H}^{+}$transport of PM- $\mathrm{H}^{+}$-ATPase ......................... 15 -

Figure 1.8 Auto-inhibition of $\mathrm{PM}-\mathrm{H}^{+}$-ATPase .............................................. 17 -

Figure 1.9 14-3-3 protein-fusicoccin-PM-H ${ }^{+}$-ATPase complex .......................... - 18 -

Figure 1.10 Two-week old barley seedling ............................................. 20 -

Figure 1.11 Toluidine blue stained cross section of barley leaves from different

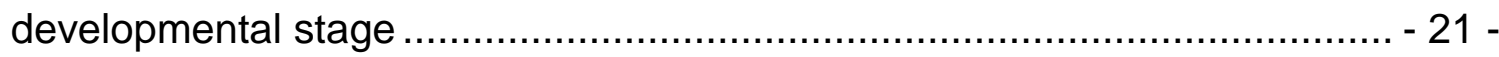

Figure 2.1 Leaf pieces in $\mathrm{pH}$ sensitive agarose gel medium ........................... - 27 -

Figure 2.2 Measurement of cell wall properties .............................................. 32 -

Figure 2.3 Thermal profile of the two step PCR reactions ............................... 35 -

Figure 2.4 Thermal profile of qPCR reactions .......................................... 36 -

Figure 2.5 Five purification steps during plasma membrane isolation................ - 41 -

Figure 2.6 Typical gel for the measurement of protein content of plasma membrane samples $42-$

Figure 2.7 Coomassie Brilliant Blue R250 stained gradient PAGE gels which were loaded with plasma membrane protein solubilised in two different ways ..... - 43 -

Figure 3.1 Leaf growth and apoplast acidification as analysed through the agarose gel system $-54-$

Figure 3.2 Time course of growth and acidification of in-vitro gel experiments .... - 55 -

Figure 3.3 Leaf growth and acidification in agarose gel under cold treatment...... - 55 Figure 3.4 Average rate of leaf elongation $(A)$ and medium acidification $(B)$ in leaves exposed to fusicoccin, vanadate and caesium treatments as tested through the

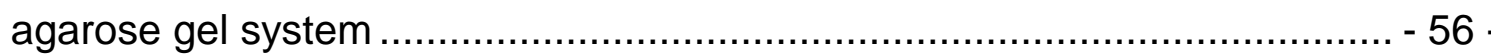

Figure 3.5 Effect of auxin on leaf growth and medium acidification using the in-vitro gel system $-57-$

Figure 3.6 Growth effect of auxin when applied in liquid medium. $-57-$

Figure 3.7 Microelectrode analyses of apoplast $\mathrm{pH}$ in the elongation zone and emerged blade-portion of leaf three of barley. 
Figure 3.8 Growth rate of leaf three in response to $\mathrm{K}^{+}$-treatments during micro $\mathrm{pH}$ measurements.

Figure 3.9 Microelectrode $\mathrm{pH}$ analyses in the leaf elongation zone of barley in response to sodium orthovanadate and fusicoccin treatments.

Figure 3.10 Growth rate of leaf three of barley in response to vanadate and fusicoccin treatments as analysed through different approaches. $-60-$

Figure 3.11 Confocal microscopic analysis of apoplastic $\mathrm{pH}$ using acridine orange fluoresce $\mathrm{pH}$ sensitive fluorescence dye. $62-$

Figure 3.12 Confocal microscopic analysis of apoplastic $\mathrm{pH}$ using 5(6)carboxyfluorescein fluoresce $\mathrm{pH}$ sensitive fluorescence dye $63-$

Figure 3.13 Carboxyfluorescein and acridine orange accumulation pattern in elongation zone and emerged blade $64-$

Figure 3.14 Effect of $\mathrm{pH}$ sensitive dyes on leaf growth rate $-64-$

Figure $3.15 \mathrm{pH}$ sensitivity of fluorochromes $65-$

Figure 3.16 Testing the responsiveness of the LVDT setup to treatments which were expected to increase $\left(37^{\circ} \mathrm{C}\right)$ or stop growth $(1 \mathrm{M} \mathrm{NaCl})$. $-66-$

Figure 3.17 The effect of test reagents in the apoplastic bathing medium on leaf growth as measured with the LVDT setup.... $67-$

Figure 3.18 Potassium dependency of the leaf growth response to fusicoccin $(5 \mu \mathrm{M})$ and vanadate $(500 \mu \mathrm{M})$ $68-$

Figure 3.19 Auxin effect on leaf elongation growth $68-$

Figure 3.20 Cell wall changes under different treatments $-69-$

Figure 3.21 Growth rate before and in response to an additional applied force ... - 70 Figure 3.22 reference genes for qPCR experiments - 71 -

Figure 3.23 Digital PCR pattern of external standard DNA $-72-$

Figure 3.24 Representative cross sections used for determination of the contribution of different tissues and air space to total leaf volume. $-73-$

Figure 3.25 Expression of PM- $\mathrm{H}^{+}$-ATPase using absolute qPCR. $-75-$

Figure 3.26 PM- $\mathrm{H}^{+}$-ATPase expression using absolute qPCR and relating expression data to total plasma membrane surface area $-76-$

Figure 3.27 Comparison of molecular biological data using leaf tissues or mesophyll protoplasts. -77 -

Figure 3.28 Impact on the quality of PAGE separation of washing steps during plasma membrane isolation $78-$ 
Figure 3.29 Protein measurement in plasma membrane vesicles using two different methods $-79-$

Figure 3.30 Typical ATPase assay ............................................................ 80 -

Figure 3.31 Kinetics of $P_{i}$ detection assay ................................................... - 80 -

Figure 3.32 Coomassie stained SDS polyacrylamide gel and Western blot of plasma membrane proteins from different leaf regions. $81-$

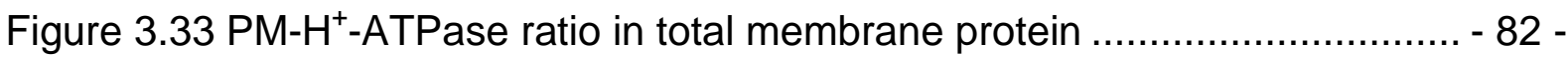

Figure 3.34 ATPase activity of inside-out plasma membrane vesicles................ - 83 -

Figure 3.35 PM- $\mathrm{H}^{+}$-ATPase immunolocalisation on leaf cross and longitudinal sections. $84-$

Figure 4.1 Supposed effect of the treatments on barley leaf cells ....................... - 95 -

Figure 4.2 Model of leaf elongation in barley leaves ...................................... - 96 -

Figure 7.1 Typical calibration curve for converting Ct values into transcript copy number $-110-$ 


\section{List of tables}

Table 1.1 Localisation of specific PM- $\mathrm{H}^{+}$-ATPase isoforms in plant body - 13 -

Table 2.1 Composition of the $1 / 2$ strength Hoagland solution for barley seedlings - 25 -

Table 2.2 Composition of the $\mathrm{pH}$ sensor for microelectrodes

$-28-$

Table 2.3 Composition of the buffer solutions used for calibrating $\mathrm{pH}$ microelectrodes

$-29-$

Table 2.4 DNase treatment and reverse transcription - 34 -

Table 2.5 Components of PCR reactions - 35 -

Table 2.6 PCR primers

Table 2.7 Composition of the stock solution ( $5 x$ concentrated) of TRIS base boric acid EDTA buffer (TBA)

Table 2.8 Components of qPCR reaction

Table 2.9 Composition of the homogenisation buffer used for membrane isolation

Table 2.10 Composition of the phase buffer used for membrane isolation

Table 2.11 Composition of the resuspension buffer used for membrane isolation

Table 2.12 Composition of Bradford reagent

Table 2.13 Composition of Laemmli buffer used for PAGE

Table 2.14 Components of the gradient PAGE system

Table 2.15 Components of the solutions for Coomassie Brilliant Blue gel staining

Table 2.16 ATPase reaction buffer and colour development reagent

Table 2.17 Fixation and embedding of leaf samples for immunohistochemistry

Table 2.18 Staining embedded leaf sections with toluidine blue

Table 2.19 Composition of blotting buffer used for Western analyses

Table 2.20 Composition of TRIS buffer saline buffer (TBS)

Table 2.21 Composition of Tween ${ }^{\circledR} 20$ TRIS buffer saline buffer (TTBS)

Table 2.22 Protocol for immunostaining of embedded leaf sections

Table 2.23 Composition of phosphate buffer saline (PBS; $\mathrm{pH} 7.4$ )

Table 2.24 Composition of protoplast isolation buffer

Table 2.25 Enzyme concentrations in protoplast isolation buffer

Table 3.1 Water content of two different regions of leaf three in two cultivars of barley

Table 3.2 The contribution of different tissues to total leaf volume in the elongation zone (EZ) and emerged blade (EB) of leaf three of barley. - 73 -

Table 3.3 Cell size calculation based on the present and literature data. $\quad 74$ - 
Table 3.4 Ct values of PM- $\mathrm{H}^{+}$-ATPase expression together with RNA content per cell in the elongation zone (EZ) and emerged blade (EB) of leaf three of barley.

Table 3.5 RNA content and PM- $\mathrm{H}^{+}$-ATPase expression in the elongation zone (EZ) and emerged blade (EB) of leaf three of barley (Golf, Jersey).

Table 4.1 Summary of data for PM- $\mathrm{H}^{+}$-ATPase when related to surface area of plasma membrane.

Table 7.1 Example for qPCR calculation of Golf cultivar.

Table 7.2 Example for qPCR calculation of Jersey cultivar.

Table 7.3 Example for qPCR calculation of Jersey protoplasts. 


\section{Abstract}

Apoplast acidification associated with growth is well-documented in roots, coleoptiles and internodes but not in leaves. In the present project on barley (Hordeum vulgare L.) advantage was taken of the high cuticle permeability in the elongation zone of leaves to measure apoplast $\mathrm{pH}$ and growth in response to application of test reagents. The role of the plasma membrane $\mathrm{H}^{+}$-ATPase (PM- $\mathrm{H}^{+}$-ATPase) and $\mathrm{K}^{+}$in this process was of particular interest. An in vitro gel system with bromocresol purple as $\mathrm{pH}$ indicator, $\mathrm{pH}$ microelectrodes and $\mathrm{pH}$-sensitive fluorescence dye combined with confocal microscopy were used to monitor apoplast $\mathrm{pH}$. Growth was measured in parallel or in separate experiments using a linear variable differential transformer (LVDT). Test reagents which blocked (vanadate) or stimulated (fusicoccin) PM- $\mathrm{H}^{+}-\mathrm{ATPase}$, or which reduced $\left(\mathrm{NH}_{4}{ }^{+}\right.$, $\mathrm{Cs}^{+}$, tetraethylammonium) $\mathrm{K}^{+}$uptake were applied. Plasma membranes were isolated from growing and mature leaf tissue and used to determine the activity (ATPase assay) and abundance (Western blotting) of $\mathrm{PM}-\mathrm{H}^{+}$-ATPase protein. Protein localisation was studied by immunohistochemistry and expression of mRNA quantified using real time PCR (qPCR). Apoplast $\mathrm{pH}$ was by up to $1.0 \mathrm{pH}$ unit lower in growing compared to nongrowing leaf tissue. Depending on the $\mathrm{K}^{+}$concentration in the bathing medium used during electrophysiological analyses, apoplast $\mathrm{pH}$ in the elongation zone ranged from $\mathrm{pH} 4.8\left(0.1 \mathrm{mM} \mathrm{K}^{+}\right)$to $\mathrm{pH} 5.8\left(10 \mathrm{mM} \mathrm{K}^{+}\right)$. In the emerged blade, apoplast $\mathrm{pH}$ remained at about $\mathrm{pH} 5.8$ irrespective of the $\mathrm{K}^{+}$concentration in the bathing medium Growth was more responsive to test reagents than to changes in apoplast $\mathrm{pH}$. Expression of $\mathrm{PM}-\mathrm{H}^{+}$ATPase was comparable between growing and non-growing leaf regions when expression was related to per unit extracted RNA or cell number. However, when expression was related to per unit surface area of plasma membrane, expression of $\mathrm{PM}^{-\mathrm{H}^{+}}$-ATPase was about twice as high in growing compared to non-growing leaf tissue. The same applied to the protein level and activity of $\mathrm{PM}-\mathrm{H}^{+}-\mathrm{ATPase}$. Immunohistochemical analyses showed that $\mathrm{PM}-\mathrm{H}^{+}-\mathrm{ATPase}$ was present in all living leaf tissues, particular in those (guard cells, phloem, and xylem parenchyma) associated with high rates of trans-membrane solute transport. It is concluded that leaf cell expansion in barley depends on the activity of the PM- $\mathrm{H}^{+}-\mathrm{ATPase}$ and $\mathrm{K}^{+}$transport processes. The higher surface density of $\mathrm{PM}-\mathrm{H}^{+}$-ATPase activity in growing barley leaf tissue aids apoplast acidification and growth. $\mathrm{A} \mathrm{H}^{+} / \mathrm{K}^{+}$co-transport system may play a key role in linking growth with apoplast $\mathrm{pH}, \mathrm{H}^{+}$pump activity and $\mathrm{K}^{+}$-uptake. 


\section{Statement of Original Authorship}

I hereby certify that the submitted work is my own work, was completed while registered as candidate for the degree of Doctor of Philosophy, and I have not obtained a degree elsewhere on the basis of the research presented in this submitted work. 


\section{Collaborations}

(i) $\mathrm{pH}$ measurements using $\mathrm{pH}$ microelectrodes were carried out under the supervision of $\mathrm{Dr}$ Anthony J. Miller at the Department of Plant Pathology and Microbiology of Rothamsted Research (Harpenden, Hertfordshire AL5 2JQ, UK). Towards the end of this project, Dr Miller moved to the John Innes Centre (Norwich Research Park, Colney, Norwich, NR4 7UH, UK), which is similar to Rothamsted Research a BBSRC (Biotechnology and Biological Sciences Research Council) funded institute.

(ii) Plasma membrane isolation, SDS PAGE, ATPase hydrolysis assays and part of the Western blot analysis was carried out in the laboratory of Dr Éva Sárvári and Dr Ilona Rácz with the help of Ádám Solti at the Department of Plant Physiology and Molecular Plant Biology, Institute of Biology, Faculty of Science, Eötvös Loránd University (Pázmány Péter sétány 1/C, Budapest, Hungary, H1117). 


\section{Acknowledgements}

- $\quad$ First of all I want to thank my supervisor Dr Wieland Fricke for his expert guidance and advice in all aspect during the three years. He not just guided my steps in science, he gave the opportunity to plan my research workflow, experiments and test my own ideas.

- I would like to thank the help to everybody who worked with me in our research group Matthieu Besse, Thorsten Knipfer, Mostefa Touati, Ehsan Bijanzadeh and Shimi Suku who helped me a lot and we could spend great time in the lab together.

- Many thanks for the technical assistance and help to Brendan, Eugen, Francis, Gwyneth, Eileen (UCD), Sue (Rothamsted), Györgyi and Zsuzsa (ELTE). Damian Egan and Eric Callaghan helped me especially a lot, and special thanks to Eric for his critical reading of the thesis.

- I would like to thank Prof. Jeremy C. Simpson for access to the confocal microscopy unit and Dr Gavin Stewart and Caragh Walpole for their help with Western blotting at UCD.

- I never will forget the days in Rothamsted, thanks a million for Dr Tony Miller for his help in all aspect and I hope I will have the chance to work together in the future.

- $\quad$ At Eötvös University I had extremely big help from Dr Éva Sárvári, Dr Ilona Rácz, Dr Szabolcs Rudnóy and from Prof. Zoltán Szigeti. Without the guides of Ádám Solti the protein part of the work would not have been successful. Dr György Csikós helped a lot in immune histochemistry.

- Enormous thanks for my wife Kriszti. Without her help I would not able to finish this research and thesis. She was always with me when I was despondent and felt that I never will finish.

- $\quad$ Thank to all of my friends at UCD, Rothamsted and ELTE whose are not mentioned by name.

- Particular thanks to IRCSET (Irish Research Council for Science, Engineering and Technology) which made this $\mathrm{PhD}$ project possible through awarding me an EMBARK post-graduate fellowship.

- $\quad$...és végül de nem utolsó sorban köszönöm a támogatást szüleimnek akik támogattak mindenben és elviselték, hogy Írországban éltem és doktoráltam. 


\section{General Introduction}

\subsection{Plant growth}

Plant growth can be defined as an irreversible increase in the size of cells, tissues, organs or whole plants (Csiszár et al., 2004). Cell expansion is generally considered to be caused by wall loosening and driven by turgor pressure (Christian et al., 2006). The term 'cell growth' mainly refers to the increase in size of proliferating cells in the cell cycle (meristematic cells), with increase in the total nucleic acid and protein content without vacuolization of the protoplast. In contrast, the term 'cell expansion' refers to the manifold increase in size of newly produced cells that is associated with the formation of a large central vacuole and finally leads to cell differentiation (PerrotRechenmann, 2010). While plants need to produce new cells to grow, it is cell expansion which leads to the physical increase in plant size and biomass.

\subsubsection{Plant cell expansion}

The enlargement of cells reflects increase in water content of cells. Irreversibility of this process is guaranteed by the plastic properties of the cell wall. From the biophysical view, plant cells need a wall which gives in to turgor pressure (mechanical driving force) and solutes which drive water uptake through osmosis. Therefore, cell expansion may be limited by the mechanical (yielding and extensibility) properties of the cell wall and the rate at which water and solutes are taken up or produced (solutes) by cells internally (Fricke \& Flowers, 1998; Fricke \& Peters, 2002).

\subsubsection{Cell wall}

It is a popular theory that expansion of leaf and root cells is controlled by cell wall properties. Based on the work of Green et al. (1971) on giant algae cells (Nitella sp.) and Lockhart's (1965) theoretical considerations, a growth model was developed which relates the growth rate $(G R)$ to extensibility properties $(m)$, yield threshold of cell wall where no cell expansion occurs $(Y)$ and cell turgor $(P)$ :

$$
\mathrm{GR}=\mathrm{m} \cdot(\mathrm{P}-\mathrm{Y})
$$

The impact of the mechanical properties of the cell wall for plant growth was found in many studies both in roots and shoots (Cosgrove, 1993; Pritchard, 1994; Cosgrove, 
1998; Hsiao \& Xu, 2000). The implication of these studies is that the rate of cell expansion, and therefore plant growth, may be regulated by altering the mechanical properties of the wall, making it 'softer' (more growth) or 'harder' (less growth). One way to alter wall properties is through changes in wall (apoplast) $\mathrm{pH}$.

Acidification can affect growth through cell wall loosening (Rayle \& Cleland, 1970) and different theories have been proposed to explain this phenomenon. One hypothesis suggested that $\mathrm{H}^{+}$directly affects non-covalent bonds between $\beta$-glucan within the cell wall, causing wall loosening (Hohl et al., 1991). Another hypothesis suggested that due to $\mathrm{H}^{+}$excretion $\mathrm{Ca}^{2+}$ ions are displaced in the cell wall and that this leads to a more flexible cell wall (Arif \& Newman, 1993). A breakthrough in our understanding of $\mathrm{pH}$-related wall loosening came in 1992 when two proteins were extracted from cucumber hypocotyls which were capable of inducing extension in isolated, heat-inactivated cell walls of several plant species. These 'wall loosening' proteins were termed 'expansins'. The pH optimum of these proteins was pH3.5 - 4.5 (McQueen-Mason et al., 1992) and this may explain at least in part why apoplast acidification increases the growth rate of plant organs.

Expansins are specifically expressed in growing tissues of monocotyledons and dicotyledonous plants. They are highly conserved in size and amino acid sequence (Cosgrove, 1996). However, studies on fescue suggest that another group of wall proteins, xyloglucan endotransglycosylases, may be more involved in regulation of cell expansion than expansins (Reidy et al., 2001).

Expansins do not induce wall extension through simple polymer hydrolysis. They mainly disrupt hydrogen bonding not just in-vivo, in a paper sheet as well and reengineering the cell wall structure facilitating plant growth (McQueen-Mason, 1995). Promoting cell wall relaxation is necessary for expansion of plant cells (Cosgrove, 1993). An overview of expansin action is given in Fig. 1.1. 


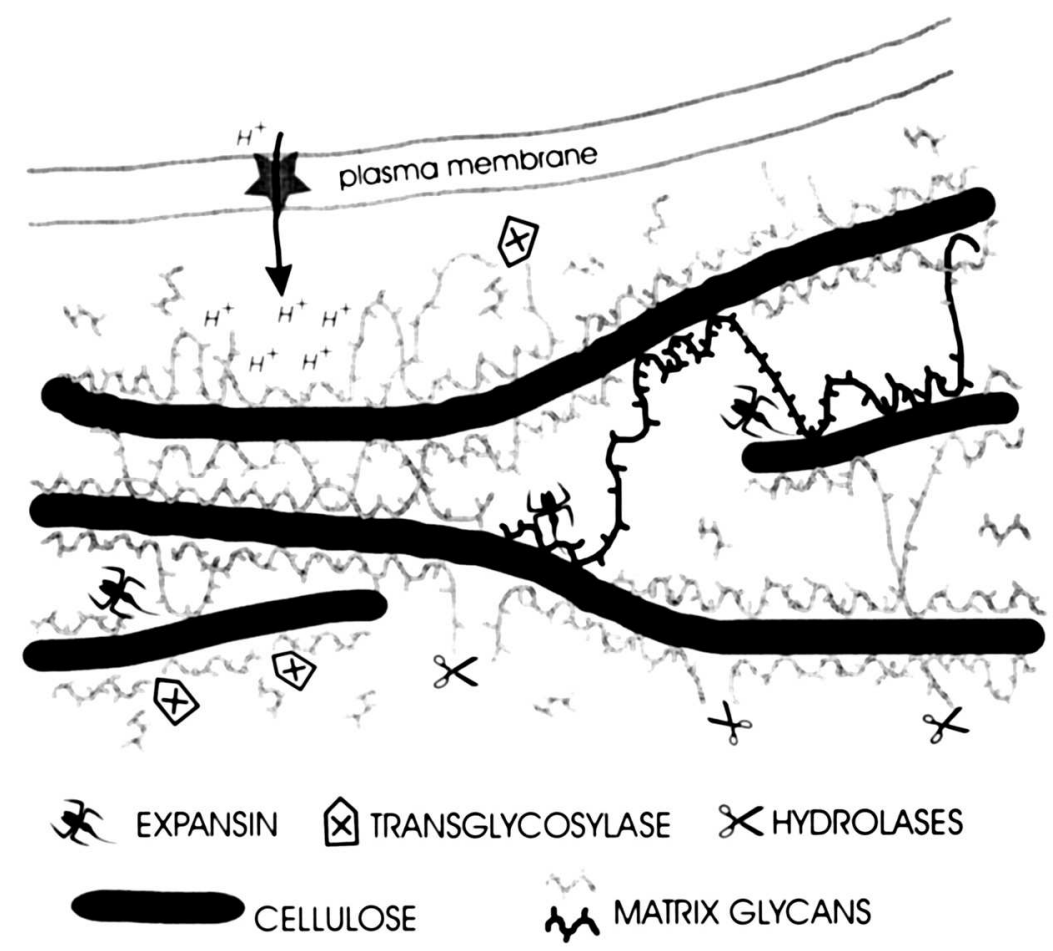

Figure 1.1 Model how expansins might interact with other wall components

Expansins might cause a transient release of short segments of matrix hemicelluloses glycans attached to cellulose microfibrils. Wall hydrolyses cut matrix glucans into shorter segments leading to weakening but not to creep of the cell wall. Transglycosylases are recombining glycans into shorter or longer pieces. $\mathrm{PM}-\mathrm{H}^{+}$ATPases may lower the wall $\mathrm{pH}$ and control enzymes by their $\mathrm{pH}$ optima. Reprint from Cosgrove (1998) based on open access policy of www.plantphysiology.org with copyright American Society of Plant Biologists.

\subsubsection{Solutes}

Based on the original growth model described above (Lockhart, 1965; Green et al., 1971), turgor pressure and solute uptake should have significant impact on cell expansion and growth. The availability of solutes seems to co-limit growth especially under water (Frensch, 1997; Hsiao et al., 1998) and salt stress (Fricke \& Peters, 2002).

Osmolality and turgor pressure change little along the elongation zone of cereal leaves (Fricke et al., 1997; Fricke \& Flowers, 1998; Martre et al., 1999; Fricke, 2002a) and roots (Pritchard, 1994). The implication of a constant turgor pressure in expanding cells might be that cells instantly deposit solutes to maintain osmolality as the osmotic force driving water uptake while they expand and cell contents become diluted (Fricke, 2002a). 


\subsubsection{Water}

In barley, it has been suggested that the rate of tissue-water transport might limit cell expansion in leaves (Fricke, 2002b). Similar conclusions have been made for soybean hypocotyls and maize leaves by the work of Boyer and colleagues who coined the term 'growth-induced water potentials' (Boyer, 2001; Tang \& Boyer 2008). The mere existance of significant gradients in water potential between growing tissue and water source suggests that the conductance of the pathway between the two is limiting water transport. In a multi-layered tissue e.g. in roots, the radial hydraulic conductance can be one to three orders of magnitude larger under transpirating than under non-transpirating conditions (Steudle, 2000). Recent studies showed that in barley roots water uptake occurred along a pathway which involved crossing of membranes. It was not clear whether osmotic forces were sufficient to support water uptake (Knipfer \& Fricke, 2011). Aquaporins have an essential role in the water transport at cellular level (Hachez et al. 2008). Aquaporins also may play essential role in elongation growth of barley leaves (Besse at al., 2011).

\subsection{2 $\mathrm{pH}$ conditions in the apoplast}

The present analyses did not, or did little distinguish between cell wall space and apoplast. The latter also comprises intercellular spaces and middle lamellae. Therefore, and for simplicity, it is referred to 'apoplast' throughout the present work. The apoplast of higher plants occupies typically $5 \%$ or less of the total tissue volume. This applies in particular to living tissues. The apoplast determines ionic conditions around the cells; it affects transport solutes into and out of cells, provides a diffusion barrier in speciliased cases (e.g. Casparian bands) and defines mechanical and osmotic conditions - conditions which may be or may not be compatible with cell expansion. The latter applies in particular to the $\mathrm{pH}$ of the apoplast. Using different methods $\mathrm{pH}$ indicators in agar, microelectrodes and fluorescence probes) a huge variety in apoplast $\mathrm{pH}$ has been reported for roots of different plant species. Values ranged from $\mathrm{pH} 4.0$ to $\mathrm{pH} 7.0$ with most values being in the region pH 5.0 to pH 6.5 (Grignon \& Sentenac, 1991). Dicotyledonous plants have generally a higher (less acidic) $\mathrm{pH}$ than monocotyledonous plants have, and apoplast pH is lower in gymno- compared to angiosperms (Grignon \& Sentenac, 1991).

In fully developed barley leaves an apoplast $\mathrm{pH}$ of $\mathrm{pH} 5.0$ was measured using microelectrodes (Felle, 2006). The $\mathrm{pH}$ varied in dependence of oxygen availability 
(anoxia) (Felle, 2005; Felle et al., 2005; Felle, 2006). Similar pH values have been reported for maize leaves using microelectrodes and fluorescence probes (Pitann et al., 2009a; Ehlert et al., 2011).

\subsection{3 'Acid growth' theory}

'Acid growth' originally was discovered by Bonner in 1934 when he described that the growth rate of Avena coleoptiles in $\mathrm{pH} 4.1$ buffer was significantly higher than in $\mathrm{pH}$ 7.2 buffer (Kutschera, 1994). Later this effect was re-discovered and characterised in more detail by Rayle \& Cleland (1970) and Hager et al., (1971). Although in the literature 'acid growth' is mainly mentioned in relation to growth effects caused by the phytohormone auxin and the fungal toxin fusicoccin, which permanently activates $\mathrm{PM}-\mathrm{H}^{+}$-ATPase, linked plant growth, acid growth is a more general phenomenon and can be induced by other factors (Vesper \& Evans, 1979). In 'acid growth', acid related cell 'wall-loosening' may constitute the initial event (Rayle \& Cleland, 1970; Cosgrove, 1993). During the past decades, the 'acid growth' theory, or parts of the underlying mechanistic model, has been questioned repeatedly (Kutschera \& Schopfer, 1985a; Kutschera, 1994; Grebe, 2005), However, with some limitation it is 'alive and well' (Lüthen et al., 1990; Hager et al., 1991; Rayle \& Cleland, 1992; Kutschera, 2006). An alternative theory for 'acid growth' is the 'facilitated solute uptake' theory. This theory states that it is not the secreted $\mathrm{H}^{+}$which are causing directly the increased growth rate through alteration of wall properties, but that a proton-coupled transport mechanism across the plasma membrane is stimulated (Brummer et al., 1984).

\subsubsection{1 'Acid growth' and effect of auxin and fusiccoccin on growth}

Almost at the same time, Darwin and Sachs proposed the theory that growth and development of plants is controlled by hormones (Darwin, 1880; Kutschera 1994). Using Avena sativa coleoptiles, Darwin, in 1880, showed that coleoptiles were bending towards the light source and once the tip of the coleoptiles was covered or cut, the coleoptiles were unable to produce this bending effect. In 1909, Fitting showed that coleoptile bending was a result of the non-homogeneous distribution of some factor, possibly a hormone (Katsumi, 2007). With gelatine cubes and glass pieces Boysen-Jensen (1913) proofed that this factor was transported from the tip to basal end of the coleoptile (Csiszár et al., 2004). Paál (1918) could induce coleoptile bending without light, changing the orientation of coleotile tips (Paál, 1918; Csiszár et 
al., 2004). Finally, in 1937, Went discovered the hormone (auxin) and showed that if the hormone was in gelatine cubes the tip was not necessary for coleoptile bending (Kutschera 1994). Heyn in 1940 proposed that auxin (in its physiological form indol acetic acid - IAA) promotes growth by enhancing cell wall extensibility. In 1934 and 1970 the 'acid growth' theory was born to explain auxin related plant growth (Kutschera, 1994). Fusicoccin, a phytotoxin of the fungus Fusicoccum amygdale, was discovered as 'super-auxin' a few years latter (Marré, 1979) and is still used today in many plant growth studies.

\subsubsection{Experimental systems using coleoptiles}

Coleoptiles of monocotyledon plants have widely been used as a model system to study plant growth. Coleptiles can be obtained on plants which need to grow for only a few days, are well characterised in terms of their phototropic or gravitropic response, show defined regions of growth and auxin production, are simple in anatomy and are easy to handle and cut. The main disadvantage, however, of coleoptiles is that their cuticle provides a permeance barrier to applied test reagents and diffusion barrier for protons and that this causes difficulties for applying treatments and measuring apoplastic $\mathrm{pH}$ (changes). In different laboratories this problem has been solved in different ways by peeling off part of the outer epidermis (Rayle, 1973), abrasion of coleoptiles with wet emery cloth prior to cutting (Kutschera \& Schopfer, 1985a), abrasion with distilled water and SiC powder (Lüthen et al., 1990) or using dry polishing cloth for abrasion of coleoptiles before excision of segments (Schopfer, 1989). None of these methods were free from artefacts; however the results have been informative.

In most experiments, the incubation medium in which $\mathrm{pH}$ measurements were conducted was slightly buffered to prevent $\mathrm{pH}$ changes as a result of changes in $\mathrm{CO}_{2}$ content of the atmosphere e.g. Rayle (1973); Stahlberg \& Van Volkenburgh (1999) and Felle (2006). At the same time, the buffer capacity of the medium may affect $\mathrm{pH}$ measurements. Probably the best system for $\mathrm{pH}$ measurement was the method of ionostat (Döring et al., 1996), because the incubation medium was not buffered and changes in $\mathrm{H}^{+}$efflux were measured rather than $\mathrm{pH}$.

\subsubsection{Acid growth of coleoptiles}

Using maize coleoptiles, which were SiC-abraded in water and analysed using a computer controlled pH stat, both auxin and fusicoccin treatments affected growth in 
a way which supported the 'acid growth' theory (Fig. 1.2). Neutral and alkaline solutions partly inhibited auxin- and fusicoccin-induced growth, whereas fusicoccininduced growth under constant $\mathrm{pH}$ conditions. Fusicoccin and auxin did not show any additive effect (Lüthen et al., 1990). Cell wall $\mathrm{pH}$ and growth rate were in close temporal correlation indicating co-regulation of apoplast solute composition (Peters et al., 1998).
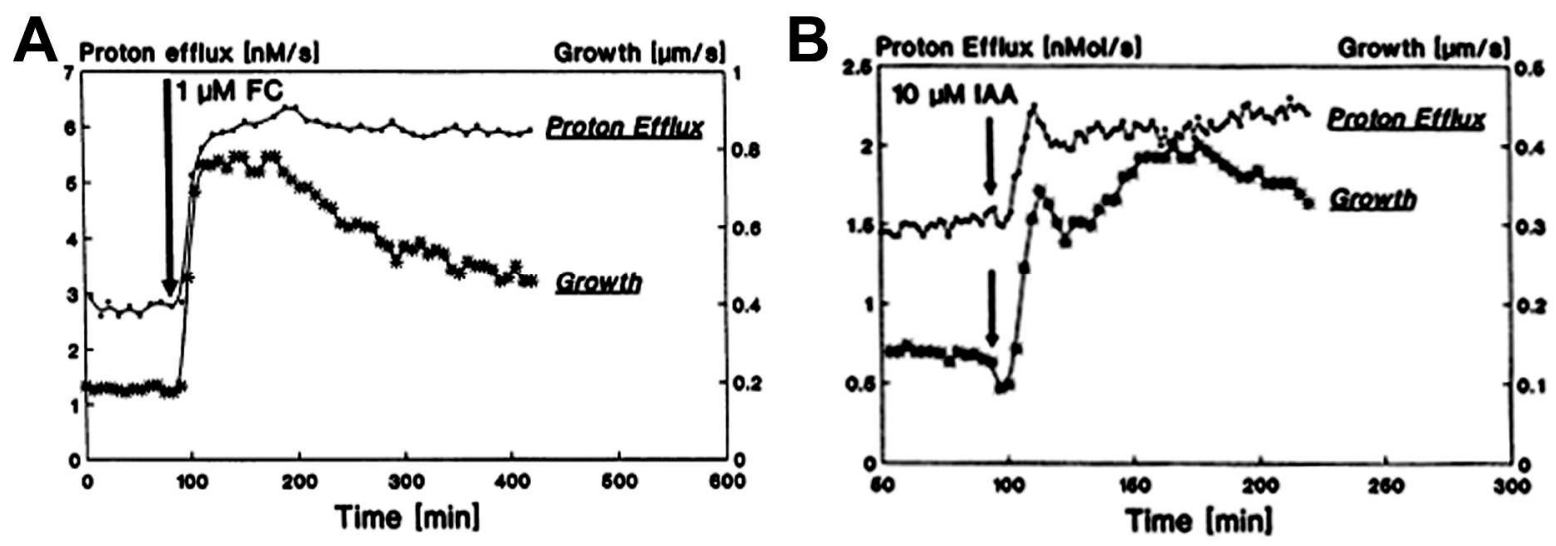

Figure 1.2 Fusicoccin and auxin effect on maize coleoptiles

Typical trace of fusicoccin $(A)$ and auxin (IAA) effect $(B)$. Dots represent the proton secretion while asterisks the coleoptiles growth rate. Experiments were carried out using $\mathrm{SiC}$ abraded maize coleoptile segments and a $\mathrm{pH}$ stat to maintain $\mathrm{pH}$. Reprint from Lüthen et al. (1990) based on open access policy of www.plantphysiology.org with copyright American Society of Plant Biologists.

Other studies suggested that fusicoccin, but not auxin, caused 'acid growth'. Using the wet emery cloth abrading technique and buffered incubation medium, fusicoccin-induced growth was totally inhibited by alkaline solutions (Kutschera \& Schopfer, 1985b) while auxin-induced growth was not affected (Kutschera \& Schopfer, 1985a). The difference between these and the above-mentioned results might have been caused by the experimental set ups. The abrading technique was different and the solution was buffered in case of Kutschera \& Schopfer (1985ab), while Lüthen at al. (1990) could use unbuffered solutions. Difference in cation composition might have impacted too, with $10 \mathrm{mM} \mathrm{KCl}$ and $1 \mathrm{mM} \mathrm{Ca}^{2+}$ used by Lüthen et al. 1990), while Kutschera \& Schopfer (1985ab) used $\mathrm{Ca}^{2+}$ in the incubation medium and $\mathrm{K}^{+}$at minimal concentrations (discussed in Lüthen et al., 1990).

It is possible that extension growth of multi-tissue organs such as roots, coleoptiles and leaves is limited mechanically by the extension of one component tissue. This idea, which dates back to the $19^{\text {th }}$ century (Kutschera, 1994), is proposed in particular for the epidermis of round, compact organs (containing little intercellular 
air space) such as hypocotyls and coleoptiles. Therfore the wall of the epidermis may be important for growth, and it is possible that 'acid growth' may occur in all tissues of an organ or only in the epidermis or in all tissue but the epidermis. This could explain discrepancies in results obtained between researchers and for different organs and species. Peeling off just part of the epidermis of coleoptiles might cause immediately changes in growth conditions but also experimental artefacts (Kutschera, 1994). It was assumed that fusicoccin may interact with proton pumps of inner coleoptile tissues whereas auxin affects $\mathrm{H}^{+}$secretion of epidermal cells. Peeling off the epidermis caused $80 \%$ less proton excretion of coleoptiles compared when coleoptiles were abraded with wet emery cloth (Kutschera et al., 1987). These results are supported by immunolocalisation results. Fusicoccin sensitive plasma membrane $\mathrm{H}^{+}$-ATPase (PM- $\mathrm{H}^{+}$-ATPase) proton pumps were found mainly in mesophyll cells rather than in the epidermis (Villalba et al., 1991); other authors, using electrophysiology, showed that auxin-induced $\mathrm{H}^{+}$pump activity did not depend on the presence of epidermal cells in maize coleoptiles (Peters et al., 1992).

\subsubsection{Acid growth of dicotyledonous leaves}

The 'acid growth' theory has been tested much less in detail on dicotyledonous compared to monocotyledonous plants (coleoptiles) and the results in the literature are in part confusing. The validity of the acid growth theory appears to depend on the species tested. Light-induced leaf expansion of bean (Phaseolus vulgaris) and silver birch (Betula pendula) clearly showed an 'acid growth' type response. Apoplast $\mathrm{pH}$ decreased within 5-15 min of illumination, parallel to an increase in growth. Exogenous acidic buffer induced loosening of the cell wall and stimulated leaf growth whereas buffer at neutral $\mathrm{pH}$ inhibited growth. Fusicoccin stimulated both leaf growth and apoplast acidification (Van Volkenburgh \& Cleland, 1980; Taylor \& Davies, 1985; Cosgrove, 1996). In contrast, leaf expansion of sycamore (Acer pseudoplatanus) and tobacco (Nicotiana tabacum) could not be explained through 'acid growth'. Apoplast acidification was not related to auxin-induced growth, yet fusicoccin-related 'acid growth' was present in tobacco leaves and independently of any auxin effect (Taylor \& Davies, 1985; Keller \& Van Volkenburgh, 1998). Growth related acidification in dicotyledonous leaves seems controlled by light and follows a partially independent pathway from photosynthesis as experiments with pea (Pisum sativum) leaves showed (Stahlberg \& Van Volkenburgh, 1999). In tobacco leaves, some mechanistic link between light-stimulated leaf growth, $\mathrm{H}^{+}$excretion and $\mathrm{K}^{+}$uptake (Stiles et al., 
2003; Stiles \& Van Volkenburgh, 2004) was observed. The role of $\mathrm{K}^{+}$could be to provide electrical counterbalance of $\mathrm{H}^{+}$rather than to provide an osmolyte for uptake (Stiles \& Van Volkenburgh, 2004).

\subsubsection{Acid growth of roots}

Early results suggested auxin linked 'acid growth' in roots (Moloney et al., 1981). However, more recent data showed that auxin increased growth of shoot and coleoptiles yet equally rapidly inhibited root growth (Christian et al., 2006). Positive 'acid ( $\mathrm{pH} 4.0$ ) growth' has been not recorded in root elongation and at $\mathrm{pH} 3.5$ organ elongation is reduced (Kutschera, 2006). In contrast with these results correlation was found between cell wall acidity and root elongation. Fusicoccin-induced $\mathrm{H}^{+}$efflux and growth rate of maize roots rather than auxin that reduced both $\mathrm{H}^{+}$efflux and root elongation (Lüthen \& Böttger, 1988).

Using $\mathrm{pH}$ microelectrodes in the elongation zone of 4 day old maize primary roots a lower $\mathrm{pH}$ was recorded than in the non-growing zone when the $\mathrm{pH}$ was higher than pH 5.0 of the incubation medium (Fig. 1.3 and Fig. 1.4). Relative elemental growth rate and surface acidity were eliminated by auxin and cyanide treatments, respectively (Fig. 1.3) (Peters \& Felle, 1999; Peters, 2004).
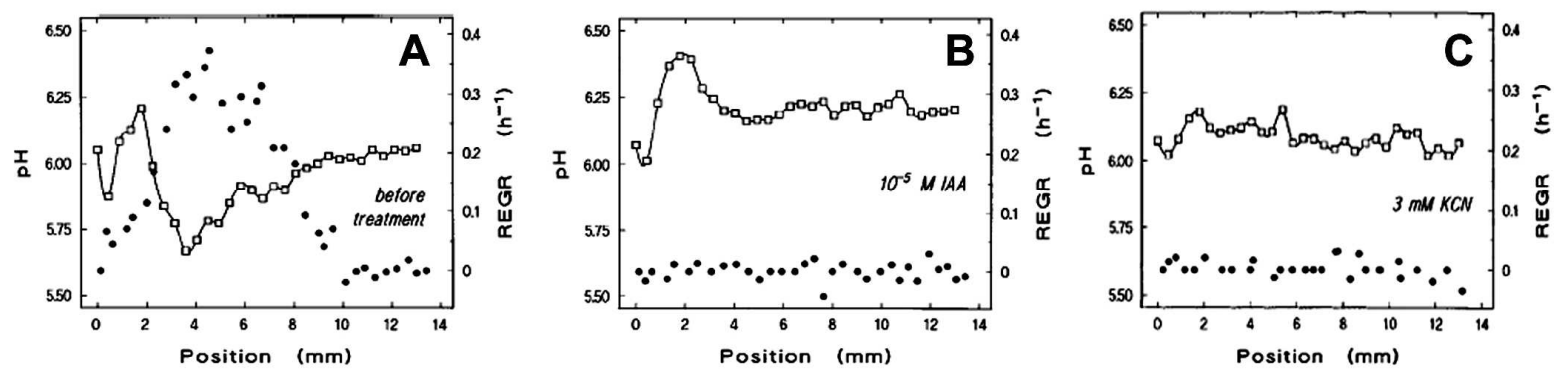

Figure 1.3 Root elongation growth rate (REGR) and apoplast pH changes

Profile of surface $\mathrm{pH}(\square)$ and REGR $(\bullet)$ along the apical $12 \mathrm{~mm}$ of a growing maize root measured in $\mathrm{pH} 6.75$ medium (A) and after $10 \mu \mathrm{M}$ IAA treatment (B) or $3 \mathrm{mM}$ KCN treatment (C). Position 0 refers to the tip of the root cap. Reprint from Peters \& Felle (1999) based on open access policy of www.plantphysiology.org with copyright American Society of Plant Biologists. 


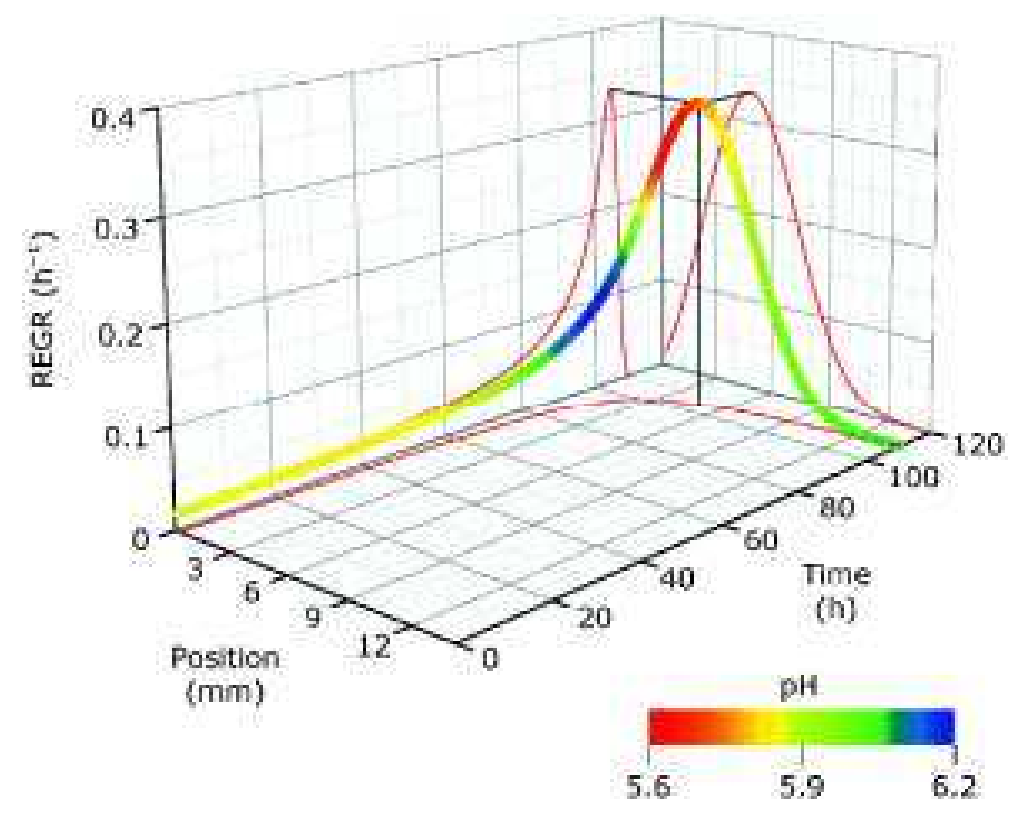

Figure 1.4 Trajectory of a root element

The figure shows the relation of the parameter time, position on the root, relative elemental growth rate (REGR) and surface $\mathrm{pH}$ (colour-coded) in growing maize root. The element considered is located at $0.2 \mathrm{~mm}$ above root apex at 0 time point. Reprint from Peters (2004) with the permission of the publisher (Licence No: 2693010825600, 'John Wiley and Sons')

Amtmann et al., (1999) using different experimental systems had similar results on barley roots. They found that $\mathrm{H}^{+}$excretion could have crucial role in activation of inward $\mathrm{K}^{+}$channels. Changes in cytosolic $\mathrm{pH}$ and $\mathrm{K}^{+}$might be significant factors which contribute to the root growth response to changes in $\mathrm{K}^{+}$supply.

\subsubsection{Potassium uptake and 'acid growth'}

Potassium is the main inorganic solute used by most plant cells to generate osmotic pressure. Its cytosolic concentration is tightly regulated. Therefore, one would expect that changes in the $\mathrm{PM}-\mathrm{H}^{+}$-ATPase pump activity affect growth not only through changes in wall properties, but also through changes in $\mathrm{K}^{+}$uptake. Recent data show that 'acid growth' and $\mathrm{K}^{+}$uptake are related processes. Auxin and fusicoccin-induced growth was not present in absence of $\mathrm{K}^{+}$(Claussen et al., 1997; Tode \& Lüthen, 2001).

Claussen et al. in 1997 observed for abraded maize coleoptiles that auxininduced growth and $\mathrm{K}^{+}$uptake were related processes. For auxin-induced growth the $\mathrm{K}^{+}$concentration in the medium was essential. In absence of $\mathrm{K}^{+}$an effect of auxin on growth was not observed, whereas when $\mathrm{K}^{+}$was added to the medium, auxin-related growth was immediately measured. The $\mathrm{K}^{+}$channel blocker triethylammonium (TEA) 
also suppressed the growth response to auxin, and when the blocker was removed, growth recovered as shown in Fig. 1.5 (Claussen et al., 1997). In a related study, a similar $\mathrm{K}^{+}$-dependency was observed for fusicoccin-induced growth (Tode \& Lüthen, 2001).
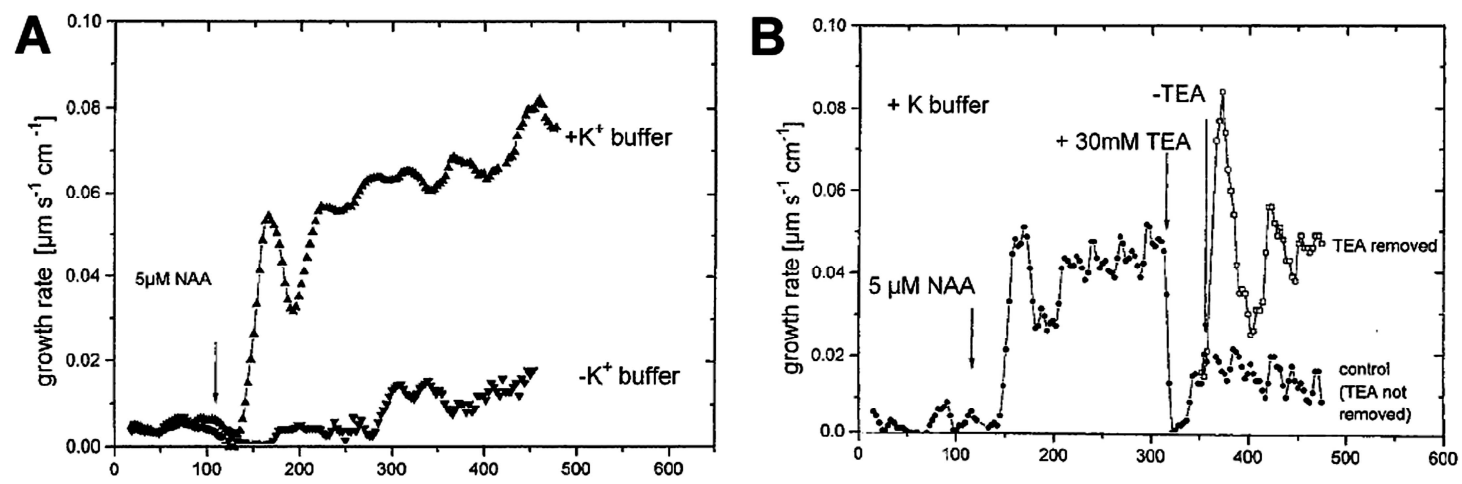

Figure 1.5 Potassium transport dependency of abraded maize coleoptiles

Potassium dependency of growth of coleoptiles was tested using a medium which contained $10 \mathrm{mM} \mathrm{K}^{+}$or no added $\mathrm{K}^{+}(\mathrm{A})$. TEA, a $\mathrm{K}^{+}$channel blocker, inhibited auxininduced growth; the blockage was completely reversible (B). When TEA was removed and replaced by incubation medium containing $10 \mathrm{mM} \mathrm{K}^{+}$and $\mathrm{NAA}$, the growth rate recovered at the level before TEA treatment. Reprint from Claussen et al. (1997) with the permission of the publisher (Licence No: 2693030934022, 'Springer')

ZMK1 and ZMK2 $\mathrm{K}^{+}$channels genes from maize were tested from the viewpoint of coleoptile growth. ZMK1 seemed to be growth related, acidification immediately increased channel activity and auxin increased its expression but acidic $\mathrm{pH}$ did not changed the expression pattern (Philippar et al., 1999). Over- expression of ZMK1 leads to $\mathrm{K}^{+}$independent growth (Philippar et al., 2006). Similar results have been obtained for the Arabidopsis $\mathrm{K}^{+}$channel AtKAT1 in growing hypocotyl and flower stalk (Philippar et al., 2004).

\subsection{Plasma membrane $\boldsymbol{H}^{+}$-ATPase}

Plasma membrane $\mathrm{H}^{+}$-ATPase (PM- $\mathrm{H}^{+}$-ATPase) was first discovered in 1946 when acid dependent glucose transport was described during the fermentation of the yeast Saccharomyces cerevisiae (Conway \& O'Malley, 1946). Cyanide and sodium azide caused plasma membrane potential decreases in Neurospora crassa within seconds, which also suggested an ATP-dependent $\mathrm{H}^{+}$pump activity (Slayman, 1965). The enzyme from fungi Schizosaccharomyces pombe and $S$. cerevisiae was isolated and shown to be a proton-pumping ATPase creating -150 to $-300 \mathrm{mV}$ plasma membrane potential in plants and fungi (Morth et al., 2011). 
PM- $\mathrm{H}^{+}$-ATPase is a single polypeptide with a molecular mass of $\sim 100 \mathrm{kDa}$ (Michelet \& Boutry, 1995). ATPase activity is usually between $1-2 \mu \mathrm{mol} \mathrm{P}_{\mathrm{i}} \mathrm{min}^{-1} \mathrm{mg}^{-1}$ in purified plasma membrane (Morsomme \& Boutry, 2000). The enzyme is essential for living plant cells as it constitutes, to the best of our current knowledge, the primary ion pump which generates the electrochemical potential across the plasma membrane. This electrochemical gradient is responsible for ionotropic signalling, secondary transport, nutrient uptake, $\mathrm{pH}$ homeostasis, salt tolerance, stomatal and leaf movements and cell growth (Palmgren, 2001; Moran, 2007; Duby \& Boutry, 2009). The PM- $\mathrm{H}^{+}$-ATPase protein is a member of the family of P-type ATPases. Other members of this family include the $\mathrm{Na}^{+}, \mathrm{K}^{+}$-ATPase, the principal ion pump in animals and humans (Morth et al., 2011).

\subsubsection{Isoforms of PM- $\mathrm{H}^{+}$-ATPase}

Using the model plant Arabidopsis thaliana twelve PM- $\mathrm{H}^{+}$-ATPase isoforms were identified from the genome (AHA1-12). The AHA12 isoforms carries two large deletions and is possibly a pseudogene (Palmgren, 2001). AHA1 and AHA2 are virtually expressed in all tissues and organs and function as housekeeping gene

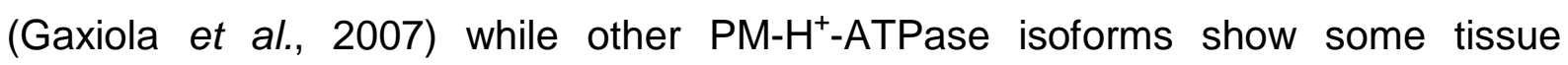
specificity of expression (Morsomme \& Boutry, 2000; Palmgren, 2001; Gaxiola et al., 2007). Tissue-specific localization of $\mathrm{PM}-\mathrm{H}^{+}$-ATPase is summarised in Table 1.1, based on information provided in (Palmgren, 2001).

There is only one isoform of $\mathrm{PM}-\mathrm{H}^{+}$-ATPase known in full detail for barley (Hordeum vulgare) based on nucleotide and protein data bases (NCBI, http://www.ncbi.nlm.nih.gov/ and UniProt http://www.uniprot.org/). However, MS / MS results suggest that there exist at least two different $\mathrm{PM}-\mathrm{H}^{+}$-ATPase isoforms in barley (Hynek et al., 2006). 
Table 1.1 Localisation of specific PM- $\mathrm{H}^{+}$-ATPase isoforms in plant body (Palmgren, 2001)

\begin{tabular}{|c|c|c|}
\hline Tissue & PM-ATPase protein & Plant \\
\hline \multicolumn{3}{|l|}{ Seedlings: } \\
\hline Cotyledon & PMA1, PMA2, PMA4 & N. plumbaginifolia \\
\hline \multicolumn{3}{|l|}{ Root: } \\
\hline Cortex parenchyma & PMA2, PMA3, PMA4 & N. plumbaginifolia \\
\hline Extension zone & PMA4 & N. plumbaginifolia \\
\hline Lateral root initials & PMA2, PMA4 & N. plumbaginifolia \\
\hline Lateral roots & PMA4, PMA9 & N. plumbaginifolia \\
\hline Root hair and epidermis & $\begin{array}{l}\text { PMA1, PMA3, PMA4 } \\
\text { MHA2 }\end{array}$ & $\begin{array}{l}\text { N. plumbaginifolia } \\
\text { Zea mays }\end{array}$ \\
\hline Root cap & PMA2, PMA4 & N. plumbaginifolia \\
\hline $\begin{array}{l}\text { Stele (central cylinder) } \\
\text { Stem: }\end{array}$ & Stem: & N. plumbaginifolia \\
\hline Axillary buds & PMA2, PMA4, PMA9 & N. plumbaginifolia \\
\hline Cortex parenchyma & PMA1, PMA2, PMA4 & N. plumbaginifolia \\
\hline Pith & PMA4 & N. plumbaginifolia \\
\hline \multirow[t]{3}{*}{ Vascular tissue } & PMA2, PMA3, PMA4, PMA9 & N. plumbaginifolia \\
\hline & MHA2 & Zea mays \\
\hline & AHA3 & A. thaliana \\
\hline \multicolumn{3}{|l|}{ Leaf: } \\
\hline \multirow[t]{3}{*}{ Guard cells } & PMA2, PMA4 & N. plumbaginifolia \\
\hline & VHA1, VHA2 & Vicia faba \\
\hline & MHA2 & Zea mays \\
\hline \multirow[t]{2}{*}{ Mesophyll } & PMA2, PMA4 & N. plumbaginifolia \\
\hline & VHA1, VHA2 & Vicia faba \\
\hline Trichomes (long) & PMA4 & N. plumbaginifolia \\
\hline Trichomes (short) & PMA6 & N. plumbaginifolia \\
\hline \multirow[t]{3}{*}{ Vascular tissue } & PMA2, PMA3, PMA4 & N. plumbaginifolia \\
\hline & MHA2 & Zea mays \\
\hline & AHA3 & A. thaliana \\
\hline \multicolumn{3}{|l|}{ Flower: } \\
\hline Carpel & PMA2 & N. plumbaginifolia \\
\hline \multirow[t]{2}{*}{ Ovules } & $\begin{array}{l}\text { PMA1, PMA2, PMA3, PMA4, } \\
\text { PMA6, PMA9 }\end{array}$ & N. plumbaginifolia \\
\hline & $\mathrm{AHA3}, \mathrm{AHA} 10$ & A. thaliana \\
\hline Nectaries & PMA2 & N. plumbaginifolia \\
\hline \multirow[t]{2}{*}{ Stamen; pollen } & $\begin{array}{l}\text { PMA1, PMA2, PMA3, PMA4, } \\
\text { PMA6, PMA6 }\end{array}$ & N. plumbaginifolia \\
\hline & AHA3, AHA9 & A. thaliana \\
\hline Style & PMA1, PMA3, PMA4 & N. plumbaginifolia \\
\hline \multirow[t]{2}{*}{ Vascular tissue } & $\begin{array}{l}\text { PMA1, PMA2, PMA3, PMA4, } \\
\text { PMA6 }\end{array}$ & N. plumbaginifolia \\
\hline & AHA3 & A. thaliana \\
\hline
\end{tabular}




\subsubsection{Structure of PM- $H^{+}$-ATPase}

The crystal structure of AHA2, a $\mathrm{PM}-\mathrm{H}^{+}$-ATPase from Ababidopsis thaliana, has recently been described (Fig. 1.6). The protein contains a transmembrane domain with ten helices (M1-10) and three cytosolic domains: a nucleotide-binding domain $(N)$, a phosphorylation domain $(P)$ and an actuator domain $(A)$. ATP is bound with the adenosine part at the $\mathrm{N}$ domain and its triphosphate group protruded towards the $\mathrm{P}$ domain. ATPase binding site was determined using 5 '-( $\beta, \gamma$-methlene)-triphosphate (AMPPCP) a non-hydrolysable analogue of ATP (Pedersen et al., 2007).

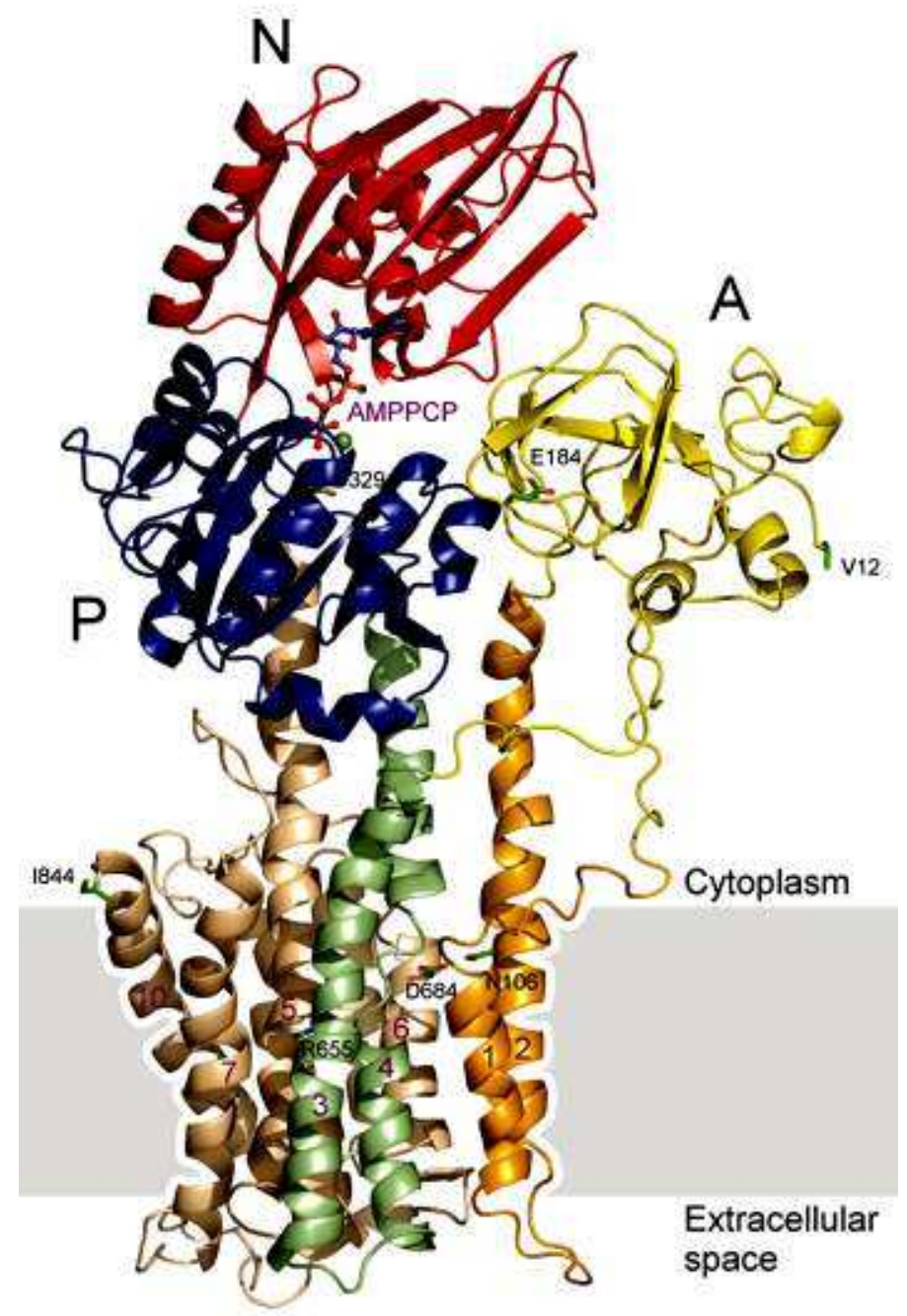

Figure 1.6 Structure of AHA2 without auto-inhibitory domain

AHA2 contains ten transmembrane helices (orange, green and brown); a nucleotide binding domain $(\mathrm{N})$, red; a phosphorylation domain $(\mathrm{P})$, blue; and an actuator domain (A); yellow. AMPPCP is shown as ball-and stick representation. The grey box represents the location of the plasma membrane; reprinted from Pedersen et al. (2007) with the permission of the publisher (Licence No: 2693040963163, 'Nature Publishing Group'). 


\subsubsection{Catalytic cycle of P-type ATPase and $\mathrm{H}^{+}$transport mechanism}

$\mathrm{PM}-\mathrm{H}^{+}$-ATPase undergoes conformational changes during each catalytic cycle. The enzyme has two distinct conformational states termed E1 and E2. The two conformation states differ in reactivity at the nucleotide binding site, which can be phosphorylated by ATP in the E1 form or by free $\mathrm{P}_{i}$ in the E2 form. $\mathrm{E} 1$ is the form that binds ATP and $\mathrm{H}^{+}$. The catalytic cycle is shown in details in Fig 1.7 (Morsomme \& Boutry, 2000; Pedersen et al., 2007).
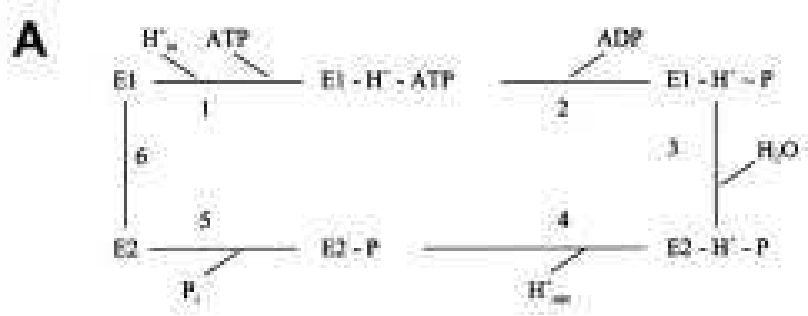

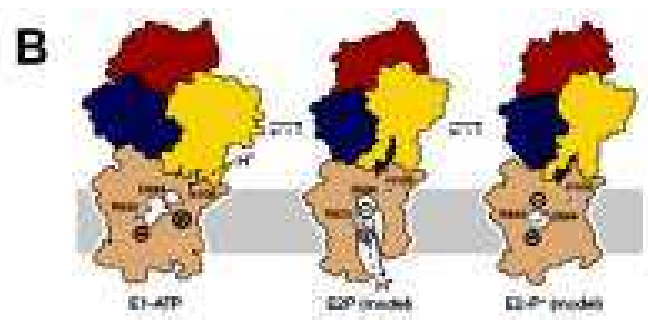

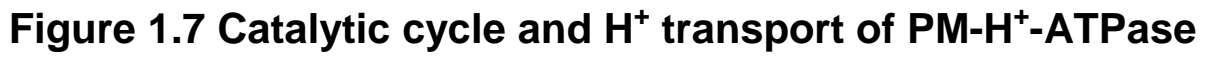

Originally the catalytic cycle was proposed for $\mathrm{Ca}^{2+}$ ATPase (subfigure A) E1 form binding ATP and $\mathrm{H}^{+}(1)$, then a high energy intermediate is formed while ADP is released (2). Conformation of the enzyme is changing from E1 to E2 (3). Proton release to cell exterior (4), finally $P_{i}$ is released (5) and conformation of the enzyme returning to form E1 (Morsomme \& Boutry, 2000). The E1 form binds $\mathrm{H}^{+}$and ATP better than the E2 binds these substances, as subfigure B shows; reprinted from Pedersen et al. (2007) with the permission of the publisher (Licence No: 2693040963163, 'Nature Publishing Group').

\subsubsection{Control of PM- $H^{+}$-ATPase}

Activity of PM- $\mathrm{H}^{+}$-ATPase is modulated by several physiological signals (such as temperature and salt stress). In comparison, there exists little evidence of a regulation of $\mathrm{PM}-\mathrm{H}^{+}$-ATPase activity through changes at the transcriptional or protein level. Moderate $\mathrm{PM}-\mathrm{H}^{+}$-ATPase expression changes have been describe for high aluminium treatment, (Shen et al., 2005), iron deficiency (Santi et al., 2005), in presence of high sugar concentration (Mito et al., 1996) and high salt treatment (Maathuis et al., 2003) .

Higher (compared to the 'average' tissue) $\mathrm{PM}-\mathrm{H}^{+}-\mathrm{ATPase}$ protein concentrations have been found in guard cells, root epidermis, phloem xylem parenchymas (Bouche-Pillon et al., 1994; Michelet \& Boutry, 1995; Morsomme \& Boutry, 2000; Palmgren, 2001; Gaxiola et al., 2007) and motor organs of seismonastic plants (Fleurat-Lessard et al., 1997; Moran, 2007).

Regulated exocytosis of vesicles that contains $\mathrm{PM}-\mathrm{H}^{+}$-ATPase molecules constitutes an alternative regulation pathway (Hager et al., 1991), yet post- 
translational modification of the enzyme seem the most common control mechanism for causing changes in PM- $\mathrm{H}^{+}$-ATPase activity (Gaxiola et al., 2007).

Phosphorylation / dephosphorylation are further mechanisms through which $\mathrm{PM}-\mathrm{H}^{+}$-ATPase can be regulated. Elicitor-induced dephosphorylation in tomato plants (Lycopersicon esculentum) resulted in an increase in PM- $\mathrm{H}^{+}$-ATPase activity (VeraEstrella et al., 1994) while subsequent phosphorylation of the enzyme reduced its activity; although $\mathrm{Ca}^{2+}$-dependent phosphorylation caused decreased $\mathrm{H}^{+}$pumping activity. Phosphorylation also activates $\mathrm{PM}-\mathrm{H}^{+}$-ATPase activity through the fusicoccin (and 14-3-3 protein) activation pathway (Morsomme \& Boutry, 2000).

The C-terminal auto-inhibitor regulation domain $(R)$ could be mainly responsible for rapid activity changes of $\mathrm{PM}-\mathrm{H}^{+}$-ATPase. Removal of the $\mathrm{R}$ domain from the enzyme by trypsin digestion activated PM- $\mathrm{H}^{+}$-ATPase (Palmgren et al., 1991). Structural information of molecular mechanism of the auto-inhibition is not available yet. In AHA2 neutralisation of the auto-inhibitory $\mathrm{R}$ domain by binding of 143-3 protein results in pump activation. Before the activation process, the penultimate Thr947 needs to be phosphorylated by a protein kinase which is induced by environmental factors such as light, nutrient status and pathogens. This phosphorylation can lead to the binding of 14-3-3 protein on the R domain complex. The Thr947 is not freely accessible to protein kinase activity, structural modification is necessary by ligand binding or kinase docking. Phosphorylation of Ser931 inhibits PM- $\mathrm{H}^{+}$-ATPase and destroys the 14-3-3 protein binding site (Sze et al., 1999; Morth et al., 2011). It seems that phosphorylation of most residues within the C-terminal domain impacts on 14-3-3 binding. The enzyme regulation is controlled by distinct protein kinases and phosphatases allowing gradual increase and decrease of the activity of PM-H+ $\mathrm{H}^{+}$-ATPase (Speth et al., 2010). More details are provided in Fig. 1.8. 

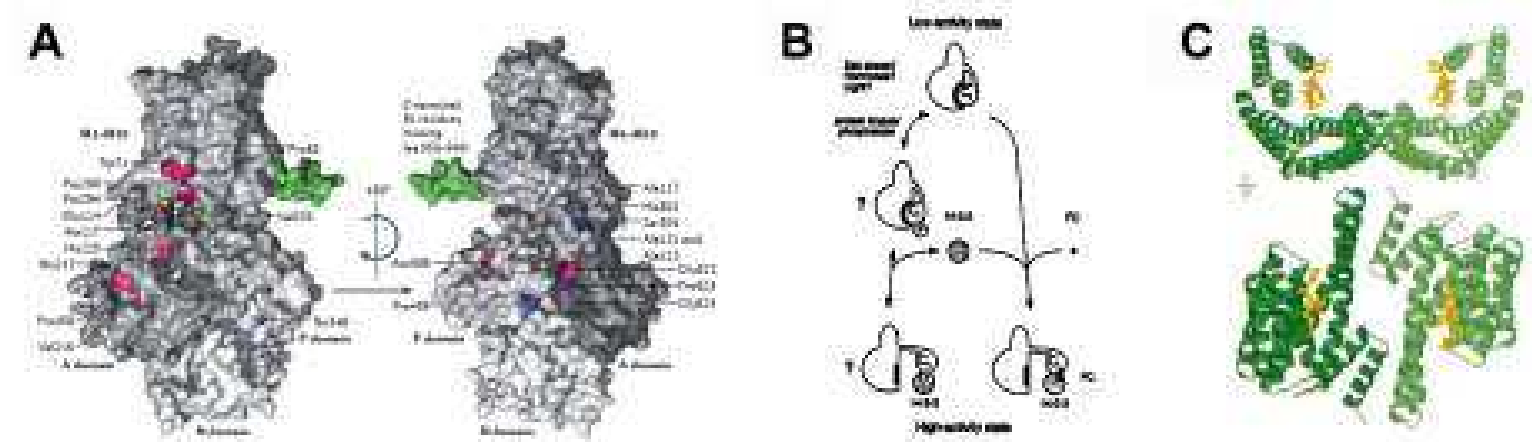

Figure 1.8 Auto-inhibition of PM-H ${ }^{+}$-ATPase

On subfigure A residues are highlighted on the $\mathrm{PM}-\mathrm{H}^{+}$-ATPase (AHA2) that interact with the regulatory domain. Blue: present in yeast; red: present in plant; yellow: present in plant $\mathrm{Ca}^{2+}$-ATPase.; green: 13 residue carboxy-terminal extension. Plant and fungal sites do not overlap, and it is likely that their pumps are inhibited by different mechanisms (Morth et al., 2011). B: schematic summary of protein kinase/phosphatise-dependent and fusicoccin-dependent activation pathway of PM$\mathrm{H}^{+}$-ATPase. Subfigure $\mathrm{C}$ shows the ribbon plot of different orientation of dimeric tobacco 14-3-3c protein (green) bound to the C-terminal end (yellow) of PMA2 (tobacco PM- $\mathrm{H}^{+}$-ATPase) (Würtele et al., 2003). Figures are reprint from Morth et al. (2011) with the permission of the publisher, Licence No: 2693050346303, 'Nature Publishing Group' (A); Sze et al. (1999) based on open access policy of www.plantcell.org with copyright American Society of Plant Biologists (B) and Würtele et al. (2003) with the permission of the publisher, Licence No: 2693070537163, 'Nature Publishing Group' (C).

\subsubsection{Fusicoccin-dependent PM- $H^{+}$-ATPase activation}

Fusicoccin (a diterpene glycoside) is a phytotoxin, produced by the fungus Fusicoccum amygdali. The fungus is host specific, but isolated fusicoccin causes higher $\mathrm{H}^{+}$efflux in any higher plant tested so far (Marré, 1979). Recent structural studies show that fusicoccin is increasing $\mathrm{H}^{+}$pump activity by stabilising the interaction between 14-3-3 protein and auto-inhibitor $\mathrm{R}$ domain of $\mathrm{PM}-\mathrm{H}^{+}$-ATPase. Fusicoccin effective due binding its plasma membrane receptor (Olivari et al., 1998) that is on the C-terminal of the R-domain of the PM- $\mathrm{H}^{+}$-ATPase (Johansson et al., 1993). This results in permanent binding of 14-3-3 protein to the regulation domain (Oecking et al., 1994) and activates PM- $\mathrm{H}^{+}$-ATPase permanently as shown in Fig. 1.8.

The toxin causes no major conformation changes; it fills a cavity between 14-3-3 protein and PM- $\mathrm{H}^{+}$-ATPase (Fig. 1.9) and increases the stability of the complex about 90 -fold (Würtele et al., 2003). 


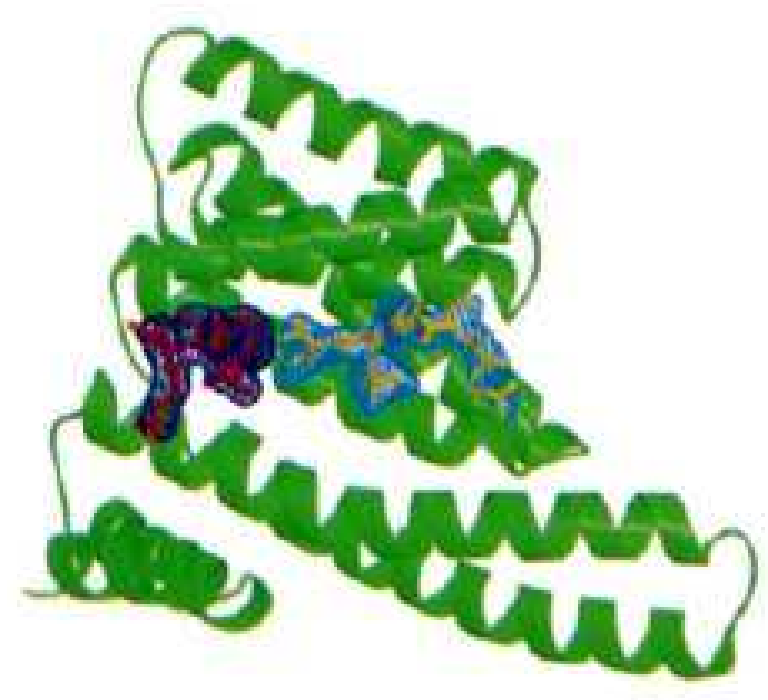

Figure 1.9 14-3-3 protein-fusicoccin-PM-H ${ }^{+}$-ATPase complex

Ribbon diagram of a 14-3-3 protein monomer (green) with $\mathrm{PM}-\mathrm{H}^{+}$-ATPase peptide (yellow) and fusicoccin (orange). Blue represent the Van der Waals space of fusicoccin and $\mathrm{PM}-\mathrm{H}^{+}$-ATPase peptide (reprint from Würtele et al. (2003) with the permission of the publisher, Licence No: 2693070537163, 'Nature Publishing Group')

\subsection{Barley}

Barley (Hordeum vulgare) was domesticated 10,000 years ago and ranks fourth among cereals after maize (Zea mays), rice (Oryza sativa) and wheat (Triticum aestivium) in terms of global production. About two-thirds of the annual global barley production is used for animal feeding and the remaining third covers the needs of malting, brewing (beer) and distilling (whiskey) industries (Schulte et al., 2009). The average annual production of barley in the world is about $1.24 \cdot 10^{11} \mathrm{~kg}$ and $62 \%$ of this is harvested in Europe. The highest yield per hectar occurs in Ireland with $5.7 \mathrm{Mg}$ ha $^{-1}$ (Kim \& Dale, 2004). In Ireland and Scotland brewing and distilling has a particularly big economic impact, not least because of the whiskey industry.

\subsubsection{The two weeks old barley seedlings and their advantage}

Barley seedlings at a developmental stage of two weeks old (between 14 - 17 days) present ideal research objects for leaf growth studies. At this stage leaf three is the main growing leaf and shows maximum or near-maximum growth rate $\left(2-3 \mathrm{~mm} \mathrm{~h}^{-1}\right)$. Older leaves, which cause self-shading and reduce the potential biomass increase have not developed yet and younger seedlings are not yet fully dependent on the external medium for supply of mineral nutrients but still receive a considerable portion through seed reserves. The base $40 \mathrm{~mm}$ of leaf three that contains the leaf 
elongation zone is enclosed by the sheath of the older leaves one and two (Fricke \& Flowers, 1998; Fricke, 2002a). There are small quantities of cuticle waxes deposited on the epidermal surface along the base $20-30 \mathrm{~mm}$ of the elongation zone. This means that the permeance of the cuticle is much higher in the elongation zone compared to the emerged blade, which makes external application of test reagents to measurements of proton extrusion from the leaf apoplast comparatively easy without having to mechanically remove the cuticle (Richardson et al., 2007).

\subsubsection{Morphology of developing barley leaves}

Barley leaves consist of two parts, the basal sheath and the leaf blade, separated by ligule and auricle. The sheath at the leaf base mechanically supports the blade which is the photosynthetic and transpirating active part of the leaf. The sheath also encloses the basal apical meristem, and any younger leaves emerge from within sheaths of older leaves. Leaves develop from the main meristem, which is located at the base. As a consequence, oldest tissues are at the leaf tip and youngest ones near the leaf base. The elongation zone of leaf three stretches to about $40 \mathrm{~mm}$ from the point of leaf insertion ('leaf base'), with highest relative elemental growth rates between $10-30 \mathrm{~mm}$ (Fricke \& Peters, 2002). In the elongation zone cells are elongating manyfold in size. Above the elongation zone is a zone which can be referred to as 'non-elongation zone'. This zone extends to the point of emergence of the developing leaf from the sheath of leaf two and contains cells which are not elongating any more but can show some lateral expansion. The fully emerged leaf blade contains fully-differentiated cells, which are not dividing or expanding any more. Details are provided in Fig. 1.10. 


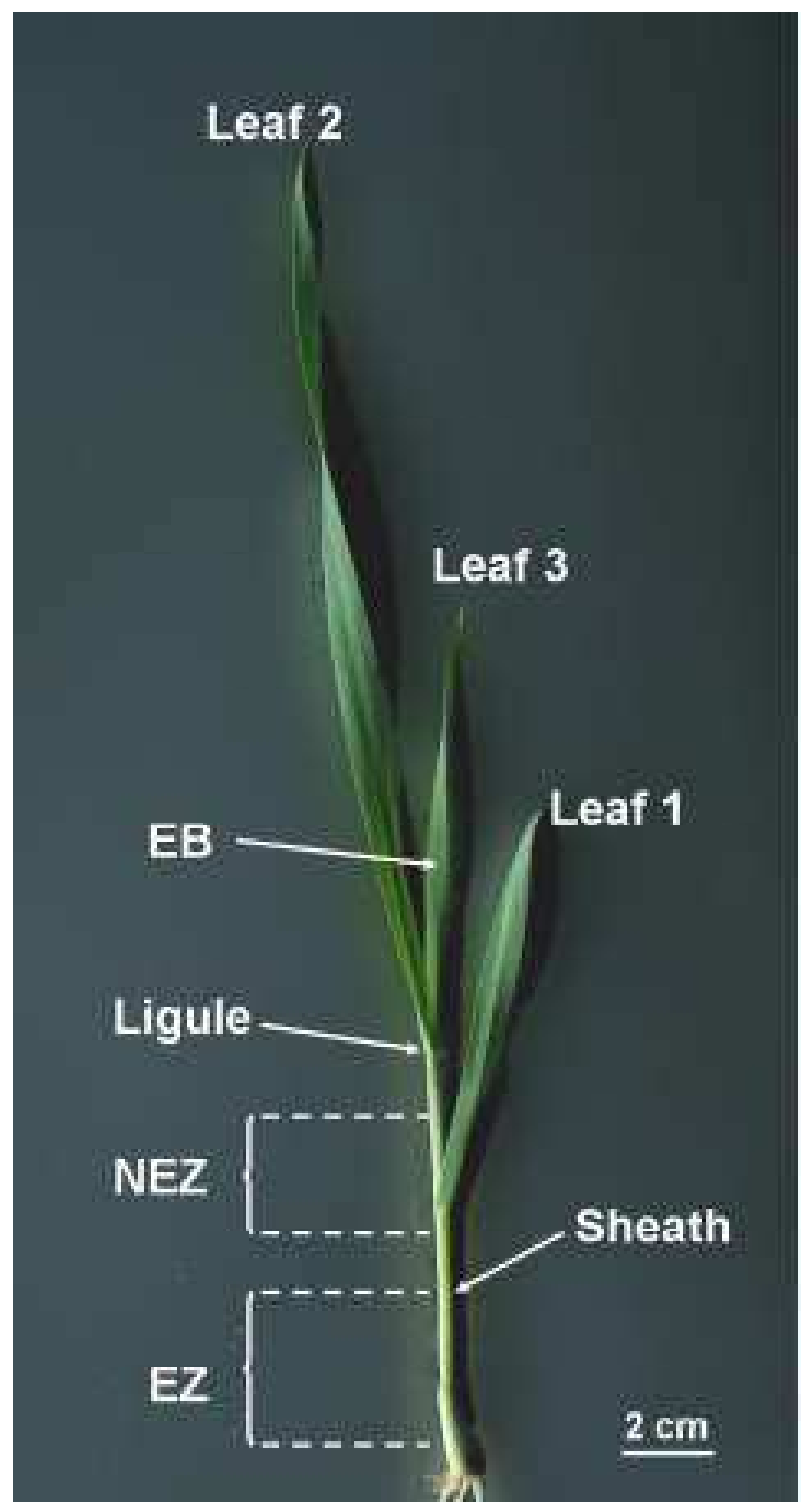

Figure 1.10 Two-week old barley seedling

The two-weeks old barley seedling has three leaves. Leaf one is the oldest leaf and leaf three is the youngest and main developing leaf. EZ: elongation zone; NEZ: nonelongation zone; EB: emerged leaf blade

\subsubsection{Anatomy of developing barley leaf}

Anatomical changes during leaf development can be visualised on cross sections of different parts of the leaf (Fig. 1.11). Cell size is increased manyfold in mature compared to immature tissue, although it is difficult to see this on cross sections, particularly in the epidermis, where elongation growth contributes most to cell enlargment. The most conspicuous difference between the different developmental stages is the specialisation of mesophyll cells for photosynthesis (chloroplast development), xylem (conductance of water and dissolved solutes) and increased intercellular spaces. 

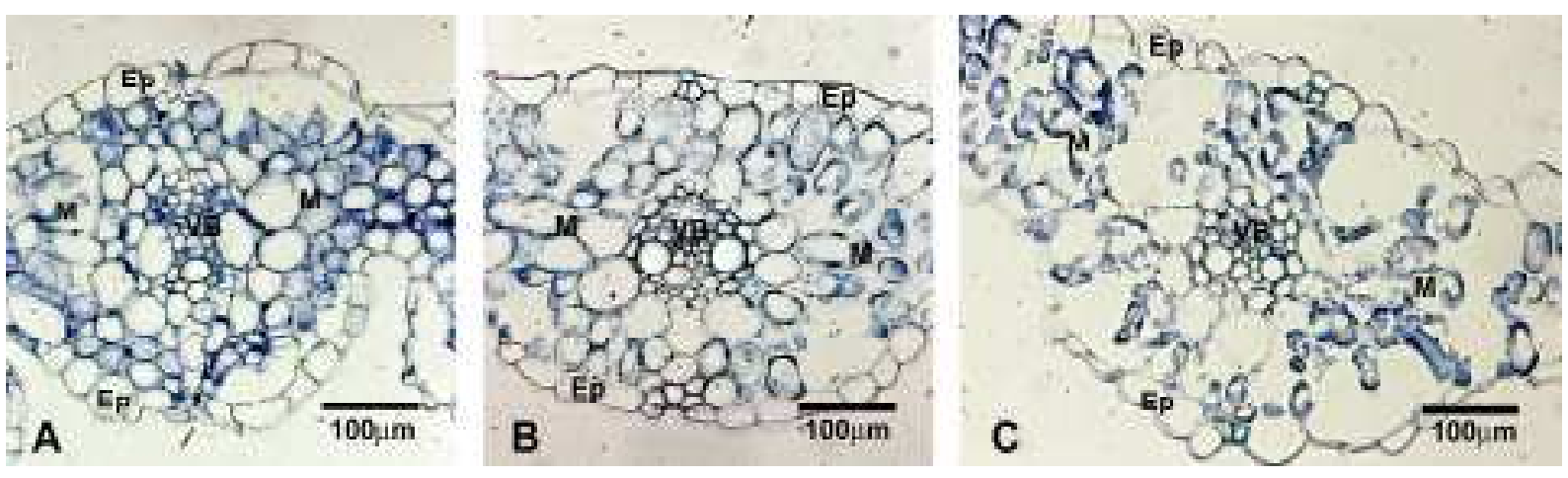

Figure 1.11 Toluidine blue stained cross section of barley leaves from different developmental stage

Cross sections from elongation zone (A) non-elongation zone (B) and fully emerged blade (C) of leaf three. Ep: epidermis; M: mesophyll cells; VB: vascular bundle.

\subsubsection{Growth and potassium uptake of barley}

The classical dual $\mathrm{K}^{+}$uptake mechanism has first been described for roots of barley (Epstein et al., 1963). Further studies proofed the relevance of high affinity $\mathrm{K}^{+}$ transporters for $\mathrm{K}^{+}$uptake; also $\mathrm{H}^{+} / \mathrm{K}^{+}$co-transport has a high significance in $\mathrm{K}^{+}$ uptake of roots (Glass et al., 1981; Amtmann et al., 1999). For barley, four HAK genes have been described (HvHAK1-4). HvHAK1 was mainly expressed in roots, HvHAK3 in both shoots and roots while HvHAK4 was mainly expressed in shoots (Rubio et al., 2000). HvHAK4 had significantly higher expression in the elongation zone of leaves compare with parts of barley seedlings (Boscari et al., 2009). HvHAK1 is very similar to AtHAK5 and seems to be a high affinity $\mathrm{K}^{+}$transporters in contrast with HvHAK2, which facilitates $\mathrm{K}^{+}$uptake in a range of low or medium affinity $\left(\mathrm{K}_{\mathrm{M}}\right.$ of about $5 \mathrm{mM}$ comparing with $\mathrm{K}_{\mathrm{M}}$ of about10 $\mu \mathrm{M}$ for HvHAK1 (Rubio et al., 2000; Senn et al., 2001; Ashley et al., 2006).

In previous studies on $\mathrm{K}^{+}$transport in barley it was concluded that apoplast $\mathrm{K}^{+}$ must exceed 3 - $5 \mathrm{mM}$ to allow growing leaf cells to take up $\mathrm{K}^{+}$through channels (Boscari et al., 2009; Volkov et al., 2009). Calculations showed that at $10 \mathrm{mM}$ apoplast $\mathrm{K}^{+}$, about $50 \%$ of $\mathrm{K}^{+}$uptake was facilitated by time-dependent inwardrectifying currents typical of Shaker $\mathrm{K}^{+}$channels such as AKT1 or AKT2. The remaining $50 \%$ was facilitated by instantaneous currents, which includes either or both, $\mathrm{K}^{+}$high-affinity transporters such as $\mathrm{HAK} / \mathrm{KUP} / \mathrm{KT}$ type $\mathrm{K}^{+} / \mathrm{H}^{+}$symporters or non-selective cation channels.

Potassium channels and transporters might study using different blockers of these proteins. Tetraethylammonia (TEA) inhibits $\mathrm{K}^{+}$transport through channels reversibly as $\mathrm{K}^{+}$analogue at the dehydration transition step (Lenaeus et al., 2005). 
$\mathrm{Cs}^{+}$ions as huge $\mathrm{K}^{+}$analogue block both channels and transporters (RodriguezNavarro \& Rubio, 2006; Szczerba et al., 2009) and $\mathrm{NH}_{4}{ }^{+}$ions with competitive manner inhibit high affinity $\mathrm{K}^{+}$transporters (Spalding et al., 1999; Kronzucker et al., 2003; Rodriguez-Navarro \& Rubio, 2006; Szczerba et al., 2006; Britto \& Kronzucker, 2008; Szczerba et al., 2009; Britto et al., 2010; Hoopen et al., 2010)

\subsection{Technical approaches}

(i) Cell wall acidification was measured using three independent methods $\mathrm{pH}$ sensitive fluorescence probe, micro $\mathrm{pH}$ electrode technique and in-vitro agarose gel system with bromocresol purple $\mathrm{pH}$ indicator. During these experiments leaf elongation was measured with a ruler (micro $\mathrm{pH}$ measurements) or image analysis tools (in-vitro gel experiments).

(ii) A linear variable differential transformer (LVDT) was used to determine the growth rate continuously and at micrometer resolution. This made it possible to record any rapid and short term response of leaf growth to application of test reagents to the apoplast of the leaf elongation zone.

(iii) Expression of $\mathrm{PM}-\mathrm{H}^{+}-\mathrm{ATPase}$ was determined by absolute $\mathrm{qPCR}$ technique and the PM- $\mathrm{H}^{+}$-ATPase enzyme ratio in total purified plasma membrane protein was measured using Western blot analysis and densitometry on Coomassie Brilliant Blue stained SDS polyacrylamide gels. Activity of the enzyme was determined as vanadate sensitive ATPase hydrolysis activity of inside-out plasma membrane vesicles.

(iv) $\mathrm{PM}-\mathrm{H}^{+}$-ATPase tissue specific distribution was studied using immunolocalisation on paraffin embedded section and a commercially-available antibody of $\mathrm{PM}-\mathrm{H}^{+}-\mathrm{ATPase}$ isoforms. 


\subsection{Objectives of the present study}

The aim of this project was to test whether apoplast $\mathrm{pH}$ differs between growing and non-growing leaf tissue of barley, how this acidification relates to growth and to which degree apoplast acidification relies on the activity, transcription and occurrence of $\mathrm{PM}-\mathrm{H}^{+}$-ATPase. The developing leaf three of barley was studied. Apoplastic $\mathrm{pH}$ and leaf elongation was measured together in the same experiments or in separate experiments. Differences in $\mathrm{pH}$ and leaf growth were followed using three independent techniques. Treatments affecting $\mathrm{PM}-\mathrm{H}^{+}$-ATPase activity (increase or decrease) or blockers of different type of $\mathrm{K}^{+}$transport (channel, transporter) were used to determine the physiological background of leaf elongation. Expression and activity of $\mathrm{PM}-\mathrm{H}^{+}$-ATPase was measured to test whether any higher acidity in the apoplast of the elongation zone originated from a higher expression of the enzyme or any other control mechanism, in particular post-translational modification. Finally

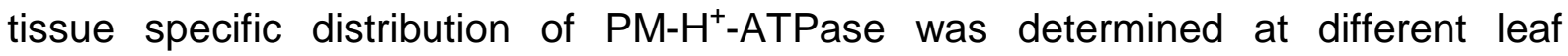
developmental stages on cross sections. 


\section{Materials and Methods}

\subsection{Plant material}

\subsubsection{Plant growth for study of leaves}

Barley seeds (Hordeum vulgare L. cv. Golf; and Hordeum vulgare L. cv. Jersey) were imbibed overnight in water, germinated in dark on approx. $0.5 \mathrm{mM} \mathrm{CaSO}_{4}$ for 3 days and exposed to light for a further 3 days while remaining on $\mathrm{CaSO}_{4}$ solution. On day seven, four seedlings were transferred into $1 \mathrm{I}$ borosilicate glass beakers wrapped in tin foil (containing $0.8-0.9$ I nutrient solution) on aerated $1 / 2$ strength Hoagland solution (Table 2.1) and grown for a further $7-11$ days at $70-80 \%$ relative humidity and $300-350$ $\mu \mathrm{mol} \mathrm{m} \mathrm{m}^{-2} \mathrm{~s}^{-1}$ photosynthetically active radiation at third-leaf level, during a $16 \mathrm{~h} / 8 \mathrm{~h}, 21$ ${ }^{\circ} \mathrm{C} / 15^{\circ} \mathrm{C}$ day / night cycle in a growth chamber (I MAGO F3000, Snijders Scientific). Nutrient solution was not replaced during plant growth. These were the growth conditions at University College Dublin, where most experiments were carried out. Some experiments, including plant growth, were also carried out at Rothamsted Research (UK) and Eötvös University (Hungary). Plants were analysed when they were 14 - $18 \mathrm{~d}$ old.

At Rothamsted Research ( $\mathrm{pH}$ microelectrode measurements) the growth temperature was different (constantly $20^{\circ} \mathrm{C}$ during day / night). At Eötvös University (plasma membrane isolation) plants were grown under a $14 \mathrm{~h} \mathrm{/} 10 \mathrm{~h}$ day / night period $\left(150 \mu \mathrm{mol} \mathrm{m} \mathrm{m}^{-2} \mathrm{~s}^{-1}\right)$ with $20 / 18 \mathrm{C}$ day / night temperature. These al terations in growth conditions were due to local availability of growth facilities and the seedlings achieved the leaf three development stage about 2 - 3 d later at Eötvös University and 1 - 2 earlier at Rothamsted Research compared with Dublin.

The barley Golf cultivar was used for most experiments. Towards the end of the study, the availability of Golf seeds became limited due to vast demand by the laboratory in general, no further commercial (breeder) availability of this cultivar and due to limited availability of growth space at UCD to grow plants to the seeding stage. Therefore, experiments which were carried out towards the end of the study, in particular plasma membrane isolation, were performed on the barley cultivar Jersey. Both, Golf and Jersey are spring barleys. 
Table 2.1 Composition of the $1 / 2$ strength Hoagland solution for barley seedlings

\begin{tabular}{|c|c|c|c|c|}
\hline $\begin{array}{l}\text { Macronutrients } \\
\text { (1I each) }\end{array}$ & $\begin{array}{l}\text { Stock } \\
(\mathrm{mM})\end{array}$ & $\begin{array}{l}\text { Amount for } \\
1 \text { I stock }(\mathrm{g})\end{array}$ & $\begin{array}{l}\text { Final concentration } \\
(\mathrm{mM})\end{array}$ & Dilution \\
\hline $\begin{array}{l}\text { (1) } \mathrm{NH}_{4} \mathrm{H}_{2} \mathrm{PO}_{4} \\
+\left(\mathrm{NH}_{4}\right)_{2} \mathrm{HPO}_{4}\end{array}$ & $\begin{array}{l}100 \\
100\end{array}$ & $\begin{array}{l}11.5 \mathrm{~g} \\
13.2\end{array}$ & $\begin{array}{l}0.5 \\
0.5 \\
\end{array}$ & $\begin{array}{l}200 x \\
200 x\end{array}$ \\
\hline (2) $\mathrm{KNO}_{3}$ & 400 & 40.4 & 2.0 & $200 x$ \\
\hline $\begin{array}{l}\text { (3) } \mathrm{MgSO}_{4} \times 7 \mathrm{H}_{2} \mathrm{O} \\
+\mathrm{NaCl}\end{array}$ & $\begin{array}{l}100 \\
100\end{array}$ & $\begin{array}{l}24.7 \\
5.84\end{array}$ & $\begin{array}{l}0.5 \\
0.5 \\
\end{array}$ & $\begin{array}{l}200 x \\
200 x\end{array}$ \\
\hline $\begin{array}{l}\text { (4) } \\
\mathrm{Ca}\left(\mathrm{NO}_{3}\right) 2 \times 4 \mathrm{H}_{2} \mathrm{O}\end{array}$ & 400 & 94,4 & 2.0 & $200 x$ \\
\hline
\end{tabular}

\begin{tabular}{l|c|c|l|l}
$\begin{array}{l}\text { Micronutrients } \\
(0.5 \text { I each) }\end{array}$ & $\begin{array}{c}\text { Stock } \\
(\mathrm{mM})\end{array}$ & $\begin{array}{c}\text { Amount for } \\
\text { 0.5I stock }(\mathrm{g})\end{array}$ & $\begin{array}{l}\text { Final concentration } \\
(\mu \mathrm{M})\end{array}$ & Dilution \\
\hline$\left(\right.$ a) $\mathrm{H}_{3} \mathrm{BO}_{3}$ & 25 & 0.775 & 6.25 & $4000 \mathrm{x}$ \\
\hline$\left(\right.$ b) $\mathrm{CuSO}_{4} \times 5 \mathrm{H}_{2} \mathrm{O}$ & 0.5 & 0.0625 & 0.125 & $4000 \mathrm{x}$ \\
\hline (c) $\mathrm{MnSO}_{4} \times \mathrm{H}_{2} \mathrm{O}$ & 2 & 0.169 & 0.5 & $4000 \mathrm{x}$ \\
\hline $\begin{array}{l}\text { (d) } \\
\mathrm{Na}_{2} \mathrm{MoO}_{4} \times 2 \mathrm{H}_{2} \mathrm{O}\end{array}$ & 0.76 & 0.092 & 0.19 & $4000 \mathrm{x}$ \\
\hline $\begin{array}{l}(\mathrm{e}) \mathrm{ZnCl}_{2} \\
\left.\mathrm{ZnSO} \mathrm{SO}_{4}\right)\end{array}$ & 2 & 0.136 & 0.5 & $4000 \mathrm{x}$ \\
\hline (f) $\mathrm{Fe}^{\text {III) }} \mathrm{NaEDTA}$ & 36 & 6.606 & 27 & $1333 \mathrm{x}$
\end{tabular}

\subsubsection{Plant growth for study of coleoptiles}

To grow coleoptiles for auxin sensitivity test Golf barley seeds were imbibed overnight in water and were germinated in the dark for $5 \mathrm{~d}$ in the growth chamber under the same temperature settings $\left(16 \mathrm{~h}\right.$ at $21^{\circ} \mathrm{C}, 8 \mathrm{~h}$ at $\left.15^{\circ} \mathrm{C}\right)$ as described for seedlings. The apical $10 \mathrm{~mm}$ of the coleoptile tip was used and the first leaf developing inside the coleoptiles was removed (compare Sakurai \& Masuda, 1978).

\subsection{Apoplast $\mathrm{pH}$ measurements}

Cell wall $\mathrm{pH}$ was measured through three independent approaches: an in-vitro gel system, electrophysiology and confocal microscopy. The in-vitro gel system involved incubating leaf segments in agarose which contained the $\mathrm{pH}$ indicator bromocresol purple. The advantage of this system was that it was easy to use. This made it possible to test many treatments and to directly relate changes in wall acidity to changes in growth rate. The $\mathrm{pH}$ microelectrode technique was used to obtain precise values of apoplast $\mathrm{pH}$ in growing and non-growing leaf regions. This technique, which was carried out at Rothamsted Research, required the most experimental effort and was used to a limited extent, due to limited funding for travel. Therefore only selected treatments were tested. Finally, intact plants were studied using 
confocal microscopy, by loading plants with $\mathrm{pH}$ fluorescence probes added to the root medium. Epidermal peels were also studied as control material.

\subsubsection{In-vitro gel system}

The base $70 \mathrm{~mm}$ of leaf three was placed into a Petri dish which had been filled with agarose medium containing the $\mathrm{pH}$ indicator bromocresol purple (Tang et al., 2004; Li et al., 2007). The younger fourth leaf was removed from inside leaf three prior to experiments.

The agarose medium contained $10 \mathrm{mM}, 1 \mathrm{mM} \mathrm{CaCl}_{2}, 0.5 \%$ agarose (gelling temperature $38.3^{\circ} \mathrm{C}$ ) and $90 \mathrm{mg} \mathrm{l}^{-1}$ bromocresol purple. Any additional test reagents were added to the medium while it was fluid and the $\mathrm{pH}$ was adjusted to 7.0 using $3 \mathrm{mM} \mathrm{KOH}$. The amount of $\mathrm{K}^{+}$added through this $\mathrm{pH}$ adjustment was negligible compared to the amount of $\mathrm{K}^{+}$added through $10 \mathrm{mM} \mathrm{K}^{+}$. Leaf pieces were placed into the medium when it was almost semi rigid and had a temperature of between 28 - $32{ }^{\circ} \mathrm{C}$. Petri dishes were incubated under the same conditions under which the plants had grown, except for cold-treatments, where dishes were incubated in the dark in a cold room $\left(5^{\circ} \mathrm{C}\right.$ ). At regular time interva ls (every hour for the first $10 \mathrm{~h}$ of incubation), Petri dishes were photographed with a Canon EOS 350D digital camera. Two replicate pictures were made every hour. Final pictures were made after $24 \mathrm{~h}$. Digital photographs were used to assess acidification of the medium and measure elongation growth of leaf pieces. ImageJ 1.410 software (http://rsbweb.nih.gov/ij) was used to measure the length of leaf pieces. Values were calibrated with the aid of graph paper which had been fixed to Petri dishes prior to the start of experiment. Due to the alkaline $\mathrm{pH}$ of the graph paper, the paper served as sort of an internal $\mathrm{pH}$ control as well since it gave the colour (bluish) of bromocresol purple in non-acidified medium. Acidic areas, which showed up as yellow in the purple-stained medium (see Fig. 2.1), were selected on pictures using the magic wand of Adobe ${ }^{\circledR}$ Photoshop ${ }^{\circledR}$ 7.0.1 (tolerance factor 10) and measured using Scion Image for Windows 4.0.3.2 (http://www.scioncorp.com, O'Neal et al., 2002).

Preparation of leaf pieces and transfer to agarose medium resulted in an immediate, non-specific acidification of the medium, most likely as a result of unpeeling leaf three from the sheaths of leaves one and two. This non-specific acidification levelled off within 4 - $5 \mathrm{~h}$. Preliminary experiments showed that the acid area value obtained after $1 \mathrm{~h}$ of incubation reflected the size of the exposed leaf surface of the individual plants therefore it was used as the reference point for the 
start of experiment $\left(A_{1}\right)$. Any areas measured at further time points 't' $\left(A_{t}\right)$ were related to this reference point according to ' $A_{t} / A_{1}$ '. Areas were expressed in $\mathrm{mm}^{2}$.

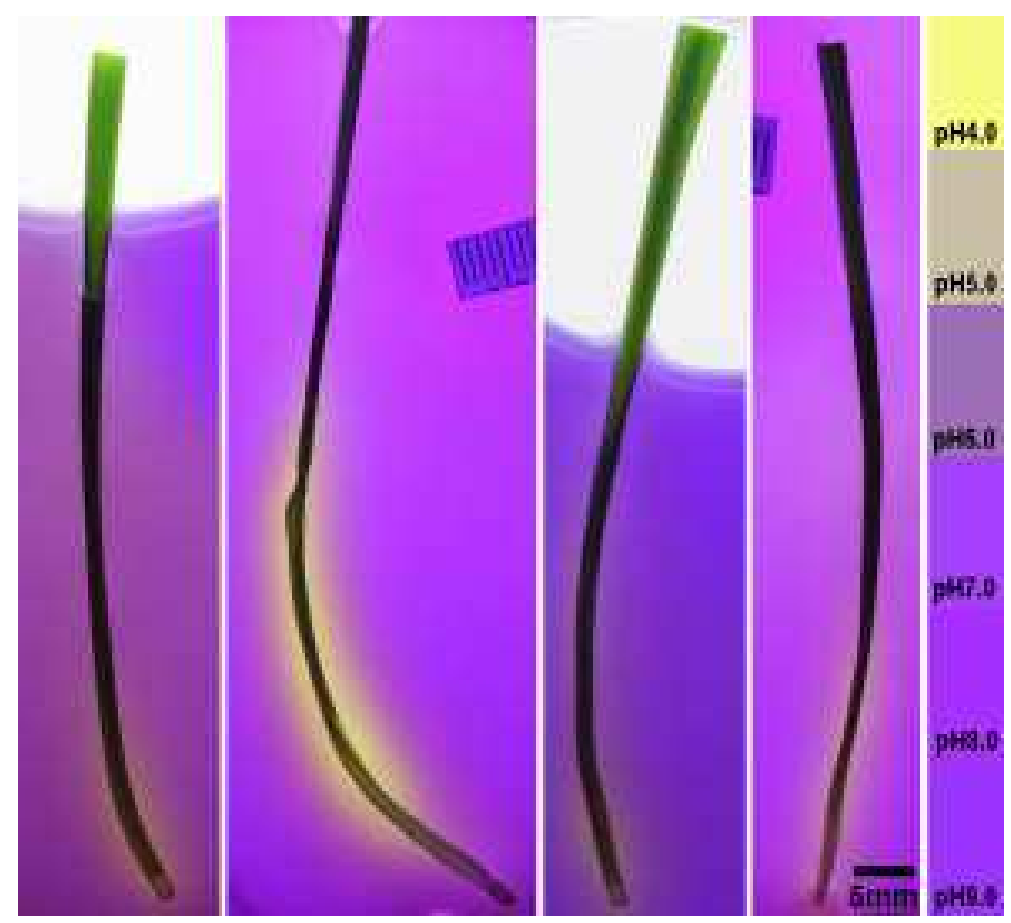

Figure 2.1 Leaf pieces in $\mathrm{pH}$ sensitive agarose gel medium

Agarose gels contained the $\mathrm{pH}$ indicator bromocresol purple $\mathrm{pH}$. This $\mathrm{pH}$ indicator shows yellowish colour at acidic, purple at neutral and blueish colour at alkaline $\mathrm{pH}$ (see right column). Basal leaf segments were $70 \mathrm{~mm}$ long at the beginning of the experiments, and their tip end was sticking out from the medium. Graph paper was used as an internal alkaline control and to calibrate length of leaf segments to measure growth during the incubation period.

\subsubsection{Microelectrode measurements}

Apoplastic $\mathrm{pH}$ was measured with the aid of $\mathrm{pH}$-sensitive microelectrodes. The elongation zone and emerged, mature portion of the developing leaf three of barley were analysed. The older leaves one and two were peeled back to expose the abaxial surface of the basal elongation zone of leaf three. The elongation zone was covered with wet tissue paper which had been soaked for the previous $24 \mathrm{~h}$ in distilled water. The latter was done to guarantee $\mathrm{pH}$ neutrality (which is not the case for tissue paper which is used 'fresh'). During experiments, the tissue paper was soaked in bath solutions, as specified in results, to alter the apoplastic environment of the leaf elongation zone. Due to the absence of a major permeability barrier (cuticle) in the elongation zone (Richardson et al., 2007), apoplastic pH could be measured directly by bringing the microelectrode in close contact with the epidermal surface. Measurements were carried out at $20-30 \mathrm{~mm}$ from the base. In the fully- 
cutinised emerged-blade portion of the developing leaf three, apoplastic $\mathrm{pH}$ was measured by inserting the microelectrode through stomatal pores (compare Fricke et al., 1994; Felle 2005;). Double-barrelled pH sensitive microelectrodes were prepared as described in Miller \& Smith (1992) using the same setup and microelectrode cocktail as described in Dennis et al. (2009). The only difference was that in the present study a $\mathrm{pH} 5.0$ rather than $\mathrm{pH} 3.0$ calibration buffer was used and that an additional pH 8.5 calibration buffer was included. Calibration was performed before and after readings. The composition of the $\mathrm{pH}$ sensitive cocktail and calibration buffers is given in Table 2.2 and Table 2.3. Microelectrode outputs were analysed with Origin ${ }^{\circledR} 6.1$ (OriginLab Corporation) software.

Analysis of one leaf region of one plant typically lasted between 2 - 6 hours, and between $1-6 \mathrm{pH}$ recordings were taken for each leaf region under room temperature and humidity in the dark. To avoid too long exposure of plants on the microelectrode rig, recordings for elongation zone and emerged blade were obtained from different plants. Elongation growth of leaf three of plants mounted on the rig was measured by measuring the length of leaf three at the beginning and end of experiments using a ruler. Preparation of plants reduced leaf elongation growth by about 50-60 \% compared to elongation growth of undisturbed plants in the growth chamber.

Table 2.2 Composition of the pH sensor for microelectrodes

Component of pH sensor

\begin{tabular}{l|l}
\hline \hline Hydrogen lonophore II Cocktail A & $35 \mathrm{mg}$ \\
\hline High molecular weight PVC & $16 \mathrm{mg}$ \\
\hline Nitrocellulose & $6 \mathrm{mg}$ \\
\hline Tetrahydrofuran (THF) & Dissolve the other components
\end{tabular}


Table 2.3 Composition of the buffer solutions used for calibrating $\mathrm{pH}$ microelectrodes

\begin{tabular}{|c|c|}
\hline pH & Composition of buffer \\
\hline 4.0 & $\begin{array}{l}20 \mathrm{mM} \mathrm{KHC}_{8} \mathrm{H}_{4} \mathrm{O}_{4} \text { (potassium hydrogen phthalate) } \\
120 \mathrm{mM} \mathrm{KCl} \\
10 \mathrm{mM} \mathrm{NaH} \\
\text { Adjust pH using } 1 \mathrm{~N} \mathrm{NaOH}\end{array}$ \\
\hline 5.0 and 6.0 & $\begin{array}{l}20 \mathrm{mM} \mathrm{MES} \mathrm{(2-[N-Morpholino]ethanesulfonic} \mathrm{acid)} \\
120 \mathrm{mM} \mathrm{KCl} \\
10 \mathrm{mM} \mathrm{NaH} \\
\text { Adjust pH using } 1 \mathrm{~N} \mathrm{NaOH}\end{array}$ \\
\hline 7.0 & $\begin{array}{l}20 \mathrm{mM} \mathrm{MOPS} \mathrm{(3-[N-Morpholino]propanesulfonic} \mathrm{acid)} \\
120 \mathrm{mM} \mathrm{KCl} \\
10 \mathrm{mM} \mathrm{NaH}_{2} \mathrm{PO}_{4} \times 2 \mathrm{H}_{2} \mathrm{O} \\
\text { Adjust pH using } 1 \mathrm{~N} \mathrm{NaOH}\end{array}$ \\
\hline 8.5 & $\begin{array}{l}20 \mathrm{mM} \text { TAPS (N-tris[Hydroxymethyl]methyl-3-amino- } \\
\text { propanesulfonic acis) } \\
120 \mathrm{mM} \mathrm{KCl} \\
10 \mathrm{mM} \mathrm{NaH} \mathrm{PO}_{4} \times 2 \mathrm{H}_{2} \mathrm{O} \\
\text { Adjust pH using } 1 \mathrm{~N} \mathrm{NaOH}\end{array}$ \\
\hline
\end{tabular}

\subsection{Confocal microscopy}

The $\mathrm{pH}$ sensitive fluorochromes $5(6)$ carboxyfluorescein $(10 \mu \mathrm{M})$ and acridine orange $(2.5 \mu \mathrm{M})$ were used. In contrast to carboxyfluorescein, acridine orange can be taken up into cells and has been widely used to monitor $\mathrm{pH}$ inside animal (Wieczorek et al., 1991; Zoccarato et al., 1999; Malnic \& Geibel, 2000) and plant cells (Pope \& Leigh, 1988; DuPont, 1989). Carboxyfluorescein is a large double-negative charged anion that can permeate the plasma membrane only in its non-fluorescing diacetate form (Babcock, 1983; Graber et al., 1986). By using its anionic form, its presence in the apoplast and absence in the symplast was guaranteed. The application of acridine orange has some limitations (Palmgren, 1991) but with adequate controls these limitations can be overcome (Clerc \& Barenholz, 1998; Manente et al., 2008). The fluorescence intensity of carboxyfluorescein between $\mathrm{pH} 4.5$ and 6.5 can be used to reflect changes in $\mathrm{pH}$ conditions in this $\mathrm{pH}$ range (Babcock, 1983; Graber et al., 1986).

Dyes were added to the root medium of intact plants in the growth chamber. Plants were allowed to take up dyes into the apoplastic space of both roots and leaves and analysed after an incubation period of $24 \mathrm{~h}$ (carboxyfluorescein) and $48-72 \mathrm{~h}$ (acridine orange). Detached leaves, epidermal peels or leaves still attached to the remainder of the plant were examined with an Olympus FV1000 confocal microscope. Dyes were excited at $488 \mathrm{~nm}$ and fluorescence was detected between 
$500-550 \mathrm{~nm}$ (carboxyfluorescein) and 516 - $536 \mathrm{~nm}$ (acridine orange). To test how effective the uptake of dye into the leaf apoplast had been during the incubation period and how $\mathrm{pH}$ sensitive the approach was, epidermal strips were peeled from first leaves of incubated barley plants or from the elongation zone and emerged blade of leaf three. The strips were placed into buffers of specified $\mathrm{pH}$ for $30 \mathrm{~min}$, before being examined under the confocal microscope. Calibration of fluorochromes was carried out with a Leica DMIL fluorescence microscope. The microscope's excitation filter was cut between $450-490 \mathrm{~nm}$ and the suppression filter at $515 \mathrm{~nm}$. For pH calibration, $50 \mathrm{mM}$ phthalate buffer (pH 4.0), $100 \mathrm{mM}$ MES / KOH (pH 5.5, $\mathrm{pH}$ 6.5) and $100 \mathrm{mM}$ TRIS-HCl (pH 7.5) was used. Digital images were analysed with ImageJ 1.410 software (http://rsbweb.nih.gov/ij) and Adobe ${ }^{\circledR}$ Photoshop ${ }^{\circledR}$ 7.0.1.

The $\mathrm{pH}$ dependence of fluorescence of 5(6)carboxyfluorescein and acridine orange were examined by recording fluorescence spectra at different $\mathrm{pH}$ using a FluoraMax-2 ${ }^{\circledR}$ (Instruments S.A.) (pH 5.0; pH 5.5; pH 6.0 - 50 mM MES-KOH; pH 6.5 - $50 \mathrm{mM}$ MES-BisTRIS and $\mathrm{pH} 7.0 ; \mathrm{pH} 7.5-50 \mathrm{mM}$ HEPES-HCl).

\section{$2.3 \quad$ LVDT measurements}

A linear variable differential transformer (LVDT) was used to measure changes in leaf length continuously and at micrometer resolution in response to treatments (compare Fricke, 2004; Fricke et al., 2004). The setup could also be used to determine changes in cell wall properties.

\subsubsection{Leaf growth measurements}

Plants were prepared in the same way as for electrophysiological analyses to be able to relate the results from both types of experiments to each other. Leaves one and two were peeled back and the exposed elongation zone of leaf three was wrapped in washed (24 $\mathrm{h}$ in distilled water) tissue paper which was soaked in the respective test solution. The wet tissue paper guaranteed a humid microclimate and prevented the elongation zone from drying out; it also allowed application of test reagents to the apoplast of elongating tissue. The base $40-50 \mathrm{~mm}$ of leaf three was wrapped to provide sufficient mechanical support to allow the leaf to remain in an upright position. Above $50 \mathrm{~mm}$ from the leaf base, the cuticle is sufficiently developed preventing the leaf tissue from drying out (Richardson et al., 2007). Roots were left in the same medium in which the particular plant had grown. The tip of leaf three was attached to fishing line and connected through cellotape to a LVDT (DFG 5.0; RS 
Components, Corby, UK). A counterweight of $2 \mathrm{~g}$ was applied. The LVDT signal was digitalised with a Burster 92101 data logger module with ICP 100 software. Changes in voltage output were recorded on PC using Pfloek 1.09 software (LS Pflanzenökologie, Universität Bayreuth, Germany). The system was calibrated by replacing the plant with a micrometer screw. The rate of growth was calculated from LVDT outputs using Origin ${ }^{\circledR} 6.1$ software (OriginLab Corporation) and Microsoft ${ }^{\circledR}$ Excel. Although leaf elongation rate was comparable between replicate plants and batches, values for treatments were expressed as percentage of the control to further minimise any plant-to-plant variation. The control value was the elongation rate of a particular plant attached to the LVDT before a treatment was applied. Typically, control plants had the elongation zone of leaf three wrapped with tissue paper soaked in either 1 or $0.1 \mathrm{mM} \mathrm{KCl}$. It took up to $1 \mathrm{~h}$ for elongation rate to reach a steady level following attachment of plants to the LVDT. Application of vanadate and $\mathrm{CsCl}$ treatments required a similar period of stabilisation (about $1 \mathrm{~h}$ ), while application of fusicoccin and ammonium treatments required leaf elongation rate to stabilise for up to 2 - $3 \mathrm{~h}$. LVDT experiments were carried out at room temperature and humidity under ambient laboratory light.

To assess how much plant preparation affected the elongation rate of leaf three, intact plants which did not have leaves one and two peeled back, were attached to the LVDT. In addition, leaf elongation rate was determined for undisturbed plants in the growth chamber by measuring twice daily the increment in leaf length with a ruler.

\subsubsection{Analysis of cell wall properties}

Cell wall elasticity and plasticity was measured with the same LVDT system as described above by applying an additional $3 \mathrm{~g}$ counterweight for $10 \mathrm{~min}$ following the approach taken by Neumann (1993) (see also Chazen \& Neumann (1994) and Sabrizhanova et al. (2005)). Plants were prepared and chemical treatments applied in the same way as for growth analyses. When the growth rate had stabilised (control, treatment), the additional $3 \mathrm{~g}$ counterweight was applied to the LVDT for 10 min and then removed; 30 - 40 min later, when growth rate had stabilised again, the experiment was repeated, and the average of these two measurements was used for calculations of wall properties. Elasticity and plasticity of walls and growth rate with and without the applied force (additional $3 \mathrm{~g}$ counterweight) was calculated from LVDT traces as detailed in Fig. 2.2. 


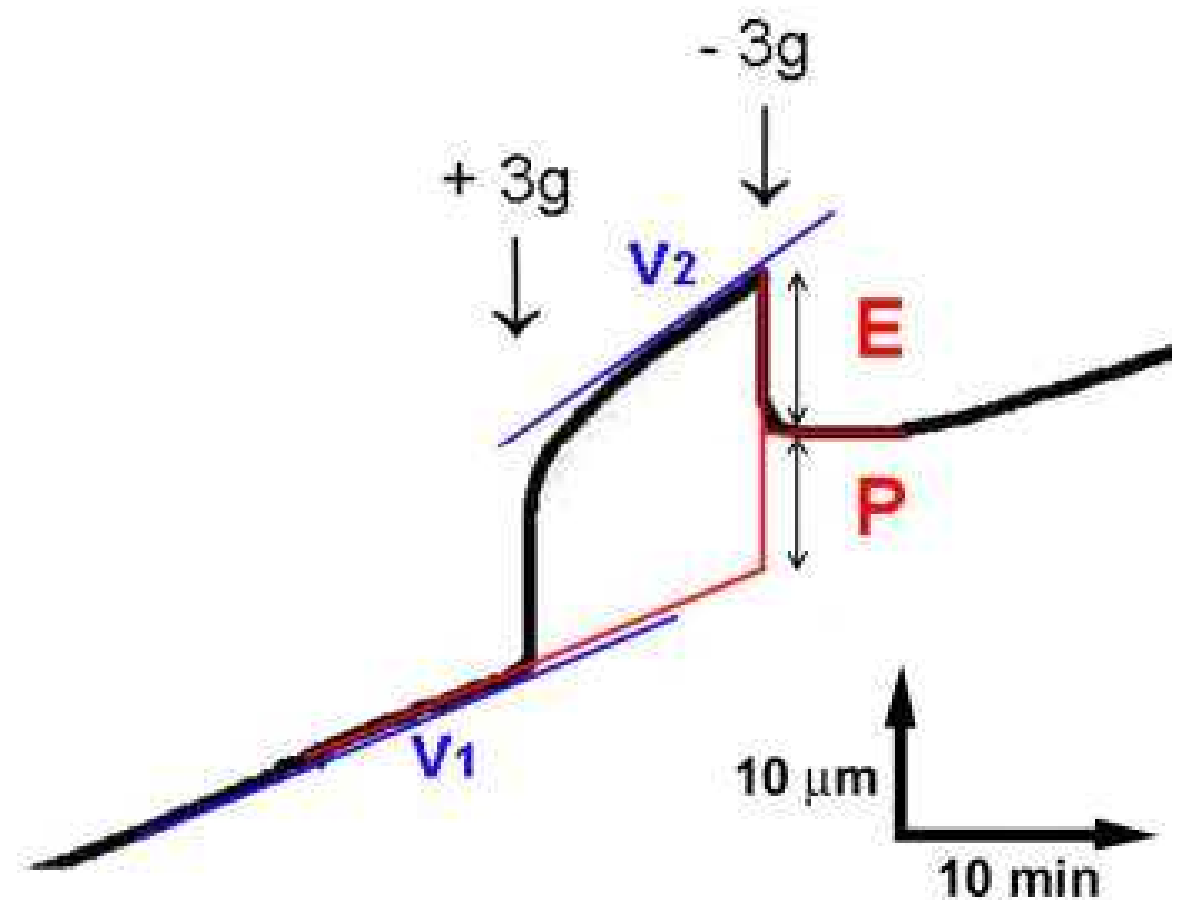

Figure 2.2 Measurement of cell wall properties

LVDT traces show the change in leaf length with time. LVDT traces before and after application of an additional $3 \mathrm{~g}$ counterweight ( $0.03 \mathrm{~N}$ of applied force), growth rates were calculated from the slope of the lines fitted to the stabilised part of traces $\left(\mathrm{v}_{1}\right.$ and $\mathrm{v}_{2}$ ). The applied force caused an extension, part of which was reversible (elasticity, E) of wall) and part of which was irreversible (plasticity, P of wall).

\section{$2.4 \quad$ Expression analyses}

The aim of expression analyses was to test whether any elevated proton efflux in the leaf elongation zone was due to higher PM- $\mathrm{H}^{+}$-ATPase expression.

\subsubsection{Plant harvest}

Plants were harvested $2-6 \mathrm{~h}$ into the photoperiod. Samples from the elongation zone were about $1 \mathrm{~cm}$ long and were cut from the mid-portion of the elongation zone (between $20-30 \mathrm{~mm}$ from the leaf base). Samples of the emerged blade were $1-2 \mathrm{~cm}$ long and taken from the mid-portion of the part of leaf three that had emerged from the sheath of leaf two. The leaf segments were weighed on a digital balance (Mettler Toledo, Sweden), immediately frozen in liquid nitrogen and stored at $-80{ }^{\circ} \mathrm{C}$ until they were used for RNA extraction. 


\subsubsection{RNA extraction and CDNA synthesis}

For RNA extraction, corresponding leaf segments from 3 - 4 plants were pooled; their combined fresh weight was between $0.04-0.07 \mathrm{~g}$ (Besse et al., 2011) Total RNA was extracted using a QUIAGEN RNeasy kit following the manufacturer's instructions. RNA was eluted into $50 \mu \mathrm{l}$ RNase free water. The concentration and quality of RNA was determined with Nanodrop ${ }^{\circledR}$ (ThermoFisher Scientific Inc., Waltham, USA).

After DNase treatment, following the manufacturer's instructions (Deoxyribonuclease I, Amplification Grade; Invitrogen Corporation, Carlsbad, California, USA), $1 \mu \mathrm{g}$ RNA was used for cDNA synthesis. CDNA synthesis was performed as recommended by the manufacturer (SuperScriptTM II Reverse Transcriptase; Invitrogen Corporation, Carlsbad, California, USA) using anchor oligo ${ }_{d} T_{16}$ primer. The final volume of cDNA was $20 \mu \mathrm{l}$. Details of the procedure and reagents used are provided in Table 2.4.

In some experiments, RNA was also extracted from protoplasts. RNA extraction from a protoplast suspension was carried out in a way similar to the one described above, with minor modifications. RNeasy lysis buffer (300 - $1000 \mu \mathrm{l})$ was added to $300-1000 \mu \mathrm{l}$ protoplast suspension ( $0.5-7$ million protoplasts) or to $1 \mathrm{ml}$ cell-free protoplast isolation medium. The latter was used as background control to reflect RNA released from broken cells or protoplasts into the isolation medium and was prepared by centrifuging the protoplast suspension at $30 \mathrm{~g}$ for $1 \mathrm{~min}$ and taking the supernatant and centrifuging it again at $12,000 \mathrm{~g}$ for $5 \mathrm{~min}$. The final volume of RNA extract for protoplasts or isolation medium was $30 \mu \mathrm{l}$ rather than $50 \mu \mathrm{l}$ as obtained for leaf extracts. 
Table 2.4 DNase treatment and reverse transcription

\begin{tabular}{|l|l}
$1 \mu \mathrm{g}(8 \mu \mathrm{l})$ RNA & \\
$1 \mu \mathrm{l} 10 \mathrm{x}$ DNasel Reaction buffer & \\
$1 \mu \mathrm{l}(1 \mathrm{U})$ DNasel Ampl. Grade enzyme & $10 \mu \mathrm{l}$ \\
\hline Incubation $15 \mathrm{~min} 25 \mathrm{C}$ & \\
& \\
$1 \mathrm{ml}$ EDTA $(25 \mu \mathrm{M})$ & $11 \mu \mathrm{l}$ \\
\hline Incubation $10 \mathrm{~min} 65 \mathrm{C}$ &
\end{tabular}

\section{Reverse transcription}

\begin{tabular}{|c|c|}
\hline $\begin{array}{l}11 \mu \mathrm{l} \text { sample from DNase treatment } \\
1 \mu \mathrm{l} \text { anchor oligo-dT primer }(100 \mu \mathrm{M}) \\
1 \mu \mathrm{l}{ }_{\mathrm{d}} \text { NTP }(10 \mathrm{mM})\end{array}$ & $13 \mu \mathrm{l}$ \\
\hline $\begin{array}{l}\text { Incubation } 5 \text { min } 65 C \\
4 \mu \mathrm{l} 5 x \text { First-Strand Buffer } \\
2 \mu \mathrm{ITT}(0.1 \mathrm{M})\end{array}$ & $19 \mu \mathrm{l}$ \\
\hline $\begin{array}{l}\text { Incubation } 2 \text { min } 42 \text { C } \\
1 \mu \mathrm{l} \text { SuperSript }{ }^{\top \mathrm{M}} \mathrm{RT} \text { Enzyme (200U) }\end{array}$ & $20 \mu \mathrm{l}$ \\
\hline $\begin{array}{l}\text { Incubation } 50 \text { min } 42 \text { C then } 70 \times 15 \\
\text { min }\end{array}$ & \\
\hline
\end{tabular}

\subsubsection{PCR}

Before cDNA samples were used for $\mathrm{QPCR}$ analysis, which required expensive reagents, the quality of CDNA, suitability of designed primers and optimum PCR conditions was tested through conventional PCR (G-Storm 482 thermocycler, Gene Technology). A GoTaq ${ }^{\circledR}$ Flexi DNA Polymerase (Promega Corporation, Madison, USA) kit was used in $25 \mu$ total volume with $1 \mu \mathrm{l}$ 200x diluted cDNA as template. A precise protocol of the PCR reaction is given in Table 2.5. Primers are listed in Table 2.6. The PCR was run in amplification two steps; after initial step (95 ${ }^{\circ}$; $30 \mathrm{~s}$ ) through 35 cycle step one $\left(95^{\circ} \mathrm{C}, 30 \mathrm{~s}\right)$ and step two $\left(60^{\circ} \mathrm{C}, 60 \mathrm{~s}\right)$ were repeated and then a final step $\left(72^{\circ} \mathrm{C}, 120 \mathrm{~s}\right)$ was used as Fi g. 2.3 shows.

PCR products were separated on $1 \%$ agarose gels in 0.5 strength TRIS base boric acid EDTA (TBA, see Table 2.7) buffer containing $1 \mu \mathrm{g} \mathrm{ml}^{-1}$ ethidium bromide and viewed under UV light (Image Master ${ }^{\circledR}$ VDS, Pharmacia Biotech, USA). 
Table 2.5 Components of PCR reactions

\begin{tabular}{|c|c|c|}
\hline Component & Volume & Final concentration \\
\hline 5x Green GoTaq ${ }^{\circledR}$ Flexi Buffer & $5 \mu \mathrm{l}$ & $1 \mathrm{x}$ \\
\hline MgCl Solution (25 mM) & $2 \mu \mathrm{l}$ & $2 \mu \mathrm{M}$ \\
\hline dNTP (10 mM) & $0.5 \mu \mathrm{l}$ & $0.2 \mu \mathrm{M}$ each nucleotide \\
\hline Forward primer (10 mM) & $0.5 \mu \mathrm{l}$ & $0.2 \mu \mathrm{M}$ \\
\hline Reverse primer (10 mM) & $0.5 \mu \mathrm{l}$ & $0.2 \mu \mathrm{M}$ \\
\hline GoTaq® DNA Polymerase (5 U / ml) & $0.125 \mu \mathrm{l}$ & $0.625 \mathrm{U}$ \\
\hline Template cDNA (200x diluted) & $1 \mu \mathrm{l}$ & $5000 x$ diluted \\
\hline Nuclease-Fee Water & $15.375 \mu \mathrm{l}$ & $\mathrm{N} / \mathrm{A}$ \\
\hline Total volume & $25 \mu \mathrm{l}$ & \\
\hline
\end{tabular}

Table 2.6 PCR primers

Primer name

Anchor oligo $\mathrm{d}_{\mathrm{d}} \mathrm{T}_{16}$

ATPase forward 5'NVTTTTTTTTTTTTTTTT3'

ATPase reverse 5'ACATCGACACCATCAACCAA3' 5'ACAACTAGGGGCTGGTCAGA3'

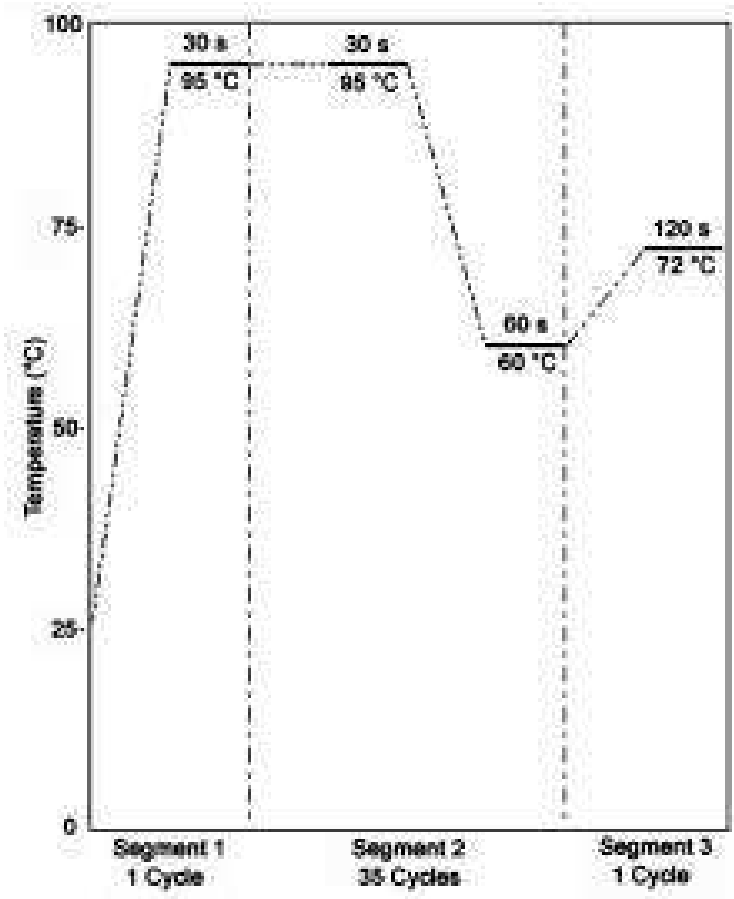

Figure 2.3 Thermal profile of the two step PCR reactions

Two step PCR protocol was used when quality of CDNA or primers were tested. This protocol was as similar as possible to the protocol used for QPCR analyses.

Table 2.7 Composition of the stock solution (5x concentrated) of TRIS base boric acid EDTA buffer (TBA)

\begin{tabular}{l|r} 
Component & Amount for 1 I \\
\hline \hline TRIS base & $53 \mathrm{~g}$ \\
\hline Boric acid & $27.5 \mathrm{~g}$ \\
\hline EDTA $(0.5 \mathrm{M}, \mathrm{pH} 8.0)$ & $20 \mathrm{ml}$
\end{tabular}




\subsection{4 $\quad$ QPCR}

qPCR expression analysis was carried out on a real time thermal cycler STRATAGENE Mx3000P (Agilent Technologies, Inc., Santa Clara, USA), using a SYBRgreen master mix and following the supplier's instructions (SYBR ${ }^{\circledR}$ Premix Ex $\mathrm{Taq}^{\mathrm{TM}}$, Takara Bio Inc, Otsu, Japan) (see Table 2.8). The reaction mix was loaded onto 96-well plates (96 Multiply PCR plate natural, SARSTEDT AG \& Co., Nümbrecht, Germany). Three technical and biological (independent batches of plants) replicates were run together with external standards (purified PM- $\mathrm{H}^{+}$-ATPase PCR product; see below) on the same plate. Samples were maintained for $10 \mathrm{~s}$ at $95^{\circ} \mathrm{C}$ as initial step, then $5 \mathrm{~s}$ at $95^{\circ} \mathrm{C}$ and $30 \mathrm{~s}$ a t $60^{\circ} \mathrm{C}$ through 45 cycles. After amplification, melting curves were recorded $\left(95^{\circ} \mathrm{C} 1 \mathrm{~min}\right.$ then temperature gradient from $55^{\circ} \mathrm{C}$ to $95^{\circ} \mathrm{C}$ in 81 steps) to check product s ize and homogeneity, see also Fig. 2.4 .

\section{Table 2.8 Components of qPCR reaction}

\begin{tabular}{|c|c|c|}
\hline Component & Final Volume & Final concentration \\
\hline SYBR $^{\circledR}$ Premix Ex Taq ${ }^{I M}$ & $6.25 \mu \mathrm{l}$ & $1 \mathrm{x}$ \\
\hline Forward primer (10 mM) & $0.25 \mu \mathrm{l}$ & $0.2 \mu \mathrm{M}$ \\
\hline Reverse primer (10 mM) & $0.25 \mu \mathrm{l}$ & $0.2 \mu \mathrm{M}$ \\
\hline Rox Dye II & $0.25 \mu \mathrm{l}$ & $\mathrm{N} / \mathrm{A}$ \\
\hline Template cDNA (200x diluted) & $1 \mu l$ & 2500x diluted \\
\hline Nuclease-Free Water & $4.5 \mu \mathrm{l}$ & $\mathrm{N} / \mathrm{A}$ \\
\hline Total volume & $12.5 \mu \mathrm{l}$ & \\
\hline
\end{tabular}

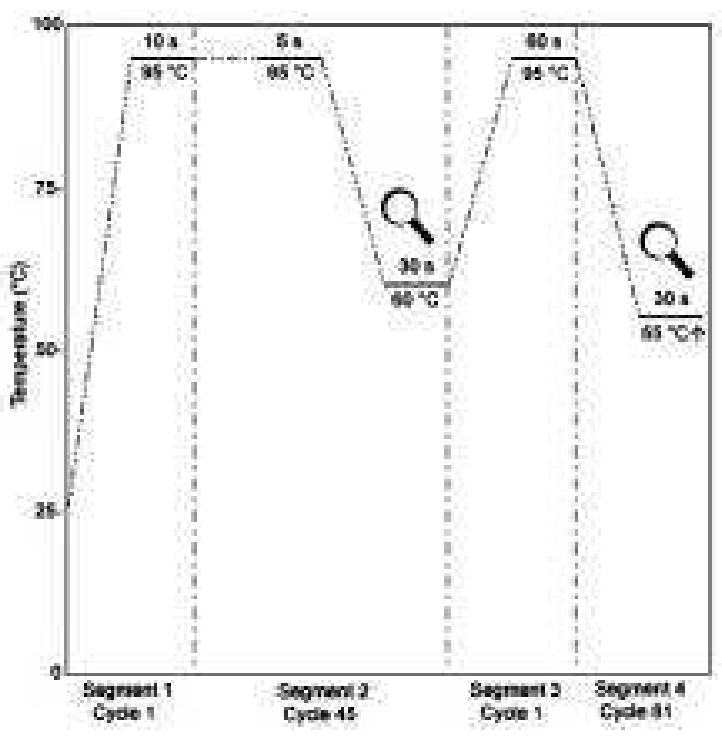

Figure 2.4 Thermal profile of qPCR reactions

Magnifying glass symbols indicate detection sites of SYBR Green fluorescence 
To quantify the number of mRNA transcripts of the target gene $\left(\mathrm{PM}-\mathrm{H}^{+}\right.$ATPase), cDNA samples which contained known copy numbers of PM- $\mathrm{H}^{+}$-ATPase cDNA molecules were required. This external standard was obtained by purifying PM- $\mathrm{H}^{+}$-ATPase PCR product and a $\mathrm{pCR}^{\circledR} 8 / \mathrm{GW} / \mathrm{TOPO}$ construct that contained the ATPase PCR product as insert. Initially, the plasmids were used as an alternative external standard in addition to purified $\mathrm{PM}-\mathrm{H}^{+}-\mathrm{ATPase}$. However, preliminary experiments showed that purification of plasmids from E. coli cells did not yield sufficiently pure product to use it as external standards.

To obtain purified ATPase PCR product, PCR was performed in $50 \mu \mathrm{l}$ volume as described above using colourless reaction buffer. After the quality of PCR product was checked by running the samples on an agarose gel, the PCR product was cleaned with a NucleaSpin ${ }^{\circledR}$ Extract II PCR clean-up / Gel extraction kit (Macherey-Nagel GmbH \& Co. KG, Germany) following the manufacturer's instructions. The purified DNA was eluted from the NucleaSpin ${ }^{\circledR}$ Extract II Column with nuclease free water. The DNA content was measured with Nanodrop ${ }^{\circledR}$ (ThermoFisher Scientific Inc., Waltham, USA) and the concentration / copy number of cDNA molecules was calculated from the expected molecular weight of the cDNA product for $\mathrm{PM}-\mathrm{H}^{+}$-ATPase $\left(100,587 \mathrm{~g} \mathrm{~mol}^{-1}\right)$. From this purified stock, dilutions of $0.5,5,50,5 \cdot 10^{2}, 5 \cdot 10^{3}, 5 \cdot 10^{4}$ and $5 \cdot 10^{5}$ copy $\mu l^{-1}$ were prepared.

\subsubsection{Analysis of qPCR data}

An absolute quantification method was used to compare the $\mathrm{PM}-\mathrm{H}^{+}-\mathrm{ATPase}$ expression between elongation zone and fully developed emerged blade. This approach was chosen in favour of the conventional $\Delta$-Ct approach (Pfaffl, 2001) because the generally most suitable reference gene of expression e.g. ubiquitin, gave more than one PCR product due to the existence of poly-ubiquitins. Using the Genevestigator (http://genevestigator.com) online application this problem (Hruz et al., 2011) could not be solved.

To further relate the copy number of transcripts to a biologically relevant size, qPCR results were expressed per cell or per $\mathrm{mm}^{2}$ plasma membrane surface. The total number of cells and plasma membrane surface contained in the plant material which was used for extraction was calculated based on the water content of leaf tissue, protoplast number and stereological electron and light microscopic analyses as detailed in section 2.5. 


\subsection{Cell size and tissue ratio measurements}

Cell size and tissue ratio in different leaf regions (elongation zone and emerged leaf blade) were determined and data combined with published data to calculate the total number of cells which were contained in samples used for qPCR analysis.

\subsubsection{Mesophyll and epidermis cell size}

The diameter of mesophyll cells was measured on living protoplasts with the help of Scion Image for Windows 4.0.3.2 (http://www.scioncorp.com) software. The data were then combined with data obtained by Volkov et al. $(2007,2009)$ for the same barley cultivar (Golf) and data obtained by Kavanagh (2010) through stereological electron-microscopic analyses. Epidermal cell size was calculated based on stereological results of Kavanagh (2010) and a light-microscopic study of Fricke \& Flowers (1998) on the same barley cultivar (Golf) studied.

\subsubsection{Tissue ratio calculation in elongation zone and emerged blade}

The percentage of cross-sectional leaf volume occupied by leaf tissues (epidermis; mesophyll including vascular parenchymateous bundle sheath; vascular bundles except parenchymateous bundle sheath) and intercellular air space was determined on paraffin-embedded toluidine blue-stained cross sections (few micrometers thick) with the help of Adobe ${ }^{\circledR}$ Photoshop ${ }^{\circledR}$ 7.0.1 and Scion Image for Windows 4.0.3.2 software. By assuming that intercellular air spaces did not contain any significant amount of liquid, but that almost all liquid was contained within tissues, it was possible to calculated the total water content (and approximate) volume of each tissue used for RNA extraction since the water content of leaf samples had been determined.

\subsubsection{Cell size and plasma membrane surface estimation for $q P C R$}

\section{$\underline{\text { analysis }}$}

Mesophyll cells volume and surface were calculated as they were spheres using the equation of $(\pi / 6) \mathrm{d}^{3}$ for volume and $\pi \mathrm{d}^{2}$ for surface. Epidermis cells were treated as long rods. In the total cell volume different cell types were present as their corrected tissue share. Corrected tissue share was calculated as dividing the tissue share by (1-share of air space) because air space did not contains any living plant cell. The 
whole calculation and data can find in the Results at section 3.3 .2 and in the Appendix.

\subsection{Plasma membrane isolation}

Plasma membranes were isolated from barley seedlings following the approach developed by Kjellbom \& Larsson (1984) and Yan et al., (1998). All steps were performed under cold conditions. For each plasma membrane isolation between 1.5 - $6 \mathrm{~g}$ of plant material was required (elongation zone; emerged blade). Between 200 - 400 barley seedlings had to be grown and harvested in each experiment.

\subsubsection{Plant harvest}

Plant tissues, elongation zone (basal $40 \mathrm{~mm}$ without the lower 1 - $2 \mathrm{~mm}$, containing meristematic zone) and emerged blade (leaf blade without the lower and upper $1 \mathrm{~cm}$ ) of barley (cv Jersey) leaf three were harvested into $50 \mathrm{ml}$ ice cold homogenisation buffer (all components are listed in Table 2.9). The tissues were gently vacuum infiltrated (3 times using a laboratory water jet vacuum pump) and used immediately for plasma membrane isolation.

Table 2.9 Composition of the homogenisation buffer used for membrane isolation

\begin{tabular}{l|l} 
Component & Final concentration \\
\hline Sucrose & $500 \mathrm{mM}$ \\
\hline EDTA & $2 \mathrm{mM}($ from $200 \mathrm{mM}$ stock $)$ \\
\hline Glycerol & $10 \%(\mathrm{v} / \mathrm{v})$ \\
\hline BSA & $0.5 \%(\mathrm{w} / \mathrm{v})$ \\
\hline DTT & $2 \mathrm{mM}$ \\
\hline PMSF & $1 \mathrm{mM}\left(\right.$ prepared freshly from $12 \mathrm{mg} \mathrm{ml}^{-1} \mathrm{EtOH}$ stock $)$ \\
\hline$\beta$-mercaptoethanol & $5 \mathrm{mM}$ \\
\hline Non-soluble PVP & $1 \%(\mathrm{w} / \mathrm{v})$ \\
\hline Na-ascorbate & $0.1 \%(\mathrm{w} / \mathrm{v})$ prepared freshly \\
\hline HEPES-KOH & $50 \mathrm{mM}$ set to $\mathrm{pH} 7.8$
\end{tabular}

\subsubsection{Preparation of microsomal fraction}

Tissues were homogenised in the homogenisation buffer with a razor blender (3 times $25 \mathrm{sec}$ ). The homogenate was filtered through four layers of gauze and one layer of Miracloths (Fisher Scientific). The filtrate was centrifuged at $11,500 \mathrm{~g}$ for 10 min at $4{ }^{\circ} \mathrm{C}$ (Sigma $3 \mathrm{~K} 15$ and $3 \mathrm{~K} 10$ bench top centrifu ge, fixed angle rotor). The supernatant was collected and centrifuged at 30,000 rpm $(\sim 82,000 \mathrm{~g})$ in a 
Beckman L7-65 ultracentrifuge for 40 min with a SW40Ti swinging bucket rotor. The resulting microsomal pellet was resuspended in phase buffer (Table 2.10).

Table 2.10 Composition of the phase buffer used for membrane isolation

Component

Sucrose

$\mathrm{KCl}$

$\mathrm{KH}_{2} \mathrm{PO}_{4}$

$\mathrm{K}_{2} \mathrm{HPO}_{4}$

$\mathrm{KOH}$
Final concentration

$330 \mathrm{mM}$

$3 \mathrm{mM}$

$5 \mathrm{mM}$

$5 \mathrm{mM}$

To adjust buffer to $\mathrm{pH} 7.8$

\subsubsection{Purification of plasma membrane vesicles}

The microsomal fraction was further fractioned by a two-phase aqueous dextran T-500 and PEG-3350 system. From the polymers, $20 \%$ (w/w) (dextran) and $40 \%$ $(w / w)$ (PEG) stock solutions were made in phase buffer. The final concentration of both polymers was $6.1 \%(\mathrm{w} / \mathrm{w})$ in the start tube, taking into account dilution through addition of phase buffer and resuspended microsomal fraction. The final weight of the tube was $12 \mathrm{~g}$. The tube was mixed by inversion 30 times and the phase separation was carried out by centrifugation at $1,500 \mathrm{~g}$ at $4{ }^{\circ} \mathrm{C}$ (Sigma $3 \mathrm{~K} 15$ and $3 \mathrm{~K} 10$ bench top centrifuge with swinging bucket rotor) for $25 \mathrm{~min}$. The upper phase was transferred into a new tube and completed to $12 \mathrm{~g}$ with fresh lower phase (prepared separately with the help of extraction funnel). The separation was done as before but for $15 \mathrm{~min}$, and this purification step was repeated 3 - 4 times until the upper phase became clear and did not show any green colour (which would have been indicative of contamination with chloroplast membranes) (Fig. 2.5). The final upper phase was diluted 3 - 4x with phase buffer and ultracentrifuged (35,000 rpm, $1 \mathrm{~h})$. The pellet was resuspended in resuspension buffer (Table 2.11) and washed by ultracentrifugation $(35,000 \mathrm{rpm}, 1 \mathrm{~h})$ two times in resuspension solution. The final purified pellet was resuspended in 50 - $150 \mu \mathrm{l}$ resuspension buffer and divided into aliquots, frozen in liquid nitrogen and stored at $-80^{\circ} \mathrm{C}$.

Table 2.11 Composition of the resuspension buffer used for membrane isolation

\begin{tabular}{l|l} 
Component & Final concentration \\
\hline \hline Sucrose & $330 \mathrm{mM}$ \\
\hline $\mathrm{KCl}$ & $3 \mathrm{mM}$ \\
\hline $\mathrm{KOH}$ & To set $\mathrm{pH} 7.8$
\end{tabular}



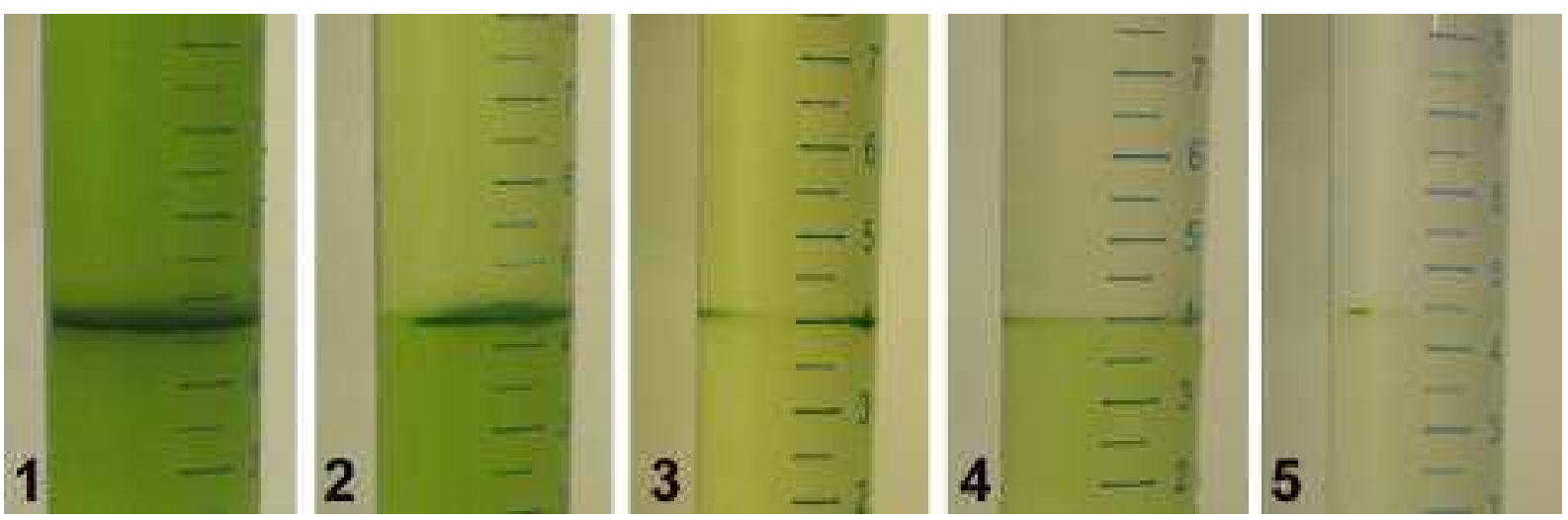

Figure 2.5 Five purification steps during plasma membrane isolation.

The upper phase becomes less and less green (indicative of thylakoid contamination). After the $5^{\text {th }}$ step the upper phase is clear, no green colour is seen.

\subsection{Determination of the total protein content of plasma membrane vesicles}

\subsubsection{Bradford method}

The protein content of plasma membrane preparation was estimated using the method of Bradford (Kruger, 2002). The reagent was prepared and filtered through Whatman no. 1 filter paper. It was stored at room temperature in an amber bottle and used within weeks. The composition of the reagent is given in Table 2.12. The assays were carried out in duplicates in $1.1 \mathrm{ml}$ final volume. For the calibration curve $0,1,2,4,6$ and $8 \mu \mathrm{g}$ bovine serum albumin (BSA) was used as standards. Absorbance was measured at $595 \mathrm{~nm}$ between 5 to $15 \mathrm{~min}$ following addition of Bradford reagent to samples (PerkinElmer Lambda25 UV/VIS Spectrophotometer)

\section{Table 2.12 Composition of Bradford reagent}

\begin{tabular}{l|r} 
Component & Amount of the component \\
\hline \hline Coomassie Brilliant Blue G250 & $100 \mathrm{mg}$ dissolved in 50 ml 95\% ethanol \\
\hline Phosphoric acid 85\% & $100 \mathrm{ml}$ \\
\hline Distilled water & Made up to $1 \mathrm{I}$
\end{tabular}

\subsubsection{Densitometric analysis of Laemmli gels}

The final values of protein concentration (used for ATPase assay, densitometry on polyacrylamide gels and Western blot analysis) were calculated from Laemmli gels (Sárvári et al, unpublished) using the modified protein solubilisation described below. Known volume of membrane vesicle sample (determined based on protein measurement using Bradford method, usually between $5-30 \mu \mathrm{l}$ ) were run on a gradient SDS polyacrylamid gel together with protein standards (Sigma). The amount 
of total membrane protein was calculating by densitometry by Phoretix 4.01 software (Phoretix International). A typical gel photo is shown in Fig. 2.6.

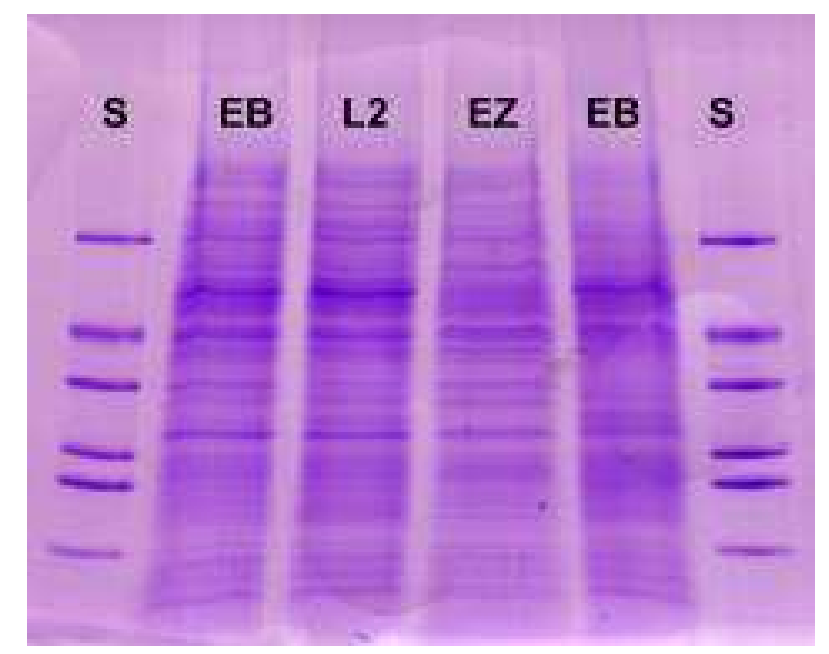

Figure 2.6 Typical gel for the measurement of protein content of plasma membrane samples

Coomassie Brilliant Blue R250 stained SDS gels were used to determine the total membrane protein content of different samples through a densitometric approach. EB - emerged leaf blade of leaf three; EZ - elongation zone of leaf three; L2 - mature blade of leaf two; S - Sigma protein standard, with a total protein content of $17.5 \mu \mathrm{g}$ ( $2.5 \mu \mathrm{g}$ each band) and proteins of molecular weights 66 (uppermost band), 45, 36, 29, 24, 20.1 and $14.2 \mathrm{kDa}$ (lowermost band).

\subsection{Polyacrylamide gel electrophoresis (PAGE)}

Qualitative and quantitative analyses were carried out on isolated plasma membrane vesicles using polyacrylamide gel electrophoresis (PAGE).

\subsubsection{Gradient polyacrylamide gel electrophoresis (PAGE)}

A gradient polyacrylamide gel electrophoresis was performed based on (Laemmli, 1970 ), with some modification in the solubilisation of membrane protein, to check the quality of isolated plasma membrane fraction and quantify its (total) protein content.

\subsubsection{Solubilisation of membrane protein}

To optimise the solubilisation of plasma membrane protein, the approach taken by Kjellbom \& Larsson (1984) was followed. Triton $X^{\circledR}-100$ detergent was added to the Laemmli buffer. Equal volumes of $0.1 \%$ Triton $^{\circledR}-100$ and plasma membrane suspension were mixed and vortexed. The mixture was then combined with an equal volume of Laemmli buffer (Table 2.13), incubated at room temperature for $30 \mathrm{~min}$ 
and heated $\left(90^{\circ} \mathrm{C}\right)$ three times for $10 \mathrm{~s}$ each follow ed by vortexing. Non-solubilised protein was removed by centrifugation $(5 \mathrm{~min}$ at $10,000 \mathrm{~g}$ ) and the supernatant used for PAGE. With this modified solubilisation procedure, almost all protein was solubilised and no pellet was observed after centrifugation. In addition, gel bands stained with Coomassie Brilliant Blue R250 were much sharper and distinct (Fig. 2.7).

Table 2.13 Composition of Laemmli buffer used for PAGE

\begin{tabular}{l|r|r}
\hline Component & Concentration in the agent & Final concentration \\
\hline TRIS-HCl pH 6.8 & $2.3 \%(\mathrm{w} / \mathrm{v})$ & $0.76 \%(\mathrm{w} / \mathrm{v})$ \\
\hline SDS & $7.15 \%(\mathrm{w} / \mathrm{v})$ & $2.38 \%(\mathrm{w} / \mathrm{v})$ \\
\hline Glycerol & $30 \%(\mathrm{v} / \mathrm{v})$ & $10 \%(\mathrm{v} / \mathrm{v})$ \\
\hline DTT & $5.5 \%(\mathrm{w} / \mathrm{v})$ & $1.83 \%(\mathrm{w} / \mathrm{v})$ \\
\hline Bromophenol blue & $0,003 \%(\mathrm{w} / \mathrm{v})$ & $0.001 \%(\mathrm{w} / \mathrm{v})$
\end{tabular}

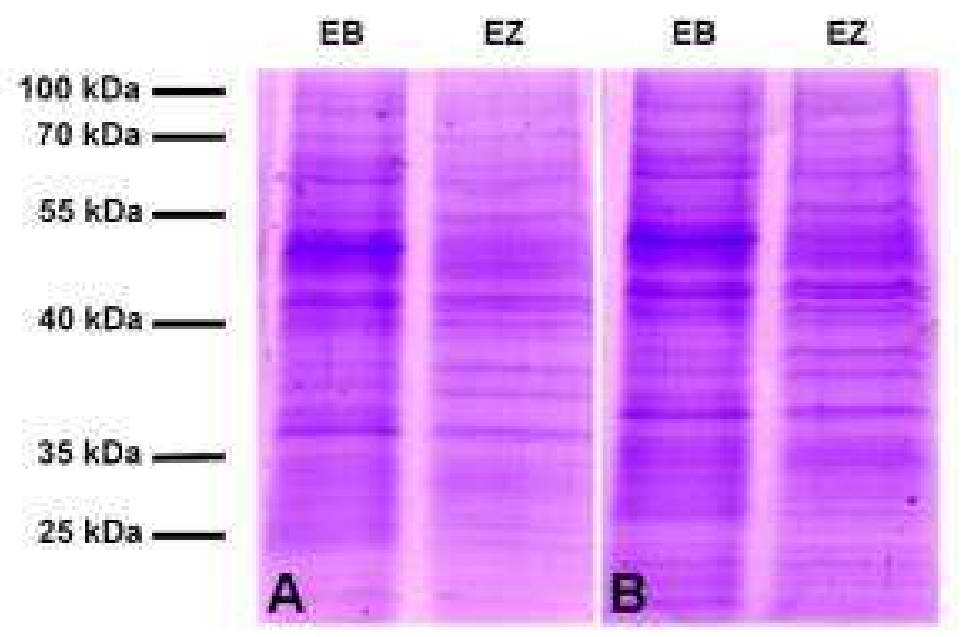

Figure 2.7 Coomassie Brilliant Blue R250 stained gradient PAGE gels which were loaded with plasma membrane protein solubilised in two different ways

Plasma membrane protein was solubilised using the conventional Laemmli solubilisation method (A) or a modification involving Triton $X^{\circledR}-100$ (B). The bands are sharper and more distinct using the modified solubilisation method. Samples were derived from the elongation zone (EZ) and emerged blade (EB) of leaf three of barley.

\subsubsection{Gradient PAGE gel system}

Solubilised proteins were separated on $7 \mathrm{~cm}$ long $10-18 \%$ gradient gels in a MiniProtean (BioRad Laboratories, Inc.) gel running system based on Laemmli (1970) under $20 \mathrm{~mA} / \mathrm{gel}$ at $4^{\circ} \mathrm{C}$ until the bromphen ol blue front exited the gel (after about $2 \mathrm{~h}$ ). The components of the gel are listed in Table 2.14. The acrylamide / bisacrylamide ratio was 30:0.8. 
Table 2.14 Components of the gradient PAGE system

Stacking gel

\begin{tabular}{l|r} 
Component & Concentration in the gel \\
\hline Acrylamide & $5 \%(\mathrm{w} / \mathrm{v})$ \\
\hline TRIS-HCl, $\mathrm{pH} 6.8$ & $125 \mathrm{mM}$ \\
\hline SDS & $0.1 \%(\mathrm{w} / \mathrm{v})$ \\
\hline TEMED & $0.01 \%(\mathrm{v} / \mathrm{v})$ \\
\hline APS (ammonium persulfate) & $0.1 \%(\mathrm{v} / \mathrm{v})$
\end{tabular}

Separation gel

\begin{tabular}{l|r|} 
Component & Concentration in the gel \\
\hline Acrylamide & $10-18 \%(\mathrm{w} / \mathrm{v})$ linear gradient \\
\hline TRIS-HCl, $\mathrm{pH} 6.8$ & $375 \mathrm{mM}$ \\
\hline SDS & $0.1 \%(\mathrm{w} / \mathrm{v})$ \\
\hline TEMED & $0.013-0.017 \%(\mathrm{v} / \mathrm{v})$ gradient \\
\hline APS & $0.04 \%(\mathrm{v} / \mathrm{v})$
\end{tabular}

Gel running buffer

\begin{tabular}{l|r} 
Component & Concentration in the buffer \\
\hline TRIS, pH 8.3 & $25 \mathrm{mM}$ \\
\hline Glycine & $192 \mathrm{mM}$ \\
\hline SDS & $0.1 \%(\mathrm{w} / \mathrm{v})$
\end{tabular}

The polyacrylamide gel was stained overnight with Coomassie Brilliant Blue R-250 and washed 3 - 4 times with washing solution (Table 2.15) on a horizontal swinging table (BIOSAN Multi MR-12). After the final washing step the gel was placed into distilled water for 20 min and then scanned with an UMAX Aster-1220S gel scanner. Each gel was stored for longer-term use in $7 \%$ acetic acid solution.

Table 2.15 Components of the solutions for Coomassie Brilliant Blue gel staining

Coomassie brilliant blue stain

\begin{tabular}{l|r} 
Component & Concentration \\
\hline Coomassie brilliant blue R-250 & $1 \%(\mathrm{w} / \mathrm{v})$ \\
\hline Methanol & $41.67 \%(\mathrm{v} / \mathrm{v})$ \\
\hline Acetic acid & $16.66 \%(\mathrm{v} / \mathrm{v})$ \\
\hline Distilled water & $41.67 \%(\mathrm{v} / \mathrm{v})$
\end{tabular}

Washing buffer

\begin{tabular}{l|r}
\hline Component & Concentration \\
\hline Methanol & $30 \%(\mathrm{v} / \mathrm{v})$ \\
\hline Acetic acid & $10 \%(\mathrm{v} / \mathrm{v})$ \\
\hline Distilled water & $60 \%(\mathrm{v} / \mathrm{v})$
\end{tabular}




\subsubsection{Linear (12\%) PAGE}

For Western blotting at UCD, Dublin, linear (12\%) polyacrylamide gels were used for protein separation. Purified and solubilised plasma membrane samples were run on the polyacrylamide gels using a Hoefer ${ }^{\mathrm{TM}}$ SE260 gel running system (Hoefer Inc, USA) at $240 \mathrm{~V}$ and $80 \mathrm{~mA}$ for $1.5 \mathrm{~h}$ using the same gel running buffer as described before (Table 2.14). For gel electrophoresis a $12 \%$ separation and $4 \%$

stacking gel were prepared following the instructions of the manufacturer (ProtoGel ${ }^{\circledR}$ $30 \%$ Kit, National Diagnostics, U.S.A.). Each well was loaded with $5 \mu \mathrm{g}$ total membrane protein. Gels were not stained, but separated proteins were blotted to nitrocellulose membrane to quantify $\mathrm{PM}-\mathrm{H}^{+}$-ATPase content of the samples by Western blot analysis.

\subsection{ATPase assay}

The ATPase assay was designed based on the method described by Sarkadi et al. (1992) and Pitann et al. (2009b). The ATP-dependent release of inorganic phosphate was followed. Precisely $3 \mu \mathrm{g}$ total membrane protein was incubated in $100 \mu$ reaction buffer (Table 2.16) at $28{ }^{\circ} \mathrm{C}$ for $60 \mathrm{~min}$ in a BIOSAN TS-100 Thermo Shaker. The reaction was stopped through addition of $50 \mu \mathrm{l} 10 \%(\mathrm{w} / \mathrm{v})$ phosphate free SDS. For colour development, $400 \mu \mathrm{l}$ colour developing reagent (Table 2.16), $1 \mathrm{ml}$ ultra-pure water and $200 \mu \mathrm{l} 1 \%$ freshly made ascorbic acid solution were added in succession to each reaction tube. Colour development occurred at $37^{\circ} \mathrm{C}$ and was completed within 20 - $30 \mathrm{~min}$. Within $1 \mathrm{~min}$ following the end of colour development, the absorbance of samples was read at $880 \mathrm{~nm}$ using a PerkinElmer Lambda25 UV/VIS Spectrophotometer. Appropriate standards (0,10, 20, 40, $60 \mathrm{nmol} \mathrm{P}_{\mathrm{i}}$ per sample of $\mathrm{K}_{2} \mathrm{HPO}_{4}$ ) were always run in parallel to samples and used to convert absorbance readings into nmol $P_{i}$ generated. 
Table 2.16 ATPase reaction buffer and colour development reagent ATPase reaction buffer

\begin{tabular}{l|r} 
Component & Concentration \\
\hline $\mathrm{MES}-\mathrm{KOH}, \mathrm{pH} \mathrm{6.5}$ & $10 \mathrm{mM}$ \\
\hline $\mathrm{MgSO}$ & $5 \mathrm{mM}$ \\
\hline Sodium ATP & $5 \mathrm{mM}$ \\
\hline $\mathrm{KCl}$ & $50 \mathrm{mM}$ \\
\hline $\mathrm{KNO}_{3}$ & $50 \mathrm{mM}$ \\
\hline $\mathrm{Brij}_{5}$ & $0.02 \%(\mathrm{w} / \mathrm{v})$ \\
\hline $\mathrm{NaN}_{3}$ & $10 \mathrm{~m} \mathrm{M}$
\end{tabular}

Colour developing reagent for ATPase reaction

\begin{tabular}{l|r}
\hline Component & Concentration \\
\hline $\mathrm{H}_{2} \mathrm{SO}_{4}$ & $2.5 \mathrm{M}$ \\
\hline Ammonium molybdate & $1 \%(\mathrm{v} / \mathrm{w})$ \\
\hline Potassium antimony (III) oxid tartrate & $0.014 \%(\mathrm{v} / \mathrm{w})$
\end{tabular}

\subsection{Approach for light microscopy}

\subsubsection{Fixation of leaf tissue}

Leaf pieces $(1 \mathrm{~cm}$ in length) from the elongation zone and emerged blade were fixed in $4 \%$ formalin (overnight, $4{ }^{\circ}$ ). To facilitate th e penetration of the fixative, samples were vacuum infiltrated ( 3 times for $10 \mathrm{sec}$ ) using a Millipore WP6122050 vacuum pump (Millipore, USA).

\subsubsection{Dehydration and embedding}

Dehydration of leaf tissue was achieved through an ethanol series, and tissues were cleared with Neo-clear ${ }^{\circledR}$ and embedded into paraffin wax. Details of the protocol are given in Table 2.17. Sections of $5 \mu \mathrm{m}$ thickness were cut using a MicroTec ${ }^{\circledR} 4060$ rotary microtome (MicroTec Laborgeräte $\mathrm{GmbH}$, Germany). Sections were mounted on slides and dried at $37{ }^{\circ} \mathrm{C}$ (overnight) and staine $\mathrm{d}$. For immunostaining, samples were mounted on APTES (3-aminopropyltriethoxysilane) coated slides, prepared based on the instruction of the supplier (Sigma-Aldrich), to prevent tissue damage during the overnight staining procedure. Slides were washed in absolute ethanol before coating and were immersed into $2 \%$ APTES (dissolved in absolute ethanol) for $5 \mathrm{~s}$, briefly rinsed in ethanol, washed in running tap water (5 min), rinsed in distilled water and dried overnight at $55-60^{\circ} \mathrm{C}$. 
Table 2.17 Fixation and embedding of leaf samples for immunohistochemistry Fixation

\begin{tabular}{|c|c|c|}
\hline & Solution & Duration \\
\hline & $4 \%$ Formalin & Overnight, $4{ }^{\circ} \mathrm{C}$ \\
\hline \multicolumn{3}{|l|}{ Dehydration } \\
\hline & Solution & Duration \\
\hline & $30 \%$ Ethanol & $1 \mathrm{~h}$ \\
\hline & $50 \%$ Ethanol & $1 \mathrm{~h}$ \\
\hline & $70 \%$ Ethanol & $1 \mathrm{~h}$ \\
\hline & $90 \%$ Ethanol & $1 \mathrm{~h}$ \\
\hline & $96 \%$ Ethanol & $1 \mathrm{~h}$ \\
\hline & Absolute Ethanol & $2 \times 1 \mathrm{~h}$ \\
\hline \multicolumn{3}{|l|}{ Clearing } \\
\hline & $50-50 \%$ Ethanol Neo-clear ${ }^{\Theta}$ & Overnight, $4^{\circ} \mathrm{C}$ \\
\hline & Neo-clear ${ }^{\Theta}$ & $2 \times 1 \mathrm{~h}$ \\
\hline \multicolumn{3}{|l|}{ Infiltration } \\
\hline & Neo-clear $\left.{ }^{(}\right)$wax & $30 \mathrm{~min}$ \\
\hline & $50-50 \%$ Nea-clear ${ }^{\circledR}$-wax & $1 \mathrm{~h}, 65^{\circ} \mathrm{C}$ \\
\hline & $100 \%$ wax & $2 \times 1 \mathrm{~h}, 65^{\circ} \mathrm{C}$ \\
\hline
\end{tabular}

\subsubsection{Staining with toluidine blue}

Paraffin-embedded sections were rehydrated, stained with $1 \%(\mathrm{w} / \mathrm{v})$ aqueous toluidine blue, washed, dehydrated, cleared and mounted in Entellan ${ }^{\circledR}$ mountant (Table 2.18). Sections were examined with a Leica DMIL and Olympus BX60 microscope.

Table 2.18 Staining embedded leaf sections with toluidine blue Rehydration

Staining

\begin{tabular}{|c|c|c|}
\hline & Solutions & Duration \\
\hline & Neo-Clear ${ }^{(} \mathrm{A}$ & $10 \mathrm{~min}$ \\
\hline & Neo-Clear ${ }^{\circledR}$ B & $10 \mathrm{~min}$ \\
\hline & Absolute ethanol & $5 \min$ \\
\hline & $96 \%$ ethanol & $5 \mathrm{~min}$ \\
\hline & $70 \%$ ethanol & $2 \min$ \\
\hline & Running water & $5 \mathrm{~min}$ \\
\hline \multicolumn{3}{|l|}{ Staining } \\
\hline & $1 \%$ aqueous toluidine blue & $10 \mathrm{~min}$ \\
\hline \multirow{2}{*}{\multicolumn{3}{|c|}{ Dehydration }} \\
\hline & & \\
\hline & $70 \%$ ethanol & Dip twice \\
\hline & $96 \%$ ethanol & Dip four times \\
\hline & Absolute ethanol 1 & $5 \mathrm{~min}$ \\
\hline & Absolute ethanol 2 & $5 \mathrm{~min}$ \\
\hline & Neo-clear ${ }^{\Theta} \mathrm{C}$ & $5 \mathrm{~min}$ \\
\hline & Neo-clear ${ }^{\circledR} \mathrm{D}$ & $5 \mathrm{~min}$ \\
\hline \multicolumn{3}{|l|}{ Mounting } \\
\hline & Entellan $^{\circledR}$ & Mount under cov \\
\hline
\end{tabular}




\subsection{Immunological methods for PM- $H^{+}-A T P a s e$ detection}

\subsubsection{Qualitative Western blot analysis}

At Eötvös University the PM- $\mathrm{H}^{+}$-ATPase content of the isolated membrane vesicles and identity and molecular weight of $\mathrm{PM}-\mathrm{H}^{+}$-ATPase protein was determined using Western blotting. Gradient SDS polyacrylamide gels were run as described above. Separated proteins were transferred onto nitrocellulose membrane (Hybound ${ }^{\mathrm{TM}}-\mathrm{C}$ Extra, Amesham-Pharmacia, USA) using the Mini Transfer Blot (BioRad Laboratories, Inc.) system. The composition of blotting buffer is given in Table 2.19. Protein transfer was carried out in an ice-cold buffer tank $\left(4{ }^{\circ} \mathrm{C}\right)$ at $90 \mathrm{~V}$ constant voltage $(\mathrm{I}<0.4 \mathrm{~A})$ for $2-3 \mathrm{~h}$.

\section{Table 2.19 Composition of blotting buffer used for Western analyses}

Component

Concentration

\begin{tabular}{l|r}
\hline TRIS-HCl, pH 8.3 & $25 \mathrm{mM}$ \\
\hline Glycine & $192 \mathrm{mM}$ \\
\hline Methanol & $10 \%(\mathrm{v} / \mathrm{v})$ \\
\hline SDS & $0.01 \%(\mathrm{w} / \mathrm{v})$
\end{tabular}

The blotted and washed nitrocellulose membrane was blocked with $3 \%$ (w/v) gelatine in TRIS buffer saline (TBS) for $1 \mathrm{~h}$ (composition is given in Table 2.20). As primary antibody, plant $\mathrm{PM}-\mathrm{H}^{+}$-ATPase specific polyclonal rabbit IgG (Agrisera, Uppsala, Sweden) was used at 1,000x dilution in TBS buffer containing $1 \%$ gelatine (overnight; room temperature). Non-bound antibody was removed by washing the membrane in Tween ${ }^{\circledR} 20$ TRIS buffer saline (TTBS) (Table 2.21), twice for $20 \mathrm{~min}$, followed by two washes for $20 \mathrm{~min}$ each in TBS. Horseradish peroxidase (HRP)labelled anti rabbit IgG produced in goat (BioRad Laboratories, Inc.) was used as secondary antibody. It was used at 3,000x dilution in TBS buffer $(2 \mathrm{~h})$. The membrane was washed in the same way as described for primary antibody and was then developed in developing solution $(0.06 \%(\mathrm{w} / \mathrm{v})$ HRP Colour Development Reagent $^{\mathrm{TM}}$ (BioRad Laboratories, Inc.)). The colour development reagent contained 4-Cl-1-naftol as active component and was dissolved in -20 $\mathrm{C}$ methanol and $0.015 \% \mathrm{H}_{2} \mathrm{O}_{2}$ in TBS. The bands were digitalized (HP Scanjet) before the membrane had dried out. 
Table 2.20 Composition of TRIS buffer saline buffer (TBS)

Component

\begin{tabular}{l|r}
\hline TRIS-HCl, pH 7.5 & $20 \mathrm{mM}$ \\
\hline $\mathrm{NaCl}$ & $150 \mathrm{mM}$
\end{tabular}

Table 2.21 Composition of Tween ${ }^{\circledR} 20$ TRIS buffer saline buffer (TTBS)

Component

\begin{tabular}{l|r}
\hline TRIS-HCl, pH 7.5 & $20 \mathrm{mM}$ \\
\hline $\mathrm{NaCl}$ & $150 \mathrm{mM}$ \\
\hline Tween $^{\Theta} 20$ & $0.005 \%(\mathrm{w} / \mathrm{v})$
\end{tabular}

\subsubsection{Quantitative Western blot analysis}

Plasma membranes could only be isolated at Eötvös University, yet the more sensitive Western blot system was available at UCD, Dublin. Therefore, Western analyses of plasma membrane fractions were carried out not only at Eötvös University but also at UCD using plasma membrane vesicle samples which had been brought back (flight back from Hungary) on dry ice. The Western analyses system at UCD was the same one as described by Collins et al. (2011).

The separated proteins were blotted onto nitrocellulose membrane (Whatman ${ }^{\circledR}$ PROTRAN BA 85) using a Hoefer ${ }^{\mathrm{TM}}$ TE22 blotting system, at $40 \mathrm{~V}$ and $120 \mathrm{~mA}$ overnight at room temperature. The gel running buffer contained $20 \%(\mathrm{v} / \mathrm{v})$ methanol. Blotted nitrocellulose membranes were stained with Ponceau $S$ stain (Sigma) and washed with washing buffer $\left(0.2 \%\right.$ Tween ${ }^{\circledR} 20$ containing gel running buffer). Thereafter, membranes were blocked with $5 \%$ skimmed milk powder in washing buffer for $1 \mathrm{~h}$, at $30 \mathrm{rpm}$ on a horizontal shaker. Primary antibody $\left(\mathrm{PM}-\mathrm{H}^{+}-\right.$ ATPase specific polyclonal rabbit IgG antibody; Agrisera, Sweden) was applied overnight at 2,500x dilution in washing buffer containing $5 \%$ milk powder, at $30 \mathrm{rpm}$ shaking. Non-bound primary antibody was removed through washing three times (10 min each; $70 \mathrm{rpm}$ ) in washing buffer. Peroxidase-labelled anti rabbit lgG produced in goat (Invitrogen Corporation, Carlsbad, California USA) was applied as secondary antibody at 10,000 x dilution in washing buffer containing $5 \%$ milk powder (2 h; $70 \mathrm{rpm}$ ). After three final washes (10 min each) in washing buffer, bound secondary antibody was visualised through an EZ-ECL Chemiluminescence Detection Kit for HRP (Biologica Industries, Israel) and LAS-4000 Luminescence Image Analyser (Fujifilm, USA). 


\subsubsection{Immunostaining of paraffin-embedded sections}

$\mathrm{PM}-\mathrm{H}^{+}$-ATPase tissue specific localisation was determined on paraffin-embedded samples using immunohistochemistry. The same $\mathrm{PM}-\mathrm{H}^{+}$-ATPase specific primary antibody was used as for Western blotting. Anti rabbit IgG alkaline phosphataselabelled antibody, produced in goat (Sigma), was applied as secondary antibody as detailed in Table 2.22. Colour development was carried out with SIGMAFAST ${ }^{\mathrm{TM}}$ Fast Red TR / Naphthol AS-MX Tablets (Sigma) following the instructions of the manufacturer. Colour development was stopped with $7 \%$ acetic acid. After a 5 min washing in running tap water, samples were mounted in $80 \%$ glycerol in phosphate buffered saline (PBS, its composition is given in Table 2.23) under a cover slip.

Table 2.22 Protocol for immunostaining of embedded leaf sections Rehydration

Blocking

\begin{tabular}{l|r}
\hline Solutions & Duration \\
\hline Neo-Clear ${ }^{\Theta} \mathrm{A}$ & $10 \mathrm{~min}$ \\
\hline Neo-Clear ${ }^{\Theta} \mathrm{B}$ & $10 \mathrm{~min}$ \\
\hline Absolute ethanol & $5 \mathrm{~min}$ \\
\hline $96 \%$ ethanol & $5 \mathrm{~min}$ \\
\hline $70 \%$ ethanol & $2 \mathrm{~min}$ \\
\hline Running water & $5 \mathrm{~min}$
\end{tabular}

Staining

\section{Colour development}

\begin{tabular}{l|l}
\hline $5 \%(\mathrm{v} / \mathrm{v})$ goat serum in PBS & $10 \mathrm{~min}$ \\
\hline
\end{tabular}

\begin{tabular}{l|r}
\hline \multicolumn{1}{c|}{ SIGMAFAST ${ }^{T M}$ Fast Red } & $2-10 \mathrm{~min}$ \\
\hline $5 \%(\mathrm{v} / \mathrm{v})$ acetic acid & $1-5 \mathrm{~min}$ \\
\cline { 2 - 3 } & $5 \mathrm{~min}$
\end{tabular}

Mounting

\begin{tabular}{l|r} 
Primary antibody (100x diluted) in & Overnight, $4 \mathrm{C}^{\mathrm{C}}$ \\
$2.5 \%(\mathrm{v} / \mathrm{v})$ goat serum in PBS & $3 \times 5 \mathrm{~min}$ \\
\hline Washing with PBS & $2 \mathrm{~h}$ \\
\hline Secondary antibody (30x diluted) in \\
$2.5 \%(\mathrm{v} / \mathrm{v})$ goat serum in PBS & $4 \times 5 \mathrm{~min}$ \\
\hline Washing with PBS
\end{tabular}

$80 \%$ glycerol in PBS

Mount under cover slip

Table 2.23 Composition of phosphate buffer saline (PBS; pH 7.4)

Component

$\mathrm{NaCl}$

$\mathrm{KCl}$

$\mathrm{Na}_{2} \mathrm{HPO}_{4} \times 2 \mathrm{H}_{2} \mathrm{O}$

$\mathrm{KH}_{2} \mathrm{PO}_{4}$
Concentration (mM)

137

2.7

8.1

1.76
Concentration (g/l)

8.00

0.20

1.44

0.24 


\subsubsection{Densitometric analysis of Western blots}

Densitometric analysis of Coomassie-stained polyacrylamide gels and Western blots was carried out with a Photetix 1D Advanced 4.01 system (Phoretix International, Newcastle, UK). Raw data were processed using Microsoft ${ }^{\circledR}$ Office Excel 2003 (Microsoft Corporation, USA) and Origin $^{\circledR} 6.1$ (OrigiLab Corporation, USA) statistical software.

\subsection{Protoplast experiments}

\subsubsection{Protoplast isolation}

Protoplasts were isolated according to Volkov et al. (2007), with some modifications.

Osmolality of the isolation buffer, incubation time and shaking frequency were optimised. Cell walls and middle lamellae from tissue of the elongation zone were digested in $500 \mathrm{mOsm} \mathrm{kg}^{-1}$ isolation buffer with $90 \mathrm{rpm}$ shaking frequency over a period of 2 - 3 hours in the dark, while pieces of the emerged blade were incubated in isolation buffer of $600 \mathrm{mOsm} \mathrm{kg}-1$ osmolalility, over a $1 \mathrm{~h}$ period and at $160 \mathrm{rpm}$ shaking frequency in the dark.

Cell wall digestive enzymes (Table 2.24) were dissolved in isolation medium (components are in Table 2.25) overnight, at $4^{\circ} \mathrm{C}$, without any shaking or vortexing. Prior to use, enzyme solutions were centrifuged (5 min, 10,000 g, mini Spin plus, Eppendorf AG, Hamburg, Germany) and the supernatant was used for cell wall digestion.

Table 2.24 Composition of protoplast isolation buffer Component Concentration

\begin{tabular}{l|r}
\hline Murashige and Skoog salt & $4 \mathrm{~g} \mathrm{l}^{-1}$ \\
\hline MES & $10 \mathrm{mM}^{-1}$ \\
\hline Sorbitol & $500-600 \mathrm{mOsm} \mathrm{kg}$ \\
\hline PVP K30 & $0.025 \%(\mathrm{w} / \mathrm{v})$ \\
\hline BSA & $0.1 \%(\mathrm{w} / \mathrm{v})$ \\
\hline KOH & Used to adjust to $\mathrm{pH} 5.7$
\end{tabular}

Table 2.25 Enzyme concentrations in protoplast isolation buffer Enzyme Concentration

\begin{tabular}{l|r}
\hline Cellulase & $1 \%(\mathrm{w} / \mathrm{v})$ \\
\hline Driselase & $0.5 \%(\mathrm{w} / \mathrm{v})$ \\
\hline Pectolyase & $0.05 \%(\mathrm{w} / \mathrm{v})$
\end{tabular}




\subsubsection{Purification of protoplasts}

After enzymatic digestion of the cell wall, protoplast were passed through a $100 \mu \mathrm{m}$ mesh and washed with 4 - 5 volume isolation buffer. Protoplasts were collected by centrifugation (30 g, 2 min; Eppendorf 5810 R, swinging bucket rotor) and resuspended in $0.3-1 \mathrm{ml}$ volume using isolation buffer. Viability of protoplasts was tested using $0.001 \%(\mathrm{w} / \mathrm{v})$ fluorescein diacate (Larkin, 1976), which was prepared from a $0.1 \%(\mathrm{w} / \mathrm{v})$ acetone stock. Protoplasts were viewed with a Leica DMIL fluorescence microscope equipped with an excitation filter (450 - $490 \mathrm{~nm})$ and suppression filter (515 nm).

Protoplasts were counted with a Neubauer ultra plane counting chamber (Hausser Scientific) under a Leica DMIL microscope. These data were used to relate expression values obtained through qPCR experiments to protoplast number.

\subsubsection{Calculation of size and surface of the protoplast}

The diameter of protoplasts was measured on micrographs taken with a Leica DMIL microscope with the help of Scion Image for Windows 4.0.3.2 software. From the diameter (d), the protoplast volume, $\left((\pi / 6) \mathrm{d}^{3}\right)$ and surface $\left(\pi \mathrm{d}^{2}\right)$ could be calculated,due to the almost perfectly spherical shape of protoplasts.

\subsection{Statistical analysis}

Statistical analysis was carried out with Origin ${ }^{\circledR} 6.1$ (OriginLab Corporation) software, using paired and independent Student's t test and one-way ANOVA. 


\section{$3 \quad$ Results}

\subsection{Apoplastic $\mathrm{pH}$ measurements}

Apoplast $\mathrm{pH}$ was measured through three independent approaches: in-vitro gel system, electrophysiology and confocal microscopy. The in-vitro gel system involved incubating leaf segments in agarose containing a $\mathrm{pH}$ indicator that made it possible to directly relate changes in apoplast acidity to changes in growth. With $\mathrm{pH}$ microelectrodes precise values of apoplast $\mathrm{pH}$ in growing and non-growing leaf regions could be obtained. Finally, confocal microscopy involved loading plants with $\mathrm{pH}$ fluorescence probes and had the advantage that intact plants could be studied.

\subsubsection{In-vitro agarose gel system}

The base $70 \mathrm{~mm}$ of leaf three was placed in agarose gel medium containing the $\mathrm{pH}$ indicator bromocresol purple. Growth was monitored parallel to acidification of the medium. The basic assumption underlying this experiment was that any changes in the extent of acidity of the medium adjacent to leaf tissue reflected similar changes in the net $\mathrm{H}^{+}$production rate (due to $\mathrm{PM}-\mathrm{H}^{+}$-ATPase activity) in the tissue's apoplast. 'Extent' of acidity can refer to either or both, changes in $\mathrm{pH}$ and changes in the area of medium which was acidic. Gel images of a typical set of experiments, involving application of fusicoccin and vanadate, are shown in Fig. 3.1 A-C.

There was a non-specific acidification of medium with a maximum acidification at the first hour following the placement of unpeeled leaf segments into the agarose. This acidification, which most likely reflected changes in apoplast $\mathrm{pH}$ caused by the unpeeling and which was not restricted to the base $40 \mathrm{~mm}$ (leaf elongation zone), disappeared within 4 - $5 \mathrm{~h}$ and then reappeared in a growth-dependent manner (Fig. 3.2 A and B). Growth dependency of acidification was also tested by applying an initial $(0-24 \mathrm{~h})$ cold treatment. There was no acidification of medium and no growth either during the cold treatment (Fig. 3.3). As soon as the cold treatment finished, growth resumed parallel to the acidification of medium (Fig. 3.3). 
A
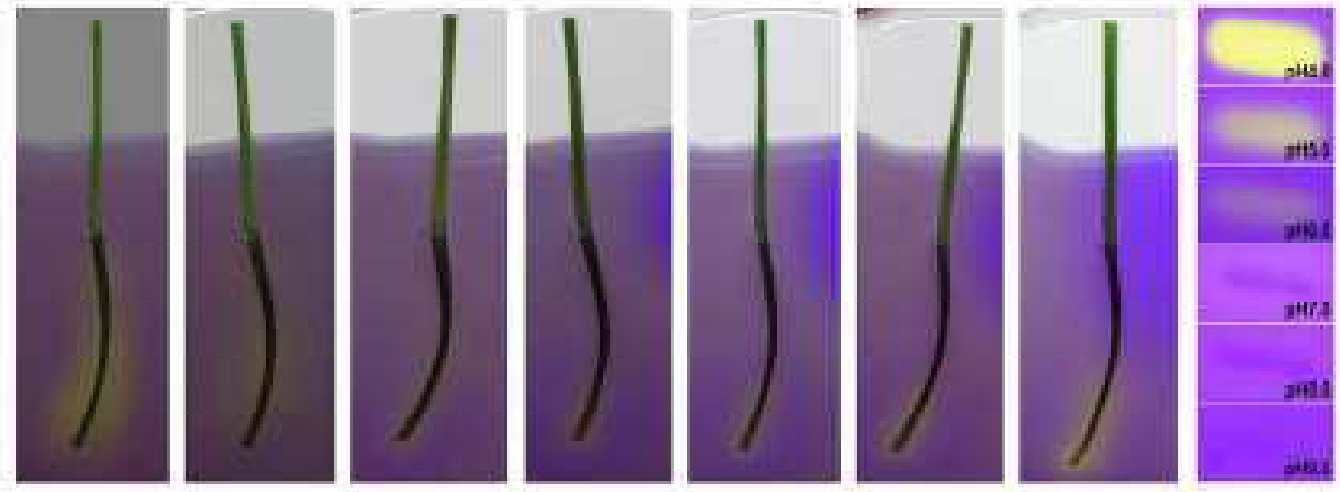

B
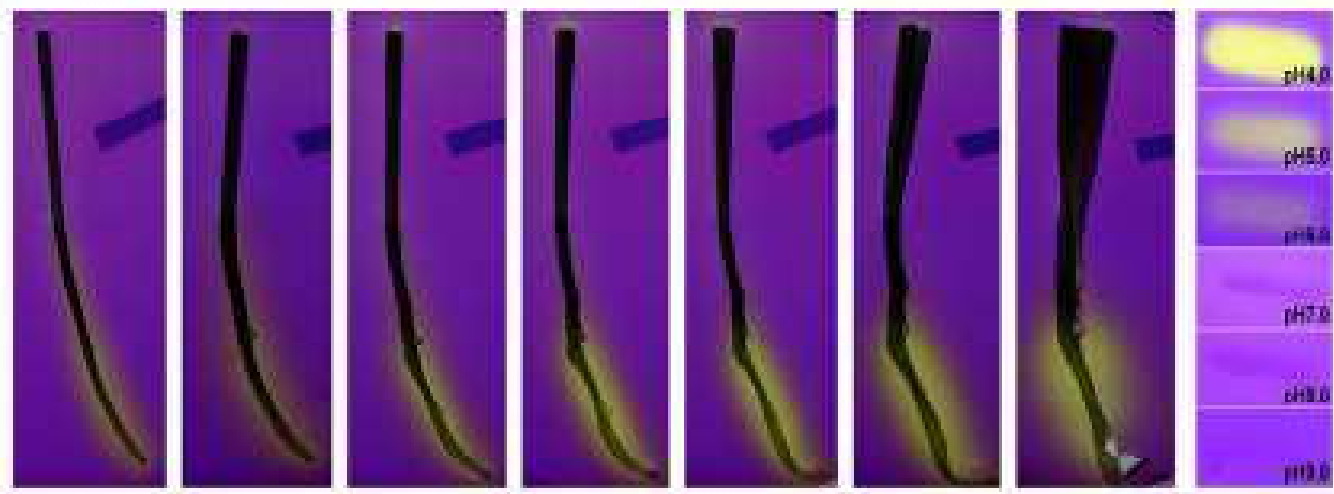

c
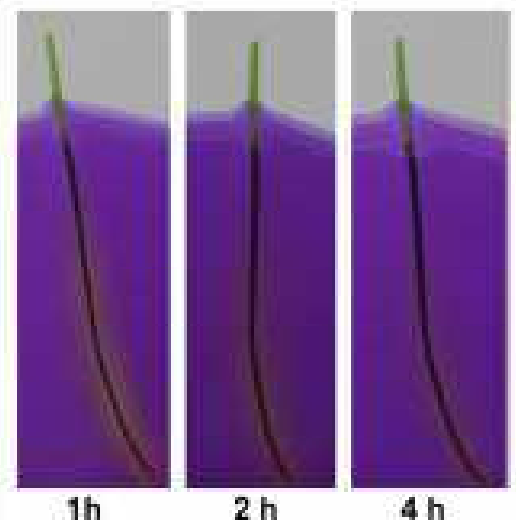

$4 \mathrm{~h}$
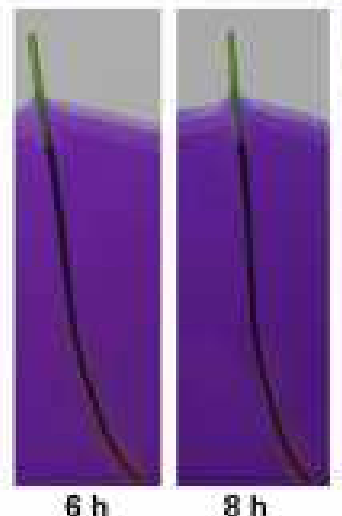

$8 \mathrm{~h}$
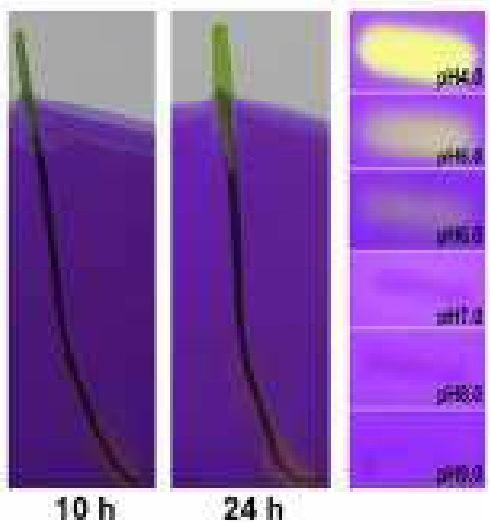

Figure 3.1 Leaf growth and apoplast acidification as analysed through the

\section{agarose gel system}

Typical images of an experiment involving control leaves (A) and leaves which were placed in agarose containing $5 \mu \mathrm{M}$ fusicoccin (B) and $500 \mu \mathrm{M}$ vanadate (C). Scale bar is $1 \mathrm{~cm}$ long. 
A

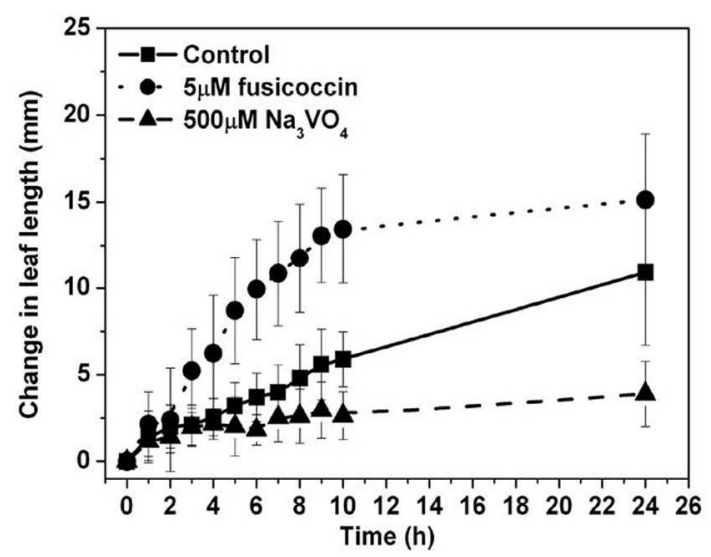

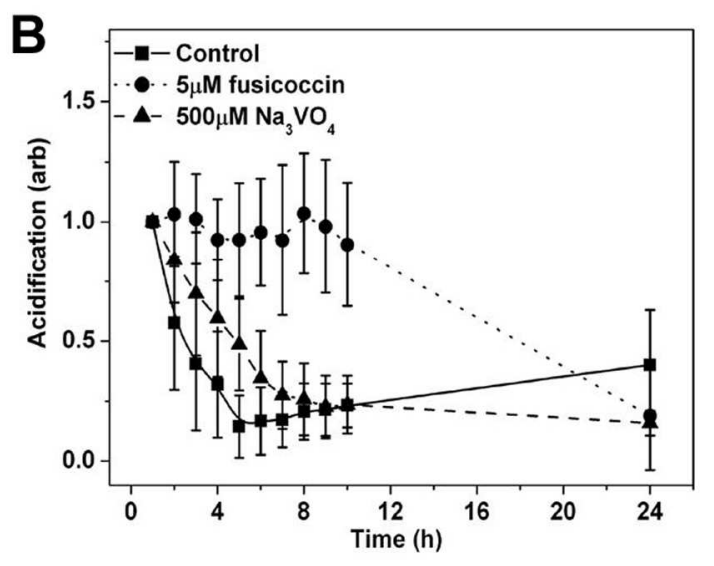

Figure 3.2 Time course of growth and acidification of in-vitro gel experiments

Typical time course of changes in leaf length (A) and medium acidification (B) in response to treatments are shown. Values are averages and standard deviations (error bars) of 27 (control) and 10 (treatments) plants.

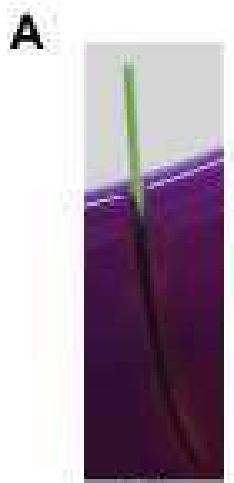

$1 \mathrm{~h}$

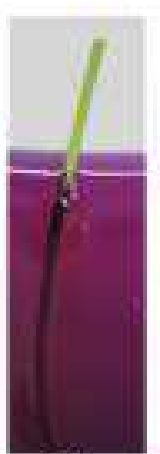

$3 \mathrm{~h}$

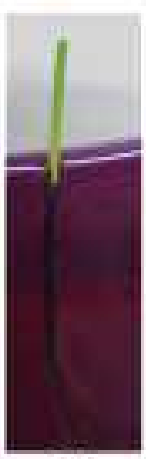

$6 \mathrm{~h}$

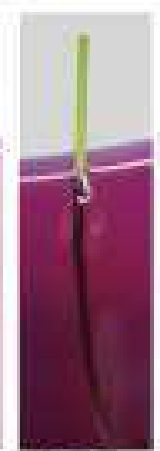

$9 \mathrm{~h}$

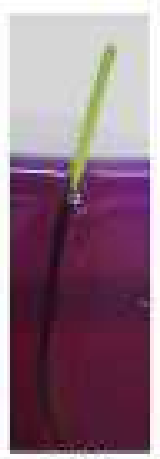

$24 \mathrm{~h}$

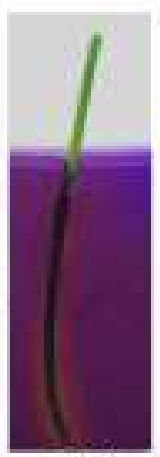

$25 \mathrm{~h}$

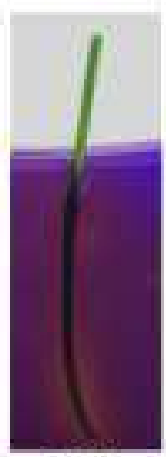

$28 \mathrm{~h}$

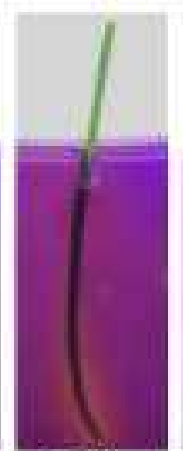

$30 \mathrm{~h}$

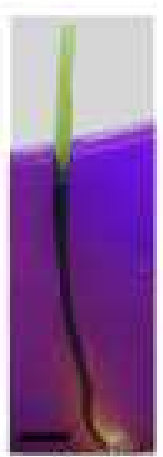

$48 \mathrm{~h}$

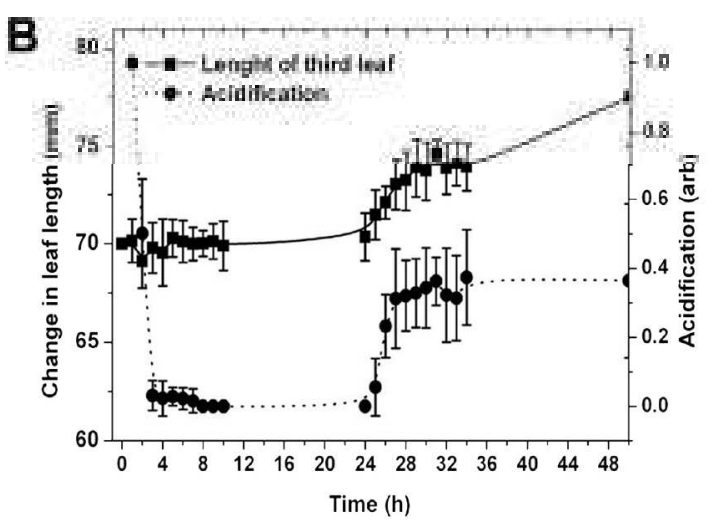

Figure 3.3 Leaf growth and acidification in agarose gel under cold treatment

Typical images of an experiment involving cold treated leaves $0-24 \mathrm{~h}$ and under control condition $24-48 \mathrm{~h}(\mathrm{~A})$. Scale bar represents $1 \mathrm{~cm}$. Response of medium acidification and change in leaf length (growth) to cold treatment and subsequent incubation in the growth chamber (B); values are averages and standard deviations (error bars) of 10 plants. 
A range of treatments was tested for their effect on medium acidification and leaf growth (Fig. 3.4). Fusicoccin increased significantly leaf elongation rate and medium acidity. Vanadate caused the opposite effect, as did caesium, which inhibits $\mathrm{K}^{+}$channels (Szczerba et al., 2009; Volkov et al., 2009).
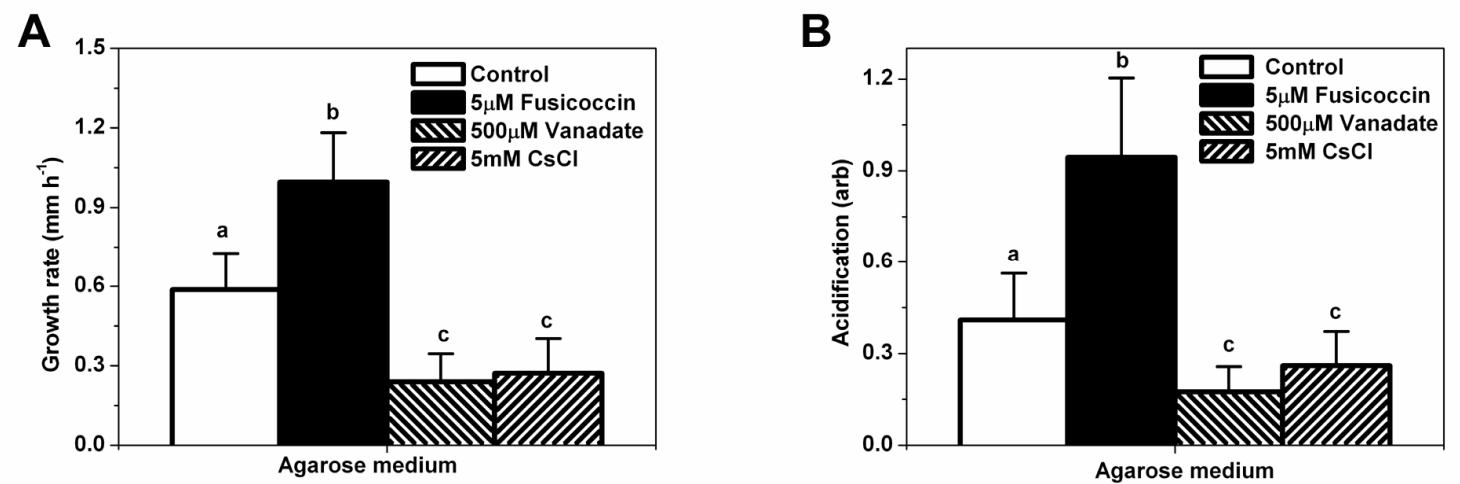

Figure 3.4 Average rate of leaf elongation (A) and medium acidification (B) in

leaves exposed to fusicoccin, vanadate and caesium treatments as tested through the agarose gel system

All media contained $10 \mathrm{mM} \mathrm{KCl}$ and test reagents were applied at $5 \mu \mathrm{M}$ (fusicoccin), $500 \mu \mathrm{M}$ (vandate) or $5 \mathrm{mM}(\mathrm{CsCl})$. Values are averages and standard deviations of 20 (control), 9 (fusicoccin), 7 (vanadate) and 14 (CsCl) plants. Different letters show a statistically significant difference at $p<0.05$ (Student's t-test and ANOVA).

Although auxin-induced growth is often related to cell wall acidification and referred to as 'acid growth', no such stimulation of either growth or acidification was observed in the present study. Using in-vitro gel system and applying the artificial auxin, $\alpha$-Naphthaleneacetic acid (NAA), growth did not change and acidification was similar to control. If anything, acidification of NAA treated plants continuously decreased whereas control plants started to slightly decrease after $5 \mathrm{~h}$ (Fig. 3.5).

Auxin-induced growth was not detected either when the experiment was carried out in liquid medium $\left(10 \mathrm{mM} \mathrm{KCl}\right.$ and $1 \mathrm{mM} \mathrm{CaCl}_{2}$ without agarose and bromocresol purple) to check whether the absence of any auxin effect was due to conditions associated with the agarose gel. To check whether it was possible to induce any auxin-specific effects, coleoptiles were tested since these represent the classical 'acid growth' system. A significant increase in growth was measured (Fig. 3.6). 

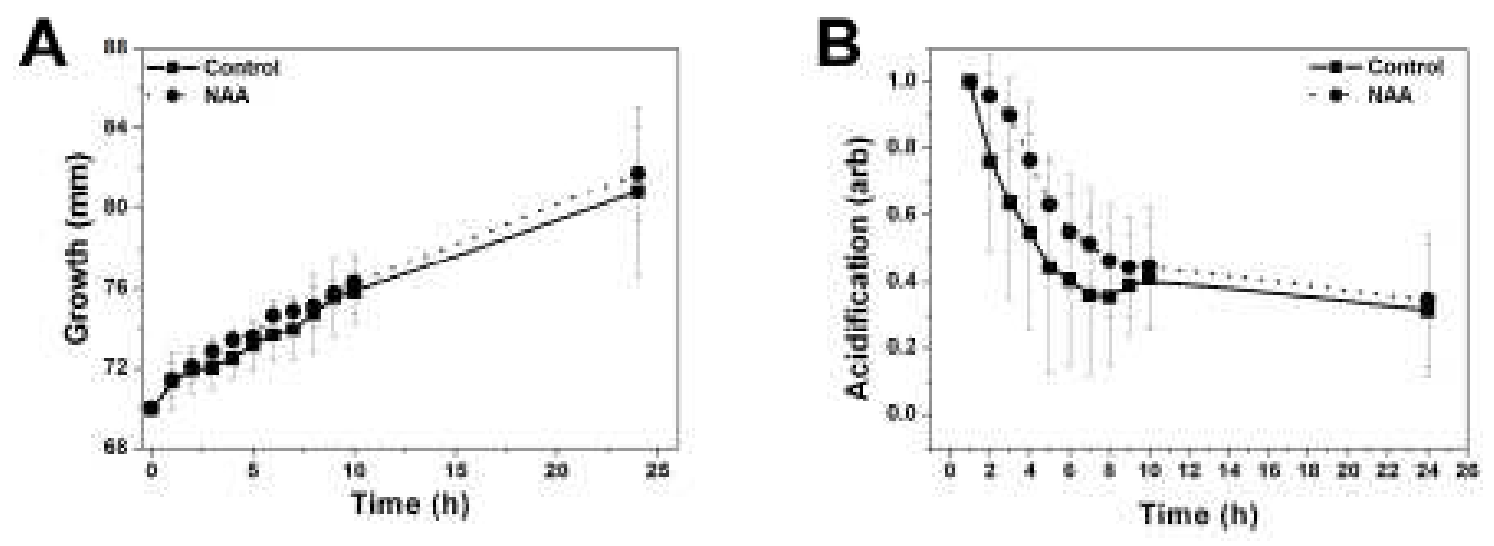

Figure 3.5 Effect of auxin on leaf growth and medium acidification using the in-vitro gel system

Difference in growth $(\mathrm{A})$ was not found between $5 \mu \mathrm{M}$ NAA treated and control plants. Medium acidification was similar in auxin-treated and non-treated (control) leaves (B). Traces are average of 10 - 27 plants, error bars represent standard errors.
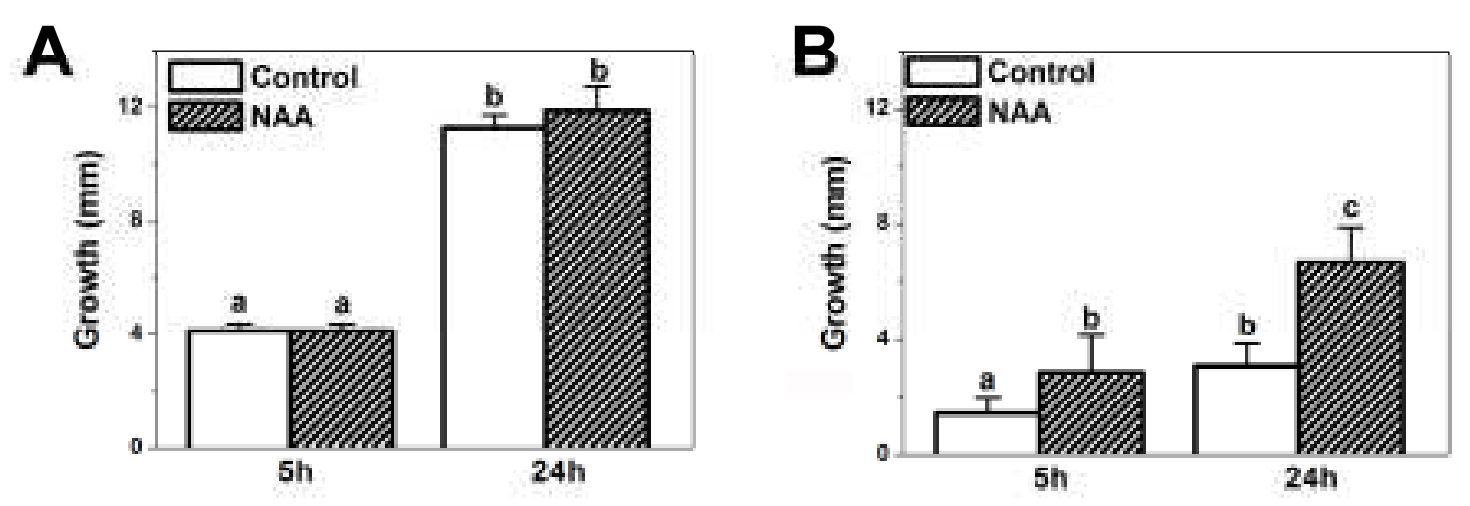

Figure 3.6 Growth effect of auxin when applied in liquid medium

NAA $(5 \mu \mathrm{M})$ effect on growth was tested in liquid medium on leaf $(A)$ and coleoptile pieces (B). Measurements were carried out at $5 \mathrm{~h}$ and $24 \mathrm{~h}$ of incubation. Values are averages and standard deviations (error bars) of 4 leaf pieces and 40 coleoptile segments. Different letters show a statistically significant difference at $p<0.05$ using Student's t-test and ANOVA.

\subsubsection{Microelectrode measurements}

Microelectrode measurements of apoplastic $\mathrm{pH}$ in the growing leaf three showed that the $\mathrm{pH}$ in the elongation zone was by up to one $\mathrm{pH}$ unit lower than the $\mathrm{pH}$ in the emerged blade (Fig. 3.7 A). Apoplastic pH in the elongation zone depended on the $\mathrm{K}^{+}$concentration in the bathing medium which was in direct contact with the leaf surface during measurements. At the lowest $\mathrm{K}^{+}$concentration tested $(0.1 \mathrm{mM})$, apoplast $\mathrm{pH}$ was 4.8. Apoplast $\mathrm{pH}$ increased with the $\mathrm{K}^{+}$concentration of the medium. At $10 \mathrm{mM} \mathrm{K}$, apoplast $\mathrm{pH}$ in the elongation zone was 5.8 and 
indistinguishable from the value in the emerged blade. In contrast to apoplast $\mathrm{pH}$ in the elongation zone, apoplast $\mathrm{pH}$ of the emerged blade did not change with bathing medium $\mathrm{K}^{+}$. When the $\mathrm{pH}$ of the bathing medium was adjusted to $\mathrm{pH} 7.0$ using $\mathrm{KOH}$ (final $\mathrm{K}$ concentration of $0.3-0.5 \mathrm{mM}$ ) apoplastic $\mathrm{pH}$ in the elongation zone was between 4.8 and 5.2. This proved that the lower apoplastic $\mathrm{pH}$ measured in the elongation zone was independent from the $\mathrm{pH}$ of the bulk (bathing) solution which was in direct contact with the apoplast, when the solution did not contain any buffer component. When the $\mathrm{pH}$ of the bathing solution was adjusted to $\mathrm{pH} 7.0$ using 100 $\mathrm{mM}$ TRIS- $\mathrm{HCl}$, including $0.1 \mathrm{mM} \mathrm{KCl}$, the $\mathrm{pH}$ of the apoplast was $6.1-6.2$ in both elongation zone and emerged blade (Fig. 3.7 B). Although this $\mathrm{pH}$ was lower by almost one $\mathrm{pH}$ unit than the $\mathrm{pH}$ of the bathing medium, this experiment showed that apoplast $\mathrm{pH}$ of the emerged blade was responsive to changes in the composition of the bathing medium and that the two were in direct contact. Bathing medium must have bypassed the cuticle and entered leaves through stomata. Growth of leaves on the microelectrode stage was not affected by $\mathrm{K}^{+}$treatments, despite the $\mathrm{K}^{+}$dependency of apoplast pH (Fig. 3.8).
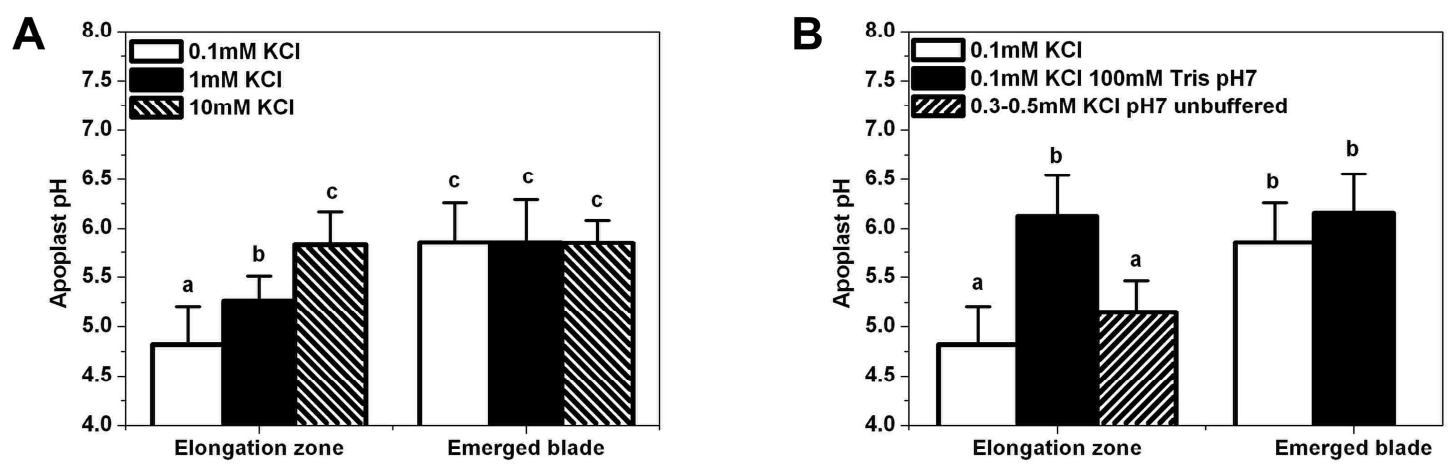

Figure 3.7 Microelectrode analyses of apoplast $\mathrm{pH}$ in the elongation zone and emerged blade-portion of leaf three of barley.

Apoplast $\mathrm{pH}$ was measured in dependence of the $\mathrm{K}^{+}$concentration (added as $\mathrm{KCl}$ ) of the electrode bathing medium which was in direct contact with the leaf tissue analysed (A). Apoplast $\mathrm{pH}$ measured when buffered solutions were applied as bathing medium (B). Values are averages \pm SD of $7-15$ measurements obtained on 3 - 6 plants of each treatment. Different letters show a statistically significant difference at $p<0.05$ (Student's t-test and ANOVA). 


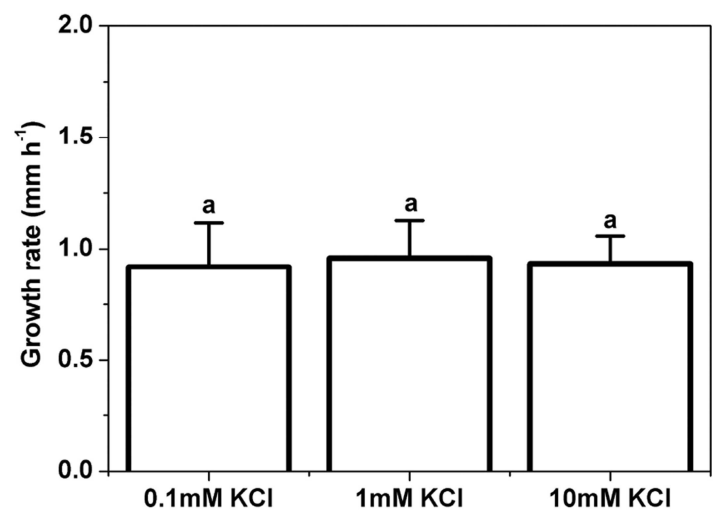

Figure 3.8 Growth rate of leaf three in response to $\mathrm{K}^{+}$-treatments during micro $\mathrm{pH}$ measurements.

Values are averages \pm SD of 7 - 15 measurements obtained on 3 - 6 plants of each treatment. Different letters show a statistically significant difference at $p<0.05$ (ANOVA).

Vanadate $\left(\mathrm{Na}_{3} \mathrm{VO}_{4}\right)$ and fusicoccin were added to the bathing medium to test whether the lower $\mathrm{pH}$ in the apoplast of the elongation zone was dependent on the activity of the PM- $\mathrm{H}^{+}$-ATPase. Vanadate, which inhibits the $\mathrm{PM}-\mathrm{H}^{+}$-ATPase, was tested at a concentration of $500 \mu \mathrm{M}$ in presence of $0.1 \mathrm{mM} \mathrm{KCl}$. Apoplast $\mathrm{pH}$ in the elongation zone increased from $\mathrm{pH} 4.8$ to $\mathrm{pH} 5.8$, precisely the $\mathrm{pH}$ value observed in the emerged blade (Fig. 3.9). Fusicoccin, which stimulates the PM- $\mathrm{H}^{+}-\mathrm{ATPase}$ (Marré, 1979; Würtele et al., 2003), was tested at a concentration of $5 \mu \mathrm{M}$ in presence of $1 \mathrm{mM} \mathrm{KCl}$. Apoplast $\mathrm{pH}$ was 5.2 and identical to the $\mathrm{pH}$ measured in absence of fusiccocin at $1 \mathrm{mM} \mathrm{KCl}$ in the bathing medium (Fig. 3.9). The rate of leaf elongation decreased in response to vanadate and increased in response to fusicoccin treatments (Fig. 3.10). This was observed for all experimental setups (Fig. 3.10). 


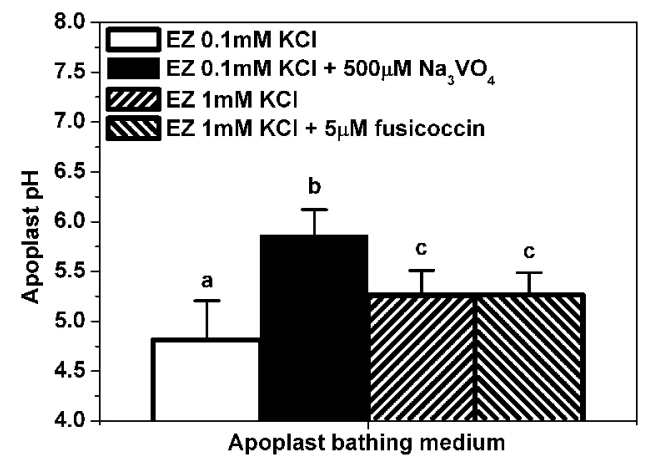

Figure 3.9 Microelectrode $\mathrm{pH}$ analyses in the leaf elongation zone of barley in response to sodium orthovanadate and fusicoccin treatments

The $\mathrm{KCl}$ concentration in the bathing medium was as indicated. Values are averages and standard deviations (error bars) of 12 (controls of $0.1 \mathrm{mM}$ and $1 \mathrm{mM} \mathrm{KCl}$ ), 4 (500 $\mu \mathrm{M}$ vanadate) and 4 (5 $\mu \mathrm{M}$ fusicoccin) datasets of between $3-6$ different plants each. Different letters show a statistically significant difference at $p<0.05$ (Student's t-test and ANOVA).

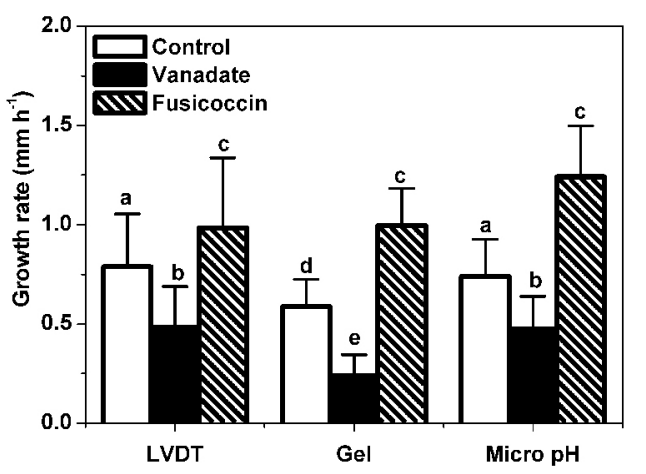

Figure 3.10 Growth rate of leaf three of barley in response to vanadate and fusicoccin treatments as analysed through different approaches

Values are averages and standard deviations (error bars) of 13 - 60 (control), 3 - 8 (vanadate) and 3 - 10 (fusicoccin) replicates. Different letters show a statistically significant difference at $p<0.05$ (Student's t-test and ANOVA).

\subsubsection{Confocal microscopy}

Acridine orange and 5(6)carboxyfluorescein are $\mathrm{pH}$ sensitive fluorescence dyes. They were used to test whether the apoplastic $\mathrm{pH}$ was lower in the elongation zone compared with emerged blade in intact barley plants. First, the system had to be calibrated. This was achieved by peeling epidermal strips from plants which had been grown for $24 \mathrm{~h}$ in the presence of 5(6)carboxyfluorescein and $48 \mathrm{~h}$ in presence 
of acridine orange in the root medium to allow sufficient uptake of dye into leaf tissue. Exposure of epidermal strips to solutions of different $\mathrm{pH}$ showed (i) that dye had been taken up into the leaf apoplast and (ii) that the fluorescence intensity of dye in the apoplast changed in the physiological $\mathrm{pH}$ range, in the same manner as observed for dye in free solution (Fig. 3.11 A, B for acridine orange and Fig. 3.12 A, B for carboxyfluorescein). Fluorescence decreased with $\mathrm{pH}$. Optical sections from the epidermis of intact third leaves showed that the fluorescence intensity, and by implication $\mathrm{pH}$, were considerably lower in the apoplast of the elongation zone than in the apoplast of the emerged blade (Fig. 3.11 C-F for acridine orange and Fig. 3.12 CF for carboxyfluorescein).

It is possible that the difference in fluorescence intensity between leaf regions resulted not from differences in apoplast $\mathrm{pH}$ but from differences in the concentration of dye accumulated during the uptake period. This was tested by peeling epidermis strips from the elongation zone and emerged blade (leaf three) of dye-loaded plants and incubating the peels in $\mathrm{pH} 7.5$ buffer solution. Peels were examined after a 30 min incubation period using a Leica epifluorescence microscope. The fluorescence intensity and by implication carboxyfluorescein and acridine orange concentration was similar in the epidermis of the two leaf regions; if anything, it was higher in the elongation zone (Fig. 3.13). This experiment showed that the lower apoplast $\mathrm{pH}$ in the epidermis of the elongation zone of intact, dye-loaded plants, was not the result of a lower fluorochrome concentration but reflected most likely a true difference in apoplast $\mathrm{pH}$ between the two leaf regions. Uptake of dyes through roots and accumulation in leaf tissue did not cause changes in leaf growth (Fig. 3.14 A, B). 

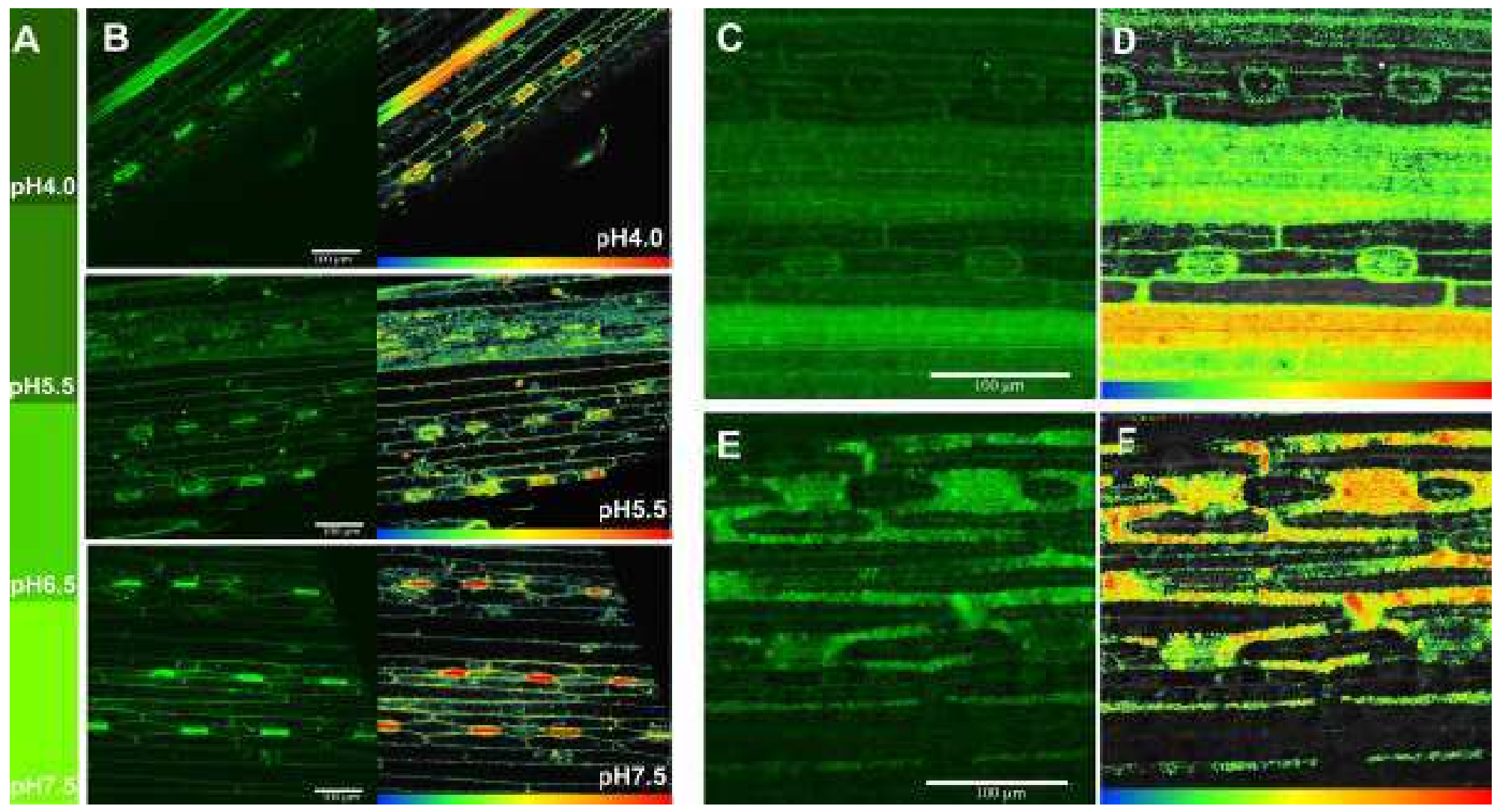

Figure 3.11 Confocal microscopic analysis of apoplastic pH using acridine orange fluoresce $\mathrm{pH}$ sensitive fluorescence dye

The $\mathrm{pH}$ sensitivity of fluorescence of dye as tested on sample droplets which contained $2.5 \mu \mathrm{M}$ acridine orange and were buffered at the $\mathrm{pH}$ indicated $(\mathrm{A})$. Confocal images of epidermal peels of the mature leaf one; following incubation of peels for $30 \mathrm{~min}$ in the solutions as shown in (B). Typical confocal images (C, $E)$ and their heat map $(D, F)$. Elongation $(C, D)$ and emerged $(E, F)$ region of leaf three of intact plants. Images containing scale bars show the original fluorescence image, while corresponding images without scale bars represent heat maps of images. 

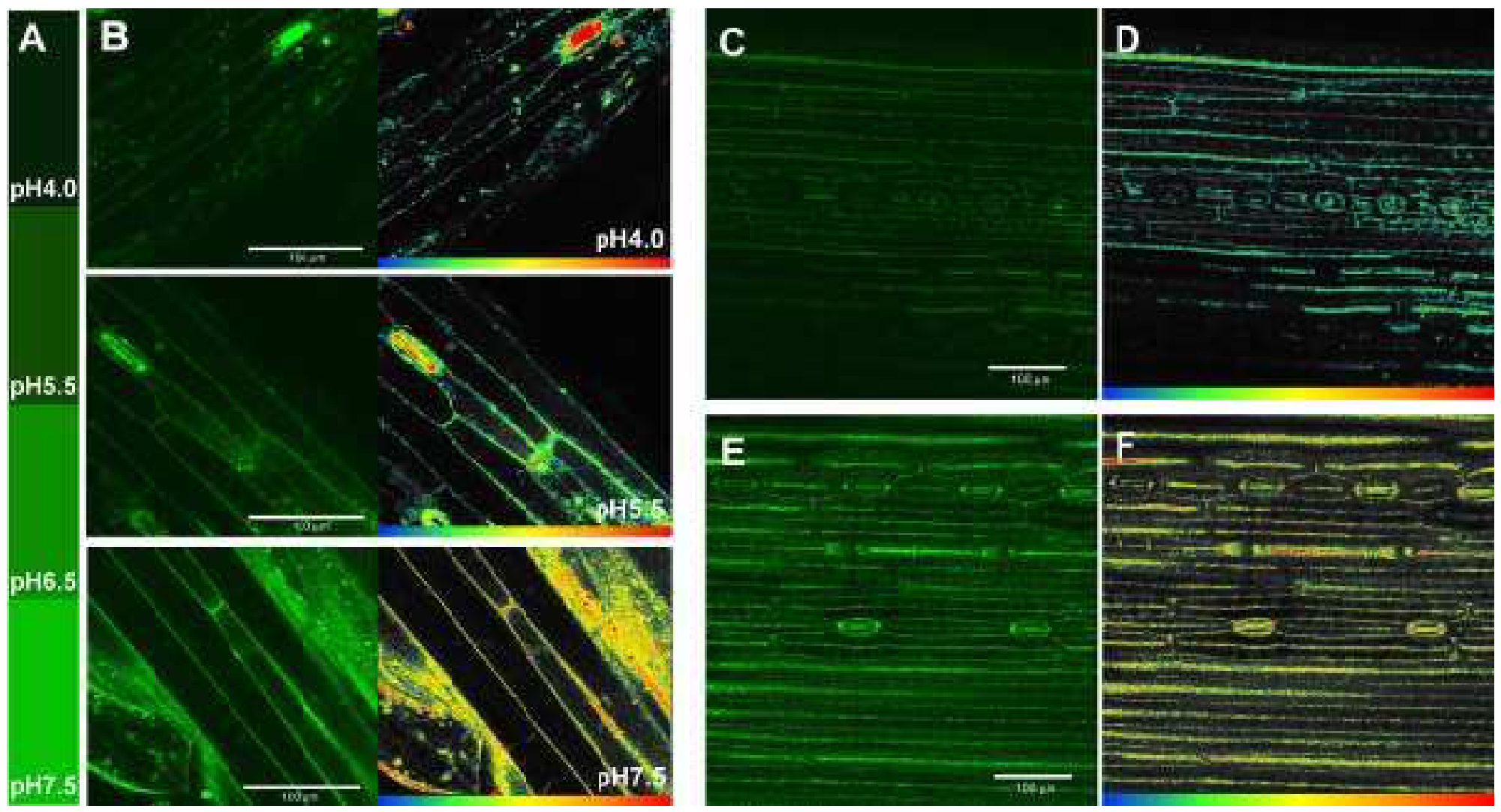

Figure 3.12 Confocal microscopic analysis of apoplastic pH using 5(6)carboxyfluorescein fluoresce $\mathrm{pH}$ sensitive fluorescence dye

The $\mathrm{pH}$ sensitivity of fluorescence of dye as tested on sample droplets which contained $10 \mu \mathrm{M}$ carboxyfluorescein and were buffered at the $\mathrm{pH}$ indicated $(\mathrm{A})$. Confocal images of epidermal peels of the mature leaf one; following incubation of peels for $30 \mathrm{~min}$ in the solutions as shown in (B). Typical confocal images $(C, E)$ and their heat map $(D, F)$. Elongation $(C, D)$ and emerged $(E, F)$ region of leaf three of intact plants. Images containing scale bars show the original fluorescence image, while corresponding images without scale bars represent heat maps of images. 

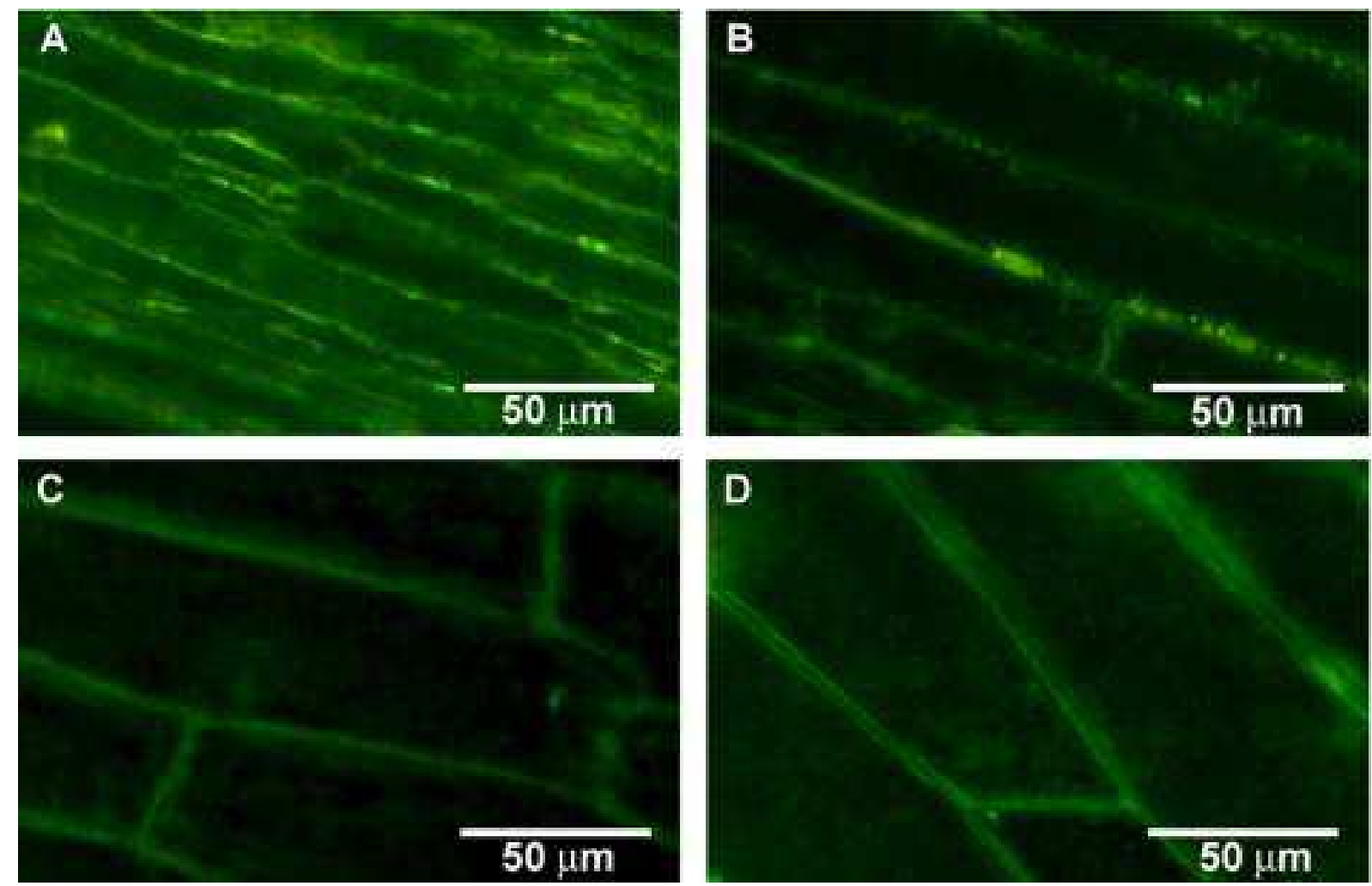

Figure 3.13 Carboxyfluorescein and acridine orange accumulation pattern in elongation zone and emerged blade

The distribution of the $\mathrm{pH}$ sensitive probes (5(6)carboxyfluorecein, $\mathrm{A}, \mathrm{C}$ and acridine orange, $B, D)$ appears to be similar in the elongation zone $(A, C)$ and emerged leaf blade $(B, D)$. The dye was taken up through the roots of intact plants and the epidermal strips of leaf three were incubated $(30 \mathrm{~min})$ in $\mathrm{pH} 7.5$ buffer prior to be viewed under the microscope (Leica DMIL; 450 - $490 \mathrm{~nm}$ excitation filter and $515 \mathrm{~nm}$ suppression filter).
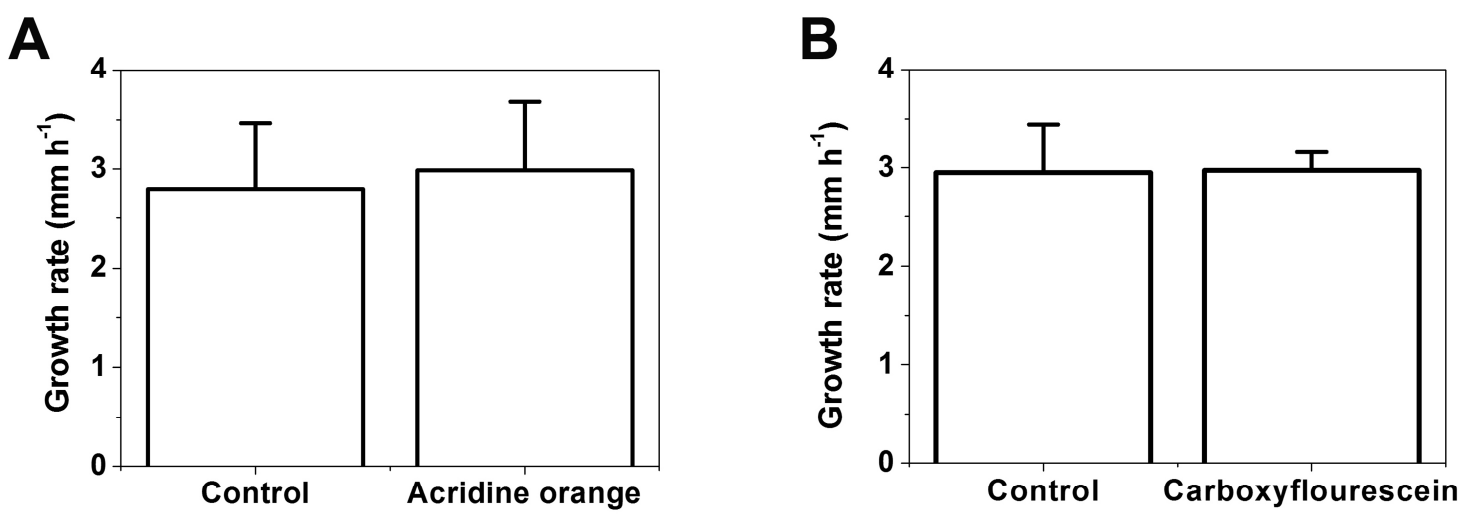

Figure 3.14 Effect of pH sensitive dyes on leaf growth rate

Growth, as measured with the LVDT on intact plants (unpeeled leaf three) did not change after $48 \mathrm{~h}$ incubation of plants in nutrient solution containing $2.5 \mu \mathrm{M}$ acridine orange (A); the same was observed for plants after $24 \mathrm{~h}$ incubation in nutrient solution containing $10 \mu \mathrm{M}$ carboxyfluorescein. Values are averages of 3 replicates, and error bars represent standard errors. 
The $\mathrm{pH}$ sensitivity of fluorochrome 5(6)carboxyfluorescein and acridine orange was determined by fluorescence spectroscopy. Both fluorescein probes showed $\mathrm{pH}$-sensitivity in the physiological $\mathrm{pH}$ range and had single peak spectra. Carboxyfluorescein showed a larger $\mathrm{pH}$ sensitivity in the $\mathrm{pH}$ range of interest compared with acridine orange (Fig. 3.15).
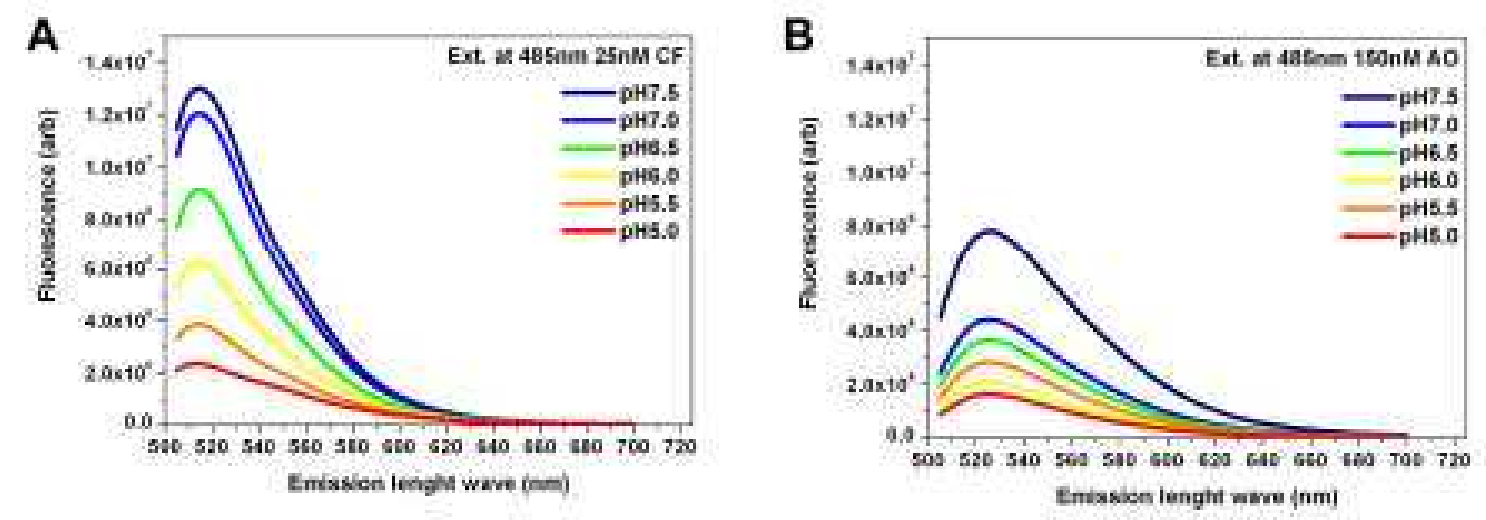

Figure $3.15 \mathrm{pH}$ sensitivity of fluorochromes

Fluorescence spectra and $\mathrm{pH}$ sensitivity of $5(6)$ carboxyfluorescein $(\mathrm{A})$ and acridine orange (B) was recorded. Both fluorochromes had $\mathrm{pH}$ sensitivity although carboxyfluorescein gave more explicit signal and better $\mathrm{pH}$ fidelity in the physiological $\mathrm{pH}$ range.

\subsection{LVDT analyses of growth responses to treatments}

\subsubsection{Leaf elongation under different treatments}

The basic assumption underlying LVDT experiments was that the wet tissue paper which was soaked in test solution and in direct contact with the surface of the elongation zone of leaf three allowed the test solution to diffuse into the apoplast. The responsiveness of setup to treatments was tested through two types of experiment, one designed to increase $\left(37^{\circ} \mathrm{C}\right)$ and on e designed to reduce growth (1 $\mathrm{M} \mathrm{NaCl}$ ). Elongation growth of grass leaves responds little to changes in ambient temperature but to the temperature close to the basal meristem (Stoddart \& Lloyd, 1986). Therefore, parts of a potato which had been heated to $37^{\circ} \mathrm{C}$ in an incubator were placed round the leaf elongation zone without any direct contact between the potato and the barley seedling. Growth started to increase within minutes (Fig. 3.16 A, B). With time, the potato cooled down and leaf elongation rate decreased. When finally $1 \mathrm{M} \mathrm{NaCl}$ was added to impose a severe osmotic stress, growth stopped instantly and remained zero or close to zero (Fig. 3.16 A, B). 


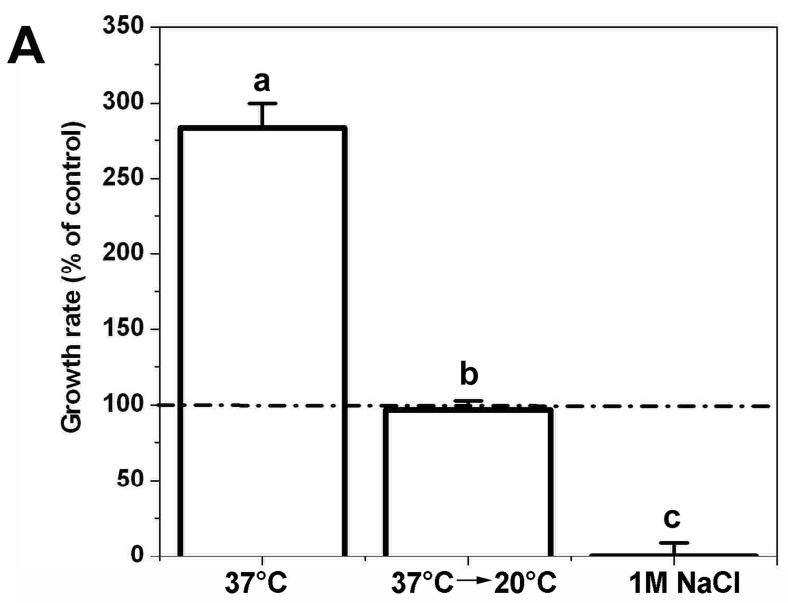

B

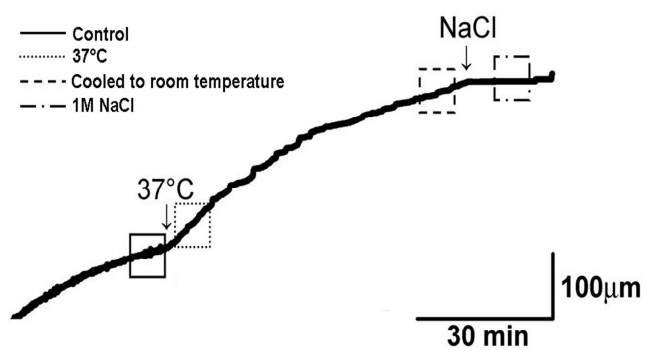

Figure 3.16 Testing the responsiveness of the LVDT setup to treatments which were expected to increase $\left(37^{\circ} \mathrm{C}\right)$ or stop growth $(1 \mathrm{M} \mathrm{NaCl})$

Average values (three plants) and standard deviations (error bars) (A) and a typical trace (B) are shown. The apoplastic bathing medium always contained $1 \mathrm{mM} \mathrm{KCl}$. Different letters show a statistically significant difference at $p<0.001$ (Student's $t$ test).

Having tested the responsiveness of the LVDT setup, treatments were applied. In presence of $1 \mathrm{mM} \mathrm{KCl}$ in the test solution fusicoccin $(5 \mu \mathrm{M})$ increased leaf elongation rate to $160 \%$ the rate observed in control plants. Vanadate, $\mathrm{CsCl}$ and $\mathrm{CsCl}$-vanadate double treatments caused a $50 \%$ decrease in growth rate (Fig. 3.17). The same was observed for the $\mathrm{K}^{+}$channel blocker tetraethylammonium (TEA) and ammonium, which blocks high-affinity $\mathrm{K}^{+}$transporters $\left(\mathrm{NH}_{4}{ }^{+}\right.$; HAK-type transporters (Kronzucker et al., 2003; Rodriguez-Navarro \& Rubio, 2006; Szczerba et al., 2006). 
A

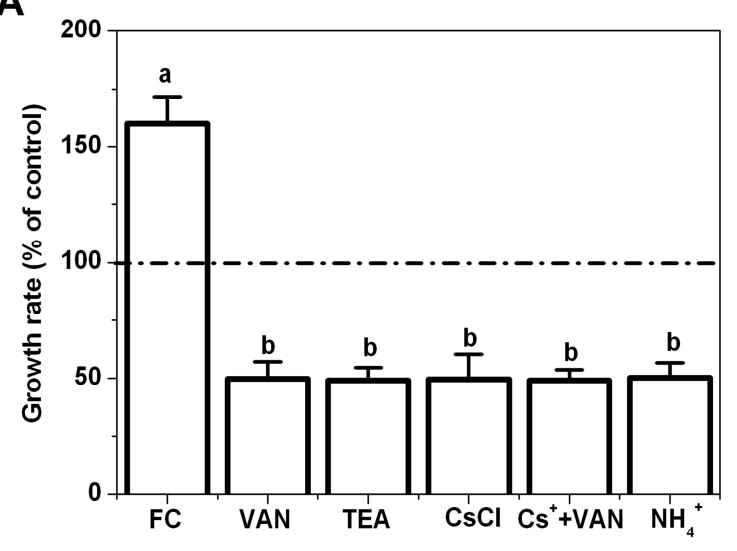

B

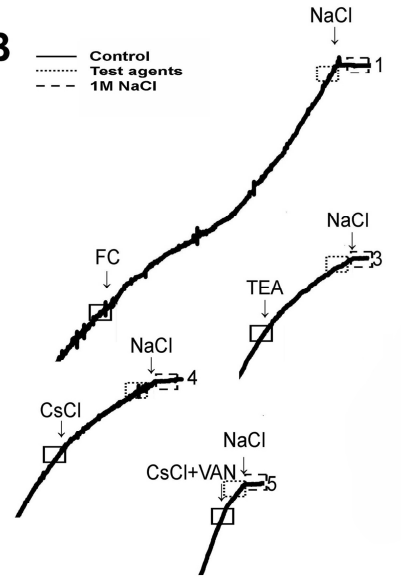

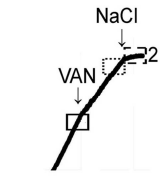

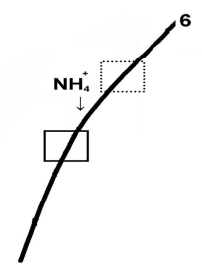

$\int_{1 \mathrm{~h}} 100 \mu \mathrm{m}$

Figure 3.17 The effect of test reagents in the apoplastic bathing medium on leaf growth as measured with the LVDT setup

Average values and standard deviations of experiments $(A)$ involving application of test reagents are shown (fusicoccin $(5 \mu \mathrm{M}, \mathrm{n}=3$ plants), vanadate (VAN, $500 \mu \mathrm{M}, 6$ plants), tetraethylammonium chloride (TEA, $50 \mathrm{mM}, 6$ plants), $\mathrm{CsCl}(40 \mathrm{mM}, 4$ plants), CsCl+VAN double-treatment $\left(40 \mathrm{mM} / 500 \mu \mathrm{M}, 3\right.$ plants), and $\left(\mathrm{NH}_{4}\right)_{2} \mathrm{SO}_{4}(20$ $\mathrm{mM}, 3$ plants)). Media always contained $1 \mathrm{mM} \mathrm{KCl}$. Typical traces of experiments (B). Growth rates are expressed as percent of the respective $\mathrm{KCl}$ control, which contained only $\mathrm{KCl}$ but no test reagents in the apoplastic bathing medium. Different letters show a statistically significant difference at $p<0.05$ (Student's t-test and ANOVA).

The effect of fusicoccin on elongation growth was dependent on the $\mathrm{K}^{+}$ concentration in the bathing medium which was in direct contact with the leaf elongation zone (Fig. 3.18). The higher the $\mathrm{K}^{+}$concentration was, the larger was the stimulation of growth. In contrast, the inhibitory effect of vanadate on leaf elongation growth did not depend on the $\mathrm{K}^{+}$concentration in the bathing medium (Fig. 3.18). This experiment showed that changes in the $\mathrm{K}^{+}$concentration per se did not affect growth but required a functional PM- $\mathrm{H}^{+}$-ATPase to affect growth. 


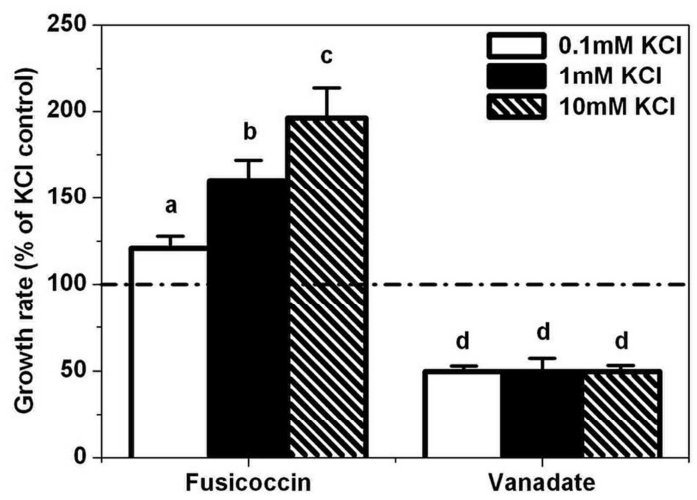

Figure 3.18 Potassium dependency of the leaf growth response to fusicoccin (5 $\mu \mathrm{M})$ and vanadate $(500 \mu \mathrm{M})$

Values are averages and standard deviations (error bars) of $3-6$ plants, and the $\mathrm{K}^{+}$ concentration of apoplastic bathing medium was as indicated. Growth rates are expressed as percent of the respective $\mathrm{KCl}$ control, which contained only $\mathrm{KCl}$ and no test reagents in the apoplastic bathing medium. Different letters show a statistically significant difference at $p<0.05$ (Student's t-test and ANOVA).

Short term (1 - 4 h) auxin-induced leaf growth was measured with the same LVDT set up. Treatments ( $5 \mu \mathrm{M}$ NAA with $1 \mathrm{mM} \mathrm{KCl})$ did not caused any significant increase in growth rate, moreover the leaf elongation rate slightly (but not significantly) decreased rather than increased (Fig. 3.19). These results suggested that leaf elongation can not be further increased by auxin treatments.

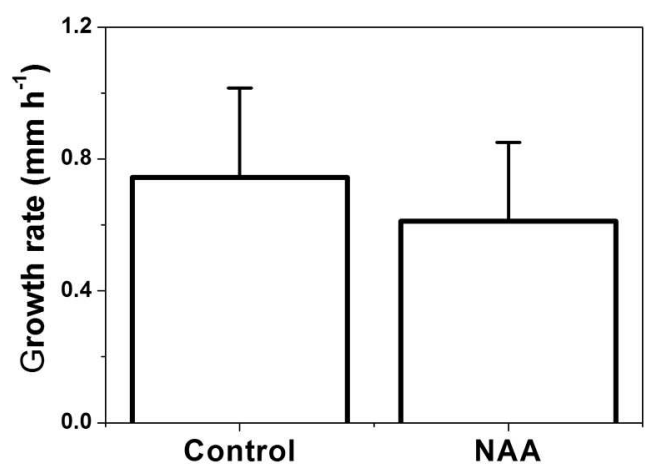

Figure 3.19 Auxin effect on leaf elongation growth

Elongation growth was monitored using the LVDT system. Growth in control (1 mM $\mathrm{KCl})$ and NAA treated plants $(1 \mathrm{mM} \mathrm{KCl}$ and $5 \mu \mathrm{M} \mathrm{NAA})$ did not significantly differ from each other. Values are averages and standard deviations (error bars) of 3 replicates. The difference in growth between control and NAA treatment is statistically not significant (Student's t-test). 


\subsubsection{Cell wall changes in response to treatments}

Changes in cell wall properties were tested for $500 \mu \mathrm{M}$ vanadate, $40 \mathrm{mM} \mathrm{CsCl}$ and 5 $\mu \mathrm{M}$ fusicoccin treatments by applying an additional $3 \mathrm{~g}$ counterweight on the LVDT system. Control plants had $1 \mathrm{mM} \mathrm{KCl}$ in the apoplast bathing medium of the elongation zone. The elastic growth component significantly changed only in response to the fusicoccin treatment, whereas plasticity was affected significantly in response to $\mathrm{CsCl}$ (Fig. 3.20 A). Additional stress $(0.03 \mathrm{~N}$ ) on the cell wall did not change the relative growth rate compared with control (1 $\mathrm{mM} \mathrm{KCl}, \Delta \Delta \mathrm{v})$, except in fusicoccin-treated leaves. Fusicoccin treatment caused a $50 \%$ increase in $\Delta \Delta \mathrm{v}$ compared with all other treatments and the control (Fig. 3.20 B).
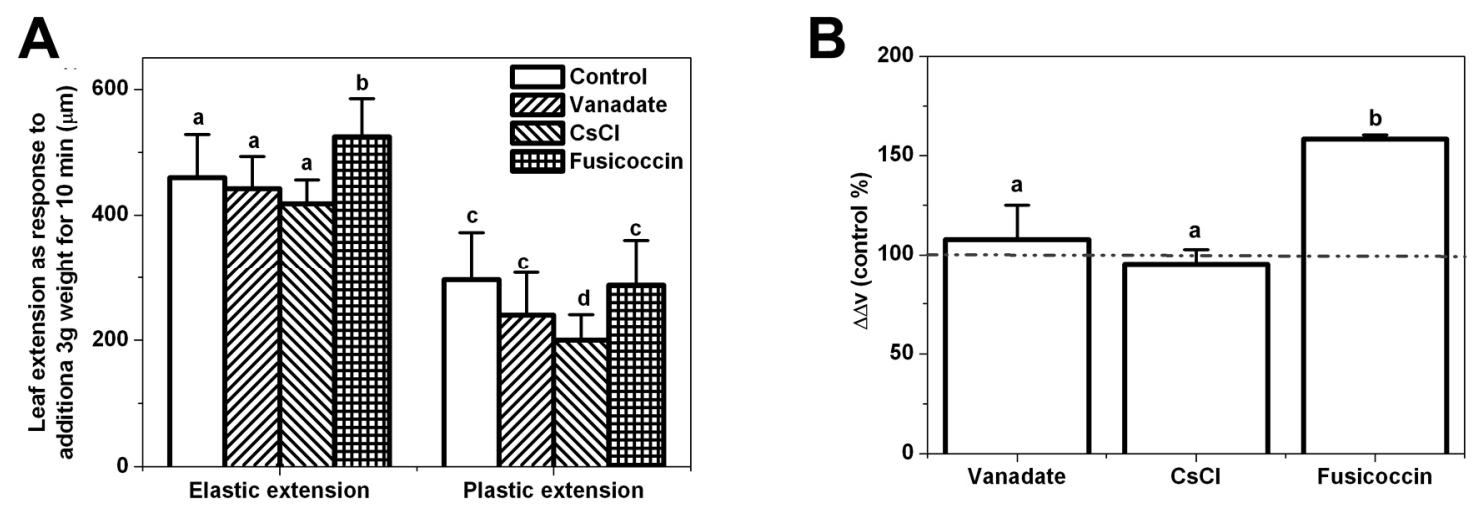

Figure 3.20 Cell wall changes under different treatments

Elastic and plastic growth (A) and $0.03 \mathrm{~N}$ stress caused growth rate (B) was measured on 3 independent plants in two replicates each. $\Delta \Delta \mathrm{v}$ means the difference between $\Delta v_{\text {control }}$ and $\Delta v_{\text {treatment }}$ where $\Delta v$ is the difference in growth rate before and under the applied additional stress $\left(\mathrm{V}_{2}-\mathrm{v}_{1}\right.$ on Fig. 3.2). Different letters show statistically different values at $p<0.05$ level with Student's t-test and ANOVA.

Growth rate before $\left(\mathrm{v}_{1}\right)$ and under $\left(\mathrm{v}_{2}\right)$ applied $0.03 \mathrm{~N}$ force was in agreement with previous effect of test reagents on growth (compare Fig. 3.17 and Fig. 3.21). The fusicoccin treatment caused a large increase in growth, although the increase was statistically not significant. 


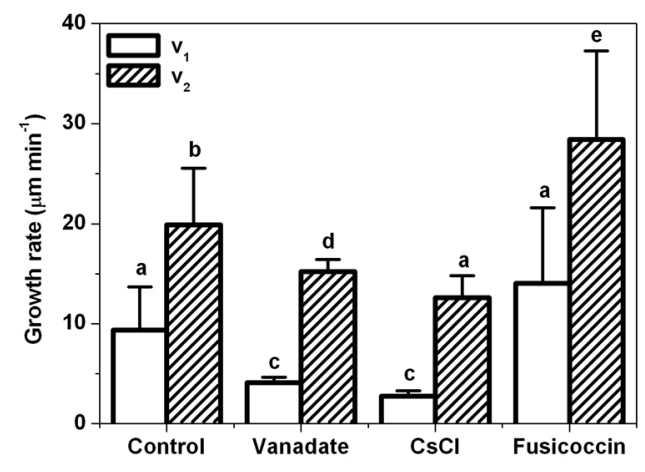

Figure 3.21 Growth rate before and in response to an additional applied force $(0.03 \mathrm{~N})$

Growth rate before $\left(\mathrm{v}_{1}\right)$ and under $\left(\mathrm{v}_{2}\right)$ applied force $(3 \mathrm{~g})$ using different treatments as vanadate $(500 \mu \mathrm{M}), \mathrm{CsCl}(40 \mathrm{mM})$ or fusicoccin $(5 \mu \mathrm{M})$. Bath medium of control plants contained $1 \mathrm{mM} \mathrm{KCl}$. Values are averages of $3-3$ replicates. Different letters shows statistically different values at $p<0.05$ level with Student's t-test and ANOVA.

\subsection{Expression analysis of PM- $H^{+}$-ATPase using qPCR}

$\mathrm{PM}-\mathrm{H}^{+}-\mathrm{ATPase}$ expression was analysed using qPCR. Altogether five reference genes (GADPH, cyclophilin, ubiquitin, HSP70 and PM- $\mathrm{H}^{+}$-ATPase) were tested in the experimental system. Only ubiquitin and the two $\mathrm{PM}-\mathrm{H}^{+}$-ATPase (Ha1 and ATPase) primer pairs showed similar expression in the elongation zone and emerged blade (Fig. 3.22 A). Other, commonly used reference genes such as actin, tubulin, EF1, LHC were not suited because growing and non-growing leaf regions had to be compared (see Besse et al., 2011; Volkov et al., 2009). Ubiquitin could not be used as reference gene because the PCR product was not homogenous but produced more than one band as agarose gel analysis showed (Fig. 3.22 B). Applying Genevestigator bioinformatics application (www.genevestigator.com) could not solve the problem. Therefore, it was decided to carry out absolute qPCR quantification to determine $\mathrm{PM}-\mathrm{H}^{+}$-ATPase expression levels in the leaf elongation zone and emerged blade. 
A

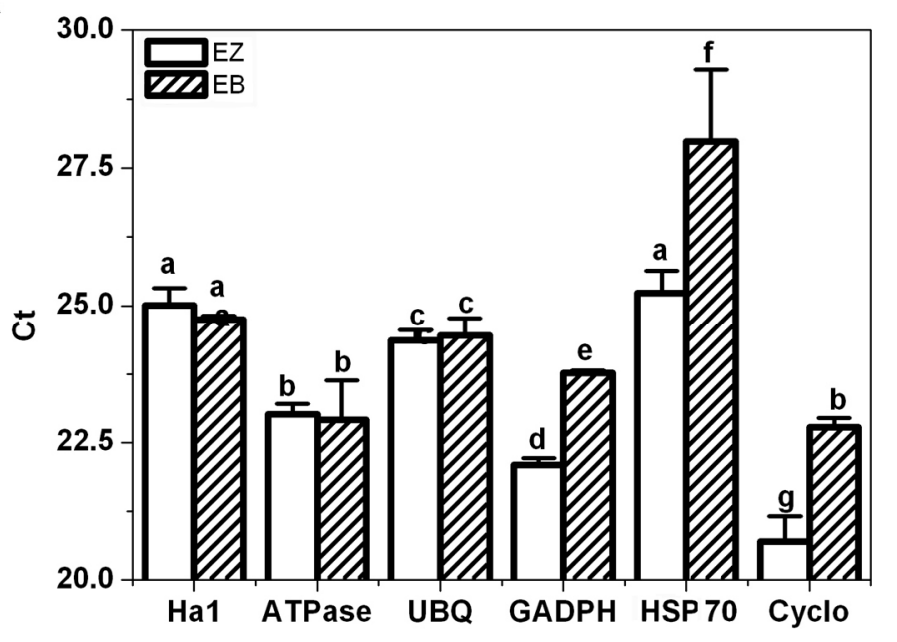

B

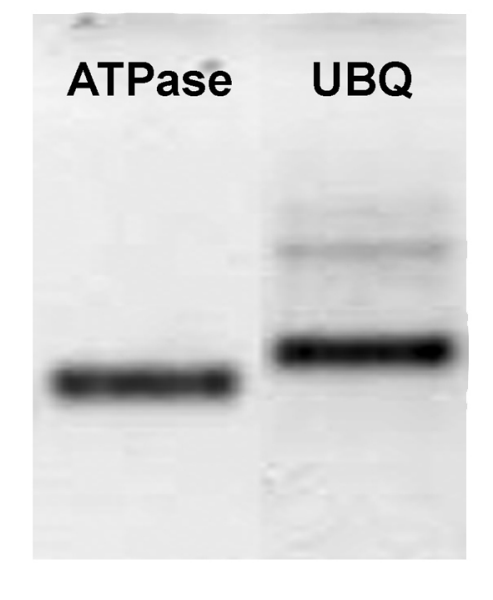

Figure 3.22 reference genes for qPCR experiments

500 pg total RNA-equivalent cDNA was used in each reaction well to check the qPCR profile of candidate reference genes. Expression, as shown as Ct-value, of the two PM- $\mathrm{H}^{+}$-ATPase PCR primer pair (Ha1 and ATPase) and ubiquitin (UBQ) was similar between the two leaf regions, effectively qualifying them as reference genes of expression. In contrast, expression of glyceraldehyde-3-phosphate dehydrogenase (GADPH), heat shock protein $70 \mathrm{kDa}$ (HSP70) and cyclophylin (Cyclo) differed significantly between leaf regions (A). Values are averages of 3 replicates and error bars represent SD. Different letters show significantly different values at $p<0.05$ level using Student's t-test and ANOVA. Agarose gel picture of PM- $\mathrm{H}^{+}$-ATPase (ATPase) and ubiquitin (UBQ) show that that ubiquitin shows more than one PCR product $(\mathrm{B})$.

\subsubsection{Quality control of the standard required for absolute qPCR}

Quality of reference DNA (purified PM-H ${ }^{+}$-ATPase PCR fragments) was validated using end point detection digital PCR technique (Vogelstein \& Kinzler, 1999). The concentration of fragments was calculated as 0.5 copy $\mu l^{-1}$ based on Nanodrop ${ }^{\circledR}$ measurements. From 40 PCR reactions 21 were PCR positive and 19 negative (Fig. 3.23). This suggested a concentration of 0.525 DNA copy $\mu l^{-1}$ in the external standard and was just $2.5 \%$ higher compared with the calculated copy concentration $\left(0.5\right.$ copy $\left.\mu l^{-1}\right)$. 
Figure 3.23 Digital PCR pattern of external standard DNA

Using digital PCR technique the concentration of the external standard for $\mathrm{PM}-\mathrm{H}^{+}-$ ATPase expression was verified. The PCR positive / negative ratio was $21 / 19$, which suggests a concentration of 0.525 copy of ATPase DNA in $1 \mu$ l of standard compared with the calculated 0.5 . Therefore, the reliability of the standard was higher than $95 \%$.

\subsubsection{Calculation of cell number and membrane surface}

Total cell volume of the leaf regions was calculated for the two barley cultivars using the water content of the plant material, cell dimensions and contribution of each tissue to total leaf symplast volume (Table 3.1). The water content differed significantly between the two leaf regions but not between the two cultivars.

Table 3.1 Water content of two different regions of leaf three in two cultivars of barley

\begin{tabular}{l|l|l|l|l} 
Cultivar & Leaf part & No replicates & Water content (\%) & SD \\
\hline \hline \multirow{3}{*}{ Golf } & Elongation zone & 3 & 92.06 & 1.57 \\
\cline { 2 - 5 } & Emerge blade & 3 & 86.78 & 2.25 \\
\hline \multirow{3}{*}{ Jersey } & Elongation zone & 7 & 93.78 & 3.12 \\
\cline { 2 - 5 } & Emerge blade & 7 & 87.78 & 1.07
\end{tabular}

The tissue volume ratio was measured on cross sections using light microscopy (Table 3..2 and Fig. 3.24) and average cell size was estimated from the present protoplast measurements and data published for Golf (Fricke \& Flowers, 1998; Volkov et al., 2007; Volkov et al., 2009, Kavanagh, 2010) (Table 3.3). Mesophyll and epidermis cell size and surface area was calculated separately and the total number of cells and surface area was calculated from data on the contribution of each tissue to total leaf symplastic volume (not considering intercellular air space). Mesophyll cell size differed between growing and mature, emerged tissues around 2.2-fold and epidermis cells differed 4.6-fold, in each case being larger in emerged tissue. The surface was about 2.6-fold and 1.9-fold higher in the emerged blade for epidermis and mesophyll, respectively. 
Table 3.2 The contribution of different tissues to total leaf volume in the elongation zone (EZ) and emerged blade (EB) of leaf three of barley. Values are given as $\%$ of the total leaf volume and are either not corrected or corrected for intercellular air space, effectively giving a contribution to total leaf symplastic volume.

\begin{tabular}{l|l|l|l|l} 
& \multicolumn{2}{|c|}{ EZ } & \multicolumn{2}{c}{ EB } \\
\hline \hline Epidermis (\%) & 24.85 & \pm 1.54 & 23.37 & \pm 2.94 \\
\hline Mesophyll (\%) & 61.75 & \pm 1.93 & 51.61 & \pm 4.36 \\
\hline Vascular bundle (\%) & 8.99 & \pm 1.97 & 4.01 & \pm 0.93 \\
\hline Intercellular air space (\%) & 4.40 & \pm 1.32 & 21.01 & \pm 4.29 \\
\hline Epidermis corrected (\%) & 26.00 & \pm 1.28 & 29.59 & \pm 3.72 \\
\hline Mesophyll corrected (\%) & 64.60 & \pm 1.96 & 65.34 & \pm 5.52 \\
\hline Vascular bundle corrected (\%) & 9.41 & \pm 1.80 & 5.08 & \pm 1.18
\end{tabular}
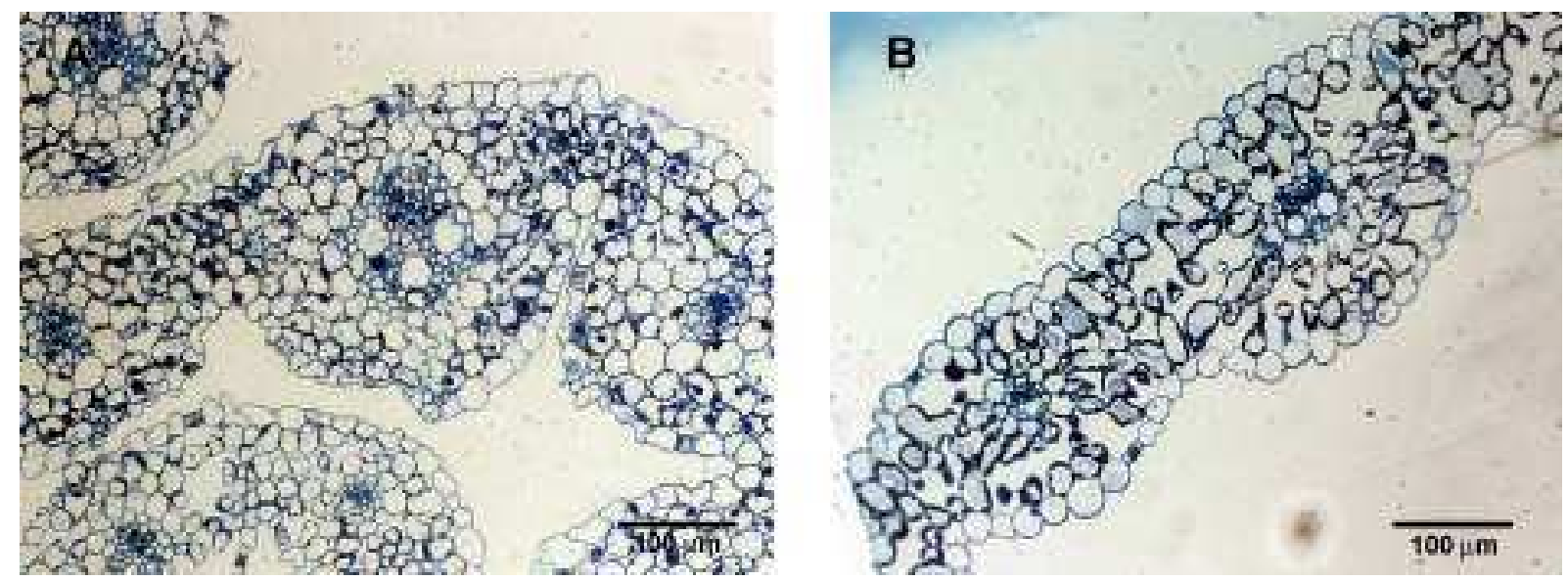

Figure 3.24 Representative cross sections used for determination of the contribution of different tissues and air space to total leaf volume

Toluidine blue stained cross sections were used to calculate the percentage of different tissues to total leaf and symplastic volume in the elongation zone (A) and emerged blade (B) of leaf three of barley. 
Table 3.3 Cell size calculation based on the present and literature data. Values shown in bold were used for to relate ATPase expression and activity data to cell volume and surface area

\begin{tabular}{|c|c|c|c|c|}
\hline & \multicolumn{2}{|c|}{ EZ } & \multicolumn{2}{|c|}{ EB } \\
\hline Cell volume & Average & SD & Average & SD \\
\hline $\begin{array}{l}\text { Epidermis cell size (Fricke \& Flowers, } \\
1998 \text { ) }\end{array}$ & 99.4 & & 461 & \\
\hline Epidermis cell size average (pl) & 99.4 & & 461 & \\
\hline Mesophyll cell size (my protoplast results) & 3.7 & & 9.4 & \\
\hline Mesophyll cell size (Volkov et al., 2007) & 8.9 & & 24.4 & \\
\hline Mesophyll cell size (Volkov et al., 2009) & 11.8 & & 17.4 & \\
\hline Mesophyll cell size (Kavanagh, 2010) & 2.08 & & 8.11 & \\
\hline Mesophyll cell size average (pl) & 6.62 & \pm 4.52 & 14.83 & \pm 7.59 \\
\hline Cell surface & & & & \\
\hline $\begin{array}{l}\text { Surface of epidermis cell (Fricke \& } \\
\text { Flowers, 1998) }\end{array}$ & 27100 & & 65200 & \\
\hline $\begin{array}{l}\text { Surface of epidermis cell (Kavanagh, } \\
\text { 2010) }\end{array}$ & 12308 & & 34809 & \\
\hline Surface of epidermis cell average $\left(\mu m^{2}\right)$ & 19,707 & $\pm 10,459$ & 50,004 & $\pm 21,490$ \\
\hline Mesophyll cell size (my protoplast results) & 1,157 & & 2,154 & \\
\hline Mesophyll cell size (Volkov et al., 2007) & 2,077 & & 4,068 & \\
\hline Mesophyll cell size (Volkov et al., 2009) & 2,506 & & 3,247 & \\
\hline Mesophyll cell size (Kavanagh, 2010) & 788 & & 1,952 & \\
\hline Surface of mesophyll cell $\left(\mu \mathrm{m}^{2}\right)$ & 1,632 & \pm 796 & 2,855 & \pm 988 \\
\hline
\end{tabular}

\subsubsection{Gene expression data based on absolute qPCR method}

Using the absolute qPCR method, together with cell size and tissue volume contributions it was found that $\mathrm{PM}-\mathrm{H}^{+}$-ATPase had a constant expression pattern in both elongation zone and emerged leaf blade; it was deemed to be a perfect reference gene in both Golf and Jersey cultivars (Fig. 3.25 and Table 3.4). The total RNA content was similar in the elongating zone and emerge leaf blade. This applied to both Golf and Jersey cultivars (Table 3.4).

Results expessed per plasma membrane surface unit were significant, being around 2 times higher $\mathrm{PM}-\mathrm{H}^{+}$-ATPase protein concentration as might be presumed in elongation zone compare with emerge blade in both barley cultivars. Absolute expression was 3 times higher in Golf compare to Jersey cultivar (Fig. 3.26). The calculation here presumed that protein translation from mRNA was linear and had equal probability in elongation zone and emerge blade. More details of the calculation can be found in the Appendix. 

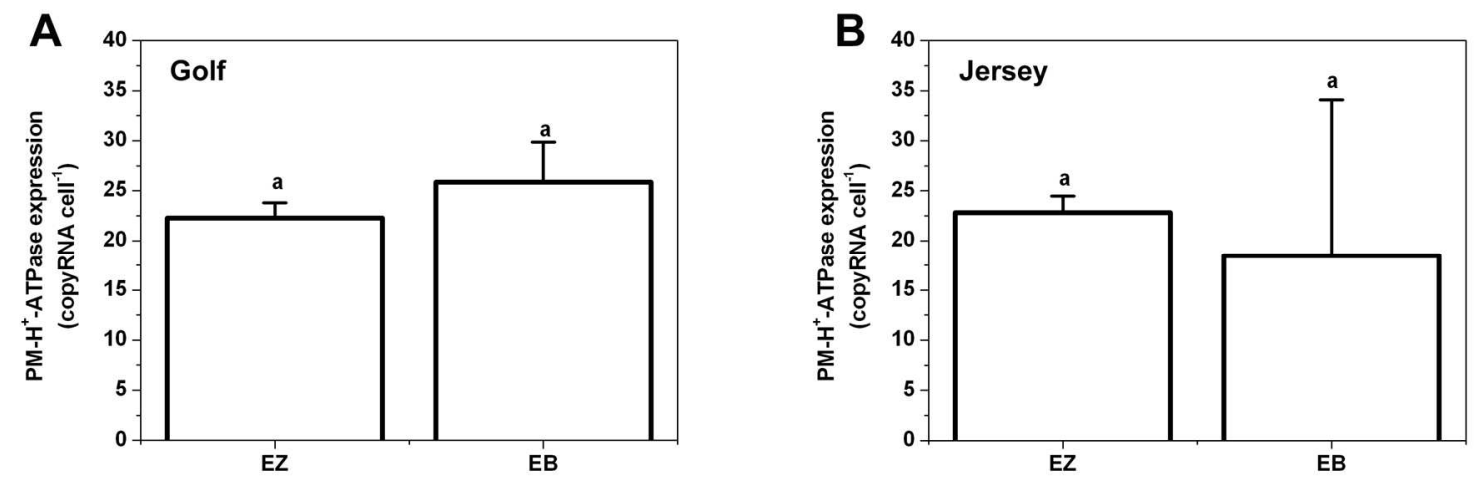

Figure 3.25 Expression of PM-H $\mathrm{H}^{+}$-ATPase using absolute qPCR

Using absolute $\mathrm{PPCR}$, the total number of mRNA transcripts was determined for each cDNA sample. The amount of cDNA obtained from a given amount of leaf region (elongation zone, EZ; emerged blade, EB) was known, as was the number of cells for each region. This made it possible to express QPCR data as mRNA copy number per cell. Results are shown for the barley cultivars Golf (A) and Jersey (B) and represent averages and standard deviation (error bars) of three independent experiments (batches of plants). PM- $\mathrm{H}^{+}$-ATPase expression (copyRNA cell ${ }^{-1}$ ) did not differ significantly between elongation zone (EZ) and emerged blade (EB) in either Golf or Jersey (Student's t-test).

Table 3.4 Ct values of PM- $\mathrm{H}^{+}$-ATPase expression together with RNA content per cell in the elongation zone (EZ) and emerged blade (EB) of leaf three of barley.

Two barley cultivars were studied, Golf and Jersey, and three independent experiments were carried out.

\begin{tabular}{l|c|c|c|c} 
& Ct & SD & RNA content $\left(\right.$ pg cell $^{-1}$ ) & SD \\
\hline EZ (Golf) & 23.8 & 0.2 & 22.3 & 1.5 \\
\hline EB (Golf) & 24.2 & 0.5 & 25.9 & 4.0 \\
\hline EZ (Jersey) & 22.7 & 0.2 & 22.8 & 1.7 \\
\hline EB (Jersey) & 22.8 & 0.2 & 18.5 & 15.6
\end{tabular}

Since the determination of cell number in a given leaf region involved large errors, an additional control experiment was conducted in which RNA was extracted from protoplast suspension of the Jersey cultivar. The number of protoplasts could easily be calculated. RNA yield of $300-1000 \mu$ protoplast suspension (about 0.5 - 7

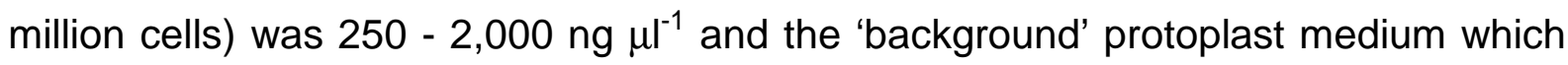
was taken as supernatant folowed gentle centrifugation of protoplasts, yielded virtually no extractable RNA (less than $1-10 \mathrm{ng}^{-1} \mathrm{l}^{-1}$, which was below the measuring range of the Nanodrop ${ }^{\circledR}$ equipment). Results for protoplasts were expressed in copy number of $\mathrm{PM}-\mathrm{H}^{+}$-ATPase transcript protoplast ${ }^{-1}$ and in copy number of $\mathrm{PM}-\mathrm{H}^{+}$ATPase transcript $\mathrm{mm}^{-2}$ protoplast plasma membrane surface area. These figures 
were in the same range as results obtained for the Jersey cultivar when calculated cell number was used as reference system (see Fig. 2.25).
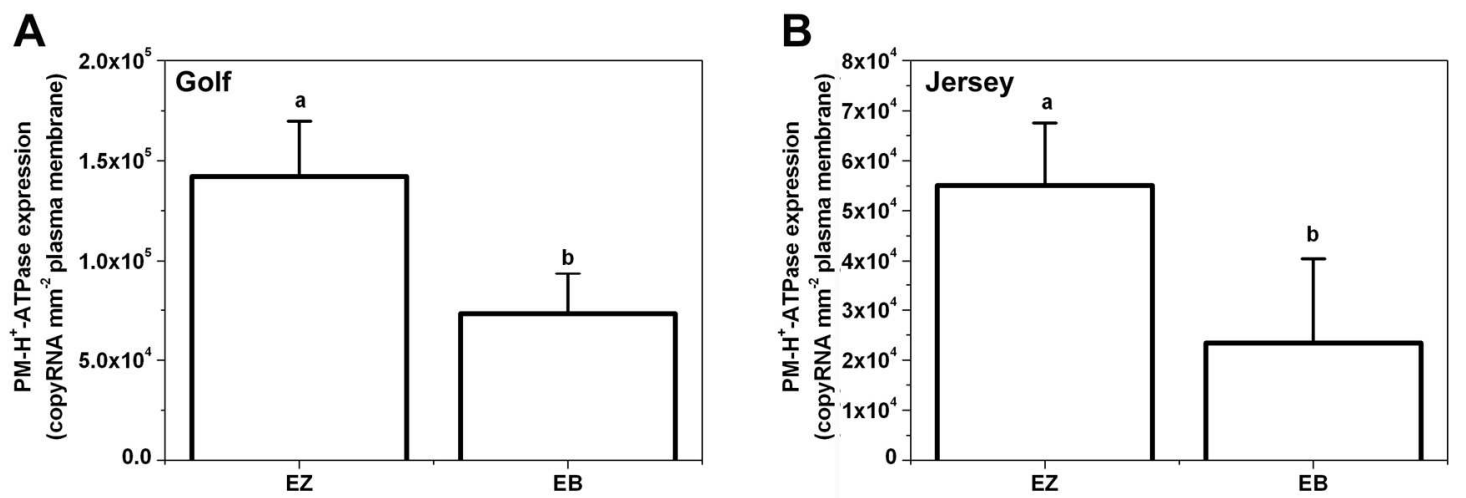

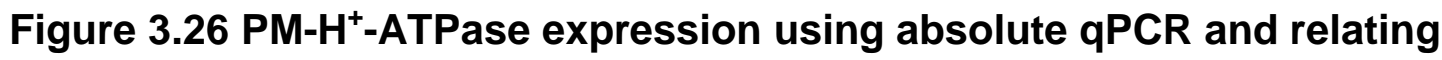
expression data to total plasma membrane surface area

$\mathrm{PM}-\mathrm{H}^{+}$-ATPase gene shows significantly (around 2 times) higher expression in the elongation zone (EZ) compared with emerged leaf blade (EB). Values for the Golf barley cultivar (A) were 3 fold higher than values for the Jersey barley cultivar (B). Results are averages and standard deviations (error bars) of three 3 independent experiments. Different letters shows statistically different values between leaf regions (student's t-test, $\mathrm{p}<0.05$ ).

Table 3.5 RNA content and PM- $\mathrm{H}^{+}$-ATPase expression in the elongation zone (EZ) and emerged blade (EB) of leaf three of barley (Golf, Jersey). Different reference systems were used. Results are averages and SD of $3-6$ independent experiments. Protoplasts were isolated only from the Jersey barley cultivar. PM, plasma membrane; protopl., protoplast.

\begin{tabular}{|c|c|c|c|c|c|c|}
\hline & \multicolumn{2}{|c|}{ RNA (pg cell $\left.{ }^{-1}\right)$} & \multicolumn{2}{|c|}{ ATPase copy cell ${ }^{-1}$} & \multicolumn{2}{|c|}{$\begin{array}{l}\text { ATPase copy } \mathrm{mm}^{-2} \\
\text { PM }\left(\times 10^{3}\right)\end{array}$} \\
\hline EZ (Golf) & 22.3 & \pm 1.5 & 300 & \pm 60 & 142 & \pm 28 \\
\hline EB (Golf) & 25.9 & \pm 4.0 & 260 & \pm 70 & 73 & \pm 20 \\
\hline EZ (Jersey) & 22.8 & \pm 1.7 & 120 & \pm 30 & 55 & \pm 12 \\
\hline EB (Jersey & 18.5 & \pm 15.6 & 80 & \pm 60 & 23 & \pm 17 \\
\hline EZ protopl. & 18.7 & \pm 17.5 & 50 & \pm 30 & 38 & \pm 23 \\
\hline EB protopl. & 20.7 & \pm 19.2 & 50 & \pm 40 & 12 & \pm 7 \\
\hline
\end{tabular}


A
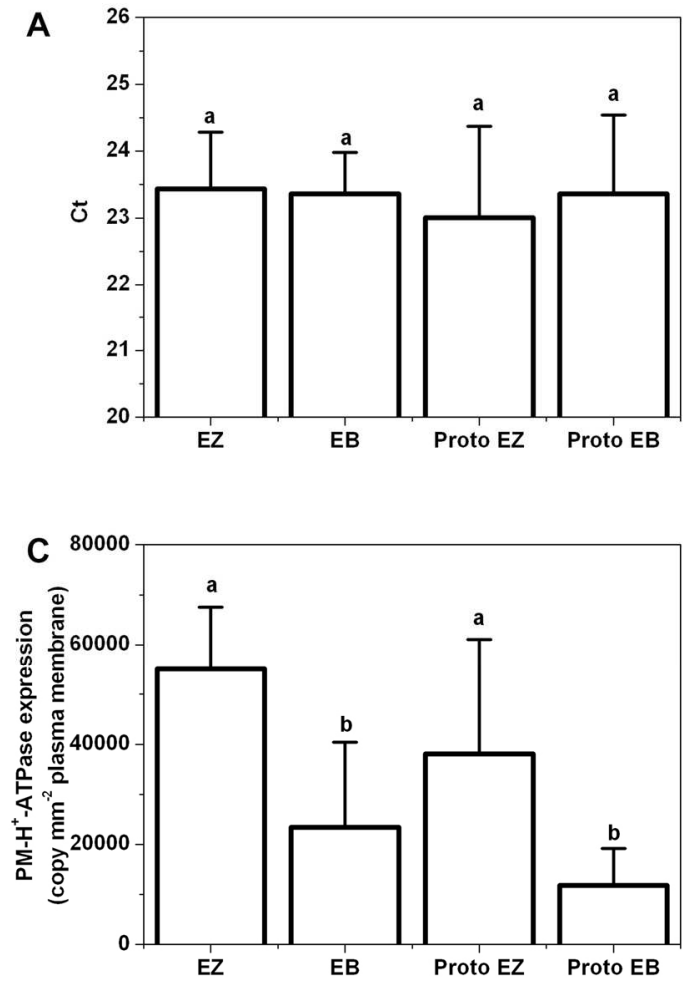
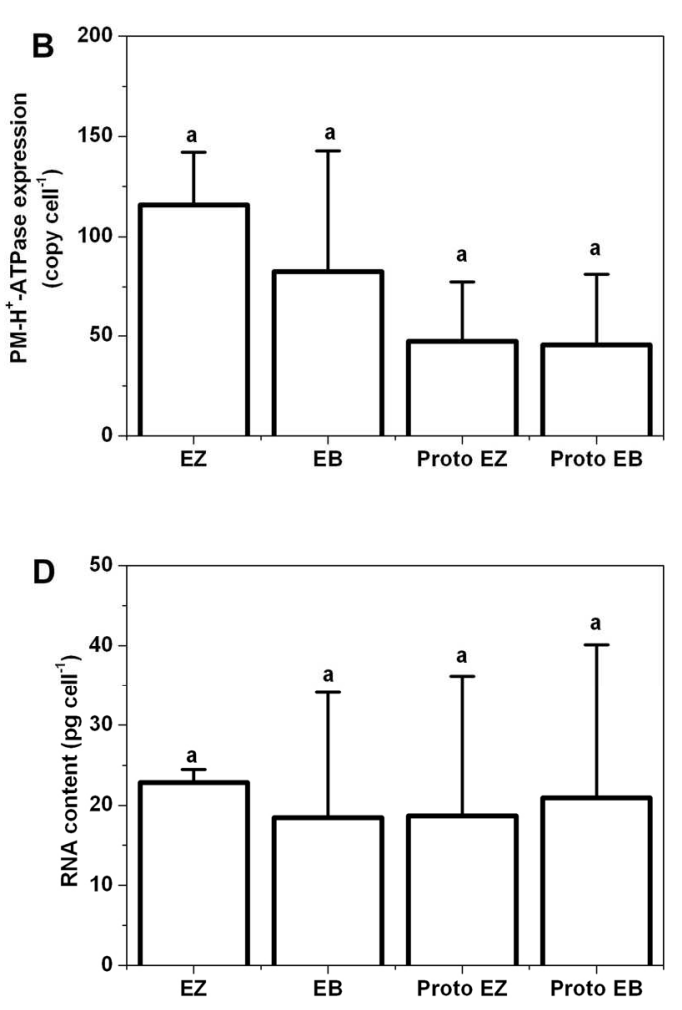

Figure 3.27 Comparison of molecular biological data using leaf tissues or mesophyll protoplasts

Ct values (A), PM- $\mathrm{H}^{+}$-ATPase copy in a cell (B), per $\mathrm{mm}^{2}$ plasma membrane $(\mathrm{C})$ and total RNA content in a cell $(D)$ was compared between experiments where RNA was isolated from whole leaf segments of the elongation zone (EZ) and emerged blade (EB) and from isolated mesophyll protoplasts of the elongation zone (Proto EZ) and emerged blade (Proto EB). Values are averages of $3-6$ batches of plants. Different letters show statistically significant differences at $p<0.05$ using Student's t-test and ANOVA. All experiments were conducted on the barley cultivar Jersey

\subsection{PM- $H^{+}$-ATPase activity and expression at protein level}

Data from qPCR experiments showed that the copy number of PM- $\mathrm{H}^{+}-\mathrm{ATPase}$ transcripts per unit plasma membrane surface area was significantly higher in growing compared with non-growing leaf tissue. This could partially explain the lower apoplast $\mathrm{pH}$ in elongating tissue. To test to which degree changes in the activity of the $\mathrm{PM}-\mathrm{H}^{+}$-ATPase protein also contributed to the lower $\mathrm{pH}$, plasma membrane fractions were isolated from growing and non-growing part of barley leaves and used to determine the activity of $\mathrm{PM}-\mathrm{H}^{+}$-ATPase. Due to the lack of availability of Golf seeds towards the end of this project, these experiments were carried out on the spring barley cultivar Jersey. 


\subsubsection{Optimization of membrane isolation and ATPase assay}

Membrane isolation and ATPase assay had to be optimized. The original method had been described for a large amount of plant tissue (125 g) (Kjellbom \& Larsson, 1984) however previous studies showed that with the method plasma membrane fraction might be purified from lower amout of plant material (Wei et al., 2007). The $P_{i}$ determination assay had been designed originally for animal membranes (Sarkadi et al., 1992), with animal cells notably lacking any vacuolar ATPases.

\subsubsection{Plasma membrane isolation}

It was impossible to harvest more than $6 \mathrm{~g}$ leaf material from the elongation zone and emerged blade portion of leaf three, given the growth constraints (growth chamber, laboratory space) since this required already between $200-400$ barley seedlings. Preliminary experiments were carried out to find the minimum amount of leaf tissue which was required for a two-phase separation system with $12 \mathrm{~g}$ final separation weight. These experiments showed that below $1 \mathrm{~g}$ initial leaf tissue virtually no membrane fraction could be obtained and above $10 \mathrm{~g}$ the plasma membrane fraction could not be separated from chloroplast membranes using 5 - 6 purification steps.

One washing step of the membrane fraction as recommended by Pitann et al. (2009b) was not enough to fully eliminate the rest of the polymers (dextran and $P E G)$ from the purified membrane fraction. In the presence of one or both of these polymers PAGE could not be carried out properly and protein bands appeared blurred on the gel (Fig. 3.28).

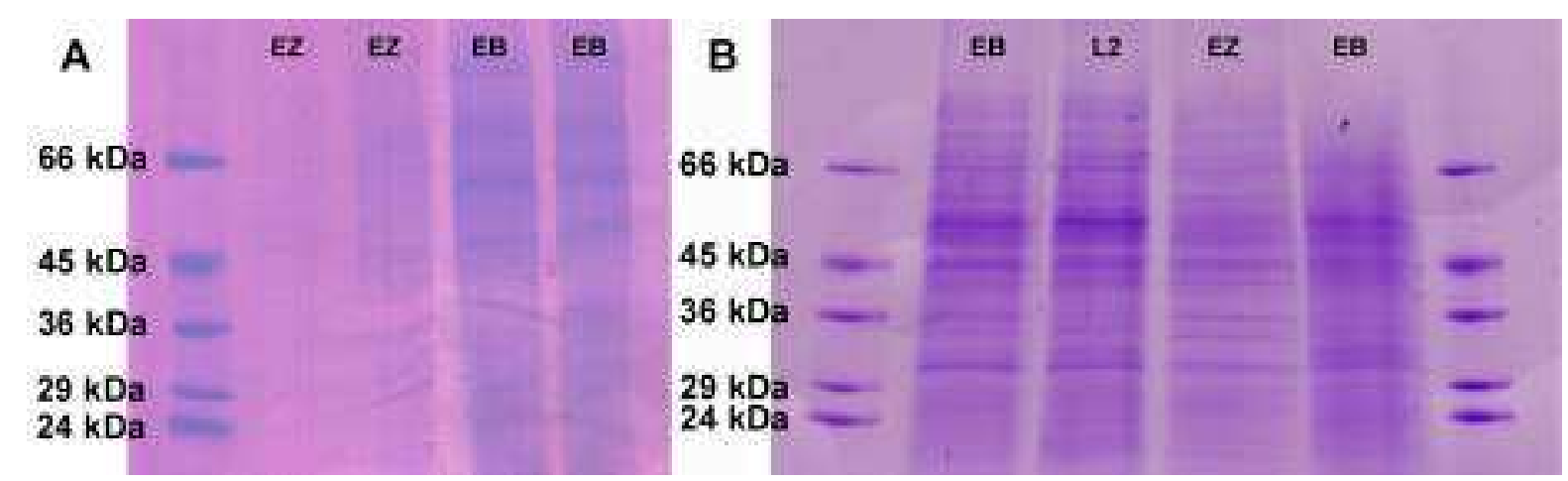

Figure 3.28 Impact on the quality of PAGE separation of washing steps during plasma membrane isolation

Residues of the polymers in plasma membrane fractions caused proteins to appear blurred on the polyacrylamide gel. One washing step was not enough to completely eliminate the polymers (A) while applying two steps (B) the blurring effect was not found on Coomassie stained gels. EZ - elongation zone, EB - emerged leaf blade and L2 - leaf blade of second leaf. 
3.4.1.2 Determination of total protein content in plasma membrane vesicles

In studies where plasma membranes have been isolated, protein concentration has typically been quantified with the Bradford method or a modification of it (Yan et al., 1998; Yan et al., 2002; Zörb et al., 2005; Pitann et al., 2009b; Zhu et al., 2009; Hatzig et al., 2010; Wakeel et al., 2010). Using this approach, it was found in the present study that protein concentration was grossly underestimated, compared to quantification of proteins through densitometry by Phoretix 4.01 software (Phoretix International) on Coomassie stained PAGE gels and calibration with protein standards (Sigma) of known protein content. (Fig. 3.29).

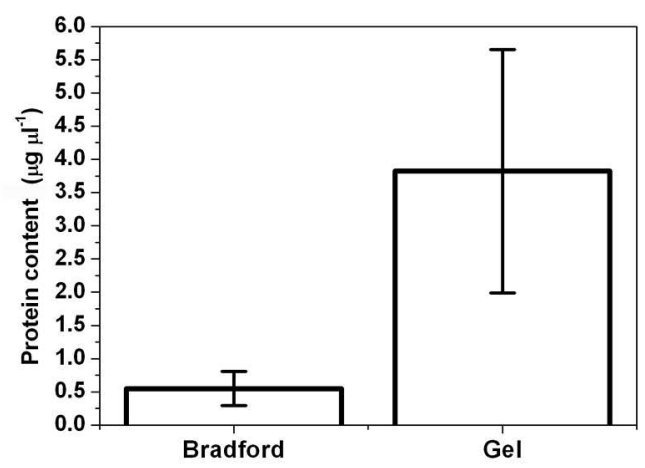

Figure 3.29 Protein measurement in plasma membrane vesicles using two different methods

The protein concentration of the plasma membrane vesicles was significantly lower when determined with the Bradford method than when determined through densitometry of samples run on PAGE gels. The difference in protein concentration between the two methods was statistically significant at $p<0.05$ (Student's t-test).

\subsubsection{ATPase assay}

Optimization of ATPase assay was carried out to find the optimal reaction volume, detection method and membrane protein amount for the assay. Preliminary experiments showed that colour development was more reproducible in $1750 \mu \mathrm{l}$ compared with $200 \mu \mathrm{l}$ (microtiter plate). The optical density of the samples had to be measured within a minute of completion of colour development, together with the calibration curve. If this was not considered, the absorbance changed rapidly (Fig. 3.31). When $3 \mu \mathrm{g}$ total membrane protein were used and the assay was run for 60 min at $28{ }^{\circ} \mathrm{C}$ reproducible and easy to measure amount of released (from ATP) amount of $P_{i}$ could be measured A typical ATPase assay is shown in Fig. 3. 30. 


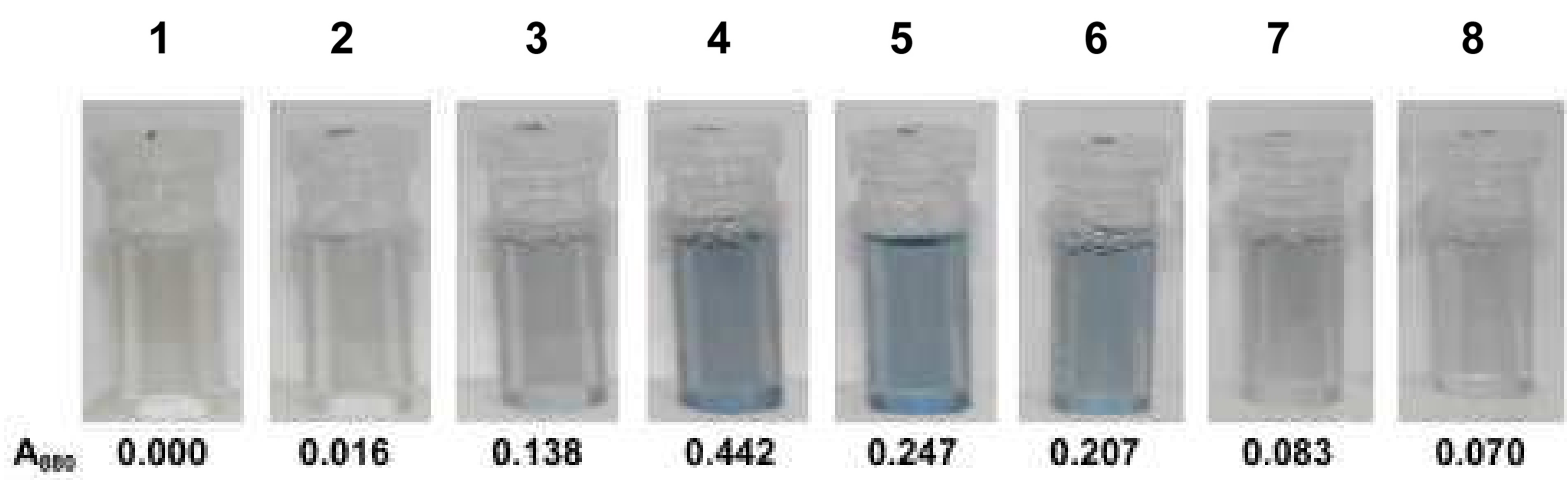

Figure 3.30 Typical ATPase assay

The concentration of $P_{i}$ was determined by a blue colour reaction (detecting the absorbance at $880 \mathrm{~nm}$ ) using calibration curve standards (1 - 4; with 0, 10, 30 and 60 $\mathrm{nmol} \mathrm{P}_{\mathrm{i}}$ per reaction. Without blocking bacterial and vacuolar type of ATPases (5) slightly more $\mathrm{P}_{\mathrm{i}}$ could be measured compared with a reaction where these ATPase were blocked with $10 \mathrm{mM} \mathrm{NaN}_{3}$ and $100 \mathrm{mM} \mathrm{KNO}_{3}$ (6); $500 \mu \mathrm{M}$ vanadate (7) blocked ATPase activity almost to the same extent as when total protein was denatured using SDS (8). Values below the tubes show the absorbance at $880 \mathrm{~nm}$.

To determine the optimal detection time of the colour development reaction kinetics was recorded (Fig. 3.31). Between 20 - 30 min the absorbance was between 0.1 - 0.6 (arbitrary units) and could be measured with high reproducibility. In addition, the calibration curve was linear in this time range.
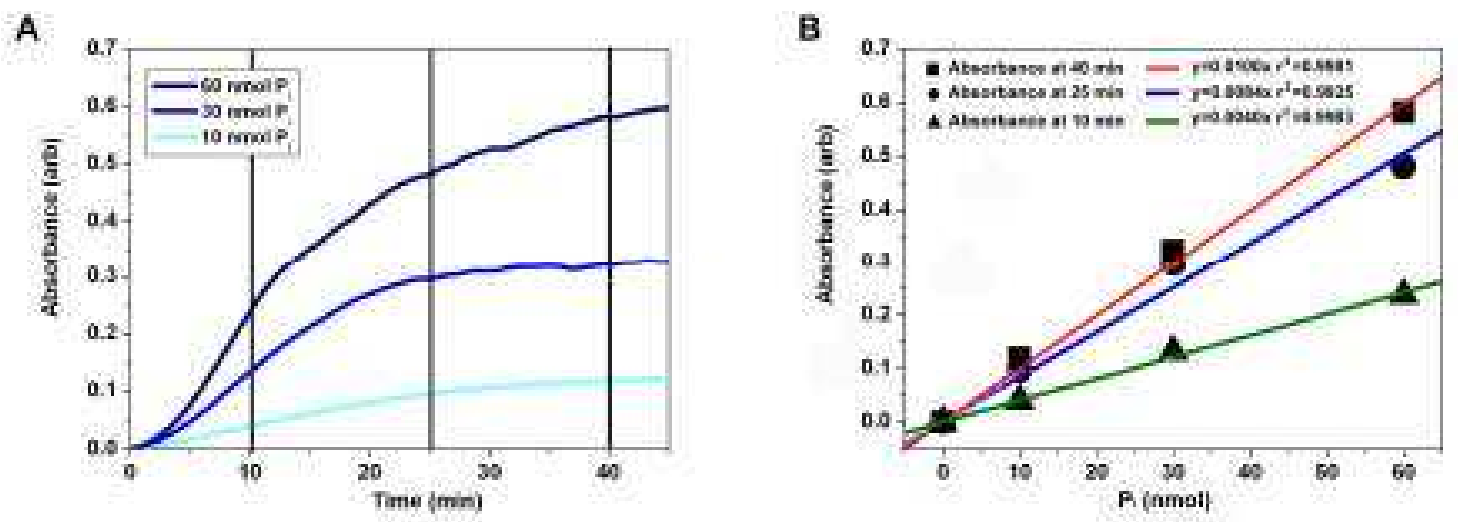

Figure 3.31 Kinetics of $P_{i}$ detection assay

Kinetics of the $P_{i}$ detection assay was recorded at 10, 30 and $60 \mathrm{nmol} \mathrm{P}_{\mathrm{i}}$ concentration (A) and calibration curve at the time point 10, 25 and 40 min (B). Before $20 \mathrm{~min}$ the absorbance values were too low to be use reliably for measurements and the absorbance changed quickly. Between 20 to $30 \mathrm{~min}$ the reaction was slower and the values ideal for measurements whereas past $40 \mathrm{~min}$ of colour development absorbance values became too high and higher $\mathrm{P}_{\mathrm{i}}$ concentrations resulted in errors. 


\subsubsection{Quality of plasma membrane fractions}

The quality of plasma membrane fractions was checked on SDS PAGE gradient gels stained with Coomassie Brilliant Blue and on Western blots. Based on SDS gels the plasma membrane protein pattern of the emerged leaf blade (leaf three) and fully expanded blade (leaf two) was comparable whereas the elongation zone of leaf three and microsomal fraction (no plasma membrane purification) of emerged blade of leaf three differ from the other two (Figure $3.32 \mathrm{~A}$ ). Western blot analysis confirmed the presence of PM- $\mathrm{H}^{+}$-ATPase in the isolates (Figure $3.32 \mathrm{~B}$ ), although based on these Western blots quantitative analysis of $\mathrm{PM}-\mathrm{H}^{+}$-ATPase density in the plasma membrane of different leaf regions could not be achieved. Subsequently, a more sensitive Western blot system (at UCD) was used to compare $\mathrm{PM}^{-\mathrm{H}^{+}-\mathrm{ATPase}}$ content of plasma membranes between elongation zone and emerged blade.
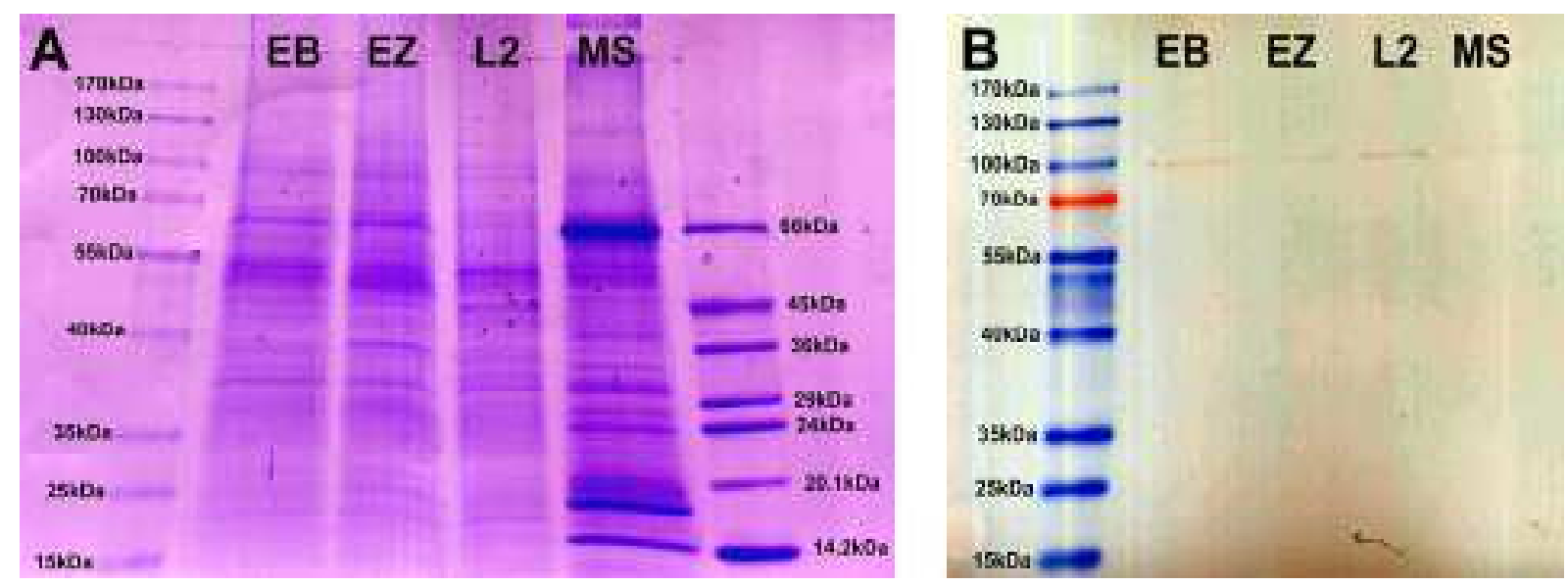

Figure 3.32 Coomassie stained SDS polyacrylamide gel and Western blot of plasma membrane proteins from different leaf regions

Gradient SDS polyacrylamide gel stained Coomassie Brilliant Blue R250 (A) shows the difference or similarity in membrane protein pattern of emerged leaf blade three (EB), elongation zone of leaf three (EZ), fully expanded leaf blade from leaf two (L2) and microsomal fraction from emerged leaf blade two (MS). Western blot (B) analysis demonstrated the presence of PM- $\mathrm{H}^{+}$-ATPase in the isolates and also that the commercially available antibody recognised barley $\mathrm{PM}^{-} \mathrm{H}^{+}$-ATPase (expected molecular weight of about $105 \mathrm{kDa}$ ). The band intensity was too weak to allow densitometric analyses of bands. This had to be done subsequently using a more sensitive detection system for the secondary antibody employed 


\subsubsection{Quantitative analysis of $P M-H^{+}$-ATPase protein}

Sensitivity of the Western blot detection system at Eötvös University, where plasma membrane isolations and ATPase enzyme assays were carried out, was not enough to perform quantitative analysis on blots. Using the same samples in Dublin (having transported the samples on dry ice from Budapest) on thinner gels and chemiluminescence detection the proportion of $\mathrm{PM}-\mathrm{H}^{+}$-ATPase in total membrane protein was measured using a densitometric approach. The same amount of total membrane protein $(5 \mu \mathrm{g})$ from the elongation zone contained 2.33 times higher concentration of PM- $\mathrm{H}^{+}$-ATPase protein than non-growing leaf blade (Fig. 3.33 A). Densitometry of Coomassie stained gradient gels supported Western blot data. A higher $\mathrm{PM}-\mathrm{H}^{+}$-ATPase protein expression was measured in the elongation zone (Fig. 3.33 B) although the difference using the $\mathrm{PM}-\mathrm{H}^{+}-\mathrm{ATPase}$ band on SDS gels (identified based on molecular weight and Western blots) was lower with the ratio between the two leaf regions being 1.5 fold compared with 2.33-fold above.

The higher sensitivity of the second Western blot approach made it possible to detect a second band on the blot, at around $70 \mathrm{kDa}$. This might represents a fragment of the PM- $\mathrm{H}^{+}$-ATPase enzyme (Fig. $3.33 \mathrm{C}$ )
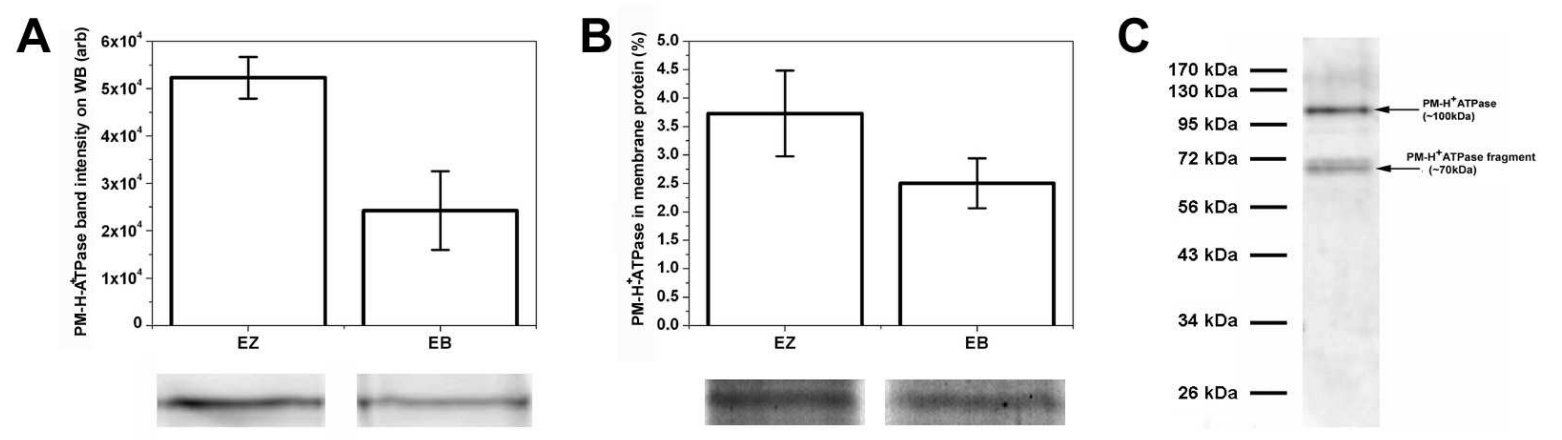

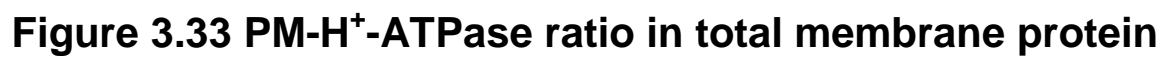

$\mathrm{PM}-\mathrm{H}^{+}$-ATPase protein, expressed on the basis of total plasma membrane protein applied onto gels (and entered into Western blots) was significantly higher in the elongation zone (EZ) compare with emerged blade (EB) (A); the same applied to densitometric analyses of Coomassie Brilliant Blue stained polyacrylamide gels (B). Results are significant using Student's t-test $(p<0.05)$. Using higher sensitivity on Western blots a second band was found which respresents most likely a $70 \mathrm{kDa}$ fragment of the PM- $\mathrm{H}^{+}$-ATPase (C). 


\subsubsection{Activity of PM- $H^{+}$-ATPase}

Vandate-sensitive ATPase activity of membrane fractions was measured using inside-out plasma membrane vesicles and an ATP hydrolysis assay. Results were expressed in nmolP $\mathrm{h}^{-1} \mu \mathrm{g}^{-1}$ total membrane protein at $28^{\circ} \mathrm{C}$. As Fig. 3.34 show $\mathrm{s}$ plasma membrane vesicles of the elongation zone had more than 2 times higher vanadate-sensitive ATPase activity compared with vesicles prepared from the emerged blade. Vacuolar and prokaryotic types of ATPases were blocked using high azide and nitrate concentration in the reaction mixture, and data were validated with vanadate sensitivity. The resulting enzyme activity represented $\mathrm{PM}-\mathrm{H}^{+}$-ATPase activity and this was two fold higher in the plasma membrane of the elongation zone compare with membranes prepared from the emerged leaf blade.

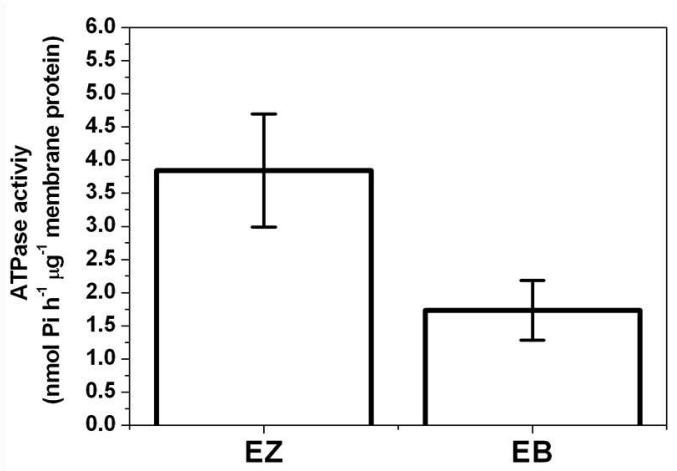

Figure 3.34 ATPase activity of inside-out plasma membrane vesicles

Vanadate-sensitive ATP hydrolysis activity of inside-out plasma membrane vesicles of the elongation zone (EZ) was more than two times higher than activity in the emerged blade of leaf three of barley (EB). Results are averages of four independent batches of membranes and $9-10$ replicate activity determinations. Differences were statistically significant $(p<0.05)$ using Student's t-test.

\subsubsection{Immunolocalisation of PM- $H^{+}$-ATPase}

Paraffin-embedded sections were used to localise the tissue-specific distribution of $\mathrm{PM}-\mathrm{H}^{+}$-ATPase protein. Alkaline phosphatase-labelled secondary antibody with fast red detection was used. Reddish colour showed the location of PM- $\mathrm{H}^{+}$-ATPase protein. There was no difference in $\mathrm{PM}^{-} \mathrm{H}^{+}$-ATPase distribution between the elongation zone (Fig. 3.35 A) and emerged blade (Fig. 3.35 B). Higher expression of $\mathrm{PM}^{-\mathrm{H}^{+}-\mathrm{ATPa} e}$ was found in guard cells (Fig. $3.35 \mathrm{E}$ ), phloem, and xylem parenchyma. $\mathrm{PM}-\mathrm{H}^{+}$-ATPase was detected virtually on the plasma membrane of every living cell. Longitudinal sections of the elongation zone (Fig. 3.35 D) provided 
further detail. Guard cells were easily identifiable. Dead parts of xylem tubes were free from red colour, whereas phloem and xylem parenchyma cells contained large amount of PM- $\mathrm{H}^{+}$-ATPase. Negative control (Fig. 3.35 C), where primary PM- $\mathrm{H}^{+}-$ ATPase specific antibody was not applied, verified the selectivity of the assay as immunospecific staining was not present.
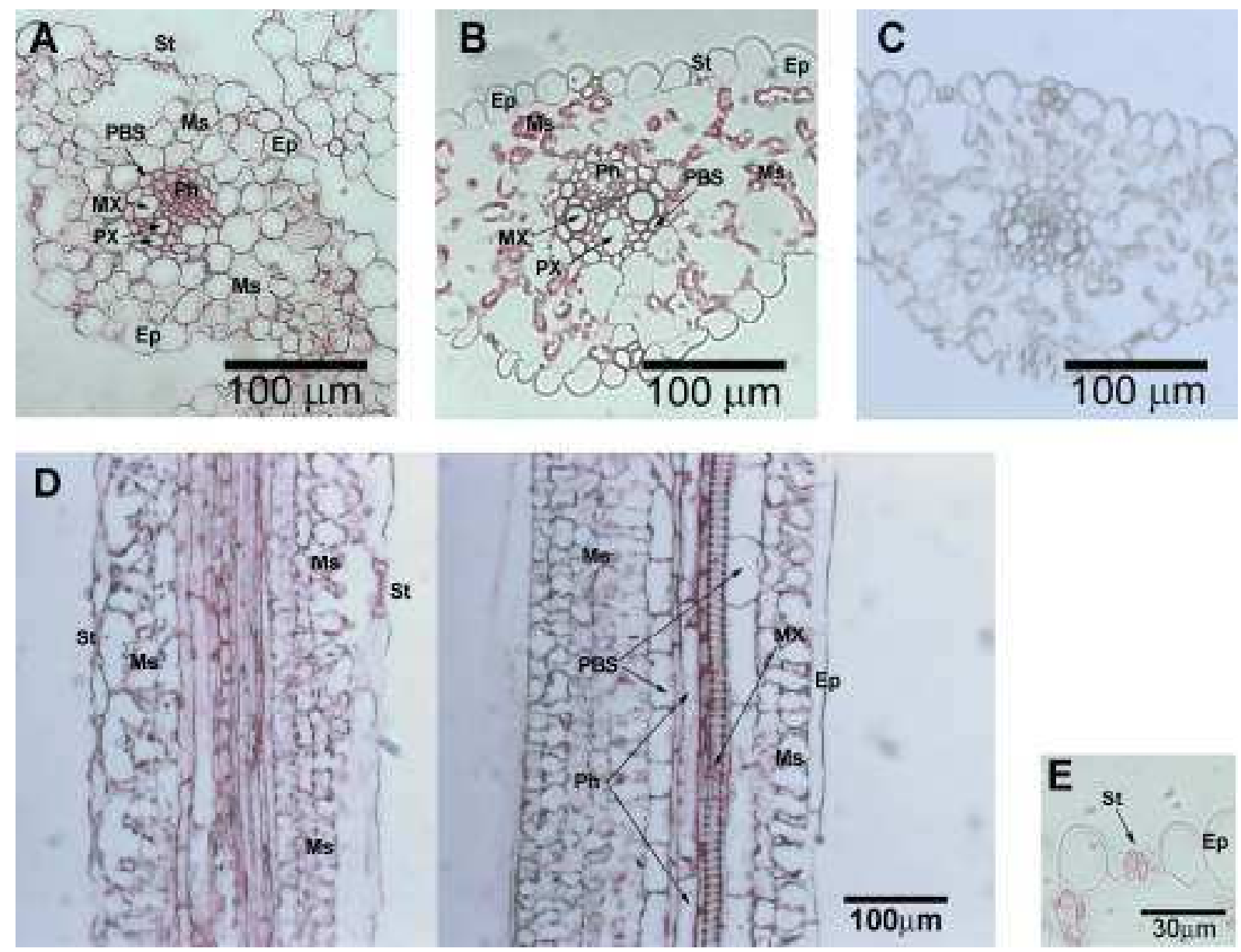

Figure 3.35 PM-H $\mathrm{H}^{+}$-ATPase immunolocalisation on leaf cross and longitudinal sections

PM- $\mathrm{H}^{+}$-ATPase expression was detectable on all plasma membranes, both in the elongation zone (A) and emerged blade (B). Higher expression was present in guard cells $(E)$, phloem and xylem and phloem subsidiary cells. Differences between elongation zone and emerged blade were not visible. Negative control (primary antibody was not applied) was free from immunolabelling (C). Longitudinal sections of elongation zones (D) were supporting observations from cross sections, stomata guard cells and vascular elements and subsidiary cells being heavily stained. Ep: epidermis; St: stomata; MX: metaxylem; PX: protoxylem; Ph: phloem; Ms: mesophyll cells; PBD: parenchymateous bundle sheath. 


\section{Discussion}

\subsection{Growth-associated apoplast acidification}

Using different methods to measure or visualise apoplastic $\mathrm{pH}$ or $\mathrm{H}^{+}$transport activity into the intercellular space, a lower $\mathrm{pH}$ was recorded in the elongation zone compared with emerged blade of barley leaves. This observation is in agreement with the 'acid growth theory' which would predict a more acid apoplast $\mathrm{pH}$ in growing tissue.

\subsubsection{Apoplast $\mathrm{pH}$ difference between growing and non-growing leaf} tissue

Three independent approaches were used to analyse apoplast $\mathrm{pH}$. Microelectrode $\mathrm{pH}$ measurements provided the most quantitative data. Also, similar to confocal analyses and contrary to the in-vitro gel system, microelectrode analyses measured $\mathrm{pH}$ in the actual wall or apoplast space. These measurements showed that the $\mathrm{pH}$ in the apoplast was by up to $1 \mathrm{pH}$ unit lower and, therefore, the $\mathrm{H}^{+}$concentration up to 10 -fold higher in elongating tissue. There do not exist any directly comparable studies on other grass leaves, although slightly different approaches have been taken for some species. When $\mathrm{pH}$ was measured in droplets placed on the exposed elongation zone of maize leaves a lower apoplastic $\mathrm{pH}$ compared with the emerged blade or elongation zone under non-growing conditions was measured; the absolute $\mathrm{pH}$ values in these droplets were significantly higher than the ones measured here, and the $\mathrm{pH}$ reading was not stable but drifted during recordings (Van Volkenburgh \& Boyer, 1985; Neves-Piestun \& Bernstein, 2001). Using $0.5 \mathrm{~g}$ of growing maize leaf segments in $2 \mathrm{ml}$ unbuffered bathing medium, Neves-Piestun \& Bernstein (2001) measured a pH of 4.8 , a value which is very similar to the value recorded here for barley leaves.

\subsubsection{Reliability of $\mathrm{pH}$ values measured in elongation zone and}

\section{emerged blade}

Microelectrode measurements revealed that apoplast $\mathrm{pH}$ in the leaf elongation zone depended on the bathing medium concentration of $\mathrm{K}^{+}$. At the lowest $\mathrm{K}^{+}$concentration tested $(0.1 \mathrm{mM})$ apoplast $\mathrm{pH}$ was 4.8 , yet at $10 \mathrm{mM} \mathrm{K}^{+}$, apoplast $\mathrm{pH}$ increased to 5.8 
and was identical to the value in emerged tissue (Fig. 3.7). Since the emerged leaf contains at its surface a major permeance barrier (cuticle) to externally applied solution, this could mean that the difference in $\mathrm{pH}$ observed between leaf regions was an artefact and reflected differences in the access of bath solution between leaf regions. If, by chance, the $\mathrm{K}^{+}$concentration in the apoplast of the emerged blade of intact plants had been $10 \mathrm{mM}$, or at least higher than $1 \mathrm{mM}$, and if none of the external bathing solution had reached the apoplast, one would have predicted an apoplast $\mathrm{pH}$ of 5.8 based on measurements for elongating tissue at $10 \mathrm{mM} \mathrm{K}^{+}$. Felle (2006) measured an apoplastic $\mathrm{K}^{+}$concentration of $2.6 \mathrm{mM}$ in mature barley leaves. Also, if the apoplast $\mathrm{K}^{+}$concentration in the leaf elongation zone in-planta was close to $10 \mathrm{mM}$, one would not expect to find a difference in apoplast $\mathrm{pH}$ between the two leaf regions in intact, undisturbed plants. Recently, Ehlert et al. (2011) reported apoplast $\mathrm{pH}$ between 4.1 and 5.9 with average mean of 5.1 for elongating maize leaf tissue as analysed through $\mathrm{pH}$ microelectrodes.

Felle (2006) inserted pH microelectrodes through stomatal pores of mature barley leaves and measured a $\mathrm{pH}$ of 4.88 . This $\mathrm{pH}$ is significantly lower than the $\mathrm{pH}$ reported here $(\mathrm{pH}$ 5.8) for emerged blade tissue. Possibly, the difference in results is due to use of $2 \mathrm{mM}$ MES / TRIS buffer ( $\mathrm{pH}$ 5.0) in the bathing medium in the study by Felle (2006). Also, measurements by Felle (2006) were carried out under illumination, stimulating PM-H ${ }^{+}$-ATPase pump activity (Stahlberg \& Van Volkenburgh, 1999), whereas the present measurements were carried out in the dark. In a natural setting, the mature blade is exposed to full, ambient light whereas the elongation zone receives less light, and this light is green-filtered due to subtending sheaths. Therefore, it is possible that the difference in apoplast $\mathrm{pH}$ between leaf regions in field-grown and -analysed plants is considerably smaller than the difference measured here with the microelectrode setup in a darkened laboratory environment or through confocal analyses on intact leaves. Vanadate experiments on detached leaves clearly showed that the lower apoplast $\mathrm{pH}$ in the barley leaf elongation zone depended on the activity of the PM- $\mathrm{H}^{+}-$ATPase.

\subsubsection{Relation between apoplast acidification and leaf growth}

Acidification of the apoplast in the elongation zone of barley leaves generally coincided with growth, but there were notable exceptions. A positive relation was best visualised by cold treatment in the in-vitro gel system (Fig. 3.3). In the same system vanadate and fusicoccin treatments caused parallel changes in the growth 
rate of leaves and acidification of medium adjacent to leaf apoplast (Fig. 3.1). Also, vanadate treatment in the microelectrode setup reduced growth and increased apoplast $\mathrm{pH}$ in the elongation zone to a value usually observed for mature tissue. However, when fusicoccin was applied in the $\mathrm{pH}$ microelectrode setup, growth increased while apoplast $\mathrm{pH}$ remained unchanged (Fig. 3.9 and 3.10). Also, changing the apoplast $\mathrm{K}^{+}$concentration from 0.1 to 1 or $10 \mathrm{mM}$ significantly increased apoplast $\mathrm{pH}$ in the elongation zone, yet growth did not change (Fig. 3.7 and 3.8). Irrespective of the underlying mechanisms, these data show that there does not exist a simple, single relation of how apoplast $\mathrm{pH}$ relates to growth in the leaf elongation zone. The seemingly contradictory fusicoccin data obtained through the microelectrode and in-vitro gel setup could be explained through differences in what these two setups measured. The in-vitro gel system measured bulk effects on $\mathrm{pH}$ further away from the leaf surface and showed an increase in the acidified area and corresponding net production rate of $\mathrm{H}^{+}$, and $\mathrm{H}^{+}$was titrated by the $\mathrm{pH}$ indicator bromocresol purple. In contrast, the microelectrode setup provided a point measurement of $\mathrm{pH}$ closer to the cell surface, irrespective of the rate at which $\mathrm{H}^{+}$diffused into surrounding bathing medium or was consumed through transport processes involving $\mathrm{K}^{+}$. Thus, while fusicoccin will have stimulated $\mathrm{H}^{+}$pumping in both setups and led to increased diffusion, apoplast $\mathrm{pH}$ may not have changed in either setup.

\section{2 $K^{+}$and apoplast acidification}

Potassium uptake coupled to $\mathrm{H}^{+}$uptake (symport) has been discussed as an alternative explanation for some of the effects associated with the 'acid growth' theory. For example, $\mathrm{K}^{+}$uptake and apoplast acidification were linked to growth in roots (Glass et al., 1981; Ullrich \& Novacky, 1990; Amtmann et al., 1999) and coleoptiles (Claussen et al., 1997; Tode \& Lüthen, 2001; Christian et al., 2006). The present data also suggest that $\mathrm{K}^{+}$transport and apoplast acidification are linked with each other in some way during elongation of barley leaf cells.

\subsubsection{Potassium uptake and leaf growth}

A previous patch-clamp study on $\mathrm{K}^{+}$transport in barley concluded that apoplast $\mathrm{K}^{+}$ must exceed 3 - $5 \mathrm{mM}$ to allow growing leaf cells to take up $\mathrm{K}^{+}$through channels (Boscari et al., 2009; Volkov et al., 2009). Calculations showed that at $10 \mathrm{mM}$ apoplast $\mathrm{K}^{+}$, about $50 \%$ of $\mathrm{K}^{+}$uptake was facilitated by time-dependent inwardrectifying currents typical of Shaker $\mathrm{K}^{+}$channels such as AKT1 or AKT2. The 
remaining $50 \%$ was facilitated by instantaneous currents, which includes either or both, $\mathrm{K}^{+}$high-affinity transporters such as HAK / KUP / KT type $\mathrm{K}^{+} / \mathrm{H}^{+}$symporters (for historical reasons, these three abbreviations denote the same type of symporters; for details see e.g. Ashley et al. (2006) and Szczerba et al. (2009)) or non-selective cation channels. At apoplast concentrations below 3 - $5 \mathrm{mM}$, uptake of $\mathrm{K}^{+}$would have to occur through high-affinity uptake mechanisms. The $\mathrm{K}^{+}$ concentrations tested in the present study covered the range 0.1 to $10 \mathrm{mM}$. Therefore, it is possible that different $\mathrm{K}^{+}$uptake mechanisms contributed to the growth and $\mathrm{pH}$ response of leaves depending on the $\mathrm{K}^{+}$concentration of bathing medium. When $\mathrm{K}^{+}$uptake was blocked through application of inhibitors $\left(\mathrm{Cs}^{+}, \mathrm{TEA}\right)$ of $\mathrm{K}^{+}$inward-rectifying Shaker-type channels, or at least reduced significantly, growth was reduced by $50 \%$. A similar reduction in growth was observed in response to vanadate and $\mathrm{CsCl}$-vanadate double treatments (applied at $10 \mathrm{mM}$ bathing medium $\mathrm{K}^{+}$; Fig. 3.17). The latter observation excludes the possibility that $\mathrm{Cs}^{+}\left(\mathrm{K}^{+}\right.$channels) and vanadate (PM- $\mathrm{H}^{+}$-ATPase) inhibited 'different' $50 \%$ of growth and were additive. Instead, growth was reduced through some common mechanism. Membrane potential was not measured in response to the above treatments, but the most likely scenario is that inhibition of $\mathrm{PM}-\mathrm{H}^{+}$-ATPase through vanadate depolarised membrane potential to such an extent that uptake of $\mathrm{K}^{+}$through channels was thermodynamically not possible. This would explain why direct blockage of channels through $\mathrm{Cs}^{+}$caused the same growth reduction as blockage of $\mathrm{PM}-\mathrm{H}^{+}-\mathrm{ATPase}$. Similarly, Tode \& Lüthen (2001) concluded from experiments involving TEA that the acid-growth type response of maize coleoptiles required the activity of inwardrectifying $\mathrm{K}^{+}$channels. Linkage of $\mathrm{K}^{+}$transport, leaf growth and cell wall acidification was found in light-induced growth of tobacco leaves (Stiles et al., 2003), yet $\mathrm{K}^{+}$ uptake was required for $\mathrm{H}^{+}$efflux and growth without any noticeable accumulation of solutes (Stiles \& Van Volkenburgh, 2004). This would exclude a primarily osmotic requirement for $\mathrm{K}^{+}$.

\subsubsection{High affinity potassium transporters and leaf growth}

High affinity $\mathrm{K}^{+}$transporters, but not $\mathrm{K}^{+}$selective channels, are reduced in transport activity by ammonium (Kronzucker et al., 2003; Rodriguez-Navarro \& Rubio, 2006; Szczerba et al., 2009; Hoopen et al., 2010). Application of $20 \mathrm{mM} \mathrm{NH}_{4}{ }^{+}$during LVDT experiments reduced growth by as much as $\mathrm{Cs}^{+}$, TEA and vanadate treatments did. This shows that high affinity $\mathrm{K}^{+}$uptake systems were involved in $\mathrm{K}^{+}$uptake and 
growth response of elongating barley leaf cells. The results also show that the three components, apoplast $\mathrm{pH}$, high-affinity and channel-mediated $\mathrm{K}^{+}$uptake were related to each other in some way that prevented inhibition of each component from being additive.

Boscari et al. (2009) observed that HvHAK4 was expressed particularly in the elongation zone of barley leaves. It is not known whether HvHAK4 functions as $\mathrm{K}^{+} / \mathrm{H}^{+}$symporter as thought for other HAK family members (Britto \& Kronzucker, 2008; Szczerba et al., 2009). If it does, HvHAK4 may not only provide a major route for $\mathrm{K}^{+}$entry into growing barley leaf cells, but also present a key mechanism through which the pump activity of the PM- $\mathrm{H}^{+}$-ATPase can be linked to osmotically-driven water uptake and apoplast acidification in growing leaf tissues. This needs to be studied further.

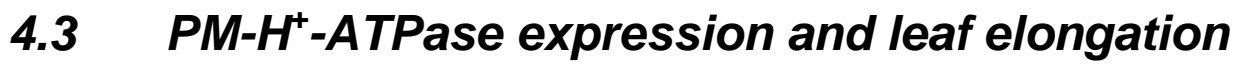

Using four independent techniques (qPCR, ATPase assay and densitometry on SDS PAGE and Western blot) it was found that the expression, activity and protein level of PM- $\mathrm{H}^{+}$-ATPase when related to the surface area of plasma membrane, was between 1.5 - 3.5 times higher in the elongation zone compared with the emerged blade (Table 4.1). The similarity in results for expression, protein level and activity may be a coincidence, but more likely reflects a true difference between growing and nongrowing barley leaf tissues.

Table 4.1 Summary of data for PM- $\mathrm{H}^{+}$-ATPase when related to surface area of plasma membrane. Ratio and standard deviation (SD) was calculated in two ways (a: averages of elongation zone (EZ) were divided by averages of emerged blade (EB) or i: average of ratio of paired EZ and EB). SDs in bracket are estimated SDs.

\begin{tabular}{l|l|l} 
Experiment type & Ratio EZ : EB & SD \\
\hline qPCR (Golf, a) & 1.96 & $\pm(0.47)$ \\
\hline qPCR (Golf, i) & 1.99 & \pm 0.28 \\
\hline qPCR (Jersey, a) & 2.36 & $\pm(0.91)$ \\
\hline qPCR (Jersey, i) & 3.53 & \pm 2.88 \\
\hline qPCR (Jersey protoplasts, a) & 2.13 & $\pm(0.70)$ \\
\hline qPCR (Jersey protoplasts, i) & 2.35 & \pm 0.49 \\
\hline Vanadate sensitive ATPase activity (Jersey, a) & 2.22 & $\pm(0.55)$ \\
\hline Coomassie stained SDS PAGE (Jersey, a) & 1.50 & $\pm(0.35)$ \\
\hline Western Blot (Jersey, a) & 2.33 & $\pm(0.72)$
\end{tabular}


Quantification of $\mathrm{PM}-\mathrm{H}^{+}$-ATPase protein level using Coomassie stained PAGE gels gave the lowest difference between elongation zone and emerged blade. This may result from individual bands, such as the band of the PM- $\mathrm{H}^{+}$-ATPase, containing numerous different proteins. For example, Hynek et al. (2006) concluded from MS / MS analyses of the PM- $\mathrm{H}^{+}$-ATPase band of plasma membrane vesicles prepared from barley aleurone layer that the band contained 22 different peptides. Together, the data suggest that the density at which functional PM- $\mathrm{H}^{+}-\mathrm{ATPase}$ is localised in the plasma membrane, or at which $\mathrm{PM}-\mathrm{H}^{+}-\mathrm{ATPase}$ is expressed per unit plasma membrane surface area of cells is about twice as high in growing as in nongrowing leaf regions. Also, expression and protein data suggest that the efficiency of translation of PM- $\mathrm{H}^{+}$-ATPase mRNA is similar in the two leaf regions.

\subsubsection{PM- $H^{+}$-ATPase density in plasma membrane and leaf growth}

The higher plasma membrane density of $\mathrm{PM}-\mathrm{H}^{+}$-ATPase in the elongation zone will aid the energisation required for continuous solute uptake, in particular uptake of $\mathrm{K}^{+}$, in growing leaf cells. It will also aid acidification of the apoplast as measured through $\mathrm{pH}$ microlelectrodes in the barley leaf elongation zone. Depending on the apoplast $\mathrm{K}^{+}$ concentration, the $\mathrm{pH}$ in the elongation zone was by up to $1.0 \mathrm{pH}$ unit lower $(\mathrm{pH}$ micro electrode measurements; Fig. 3.7) in the elongation zone compared with emerged blade. This corresponds to a 10 -fold difference in apoplast $\mathrm{H}^{+}$concentration and suggests that there exist post-translational modifications which further increase the PM- $\mathrm{H}^{+}$ATPase pump activity in growing barley leaf cells. Having said this, the wall space of growing cells is smaller (thinner walls) and this will aid apoplast acidification for a given pump activity. Apoplast acidification also depends on factors which are not related directly to the protein level and activity of PM- $\mathrm{H}^{+}$-ATPase such as apoplast $\mathrm{K}^{+}$concentration (Claussen et al., 1997;Tode \& Lüthen, 2001), temperature (Stoddart \& Lloyd, 1986; Pollock et al., 1990) hormones (especially auxin, e.g.: Rayle \& Cleland, 1970; Hager et al., 1971; Rayle \& Cleland, 1992; Claussen et al., 1997; Tode \& Lüthen, 2001; Hager, 2003; Grebe, 2005; Kutschera, 2006) and light (Van Volkenburgh \& Cleland, 1980; Stahlberg \& Van Volkenburgh, 1999). 


\subsection{2 qPCR data}

Determination of cell size and cell number can involve comparably large errors, due to the variation in size between populations and types of cell and due to small difference in cell radius (protoplasts) causing large differences in calculated cell volumes. Despite these intrinsic uncertainties, the present calculations showed that the PM- $\mathrm{H}^{+}$-ATPase expression per cell is very similar in growing and non-growing leaf tissue. Due to the lower surface area of the plasma membrane in growing cells (always assuming that there are no major invaginations of the plasma membrane, or that these would not differ between leaf regions), the density of PM- $\mathrm{H}^{+}$-ATPase is higher than the density in non-growing cells. As growing cells reach their full size, plasma membrane surface area increases leading to a continuous 'dilution' of PM$\mathrm{H}^{+}$-ATPase molecules. In such a scenario, the amount of $\mathrm{PM}-\mathrm{H}^{+}$-ATPase per cell seems to be a fixed size, and cessation of growth seems to coincide with a continuous dilution of $\mathrm{PM}-\mathrm{H}^{+}$-ATPas activity, resulting in decreasing rates of apoplast acidification (see also Fig. 3.25, Fig. 3.26 and Fig. 3.27). qPCR analysis of mesophyll protoplasts isolated from the elongation zone and emerged blade of the barley cultivar Jersey further supported the reliability of the calculated cell numbers of qPCR samples. Total RNA content of Golf and Jersey tissues per cell was very similar to total RNA content per protoplast. $\mathrm{PM}-\mathrm{H}^{+}$-ATPase expression data obtained for protoplasts, when expressed per protoplast number or total plasma membrane surface were lower but not significantly different to the other qPCR data for Jersey where expression was related to the calculated cell number or total membrane surface (see Table 3.5 and Fig. 3.27). The lower expression values are in agreement with immuno localisation results on leaf cross-sections which showed that mesophyll cells have a comparatively (to other leaf tissues) lower $\mathrm{PM}-\mathrm{H}^{+}-\mathrm{ATPase}$ expression. For RNA extraction from leaf segments, all types of cells were homogenised and accordingly averaged. In contrast, protoplasts were islolated only from mesophyll.

qPCR expression analyses also showed that the $\mathrm{Ct}$ value of $\mathrm{PM}-\mathrm{H}^{+}$-ATPase expression was almost identical in growing and non-growing leaf regions using the same amount of total RNA (250 - $500 \mathrm{pg}$ ). Therefore, when expression data are related to unit of extracted RNA, PM-H+-ATPase (Ha1 AY136627; Gl:23306665) is an ideal reference gene for expression analysis when comparing growing and nongrowing leaf regions, in agreement with Boscari et al. (2009) and Besse et al. (2011) (see Table 3.5 and Fig. 3.27). The same applies to the $\mathrm{PM}-\mathrm{H}^{+}$-ATPase isoforms AHA1 and AHA2 in Arabidopsis (Gaxiola et al., 2007). 


\subsubsection{Immunolocalisation of PM- $H^{+}$-ATPase}

Immunohistological analyses provided results which are in agreement with previous studies on the tissue localisation of PM- $\mathrm{H}^{+}$-ATPase protein (Villalba et al., 1991; Bouche-Pillon et al., 1994; Michelet \& Boutry, 1995; Morsomme \& Boutry, 2000; Palmgren, 2001; Gaxiola et al., 2007). Most staining, and by implication, $\mathrm{PM}-\mathrm{H}^{+}-$ ATPase protein, was observed in those leaf tissues which are characterised by high rates of solute exchange across the plasma membrane (guard cells) or high rates of solute loading / unloading associated with long-distance transport pathways (phloem; xylem parenchyma). Interestingly, but in agreement with previous studies, epidermis cells were not enriched in PM- $\mathrm{H}^{+}$-ATPase (Villalba et al., 1991). This was observed in elongation zone and emerged blade and shows that there exists a cell-type-specific control of PM- $\mathrm{H}^{+}$-ATPase protein level which is superimposed on any developmental gradient.

\subsection{Leaf growth and changes in cell wall properties}

The effect of chemical treatments (vanadate, $\mathrm{CsCl}$, fusicoccin) on cell wall properties was followed with the LVDT system. Fusicoccin increased the elasticity without affecting the plasticity of walls. In contrast, $\mathrm{CsCl}$ decreased the plastic component yet did not alter the elastic component of cell wall. Vanadate did not modify either component. From these results it can be concluded that PM- $\mathrm{H}^{+}$-ATPase activity, which is inhibited by vandate, is not required to maintain wall elasticity or plasticity. The fusicoccin treatment did not cause changes in the plastic component of the cell wall. Since plasticity is the relevant size for growth (irreversible expansion), and since plasticity is thought to change with apoplast $\mathrm{pH}$ through action of expansions (Cosgrove, 1996), fusicoccin probably did not decrease the apoplast pH (in agreement with the microelectrode measurements where fusicoccin failed to cause apoplast acidification) or it facilitated leaf elongation through a mechanism other than 'acid growth'. The increased $\Delta \Delta v$ suggests that in the background of fusicoccinrelated growth facilitated $\mathrm{K}^{+}$uptake may be found (both $\mathrm{v}_{1}$ and $\mathrm{v}_{2}$ were higher than in the control). The increased elasticity of the cell wall may be caused by a cell wall modifying protein or enzyme activated by increased $\mathrm{H}^{+}$transport acrosss the plasma membrane into the cell wall space as the experiments with the agarose gel system showed. If fusicoccin increased the $\mathrm{H}^{+}$excretion through plasma membrane and the $\mathrm{H}^{+}$returned into the cell through $\mathrm{H}^{+} / \mathrm{K}^{+}$symport, then micro $\mathrm{pH}$ measurements, 
in-vitro gel records and cell wall property data would support each other. However, this would require that the change in $\mathrm{H}^{+}$concentration close to the site where proteins act in the wall was either so small or so inaccessible that it could not be measured with the microelectrodes.

\section{5 'Acid growth' in barley leaves?}

Auxin is one of the most important hormones in plants and its involvement in growth is unquestionable, at least in coleoptiles (Rayle \& Cleland, 1970; Lüthen et al., 1990; Rayle \& Cleland, 1992; Kutschera, 1994) or roots (Christian et al., 2006; Kutschera, 2006).

Surprisingly, in the present study the artificial auxin NAA did not cause any effect on leaf growth or apoplast acidification as tested through the in-vitro gel system (Fig. 3.6) or LVDT measurements (Fig. 3.19). In a related study on the barley cultivar investigated here, the elongation zone was not exposed by peeling back the sheath of leaves one and two but, instead, a small window was cut into these sheaths, causing less physical damage to the plant. Even in this system, application of 5 and $10 \mu \mathrm{M}$ indole acetic acid (IAA) to the apoplast of the elongation zone did not increase the growth rate of leaves (Touati et al., unpublished). For some reason, the barley leaves tested here seem not to be sensitive to externally-applied auxin. A possible interpretation could be that the third leaf, when measured in this project was in the development stage of maximum growth, and the internal auxin concentration might have been so high that any auxin-dependent growth mechanisms was saturated and externally applied auxin could not cause any further increase in growth. The elongation zone of leaf one of wheat has been reported to contain IAA at 500 - $600 \mathrm{ng} \mathrm{g}^{-1}$ fresh weight (Vysotskaya et al., 2003) and this would mean that IAA oocurs naturally in the $\mu \mathrm{M}$ range.

\subsection{Model of leaf growth in barley}

Under different treatments the role of $\mathrm{PM}-\mathrm{H}^{+}$-ATPase and high or low affinity $\mathrm{K}^{+}$ uptake system was tested in relation to elongation growth and apoplast acidification in leaf three of barley. The predicted effects of test reagents on growth and acidification are summarised in Fig. 4.1. The results partly support the classical 'acid growth' theory and partly the 'facilitated solute uptake' theory. PM- $\mathrm{H}^{+}$-ATPase dependent $\mathrm{H}^{+}$excretion is essential for at least $50 \%$ of leaf growth. However, the equilibrium $\mathrm{pH}$ is not necessarily reflecting changes in transmembrane $\mathrm{H}^{+}$pumping 
because $\mathrm{H}^{+} / \mathrm{K}^{+}$symport might transport protons back into the cell as Fig. 4.1 shows. Treatments with different $\mathrm{K}^{+}$transport blockers (TEA, $\mathrm{CsCl}, \mathrm{NH}_{4}^{+}$) and their double treatments with sodium-orthovanadate, the $\mathrm{PM}-\mathrm{H}^{+}$-ATPase blocker, suggested that in the background of the 'acid growth' of barley leaves an active HAK type $\mathrm{K}^{+}$uptake system might play a key role in facilitating a $\mathrm{H}^{+} / \mathrm{K}^{+}$symport mechanism (Bañuelos et al., 2002; Bucker et al., 2006; Britto \& Kronzucker, 2008; Szczerba et al., 2009). Acidification of the cell wall or protonation of some enzymes in the cell wall might have additional important role in growth as cell wall property measurements showed. HvHAK4, a member of the family of $\mathrm{K}^{+}$transporters, is mainly present in barley shoots (Rubio et al., 2000) and it has significantly higher expression in the leaf elongation zone (Boscari et al., 2009), further supporting the idea of a combined 'acid growth' and 'facilitated solute uptake'.

Based on qPCR, enzyme activity and Western blot result, PM- $\mathrm{H}^{+}$-ATPase expression in the plasma membrane might be controlled by a simple mechanism. The enzyme density in the plasma membrane can be diluted by cell growth; its density in the plasma membrane changes with cell size. The total number of $\mathrm{PM}-\mathrm{H}^{+}-$ ATPase molecules was constant at cellular level while the total membrane surface increasing more than two-fold during cell development (Fig. 3.25 and Fig. 3.26). Taking into consideration all of the present results (expression analysis and physiological measurements with $\mathrm{pH}, \mathrm{H}^{+}$transport activity and $\mathrm{K}^{+}$uptake during the leaf development) and published information about expression of HvHAK4 (Rubio et al., 2000; Boscari et al., 2009) leads to the model shown on Fig. 4.2. The $50 \%$ of leaf growth that was sensitive to inhibition of $\mathrm{PM}-\mathrm{H}^{+}$-ATPase requires high expression of HvHAK4 in the elongation zone (Boscari et al., 2009) and a high plasma membrane density of PM- $\mathrm{H}^{+}$-ATPase molecules. 

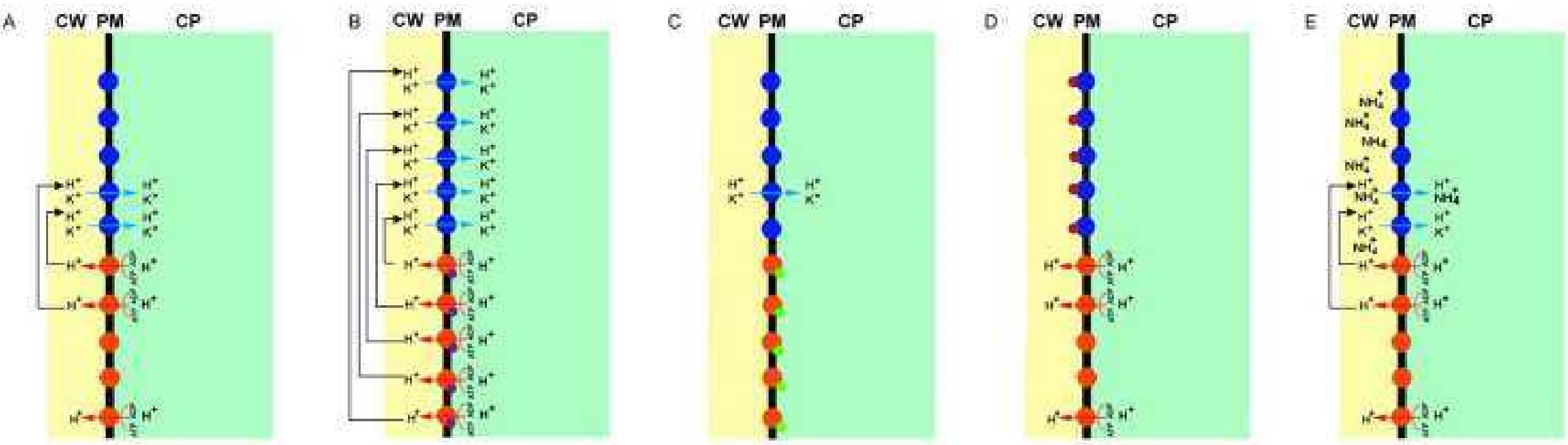

\section{Figure 4.1 Supposed effect of the treatments on barley leaf cells}

On the sketches cell wall (apoplast, $\mathrm{CW}$ ) is labelled with yellow colour, cytoplasm (CP) is green and black lines refer to plasma membrane (PM). Orange balls symbolise PM- $\mathrm{H}^{+}$-ATPase and blue balls are high affinity $\mathrm{H}^{+} / \mathrm{K}^{+}$symporters. Under control conditions $\mathrm{PM}-\mathrm{H}^{+}-$ ATPases pump out the $\mathrm{H}^{+}$and $\mathrm{K}^{+}$are taken up into the cell through high affinity $\mathrm{K}^{+}$transporters (A). Fusicoccin (purple dots) permanently activate all the proton pumps and this massive $\mathrm{H}^{+}$efflux is short cut by $\mathrm{K}^{+}$transporter activity, causing higher turgor pressure in the cells and accelerates leaf growth (B). Vanadate (green dots) permanently blocks PM- $\mathrm{H}^{+}$-ATPase and without $\mathrm{H}^{+}$transport $\mathrm{K}^{+}$uptake and growth are inhibited $(\mathrm{C})$. Caesium ions blocks (deep red dots) $\mathrm{K}^{+}$transporters and reduce leaf growth (D) and ammonium ions (NH ${ }_{4}^{+}$) reduce active $\mathrm{K}^{+}$accumulation through a competitive way and reduce growth (E). 

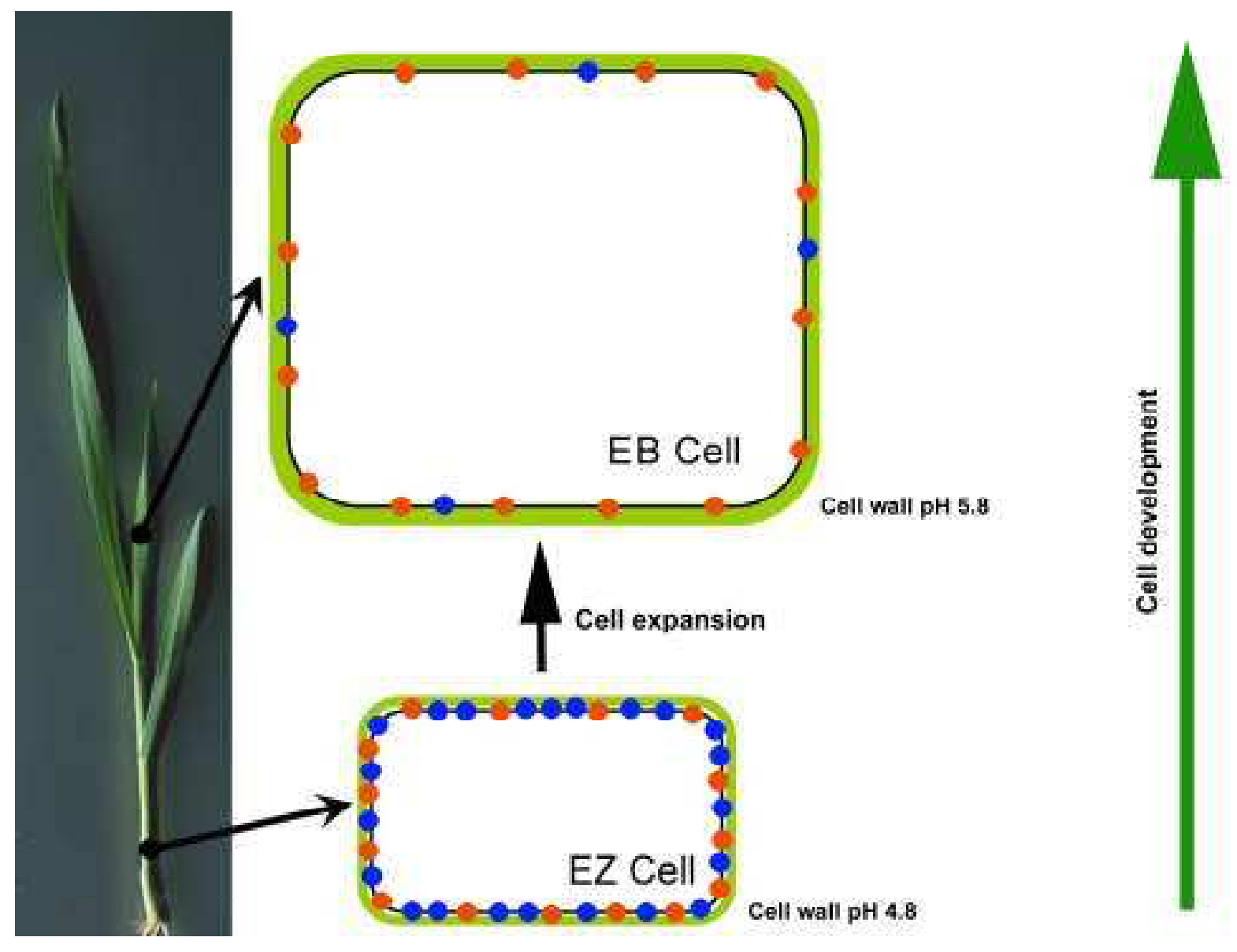

Figure 4.2 Model of leaf elongation in barley leaves

Cell size and membrane surface are increased 2 - 3 fold during cell development, as cells expand in the elongation zone (EZ) and finally reach full maturity in the emerged blade (EB). The number of $\mathrm{PM}-\mathrm{H}^{+}-\mathrm{ATPase}$ molecules (orange balls) per cell is constant where as HvHAK4 (blue balls) expression (and presumably protein level) per cell decreases significantly during cell development. Therefore, both the maximum proton transport and $\mathrm{K}^{+}$accumulation capacity are significantly higher in the elongation zone than in the emerged blade cell and can facilitate elongation growth through 'acid growth' and 'solute accumulation'. On the figure light green colour represents the cell wall and the black line the plasma membrane. 


\section{$5 \quad$ Conclusions and future work}

\subsection{Conclusions}

(i) In this study the $\mathrm{pH}$ and $\mathrm{H}^{+}$transport activity were examined in the elongation zone and the non-growing emerged blade portion of leaf three of barley, using three independent approaches - an in-vitro gel system with bromochresol purple as $\mathrm{pH}$ indicator, confocal microscopy combined with $\mathrm{pH}$ sensitive fluoresceince probes and microelectrode technique. All techniques show a lower $\mathrm{pH} /$ higher proton efflux in the elongation zone compared with emerged blade and support the classical 'acid growth' theory for the elongation growth of plant organs.

(ii) Experiments with $\mathrm{K}^{+}$channel and transporter blockers, and with $\mathrm{PM}-\mathrm{H}^{+}-$ ATPase activator and blocker point to new aspects of the acid growth theory when applied to barley leaves. LVDT measurements, analyses of cell wall property and microelectrode $\mathrm{pH}$ results suggest that a lower or higher $\mathrm{H}^{+}$transport activity is not linked directly to leaf growth, but linked through a $\mathrm{H}^{+} / \mathrm{K}^{+}$symport system which facilitates solute (especially $\mathrm{K}^{+}$) uptake into growing cells. Changes in cell wall properties suggest that elongation of barley leaves can be described with a combination of the classical 'acid growth' and the 'facilitated solute uptake' theory.

(iii) In expression studies, both at the gene and protein level, a two fold higher $\mathrm{PM}-\mathrm{H}^{+}$-ATPase density per unit plasma membrane surface area is found in growing compared with non-growing leaf tissue. $\mathrm{PM}-\mathrm{H}^{+}$-ATPase seems an ideal reference gene in studies where growing and non-growing barley leaf tissues need to be compared. The copy number of the enzyme in the plasma membrane might be controlled by a simple mechanism of growth-dilution: the total amount of $\mathrm{PM}-\mathrm{H}^{+}$ATPase is constant in the cells and the plasma membrane surface increases during cell and tissue development.

(iv) Immunohistological analyses show that $\mathrm{PM}-\mathrm{H}^{+}-\mathrm{ATPase}$ protein is present mainly in those leaf tissues which are characterised by high rates of solute exchange across the plasma membrane (guard cells) or high rates of solute loading / unloading associated with long-distance transport pathways (phloem; xylem parenchyma). This applies to both elongation zone and emerged blade and shows that there exists a cell-type-specific control of $\mathrm{PM}-\mathrm{H}^{+}$-ATPase protein level which is superimposed on any developmental gradient. 


\section{$5.2 \quad$ Future works}

(i) Due to limited financial resources only some $\mathrm{pH}$ micro electrode measurements could be carried out. It would be interesting to further study the relation between apoplastic $\mathrm{K}^{+}$concentration and cell wall acidification applying 10 $\mathrm{mM} \mathrm{KCl}$ treatment togheter with $5 \mu \mathrm{M}$ fucicoccin and $\mathrm{K}^{+}$transporter blockers e.g. $\mathrm{CsCl}$, TEA or $\mathrm{NH}_{4}^{+}$.

(ii) Using inside-out plasma membrane vesicles and fluorimetric approach proton pumping activity could be monitored. Within this project preliminary experiments were carried out and 5(6)carboxyfluorescein seem a good candidate for these probes (better for this purpose than acridine orange that was used by many previous studies e.g. Yan et al. (1998); Yan et al. (2002); Zörb et al. (2005); Pitann et al. (2009b); Zhu et al. (2009); Wakeel et al. (2010). Due to time constraints, these experiments could not be finished. Results of these vesicular transport assays could further support PM- $\mathrm{H}^{+}$-ATPase activity data.

(iii) Most of the present data point to HvHAK4 playing a key role in leaf cell elongation growth in barley. HvHAK4 is a putative $\mathrm{K}^{+} / \mathrm{H}^{+}$symporter, yet the precise function and characteristics of this transporter remain unknown. It would be good to carry out functionality tests of HvHAK4 and its regulation through test reagents which also impact on growth and PM- $\mathrm{H}^{+}$-ATPase. 


\section{$6 \quad$ Literature}

Amtmann A, Jelitto TC, Sanders D. 1999. $\mathrm{K}^{+}$-selective inward-rectifying channels and apoplastic $\mathrm{pH}$ in barley roots. Plant Physiol. 120: 331-338.

Arif I, Newman I. 1993. Proton efflux from oat coleoptile cells and exchange with wall calcium after IAA or fusicoccin treatment. Planta 189: 377-383.

Ashley MK, Grant M, Grabov A. 2006. Plant responses to potassium deficiencies: A role for potassium transport proteins. J. Exp. Bot. 57: 425-436.

Babcock DF. 1983. Examination of the intracellular ionic environment and of ionophore action by null point measurements employing the fluorescein chromophore. J. Biol. Chem. 258: 6380-6389.

Bañuelos MA, Garciadeblas B, Cubero B, Rodríguez-Navarro A. 2002. Inventory and functional characterization of the HAK potassium transporters of rice. Plant Physiol. 130: 784-795.

Besse M, Knipfer T, Miller AJ, Verdeil J-L, Jahn TP, Fricke W. 2011. Developmental pattern of aquaporin expression in barley (Hordeum vulgare L.) leaves. J. Exp. Bot. 62: 4127-4142.

Boscari A, Clément M, Volkov V, Golldack D, Hybiak J, Miller AJ, Amtmann A, Fricke W. 2009. Potassium channels in barley: Cloning, functional characterization and expression analyses in relation to leaf growth and development. Plant, Cell Environ. 32: 1761-1777.

Bouche-Pillon S, Fleurat-Lessard P, Fromont JC, Serrano R, Bonnemain JL. 1994. Immunolocalization of the plasma membrane $\mathrm{H}^{+}$-ATPase in minor veins of Vicia faba in relation to phloem loading. Plant Physiol. 105: 691-697.

Boyer JS. 2001. Growth-induced water potentials originate from wall yielding during growth. J. Exp. Bot. 52: 1483-1488.

Britto DT, Ebrahimi-Ardebili S, Hamam AM, Coskun D, Kronzucker HJ. 2010. ${ }^{42} \mathrm{~K}$ analysis of sodium-induced potassium efflux in barley: Mechanism and relevance to salt tolerance. New Phytol. 186: 373-384.

Britto DT, Kronzucker HJ. 2008. Cellular mechanisms of potassium transport in plants. Physiol. Plant. 133: 637-650.

Brummer B, Felle H, Parish RW. 1984. Evidence that acid solutions induce plant cell elongation by acidifying the cytosol and stimulating the proton pump. FEBS Letters 174: 223-227.

Bucker CA, de Souza SR, Fernandes MS. 2006. Effects of fusicoccin and vanadate on proton extrusion and potassium uptake by rice. J. Plant Nutr. 29: 485-496.

Chazen O, Neumann PM. 1994. Hydraulic signals from the roots and rapid cell-wall hardening in growing maize (Zea mays L.) leaves are primary responses to polyethylene glycol-induced water deficits. Plant Physiol. 104: 1385-1392.

Christian M, Steffens B, Schenck D, Burmester S, Böttger M, Lüthen H 2006. How does auxin enhance cell elongation? Roles of auxin-binding proteins and potassium channels in growth control. Plant Biol. 346-352.

Claussen M, Lüthen H, Blatt M, Bottger M. 1997. Auxin-induced growth and its linkage to potassium channels. Planta 201: 227-234.

Clerc S, Barenholz Y. 1998. A quantitative model for using acridine orange as a transmembrane pH gradient probe. Anal. Biochem. 259: 104-111. 
Collins D, Walpole C, Ryan E, Winter D, Baird A, Stewart G. 2011. UT-B1 mediates transepithelial urea flux in the rat gastrointestinal tract. J. Membr. Biol. 239: 123-130.

Conway EJ, O'Malley E. 1946. The nature of the cation exchanges during yeast fermentation, with formation of 0.02N-H ion. Biochem. J. 40: 59-67.

Cosgrove DJ. 1993. Wall extensibility - its nature, measurement and relationship to plant-cell growth. New Phytol. 124: 1-23.

Cosgrove DJ 1996. Plant cell enlargement and the action of expansins. BioEssays 18: $533-540$.

Cosgrove DJ. 1998. Cell wall loosening by expansins. Plant Physiol. 118: 333-339.

Csiszár J, Erdei L, Pécsváradi A, Szabó M, Tari I. 2004. Növényélettan, növekedés- és fejlődésélettan (Plant physiology, growth and developing physiology). Szeged, JATEPress.

Darwin C. 1880. The power of movement in plants, chapter ix sensitiveness of plants to light: Its transmitted effects. London, John Murray.

Dennis PG, Hirsch PR, Smith SJ, Taylor RG, Valsami-Jones E, Miller AJ. 2009. Linking rhizoplane $\mathrm{pH}$ and bacterial density at the microhabitat scale. J. Microbiol. Methods 76: 101-104

Döring O, Busch M, Lüthje S, Lüthen H, Hilgendorf F, Böttger M. 1996. lonostats. Protoplasma 194: 1-10.

Duby G, Boutry M. 2009. The plant plasma membrane proton pump ATPase: A highly regulated P-type ATPase with multiple physiological roles. European $\mathrm{J}$. Physiol. 457: 645-655.

DuPont FM. 1989. Effect of temperature on the plasma membrane and tonoplast ATPases of barley roots : Comparison of results obtained with acridine orange and quinacrine. Plant Physiol. 89: 1401-1412.

Ehlert C, Plassard C, Cookson SJ, Tardieu F, Simonneau T. 2011. Do pH changes in the leaf apoplast contribute to rapid inhibition of leaf elongation rate by water stress? Comparison of stress responses induced by polyethylene glycol and down-regulation of root hydraulic conductivity. Plant Cell Environ. 34: 1258-1266.

Epstein E, Rains DW, Elzam OE. 1963. Resolution of dual mechanisms of potassium absorption by barley roots. PNAS 49: 684-692.

Felle HH. 2005. pH regulation in anoxic plants. Annals Bot. 96: 519-532.

Felle HH. 2006. Apoplastic pH during low-oxygen stress in barley. Annals Bot. 98: 1085-1093.

Felle HH, Herrmann A, Huckelhoven R, Kogel KH. 2005. Root-to-shoot signalling: Apoplastic alkalinization, a general stress response and defence factor in barley (Hordeum vulgare). Protoplasma 227: 17-24.

Fleurat-Lessard P, Bouche-Pillon S, Leloup C, Bonnemain JL. 1997. Distribution and activity of the plasma membrane $\mathrm{H}^{+}$-ATPase in Mimosa pudica $\mathrm{L}$ in relation to ionic fluxes and leaf movements. Plant Physiol. 113: 747-754.

Frensch J. 1997. Primary responses of root and leaf elongation to water deficits in the atmosphere and soil solution. J. Exp. Bot. 48: 985-999.

Fricke W. 2002a. Biophysical limitation of cell elongation in cereal leaves. Annals Bot. 90: 157-167.

Fricke W. 2002b. Biophysical limitation of leaf cell elongation in source-reduced barley. Planta 215: 327-338. 
Fricke W. 2004. Rapid and tissue-specific accumulation of solutes in the growth zone of barley leaves in response to salinity. Planta 219: 515.

Fricke W, Akhiyarova G, Veselov D, Kudoyarova G. 2004. Rapid and tissuespecific changes in $A B A$ and in growth rate in response to salinity in barley leaves. J. Exp. Bot. 55: 1115-1123.

Fricke W, Flowers TJ. 1998. Control of leaf cell elongation in barley. Generation rates of osmotic pressure and turgor, and growth-associated water potential gradients. Planta 206: 53-65.

Fricke W, Leigh RA, Tomos AD. 1994. Concentrations of inorganic and organic solutes in extracts from invidual epidermal, mesophyll and bundle-sheath cells of barley leaves. Planta 192: 310-316.

Fricke W, McDonald AJS, Mattson-Djos L. 1997. Why do leaves and leaf cells of $\mathrm{N}$-limited barley elongate at reduced rates? Planta 202: 522-530.

Fricke W, Peters WS. 2002. The biophysics of leaf growth in salt-stressed barley. A study at the cell level. Plant Physiol. 129: 374-388.

Gaxiola RA, Palmgren MG, Schumacher K. 2007. Plant proton pumps. FEBS Letters 581: 2204-2214.

Glass ADM, Siddiqi MY, Giles KI. 1981. Correlations between potassium uptake and hydrogen efflux in barley varieties: A potential screening method for the isolation of nutrient efficient lines. Plant Physiol. 68: 457-459.

Graber ML, DiLillo DC, Friedman BL, Pastoriza-Munoz E. 1986. Characteristics of fluoroprobes for measuring intracellular pH. Anal. Biochem. 156: 202-212.

Grebe M. 2005. Growth by auxin: When a weed needs acid. Science 310: 60-61.

Green PB, Erickson RO, Buggy J. 1971. Metabolic and physical control of cell elongation rate: In vivo studies in nitella. Plant Physiol. 47: 423-430.

Grignon C, Sentenac H. 1991. pH and ionic conditions in the apoplast. Ann. Rev. Plant Physiol. Plant Mol. Biol. 42: 103-128.

Hachez C, Heinen RB, Draye X, Chaumont F. 2008. The expression pattern of plasma membrane aquaporins in maize leaf highlights their role in hydraulic regulation. Plant Mol. Biol. 68: 337-353.

Hager A. 2003. Role of the plasma membrane $\mathrm{H}^{+}$-ATPase in auxin-induced elongation growth: Historical and new aspects. J. Plant Res. 116: 483-505.

Hager A, Debus G, Edel HG, Stransky H, Serrano R. 1991. Auxin induces exocytosis and the rapid synthesis of a high-turnover pool of plasmamembrane $\mathrm{H}^{+}$-ATPase. Planta 185: 527-537.

Hager A, Menzel H, Krauss A. 1971. Experiments and hypothesis concerning primary action of auxin in elongation growth. Planta 100: 47-71.

Hatzig S, Hanstein S, Schubert S. 2010. Apoplast acidification is not a necessary determinant for the resistance of maize in the first phase of salt stress. J. Plant Nut. Soil Sci. 173: 559-562.

Hohl M, Hong YN, Schopfer P. 1991. Acid- and enzyme-mediated solubilization of cell-wall $\beta-1.3, \beta-1.4-D-g l u c a n$ in maize coleoptiles : Implications for auxinmediated growth. Plant Physiol. 95: 1012-1018.

Hoopen FT, Cuin TA, Pedas P, Hegelund JN, Shabala S, Schjoerring JK, Jahn TP. 2010. Competition between uptake of ammonium and potassium in barley and Arabidopsis roots: Molecular mechanisms and physiological consequences. J. Exp. Bot. 61: 2303-2315. 
Hruz T, Wyss M, Docquier M, Pfaffl M, Masanetz S, Borghi L, Verbrugghe P, Kalaydjieva L, Bleuler S, Laule O, Descombes P, Gruissem W, Zimmermann P. 2011. Refgenes: Identification of reliable and condition specific reference genes for RT-qPCR data normalization. BMC Genomics 12: 156.

Hsiao TC, Frensch J, Rojas-Lara BA. 1998. The pressure-jump technique shows maize leaf growth to be enhanced by increases in turgor only when water status is not too high. Plant, Cell Environ. 21: 33-42.

Hsiao TC, Xu LK. 2000. Sensitivity of growth of roots versus leaves to water stress: Biophysical analysis and relation to water transport. J. Exp. Bot. 51: 15951616.

Hynek R, Svensson B, Jensen ONr, Barkholt V, Finnie C. 2006. Enrichment and identification of integral membrane proteins from barley aleurone layers by reversed-phase chromatography, SDS-PAGE, and LC-MS/MS. J. Proteome Res. 5: 3105-3113.

Johansson F, Sommarin M, Larsson C. 1993. Fusicoccin activates the plasmamembrane $\mathrm{H}^{+}$-ATPase by a mechanism involving the c-terminal inhibitory domain. Plant Cell 5: 321-327.

Katsumi M. 2007. Studies on plant growth substances in japan before 1945. Plant Biotech. 24: 155-163.

Kavanagh CA. 2010. Changes in cell ultrastructure during leaf development in barley (Hordeum vulgare L.) and in response to salinity. MSc Thesis, University College Dublin, Dublin.

Keller CP, Van Volkenburgh E. 1998. Evidence that auxin-induced growth of tobacco leaf tissues does not involve cell wall acidification. Plant Physiol. 118: 557-564.

Kim S, Dale BE. 2004. Global potential bioethanol production from wasted crops and crop residues. Biomass and Bioenergy 26: 361-375.

Kjellbom P, Larsson C. 1984. Preparation and polypeptide composition of chlorophyll-free plasma-membranes from leaves of light-grown spinach and barley. Physiol. Plant. 62: 501-509.

Knipfer T, Fricke W. 2011. Water uptake by seminal and adventitious roots in relation to whole-plant water flow in barley (Hordeum vulgare L.). J. Exp. Bot. 62: 717-733.

Kronzucker HJ, Szczerba MW, Britto DT. 2003. Cytosolic potassium homeostasis revisited: ${ }^{42} \mathrm{~K}$-tracer analysis in Hordeum vulgare L. Reveals set-point variations in $\mathrm{K}^{+}$. Planta 217: 540-546.

Kruger $\mathbf{N}$ 2002. The Bradford method for protein quantitation. The protein protocols handbook, 15: (4) 15-21.

Kutschera U. 1994. Tansley review no. 66. The current status of the acid-growth hypothesis. New Phytol. 126: 549-569.

Kutschera U. 2006. Acid growth and plant development. Science 311: 952-954.

Kutschera U, Bergfeld R, Schopfer P. 1987. Cooperation of epidermis and inner tissues in auxin-mediated growth of maize coleoptiles. Planta 170: 168-180.

Kutschera U, Schopfer P. 1985a. Evidence against the acid-growth theory of auxin action. Planta 163: 483-493.

Kutschera U, Schopfer P. 1985b. Evidence for the acid-growth theory of fusicoccin action. Planta 163: 494-499. 
Laemmli UK. 1970. Cleavage of structural proteins during the assembly of the head of bacteriophage T4. Nature 227: 680-685.

Larkin PJ. 1976. Purification and viability determinations of plant protoplasts. Planta 128: 213-216.

Lenaeus MJ, Vamvouka M, Focia PJ, Gross A. 2005. Structural basis of TEA blockade in a model potassium channel. Nature Struct. Mol. Biol. 12: 454-459.

Li L, Li S-M, Sun J-H, Zhou L-L, Bao X-G, Zhang H-G, Zhang F-S. 2007. Diversity enhances agricultural productivity via rhizosphere phosphorus facilitation on phosphorus-deficient soils. PNAS 104: 11192-11196.

Lockhart JA. 1965. An analysis of irreversible plant cell elongation. J Theor. Biol. 8: 264-275.

Lüthen H, Bigdon M, Böttger M. 1990. Reexamination of the acid growth theory of auxin action. Plant Physiol. 93: 931-939.

Lüthen H, Böttger M. 1988. Kinetics of proton secretion and growth in maize roots action of various plant-growth effectors. Plant Sci. 54: 37-43.

Maathuis FJM, Filatov V, Herzyk P, C. Krijger G, B. Axelsen K, Chen S, Green BJ, Li Y, Madagan KL, Sánchez-Fernández R, Forde BG, Palmgren MG, Rea PA, Williams LE, Sanders D, Amtmann A. 2003. Transcriptome analysis of root transporters reveals participation of multiple gene families in the response to cation stress. Plant J. 35: 675-692.

Malnic G, Geibel JP. 2000. Cell $\mathrm{pH}$ and $\mathrm{H}^{+}$secretion by $\mathrm{S} 3$ segment of mammalian kidney: Role of H+-ATPase and $\mathrm{Cl}^{-}$. .J. Membr. Biol. 178: 115-125.

Manente S, Pieri SD, lero A, Rigo C, Bragadin M. 2008. A comparison between the responses of neutral red and acridine orange: Acridine orange should be preferential and alternative to neutral red as a dye for the monitoring of contaminants by means of biological sensors. Anal. Biochem. 383: 316-319.

Marré E. 1979. Fusicoccin - tool in plant physiology. Ann. Rev. Plant Physiol. Plant Mol. Biol. 30: 273-288.

Martre P, Bogeat-Triboulot M-B, Durand J-L. 1999. Measurement of a growthinduced water potential gradient in tall fescue leaves. New Phytol. 142: 435439.

McQueen-Mason S, Durachko DM, Cosgrove DJ. 1992. Two endogenous proteins that induce cell wall extension in plants. Plant Cell 4: 1425-1433.

McQueen-Mason SJ. 1995. Expansins and cell wall expansion. J. Exp. Bot. 46: 1639-1650.

Michelet B, Boutry M. 1995. The plasma membrane $\mathrm{H}^{+}$-ATPase: A highly regulated enzyme with multiple physiological functions. Plant Physiol. 108: 1-6.

Miller AJ, Smith SJ. 1992. The mechanism of nitrate transport across the tonoplast of barley root cells. Planta 187: 554-557.

Mito N, Wimmers LE, Bennett AB. 1996. Sugar regulates mrna abundance of $\mathrm{h}^{+}-$ atpase gene family members in tomato. Plant Physiol. 112: 1229-1236.

Moloney MM, Elliott MC, Cleland RE. 1981. Acid growth effects in maize roots evidence for a link between auxin-economy and proton extrusion in the control of root-growth. Planta 152: 285-291.

Moran N. 2007. Osmoregulation of leaf motor cells. FEBS Letters 581: 2337-2347.

Morsomme P, Boutry M. 2000. The plant plasma membrane $\mathrm{H}^{+}$-ATPase: Structure, function and regulation. BBA - Biomembr. 1465: 1-16. 
Morth JP, Pedersen BP, Buch-Pedersen MJ, Andersen JP, Vilsen B, Palmgren MG, Nissen P. 2011. A structural overview of the plasma membrane $\mathrm{Na}^{+}, \mathrm{K}^{+}$ATPase and $\mathrm{H}^{+}$-ATPase ion pumps. Nature Rev. Mol. Cell. Biol. 12: 60-70.

Neumann PM. 1993. Rapid and reversible modifications of extension capacity of cell walls in elongating maize leaf tissues responding to root addition and removal of $\mathrm{NaCl}$. Plant, Cell Environ. 16: 1107-1114.

Neves-Piestun BG, Bernstein N. 2001. Salinity-induced inhibition of leaf elongation in maize is not mediated by changes in cell wall acidification capacity. Plant Physiol. 125: 1419-1428.

O'Neal ME, Landis DA, Isaacs R. 2002. An inexpensive, accurate method for measuring leaf area and defoliation through digital image analysis. J. Econ. Entom. 95: 1190-1194.

Oecking C, Eckerskorn C, Weiler EW. 1994. The fusicoccin receptor of plants is a member of the 14-3-3-superfamily of eukaryotic regulatory proteins. FEBS Letters 352: 163-166.

Olivari C, Meanti C, De Michelis MI, Rasi-Caldogno F. 1998. Fusicoccin binding to its plasma membrane receptor and the activation of the plasma membrane $\mathrm{H}^{+}$ATPase. IV. Fusicoccin induces the association between the plasma membrane $\mathrm{H}^{+}$-ATPase and the fusicoccin receptor. Plant Physiol. 116: 529537.

Paál Á. 1918. Über phototropsche Reizleitungen. Jehrb. wiss. Bot. 58: 406-458.

Palmgren MG. 1991. Acridine-orange as a probe for measuring $\mathrm{pH}$ gradients across membranes - mechanism and limitations. Anal. Biochem. 192: 316-321.

Palmgren MG. 2001. Plant plasma membrane $\mathrm{H}^{+}$-ATPases: Powerhouses for nutrient uptake. Ann. Rev. Plant Physiol. Plant Mol. Biol. 52: 817-845.

Palmgren MG, Sommarin M, Serrano R, Larsson C. 1991. Identification of an autoinhibitory domain in the C-terminal region of the plant plasma membrane $\mathrm{H}^{+}$-ATPase. J. Biol. Chem. 266: 20470-20475.

Pedersen BP, Buch-Pedersen MJ, Morth JP, Palmgren MG, Nissen P. 2007. Crystal structure of the plasma membrane proton pump. Nature 450: 11111119.

Perrot-Rechenmann C. 2010. Cellular responses to auxin: Division versus expansion. Cold Spring Harbor Persp. Biol. 2: a001446; 1-15.

Peters WS. 2004. Growth rate gradients and extracellular pH in roots: How to control an explosion. New Phytol. 162: 571-574.

Peters WS, Felle HH. 1999. The correlation of profiles of surface $\mathrm{pH}$ and elongation growth in maize roots. Plant Physiol. 121: 905-912.

Peters WS, Luthen H, Bottger M, Felle H. 1998. The temporal correlation of changes in apoplast $\mathrm{pH}$ and growth rate in maize coleoptile segments. Austr. J. Plant Physiol. 25: 21-25.

Peters WS, Richter U, Felle HH. 1992. Auxin-induced $\mathrm{H}^{+}$-pump stimulation does not depend on the presence of epidermal-cells in corn coleoptiles. Planta 186: 313-316.

Pfaffl MW. 2001. A new mathematical model for relative quantification in real-time RT-PCR. Nucl. Acids Res. 29: e45.

Philippar K, Büchsenschütz K, Edwards D, Löffler J, Lüthen H, Kranz E, Edwards K, Hedrich R. 2006. The auxin-induced $\mathrm{k}^{+}$channel gene ZMK1 in maize functions in coleoptile growth and is required for embryo development. Plant Mol. Biol. 61: 757-768. 
Philippar K, Fuchs I, Lüthen H, Hoth S, Bauer CS, Haga K, Thiel G, Ljung K, Sandberg G, Böttger M, Becker D, Hedrich R. 1999. Auxin-induced $\mathrm{K}^{+}$ channel expression represents an essential step in coleoptile growth and gravitropism. PNAS 96: 12186-12191.

Philippar K, Ivashikina N, Ache P, Christian M, Lüthen H, Palme K, Hedrich R. 2004. Auxin activates KAT1 and KAT2, two $\mathrm{K}^{+}$-channel genes expressed in seedlings of Arabidopsis thaliana. Plant J. 37: 815-827.

Pitann B, Kranz T, Muhling KH. 2009a. The apoplastic pH and its significance in adaptation to salinity in maize (Zea mays L.): Comparison of fluorescence microscopy and ph-sensitive microelectrodes. Plant Sci. 176: 497-504.

Pitann B, Schubert S, Muhling KH. 2009b. Decline in leaf growth under salt stress is due to an inhibition of $\mathrm{H}$--pumping activity and increase in apoplastic $\mathrm{pH}$ of maize leaves. J. Plant Nutr. Soil Sci. 172: 535-543.

Pollock CJ, Tomos AD, Thomas A, Smith CJ, Lloyd EJ, Stoddart JL. 1990. Extension growth in a barley mutant with reduced sensitivity to lowtemperature. New Phytol. 115: 617-623.

Pope AJ, Leigh RA. 1988. Dissipation of ph gradients in tonoplast vesicles and liposomes by mixtures of acridine orange and anions: Implications for the use of acridine orange as a pH probe. Plant Physiol. 86: 1315-1322.

Pritchard J. 1994. The control of cell expansion in roots. New Phytol. 127: 3-26.

Rayle DL. 1973. Auxin-induced hydrogen-ion secretion in avena coleoptiles and its implications. Planta 114: 63-73.

Rayle DL, Cleland R. 1970. Enhancement of wall loosening and elongation by acid solutions. Plant Physiol. 46: 250-253.

Rayle DL, Cleland RE. 1992. The acid growth theory of auxin-induced cell elongation is alive and well. Plant Physiol. 99: 1271-1274.

Reidy B, McQueen-Mason S, Nösberger J, Fleming A. 2001. Differential expression of $\alpha$ - and $\beta$-expansin genes in the elongating leaf of festuca pratensis. Plant Mol. Biol. 46: 491-504.

Richardson A, Wojciechowski T, Franke R, Schreiber L, Kerstiens G, Jarvis M, Fricke W. 2007. Cuticular permeance in relation to wax and cutin development along the growing barley (Hordeum vulgare) leaf. Planta 225: 1471-1481.

Rodriguez-Navarro A, Rubio F. 2006. High-affinity potassium and sodium transport systems in plants. J. Exp. Bot. 57: 1149-1160.

Rubio F, Santa-María GE, Rodríguez-Navarro A. 2000. Cloning of Arabidopsis and barley cDNAs encoding HAK potassium transporters in root and shoot cells. Physiol. Plant. 109: 34-43.

Sabirzhanova IB, Sabirzhanov BE, Chemeris AV, Veselov DS, Kudoyarova GR. 2005. Fast changes in expression of expansin gene and leaf extensibility in osmotically stressed maize plants. Plant Physiol. Biochem. 43: 419-422.

Sakurai N, Masuda Y. 1978. Auxin-induced changes in barley coleoptile cell-wall composition. Plant Cell Physiol. 19: 1217-1223.

Santi S, Cesco S, Varanini Z, Pinton R. 2005. Two plasma membrane $\mathrm{H}^{+}$-ATPase genes are differentially expressed in iron-deficient cucumber plants. Plant Physiol. Biochem. 43: 287-292. 
Sarkadi B, Price EM, Boucher RC, Germann UA, Scarborough GA. 1992. Expression of the human multidrug resistance cdna in insect cells generates a high-activity drug-stimulated membrane ATPase. J. Biol. Chem. 267: 48544858.

Schopfer P. 1989. pH-dependence of extension growth in Avena-coleopiles and its implications for the mechanism of auxin action. Plant Physiol. 90: 202-207.

Schulte D, Close TJ, Graner A, Langridge P, Matsumoto T, Muehlbauer G, Sato K, Schulman AH, Waugh R, Wise RP, Stein N. 2009. The international barley sequencing consortium - At the threshold of efficient access to the barley genome. Plant Physiol. 149: 142-147.

Senn ME, Rubio F, Bañuelos MA, Rodríguez-Navarro A. 2001. Comparative functional features of plant potassium hvhak1 and hvhak2 transporters. J. Biol. Chem. 276: 44563-44569.

Shen H, He LF, Sasaki T, Yamamoto Y, Zheng SJ, Ligaba A, Yan XL, Ahn SJ, Yamaguchi M, Sasakawa H, Matsumoto H. 2005. Citrate secretion coupled with the modulation of soybean root tip under aluminum stress. Up-regulation of transcription, translation, and threonine-oriented phosphorylation of plasma membrane $\mathrm{H}^{+}$-ATPase. Plant Physiol. 138: 287-296.

Slayman CL. 1965. Electrical properties of Neurospora crassa. J. General Physiol. 49: 69-92.

Spalding EP, Hirsch RE, Lewis DR, Qi Z, Sussman MR, Lewis BD. 1999. Potassium uptake supporting plant growth in the absence of AKT1 channel activity: Inhibition by ammonium and stimulation by sodium. J. Gen. Physiol. 113: 909-918.

Speth C, Jaspert N, Marcon C, Oecking C. 2010. Regulation of the plant plasma membrane $\mathrm{H}^{+}$-ATPase by its c-terminal domain: What do we know for sure? European J. Cell Biol. 89: 145-151.

Stahlberg R, Van Volkenburgh E. 1999. The effect of light on membrane potential, apoplastic $\mathrm{pH}$ and cell expansion in leaves of Pisum sativum L. var. Argenteum. - role of the plasma-membrane $\mathrm{H}^{+}$-ATPase and photosynthesis. Planta 208: 188-195.

Steudle E. 2000. Water uptake by roots: Effects of water deficit. J. Exp. Bot. 51: 1531-1542.

Stiles K, McClintick A, Volkenburgh E. 2003. A developmental gradient in the mechanism of $\mathrm{K}^{+}$uptake during light-stimulated leaf growth in Nicotiana tabacum L. Planta 217: 587-596.

Stiles KA, Van Volkenburgh E 2004. Role of $\mathrm{K}^{+}$in leaf growth: $\mathrm{K}^{+}$uptake is required for light-stimulated $\mathrm{H}^{+}$efflux but not solute accumulation. Plant, Cell Environ. 27: 315-325.

Stoddart JL, Lloyd EJ. 1986. Modification by gibberellin of the growth-temperature relationship in mutant and normal genotypes of several cereals. Planta 167: 364-368.

Szczerba MW, Britto DT, Kronzucker HJ. 2006. Rapid, futile $\mathrm{K}^{+}$cycling and poolsize dynamics define low-affinity potassium transport in barley. Plant Physiol. 141: 1494-1507.

Szczerba MW, Britto DT, Kronzucker HJ. 2009. $\mathrm{K}^{+}$transport in plants: Physiology and molecular biology. J. Plant Physiol. 166: 447-466.

Sze H, Li X, Palmgren MG. 1999. Energization of plant cell membranes by $\mathrm{H}_{+-}$ pumping ATPases: Regulation and biosynthesis. Plant Cell 11: 677-690. 
Tang AC, Boyer JS. 2008. Xylem tension affects growth-induced water potential and daily elongation of maize leaves. J. Exp. Bot. 59: 753-764.

Tang C, Drevon JJ, Jaillard B, Souche G, Hinsinger P. 2004. Proton release of two genotypes of bean (Phaseolus vulgaris L.) as affected by $N$ nutrition and $P$ deficiency. Plant Soil 260: 59-68.

Taylor G, Davies WJ. 1985. The control of leaf growth of betula and acer by photoenvironment. New Phytol. 101: 259-268.

Tode K, Lüthen H. 2001. Fusicoccin- and IAA-induced elongation growth share the same pattern of $\mathrm{K}^{+}$dependence. J. Exp. Bot. 52: 251-255.

Ullrich Cl, Novacky AJ. 1990. Extracellular and intracellular ph and membranepotential changes induced by $\mathrm{K}^{+}, \mathrm{Cl}^{-}, \mathrm{H}_{2} \mathrm{PO}_{4}^{-}$, and $\mathrm{NO}_{3}{ }^{-}$uptake and fusicoccin in root hairs of limnobium-stoloniferum. Plant Physiol. 94: 1561-1567.

Van Volkenburgh E, Boyer JS. 1985. Inhibitory effects of water deficit on maize leaf elongation. Plant Physiol. 77: 190-194.

Van Volkenburgh E, Cleland RE. 1980. Proton excretion and cell expansion in bean Phaseolus vulgaris leaves. Planta 148: 273-278.

Vera-Estrella R, Barkla BJ, Higgins VJ, Blumwald E. 1994. Plant defense response to fungal pathogens (activation of host-plasma membrane $\mathrm{H}^{+}$ATPase by elicitor-induced enzyme dephosphorylation). Plant Physiol. 104: 209-215.

Vesper MJ, Evans ML. 1979. Nonhormonal induction of $\mathrm{H}^{+}$efflux from plant tissues and its correlation with growth. PNAS 76: 6366-6370.

Villalba JM, Lützelschwab M, Serrano R. 1991. Immunocytolocalization of plasmamembrane $\mathrm{H}^{+}$-ATPase in maize coleoptiles and enclosed leaves. Planta 185: 458-461.

Vogelstein B, Kinzler KW. 1999. Digital PCR. PNAS 96: 9236-9241.

Volkov V, Boscari A, Clément M, Miller AJ, Amtmann A, Fricke W. 2009. Electrophysiological characterization of pathways for $\mathrm{K}^{+}$uptake into growing and non-growing leaf cells of barley. Plant, Cell Environ. 32: 1778-1790.

Volkov V, Hachez C, Moshelion M, Draye X, Chaumont F, Fricke W. 2007. Water permeability differs between growing and non-growing barley leaf tissues. .J. Exp. Bot. 58: 377-390.

Vysotskaya LB, Arkhipova TN, Timergalina LN, Veselov SY, Dedov AV, Kudoyarova GR. 2003. Effect of partial root excision on shoot water relations. J. Plant Physiol. 160: 1011-1015.

Wakeel A, Hanstein S, Pitann B, Schubert S. 2010. Hydrolytic and pumping activity of $\mathrm{H}+-$ ATPase from leaves of sugar beet (Beta vulgaris L.) as affected by salt stress. J. Plant Physiol. 167: 725-731.

Wei WX, Alexandersson E, Golldack D, Miller AJ, Kjellborn PO, Fricke W. 2007. HvPIP1;6, a barley (Hordeum vulgare L.) plasma membrane water channel particularly expressed in growing compared with non-growing leaf tissues. Plant Cell Physiol. 48: 1132-1147.

Wieczorek H, Putzenlechner M, Zeiske W, Klein U. 1991. A vacuolar-type proton pump energizes $\mathrm{K}^{+} / \mathrm{H}^{+}$antiport in an animal plasma-membrane. J. Biol. Chem. 266: 15340-15347.

Würtele M, Jelich-Ottmann C, Wittinghofer A, Oecking C. 2003. Structural view of a fungal toxin acting on a 14-3-3 regulatory complex. EMBO J. 22: 987-994. 
Yan F, Feuerle R, Schaffer S, Fortmeier H, Schubert S. 1998. Adaptation of active proton pumping and plasmalemma ATPase activity of corn roots to low root medium pH. Plant Physiol. 117: 311-319.

Yan F, Zhu Y, Muller C, Zorb C, Schubert S. 2002. Adaptation of $\mathrm{H}^{+}$-pumping and plasma membrane $\mathrm{H}^{+}$ATPase activity in proteoid roots of white lupin under phosphate deficiency. Plant Physiol. 129: 50-63.

Zhu Y, Tingjun DI, Guohua XU, Xi C, Houqing Z, Feng YAN, Qirong S. 2009. Adaptation of plasma membrane $\mathrm{H}^{+}$-ATPase of rice roots to low $\mathrm{pH}$ as related to ammonium nutrition. Plant, Cell Environ. 32: 1428-1440.

Zoccarato F, Cavallini L, Alexandre A. 1999. The pH-sensitive dye acridine orange as a tool to monitorexocytosis/endocytosis in synaptosomes. J. Neurochem. 72: 625-633.

Zörb C, Stracke B, Tramnitz B, Denter D, Sümer A, Mühling KH, Yan F, Schubert S. 2005. Does $\mathrm{H}^{+}$pumping by plasmalemma ATPase limit leaf growth of maize Zea mays during the first phase of salt stress? J. Plant Nutr. Soil Sci. 168: 550-557. 


\section{$7 \quad$ Appendix}

\subsection{Processing of $q P C R$ data}

(i) Total cell volume was considered to equal the total water content of plant tissue (neglecting any water in intercellular space). The water content was calculated from the fresh weight of the samples:

$$
\begin{aligned}
m_{w} & =m_{F W} \cdot w_{\%}[\mathrm{~g}] \\
V_{\text {cell }} & =m_{w} \cdot 10^{12}\left[\mu \mathrm{m}^{3}\right]
\end{aligned}
$$

where: $m_{w}$ : amount of water in the tissue $(\mathrm{g}) ; m_{F W}$ : fresh weight of tissue $(\mathrm{g})$ and $w_{\%}$ : percentage water content of the tissue, $100 \cdot\left(\frac{m_{F W}-m_{D W}}{m_{F W}}\right) ; m_{D W}$, dry weight); $V_{\text {cell }}$ : total cell volume $\left(\mu \mathrm{m}^{3}\right)$.

(ii) From water content, from the proportion of leaf volume occupied by epidermis (0.26) and mesophyll (0.646) and from the cell sizes $\left(99,372 \mu \mathrm{m}^{3}\right.$ for epidermis cells in elongation zone; $461,552 \mu \mathrm{m}^{3}$ for epidermis cells in emerged blade; $6,620 \mu \mathrm{m}^{3}$ for mesophyll cells in elongation zone and 14,830 for mesophyll cells in emerged leaf blade) the number of epidermal cells, mesophyll cells and total number of the cells were calculated:

Elongation zone:

$$
N_{\text {Epcell }}=\frac{V_{\text {cell }} \cdot 0.260}{99,372} ; N_{\text {Mcell }}=\frac{V_{\text {cell }} \cdot 0.646}{6,620} \text { [piece] }
$$

Emerged Blade:

$$
N_{\text {Epcell }}=\frac{V_{\text {cell }} 0.296}{461,552} ; N_{\text {Mcell }}=\frac{V_{\text {cell }} 0.653}{14,830} \text { [piece] }
$$

Total cell number:

$$
N_{\text {cell }}=N_{\text {Epcell }}+N_{\text {Mcell }} \text { [piece] }
$$

where: $N_{\text {Epcell: }}$ number of epidermal cells; $N_{\text {Mcell }}$ : number of mesophyll cells and $N_{\text {cell }}$ : total cell number.

(iii) Plasma membrane surface was calculated as:

$$
\begin{array}{ll}
\text { Elongation zone: } & A=N_{\text {Epcell }} \cdot 19,704+N_{\text {Mcell }} \cdot 1,632\left[\mu \mathrm{m}^{2}\right] \\
\text { Emerge blade: } & A=N_{\text {Epcell }} \cdot 50,004+N_{\text {Mcell }} \cdot 2,855\left[\mu \mathrm{m}^{2}\right]
\end{array}
$$

where: $A$ : plasma membrane surface of the sample $\left(\mu \mathrm{m}^{2}\right)$. 
(iv) Calculation of the PM- $\mathrm{H}^{+}$-ATPase copy number in the sample was carried out with the help of calibration curve using $\mathrm{PM}-\mathrm{H}^{+}$-ATPase DNA standard. This calibration curve was different for each qPCR measurement. An example of this calculation may be found in Fig. 7.1.

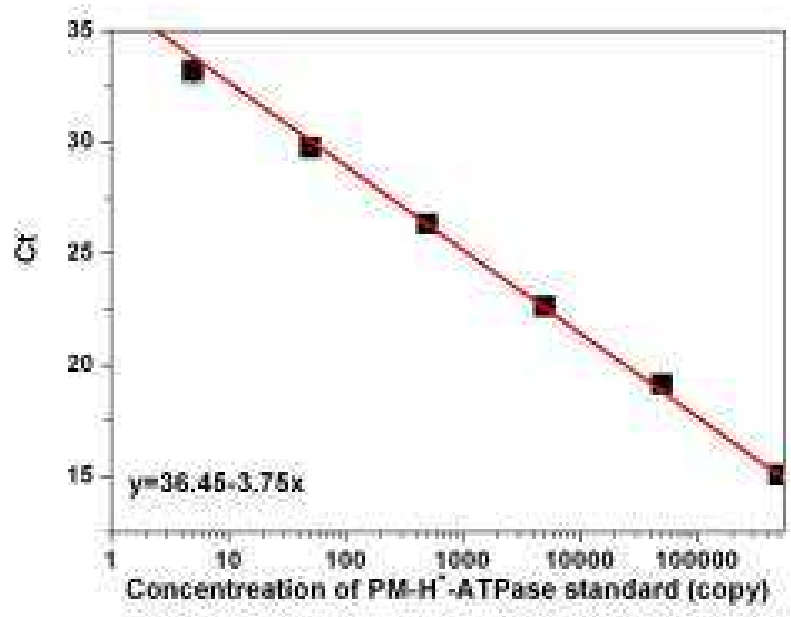

Figure 7.1 Typical calibration curve for converting Ct values into transcript copy number

For calibration three replicates were used and $r^{2}$ of the fitted line was always higher than 0.98 .

From the calibration curve $\mathrm{Ct}$ values were converted into copy number of $\mathrm{PM}-\mathrm{H}^{+}$ATPase transcript. For example, using the above calibration curve resulted in the following:

$$
N_{P M-H^{+}-\text {ATPase }}=10^{\frac{36.45-\overline{C_{t}}}{3.75}} \text { [copy] }
$$

where: $N_{P M-H^{+}-A T P a s e}$ : copy number of PM- $\mathrm{H}^{+}$-ATPase in the PCR sample (typically $250 \mathrm{pg}) ; \overline{C t}$ : average $\mathrm{Ct}$ values of 3 technical replicates.

(v) From the copy number of PCR reaction the total copy number in $1 \mu \mathrm{g}$ RNA could easily be calculated through multiplying the results with respective dilution factors; these were typically 4,000 using $250 \mathrm{pg}$ template in each reaction:

$$
N_{\text {copy } 1 \mu \mathrm{g}}=N_{P M-H^{+}-\text {ATPase }} \cdot 4,000 \text { [copy] }
$$

where: $N_{\text {copyl } 1 \mu g}$ is the PM- $\mathrm{H}^{+}$-ATPase copy number in $1 \mu \mathrm{g}$ RNA 
(vi) The copy number of transcript in $1 \mu \mathrm{g}$ RNA could then be multiplied by the total RNA content of the leaf sample used for extraction of RNA:

$$
N_{\text {totalcopy }}=N_{\text {copy } 1 \mu \mathrm{g}} \cdot m_{R N A}[\mathrm{copy}]
$$

where: $N_{\text {totalcopy }}$ : the total PM- $\mathrm{H}^{+}$-ATPase mRNA copy in the sample; $m_{R N A}$ is amount of total RNA $(\mu \mathrm{g})$ in the sample.

(vii) Finally, this total copy number of $\mathrm{PM}-\mathrm{H}^{+}$-ATPase transcripts could then be realted to the total number of cells or the total plasma membrane surface area in the leaf sample:

$$
\begin{gathered}
c_{\text {copy.cell }}=\frac{N_{\text {totalcopy }}}{N_{\text {cell }}} \text { [copy cell }{ }^{-1} \text { ] } \\
c_{\text {copy } \cdot A^{-1}}=\frac{N_{\text {totalcopy }}}{A} \cdot 10^{6} \text { [copy } \mathrm{mm}^{-2} \text { ] }
\end{gathered}
$$

where: $c_{\text {copy.cell }}$ : PM- $\mathrm{H}^{+}$-ATPase copy number in a single cell; $c_{\text {copy } \cdot A^{-1}}: \mathrm{PM}-\mathrm{H}^{+}-\mathrm{ATPase}$ copy number in $1 \mathrm{~mm}^{2}$ plasma membrane.

Example for these calculations can be found on Table 7.1 for Golf and Table 7.2 for Jersey barley cultivar. 
Table 7.1 Example for qPCR calculation of Golf cultivar. S1 - 3 label different batches

\begin{tabular}{|c|c|c|c|c|c|c|}
\hline & \multicolumn{3}{|c|}{ Elongation zone } & \multicolumn{3}{|c|}{ Emerged blade } \\
\hline & S1 & $\mathbf{S 2}$ & S3 & S1 & S2 & S3 \\
\hline Fresh weight (mg) & 56.6 & 57.7 & 50.0 & 53.5 & 50.7 & 48.7 \\
\hline Water content (mg) & 52.1 & 51.3 & 46.0 & 46.4 & 44.0 & 42.3 \\
\hline Number of epidermis cells $\left(\times 10^{4}\right)$ & 13.6 & 13.4 & 12.0 & 2.98 & 2.82 & 2.71 \\
\hline Number of mesophyll cells $\left(\times 10^{6}\right)$ & 5.08 & 5.00 & 4.49 & 2.04 & 1.94 & 1.86 \\
\hline Total number of cells $\left(\times 10^{6}\right)$ & 5.22 & 5.14 & 4.61 & 2.07 & 1.97 & 1.87 \\
\hline $\begin{array}{l}\text { Total membrane surface of } \\
\text { epidermis cells }\left(\mathrm{mm}^{2} \times 10^{3}\right)\end{array}$ & 2.69 & 2.64 & 2.37 & 1.49 & 1.41 & 1.36 \\
\hline $\begin{array}{l}\text { Total membrane surface of } \\
\text { mesophyll cells }\left(\mathrm{mm}^{2} \times 10^{3}\right)\end{array}$ & 8.30 & 8.17 & 7.33 & 5.84 & 5.53 & 5.31 \\
\hline $\begin{array}{l}\text { Total membrane surface of the } \\
\text { sample }\left(\mathrm{mm}^{2} \times 10^{3}\right)\end{array}$ & 10.9 & 10.8 & 9.70 & 7.32 & 6.94 & 6.67 \\
\hline Total RNA in the sample $(\mu \mathrm{g})$ & 123 & 106 & 105 & 61.3 & 51.9 & 40.9 \\
\hline $\begin{array}{l}\text { PM- } H^{+} \text {-ATPase copy in } 1 \mu \mathrm{g} \text { RNA } \\
\left(\times 10^{6}\right)\end{array}$ & 14.8 & 11.5 & 13.7 & 9.91 & 6.63 & 14.1 \\
\hline $\begin{array}{l}\text { PM- } \mathrm{H}^{+}-\text {ATPase copy in the } \\
\text { sample }\left(\times 10^{9}\right)\end{array}$ & 1.83 & 1.21 & 1.43 & 0.607 & 0.344 & 0.577 \\
\hline PM-H ${ }^{+}$-ATPase copy in a cell & 350 & 236 & 312 & 293 & 175 & 306 \\
\hline 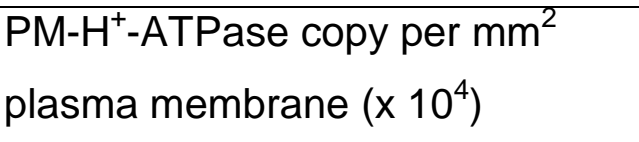 & 166 & 112 & 148 & 83.0 & 49.6 & 86.6 \\
\hline
\end{tabular}


Table 7.2 Example for qPCR calculation of Jersey cultivar. S1 - 3 label different batches

\begin{tabular}{|c|c|c|c|c|c|c|}
\hline & \multicolumn{3}{|c|}{ Elongation zone } & \multicolumn{3}{|c|}{ Emerged blade } \\
\hline & S1 & $\mathbf{S 2}$ & S3 & S1 & S2 & S3 \\
\hline Fresh weight (mg) & 69.2 & 57.6 & 58.7 & 77.1 & 74.9 & 62.2 \\
\hline Water content $(\mathrm{mg})$ & 64.9 & 54.0 & 55.1 & 68.5 & 66.5 & 55.2 \\
\hline Number of epidermis cells $\left(\times 10^{4}\right)$ & 17.0 & 14.1 & 14.4 & 4.39 & 4.27 & 3.54 \\
\hline Number of mesophyll cells $\left(\times 10^{6}\right)$ & 6.33 & 5.27 & 5.37 & 3.01 & 2.93 & 2.43 \\
\hline Total number of cells $\left(\times 10^{6}\right)$ & 6.50 & 5.41 & 5.52 & 3.06 & 2.97 & 2.47 \\
\hline $\begin{array}{l}\text { Total membrane surface of } \\
\text { epidermis cells }\left(\mathrm{mm}^{2} \times 10^{3}\right)\end{array}$ & 3.35 & 2.79 & 2.84 & 2.20 & 2.13 & 1.77 \\
\hline $\begin{array}{l}\text { Total membrane surface of } \\
\text { mesophyll cells }\left(\mathrm{mm}^{2} \times 10^{3}\right)\end{array}$ & 10.3 & 8.60 & 8.77 & 8.61 & 8.36 & 6.94 \\
\hline $\begin{array}{l}\text { Total membrane surface of the } \\
\text { sample }\left(\mathrm{mm}^{2} \times 10^{3}\right)\end{array}$ & 13.7 & 11.4 & 11.6 & 10.8 & 10.5 & 8.71 \\
\hline Total RNA in the sample $(\mu \mathrm{g})$ & 161 & 119 & 121 & 24.7 & 108 & 26.8 \\
\hline $\begin{array}{l}\text { PM- }{ }^{+} \text {-ATPase copy in } 1 \mu \mathrm{g} \text { RNA } \\
\left(\times 10^{6}\right)\end{array}$ & 5.90 & 4.76 & 4.45 & 4.52 & 4.13 & 5.56 \\
\hline $\begin{array}{l}\text { PM- } \mathrm{H}^{+} \text {-ATPase copy in the } \\
\text { sample }\left(\times 10^{9}\right)\end{array}$ & 9.49 & 5.65 & 5.34 & 1.11 & 4.47 & 1.49 \\
\hline PM-H ${ }^{+}$-ATPase copy in a cell & 146 & 104 & 97 & 36 & 150 & 60 \\
\hline $\begin{array}{l}\text { PM- } \mathrm{H}^{+} \text {-ATPase copy per } \mathrm{mm}^{2} \\
\text { plasma membrane }\left(\times 10^{4}\right)\end{array}$ & 6.94 & 4.97 & 4.60 & 1.03 & 4.26 & 1.71 \\
\hline
\end{tabular}


Table 7.3 Example for qPCR calculation of Jersey protoplasts. S1 - 3 label different batches

\begin{tabular}{|c|c|c|c|c|c|c|}
\hline & \multicolumn{3}{|c|}{ Elongation zone } & \multicolumn{3}{|c|}{ Emerged blade } \\
\hline & S1 & S2 & S3 & S1 & S2 & S3 \\
\hline Protoplast No $\left(\times 10^{6}\right)$ & 5.13 & 5.05 & 5.51 & 5.57 & 3.84 & 7.85 \\
\hline Surface $\left(\mathrm{mm}^{2} \times 10^{10}\right)$ & 8.37 & 8.24 & 9.00 & 1.59 & 1.10 & 2.24 \\
\hline Total RNA( $\square \mathrm{g})$ & 26.5 & 28.2 & 37.9 & 31.6 & 29.2 & 65.3 \\
\hline $\begin{array}{l}\text { PM- } H^{+} \text {-ATPase copy in } 1 \mu \mathrm{g} \text { RNA } \\
\left(\times 10^{6}\right)\end{array}$ & 5.34 & 3.95 & 7.02 & 3.09 & 2.06 & 5.60 \\
\hline $\begin{array}{l}\text { PM- } H^{+} \text {-ATPase copy in the } \\
\text { sample } \\
\left(\times 10^{7}\right)\end{array}$ & 14.1 & 11.1 & 26.6 & 9.75 & 6.00 & 36.6 \\
\hline PM-H $\mathrm{H}^{+}$-ATPase copy in a cell & 27.6 & 22.0 & 48.3 & 17.5 & 15.6 & 46.6 \\
\hline $\begin{array}{l}\text { PM- }{ }^{+} \text {-ATPase copy in } 1 \mathrm{~mm}^{2} \\
\text { plasma membrane }\left(\times 10^{4}\right)\end{array}$ & 1.69 & 1.35 & 2.96 & 0.613 & 0.548 & 1.63 \\
\hline
\end{tabular}




\subsection{List of chemicals}

$\left(\mathrm{NH}_{4}\right)_{2} \mathrm{HPO}_{4}$

M\&B

5(6)carboxyfluorescein

Sigma

Acetic acid

Reanal, BDH

Acridine orange

$\mathrm{BDH}$

Acylamide $\left(\mathrm{C}_{3} \mathrm{H}_{5} \mathrm{NO}\right)$

Sigma-Aldrich

Agarose

Bioline

Ammonium molibdate

$M \& B$

APS (ammonium persulfate; $\left(\mathrm{NH}_{4}\right)_{2} \mathrm{~S}_{2} \mathrm{O}_{8}$ )

Sigma-Aldrich

APTES (3-aminopropyltriethoxysilane)

Sigma-Aldrich

Ascorbic acid

Szkarabeusz

ATP (adenosine 5'-triphosphate disodium salt hydrate)

Sigma

Bis acrylamide (N,N'-methylenebis(acrylamide), $\mathrm{C}_{7} \mathrm{H}_{10} \mathrm{~N}_{2} \mathrm{O}_{2}$ ) Sigma

BIS-TRIS propane $\left(\mathrm{CH}_{2}\left[\mathrm{CH}_{2} \mathrm{NHC}\left(\mathrm{CH}_{2} \mathrm{OH}\right)_{3}\right]_{2}\right)$

Sigma

Boric acid

$\mathrm{BDH}$

$\mathrm{Brij}^{\mathrm{TM}} 58$

Sigma

Bromocresol purple

DIFCO

Bromophenol blue $\left(\mathrm{C}_{19} \mathrm{H}_{10} \mathrm{Br}_{4} \mathrm{O}_{5} \mathrm{~S}\right)$

Reanal

BSA (bovine serum albumin fraction $\mathrm{V}$ )

Sigma-Aldrich

$\mathrm{Ca}\left(\mathrm{NO}_{3}\right)_{2} \times 4 \mathrm{H}_{2} \mathrm{O}$

Reanal, BDH

$\mathrm{CaCl}_{2}$

Reanal, BDH

$\mathrm{CaSO}_{4}$

$\mathrm{BDH}$

Cellulase

Worthington

Coomassie brilliant blue R-250 $\left(\mathrm{C}_{45} \mathrm{H}_{44} \mathrm{~N}_{3} \mathrm{NaO}_{7} \mathrm{~S}_{2}\right)$

Reanal

$\mathrm{CsCl}$

Gibco BLR

$\mathrm{CuSO}_{4} \times 5 \mathrm{H}_{2} \mathrm{O}$

$\mathrm{BDH}$

Dextran T-500

Sigma-Aldrich

Driselase

Sigma

DTT (dithiothreitol, $\mathrm{C}_{4} \mathrm{H}_{10} \mathrm{O}_{2} \mathrm{~S}_{2}$ )

Sigma, Fluka

EDTA

Reanal, BDH

Entellan ${ }^{\circledR}$

Merck

Ethanol

Merck

Ethidium bromide

Sigma

Fe ${ }^{\text {IIINaEDTA }}$

$\mathrm{BDH}$

Formalin

$\mathrm{BDH}$ 
Fusicoccin

Glycerol

Glycine

$\mathrm{H}_{2} \mathrm{SO}_{4}$

$\mathrm{H}_{3} \mathrm{BO}_{3}$

$\mathrm{HCl}$

HEPES $\left(\mathrm{C}_{8} \mathrm{H}_{18} \mathrm{~N}_{2} \mathrm{O}_{4} \mathrm{~S}\right)$

Hydrogen lonophore II Cocktail A

$\mathrm{K}_{2} \mathrm{HPO}_{4}$

$\mathrm{KCl}$

$\mathrm{KH}_{2} \mathrm{PO}_{4}$

$\mathrm{KNO}_{3}$

$\mathrm{KOH}$

MES (2-[N-morpholino]ethanesulfonic acid, $\mathrm{C}_{6} \mathrm{H}_{13} \mathrm{NO}_{4} \mathrm{~S}$ )

Methanol

$\mathrm{MgSO}_{4} \times 7 \mathrm{H}_{2} \mathrm{O}$

$\mathrm{MnSO}_{4} \times \mathrm{H}_{2} \mathrm{O}$

MOPS (3-[N-morpholino]propanesulfonic acid, $\mathrm{C}_{7} \mathrm{H}_{15} \mathrm{NO}_{4} \mathrm{~S}$ )

$\mathrm{Na}_{2} \mathrm{HPO}_{4} \times 2 \mathrm{H}_{2} \mathrm{O}$

$\mathrm{Na}_{2} \mathrm{MoO}_{4} \times 2 \mathrm{H}_{2} \mathrm{O}$

$\mathrm{Na}_{3} \mathrm{VO}_{4}$

NAA (1-naphthaleneacetic acid, $\mathrm{C}_{12} \mathrm{H}_{10} \mathrm{O}_{2}$ )

Na-ascorbate

$\mathrm{NaCl}$

$\mathrm{NaH}_{2} \mathrm{PO}_{4} \times 2 \mathrm{H}_{2} \mathrm{O}$

$\mathrm{NaN}_{3}$

$\mathrm{NaOH}$

Neo-clear ${ }^{\circledR}$

$\mathrm{NH}_{4} \mathrm{H}_{2} \mathrm{PO}_{4}$

Nitrocellulose

Non soluble PVP (polyvinylpyrrolidone)

Paraffin wax

Pectolyase

PEG-3350

Phtalate buffer
Sigma

Reanal, Fluka

Reanal

Molar

$\mathrm{BDH}$

$\mathrm{BDH}$

Sigma

Fluka

Reanal, BDH

Reanal, BDH

Reanal, BDH

Reanal, BDH

Reanal, BDH

Sigma

Reanal, BDH

Reanal, BDH

$\mathrm{BDH}$

Sigma

$\mathrm{BDH}$

$\mathrm{BDH}$

Sigma

Sigma

Fluka

$\mathrm{BDH}$

$\mathrm{BDH}$

Sigma

$\mathrm{BDH}$

Merck

M\&B

Sigma

Serva

$\mathrm{BDH}$

Sigma

Sigma

Sigma 
PMSF (phenylmethylsulfonyl fluoride, $\mathrm{C}_{7} \mathrm{H}_{7} \mathrm{FO}_{2} \mathrm{~S}$ )

Sigma

Potassium antimony (III) oxid tartrate

$\mathrm{BDH}$

Potassium hydrogen phthalate $\left(\mathrm{KHC}_{8} \mathrm{H}_{4} \mathrm{O}_{4}\right)$

Sigma-Aldrich

PVC (high molecular weight polyvinyl chloride)

Fluka

PVP K30 (polyvinylpyrrolidone)

Sigma

SDS (Sodium dodecyl sulfate, $\mathrm{CH}_{3}\left(\mathrm{CH}_{2}\right){ }_{11} \mathrm{OSO}_{3} \mathrm{Na}$ )

Sigma

Sorbitol

Sigma

Sucrose $\left(\mathrm{C}_{12} \mathrm{H}_{22} \mathrm{O}_{11}\right)$

Reanal, Sigma

TAPS (N-tris[Hydroxymethyl]methyl-3-amino-propanesulfonic acis) Sigma

TEMED ( $N, N, N^{\prime}, N^{\prime}$-tetramethylethylenediamine, $\left.\mathrm{C}_{6} \mathrm{H}_{16} \mathrm{~N}_{2}\right) \quad$ Fluka

THF (tetrahydrofuran, $\mathrm{C}_{4} \mathrm{H}_{8} \mathrm{O}$ )

Sigma-Aldrich

Toluidine blue

Sigma

TRIS (tris(hydroxymethyl)aminomethane, $\mathrm{NH}_{2} \mathrm{C}\left(\mathrm{CH}_{2} \mathrm{OH}\right)_{3}$ )

Reanal, |B|

Triton ${ }^{\circledR} \mathrm{X}-100$

Reanal, Sigma

Tween ${ }^{\circledR} 20$

Sigma

$\mathrm{ZnCl}_{2}$

$\mathrm{BDH}$

$\beta$-mercapto ethanol $\left(\mathrm{HSCH}_{2} \mathrm{CH}_{2} \mathrm{OH}\right)$

Sigma

$\alpha$-Naphthaleneacetic acid (NAA)

Sigma 


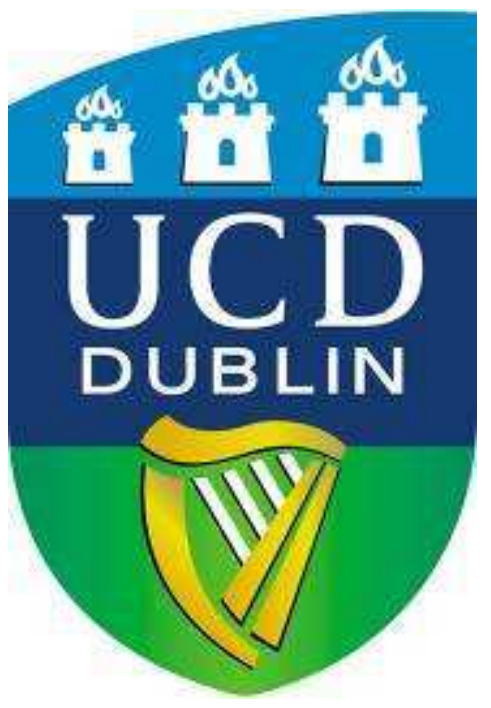

\section{Apoplast acidification in growing barley (Hordeum vulgare L.) leaves}

\section{Tamás Visnovitz ('Okleveles Biológus'; MSc)}

The thesis is submitted to University College Dublin in fulfilment of the requirements for the degree of Doctor of Philosophy

\section{School of Biology and Environmental Science}

Head of School: Prof. Thomas Bolger

Principal Supervisor: Dr Wieland Fricke

Members of the Doctoral Studies Panel: Dr Paul McCabe \& Prof. Bruce Osborne 


\section{Contents}

Contents _ $i i$

List of figures__ v $v$

List of tables___viii

Abstract _ $x$

Statement of Original Authorship ___

Collaborations __ xii

Acknowledgements __ xiii

1 General Introduction __ 1 -

1.1 Plant growth 1 -

1.1.1 Plant cell expansion __ -1 -

1.1.1.1 Cell wall

1.1.1.2 Solutes — 3 -

1.1.1.3 Water -4 -

1.1.2 $\mathrm{pH}$ conditions in the apoplast

1.1.3 'Acid growth' theory _- 5 -

1.1.3.1 'Acid growth' and effect of auxin and fusiccoccin on growth

1.1.3.2 Experimental systems using coleoptiles__ - 6 -

1.1.3.3 Acid growth of coleoptiles___ -6 -

1.1.3.4 Acid growth of dicotyledonous leaves___ -8 -

1.1.3.5 Acid growth of roots -9 -

1.1.4 Potassium uptake and 'acid growth'___ 10 -

1.2 Plasma membrane $\mathrm{H}^{+}$-ATPase ___

1.2.1 Isoforms of PM- $\mathrm{H}^{+}$-ATPase____ -12 -

1.2.2 Structure of PM- $\mathrm{H}^{+}$-ATPase -14 -

1.2.3 Catalytic cycle of P-type ATPase and $\mathrm{H}^{+}$transport mechanism ___ 15 -

1.2.4 Control of PM- $\mathrm{H}^{+}$-ATPase _ 15 -

1.2.5 Fusicoccin-dependent PM- $\mathrm{H}^{+}$-ATPase activation ___ 17 -

1.3 Barley _ 18 -

1.3.1 The two weeks old barley seedlings and their advantage ___ -18 -

1.3.1.1 Morphology of developing barley leaves___ 19 -

1.3.1.2 Anatomy of developing barley leaf -20 -

1.3.2 Growth and potassium uptake of barley _ 21 -

\subsection{Technical approaches _ 22 -}

1.5 Objectives of the present study _ 23 -

2 Materials and Methods _ 24 -

2.1 Plant material ___ 24 -

2.1.1 Plant growth for study of leaves ___ 24 -

2.1.2 Plant growth for study of coleoptiles __ 25 -

2.2 Apoplast pH measurements ___ 25 -

2.2.1 In-vitro gel system_- 26 -

2.2.2 Microelectrode measurements __ 27 -

2.3 Confocal microscopy ___ 29 -

2.3 LVDT measurements ___ 30 -

2.3.1 Leaf growth measurements ___ -30 -

2.3.2 Analysis of cell wall properties ___ -31 - 
2.4 Expression analyses ___ 32 -

2.4.1 Plant harvest - 32 -

2.4.2 RNA extraction and cDNA synthesis ___ 33 -

2.4.3 PCR -34 -

2.4.4 qPCR_- 36 -

2.4.5 Analysis of qPCR data___ 37 -

2.5 Cell size and tissue ratio measurements____ 38 -

2.5.1 Mesophyll and epidermis cell size __ - 38 -

2.5.2 Tissue ratio calculation in elongation zone and emerged blade ___ 38 -

2.5.3 Cell size and plasma membrane surface estimation for qPCR analysis ___ 38 -

2.6 Plasma membrane isolation ___ 39 -

2.6.1 Plant harvest -39 -

2.6.2 Preparation of microsomal fraction___ 39 -

2.6.3 Purification of plasma membrane vesicles___ -40 -

2.7 Determination of the total protein content of plasma membrane vesicles - 41 -

2.7.1 Bradford method__ - 41 -

2.7.2 Densitometric analysis of Laemmli gels ___ -41 -

2.8 Polyacrylamide gel electrophoresis (PAGE) __

2.8.1 Gradient polyacrylamide gel electrophoresis (PAGE)___ -42 -

2.8.1.1 Solubilisation of membrane protein __ -42 -

2.8.1.2 Gradient PAGE gel system _ 43 -

2.8.2 Linear (12\%) PAGE___ - 45 -

2.9 ATPase assay ____ 45 -

2.10 Approach for light microscopy ___ 46 -

2.10.1 Fixation of leaf tissue ___ -46 -

2.10.2 Dehydration and embedding __ -46 -

2.10.3 Staining with toluidine blue __- 47 -

2.11 Immunological methods for $\mathrm{PM}-\mathrm{H}^{+}$-ATPase detection ___ 48 -

2.11.1 Qualitative Western blot analysis___ -48 -

2.11.2 Quantitative Western blot analysis__ - 49 -

2.11.3 Immunostaining of paraffin-embedded sections ___ -50 -

2.11.4 Densitometric analysis of Western blots ___ 51 -

2.12 Protoplast experiments ___ _ 51 -

2.12.1 Protoplast isolation___ -51 -

2.12.2 Purification of protoplasts _ -52 -

2.12.3 Calculation of size and surface of the protoplast___ -52 -

2.13 Statistical analysis____ 52 -

3 Results _ 53 -

3.1 Apoplastic pH measurements ___

3.1.1 In-vitro agarose gel system ___ - 53 -

3.1.2 Microelectrode measurements _ -57 -

3.1.1 Confocal microscopy ___ - 60 -

3.2 LVDT analyses of growth responses to treatments ___ 65 -

3.2.1 Leaf elongation under different treatments_____ -65 -

3.2.2 Cell wall changes in response to treatments ___ 69 -

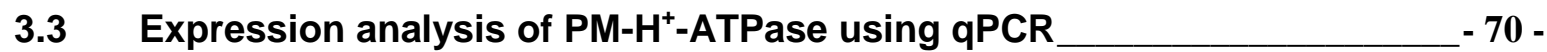

3.3.1 Quality control of the standard required for absolute qPCR

3.3.2 Calculation of cell number and membrane surface _- 72 -

3.3.3 Gene expression data based on absolute qPCR method___

3.4 PM- $\mathrm{H}^{+}$-ATPase activity and expression at protein level ___ 77 -

3.4.1 Optimization of membrane isolation and ATPase assay _____ -78 -

3.4.1.1 Plasma membrane isolation__ -78 -

3.4.1.2 Determination of total protein content in plasma membrane vesicles ___ -79 - 
3.4.1.3 ATPase assay ___ 79 -

3.4.2 Quality of plasma membrane fractions -81 -

3.4.3 Quantitative analysis of PM- $\mathrm{H}^{+}$-ATPase protein __ -82 -

3.4.4 Activity of PM- $\mathrm{H}^{+}$-ATPase _ 83 -

3.4.5 Immunolocalisation of PM- $\mathrm{H}^{+}-\mathrm{ATPase} \_-83$ -

4 Discussion _ 85 -

4.1 Growth-associated apoplast acidification ___ 85 -

4.1.1 Apoplast $\mathrm{pH}$ difference between growing and non-growing leaf tissue ___ -85 -

4.1.2 Reliability of $\mathrm{pH}$ values measured in elongation zone and emerged blade ___ -85 -

4.1.3 Relation between apoplast acidification and leaf growth __ 86 -

4.2 $\mathrm{K}^{+}$and apoplast acidification ___ 87 -

4.2.1 Potassium uptake and leaf growth ___ 87 -

4.2.2 High affinity potassium transporters and leaf growth___ -88 -

4.3 PM- $\mathrm{H}^{+}$-ATPase expression and leaf elongation _ 89 -

4.3.1 PM- $\mathrm{H}^{+}$-ATPase density in plasma membrane and leaf growth ___ -90 -

4.3.2 $\mathrm{gPCR}$ data__ -91 -

4.3.4 Immunolocalisation of PM- $\mathrm{H}^{+}$-ATPase _ 92 -

4.4 Leaf growth and changes in cell wall properties___ 92 -

4.5 'Acid growth' in barley leaves? ___ 93 -

4.6 Model of leaf growth in barley ___ 93 -

5 Conclusions and future work

5.1 Conclusions ___ 97 -

5.2 Future works ___ 98 -

6 Literature _ 99

7 Appendix _ 109 -

7.1 Processing of qPCR data___ 109 -

7.2 List of chemicals ___ 115 - 


\section{List of figures}

Figure 1.1 Model how expansins might interact with other wall components ......... - 3 -

Figure 1.2 Fusicoccin and auxin effect on maize coleoptiles............................ 7 -

Figure 1.3 Root elongation growth rate (REGR) and apoplast pH changes .......... - 9 -

Figure 1.4 Trajectory of a root element .................................................. 10

Figure 1.5 Potassium transport dependency of abraded maize coleoptiles ......... - 11 -

Figure 1.6 Structure of AHA2 without auto-inhibitory domain ........................... - 14 -

Figure 1.7 Catalytic cycle and $\mathrm{H}^{+}$transport of PM- $\mathrm{H}^{+}$-ATPase ......................... 15 -

Figure 1.8 Auto-inhibition of $\mathrm{PM}-\mathrm{H}^{+}$-ATPase .............................................. 17 -

Figure 1.9 14-3-3 protein-fusicoccin-PM-H ${ }^{+}$-ATPase complex .......................... - 18 -

Figure 1.10 Two-week old barley seedling ............................................. 20 -

Figure 1.11 Toluidine blue stained cross section of barley leaves from different

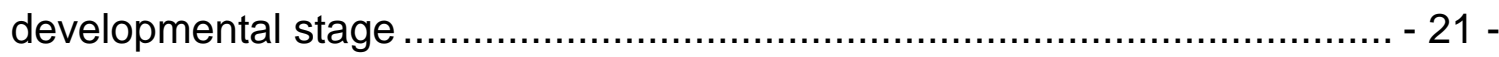

Figure 2.1 Leaf pieces in $\mathrm{pH}$ sensitive agarose gel medium ........................... - 27 -

Figure 2.2 Measurement of cell wall properties .............................................. 32 -

Figure 2.3 Thermal profile of the two step PCR reactions ............................... 35 -

Figure 2.4 Thermal profile of qPCR reactions .......................................... 36 -

Figure 2.5 Five purification steps during plasma membrane isolation................ - 41 -

Figure 2.6 Typical gel for the measurement of protein content of plasma membrane samples $42-$

Figure 2.7 Coomassie Brilliant Blue R250 stained gradient PAGE gels which were loaded with plasma membrane protein solubilised in two different ways ..... - 43 -

Figure 3.1 Leaf growth and apoplast acidification as analysed through the agarose gel system $-54-$

Figure 3.2 Time course of growth and acidification of in-vitro gel experiments .... - 55 -

Figure 3.3 Leaf growth and acidification in agarose gel under cold treatment...... - 55 Figure 3.4 Average rate of leaf elongation $(A)$ and medium acidification $(B)$ in leaves exposed to fusicoccin, vanadate and caesium treatments as tested through the

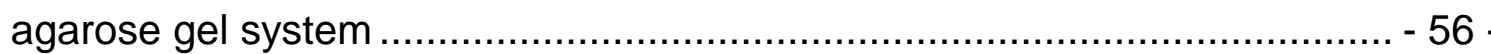

Figure 3.5 Effect of auxin on leaf growth and medium acidification using the in-vitro gel system $-57-$

Figure 3.6 Growth effect of auxin when applied in liquid medium. $-57-$

Figure 3.7 Microelectrode analyses of apoplast $\mathrm{pH}$ in the elongation zone and emerged blade-portion of leaf three of barley. 
Figure 3.8 Growth rate of leaf three in response to $\mathrm{K}^{+}$-treatments during micro $\mathrm{pH}$ measurements.

Figure 3.9 Microelectrode $\mathrm{pH}$ analyses in the leaf elongation zone of barley in response to sodium orthovanadate and fusicoccin treatments.

Figure 3.10 Growth rate of leaf three of barley in response to vanadate and fusicoccin treatments as analysed through different approaches. $-60-$

Figure 3.11 Confocal microscopic analysis of apoplastic $\mathrm{pH}$ using acridine orange fluoresce $\mathrm{pH}$ sensitive fluorescence dye. $62-$

Figure 3.12 Confocal microscopic analysis of apoplastic $\mathrm{pH}$ using 5(6)carboxyfluorescein fluoresce $\mathrm{pH}$ sensitive fluorescence dye $63-$

Figure 3.13 Carboxyfluorescein and acridine orange accumulation pattern in elongation zone and emerged blade $64-$

Figure 3.14 Effect of $\mathrm{pH}$ sensitive dyes on leaf growth rate $-64-$

Figure $3.15 \mathrm{pH}$ sensitivity of fluorochromes $65-$

Figure 3.16 Testing the responsiveness of the LVDT setup to treatments which were expected to increase $\left(37^{\circ} \mathrm{C}\right)$ or stop growth $(1 \mathrm{M} \mathrm{NaCl})$. $-66-$

Figure 3.17 The effect of test reagents in the apoplastic bathing medium on leaf growth as measured with the LVDT setup.... $67-$

Figure 3.18 Potassium dependency of the leaf growth response to fusicoccin $(5 \mu \mathrm{M})$ and vanadate $(500 \mu \mathrm{M})$ $68-$

Figure 3.19 Auxin effect on leaf elongation growth $68-$

Figure 3.20 Cell wall changes under different treatments $-69-$

Figure 3.21 Growth rate before and in response to an additional applied force ... - 70 Figure 3.22 reference genes for qPCR experiments - 71 -

Figure 3.23 Digital PCR pattern of external standard DNA $-72-$

Figure 3.24 Representative cross sections used for determination of the contribution of different tissues and air space to total leaf volume. $-73-$

Figure 3.25 Expression of PM- $\mathrm{H}^{+}$-ATPase using absolute qPCR. $-75-$

Figure 3.26 PM- $\mathrm{H}^{+}$-ATPase expression using absolute qPCR and relating expression data to total plasma membrane surface area $-76-$

Figure 3.27 Comparison of molecular biological data using leaf tissues or mesophyll protoplasts. -77 -

Figure 3.28 Impact on the quality of PAGE separation of washing steps during plasma membrane isolation $78-$ 
Figure 3.29 Protein measurement in plasma membrane vesicles using two different methods $-79-$

Figure 3.30 Typical ATPase assay ............................................................ 80 -

Figure 3.31 Kinetics of $P_{i}$ detection assay ................................................... - 80 -

Figure 3.32 Coomassie stained SDS polyacrylamide gel and Western blot of plasma membrane proteins from different leaf regions. $81-$

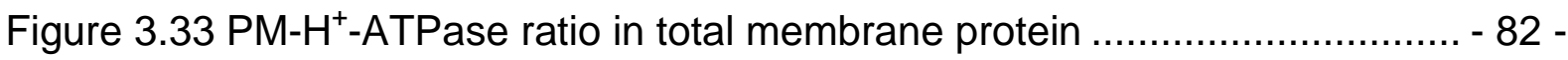

Figure 3.34 ATPase activity of inside-out plasma membrane vesicles................ - 83 -

Figure 3.35 PM- $\mathrm{H}^{+}$-ATPase immunolocalisation on leaf cross and longitudinal sections. $84-$

Figure 4.1 Supposed effect of the treatments on barley leaf cells ....................... - 95 -

Figure 4.2 Model of leaf elongation in barley leaves ...................................... - 96 -

Figure 7.1 Typical calibration curve for converting Ct values into transcript copy number $-110-$ 


\section{List of tables}

Table 1.1 Localisation of specific PM- $\mathrm{H}^{+}$-ATPase isoforms in plant body - 13 -

Table 2.1 Composition of the $1 / 2$ strength Hoagland solution for barley seedlings - 25 -

Table 2.2 Composition of the $\mathrm{pH}$ sensor for microelectrodes

$-28-$

Table 2.3 Composition of the buffer solutions used for calibrating $\mathrm{pH}$ microelectrodes

$-29-$

Table 2.4 DNase treatment and reverse transcription - 34 -

Table 2.5 Components of PCR reactions - 35 -

Table 2.6 PCR primers

Table 2.7 Composition of the stock solution ( $5 x$ concentrated) of TRIS base boric acid EDTA buffer (TBA)

Table 2.8 Components of qPCR reaction

Table 2.9 Composition of the homogenisation buffer used for membrane isolation

Table 2.10 Composition of the phase buffer used for membrane isolation

Table 2.11 Composition of the resuspension buffer used for membrane isolation

Table 2.12 Composition of Bradford reagent

Table 2.13 Composition of Laemmli buffer used for PAGE

Table 2.14 Components of the gradient PAGE system

Table 2.15 Components of the solutions for Coomassie Brilliant Blue gel staining

Table 2.16 ATPase reaction buffer and colour development reagent

Table 2.17 Fixation and embedding of leaf samples for immunohistochemistry

Table 2.18 Staining embedded leaf sections with toluidine blue

Table 2.19 Composition of blotting buffer used for Western analyses

Table 2.20 Composition of TRIS buffer saline buffer (TBS)

Table 2.21 Composition of Tween ${ }^{\circledR} 20$ TRIS buffer saline buffer (TTBS)

Table 2.22 Protocol for immunostaining of embedded leaf sections

Table 2.23 Composition of phosphate buffer saline (PBS; $\mathrm{pH} 7.4$ )

Table 2.24 Composition of protoplast isolation buffer

Table 2.25 Enzyme concentrations in protoplast isolation buffer

Table 3.1 Water content of two different regions of leaf three in two cultivars of barley

Table 3.2 The contribution of different tissues to total leaf volume in the elongation zone (EZ) and emerged blade (EB) of leaf three of barley. - 73 -

Table 3.3 Cell size calculation based on the present and literature data. $\quad 74$ - 
Table 3.4 Ct values of PM- $\mathrm{H}^{+}$-ATPase expression together with RNA content per cell in the elongation zone (EZ) and emerged blade (EB) of leaf three of barley.

Table 3.5 RNA content and PM- $\mathrm{H}^{+}$-ATPase expression in the elongation zone (EZ) and emerged blade (EB) of leaf three of barley (Golf, Jersey).

Table 4.1 Summary of data for PM- $\mathrm{H}^{+}$-ATPase when related to surface area of plasma membrane.

Table 7.1 Example for qPCR calculation of Golf cultivar.

Table 7.2 Example for qPCR calculation of Jersey cultivar.

Table 7.3 Example for qPCR calculation of Jersey protoplasts. 


\section{Abstract}

Apoplast acidification associated with growth is well-documented in roots, coleoptiles and internodes but not in leaves. In the present project on barley (Hordeum vulgare L.) advantage was taken of the high cuticle permeability in the elongation zone of leaves to measure apoplast $\mathrm{pH}$ and growth in response to application of test reagents. The role of the plasma membrane $\mathrm{H}^{+}$-ATPase (PM- $\mathrm{H}^{+}$-ATPase) and $\mathrm{K}^{+}$in this process was of particular interest. An in vitro gel system with bromocresol purple as $\mathrm{pH}$ indicator, $\mathrm{pH}$ microelectrodes and $\mathrm{pH}$-sensitive fluorescence dye combined with confocal microscopy were used to monitor apoplast $\mathrm{pH}$. Growth was measured in parallel or in separate experiments using a linear variable differential transformer (LVDT). Test reagents which blocked (vanadate) or stimulated (fusicoccin) PM- $\mathrm{H}^{+}-\mathrm{ATPase}$, or which reduced $\left(\mathrm{NH}_{4}{ }^{+}\right.$, $\mathrm{Cs}^{+}$, tetraethylammonium) $\mathrm{K}^{+}$uptake were applied. Plasma membranes were isolated from growing and mature leaf tissue and used to determine the activity (ATPase assay) and abundance (Western blotting) of $\mathrm{PM}-\mathrm{H}^{+}$-ATPase protein. Protein localisation was studied by immunohistochemistry and expression of mRNA quantified using real time PCR (qPCR). Apoplast $\mathrm{pH}$ was by up to $1.0 \mathrm{pH}$ unit lower in growing compared to nongrowing leaf tissue. Depending on the $\mathrm{K}^{+}$concentration in the bathing medium used during electrophysiological analyses, apoplast $\mathrm{pH}$ in the elongation zone ranged from $\mathrm{pH} 4.8\left(0.1 \mathrm{mM} \mathrm{K}^{+}\right)$to $\mathrm{pH} 5.8\left(10 \mathrm{mM} \mathrm{K}^{+}\right)$. In the emerged blade, apoplast $\mathrm{pH}$ remained at about $\mathrm{pH} 5.8$ irrespective of the $\mathrm{K}^{+}$concentration in the bathing medium Growth was more responsive to test reagents than to changes in apoplast $\mathrm{pH}$. Expression of $\mathrm{PM}-\mathrm{H}^{+}$ATPase was comparable between growing and non-growing leaf regions when expression was related to per unit extracted RNA or cell number. However, when expression was related to per unit surface area of plasma membrane, expression of $\mathrm{PM}^{-\mathrm{H}^{+}}$-ATPase was about twice as high in growing compared to non-growing leaf tissue. The same applied to the protein level and activity of $\mathrm{PM}-\mathrm{H}^{+}-\mathrm{ATPase}$. Immunohistochemical analyses showed that $\mathrm{PM}-\mathrm{H}^{+}-\mathrm{ATPase}$ was present in all living leaf tissues, particular in those (guard cells, phloem, and xylem parenchyma) associated with high rates of trans-membrane solute transport. It is concluded that leaf cell expansion in barley depends on the activity of the PM- $\mathrm{H}^{+}-\mathrm{ATPase}$ and $\mathrm{K}^{+}$transport processes. The higher surface density of $\mathrm{PM}-\mathrm{H}^{+}$-ATPase activity in growing barley leaf tissue aids apoplast acidification and growth. $\mathrm{A} \mathrm{H}^{+} / \mathrm{K}^{+}$co-transport system may play a key role in linking growth with apoplast $\mathrm{pH}, \mathrm{H}^{+}$pump activity and $\mathrm{K}^{+}$-uptake. 


\section{Statement of Original Authorship}

I hereby certify that the submitted work is my own work, was completed while registered as candidate for the degree of Doctor of Philosophy, and I have not obtained a degree elsewhere on the basis of the research presented in this submitted work. 


\section{Collaborations}

(i) $\mathrm{pH}$ measurements using $\mathrm{pH}$ microelectrodes were carried out under the supervision of $\mathrm{Dr}$ Anthony J. Miller at the Department of Plant Pathology and Microbiology of Rothamsted Research (Harpenden, Hertfordshire AL5 2JQ, UK). Towards the end of this project, Dr Miller moved to the John Innes Centre (Norwich Research Park, Colney, Norwich, NR4 7UH, UK), which is similar to Rothamsted Research a BBSRC (Biotechnology and Biological Sciences Research Council) funded institute.

(ii) Plasma membrane isolation, SDS PAGE, ATPase hydrolysis assays and part of the Western blot analysis was carried out in the laboratory of Dr Éva Sárvári and Dr Ilona Rácz with the help of Ádám Solti at the Department of Plant Physiology and Molecular Plant Biology, Institute of Biology, Faculty of Science, Eötvös Loránd University (Pázmány Péter sétány 1/C, Budapest, Hungary, H1117). 


\section{Acknowledgements}

- $\quad$ First of all I want to thank my supervisor Dr Wieland Fricke for his expert guidance and advice in all aspect during the three years. He not just guided my steps in science, he gave the opportunity to plan my research workflow, experiments and test my own ideas.

- I would like to thank the help to everybody who worked with me in our research group Matthieu Besse, Thorsten Knipfer, Mostefa Touati, Ehsan Bijanzadeh and Shimi Suku who helped me a lot and we could spend great time in the lab together.

- Many thanks for the technical assistance and help to Brendan, Eugen, Francis, Gwyneth, Eileen (UCD), Sue (Rothamsted), Györgyi and Zsuzsa (ELTE). Damian Egan and Eric Callaghan helped me especially a lot, and special thanks to Eric for his critical reading of the thesis.

- I would like to thank Prof. Jeremy C. Simpson for access to the confocal microscopy unit and Dr Gavin Stewart and Caragh Walpole for their help with Western blotting at UCD.

- I never will forget the days in Rothamsted, thanks a million for Dr Tony Miller for his help in all aspect and I hope I will have the chance to work together in the future.

- $\quad$ At Eötvös University I had extremely big help from Dr Éva Sárvári, Dr Ilona Rácz, Dr Szabolcs Rudnóy and from Prof. Zoltán Szigeti. Without the guides of Ádám Solti the protein part of the work would not have been successful. Dr György Csikós helped a lot in immune histochemistry.

- Enormous thanks for my wife Kriszti. Without her help I would not able to finish this research and thesis. She was always with me when I was despondent and felt that I never will finish.

- $\quad$ Thank to all of my friends at UCD, Rothamsted and ELTE whose are not mentioned by name.

- Particular thanks to IRCSET (Irish Research Council for Science, Engineering and Technology) which made this $\mathrm{PhD}$ project possible through awarding me an EMBARK post-graduate fellowship.

- $\quad$...és végül de nem utolsó sorban köszönöm a támogatást szüleimnek akik támogattak mindenben és elviselték, hogy Írországban éltem és doktoráltam. 


\section{General Introduction}

\subsection{Plant growth}

Plant growth can be defined as an irreversible increase in the size of cells, tissues, organs or whole plants (Csiszár et al., 2004). Cell expansion is generally considered to be caused by wall loosening and driven by turgor pressure (Christian et al., 2006). The term 'cell growth' mainly refers to the increase in size of proliferating cells in the cell cycle (meristematic cells), with increase in the total nucleic acid and protein content without vacuolization of the protoplast. In contrast, the term 'cell expansion' refers to the manifold increase in size of newly produced cells that is associated with the formation of a large central vacuole and finally leads to cell differentiation (PerrotRechenmann, 2010). While plants need to produce new cells to grow, it is cell expansion which leads to the physical increase in plant size and biomass.

\subsubsection{Plant cell expansion}

The enlargement of cells reflects increase in water content of cells. Irreversibility of this process is guaranteed by the plastic properties of the cell wall. From the biophysical view, plant cells need a wall which gives in to turgor pressure (mechanical driving force) and solutes which drive water uptake through osmosis. Therefore, cell expansion may be limited by the mechanical (yielding and extensibility) properties of the cell wall and the rate at which water and solutes are taken up or produced (solutes) by cells internally (Fricke \& Flowers, 1998; Fricke \& Peters, 2002).

\subsubsection{Cell wall}

It is a popular theory that expansion of leaf and root cells is controlled by cell wall properties. Based on the work of Green et al. (1971) on giant algae cells (Nitella sp.) and Lockhart's (1965) theoretical considerations, a growth model was developed which relates the growth rate $(G R)$ to extensibility properties $(m)$, yield threshold of cell wall where no cell expansion occurs $(Y)$ and cell turgor $(P)$ :

$$
\mathrm{GR}=\mathrm{m} \cdot(\mathrm{P}-\mathrm{Y})
$$

The impact of the mechanical properties of the cell wall for plant growth was found in many studies both in roots and shoots (Cosgrove, 1993; Pritchard, 1994; Cosgrove, 
1998; Hsiao \& Xu, 2000). The implication of these studies is that the rate of cell expansion, and therefore plant growth, may be regulated by altering the mechanical properties of the wall, making it 'softer' (more growth) or 'harder' (less growth). One way to alter wall properties is through changes in wall (apoplast) $\mathrm{pH}$.

Acidification can affect growth through cell wall loosening (Rayle \& Cleland, 1970) and different theories have been proposed to explain this phenomenon. One hypothesis suggested that $\mathrm{H}^{+}$directly affects non-covalent bonds between $\beta$-glucan within the cell wall, causing wall loosening (Hohl et al., 1991). Another hypothesis suggested that due to $\mathrm{H}^{+}$excretion $\mathrm{Ca}^{2+}$ ions are displaced in the cell wall and that this leads to a more flexible cell wall (Arif \& Newman, 1993). A breakthrough in our understanding of $\mathrm{pH}$-related wall loosening came in 1992 when two proteins were extracted from cucumber hypocotyls which were capable of inducing extension in isolated, heat-inactivated cell walls of several plant species. These 'wall loosening' proteins were termed 'expansins'. The pH optimum of these proteins was pH3.5 - 4.5 (McQueen-Mason et al., 1992) and this may explain at least in part why apoplast acidification increases the growth rate of plant organs.

Expansins are specifically expressed in growing tissues of monocotyledons and dicotyledonous plants. They are highly conserved in size and amino acid sequence (Cosgrove, 1996). However, studies on fescue suggest that another group of wall proteins, xyloglucan endotransglycosylases, may be more involved in regulation of cell expansion than expansins (Reidy et al., 2001).

Expansins do not induce wall extension through simple polymer hydrolysis. They mainly disrupt hydrogen bonding not just in-vivo, in a paper sheet as well and reengineering the cell wall structure facilitating plant growth (McQueen-Mason, 1995). Promoting cell wall relaxation is necessary for expansion of plant cells (Cosgrove, 1993). An overview of expansin action is given in Fig. 1.1. 


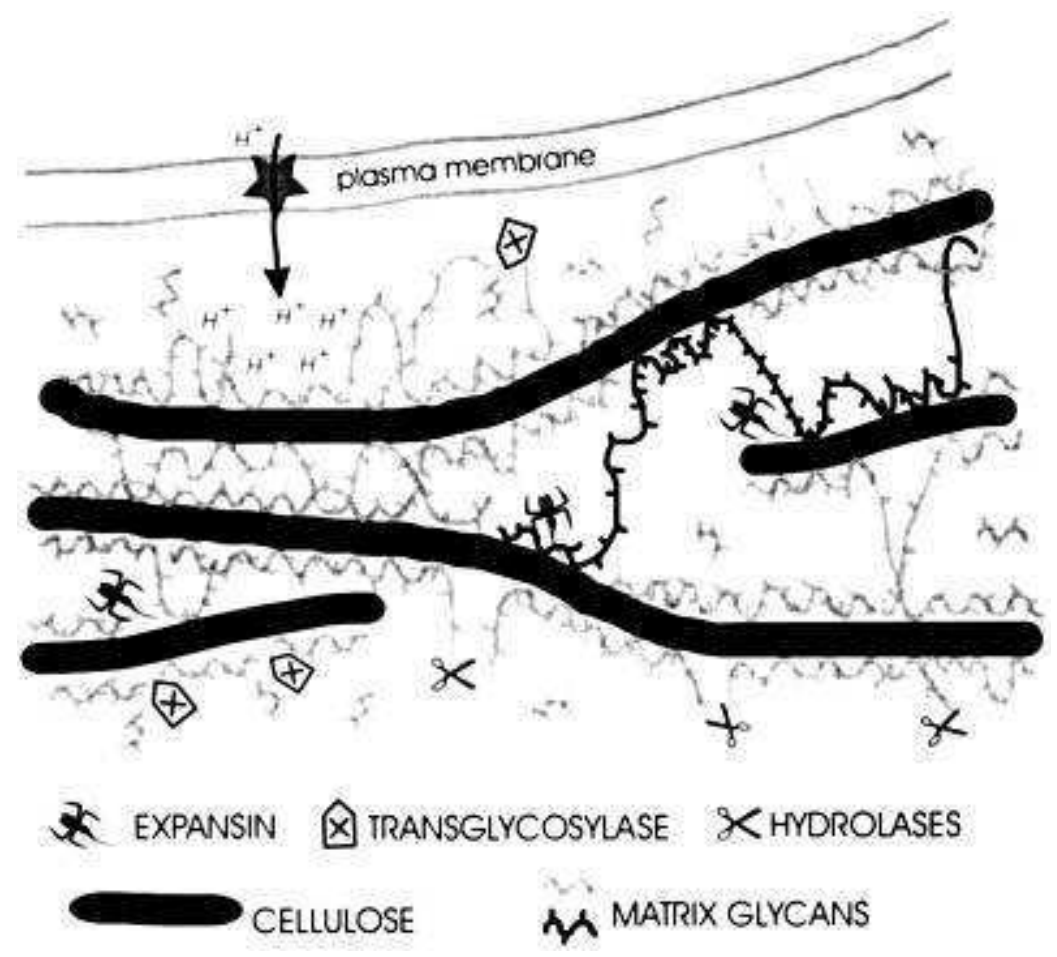

Figure 1.1 Model how expansins might interact with other wall components

Expansins might cause a transient release of short segments of matrix hemicelluloses glycans attached to cellulose microfibrils. Wall hydrolyses cut matrix glucans into shorter segments leading to weakening but not to creep of the cell wall. Transglycosylases are recombining glycans into shorter or longer pieces. $\mathrm{PM}-\mathrm{H}^{+}$ATPases may lower the wall $\mathrm{pH}$ and control enzymes by their $\mathrm{pH}$ optima. Reprint from Cosgrove (1998) based on open access policy of www.plantphysiology.org with copyright American Society of Plant Biologists.

\subsubsection{Solutes}

Based on the original growth model described above (Lockhart, 1965; Green et al., 1971), turgor pressure and solute uptake should have significant impact on cell expansion and growth. The availability of solutes seems to co-limit growth especially under water (Frensch, 1997; Hsiao et al., 1998) and salt stress (Fricke \& Peters, 2002).

Osmolality and turgor pressure change little along the elongation zone of cereal leaves (Fricke et al., 1997; Fricke \& Flowers, 1998; Martre et al., 1999; Fricke, 2002a) and roots (Pritchard, 1994). The implication of a constant turgor pressure in expanding cells might be that cells instantly deposit solutes to maintain osmolality as the osmotic force driving water uptake while they expand and cell contents become diluted (Fricke, 2002a). 


\subsubsection{Water}

In barley, it has been suggested that the rate of tissue-water transport might limit cell expansion in leaves (Fricke, 2002b). Similar conclusions have been made for soybean hypocotyls and maize leaves by the work of Boyer and colleagues who coined the term 'growth-induced water potentials' (Boyer, 2001; Tang \& Boyer 2008). The mere existance of significant gradients in water potential between growing tissue and water source suggests that the conductance of the pathway between the two is limiting water transport. In a multi-layered tissue e.g. in roots, the radial hydraulic conductance can be one to three orders of magnitude larger under transpirating than under non-transpirating conditions (Steudle, 2000). Recent studies showed that in barley roots water uptake occurred along a pathway which involved crossing of membranes. It was not clear whether osmotic forces were sufficient to support water uptake (Knipfer \& Fricke, 2011). Aquaporins have an essential role in the water transport at cellular level (Hachez et al. 2008). Aquaporins also may play essential role in elongation growth of barley leaves (Besse at al., 2011).

\subsection{2 $\mathrm{pH}$ conditions in the apoplast}

The present analyses did not, or did little distinguish between cell wall space and apoplast. The latter also comprises intercellular spaces and middle lamellae. Therefore, and for simplicity, it is referred to 'apoplast' throughout the present work. The apoplast of higher plants occupies typically $5 \%$ or less of the total tissue volume. This applies in particular to living tissues. The apoplast determines ionic conditions around the cells; it affects transport solutes into and out of cells, provides a diffusion barrier in speciliased cases (e.g. Casparian bands) and defines mechanical and osmotic conditions - conditions which may be or may not be compatible with cell expansion. The latter applies in particular to the $\mathrm{pH}$ of the apoplast. Using different methods $\mathrm{pH}$ indicators in agar, microelectrodes and fluorescence probes) a huge variety in apoplast $\mathrm{pH}$ has been reported for roots of different plant species. Values ranged from $\mathrm{pH} 4.0$ to $\mathrm{pH} 7.0$ with most values being in the region pH 5.0 to pH 6.5 (Grignon \& Sentenac, 1991). Dicotyledonous plants have generally a higher (less acidic) $\mathrm{pH}$ than monocotyledonous plants have, and apoplast pH is lower in gymno- compared to angiosperms (Grignon \& Sentenac, 1991).

In fully developed barley leaves an apoplast $\mathrm{pH}$ of $\mathrm{pH} 5.0$ was measured using microelectrodes (Felle, 2006). The $\mathrm{pH}$ varied in dependence of oxygen availability 
(anoxia) (Felle, 2005; Felle et al., 2005; Felle, 2006). Similar pH values have been reported for maize leaves using microelectrodes and fluorescence probes (Pitann et al., 2009a; Ehlert et al., 2011).

\subsection{3 'Acid growth' theory}

'Acid growth' originally was discovered by Bonner in 1934 when he described that the growth rate of Avena coleoptiles in $\mathrm{pH} 4.1$ buffer was significantly higher than in $\mathrm{pH}$ 7.2 buffer (Kutschera, 1994). Later this effect was re-discovered and characterised in more detail by Rayle \& Cleland (1970) and Hager et al., (1971). Although in the literature 'acid growth' is mainly mentioned in relation to growth effects caused by the phytohormone auxin and the fungal toxin fusicoccin, which permanently activates $\mathrm{PM}-\mathrm{H}^{+}$-ATPase, linked plant growth, acid growth is a more general phenomenon and can be induced by other factors (Vesper \& Evans, 1979). In 'acid growth', acid related cell 'wall-loosening' may constitute the initial event (Rayle \& Cleland, 1970; Cosgrove, 1993). During the past decades, the 'acid growth' theory, or parts of the underlying mechanistic model, has been questioned repeatedly (Kutschera \& Schopfer, 1985a; Kutschera, 1994; Grebe, 2005), However, with some limitation it is 'alive and well' (Lüthen et al., 1990; Hager et al., 1991; Rayle \& Cleland, 1992; Kutschera, 2006). An alternative theory for 'acid growth' is the 'facilitated solute uptake' theory. This theory states that it is not the secreted $\mathrm{H}^{+}$which are causing directly the increased growth rate through alteration of wall properties, but that a proton-coupled transport mechanism across the plasma membrane is stimulated (Brummer et al., 1984).

\subsubsection{1 'Acid growth' and effect of auxin and fusiccoccin on growth}

Almost at the same time, Darwin and Sachs proposed the theory that growth and development of plants is controlled by hormones (Darwin, 1880; Kutschera 1994). Using Avena sativa coleoptiles, Darwin, in 1880, showed that coleoptiles were bending towards the light source and once the tip of the coleoptiles was covered or cut, the coleoptiles were unable to produce this bending effect. In 1909, Fitting showed that coleoptile bending was a result of the non-homogeneous distribution of some factor, possibly a hormone (Katsumi, 2007). With gelatine cubes and glass pieces Boysen-Jensen (1913) proofed that this factor was transported from the tip to basal end of the coleoptile (Csiszár et al., 2004). Paál (1918) could induce coleoptile bending without light, changing the orientation of coleotile tips (Paál, 1918; Csiszár et 
al., 2004). Finally, in 1937, Went discovered the hormone (auxin) and showed that if the hormone was in gelatine cubes the tip was not necessary for coleoptile bending (Kutschera 1994). Heyn in 1940 proposed that auxin (in its physiological form indol acetic acid - IAA) promotes growth by enhancing cell wall extensibility. In 1934 and 1970 the 'acid growth' theory was born to explain auxin related plant growth (Kutschera, 1994). Fusicoccin, a phytotoxin of the fungus Fusicoccum amygdale, was discovered as 'super-auxin' a few years latter (Marré, 1979) and is still used today in many plant growth studies.

\subsubsection{Experimental systems using coleoptiles}

Coleoptiles of monocotyledon plants have widely been used as a model system to study plant growth. Coleptiles can be obtained on plants which need to grow for only a few days, are well characterised in terms of their phototropic or gravitropic response, show defined regions of growth and auxin production, are simple in anatomy and are easy to handle and cut. The main disadvantage, however, of coleoptiles is that their cuticle provides a permeance barrier to applied test reagents and diffusion barrier for protons and that this causes difficulties for applying treatments and measuring apoplastic $\mathrm{pH}$ (changes). In different laboratories this problem has been solved in different ways by peeling off part of the outer epidermis (Rayle, 1973), abrasion of coleoptiles with wet emery cloth prior to cutting (Kutschera \& Schopfer, 1985a), abrasion with distilled water and SiC powder (Lüthen et al., 1990) or using dry polishing cloth for abrasion of coleoptiles before excision of segments (Schopfer, 1989). None of these methods were free from artefacts; however the results have been informative.

In most experiments, the incubation medium in which $\mathrm{pH}$ measurements were conducted was slightly buffered to prevent $\mathrm{pH}$ changes as a result of changes in $\mathrm{CO}_{2}$ content of the atmosphere e.g. Rayle (1973); Stahlberg \& Van Volkenburgh (1999) and Felle (2006). At the same time, the buffer capacity of the medium may affect $\mathrm{pH}$ measurements. Probably the best system for $\mathrm{pH}$ measurement was the method of ionostat (Döring et al., 1996), because the incubation medium was not buffered and changes in $\mathrm{H}^{+}$efflux were measured rather than $\mathrm{pH}$.

\subsubsection{Acid growth of coleoptiles}

Using maize coleoptiles, which were SiC-abraded in water and analysed using a computer controlled pH stat, both auxin and fusicoccin treatments affected growth in 
a way which supported the 'acid growth' theory (Fig. 1.2). Neutral and alkaline solutions partly inhibited auxin- and fusicoccin-induced growth, whereas fusicoccininduced growth under constant $\mathrm{pH}$ conditions. Fusicoccin and auxin did not show any additive effect (Lüthen et al., 1990). Cell wall $\mathrm{pH}$ and growth rate were in close temporal correlation indicating co-regulation of apoplast solute composition (Peters et al., 1998).
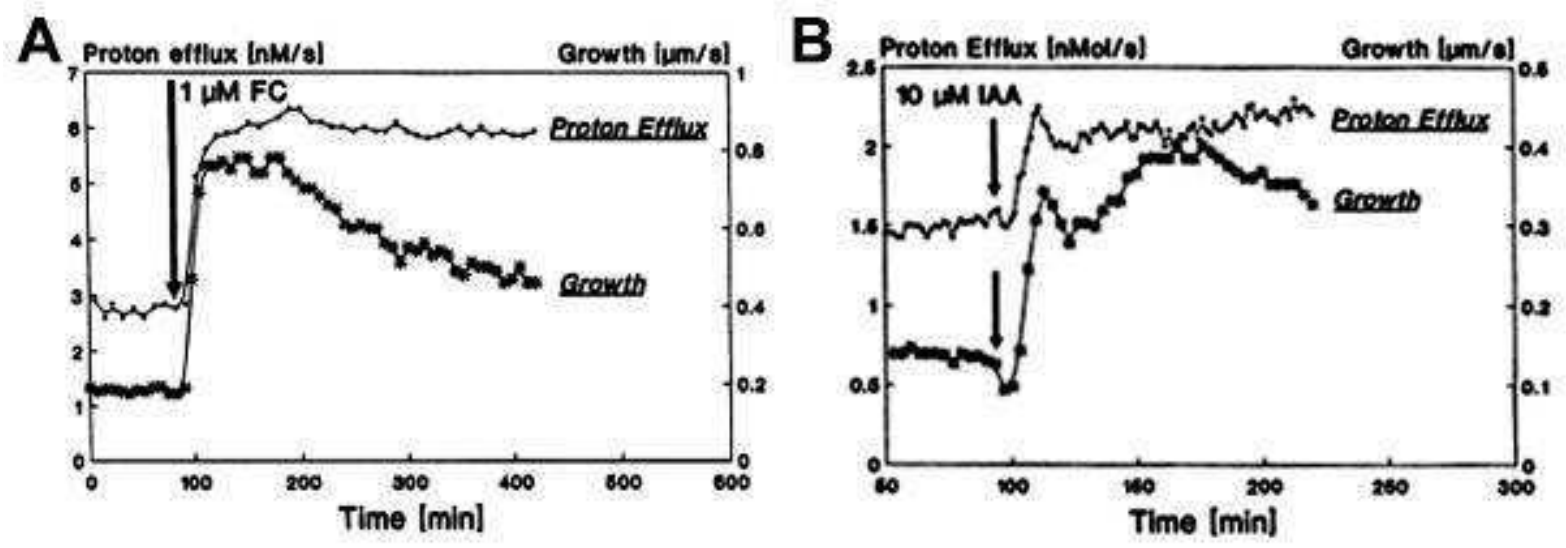

Figure 1.2 Fusicoccin and auxin effect on maize coleoptiles

Typical trace of fusicoccin $(A)$ and auxin (IAA) effect $(B)$. Dots represent the proton secretion while asterisks the coleoptiles growth rate. Experiments were carried out using $\mathrm{SiC}$ abraded maize coleoptile segments and a $\mathrm{pH}$ stat to maintain $\mathrm{pH}$. Reprint from Lüthen et al. (1990) based on open access policy of www.plantphysiology.org with copyright American Society of Plant Biologists.

Other studies suggested that fusicoccin, but not auxin, caused 'acid growth'. Using the wet emery cloth abrading technique and buffered incubation medium, fusicoccin-induced growth was totally inhibited by alkaline solutions (Kutschera \& Schopfer, 1985b) while auxin-induced growth was not affected (Kutschera \& Schopfer, 1985a). The difference between these and the above-mentioned results might have been caused by the experimental set ups. The abrading technique was different and the solution was buffered in case of Kutschera \& Schopfer (1985ab), while Lüthen at al. (1990) could use unbuffered solutions. Difference in cation composition might have impacted too, with $10 \mathrm{mM} \mathrm{KCl}$ and $1 \mathrm{mM} \mathrm{Ca}^{2+}$ used by Lüthen et al. 1990), while Kutschera \& Schopfer (1985ab) used $\mathrm{Ca}^{2+}$ in the incubation medium and $\mathrm{K}^{+}$at minimal concentrations (discussed in Lüthen et al., 1990).

It is possible that extension growth of multi-tissue organs such as roots, coleoptiles and leaves is limited mechanically by the extension of one component tissue. This idea, which dates back to the $19^{\text {th }}$ century (Kutschera, 1994), is proposed in particular for the epidermis of round, compact organs (containing little intercellular 
air space) such as hypocotyls and coleoptiles. Therfore the wall of the epidermis may be important for growth, and it is possible that 'acid growth' may occur in all tissues of an organ or only in the epidermis or in all tissue but the epidermis. This could explain discrepancies in results obtained between researchers and for different organs and species. Peeling off just part of the epidermis of coleoptiles might cause immediately changes in growth conditions but also experimental artefacts (Kutschera, 1994). It was assumed that fusicoccin may interact with proton pumps of inner coleoptile tissues whereas auxin affects $\mathrm{H}^{+}$secretion of epidermal cells. Peeling off the epidermis caused $80 \%$ less proton excretion of coleoptiles compared when coleoptiles were abraded with wet emery cloth (Kutschera et al., 1987). These results are supported by immunolocalisation results. Fusicoccin sensitive plasma membrane $\mathrm{H}^{+}$-ATPase (PM- $\mathrm{H}^{+}$-ATPase) proton pumps were found mainly in mesophyll cells rather than in the epidermis (Villalba et al., 1991); other authors, using electrophysiology, showed that auxin-induced $\mathrm{H}^{+}$pump activity did not depend on the presence of epidermal cells in maize coleoptiles (Peters et al., 1992).

\subsubsection{Acid growth of dicotyledonous leaves}

The 'acid growth' theory has been tested much less in detail on dicotyledonous compared to monocotyledonous plants (coleoptiles) and the results in the literature are in part confusing. The validity of the acid growth theory appears to depend on the species tested. Light-induced leaf expansion of bean (Phaseolus vulgaris) and silver birch (Betula pendula) clearly showed an 'acid growth' type response. Apoplast $\mathrm{pH}$ decreased within 5-15 min of illumination, parallel to an increase in growth. Exogenous acidic buffer induced loosening of the cell wall and stimulated leaf growth whereas buffer at neutral $\mathrm{pH}$ inhibited growth. Fusicoccin stimulated both leaf growth and apoplast acidification (Van Volkenburgh \& Cleland, 1980; Taylor \& Davies, 1985; Cosgrove, 1996). In contrast, leaf expansion of sycamore (Acer pseudoplatanus) and tobacco (Nicotiana tabacum) could not be explained through 'acid growth'. Apoplast acidification was not related to auxin-induced growth, yet fusicoccin-related 'acid growth' was present in tobacco leaves and independently of any auxin effect (Taylor \& Davies, 1985; Keller \& Van Volkenburgh, 1998). Growth related acidification in dicotyledonous leaves seems controlled by light and follows a partially independent pathway from photosynthesis as experiments with pea (Pisum sativum) leaves showed (Stahlberg \& Van Volkenburgh, 1999). In tobacco leaves, some mechanistic link between light-stimulated leaf growth, $\mathrm{H}^{+}$excretion and $\mathrm{K}^{+}$uptake (Stiles et al., 
2003; Stiles \& Van Volkenburgh, 2004) was observed. The role of $\mathrm{K}^{+}$could be to provide electrical counterbalance of $\mathrm{H}^{+}$rather than to provide an osmolyte for uptake (Stiles \& Van Volkenburgh, 2004).

\subsubsection{Acid growth of roots}

Early results suggested auxin linked 'acid growth' in roots (Moloney et al., 1981). However, more recent data showed that auxin increased growth of shoot and coleoptiles yet equally rapidly inhibited root growth (Christian et al., 2006). Positive 'acid ( $\mathrm{pH} 4.0$ ) growth' has been not recorded in root elongation and at $\mathrm{pH} 3.5$ organ elongation is reduced (Kutschera, 2006). In contrast with these results correlation was found between cell wall acidity and root elongation. Fusicoccin-induced $\mathrm{H}^{+}$efflux and growth rate of maize roots rather than auxin that reduced both $\mathrm{H}^{+}$efflux and root elongation (Lüthen \& Böttger, 1988).

Using $\mathrm{pH}$ microelectrodes in the elongation zone of 4 day old maize primary roots a lower $\mathrm{pH}$ was recorded than in the non-growing zone when the $\mathrm{pH}$ was higher than pH 5.0 of the incubation medium (Fig. 1.3 and Fig. 1.4). Relative elemental growth rate and surface acidity were eliminated by auxin and cyanide treatments, respectively (Fig. 1.3) (Peters \& Felle, 1999; Peters, 2004).
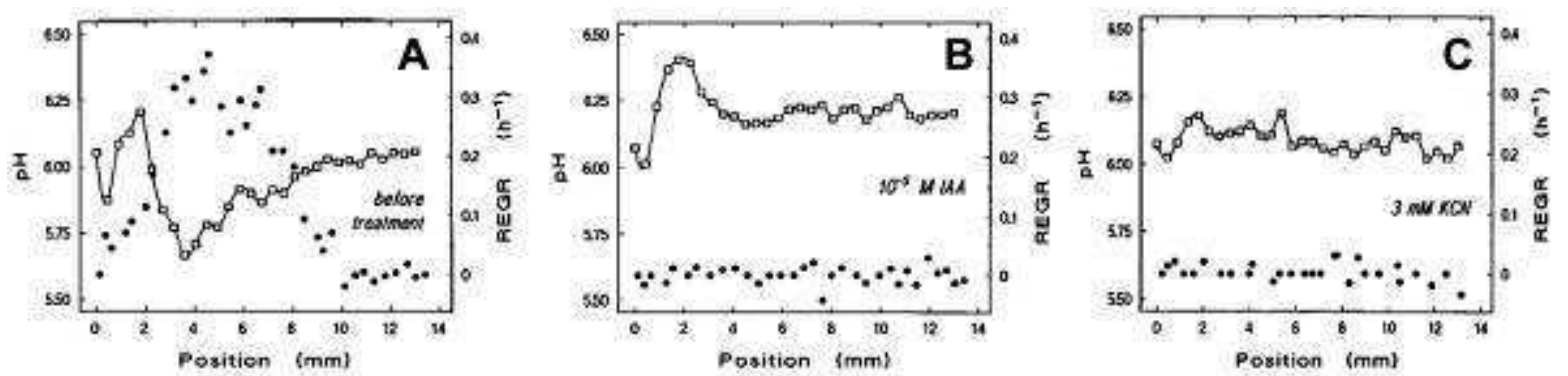

Figure 1.3 Root elongation growth rate (REGR) and apoplast pH changes

Profile of surface $\mathrm{pH}(\square)$ and REGR $(\bullet)$ along the apical $12 \mathrm{~mm}$ of a growing maize root measured in $\mathrm{pH} 6.75$ medium (A) and after $10 \mu \mathrm{M}$ IAA treatment (B) or $3 \mathrm{mM}$ KCN treatment (C). Position 0 refers to the tip of the root cap. Reprint from Peters \& Felle (1999) based on open access policy of www.plantphysiology.org with copyright American Society of Plant Biologists. 


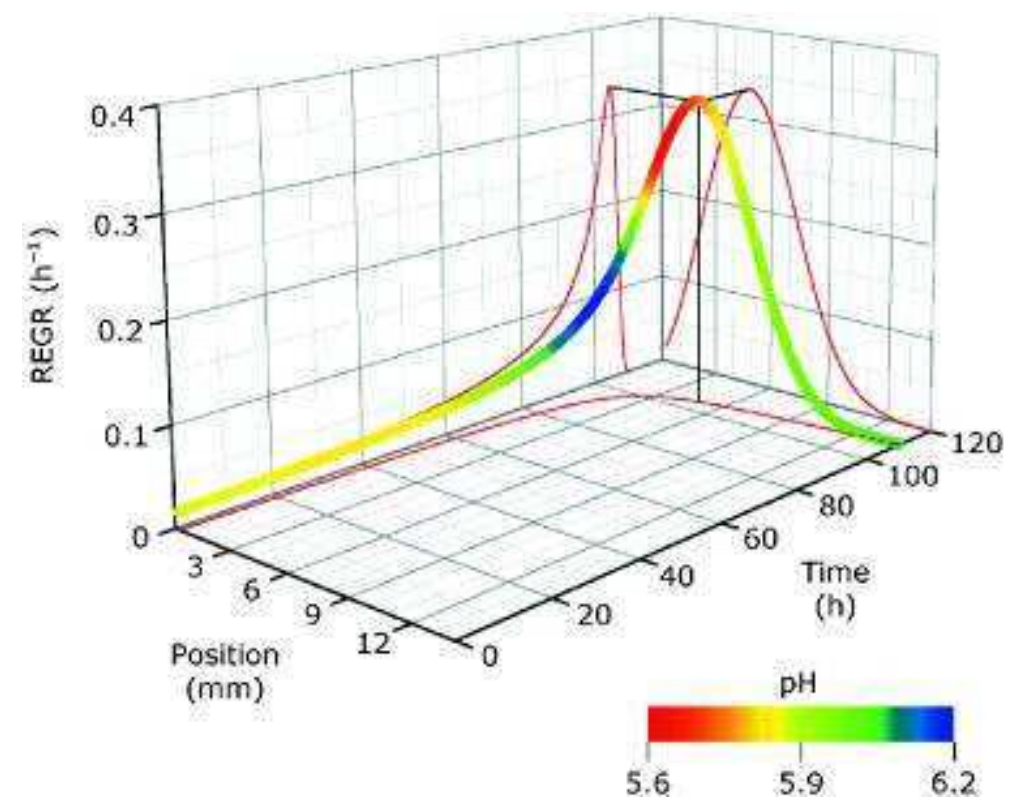

Figure 1.4 Trajectory of a root element

The figure shows the relation of the parameter time, position on the root, relative elemental growth rate (REGR) and surface $\mathrm{pH}$ (colour-coded) in growing maize root. The element considered is located at $0.2 \mathrm{~mm}$ above root apex at 0 time point. Reprint from Peters (2004) with the permission of the publisher (Licence No: 2693010825600, 'John Wiley and Sons')

Amtmann et al., (1999) using different experimental systems had similar results on barley roots. They found that $\mathrm{H}^{+}$excretion could have crucial role in activation of inward $\mathrm{K}^{+}$channels. Changes in cytosolic $\mathrm{pH}$ and $\mathrm{K}^{+}$might be significant factors which contribute to the root growth response to changes in $\mathrm{K}^{+}$supply.

\subsubsection{Potassium uptake and 'acid growth'}

Potassium is the main inorganic solute used by most plant cells to generate osmotic pressure. Its cytosolic concentration is tightly regulated. Therefore, one would expect that changes in the $\mathrm{PM}-\mathrm{H}^{+}$-ATPase pump activity affect growth not only through changes in wall properties, but also through changes in $\mathrm{K}^{+}$uptake. Recent data show that 'acid growth' and $\mathrm{K}^{+}$uptake are related processes. Auxin and fusicoccin-induced growth was not present in absence of $\mathrm{K}^{+}$(Claussen et al., 1997; Tode \& Lüthen, 2001).

Claussen et al. in 1997 observed for abraded maize coleoptiles that auxininduced growth and $\mathrm{K}^{+}$uptake were related processes. For auxin-induced growth the $\mathrm{K}^{+}$concentration in the medium was essential. In absence of $\mathrm{K}^{+}$an effect of auxin on growth was not observed, whereas when $\mathrm{K}^{+}$was added to the medium, auxin-related growth was immediately measured. The $\mathrm{K}^{+}$channel blocker triethylammonium (TEA) 
also suppressed the growth response to auxin, and when the blocker was removed, growth recovered as shown in Fig. 1.5 (Claussen et al., 1997). In a related study, a similar $\mathrm{K}^{+}$-dependency was observed for fusicoccin-induced growth (Tode \& Lüthen, 2001).
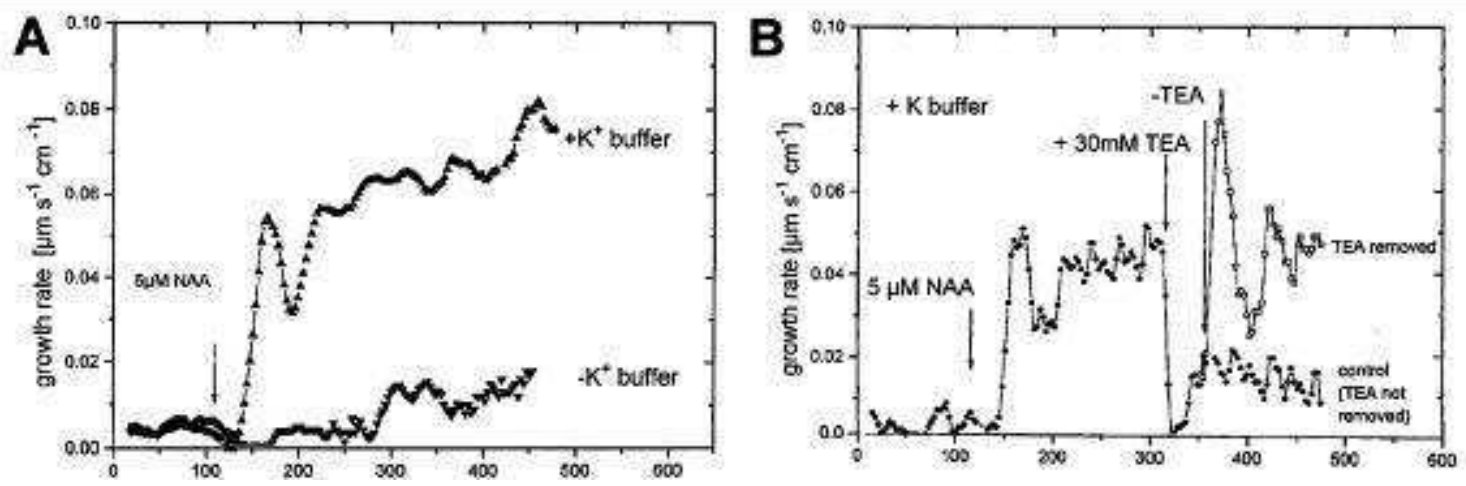

Figure 1.5 Potassium transport dependency of abraded maize coleoptiles

Potassium dependency of growth of coleoptiles was tested using a medium which contained $10 \mathrm{mM} \mathrm{K}^{+}$or no added $\mathrm{K}^{+}(\mathrm{A})$. TEA, a $\mathrm{K}^{+}$channel blocker, inhibited auxininduced growth; the blockage was completely reversible (B). When TEA was removed and replaced by incubation medium containing $10 \mathrm{mM} \mathrm{K}^{+}$and $\mathrm{NAA}$, the growth rate recovered at the level before TEA treatment. Reprint from Claussen et al. (1997) with the permission of the publisher (Licence No: 2693030934022, 'Springer')

ZMK1 and ZMK2 $\mathrm{K}^{+}$channels genes from maize were tested from the viewpoint of coleoptile growth. ZMK1 seemed to be growth related, acidification immediately increased channel activity and auxin increased its expression but acidic $\mathrm{pH}$ did not changed the expression pattern (Philippar et al., 1999). Over- expression of ZMK1 leads to $\mathrm{K}^{+}$independent growth (Philippar et al., 2006). Similar results have been obtained for the Arabidopsis $\mathrm{K}^{+}$channel AtKAT1 in growing hypocotyl and flower stalk (Philippar et al., 2004).

\subsection{Plasma membrane $\boldsymbol{H}^{+}$-ATPase}

Plasma membrane $\mathrm{H}^{+}$-ATPase (PM- $\mathrm{H}^{+}$-ATPase) was first discovered in 1946 when acid dependent glucose transport was described during the fermentation of the yeast Saccharomyces cerevisiae (Conway \& O'Malley, 1946). Cyanide and sodium azide caused plasma membrane potential decreases in Neurospora crassa within seconds, which also suggested an ATP-dependent $\mathrm{H}^{+}$pump activity (Slayman, 1965). The enzyme from fungi Schizosaccharomyces pombe and $S$. cerevisiae was isolated and shown to be a proton-pumping ATPase creating -150 to $-300 \mathrm{mV}$ plasma membrane potential in plants and fungi (Morth et al., 2011). 
PM- $\mathrm{H}^{+}$-ATPase is a single polypeptide with a molecular mass of $\sim 100 \mathrm{kDa}$ (Michelet \& Boutry, 1995). ATPase activity is usually between $1-2 \mu \mathrm{mol} \mathrm{P}_{\mathrm{i}} \mathrm{min}^{-1} \mathrm{mg}^{-1}$ in purified plasma membrane (Morsomme \& Boutry, 2000). The enzyme is essential for living plant cells as it constitutes, to the best of our current knowledge, the primary ion pump which generates the electrochemical potential across the plasma membrane. This electrochemical gradient is responsible for ionotropic signalling, secondary transport, nutrient uptake, $\mathrm{pH}$ homeostasis, salt tolerance, stomatal and leaf movements and cell growth (Palmgren, 2001; Moran, 2007; Duby \& Boutry, 2009). The PM- $\mathrm{H}^{+}$-ATPase protein is a member of the family of P-type ATPases. Other members of this family include the $\mathrm{Na}^{+}, \mathrm{K}^{+}$-ATPase, the principal ion pump in animals and humans (Morth et al., 2011).

\subsubsection{Isoforms of PM- $\mathrm{H}^{+}$-ATPase}

Using the model plant Arabidopsis thaliana twelve PM- $\mathrm{H}^{+}$-ATPase isoforms were identified from the genome (AHA1-12). The AHA12 isoforms carries two large deletions and is possibly a pseudogene (Palmgren, 2001). AHA1 and AHA2 are virtually expressed in all tissues and organs and function as housekeeping gene

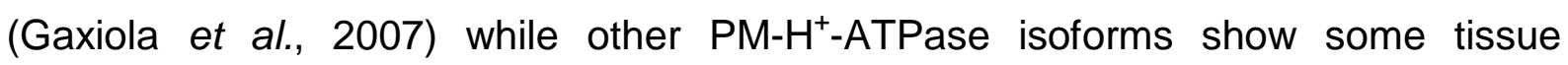
specificity of expression (Morsomme \& Boutry, 2000; Palmgren, 2001; Gaxiola et al., 2007). Tissue-specific localization of $\mathrm{PM}-\mathrm{H}^{+}$-ATPase is summarised in Table 1.1, based on information provided in (Palmgren, 2001).

There is only one isoform of $\mathrm{PM}-\mathrm{H}^{+}$-ATPase known in full detail for barley (Hordeum vulgare) based on nucleotide and protein data bases (NCBI, http://www.ncbi.nlm.nih.gov/ and UniProt http://www.uniprot.org/). However, MS / MS results suggest that there exist at least two different $\mathrm{PM}-\mathrm{H}^{+}$-ATPase isoforms in barley (Hynek et al., 2006). 
Table 1.1 Localisation of specific PM- $\mathrm{H}^{+}$-ATPase isoforms in plant body (Palmgren, 2001)

\begin{tabular}{|c|c|c|}
\hline Tissue & PM-ATPase protein & Plant \\
\hline \multicolumn{3}{|l|}{ Seedlings: } \\
\hline Cotyledon & PMA1, PMA2, PMA4 & N. plumbaginifolia \\
\hline \multicolumn{3}{|l|}{ Root: } \\
\hline Cortex parenchyma & PMA2, PMA3, PMA4 & N. plumbaginifolia \\
\hline Extension zone & PMA4 & N. plumbaginifolia \\
\hline Lateral root initials & PMA2, PMA4 & N. plumbaginifolia \\
\hline Lateral roots & PMA4, PMA9 & N. plumbaginifolia \\
\hline Root hair and epidermis & $\begin{array}{l}\text { PMA1, PMA3, PMA4 } \\
\text { MHA2 }\end{array}$ & $\begin{array}{l}\text { N. plumbaginifolia } \\
\text { Zea mays }\end{array}$ \\
\hline Root cap & PMA2, PMA4 & N. plumbaginifolia \\
\hline $\begin{array}{l}\text { Stele (central cylinder) } \\
\text { Stem: }\end{array}$ & Stem: & N. plumbaginifolia \\
\hline Axillary buds & PMA2, PMA4, PMA9 & N. plumbaginifolia \\
\hline Cortex parenchyma & PMA1, PMA2, PMA4 & N. plumbaginifolia \\
\hline Pith & PMA4 & N. plumbaginifolia \\
\hline \multirow[t]{3}{*}{ Vascular tissue } & PMA2, PMA3, PMA4, PMA9 & N. plumbaginifolia \\
\hline & MHA2 & Zea mays \\
\hline & AHA3 & A. thaliana \\
\hline \multicolumn{3}{|l|}{ Leaf: } \\
\hline \multirow[t]{3}{*}{ Guard cells } & PMA2, PMA4 & N. plumbaginifolia \\
\hline & VHA1, VHA2 & Vicia faba \\
\hline & MHA2 & Zea mays \\
\hline \multirow[t]{2}{*}{ Mesophyll } & PMA2, PMA4 & N. plumbaginifolia \\
\hline & VHA1, VHA2 & Vicia faba \\
\hline Trichomes (long) & PMA4 & N. plumbaginifolia \\
\hline Trichomes (short) & PMA6 & N. plumbaginifolia \\
\hline \multirow[t]{3}{*}{ Vascular tissue } & PMA2, PMA3, PMA4 & N. plumbaginifolia \\
\hline & MHA2 & Zea mays \\
\hline & AHA3 & A. thaliana \\
\hline \multicolumn{3}{|l|}{ Flower: } \\
\hline Carpel & PMA2 & N. plumbaginifolia \\
\hline \multirow[t]{2}{*}{ Ovules } & $\begin{array}{l}\text { PMA1, PMA2, PMA3, PMA4, } \\
\text { PMA6, PMA9 }\end{array}$ & N. plumbaginifolia \\
\hline & $\mathrm{AHA3}, \mathrm{AHA} 10$ & A. thaliana \\
\hline Nectaries & PMA2 & N. plumbaginifolia \\
\hline \multirow[t]{2}{*}{ Stamen; pollen } & $\begin{array}{l}\text { PMA1, PMA2, PMA3, PMA4, } \\
\text { PMA6, PMA6 }\end{array}$ & N. plumbaginifolia \\
\hline & AHA3, AHA9 & A. thaliana \\
\hline Style & PMA1, PMA3, PMA4 & N. plumbaginifolia \\
\hline \multirow[t]{2}{*}{ Vascular tissue } & $\begin{array}{l}\text { PMA1, PMA2, PMA3, PMA4, } \\
\text { PMA6 }\end{array}$ & N. plumbaginifolia \\
\hline & AHA3 & A. thaliana \\
\hline
\end{tabular}




\subsubsection{Structure of PM- $H^{+}$-ATPase}

The crystal structure of AHA2, a $\mathrm{PM}-\mathrm{H}^{+}$-ATPase from Ababidopsis thaliana, has recently been described (Fig. 1.6). The protein contains a transmembrane domain with ten helices (M1-10) and three cytosolic domains: a nucleotide-binding domain $(N)$, a phosphorylation domain $(P)$ and an actuator domain $(A)$. ATP is bound with the adenosine part at the $\mathrm{N}$ domain and its triphosphate group protruded towards the $\mathrm{P}$ domain. ATPase binding site was determined using 5'-( $\beta, \gamma$-methlene)-triphosphate (AMPPCP) a non-hydrolysable analogue of ATP (Pedersen et al., 2007).

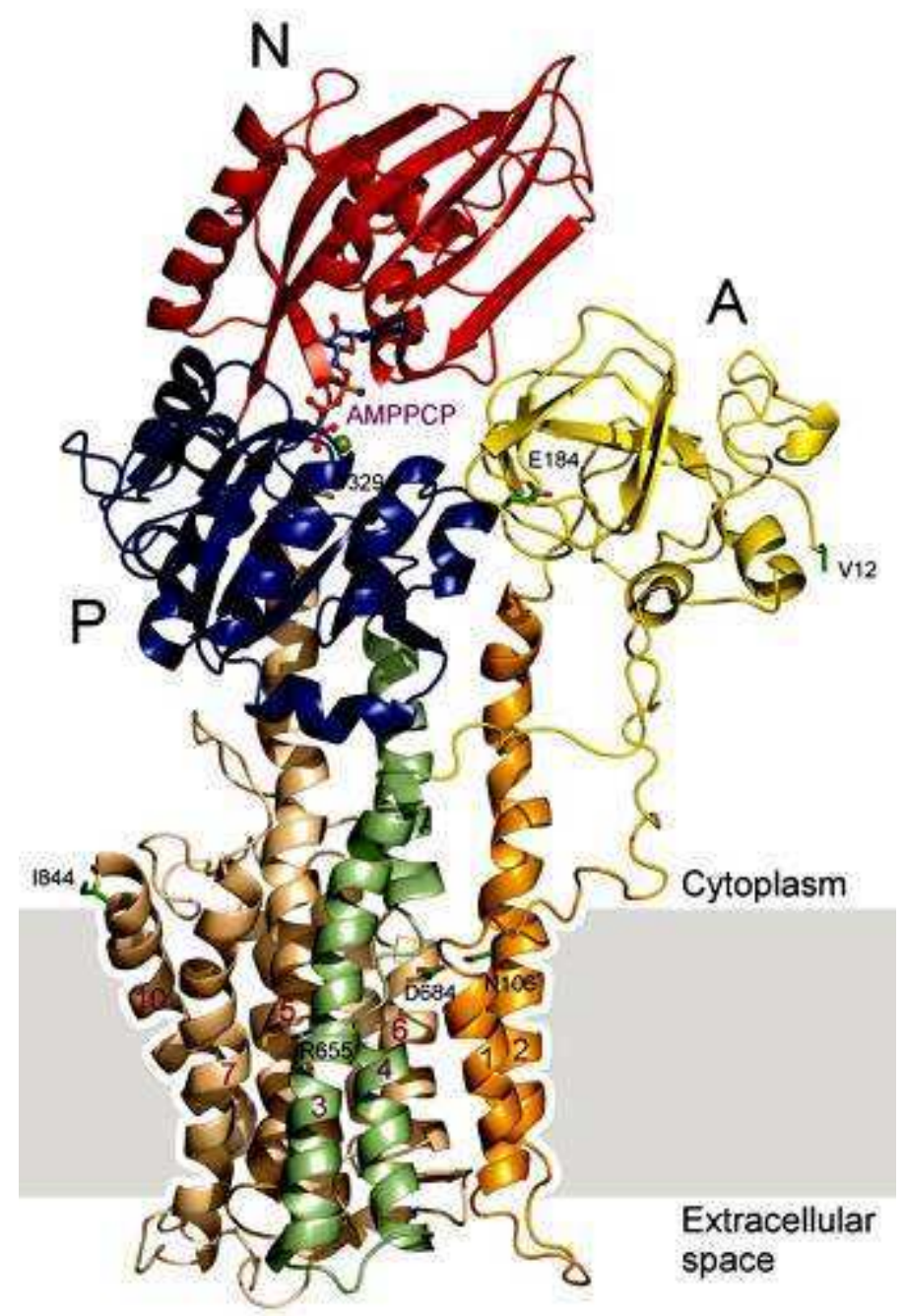

Figure 1.6 Structure of AHA2 without auto-inhibitory domain

AHA2 contains ten transmembrane helices (orange, green and brown); a nucleotide binding domain $(\mathrm{N})$, red; a phosphorylation domain $(\mathrm{P})$, blue; and an actuator domain (A); yellow. AMPPCP is shown as ball-and stick representation. The grey box represents the location of the plasma membrane; reprinted from Pedersen et al. (2007) with the permission of the publisher (Licence No: 2693040963163, 'Nature Publishing Group'). 


\subsubsection{Catalytic cycle of P-type ATPase and $\mathrm{H}^{+}$transport mechanism}

$\mathrm{PM}-\mathrm{H}^{+}$-ATPase undergoes conformational changes during each catalytic cycle. The enzyme has two distinct conformational states termed E1 and E2. The two conformation states differ in reactivity at the nucleotide binding site, which can be phosphorylated by ATP in the E1 form or by free $\mathrm{P}_{i}$ in the E2 form. $\mathrm{E} 1$ is the form that binds ATP and $\mathrm{H}^{+}$. The catalytic cycle is shown in details in Fig 1.7 (Morsomme \& Boutry, 2000; Pedersen et al., 2007).

A

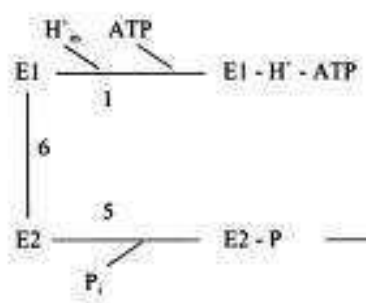

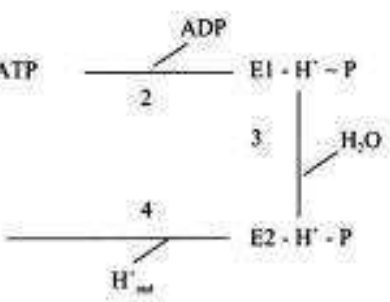

B

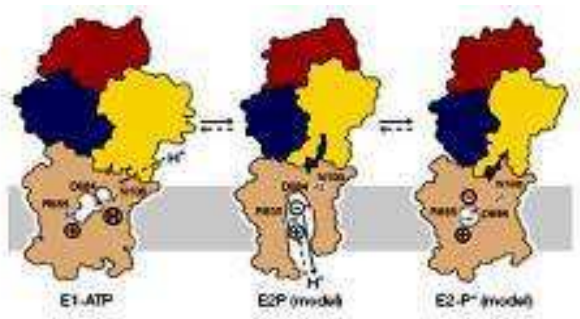

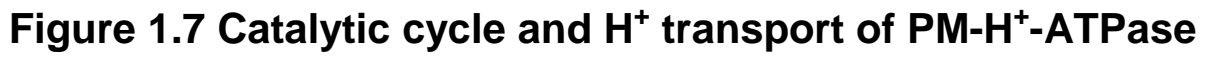

Originally the catalytic cycle was proposed for $\mathrm{Ca}^{2+}$ ATPase (subfigure A) E1 form binding ATP and $\mathrm{H}^{+}(1)$, then a high energy intermediate is formed while ADP is released (2). Conformation of the enzyme is changing from E1 to E2 (3). Proton release to cell exterior (4), finally $P_{i}$ is released (5) and conformation of the enzyme returning to form E1 (Morsomme \& Boutry, 2000). The E1 form binds $\mathrm{H}^{+}$and ATP better than the E2 binds these substances, as subfigure B shows; reprinted from Pedersen et al. (2007) with the permission of the publisher (Licence No: 2693040963163, 'Nature Publishing Group').

\subsubsection{Control of PM- $H^{+}$-ATPase}

Activity of PM- $\mathrm{H}^{+}$-ATPase is modulated by several physiological signals (such as temperature and salt stress). In comparison, there exists little evidence of a regulation of $\mathrm{PM}-\mathrm{H}^{+}$-ATPase activity through changes at the transcriptional or protein level. Moderate $\mathrm{PM}-\mathrm{H}^{+}$-ATPase expression changes have been describe for high aluminium treatment, (Shen et al., 2005), iron deficiency (Santi et al., 2005), in presence of high sugar concentration (Mito et al., 1996) and high salt treatment (Maathuis et al., 2003) .

Higher (compared to the 'average' tissue) $\mathrm{PM}-\mathrm{H}^{+}$-ATPase protein concentrations have been found in guard cells, root epidermis, phloem xylem parenchymas (Bouche-Pillon et al., 1994; Michelet \& Boutry, 1995; Morsomme \& Boutry, 2000; Palmgren, 2001; Gaxiola et al., 2007) and motor organs of seismonastic plants (Fleurat-Lessard et al., 1997; Moran, 2007).

Regulated exocytosis of vesicles that contains $\mathrm{PM}-\mathrm{H}^{+}$-ATPase molecules constitutes an alternative regulation pathway (Hager et al., 1991), yet post- 
translational modification of the enzyme seem the most common control mechanism for causing changes in PM- $\mathrm{H}^{+}$-ATPase activity (Gaxiola et al., 2007).

Phosphorylation / dephosphorylation are further mechanisms through which $\mathrm{PM}-\mathrm{H}^{+}$-ATPase can be regulated. Elicitor-induced dephosphorylation in tomato plants (Lycopersicon esculentum) resulted in an increase in PM- $\mathrm{H}^{+}$-ATPase activity (VeraEstrella et al., 1994) while subsequent phosphorylation of the enzyme reduced its activity; although $\mathrm{Ca}^{2+}$-dependent phosphorylation caused decreased $\mathrm{H}^{+}$pumping activity. Phosphorylation also activates $\mathrm{PM}-\mathrm{H}^{+}$-ATPase activity through the fusicoccin (and 14-3-3 protein) activation pathway (Morsomme \& Boutry, 2000).

The C-terminal auto-inhibitor regulation domain $(R)$ could be mainly responsible for rapid activity changes of $\mathrm{PM}-\mathrm{H}^{+}$-ATPase. Removal of the $\mathrm{R}$ domain from the enzyme by trypsin digestion activated PM- $\mathrm{H}^{+}$-ATPase (Palmgren et al., 1991). Structural information of molecular mechanism of the auto-inhibition is not available yet. In AHA2 neutralisation of the auto-inhibitory $\mathrm{R}$ domain by binding of 143-3 protein results in pump activation. Before the activation process, the penultimate Thr947 needs to be phosphorylated by a protein kinase which is induced by environmental factors such as light, nutrient status and pathogens. This phosphorylation can lead to the binding of 14-3-3 protein on the R domain complex. The Thr947 is not freely accessible to protein kinase activity, structural modification is necessary by ligand binding or kinase docking. Phosphorylation of Ser931 inhibits PM- $\mathrm{H}^{+}$-ATPase and destroys the 14-3-3 protein binding site (Sze et al., 1999; Morth et al., 2011). It seems that phosphorylation of most residues within the C-terminal domain impacts on 14-3-3 binding. The enzyme regulation is controlled by distinct protein kinases and phosphatases allowing gradual increase and decrease of the activity of PM-H+ $\mathrm{H}^{+}$-ATPase (Speth et al., 2010). More details are provided in Fig. 1.8. 

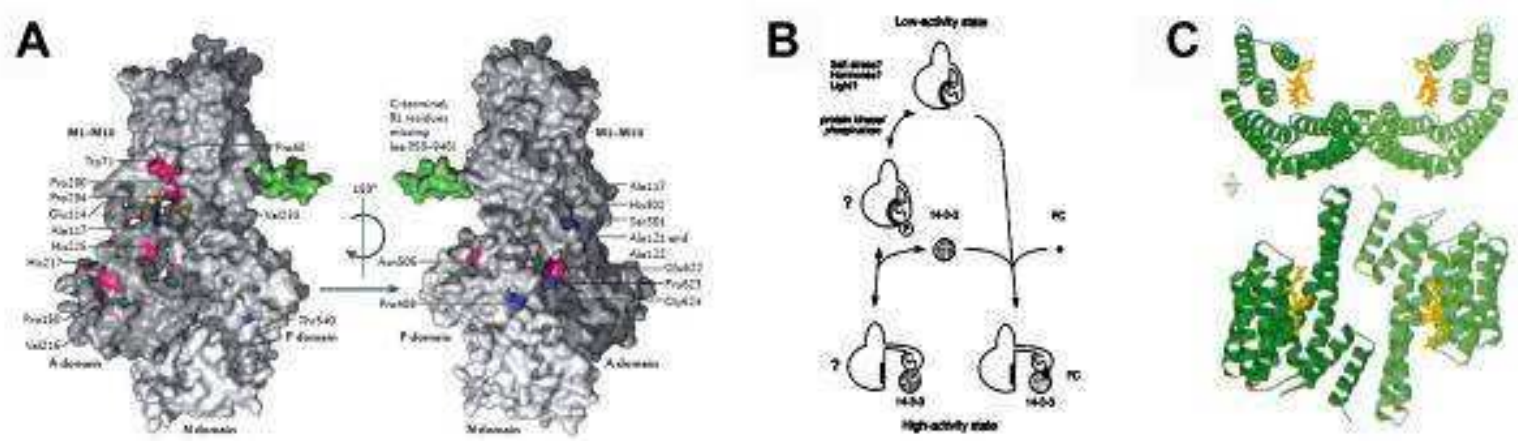

Figure 1.8 Auto-inhibition of PM- $\mathrm{H}^{+}$-ATPase

On subfigure A residues are highlighted on the $\mathrm{PM}-\mathrm{H}^{+}$-ATPase (AHA2) that interact with the regulatory domain. Blue: present in yeast; red: present in plant; yellow: present in plant $\mathrm{Ca}^{2+}$-ATPase.; green: 13 residue carboxy-terminal extension. Plant and fungal sites do not overlap, and it is likely that their pumps are inhibited by different mechanisms (Morth et al., 2011). B: schematic summary of protein kinase/phosphatise-dependent and fusicoccin-dependent activation pathway of PM$\mathrm{H}^{+}$-ATPase. Subfigure $\mathrm{C}$ shows the ribbon plot of different orientation of dimeric tobacco 14-3-3c protein (green) bound to the C-terminal end (yellow) of PMA2 (tobacco PM- $\mathrm{H}^{+}$-ATPase) (Würtele et al., 2003). Figures are reprint from Morth et al. (2011) with the permission of the publisher, Licence No: 2693050346303, 'Nature Publishing Group' (A); Sze et al. (1999) based on open access policy of www.plantcell.org with copyright American Society of Plant Biologists (B) and Würtele et al. (2003) with the permission of the publisher, Licence No: 2693070537163, 'Nature Publishing Group' (C).

\subsubsection{Fusicoccin-dependent PM- $H^{+}$-ATPase activation}

Fusicoccin (a diterpene glycoside) is a phytotoxin, produced by the fungus Fusicoccum amygdali. The fungus is host specific, but isolated fusicoccin causes higher $\mathrm{H}^{+}$efflux in any higher plant tested so far (Marré, 1979). Recent structural studies show that fusicoccin is increasing $\mathrm{H}^{+}$pump activity by stabilising the interaction between 14-3-3 protein and auto-inhibitor $\mathrm{R}$ domain of $\mathrm{PM}-\mathrm{H}^{+}$-ATPase. Fusicoccin effective due binding its plasma membrane receptor (Olivari et al., 1998) that is on the C-terminal of the R-domain of the PM- $\mathrm{H}^{+}$-ATPase (Johansson et al., 1993). This results in permanent binding of 14-3-3 protein to the regulation domain (Oecking et al., 1994) and activates PM- $\mathrm{H}^{+}$-ATPase permanently as shown in Fig. 1.8.

The toxin causes no major conformation changes; it fills a cavity between 14-3-3 protein and PM- $\mathrm{H}^{+}$-ATPase (Fig. 1.9) and increases the stability of the complex about 90 -fold (Würtele et al., 2003). 


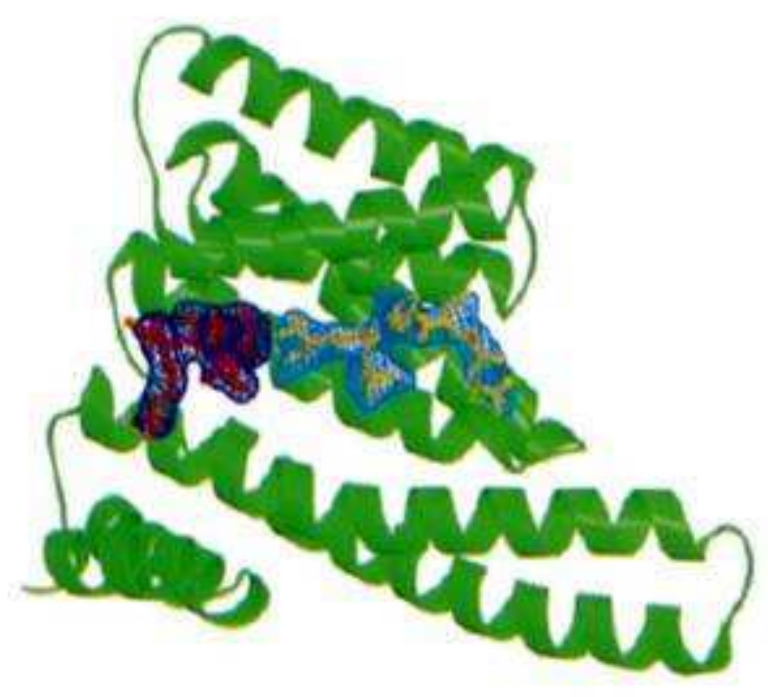

Figure 1.9 14-3-3 protein-fusicoccin-PM-H ${ }^{+}$-ATPase complex

Ribbon diagram of a 14-3-3 protein monomer (green) with $\mathrm{PM}-\mathrm{H}^{+}$-ATPase peptide (yellow) and fusicoccin (orange). Blue represent the Van der Waals space of fusicoccin and $\mathrm{PM}-\mathrm{H}^{+}$-ATPase peptide (reprint from Würtele et al. (2003) with the permission of the publisher, Licence No: 2693070537163, 'Nature Publishing Group')

\subsection{Barley}

Barley (Hordeum vulgare) was domesticated 10,000 years ago and ranks fourth among cereals after maize (Zea mays), rice (Oryza sativa) and wheat (Triticum aestivium) in terms of global production. About two-thirds of the annual global barley production is used for animal feeding and the remaining third covers the needs of malting, brewing (beer) and distilling (whiskey) industries (Schulte et al., 2009). The average annual production of barley in the world is about $1.24 \cdot 10^{11} \mathrm{~kg}$ and $62 \%$ of this is harvested in Europe. The highest yield per hectar occurs in Ireland with $5.7 \mathrm{Mg}$ $\mathrm{ha}^{-1}$ (Kim \& Dale, 2004). In Ireland and Scotland brewing and distilling has a particularly big economic impact, not least because of the whiskey industry.

\subsubsection{The two weeks old barley seedlings and their advantage}

Barley seedlings at a developmental stage of two weeks old (between 14 - 17 days) present ideal research objects for leaf growth studies. At this stage leaf three is the main growing leaf and shows maximum or near-maximum growth rate $\left(2-3 \mathrm{~mm} \mathrm{~h}^{-1}\right)$. Older leaves, which cause self-shading and reduce the potential biomass increase have not developed yet and younger seedlings are not yet fully dependent on the external medium for supply of mineral nutrients but still receive a considerable portion through seed reserves. The base $40 \mathrm{~mm}$ of leaf three that contains the leaf 
elongation zone is enclosed by the sheath of the older leaves one and two (Fricke \& Flowers, 1998; Fricke, 2002a). There are small quantities of cuticle waxes deposited on the epidermal surface along the base $20-30 \mathrm{~mm}$ of the elongation zone. This means that the permeance of the cuticle is much higher in the elongation zone compared to the emerged blade, which makes external application of test reagents to measurements of proton extrusion from the leaf apoplast comparatively easy without having to mechanically remove the cuticle (Richardson et al., 2007).

\subsubsection{Morphology of developing barley leaves}

Barley leaves consist of two parts, the basal sheath and the leaf blade, separated by ligule and auricle. The sheath at the leaf base mechanically supports the blade which is the photosynthetic and transpirating active part of the leaf. The sheath also encloses the basal apical meristem, and any younger leaves emerge from within sheaths of older leaves. Leaves develop from the main meristem, which is located at the base. As a consequence, oldest tissues are at the leaf tip and youngest ones near the leaf base. The elongation zone of leaf three stretches to about $40 \mathrm{~mm}$ from the point of leaf insertion ('leaf base'), with highest relative elemental growth rates between $10-30 \mathrm{~mm}$ (Fricke \& Peters, 2002). In the elongation zone cells are elongating manyfold in size. Above the elongation zone is a zone which can be referred to as 'non-elongation zone'. This zone extends to the point of emergence of the developing leaf from the sheath of leaf two and contains cells which are not elongating any more but can show some lateral expansion. The fully emerged leaf blade contains fully-differentiated cells, which are not dividing or expanding any more. Details are provided in Fig. 1.10. 


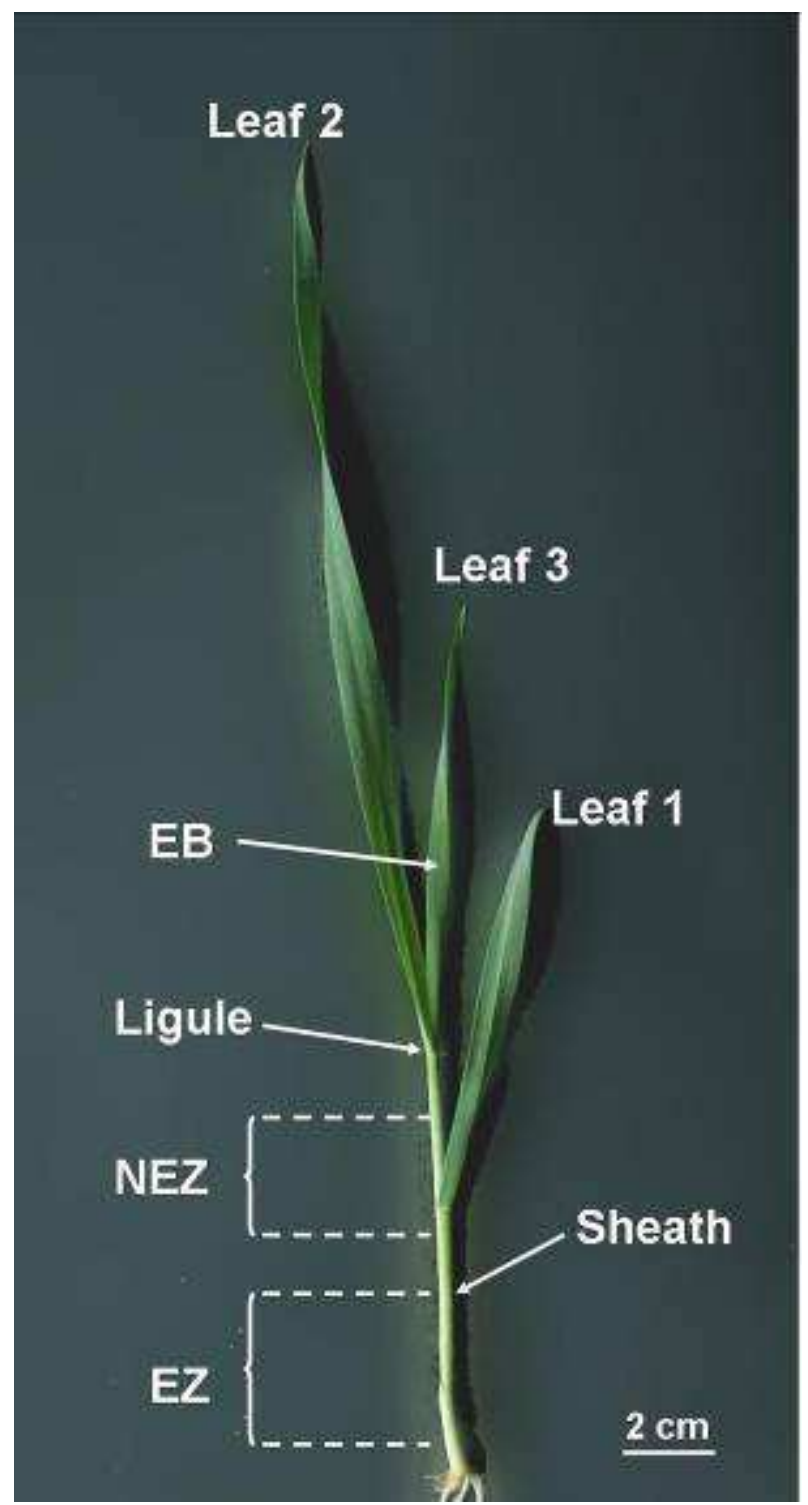

Figure 1.10 Two-week old barley seedling

The two-weeks old barley seedling has three leaves. Leaf one is the oldest leaf and leaf three is the youngest and main developing leaf. EZ: elongation zone; NEZ: nonelongation zone; EB: emerged leaf blade

\subsubsection{Anatomy of developing barley leaf}

Anatomical changes during leaf development can be visualised on cross sections of different parts of the leaf (Fig. 1.11). Cell size is increased manyfold in mature compared to immature tissue, although it is difficult to see this on cross sections, particularly in the epidermis, where elongation growth contributes most to cell enlargment. The most conspicuous difference between the different developmental stages is the specialisation of mesophyll cells for photosynthesis (chloroplast development), xylem (conductance of water and dissolved solutes) and increased intercellular spaces. 

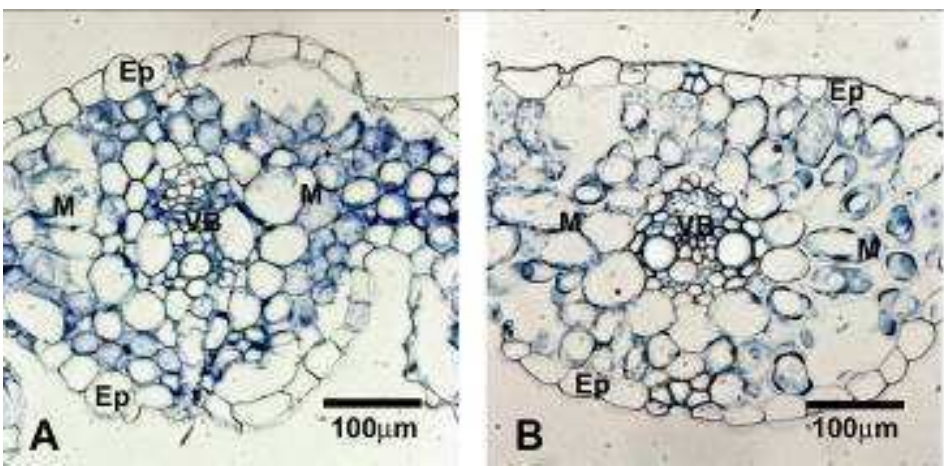

Figure 1.11 Toluidine blue stained cross section of barley leaves from different developmental stage

Cross sections from elongation zone (A) non-elongation zone (B) and fully emerged blade $(C)$ of leaf three. Ep: epidermis; M: mesophyll cells; VB: vascular bundle.

\subsubsection{Growth and potassium uptake of barley}

The classical dual $\mathrm{K}^{+}$uptake mechanism has first been described for roots of barley (Epstein et al., 1963). Further studies proofed the relevance of high affinity $\mathrm{K}^{+}$ transporters for $\mathrm{K}^{+}$uptake; also $\mathrm{H}^{+} / \mathrm{K}^{+}$co-transport has a high significance in $\mathrm{K}^{+}$ uptake of roots (Glass et al., 1981; Amtmann et al., 1999). For barley, four HAK genes have been described (HvHAK1-4). HvHAK1 was mainly expressed in roots, HvHAK3 in both shoots and roots while HvHAK4 was mainly expressed in shoots (Rubio et al., 2000). HvHAK4 had significantly higher expression in the elongation zone of leaves compare with parts of barley seedlings (Boscari et al., 2009). HvHAK1 is very similar to AtHAK5 and seems to be a high affinity $\mathrm{K}^{+}$transporters in contrast with HvHAK2, which facilitates $\mathrm{K}^{+}$uptake in a range of low or medium affinity $\left(\mathrm{K}_{\mathrm{M}}\right.$ of about $5 \mathrm{mM}$ comparing with $\mathrm{K}_{\mathrm{M}}$ of about10 $\mu \mathrm{M}$ for HvHAK1 (Rubio et al., 2000; Senn et al., 2001; Ashley et al., 2006).

In previous studies on $\mathrm{K}^{+}$transport in barley it was concluded that apoplast $\mathrm{K}^{+}$ must exceed 3 - $5 \mathrm{mM}$ to allow growing leaf cells to take up $\mathrm{K}^{+}$through channels (Boscari et al., 2009; Volkov et al., 2009). Calculations showed that at $10 \mathrm{mM}$ apoplast $\mathrm{K}^{+}$, about $50 \%$ of $\mathrm{K}^{+}$uptake was facilitated by time-dependent inwardrectifying currents typical of Shaker $\mathrm{K}^{+}$channels such as AKT1 or AKT2. The remaining $50 \%$ was facilitated by instantaneous currents, which includes either or both, $\mathrm{K}^{+}$high-affinity transporters such as $\mathrm{HAK} / \mathrm{KUP} / \mathrm{KT}$ type $\mathrm{K}^{+} / \mathrm{H}^{+}$symporters or non-selective cation channels.

Potassium channels and transporters might study using different blockers of these proteins. Tetraethylammonia (TEA) inhibits $\mathrm{K}^{+}$transport through channels reversibly as $\mathrm{K}^{+}$analogue at the dehydration transition step (Lenaeus et al., 2005). 
$\mathrm{Cs}^{+}$ions as huge $\mathrm{K}^{+}$analogue block both channels and transporters (RodriguezNavarro \& Rubio, 2006; Szczerba et al., 2009) and $\mathrm{NH}_{4}{ }^{+}$ions with competitive manner inhibit high affinity $\mathrm{K}^{+}$transporters (Spalding et al., 1999; Kronzucker et al., 2003; Rodriguez-Navarro \& Rubio, 2006; Szczerba et al., 2006; Britto \& Kronzucker, 2008; Szczerba et al., 2009; Britto et al., 2010; Hoopen et al., 2010)

\subsection{Technical approaches}

(i) Cell wall acidification was measured using three independent methods $\mathrm{pH}$ sensitive fluorescence probe, micro $\mathrm{pH}$ electrode technique and in-vitro agarose gel system with bromocresol purple $\mathrm{pH}$ indicator. During these experiments leaf elongation was measured with a ruler (micro $\mathrm{pH}$ measurements) or image analysis tools (in-vitro gel experiments).

(ii) A linear variable differential transformer (LVDT) was used to determine the growth rate continuously and at micrometer resolution. This made it possible to record any rapid and short term response of leaf growth to application of test reagents to the apoplast of the leaf elongation zone.

(iii) Expression of $\mathrm{PM}-\mathrm{H}^{+}-\mathrm{ATPase}$ was determined by absolute $\mathrm{qPCR}$ technique and the PM- $\mathrm{H}^{+}$-ATPase enzyme ratio in total purified plasma membrane protein was measured using Western blot analysis and densitometry on Coomassie Brilliant Blue stained SDS polyacrylamide gels. Activity of the enzyme was determined as vanadate sensitive ATPase hydrolysis activity of inside-out plasma membrane vesicles.

(iv) $\mathrm{PM}-\mathrm{H}^{+}$-ATPase tissue specific distribution was studied using immunolocalisation on paraffin embedded section and a commercially-available antibody of $\mathrm{PM}-\mathrm{H}^{+}-\mathrm{ATPase}$ isoforms. 


\subsection{Objectives of the present study}

The aim of this project was to test whether apoplast $\mathrm{pH}$ differs between growing and non-growing leaf tissue of barley, how this acidification relates to growth and to which degree apoplast acidification relies on the activity, transcription and occurrence of $\mathrm{PM}-\mathrm{H}^{+}$-ATPase. The developing leaf three of barley was studied. Apoplastic $\mathrm{pH}$ and leaf elongation was measured together in the same experiments or in separate experiments. Differences in $\mathrm{pH}$ and leaf growth were followed using three independent techniques. Treatments affecting $\mathrm{PM}-\mathrm{H}^{+}$-ATPase activity (increase or decrease) or blockers of different type of $\mathrm{K}^{+}$transport (channel, transporter) were used to determine the physiological background of leaf elongation. Expression and activity of $\mathrm{PM}-\mathrm{H}^{+}$-ATPase was measured to test whether any higher acidity in the apoplast of the elongation zone originated from a higher expression of the enzyme or any other control mechanism, in particular post-translational modification. Finally

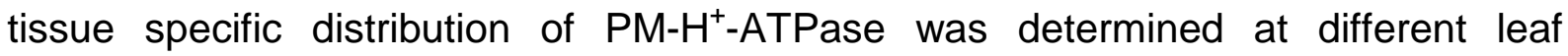
developmental stages on cross sections. 


\section{Materials and Methods}

\subsection{Plant material}

\subsubsection{Plant growth for study of leaves}

Barley seeds (Hordeum vulgare L. cv. Golf; and Hordeum vulgare L. cv. Jersey) were imbibed overnight in water, germinated in dark on approx. $0.5 \mathrm{mM} \mathrm{CaSO}_{4}$ for 3 days and exposed to light for a further 3 days while remaining on $\mathrm{CaSO}_{4}$ solution. On day seven, four seedlings were transferred into $1 \mathrm{I}$ borosilicate glass beakers wrapped in tin foil (containing $0.8-0.9$ I nutrient solution) on aerated $1 / 2$ strength Hoagland solution (Table 2.1) and grown for a further $7-11$ days at $70-80 \%$ relative humidity and $300-350$ $\mu \mathrm{mol} \mathrm{m} \mathrm{m}^{-2} \mathrm{~s}^{-1}$ photosynthetically active radiation at third-leaf level, during a $16 \mathrm{~h} / 8 \mathrm{~h}, 21$ ${ }^{\circ} \mathrm{C} / 15^{\circ} \mathrm{C}$ day / night cycle in a growth chamber (I MAGO F3000, Snijders Scientific). Nutrient solution was not replaced during plant growth. These were the growth conditions at University College Dublin, where most experiments were carried out. Some experiments, including plant growth, were also carried out at Rothamsted Research (UK) and Eötvös University (Hungary). Plants were analysed when they were 14 - $18 \mathrm{~d}$ old.

At Rothamsted Research ( $\mathrm{pH}$ microelectrode measurements) the growth temperature was different (constantly $20^{\circ} \mathrm{C}$ during day / night). At Eötvös University (plasma membrane isolation) plants were grown under a $14 \mathrm{~h} \mathrm{/} 10 \mathrm{~h}$ day / night period $\left(150 \mu \mathrm{mol} \mathrm{m} \mathrm{m}^{-2} \mathrm{~s}^{-1}\right)$ with $20 / 18 \mathrm{C}$ day / night temperature. These al terations in growth conditions were due to local availability of growth facilities and the seedlings achieved the leaf three development stage about 2 - 3 d later at Eötvös University and 1 - 2 earlier at Rothamsted Research compared with Dublin.

The barley Golf cultivar was used for most experiments. Towards the end of the study, the availability of Golf seeds became limited due to vast demand by the laboratory in general, no further commercial (breeder) availability of this cultivar and due to limited availability of growth space at UCD to grow plants to the seeding stage. Therefore, experiments which were carried out towards the end of the study, in particular plasma membrane isolation, were performed on the barley cultivar Jersey. Both, Golf and Jersey are spring barleys. 
Table 2.1 Composition of the $1 / 2$ strength Hoagland solution for barley seedlings

\begin{tabular}{|c|c|c|c|c|}
\hline $\begin{array}{l}\text { Macronutrients } \\
\text { (1I each) }\end{array}$ & $\begin{array}{l}\text { Stock } \\
(\mathrm{mM})\end{array}$ & $\begin{array}{l}\text { Amount for } \\
1 \text { I stock }(\mathrm{g})\end{array}$ & $\begin{array}{l}\text { Final concentration } \\
(\mathrm{mM})\end{array}$ & Dilution \\
\hline $\begin{array}{l}\text { (1) } \mathrm{NH}_{4} \mathrm{H}_{2} \mathrm{PO}_{4} \\
+\left(\mathrm{NH}_{4}\right)_{2} \mathrm{HPO}_{4}\end{array}$ & $\begin{array}{l}100 \\
100\end{array}$ & $\begin{array}{l}11.5 \mathrm{~g} \\
13.2\end{array}$ & $\begin{array}{l}0.5 \\
0.5 \\
\end{array}$ & $\begin{array}{l}200 x \\
200 x\end{array}$ \\
\hline (2) $\mathrm{KNO}_{3}$ & 400 & 40.4 & 2.0 & $200 x$ \\
\hline $\begin{array}{l}\text { (3) } \mathrm{MgSO}_{4} \times 7 \mathrm{H}_{2} \mathrm{O} \\
+\mathrm{NaCl}\end{array}$ & $\begin{array}{l}100 \\
100\end{array}$ & $\begin{array}{l}24.7 \\
5.84\end{array}$ & $\begin{array}{l}0.5 \\
0.5 \\
\end{array}$ & $\begin{array}{l}200 x \\
200 x\end{array}$ \\
\hline $\begin{array}{l}\text { (4) } \\
\mathrm{Ca}\left(\mathrm{NO}_{3}\right) 2 \times 4 \mathrm{H}_{2} \mathrm{O}\end{array}$ & 400 & 94,4 & 2.0 & $200 x$ \\
\hline
\end{tabular}

\begin{tabular}{l|c|c|l|l}
$\begin{array}{l}\text { Micronutrients } \\
(0.5 \text { I each) }\end{array}$ & $\begin{array}{c}\text { Stock } \\
(\mathrm{mM})\end{array}$ & $\begin{array}{c}\text { Amount for } \\
\text { 0.5I stock }(\mathrm{g})\end{array}$ & $\begin{array}{l}\text { Final concentration } \\
(\mu \mathrm{M})\end{array}$ & Dilution \\
\hline$\left(\right.$ a) $\mathrm{H}_{3} \mathrm{BO}_{3}$ & 25 & 0.775 & 6.25 & $4000 \mathrm{x}$ \\
\hline$\left(\right.$ b) $\mathrm{CuSO}_{4} \times 5 \mathrm{H}_{2} \mathrm{O}$ & 0.5 & 0.0625 & 0.125 & $4000 \mathrm{x}$ \\
\hline (c) $\mathrm{MnSO}_{4} \times \mathrm{H}_{2} \mathrm{O}$ & 2 & 0.169 & 0.5 & $4000 \mathrm{x}$ \\
\hline $\begin{array}{l}\text { (d) } \\
\mathrm{Na}_{2} \mathrm{MoO}_{4} \times 2 \mathrm{H}_{2} \mathrm{O}\end{array}$ & 0.76 & 0.092 & 0.19 & $4000 \mathrm{x}$ \\
\hline $\begin{array}{l}(\mathrm{e}) \mathrm{ZnCl}_{2} \\
\left.\mathrm{ZnSO} \mathrm{SO}_{4}\right)\end{array}$ & 2 & 0.136 & 0.5 & $4000 \mathrm{x}$ \\
\hline (f) $\mathrm{Fe}^{\text {III) }} \mathrm{NaEDTA}$ & 36 & 6.606 & 27 & $1333 \mathrm{x}$
\end{tabular}

\subsubsection{Plant growth for study of coleoptiles}

To grow coleoptiles for auxin sensitivity test Golf barley seeds were imbibed overnight in water and were germinated in the dark for $5 \mathrm{~d}$ in the growth chamber under the same temperature settings $\left(16 \mathrm{~h}\right.$ at $21^{\circ} \mathrm{C}, 8 \mathrm{~h}$ at $\left.15^{\circ} \mathrm{C}\right)$ as described for seedlings. The apical $10 \mathrm{~mm}$ of the coleoptile tip was used and the first leaf developing inside the coleoptiles was removed (compare Sakurai \& Masuda, 1978).

\subsection{Apoplast $\mathrm{pH}$ measurements}

Cell wall $\mathrm{pH}$ was measured through three independent approaches: an in-vitro gel system, electrophysiology and confocal microscopy. The in-vitro gel system involved incubating leaf segments in agarose which contained the $\mathrm{pH}$ indicator bromocresol purple. The advantage of this system was that it was easy to use. This made it possible to test many treatments and to directly relate changes in wall acidity to changes in growth rate. The $\mathrm{pH}$ microelectrode technique was used to obtain precise values of apoplast $\mathrm{pH}$ in growing and non-growing leaf regions. This technique, which was carried out at Rothamsted Research, required the most experimental effort and was used to a limited extent, due to limited funding for travel. Therefore only selected treatments were tested. Finally, intact plants were studied using 
confocal microscopy, by loading plants with $\mathrm{pH}$ fluorescence probes added to the root medium. Epidermal peels were also studied as control material.

\subsubsection{In-vitro gel system}

The base $70 \mathrm{~mm}$ of leaf three was placed into a Petri dish which had been filled with agarose medium containing the $\mathrm{pH}$ indicator bromocresol purple (Tang et al., 2004; Li et al., 2007). The younger fourth leaf was removed from inside leaf three prior to experiments.

The agarose medium contained $10 \mathrm{mM}, 1 \mathrm{mM} \mathrm{CaCl}_{2}, 0.5 \%$ agarose (gelling temperature $38.3^{\circ} \mathrm{C}$ ) and $90 \mathrm{mg} \mathrm{l}^{-1}$ bromocresol purple. Any additional test reagents were added to the medium while it was fluid and the $\mathrm{pH}$ was adjusted to 7.0 using $3 \mathrm{mM} \mathrm{KOH}$. The amount of $\mathrm{K}^{+}$added through this $\mathrm{pH}$ adjustment was negligible compared to the amount of $\mathrm{K}^{+}$added through $10 \mathrm{mM} \mathrm{K}^{+}$. Leaf pieces were placed into the medium when it was almost semi rigid and had a temperature of between 28 - $32^{\circ} \mathrm{C}$. Petri dishes were incubated under the same conditions under which the plants had grown, except for cold-treatments, where dishes were incubated in the dark in a cold room $\left(5^{\circ} \mathrm{C}\right.$ ). At regular time interva ls (every hour for the first $10 \mathrm{~h}$ of incubation), Petri dishes were photographed with a Canon EOS 350D digital camera. Two replicate pictures were made every hour. Final pictures were made after $24 \mathrm{~h}$. Digital photographs were used to assess acidification of the medium and measure elongation growth of leaf pieces. ImageJ 1.410 software (http://rsbweb.nih.gov/ij) was used to measure the length of leaf pieces. Values were calibrated with the aid of graph paper which had been fixed to Petri dishes prior to the start of experiment. Due to the alkaline $\mathrm{pH}$ of the graph paper, the paper served as sort of an internal $\mathrm{pH}$ control as well since it gave the colour (bluish) of bromocresol purple in non-acidified medium. Acidic areas, which showed up as yellow in the purple-stained medium (see Fig. 2.1), were selected on pictures using the magic wand of Adobe ${ }^{\circledR}$ Photoshop ${ }^{\circledR}$ 7.0.1 (tolerance factor 10) and measured using Scion Image for Windows 4.0.3.2 (http://www.scioncorp.com, O'Neal et al., 2002).

Preparation of leaf pieces and transfer to agarose medium resulted in an immediate, non-specific acidification of the medium, most likely as a result of unpeeling leaf three from the sheaths of leaves one and two. This non-specific acidification levelled off within 4 - $5 \mathrm{~h}$. Preliminary experiments showed that the acid area value obtained after $1 \mathrm{~h}$ of incubation reflected the size of the exposed leaf surface of the individual plants therefore it was used as the reference point for the 
start of experiment $\left(A_{1}\right)$. Any areas measured at further time points 't' $\left(A_{t}\right)$ were related to this reference point according to ' $A_{t} / A_{1}$ '. Areas were expressed in $\mathrm{mm}^{2}$.

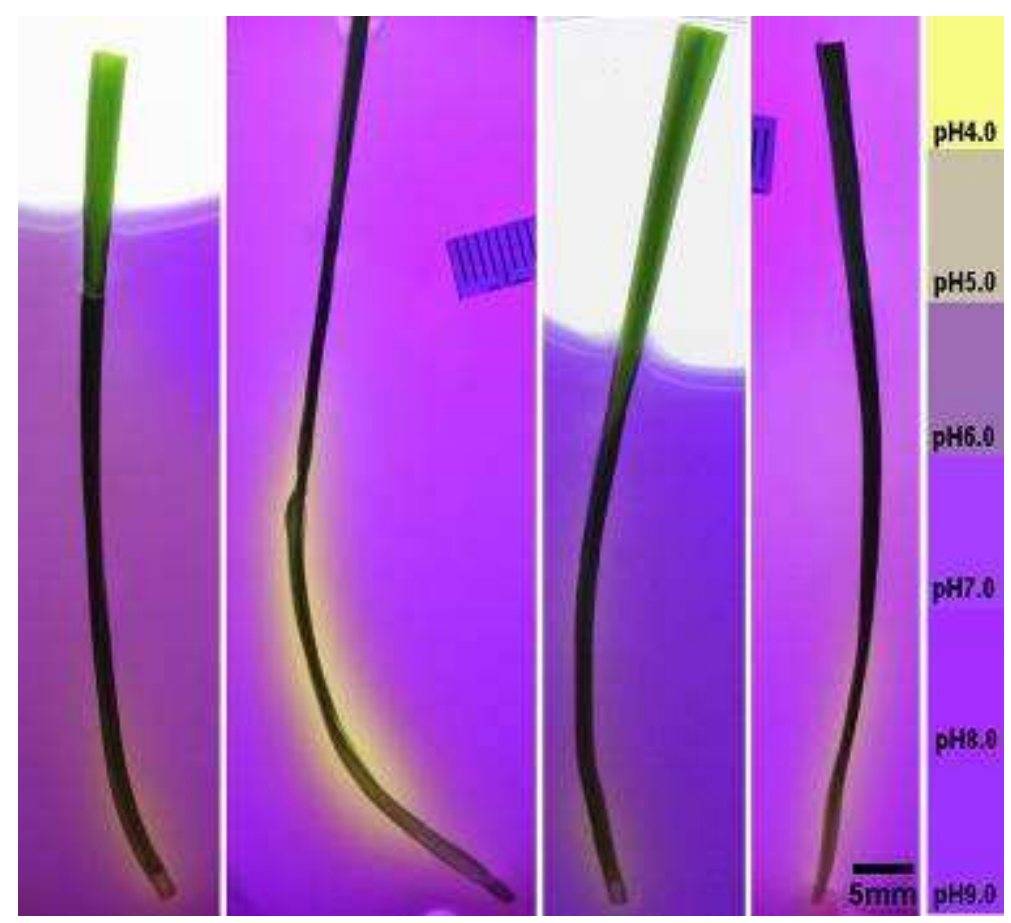

Figure 2.1 Leaf pieces in $\mathrm{pH}$ sensitive agarose gel medium

Agarose gels contained the $\mathrm{pH}$ indicator bromocresol purple $\mathrm{pH}$. This $\mathrm{pH}$ indicator shows yellowish colour at acidic, purple at neutral and blueish colour at alkaline $\mathrm{pH}$ (see right column). Basal leaf segments were $70 \mathrm{~mm}$ long at the beginning of the experiments, and their tip end was sticking out from the medium. Graph paper was used as an internal alkaline control and to calibrate length of leaf segments to measure growth during the incubation period.

\subsubsection{Microelectrode measurements}

Apoplastic $\mathrm{pH}$ was measured with the aid of $\mathrm{pH}$-sensitive microelectrodes. The elongation zone and emerged, mature portion of the developing leaf three of barley were analysed. The older leaves one and two were peeled back to expose the abaxial surface of the basal elongation zone of leaf three. The elongation zone was covered with wet tissue paper which had been soaked for the previous $24 \mathrm{~h}$ in distilled water. The latter was done to guarantee $\mathrm{pH}$ neutrality (which is not the case for tissue paper which is used 'fresh'). During experiments, the tissue paper was soaked in bath solutions, as specified in results, to alter the apoplastic environment of the leaf elongation zone. Due to the absence of a major permeability barrier (cuticle) in the elongation zone (Richardson et al., 2007), apoplastic pH could be measured directly by bringing the microelectrode in close contact with the epidermal surface. Measurements were carried out at $20-30 \mathrm{~mm}$ from the base. In the fully- 
cutinised emerged-blade portion of the developing leaf three, apoplastic $\mathrm{pH}$ was measured by inserting the microelectrode through stomatal pores (compare Fricke et al., 1994; Felle 2005;). Double-barrelled pH sensitive microelectrodes were prepared as described in Miller \& Smith (1992) using the same setup and microelectrode cocktail as described in Dennis et al. (2009). The only difference was that in the present study a $\mathrm{pH} 5.0$ rather than $\mathrm{pH} 3.0$ calibration buffer was used and that an additional pH 8.5 calibration buffer was included. Calibration was performed before and after readings. The composition of the $\mathrm{pH}$ sensitive cocktail and calibration buffers is given in Table 2.2 and Table 2.3. Microelectrode outputs were analysed with Origin ${ }^{\circledR} 6.1$ (OriginLab Corporation) software.

Analysis of one leaf region of one plant typically lasted between 2 - 6 hours, and between $1-6 \mathrm{pH}$ recordings were taken for each leaf region under room temperature and humidity in the dark. To avoid too long exposure of plants on the microelectrode rig, recordings for elongation zone and emerged blade were obtained from different plants. Elongation growth of leaf three of plants mounted on the rig was measured by measuring the length of leaf three at the beginning and end of experiments using a ruler. Preparation of plants reduced leaf elongation growth by about 50-60 \% compared to elongation growth of undisturbed plants in the growth chamber.

Table 2.2 Composition of the pH sensor for microelectrodes

Component of pH sensor

\begin{tabular}{l|l}
\hline \hline Hydrogen lonophore II Cocktail A & $35 \mathrm{mg}$ \\
\hline High molecular weight PVC & $16 \mathrm{mg}$ \\
\hline Nitrocellulose & $6 \mathrm{mg}$ \\
\hline Tetrahydrofuran (THF) & Dissolve the other components
\end{tabular}


Table 2.3 Composition of the buffer solutions used for calibrating $\mathrm{pH}$ microelectrodes

\begin{tabular}{|c|c|}
\hline pH & Composition of buffer \\
\hline 4.0 & $\begin{array}{l}20 \mathrm{mM} \mathrm{KHC}_{8} \mathrm{H}_{4} \mathrm{O}_{4} \text { (potassium hydrogen phthalate) } \\
120 \mathrm{mM} \mathrm{KCl} \\
10 \mathrm{mM} \mathrm{NaH} \\
\text { Adjust pH using } 1 \mathrm{~N} \mathrm{NaOH}\end{array}$ \\
\hline 5.0 and 6.0 & $\begin{array}{l}20 \mathrm{mM} \mathrm{MES} \mathrm{(2-[N-Morpholino]ethanesulfonic} \mathrm{acid)} \\
120 \mathrm{mM} \mathrm{KCl} \\
10 \mathrm{mM} \mathrm{NaH} \\
\text { Adjust pH using } 1 \mathrm{~N} \mathrm{NaOH}\end{array}$ \\
\hline 7.0 & $\begin{array}{l}20 \mathrm{mM} \mathrm{MOPS} \mathrm{(3-[N-Morpholino]propanesulfonic} \mathrm{acid)} \\
120 \mathrm{mM} \mathrm{KCl} \\
10 \mathrm{mM} \mathrm{NaH}_{2} \mathrm{PO}_{4} \times 2 \mathrm{H}_{2} \mathrm{O} \\
\text { Adjust pH using } 1 \mathrm{~N} \mathrm{NaOH}\end{array}$ \\
\hline 8.5 & $\begin{array}{l}20 \mathrm{mM} \text { TAPS (N-tris[Hydroxymethyl]methyl-3-amino- } \\
\text { propanesulfonic acis) } \\
120 \mathrm{mM} \mathrm{KCl} \\
10 \mathrm{mM} \mathrm{NaH} \mathrm{PO}_{4} \times 2 \mathrm{H}_{2} \mathrm{O} \\
\text { Adjust pH using } 1 \mathrm{~N} \mathrm{NaOH}\end{array}$ \\
\hline
\end{tabular}

\subsection{Confocal microscopy}

The $\mathrm{pH}$ sensitive fluorochromes $5(6)$ carboxyfluorescein $(10 \mu \mathrm{M})$ and acridine orange $(2.5 \mu \mathrm{M})$ were used. In contrast to carboxyfluorescein, acridine orange can be taken up into cells and has been widely used to monitor $\mathrm{pH}$ inside animal (Wieczorek et al., 1991; Zoccarato et al., 1999; Malnic \& Geibel, 2000) and plant cells (Pope \& Leigh, 1988; DuPont, 1989). Carboxyfluorescein is a large double-negative charged anion that can permeate the plasma membrane only in its non-fluorescing diacetate form (Babcock, 1983; Graber et al., 1986). By using its anionic form, its presence in the apoplast and absence in the symplast was guaranteed. The application of acridine orange has some limitations (Palmgren, 1991) but with adequate controls these limitations can be overcome (Clerc \& Barenholz, 1998; Manente et al., 2008). The fluorescence intensity of carboxyfluorescein between $\mathrm{pH} 4.5$ and 6.5 can be used to reflect changes in $\mathrm{pH}$ conditions in this $\mathrm{pH}$ range (Babcock, 1983; Graber et al., 1986).

Dyes were added to the root medium of intact plants in the growth chamber. Plants were allowed to take up dyes into the apoplastic space of both roots and leaves and analysed after an incubation period of $24 \mathrm{~h}$ (carboxyfluorescein) and $48-72 \mathrm{~h}$ (acridine orange). Detached leaves, epidermal peels or leaves still attached to the remainder of the plant were examined with an Olympus FV1000 confocal microscope. Dyes were excited at $488 \mathrm{~nm}$ and fluorescence was detected between 
$500-550 \mathrm{~nm}$ (carboxyfluorescein) and 516 - $536 \mathrm{~nm}$ (acridine orange). To test how effective the uptake of dye into the leaf apoplast had been during the incubation period and how $\mathrm{pH}$ sensitive the approach was, epidermal strips were peeled from first leaves of incubated barley plants or from the elongation zone and emerged blade of leaf three. The strips were placed into buffers of specified $\mathrm{pH}$ for $30 \mathrm{~min}$, before being examined under the confocal microscope. Calibration of fluorochromes was carried out with a Leica DMIL fluorescence microscope. The microscope's excitation filter was cut between $450-490 \mathrm{~nm}$ and the suppression filter at $515 \mathrm{~nm}$. For pH calibration, $50 \mathrm{mM}$ phthalate buffer (pH 4.0), $100 \mathrm{mM}$ MES / KOH (pH 5.5, $\mathrm{pH}$ 6.5) and $100 \mathrm{mM}$ TRIS-HCl (pH 7.5) was used. Digital images were analysed with ImageJ 1.410 software (http://rsbweb.nih.gov/ij) and Adobe ${ }^{\circledR}$ Photoshop ${ }^{\circledR}$ 7.0.1.

The $\mathrm{pH}$ dependence of fluorescence of 5(6)carboxyfluorescein and acridine orange were examined by recording fluorescence spectra at different $\mathrm{pH}$ using a FluoraMax-2 ${ }^{\circledR}$ (Instruments S.A.) (pH 5.0; pH 5.5; pH 6.0 - 50 mM MES-KOH; pH 6.5 - $50 \mathrm{mM}$ MES-BisTRIS and $\mathrm{pH} 7.0 ; \mathrm{pH} 7.5-50 \mathrm{mM}$ HEPES-HCl).

\section{$2.3 \quad$ LVDT measurements}

A linear variable differential transformer (LVDT) was used to measure changes in leaf length continuously and at micrometer resolution in response to treatments (compare Fricke, 2004; Fricke et al., 2004). The setup could also be used to determine changes in cell wall properties.

\subsubsection{Leaf growth measurements}

Plants were prepared in the same way as for electrophysiological analyses to be able to relate the results from both types of experiments to each other. Leaves one and two were peeled back and the exposed elongation zone of leaf three was wrapped in washed (24 $\mathrm{h}$ in distilled water) tissue paper which was soaked in the respective test solution. The wet tissue paper guaranteed a humid microclimate and prevented the elongation zone from drying out; it also allowed application of test reagents to the apoplast of elongating tissue. The base $40-50 \mathrm{~mm}$ of leaf three was wrapped to provide sufficient mechanical support to allow the leaf to remain in an upright position. Above $50 \mathrm{~mm}$ from the leaf base, the cuticle is sufficiently developed preventing the leaf tissue from drying out (Richardson et al., 2007). Roots were left in the same medium in which the particular plant had grown. The tip of leaf three was attached to fishing line and connected through cellotape to a LVDT (DFG 5.0; RS 
Components, Corby, UK). A counterweight of $2 \mathrm{~g}$ was applied. The LVDT signal was digitalised with a Burster 92101 data logger module with ICP 100 software. Changes in voltage output were recorded on PC using Pfloek 1.09 software (LS Pflanzenökologie, Universität Bayreuth, Germany). The system was calibrated by replacing the plant with a micrometer screw. The rate of growth was calculated from LVDT outputs using Origin ${ }^{\circledR} 6.1$ software (OriginLab Corporation) and Microsoft ${ }^{\circledR}$ Excel. Although leaf elongation rate was comparable between replicate plants and batches, values for treatments were expressed as percentage of the control to further minimise any plant-to-plant variation. The control value was the elongation rate of a particular plant attached to the LVDT before a treatment was applied. Typically, control plants had the elongation zone of leaf three wrapped with tissue paper soaked in either 1 or $0.1 \mathrm{mM} \mathrm{KCl}$. It took up to $1 \mathrm{~h}$ for elongation rate to reach a steady level following attachment of plants to the LVDT. Application of vanadate and $\mathrm{CsCl}$ treatments required a similar period of stabilisation (about $1 \mathrm{~h}$ ), while application of fusicoccin and ammonium treatments required leaf elongation rate to stabilise for up to 2 - $3 \mathrm{~h}$. LVDT experiments were carried out at room temperature and humidity under ambient laboratory light.

To assess how much plant preparation affected the elongation rate of leaf three, intact plants which did not have leaves one and two peeled back, were attached to the LVDT. In addition, leaf elongation rate was determined for undisturbed plants in the growth chamber by measuring twice daily the increment in leaf length with a ruler.

\subsubsection{Analysis of cell wall properties}

Cell wall elasticity and plasticity was measured with the same LVDT system as described above by applying an additional $3 \mathrm{~g}$ counterweight for $10 \mathrm{~min}$ following the approach taken by Neumann (1993) (see also Chazen \& Neumann (1994) and Sabrizhanova et al. (2005)). Plants were prepared and chemical treatments applied in the same way as for growth analyses. When the growth rate had stabilised (control, treatment), the additional $3 \mathrm{~g}$ counterweight was applied to the LVDT for 10 min and then removed; 30 - 40 min later, when growth rate had stabilised again, the experiment was repeated, and the average of these two measurements was used for calculations of wall properties. Elasticity and plasticity of walls and growth rate with and without the applied force (additional $3 \mathrm{~g}$ counterweight) was calculated from LVDT traces as detailed in Fig. 2.2. 


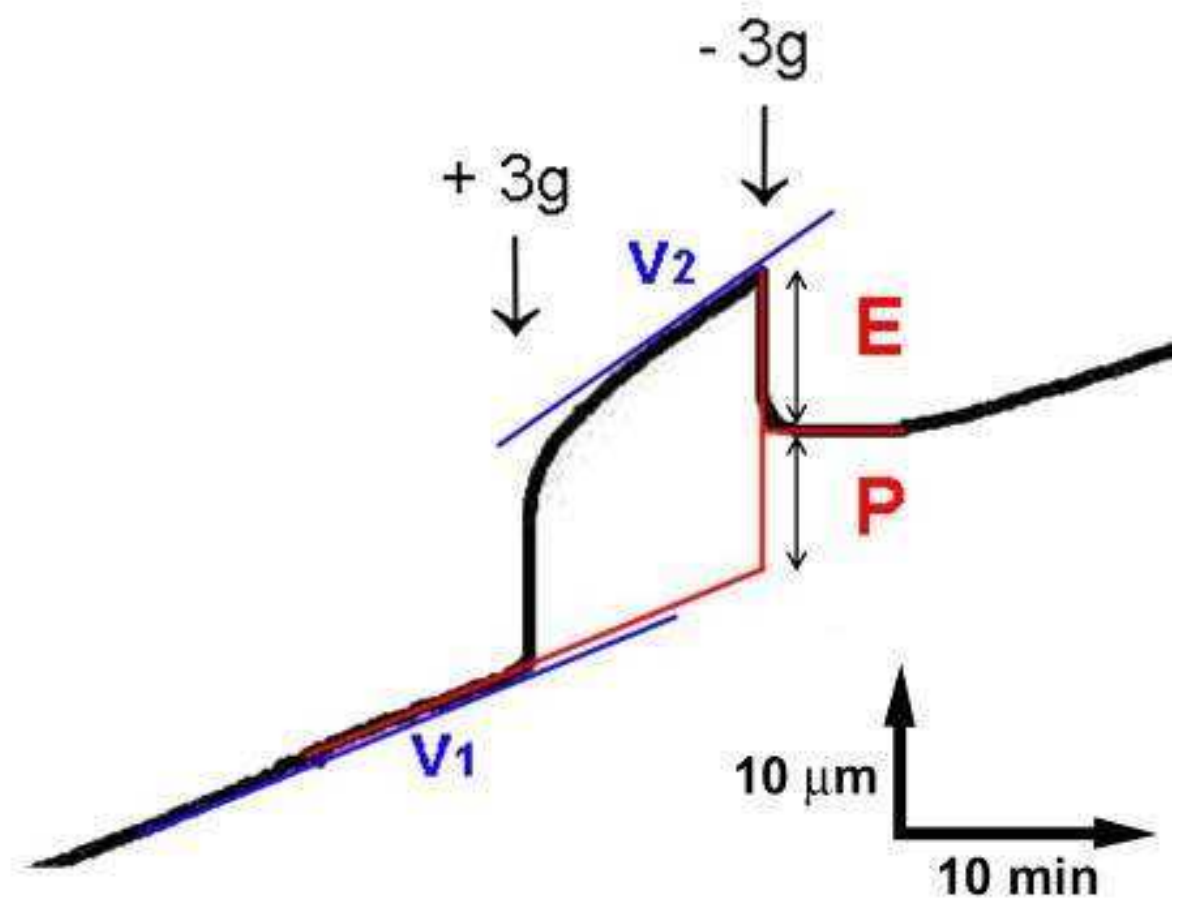

Figure 2.2 Measurement of cell wall properties

LVDT traces show the change in leaf length with time. LVDT traces before and after application of an additional $3 \mathrm{~g}$ counterweight ( $0.03 \mathrm{~N}$ of applied force), growth rates were calculated from the slope of the lines fitted to the stabilised part of traces $\left(\mathrm{v}_{1}\right.$ and $\mathrm{v}_{2}$ ). The applied force caused an extension, part of which was reversible (elasticity, E) of wall) and part of which was irreversible (plasticity, P of wall).

\section{$2.4 \quad$ Expression analyses}

The aim of expression analyses was to test whether any elevated proton efflux in the leaf elongation zone was due to higher PM- $\mathrm{H}^{+}$-ATPase expression.

\subsubsection{Plant harvest}

Plants were harvested $2-6 \mathrm{~h}$ into the photoperiod. Samples from the elongation zone were about $1 \mathrm{~cm}$ long and were cut from the mid-portion of the elongation zone (between $20-30 \mathrm{~mm}$ from the leaf base). Samples of the emerged blade were $1-2 \mathrm{~cm}$ long and taken from the mid-portion of the part of leaf three that had emerged from the sheath of leaf two. The leaf segments were weighed on a digital balance (Mettler Toledo, Sweden), immediately frozen in liquid nitrogen and stored at $-80{ }^{\circ} \mathrm{C}$ until they were used for RNA extraction. 


\subsubsection{RNA extraction and CDNA synthesis}

For RNA extraction, corresponding leaf segments from 3 - 4 plants were pooled; their combined fresh weight was between $0.04-0.07 \mathrm{~g}$ (Besse et al., 2011) Total RNA was extracted using a QUIAGEN RNeasy kit following the manufacturer's instructions. RNA was eluted into $50 \mu \mathrm{l}$ RNase free water. The concentration and quality of RNA was determined with Nanodrop ${ }^{\circledR}$ (ThermoFisher Scientific Inc., Waltham, USA).

After DNase treatment, following the manufacturer's instructions (Deoxyribonuclease I, Amplification Grade; Invitrogen Corporation, Carlsbad, California, USA), $1 \mu \mathrm{g}$ RNA was used for cDNA synthesis. CDNA synthesis was performed as recommended by the manufacturer (SuperScriptTM II Reverse Transcriptase; Invitrogen Corporation, Carlsbad, California, USA) using anchor oligo ${ }_{d} T_{16}$ primer. The final volume of cDNA was $20 \mu \mathrm{l}$. Details of the procedure and reagents used are provided in Table 2.4.

In some experiments, RNA was also extracted from protoplasts. RNA extraction from a protoplast suspension was carried out in a way similar to the one described above, with minor modifications. RNeasy lysis buffer (300 - $1000 \mu \mathrm{l})$ was added to $300-1000 \mu \mathrm{l}$ protoplast suspension ( $0.5-7$ million protoplasts) or to $1 \mathrm{ml}$ cell-free protoplast isolation medium. The latter was used as background control to reflect RNA released from broken cells or protoplasts into the isolation medium and was prepared by centrifuging the protoplast suspension at $30 \mathrm{~g}$ for $1 \mathrm{~min}$ and taking the supernatant and centrifuging it again at $12,000 \mathrm{~g}$ for $5 \mathrm{~min}$. The final volume of RNA extract for protoplasts or isolation medium was $30 \mu \mathrm{l}$ rather than $50 \mu \mathrm{l}$ as obtained for leaf extracts. 
Table 2.4 DNase treatment and reverse transcription

\begin{tabular}{|l|l}
$1 \mu \mathrm{g}(8 \mu \mathrm{l})$ RNA & \\
$1 \mu \mathrm{l} 10 \mathrm{x}$ DNasel Reaction buffer & \\
$1 \mu \mathrm{l}(1 \mathrm{U})$ DNasel Ampl. Grade enzyme & $10 \mu \mathrm{l}$ \\
\hline Incubation $15 \mathrm{~min} 25 \mathrm{C}$ & \\
& \\
$1 \mathrm{ml}$ EDTA $(25 \mu \mathrm{M})$ & $11 \mu \mathrm{l}$ \\
\hline Incubation $10 \mathrm{~min} 65 \mathrm{C}$ &
\end{tabular}

\section{Reverse transcription}

\begin{tabular}{|c|c|}
\hline $\begin{array}{l}11 \mu \mathrm{l} \text { sample from DNase treatment } \\
1 \mu \mathrm{l} \text { anchor oligo-dT primer }(100 \mu \mathrm{M}) \\
1 \mu \mathrm{l}{ }_{\mathrm{d}} \text { NTP }(10 \mathrm{mM})\end{array}$ & $13 \mu \mathrm{l}$ \\
\hline $\begin{array}{l}\text { Incubation } 5 \text { min } 65 C \\
4 \mu \mathrm{l} 5 x \text { First-Strand Buffer } \\
2 \mu \mathrm{ITT}(0.1 \mathrm{M})\end{array}$ & $19 \mu \mathrm{l}$ \\
\hline $\begin{array}{l}\text { Incubation } 2 \text { min } 42 \text { C } \\
1 \mu \mathrm{l} \text { SuperSript }{ }^{\top \mathrm{M}} \mathrm{RT} \text { Enzyme (200U) }\end{array}$ & $20 \mu \mathrm{l}$ \\
\hline $\begin{array}{l}\text { Incubation } 50 \text { min } 42 \text { C then } 70 \times 15 \\
\text { min }\end{array}$ & \\
\hline
\end{tabular}

\subsubsection{PCR}

Before cDNA samples were used for $\mathrm{QPCR}$ analysis, which required expensive reagents, the quality of CDNA, suitability of designed primers and optimum PCR conditions was tested through conventional PCR (G-Storm 482 thermocycler, Gene Technology). A GoTaq ${ }^{\circledR}$ Flexi DNA Polymerase (Promega Corporation, Madison, USA) kit was used in $25 \mu$ total volume with $1 \mu \mathrm{l}$ 200x diluted cDNA as template. A precise protocol of the PCR reaction is given in Table 2.5. Primers are listed in Table 2.6. The PCR was run in amplification two steps; after initial step (95 ${ }^{\circ}$; $30 \mathrm{~s}$ ) through 35 cycle step one $\left(95^{\circ} \mathrm{C}, 30 \mathrm{~s}\right)$ and step two $\left(60^{\circ} \mathrm{C}, 60 \mathrm{~s}\right)$ were repeated and then a final step $\left(72^{\circ} \mathrm{C}, 120 \mathrm{~s}\right)$ was used as Fi g. 2.3 shows.

PCR products were separated on $1 \%$ agarose gels in 0.5 strength TRIS base boric acid EDTA (TBA, see Table 2.7) buffer containing $1 \mu \mathrm{g} \mathrm{ml}^{-1}$ ethidium bromide and viewed under UV light (Image Master ${ }^{\circledR}$ VDS, Pharmacia Biotech, USA). 
Table 2.5 Components of PCR reactions

\begin{tabular}{|c|c|c|}
\hline Component & Volume & Final concentration \\
\hline 5x Green GoTaq ${ }^{\circledR}$ Flexi Buffer & $5 \mu \mathrm{l}$ & $1 \mathrm{x}$ \\
\hline MgCl Solution (25 mM) & $2 \mu \mathrm{l}$ & $2 \mu \mathrm{M}$ \\
\hline dNTP (10 mM) & $0.5 \mu \mathrm{l}$ & $0.2 \mu \mathrm{M}$ each nucleotide \\
\hline Forward primer (10 mM) & $0.5 \mu \mathrm{l}$ & $0.2 \mu \mathrm{M}$ \\
\hline Reverse primer (10 mM) & $0.5 \mu \mathrm{l}$ & $0.2 \mu \mathrm{M}$ \\
\hline GoTaq® DNA Polymerase (5 U / ml) & $0.125 \mu \mathrm{l}$ & $0.625 \mathrm{U}$ \\
\hline Template cDNA (200x diluted) & $1 \mu \mathrm{l}$ & $5000 x$ diluted \\
\hline Nuclease-Fee Water & $15.375 \mu \mathrm{l}$ & $\mathrm{N} / \mathrm{A}$ \\
\hline Total volume & $25 \mu \mathrm{l}$ & \\
\hline
\end{tabular}

Table 2.6 PCR primers

Primer name

Anchor oligo $\mathrm{d}_{\mathrm{d}} \mathrm{T}_{16}$

Primer sequence

ATPase forward 5'NVTTTTTTTTTTTTTTTT3'

ATPase reverse 5'ACATCGACACCATCAACCAA3' 5'ACAACTAGGGGCTGGTCAGA3'

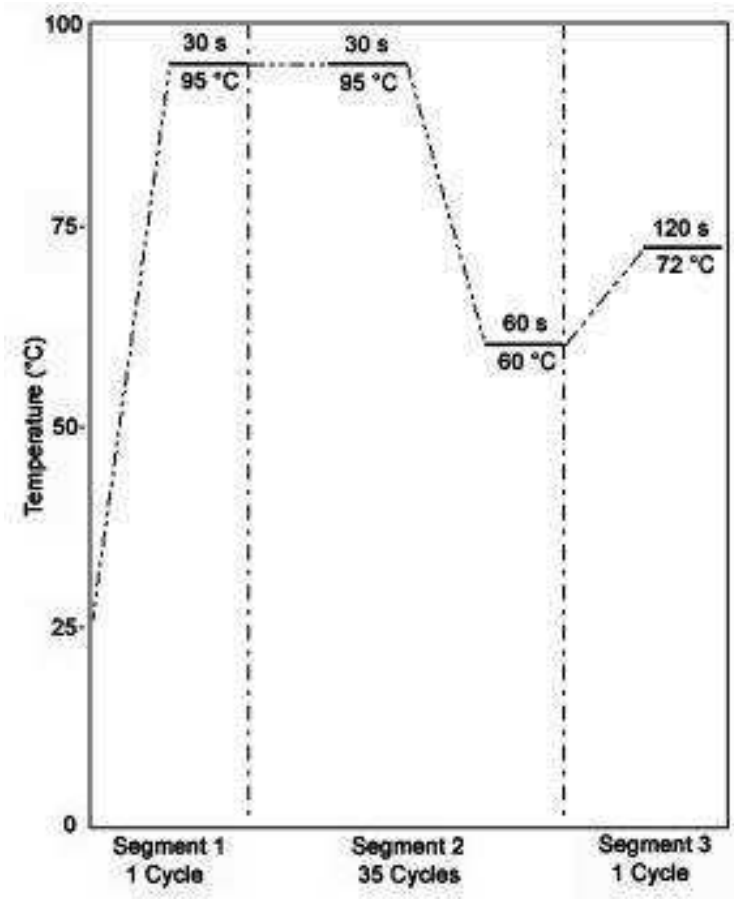

Figure 2.3 Thermal profile of the two step PCR reactions

Two step PCR protocol was used when quality of CDNA or primers were tested. This protocol was as similar as possible to the protocol used for QPCR analyses.

Table 2.7 Composition of the stock solution (5x concentrated) of TRIS base boric acid EDTA buffer (TBA)

\begin{tabular}{l|r} 
Component & Amount for 1 I \\
\hline \hline TRIS base & $53 \mathrm{~g}$ \\
\hline Boric acid & $27.5 \mathrm{~g}$ \\
\hline EDTA $(0.5 \mathrm{M}, \mathrm{pH} 8.0)$ & $20 \mathrm{ml}$
\end{tabular}




\subsection{4 $\quad$ QPCR}

qPCR expression analysis was carried out on a real time thermal cycler STRATAGENE Mx3000P (Agilent Technologies, Inc., Santa Clara, USA), using a SYBRgreen master mix and following the supplier's instructions (SYBR ${ }^{\circledR}$ Premix Ex $\mathrm{Taq}^{\mathrm{TM}}$, Takara Bio Inc, Otsu, Japan) (see Table 2.8). The reaction mix was loaded onto 96-well plates (96 Multiply PCR plate natural, SARSTEDT AG \& Co., Nümbrecht, Germany). Three technical and biological (independent batches of plants) replicates were run together with external standards (purified PM- $\mathrm{H}^{+}-\mathrm{ATPase}$ PCR product; see below) on the same plate. Samples were maintained for $10 \mathrm{~s}$ at $95^{\circ} \mathrm{C}$ as initial step, then $5 \mathrm{~s}$ at $95^{\circ} \mathrm{C}$ and $30 \mathrm{~s}$ a t $60^{\circ} \mathrm{C}$ through 45 cycles. After amplification, melting curves were recorded $\left(95^{\circ} \mathrm{C} 1 \mathrm{~min}\right.$ then temperature gradient from $55^{\circ} \mathrm{C}$ to $95^{\circ} \mathrm{C}$ in 81 steps) to check product s ize and homogeneity, see also Fig. 2.4.

\section{Table 2.8 Components of qPCR reaction}

\begin{tabular}{|c|c|c|}
\hline Component & Final Volume & Final concentration \\
\hline SYBR $^{\circledR}$ Premix Ex Taq ${ }^{I M}$ & $6.25 \mu \mathrm{l}$ & $1 \mathrm{x}$ \\
\hline Forward primer (10 mM) & $0.25 \mu l$ & $0.2 \mu \mathrm{M}$ \\
\hline Reverse primer (10 mM) & $0.25 \mu \mathrm{l}$ & $0.2 \mu \mathrm{M}$ \\
\hline Rox Dye II & $0.25 \mu \mathrm{l}$ & $\mathrm{N} / \mathrm{A}$ \\
\hline Template cDNA (200x diluted) & $1 \mu \mathrm{l}$ & 2500x diluted \\
\hline Nuclease-Free Water & $4.5 \mu \mathrm{l}$ & $\mathrm{N} / \mathrm{A}$ \\
\hline Total volume & $12.5 \mu \mathrm{l}$ & \\
\hline
\end{tabular}

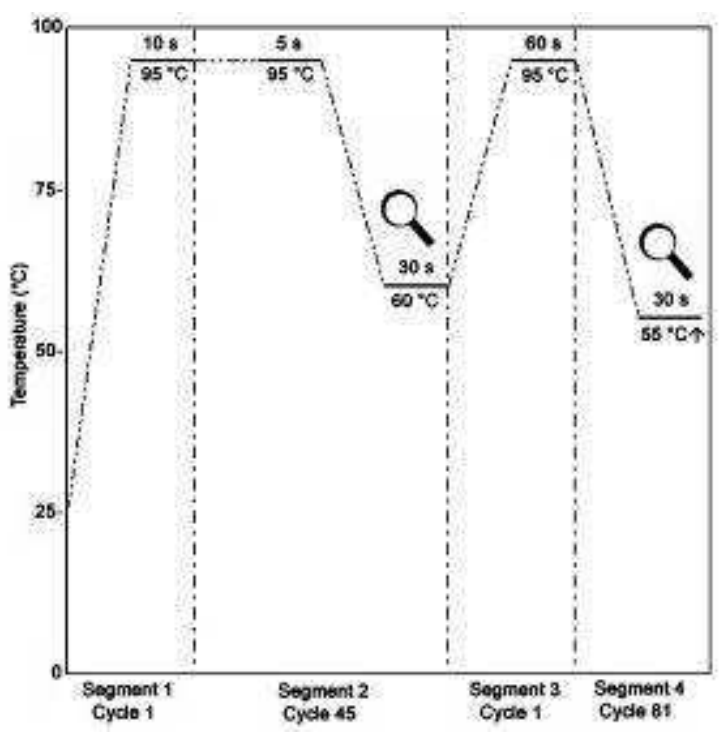

Figure 2.4 Thermal profile of qPCR reactions

Magnifying glass symbols indicate detection sites of SYBR Green fluorescence 
To quantify the number of mRNA transcripts of the target gene $\left(\mathrm{PM}-\mathrm{H}^{+}\right.$ATPase), cDNA samples which contained known copy numbers of PM- $\mathrm{H}^{+}$-ATPase cDNA molecules were required. This external standard was obtained by purifying PM- $\mathrm{H}^{+}$-ATPase PCR product and a $\mathrm{pCR}^{\circledR} 8 / \mathrm{GW} / \mathrm{TOPO}$ construct that contained the ATPase PCR product as insert. Initially, the plasmids were used as an alternative external standard in addition to purified $\mathrm{PM}-\mathrm{H}^{+}-\mathrm{ATPase}$. However, preliminary experiments showed that purification of plasmids from E. coli cells did not yield sufficiently pure product to use it as external standards.

To obtain purified ATPase PCR product, PCR was performed in $50 \mu \mathrm{l}$ volume as described above using colourless reaction buffer. After the quality of PCR product was checked by running the samples on an agarose gel, the PCR product was cleaned with a NucleaSpin ${ }^{\circledR}$ Extract II PCR clean-up / Gel extraction kit (Macherey-Nagel GmbH \& Co. KG, Germany) following the manufacturer's instructions. The purified DNA was eluted from the NucleaSpin ${ }^{\circledR}$ Extract II Column with nuclease free water. The DNA content was measured with Nanodrop ${ }^{\circledR}$ (ThermoFisher Scientific Inc., Waltham, USA) and the concentration / copy number of cDNA molecules was calculated from the expected molecular weight of the cDNA product for $\mathrm{PM}-\mathrm{H}^{+}$-ATPase $\left(100,587 \mathrm{~g} \mathrm{~mol}^{-1}\right)$. From this purified stock, dilutions of $0.5,5,50,5 \cdot 10^{2}, 5 \cdot 10^{3}, 5 \cdot 10^{4}$ and $5 \cdot 10^{5}$ copy $\mu l^{-1}$ were prepared.

\subsubsection{Analysis of qPCR data}

An absolute quantification method was used to compare the $\mathrm{PM}-\mathrm{H}^{+}-\mathrm{ATPase}$ expression between elongation zone and fully developed emerged blade. This approach was chosen in favour of the conventional $\Delta$-Ct approach (Pfaffl, 2001) because the generally most suitable reference gene of expression e.g. ubiquitin, gave more than one PCR product due to the existence of poly-ubiquitins. Using the Genevestigator (http://genevestigator.com) online application this problem (Hruz et al., 2011) could not be solved.

To further relate the copy number of transcripts to a biologically relevant size, qPCR results were expressed per cell or per $\mathrm{mm}^{2}$ plasma membrane surface. The total number of cells and plasma membrane surface contained in the plant material which was used for extraction was calculated based on the water content of leaf tissue, protoplast number and stereological electron and light microscopic analyses as detailed in section 2.5. 


\subsection{Cell size and tissue ratio measurements}

Cell size and tissue ratio in different leaf regions (elongation zone and emerged leaf blade) were determined and data combined with published data to calculate the total number of cells which were contained in samples used for qPCR analysis.

\subsubsection{Mesophyll and epidermis cell size}

The diameter of mesophyll cells was measured on living protoplasts with the help of Scion Image for Windows 4.0.3.2 (http://www.scioncorp.com) software. The data were then combined with data obtained by Volkov et al. $(2007,2009)$ for the same barley cultivar (Golf) and data obtained by Kavanagh (2010) through stereological electron-microscopic analyses. Epidermal cell size was calculated based on stereological results of Kavanagh (2010) and a light-microscopic study of Fricke \& Flowers (1998) on the same barley cultivar (Golf) studied.

\subsubsection{Tissue ratio calculation in elongation zone and emerged blade}

The percentage of cross-sectional leaf volume occupied by leaf tissues (epidermis; mesophyll including vascular parenchymateous bundle sheath; vascular bundles except parenchymateous bundle sheath) and intercellular air space was determined on paraffin-embedded toluidine blue-stained cross sections (few micrometers thick) with the help of Adobe ${ }^{\circledR}$ Photoshop ${ }^{\circledR}$ 7.0.1 and Scion Image for Windows 4.0.3.2 software. By assuming that intercellular air spaces did not contain any significant amount of liquid, but that almost all liquid was contained within tissues, it was possible to calculated the total water content (and approximate) volume of each tissue used for RNA extraction since the water content of leaf samples had been determined.

\subsubsection{Cell size and plasma membrane surface estimation for $q P C R$}

\section{$\underline{\text { analysis }}$}

Mesophyll cells volume and surface were calculated as they were spheres using the equation of $(\pi / 6) \mathrm{d}^{3}$ for volume and $\pi \mathrm{d}^{2}$ for surface. Epidermis cells were treated as long rods. In the total cell volume different cell types were present as their corrected tissue share. Corrected tissue share was calculated as dividing the tissue share by (1-share of air space) because air space did not contains any living plant cell. The 
whole calculation and data can find in the Results at section 3.3 .2 and in the Appendix.

\subsection{Plasma membrane isolation}

Plasma membranes were isolated from barley seedlings following the approach developed by Kjellbom \& Larsson (1984) and Yan et al., (1998). All steps were performed under cold conditions. For each plasma membrane isolation between 1.5 - $6 \mathrm{~g}$ of plant material was required (elongation zone; emerged blade). Between 200 - 400 barley seedlings had to be grown and harvested in each experiment.

\subsubsection{Plant harvest}

Plant tissues, elongation zone (basal $40 \mathrm{~mm}$ without the lower 1 - $2 \mathrm{~mm}$, containing meristematic zone) and emerged blade (leaf blade without the lower and upper $1 \mathrm{~cm}$ ) of barley (cv Jersey) leaf three were harvested into $50 \mathrm{ml}$ ice cold homogenisation buffer (all components are listed in Table 2.9). The tissues were gently vacuum infiltrated (3 times using a laboratory water jet vacuum pump) and used immediately for plasma membrane isolation.

Table 2.9 Composition of the homogenisation buffer used for membrane isolation

\begin{tabular}{l|l} 
Component & Final concentration \\
\hline Sucrose & $500 \mathrm{mM}$ \\
\hline EDTA & $2 \mathrm{mM}($ from $200 \mathrm{mM}$ stock $)$ \\
\hline Glycerol & $10 \%(\mathrm{v} / \mathrm{v})$ \\
\hline BSA & $0.5 \%(\mathrm{w} / \mathrm{v})$ \\
\hline DTT & $2 \mathrm{mM}$ \\
\hline PMSF & $1 \mathrm{mM}\left(\right.$ prepared freshly from $12 \mathrm{mg} \mathrm{ml}^{-1} \mathrm{EtOH}$ stock $)$ \\
\hline$\beta$-mercaptoethanol & $5 \mathrm{mM}$ \\
\hline Non-soluble PVP & $1 \%(\mathrm{w} / \mathrm{v})$ \\
\hline Na-ascorbate & $0.1 \%(\mathrm{w} / \mathrm{v})$ prepared freshly \\
\hline HEPES-KOH & $50 \mathrm{mM}$ set to $\mathrm{pH} 7.8$
\end{tabular}

\subsubsection{Preparation of microsomal fraction}

Tissues were homogenised in the homogenisation buffer with a razor blender (3 times $25 \mathrm{sec}$ ). The homogenate was filtered through four layers of gauze and one layer of Miracloths (Fisher Scientific). The filtrate was centrifuged at $11,500 \mathrm{~g}$ for 10 min at $4{ }^{\circ} \mathrm{C}$ (Sigma $3 \mathrm{~K} 15$ and $3 \mathrm{~K} 10$ bench top centrifu ge, fixed angle rotor). The supernatant was collected and centrifuged at 30,000 rpm $(\sim 82,000 \mathrm{~g})$ in a 
Beckman L7-65 ultracentrifuge for 40 min with a SW40Ti swinging bucket rotor. The resulting microsomal pellet was resuspended in phase buffer (Table 2.10).

Table 2.10 Composition of the phase buffer used for membrane isolation

Component

Sucrose

$\mathrm{KCl}$

$\mathrm{KH}_{2} \mathrm{PO}_{4}$

$\mathrm{K}_{2} \mathrm{HPO}_{4}$

$\mathrm{KOH}$
Final concentration

$330 \mathrm{mM}$

$3 \mathrm{mM}$

$5 \mathrm{mM}$

$5 \mathrm{mM}$

To adjust buffer to $\mathrm{pH} 7.8$

\subsubsection{Purification of plasma membrane vesicles}

The microsomal fraction was further fractioned by a two-phase aqueous dextran T-500 and PEG-3350 system. From the polymers, $20 \%$ (w/w) (dextran) and $40 \%$ $(w / w)$ (PEG) stock solutions were made in phase buffer. The final concentration of both polymers was $6.1 \%(\mathrm{w} / \mathrm{w})$ in the start tube, taking into account dilution through addition of phase buffer and resuspended microsomal fraction. The final weight of the tube was $12 \mathrm{~g}$. The tube was mixed by inversion 30 times and the phase separation was carried out by centrifugation at $1,500 \mathrm{~g}$ at $4{ }^{\circ} \mathrm{C}$ (Sigma $3 \mathrm{~K} 15$ and $3 \mathrm{~K} 10$ bench top centrifuge with swinging bucket rotor) for $25 \mathrm{~min}$. The upper phase was transferred into a new tube and completed to $12 \mathrm{~g}$ with fresh lower phase (prepared separately with the help of extraction funnel). The separation was done as before but for $15 \mathrm{~min}$, and this purification step was repeated 3 - 4 times until the upper phase became clear and did not show any green colour (which would have been indicative of contamination with chloroplast membranes) (Fig. 2.5). The final upper phase was diluted 3 - 4x with phase buffer and ultracentrifuged (35,000 rpm, $1 \mathrm{~h})$. The pellet was resuspended in resuspension buffer (Table 2.11) and washed by ultracentrifugation $(35,000 \mathrm{rpm}, 1 \mathrm{~h})$ two times in resuspension solution. The final purified pellet was resuspended in 50 - $150 \mu \mathrm{l}$ resuspension buffer and divided into aliquots, frozen in liquid nitrogen and stored at $-80^{\circ} \mathrm{C}$.

Table 2.11 Composition of the resuspension buffer used for membrane isolation

\begin{tabular}{l|l} 
Component & Final concentration \\
\hline \hline Sucrose & $330 \mathrm{mM}$ \\
\hline $\mathrm{KCl}$ & $3 \mathrm{mM}$ \\
\hline $\mathrm{KOH}$ & To set $\mathrm{pH} 7.8$
\end{tabular}



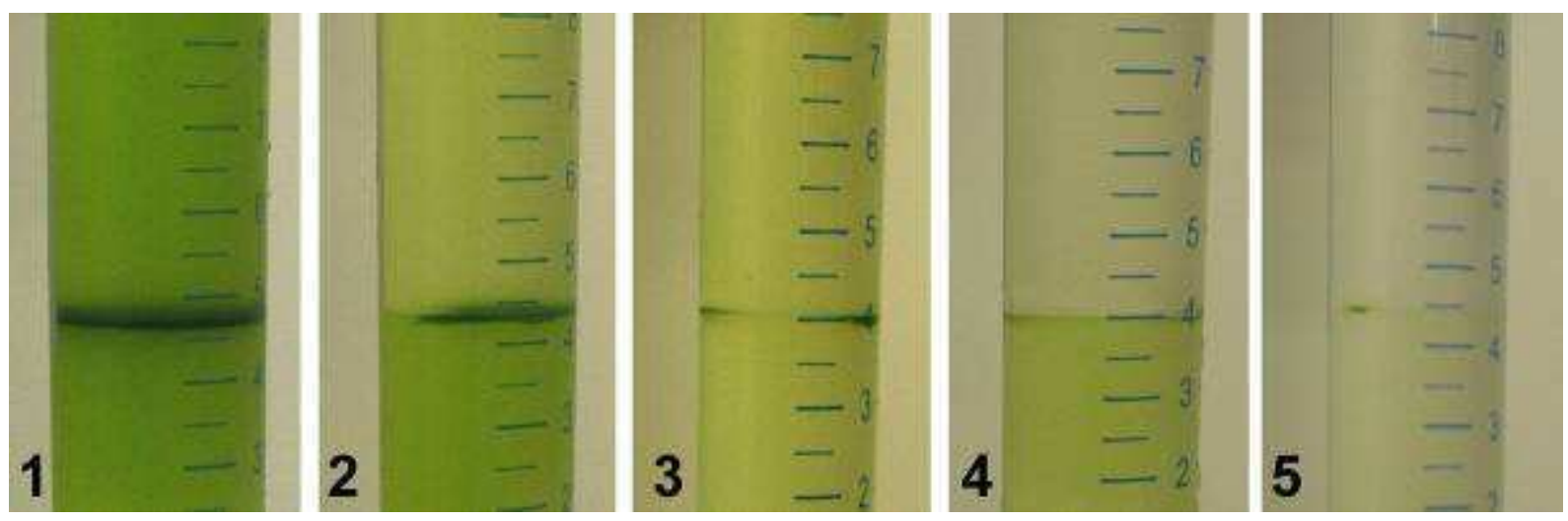

Figure 2.5 Five purification steps during plasma membrane isolation.

The upper phase becomes less and less green (indicative of thylakoid contamination). After the $5^{\text {th }}$ step the upper phase is clear, no green colour is seen.

\subsection{Determination of the total protein content of plasma membrane vesicles}

\subsubsection{Bradford method}

The protein content of plasma membrane preparation was estimated using the method of Bradford (Kruger, 2002). The reagent was prepared and filtered through Whatman no. 1 filter paper. It was stored at room temperature in an amber bottle and used within weeks. The composition of the reagent is given in Table 2.12. The assays were carried out in duplicates in $1.1 \mathrm{ml}$ final volume. For the calibration curve $0,1,2,4,6$ and $8 \mu \mathrm{g}$ bovine serum albumin (BSA) was used as standards. Absorbance was measured at $595 \mathrm{~nm}$ between 5 to $15 \mathrm{~min}$ following addition of Bradford reagent to samples (PerkinElmer Lambda25 UV/VIS Spectrophotometer)

\section{Table 2.12 Composition of Bradford reagent}

\begin{tabular}{l|r} 
Component & Amount of the component \\
\hline \hline Coomassie Brilliant Blue G250 & $100 \mathrm{mg}$ dissolved in 50 ml 95\% ethanol \\
\hline Phosphoric acid 85\% & $100 \mathrm{ml}$ \\
\hline Distilled water & Made up to $1 \mathrm{I}$
\end{tabular}

\subsubsection{Densitometric analysis of Laemmli gels}

The final values of protein concentration (used for ATPase assay, densitometry on polyacrylamide gels and Western blot analysis) were calculated from Laemmli gels (Sárvári et al, unpublished) using the modified protein solubilisation described below. Known volume of membrane vesicle sample (determined based on protein measurement using Bradford method, usually between $5-30 \mu \mathrm{l}$ ) were run on a gradient SDS polyacrylamid gel together with protein standards (Sigma). The amount 
of total membrane protein was calculating by densitometry by Phoretix 4.01 software (Phoretix International). A typical gel photo is shown in Fig. 2.6.

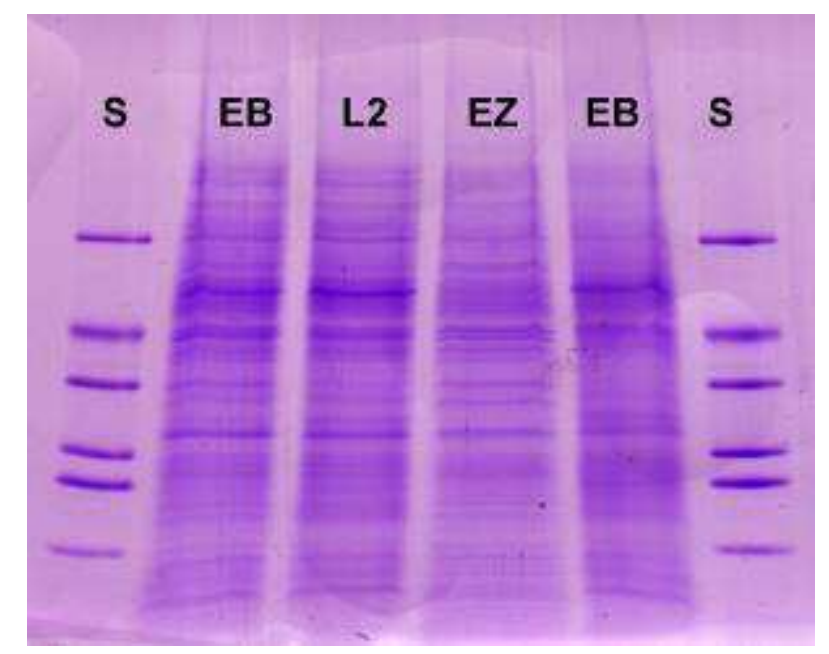

Figure 2.6 Typical gel for the measurement of protein content of plasma membrane samples

Coomassie Brilliant Blue R250 stained SDS gels were used to determine the total membrane protein content of different samples through a densitometric approach. EB - emerged leaf blade of leaf three; EZ - elongation zone of leaf three; L2 - mature blade of leaf two; S - Sigma protein standard, with a total protein content of $17.5 \mu \mathrm{g}$ ( $2.5 \mu \mathrm{g}$ each band) and proteins of molecular weights 66 (uppermost band), 45, 36, 29, 24, 20.1 and $14.2 \mathrm{kDa}$ (lowermost band).

\subsection{Polyacrylamide gel electrophoresis (PAGE)}

Qualitative and quantitative analyses were carried out on isolated plasma membrane vesicles using polyacrylamide gel electrophoresis (PAGE).

\subsubsection{Gradient polyacrylamide gel electrophoresis (PAGE)}

A gradient polyacrylamide gel electrophoresis was performed based on (Laemmli, 1970 ), with some modification in the solubilisation of membrane protein, to check the quality of isolated plasma membrane fraction and quantify its (total) protein content.

\subsubsection{Solubilisation of membrane protein}

To optimise the solubilisation of plasma membrane protein, the approach taken by Kjellbom \& Larsson (1984) was followed. Triton $X^{\circledR}-100$ detergent was added to the Laemmli buffer. Equal volumes of $0.1 \%$ Triton $^{\circledR}-100$ and plasma membrane suspension were mixed and vortexed. The mixture was then combined with an equal volume of Laemmli buffer (Table 2.13), incubated at room temperature for $30 \mathrm{~min}$ 
and heated $\left(90^{\circ} \mathrm{C}\right)$ three times for $10 \mathrm{~s}$ each follow ed by vortexing. Non-solubilised protein was removed by centrifugation $(5 \mathrm{~min}$ at $10,000 \mathrm{~g}$ ) and the supernatant used for PAGE. With this modified solubilisation procedure, almost all protein was solubilised and no pellet was observed after centrifugation. In addition, gel bands stained with Coomassie Brilliant Blue R250 were much sharper and distinct (Fig. 2.7).

Table 2.13 Composition of Laemmli buffer used for PAGE

\begin{tabular}{l|r|r}
\hline Component & Concentration in the agent & Final concentration \\
\hline TRIS-HCl pH 6.8 & $2.3 \%(\mathrm{w} / \mathrm{v})$ & $0.76 \%(\mathrm{w} / \mathrm{v})$ \\
\hline SDS & $7.15 \%(\mathrm{w} / \mathrm{v})$ & $2.38 \%(\mathrm{w} / \mathrm{v})$ \\
\hline Glycerol & $30 \%(\mathrm{v} / \mathrm{v})$ & $10 \%(\mathrm{v} / \mathrm{v})$ \\
\hline DTT & $5.5 \%(\mathrm{w} / \mathrm{v})$ & $1.83 \%(\mathrm{w} / \mathrm{v})$ \\
\hline Bromophenol blue & $0,003 \%(\mathrm{w} / \mathrm{v})$ & $0.001 \%(\mathrm{w} / \mathrm{v})$
\end{tabular}

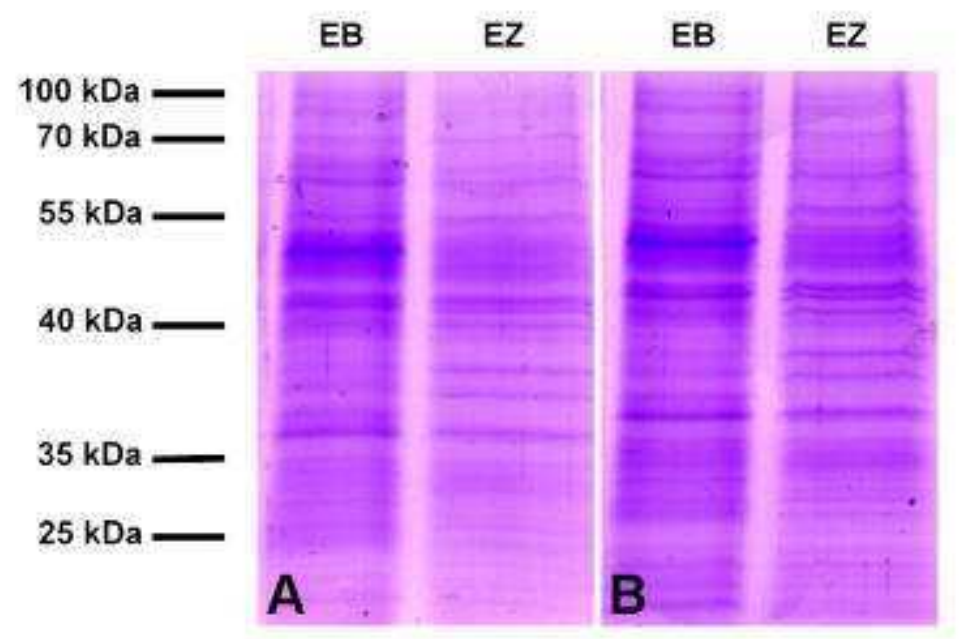

Figure 2.7 Coomassie Brilliant Blue R250 stained gradient PAGE gels which were loaded with plasma membrane protein solubilised in two different ways

Plasma membrane protein was solubilised using the conventional Laemmli solubilisation method (A) or a modification involving Triton $X^{\circledR}-100$ (B). The bands are sharper and more distinct using the modified solubilisation method. Samples were derived from the elongation zone (EZ) and emerged blade (EB) of leaf three of barley.

\subsubsection{Gradient PAGE gel system}

Solubilised proteins were separated on $7 \mathrm{~cm}$ long $10-18 \%$ gradient gels in a MiniProtean (BioRad Laboratories, Inc.) gel running system based on Laemmli (1970) under $20 \mathrm{~mA} / \mathrm{gel}$ at $4^{\circ} \mathrm{C}$ until the bromphen ol blue front exited the gel (after about $2 \mathrm{~h}$ ). The components of the gel are listed in Table 2.14. The acrylamide / bisacrylamide ratio was 30:0.8. 
Table 2.14 Components of the gradient PAGE system

Stacking gel

\begin{tabular}{l|r} 
Component & Concentration in the gel \\
\hline Acrylamide & $5 \%(\mathrm{w} / \mathrm{v})$ \\
\hline TRIS-HCl, $\mathrm{pH} 6.8$ & $125 \mathrm{mM}$ \\
\hline SDS & $0.1 \%(\mathrm{w} / \mathrm{v})$ \\
\hline TEMED & $0.01 \%(\mathrm{v} / \mathrm{v})$ \\
\hline APS (ammonium persulfate) & $0.1 \%(\mathrm{v} / \mathrm{v})$
\end{tabular}

Separation gel

\begin{tabular}{l|r|} 
Component & Concentration in the gel \\
\hline Acrylamide & $10-18 \%(\mathrm{w} / \mathrm{v})$ linear gradient \\
\hline TRIS-HCl, $\mathrm{pH} 6.8$ & $375 \mathrm{mM}$ \\
\hline SDS & $0.1 \%(\mathrm{w} / \mathrm{v})$ \\
\hline TEMED & $0.013-0.017 \%(\mathrm{v} / \mathrm{v})$ gradient \\
\hline APS & $0.04 \%(\mathrm{v} / \mathrm{v})$
\end{tabular}

Gel running buffer

\begin{tabular}{l|r} 
Component & Concentration in the buffer \\
\hline TRIS, pH 8.3 & $25 \mathrm{mM}$ \\
\hline Glycine & $192 \mathrm{mM}$ \\
\hline SDS & $0.1 \%(\mathrm{w} / \mathrm{v})$
\end{tabular}

The polyacrylamide gel was stained overnight with Coomassie Brilliant Blue R-250 and washed 3 - 4 times with washing solution (Table 2.15) on a horizontal swinging table (BIOSAN Multi MR-12). After the final washing step the gel was placed into distilled water for 20 min and then scanned with an UMAX Aster-1220S gel scanner. Each gel was stored for longer-term use in $7 \%$ acetic acid solution.

Table 2.15 Components of the solutions for Coomassie Brilliant Blue gel staining

Coomassie brilliant blue stain

\begin{tabular}{l|r} 
Component & Concentration \\
\hline Coomassie brilliant blue R-250 & $1 \%(\mathrm{w} / \mathrm{v})$ \\
\hline Methanol & $41.67 \%(\mathrm{v} / \mathrm{v})$ \\
\hline Acetic acid & $16.66 \%(\mathrm{v} / \mathrm{v})$ \\
\hline Distilled water & $41.67 \%(\mathrm{v} / \mathrm{v})$
\end{tabular}

Washing buffer

\begin{tabular}{l|r}
\hline Component & Concentration \\
\hline Methanol & $30 \%(\mathrm{v} / \mathrm{v})$ \\
\hline Acetic acid & $10 \%(\mathrm{v} / \mathrm{v})$ \\
\hline Distilled water & $60 \%(\mathrm{v} / \mathrm{v})$
\end{tabular}




\subsubsection{Linear (12\%) PAGE}

For Western blotting at UCD, Dublin, linear (12\%) polyacrylamide gels were used for protein separation. Purified and solubilised plasma membrane samples were run on the polyacrylamide gels using a Hoefer ${ }^{\mathrm{TM}}$ SE260 gel running system (Hoefer Inc, USA) at $240 \mathrm{~V}$ and $80 \mathrm{~mA}$ for $1.5 \mathrm{~h}$ using the same gel running buffer as described before (Table 2.14). For gel electrophoresis a $12 \%$ separation and $4 \%$

stacking gel were prepared following the instructions of the manufacturer (ProtoGel ${ }^{\circledR}$ $30 \%$ Kit, National Diagnostics, U.S.A.). Each well was loaded with $5 \mu \mathrm{g}$ total membrane protein. Gels were not stained, but separated proteins were blotted to nitrocellulose membrane to quantify $\mathrm{PM}-\mathrm{H}^{+}$-ATPase content of the samples by Western blot analysis.

\subsection{ATPase assay}

The ATPase assay was designed based on the method described by Sarkadi et al. (1992) and Pitann et al. (2009b). The ATP-dependent release of inorganic phosphate was followed. Precisely $3 \mu \mathrm{g}$ total membrane protein was incubated in $100 \mu$ reaction buffer (Table 2.16) at $28{ }^{\circ} \mathrm{C}$ for $60 \mathrm{~min}$ in a BIOSAN TS-100 Thermo Shaker. The reaction was stopped through addition of $50 \mu \mathrm{l} 10 \%(\mathrm{w} / \mathrm{v})$ phosphate free SDS. For colour development, $400 \mu \mathrm{l}$ colour developing reagent (Table 2.16), $1 \mathrm{ml}$ ultra-pure water and $200 \mu \mathrm{l} 1 \%$ freshly made ascorbic acid solution were added in succession to each reaction tube. Colour development occurred at $37^{\circ} \mathrm{C}$ and was completed within 20 - $30 \mathrm{~min}$. Within $1 \mathrm{~min}$ following the end of colour development, the absorbance of samples was read at $880 \mathrm{~nm}$ using a PerkinElmer Lambda25 UV/VIS Spectrophotometer. Appropriate standards (0,10, 20, 40, $60 \mathrm{nmol} \mathrm{P}_{\mathrm{i}}$ per sample of $\mathrm{K}_{2} \mathrm{HPO}_{4}$ ) were always run in parallel to samples and used to convert absorbance readings into nmol $P_{i}$ generated. 
Table 2.16 ATPase reaction buffer and colour development reagent ATPase reaction buffer

\begin{tabular}{l|r} 
Component & Concentration \\
\hline $\mathrm{MES}-\mathrm{KOH}, \mathrm{pH} \mathrm{6.5}$ & $10 \mathrm{mM}$ \\
\hline $\mathrm{MgSO}$ & $5 \mathrm{mM}$ \\
\hline Sodium ATP & $5 \mathrm{mM}$ \\
\hline $\mathrm{KCl}$ & $50 \mathrm{mM}$ \\
\hline $\mathrm{KNO}_{3}$ & $50 \mathrm{mM}$ \\
\hline $\mathrm{Brij}_{5}$ & $0.02 \%(\mathrm{w} / \mathrm{v})$ \\
\hline $\mathrm{NaN}_{3}$ & $10 \mathrm{~m} \mathrm{M}$
\end{tabular}

Colour developing reagent for ATPase reaction

\begin{tabular}{l|r}
\hline Component & Concentration \\
\hline $\mathrm{H}_{2} \mathrm{SO}_{4}$ & $2.5 \mathrm{M}$ \\
\hline Ammonium molybdate & $1 \%(\mathrm{v} / \mathrm{w})$ \\
\hline Potassium antimony (III) oxid tartrate & $0.014 \%(\mathrm{v} / \mathrm{w})$
\end{tabular}

\subsection{Approach for light microscopy}

\subsubsection{Fixation of leaf tissue}

Leaf pieces $(1 \mathrm{~cm}$ in length) from the elongation zone and emerged blade were fixed in $4 \%$ formalin (overnight, $4{ }^{\circ}$ ). To facilitate th e penetration of the fixative, samples were vacuum infiltrated ( 3 times for $10 \mathrm{sec}$ ) using a Millipore WP6122050 vacuum pump (Millipore, USA).

\subsubsection{Dehydration and embedding}

Dehydration of leaf tissue was achieved through an ethanol series, and tissues were cleared with Neo-clear ${ }^{\circledR}$ and embedded into paraffin wax. Details of the protocol are given in Table 2.17. Sections of $5 \mu \mathrm{m}$ thickness were cut using a MicroTec ${ }^{\circledR} 4060$ rotary microtome (MicroTec Laborgeräte $\mathrm{GmbH}$, Germany). Sections were mounted on slides and dried at $37{ }^{\circ} \mathrm{C}$ (overnight) and staine $\mathrm{d}$. For immunostaining, samples were mounted on APTES (3-aminopropyltriethoxysilane) coated slides, prepared based on the instruction of the supplier (Sigma-Aldrich), to prevent tissue damage during the overnight staining procedure. Slides were washed in absolute ethanol before coating and were immersed into $2 \%$ APTES (dissolved in absolute ethanol) for $5 \mathrm{~s}$, briefly rinsed in ethanol, washed in running tap water (5 min), rinsed in distilled water and dried overnight at $55-60^{\circ} \mathrm{C}$. 
Table 2.17 Fixation and embedding of leaf samples for immunohistochemistry Fixation

\begin{tabular}{|c|c|c|}
\hline & Solution & Duration \\
\hline & $4 \%$ Formalin & Overnight, $4{ }^{\circ} \mathrm{C}$ \\
\hline \multicolumn{3}{|l|}{ Dehydration } \\
\hline & Solution & Duration \\
\hline & $30 \%$ Ethanol & $1 \mathrm{~h}$ \\
\hline & $50 \%$ Ethanol & $1 \mathrm{~h}$ \\
\hline & $70 \%$ Ethanol & $1 \mathrm{~h}$ \\
\hline & $90 \%$ Ethanol & $1 \mathrm{~h}$ \\
\hline & $96 \%$ Ethanol & $1 \mathrm{~h}$ \\
\hline & Absolute Ethanol & $2 \times 1 \mathrm{~h}$ \\
\hline \multicolumn{3}{|l|}{ Clearing } \\
\hline & $50-50 \%$ Ethanol Neo-clear ${ }^{\Theta}$ & Overnight, $4^{\circ} \mathrm{C}$ \\
\hline & Neo-clear ${ }^{\Theta}$ & $2 \times 1 \mathrm{~h}$ \\
\hline \multicolumn{3}{|l|}{ Infiltration } \\
\hline & Neo-clear $\left.{ }^{(}\right)$wax & $30 \mathrm{~min}$ \\
\hline & $50-50 \%$ Nea-clear ${ }^{\circledR}$-wax & $1 \mathrm{~h}, 65^{\circ} \mathrm{C}$ \\
\hline & $100 \%$ wax & $2 \times 1 \mathrm{~h}, 65^{\circ} \mathrm{C}$ \\
\hline
\end{tabular}

\subsubsection{Staining with toluidine blue}

Paraffin-embedded sections were rehydrated, stained with $1 \%(\mathrm{w} / \mathrm{v})$ aqueous toluidine blue, washed, dehydrated, cleared and mounted in Entellan ${ }^{\circledR}$ mountant (Table 2.18). Sections were examined with a Leica DMIL and Olympus BX60 microscope.

Table 2.18 Staining embedded leaf sections with toluidine blue Rehydration

Staining

\begin{tabular}{|c|c|c|}
\hline & Solutions & Duration \\
\hline & Neo-Clear ${ }^{(} \mathrm{A}$ & $10 \mathrm{~min}$ \\
\hline & Neo-Clear ${ }^{\circledR}$ B & $10 \mathrm{~min}$ \\
\hline & Absolute ethanol & $5 \min$ \\
\hline & $96 \%$ ethanol & $5 \mathrm{~min}$ \\
\hline & $70 \%$ ethanol & $2 \min$ \\
\hline & Running water & $5 \mathrm{~min}$ \\
\hline \multicolumn{3}{|l|}{ Staining } \\
\hline & $1 \%$ aqueous toluidine blue & $10 \mathrm{~min}$ \\
\hline \multirow{2}{*}{\multicolumn{3}{|c|}{ Dehydration }} \\
\hline & & \\
\hline & $70 \%$ ethanol & Dip twice \\
\hline & $96 \%$ ethanol & Dip four times \\
\hline & Absolute ethanol 1 & $5 \mathrm{~min}$ \\
\hline & Absolute ethanol 2 & $5 \mathrm{~min}$ \\
\hline & Neo-clear ${ }^{\Theta} \mathrm{C}$ & $5 \mathrm{~min}$ \\
\hline & Neo-clear ${ }^{\circledR} \mathrm{D}$ & $5 \mathrm{~min}$ \\
\hline \multicolumn{3}{|l|}{ Mounting } \\
\hline & Entellan $^{\circledR}$ & Mount under cov \\
\hline
\end{tabular}




\subsection{Immunological methods for PM- $H^{+}-A T P a s e$ detection}

\subsubsection{Qualitative Western blot analysis}

At Eötvös University the PM- $\mathrm{H}^{+}$-ATPase content of the isolated membrane vesicles and identity and molecular weight of $\mathrm{PM}-\mathrm{H}^{+}$-ATPase protein was determined using Western blotting. Gradient SDS polyacrylamide gels were run as described above. Separated proteins were transferred onto nitrocellulose membrane (Hybound ${ }^{\mathrm{TM}}-\mathrm{C}$ Extra, Amesham-Pharmacia, USA) using the Mini Transfer Blot (BioRad Laboratories, Inc.) system. The composition of blotting buffer is given in Table 2.19. Protein transfer was carried out in an ice-cold buffer tank $\left(4{ }^{\circ} \mathrm{C}\right)$ at $90 \mathrm{~V}$ constant voltage $(\mathrm{I}<0.4 \mathrm{~A})$ for $2-3 \mathrm{~h}$.

\section{Table 2.19 Composition of blotting buffer used for Western analyses}

Component

Concentration

\begin{tabular}{l|r}
\hline TRIS-HCl, pH 8.3 & $25 \mathrm{mM}$ \\
\hline Glycine & $192 \mathrm{mM}$ \\
\hline Methanol & $10 \%(\mathrm{v} / \mathrm{v})$ \\
\hline SDS & $0.01 \%(\mathrm{w} / \mathrm{v})$
\end{tabular}

The blotted and washed nitrocellulose membrane was blocked with $3 \%$ (w/v) gelatine in TRIS buffer saline (TBS) for $1 \mathrm{~h}$ (composition is given in Table 2.20). As primary antibody, plant $\mathrm{PM}-\mathrm{H}^{+}$-ATPase specific polyclonal rabbit IgG (Agrisera, Uppsala, Sweden) was used at 1,000x dilution in TBS buffer containing $1 \%$ gelatine (overnight; room temperature). Non-bound antibody was removed by washing the membrane in Tween ${ }^{\circledR} 20$ TRIS buffer saline (TTBS) (Table 2.21), twice for $20 \mathrm{~min}$, followed by two washes for $20 \mathrm{~min}$ each in TBS. Horseradish peroxidase (HRP)labelled anti rabbit IgG produced in goat (BioRad Laboratories, Inc.) was used as secondary antibody. It was used at 3,000x dilution in TBS buffer $(2 \mathrm{~h})$. The membrane was washed in the same way as described for primary antibody and was then developed in developing solution $(0.06 \%(\mathrm{w} / \mathrm{v})$ HRP Colour Development Reagent $^{\mathrm{TM}}$ (BioRad Laboratories, Inc.)). The colour development reagent contained 4-Cl-1-naftol as active component and was dissolved in -20 $\mathrm{C}$ methanol and $0.015 \% \mathrm{H}_{2} \mathrm{O}_{2}$ in TBS. The bands were digitalized (HP Scanjet) before the membrane had dried out. 
Table 2.20 Composition of TRIS buffer saline buffer (TBS)

Component

\begin{tabular}{l|r}
\hline TRIS-HCl, pH 7.5 & $20 \mathrm{mM}$ \\
\hline $\mathrm{NaCl}$ & $150 \mathrm{mM}$
\end{tabular}

Table 2.21 Composition of Tween ${ }^{\circledR} 20$ TRIS buffer saline buffer (TTBS)

Component

\begin{tabular}{l|r}
\hline TRIS-HCl, pH 7.5 & $20 \mathrm{mM}$ \\
\hline $\mathrm{NaCl}$ & $150 \mathrm{mM}$ \\
\hline Tween $^{\Theta} 20$ & $0.005 \%(\mathrm{w} / \mathrm{v})$
\end{tabular}

\subsubsection{Quantitative Western blot analysis}

Plasma membranes could only be isolated at Eötvös University, yet the more sensitive Western blot system was available at UCD, Dublin. Therefore, Western analyses of plasma membrane fractions were carried out not only at Eötvös University but also at UCD using plasma membrane vesicle samples which had been brought back (flight back from Hungary) on dry ice. The Western analyses system at UCD was the same one as described by Collins et al. (2011).

The separated proteins were blotted onto nitrocellulose membrane (Whatman ${ }^{\circledR}$ PROTRAN BA 85) using a Hoefer ${ }^{\mathrm{TM}}$ TE22 blotting system, at $40 \mathrm{~V}$ and $120 \mathrm{~mA}$ overnight at room temperature. The gel running buffer contained $20 \%(\mathrm{v} / \mathrm{v})$ methanol. Blotted nitrocellulose membranes were stained with Ponceau $S$ stain (Sigma) and washed with washing buffer $\left(0.2 \%\right.$ Tween ${ }^{\circledR} 20$ containing gel running buffer). Thereafter, membranes were blocked with $5 \%$ skimmed milk powder in washing buffer for $1 \mathrm{~h}$, at $30 \mathrm{rpm}$ on a horizontal shaker. Primary antibody $\left(\mathrm{PM}-\mathrm{H}^{+}-\right.$ ATPase specific polyclonal rabbit IgG antibody; Agrisera, Sweden) was applied overnight at 2,500x dilution in washing buffer containing $5 \%$ milk powder, at $30 \mathrm{rpm}$ shaking. Non-bound primary antibody was removed through washing three times (10 min each; $70 \mathrm{rpm}$ ) in washing buffer. Peroxidase-labelled anti rabbit lgG produced in goat (Invitrogen Corporation, Carlsbad, California USA) was applied as secondary antibody at 10,000 x dilution in washing buffer containing $5 \%$ milk powder (2 h; $70 \mathrm{rpm}$ ). After three final washes (10 min each) in washing buffer, bound secondary antibody was visualised through an EZ-ECL Chemiluminescence Detection Kit for HRP (Biologica Industries, Israel) and LAS-4000 Luminescence Image Analyser (Fujifilm, USA). 


\subsubsection{Immunostaining of paraffin-embedded sections}

$\mathrm{PM}-\mathrm{H}^{+}$-ATPase tissue specific localisation was determined on paraffin-embedded samples using immunohistochemistry. The same $\mathrm{PM}-\mathrm{H}^{+}$-ATPase specific primary antibody was used as for Western blotting. Anti rabbit IgG alkaline phosphataselabelled antibody, produced in goat (Sigma), was applied as secondary antibody as detailed in Table 2.22. Colour development was carried out with SIGMAFAST ${ }^{\mathrm{TM}}$ Fast Red TR / Naphthol AS-MX Tablets (Sigma) following the instructions of the manufacturer. Colour development was stopped with $7 \%$ acetic acid. After a 5 min washing in running tap water, samples were mounted in $80 \%$ glycerol in phosphate buffered saline (PBS, its composition is given in Table 2.23) under a cover slip.

Table 2.22 Protocol for immunostaining of embedded leaf sections Rehydration

Blocking

\begin{tabular}{l|r}
\hline Solutions & Duration \\
\hline Neo-Clear ${ }^{\Theta} \mathrm{A}$ & $10 \mathrm{~min}$ \\
\hline Neo-Clear ${ }^{\Theta} \mathrm{B}$ & $10 \mathrm{~min}$ \\
\hline Absolute ethanol & $5 \mathrm{~min}$ \\
\hline $96 \%$ ethanol & $5 \mathrm{~min}$ \\
\hline $70 \%$ ethanol & $2 \mathrm{~min}$ \\
\hline Running water & $5 \mathrm{~min}$
\end{tabular}

Staining

\section{Colour development}

\begin{tabular}{l|l}
\hline $5 \%(\mathrm{v} / \mathrm{v})$ goat serum in PBS & $10 \mathrm{~min}$ \\
\hline
\end{tabular}

\begin{tabular}{l|r}
\hline \multicolumn{1}{c|}{ SIGMAFAST ${ }^{T M}$ Fast Red } & $2-10 \mathrm{~min}$ \\
\hline $5 \%(\mathrm{v} / \mathrm{v})$ acetic acid & $1-5 \mathrm{~min}$ \\
\cline { 2 - 3 } & $5 \mathrm{~min}$
\end{tabular}

Mounting

\begin{tabular}{l|r} 
Primary antibody (100x diluted) in & Overnight, $4 \mathrm{C}^{\mathrm{C}}$ \\
$2.5 \%(\mathrm{v} / \mathrm{v})$ goat serum in PBS & $3 \times 5 \mathrm{~min}$ \\
\hline Washing with PBS & $2 \mathrm{~h}$ \\
\hline Secondary antibody (30x diluted) in \\
$2.5 \%(\mathrm{v} / \mathrm{v})$ goat serum in PBS & $4 \times 5 \mathrm{~min}$ \\
\hline Washing with PBS
\end{tabular}

$80 \%$ glycerol in PBS

Mount under cover slip

Table 2.23 Composition of phosphate buffer saline (PBS; pH 7.4)

Component

$\mathrm{NaCl}$

$\mathrm{KCl}$

$\mathrm{Na}_{2} \mathrm{HPO}_{4} \times 2 \mathrm{H}_{2} \mathrm{O}$

$\mathrm{KH}_{2} \mathrm{PO}_{4}$
Concentration (mM)

137

2.7

8.1

1.76
Concentration (g/l)

8.00

0.20

1.44

0.24 


\subsubsection{Densitometric analysis of Western blots}

Densitometric analysis of Coomassie-stained polyacrylamide gels and Western blots was carried out with a Photetix 1D Advanced 4.01 system (Phoretix International, Newcastle, UK). Raw data were processed using Microsoft ${ }^{\circledR}$ Office Excel 2003 (Microsoft Corporation, USA) and Origin $^{\circledR} 6.1$ (OrigiLab Corporation, USA) statistical software.

\subsection{Protoplast experiments}

\subsubsection{Protoplast isolation}

Protoplasts were isolated according to Volkov et al. (2007), with some modifications.

Osmolality of the isolation buffer, incubation time and shaking frequency were optimised. Cell walls and middle lamellae from tissue of the elongation zone were digested in $500 \mathrm{mOsm} \mathrm{kg}^{-1}$ isolation buffer with $90 \mathrm{rpm}$ shaking frequency over a period of 2 - 3 hours in the dark, while pieces of the emerged blade were incubated in isolation buffer of $600 \mathrm{mOsm} \mathrm{kg}-1$ osmolalility, over a $1 \mathrm{~h}$ period and at $160 \mathrm{rpm}$ shaking frequency in the dark.

Cell wall digestive enzymes (Table 2.24) were dissolved in isolation medium (components are in Table 2.25) overnight, at $4^{\circ} \mathrm{C}$, without any shaking or vortexing. Prior to use, enzyme solutions were centrifuged (5 min, 10,000 g, mini Spin plus, Eppendorf AG, Hamburg, Germany) and the supernatant was used for cell wall digestion.

Table 2.24 Composition of protoplast isolation buffer Component Concentration

\begin{tabular}{l|r}
\hline Murashige and Skoog salt & $4 \mathrm{~g} \mathrm{l}^{-1}$ \\
\hline MES & $10 \mathrm{mM}^{-1}$ \\
\hline Sorbitol & $500-600 \mathrm{mOsm} \mathrm{kg}$ \\
\hline PVP K30 & $0.025 \%(\mathrm{w} / \mathrm{v})$ \\
\hline BSA & $0.1 \%(\mathrm{w} / \mathrm{v})$ \\
\hline KOH & Used to adjust to $\mathrm{pH} 5.7$
\end{tabular}

Table 2.25 Enzyme concentrations in protoplast isolation buffer Enzyme Concentration

\begin{tabular}{l|r}
\hline Cellulase & $1 \%(\mathrm{w} / \mathrm{v})$ \\
\hline Driselase & $0.5 \%(\mathrm{w} / \mathrm{v})$ \\
\hline Pectolyase & $0.05 \%(\mathrm{w} / \mathrm{v})$
\end{tabular}




\subsubsection{Purification of protoplasts}

After enzymatic digestion of the cell wall, protoplast were passed through a $100 \mu \mathrm{m}$ mesh and washed with 4 - 5 volume isolation buffer. Protoplasts were collected by centrifugation (30 g, 2 min; Eppendorf 5810 R, swinging bucket rotor) and resuspended in $0.3-1 \mathrm{ml}$ volume using isolation buffer. Viability of protoplasts was tested using $0.001 \%(\mathrm{w} / \mathrm{v})$ fluorescein diacate (Larkin, 1976), which was prepared from a $0.1 \%(\mathrm{w} / \mathrm{v})$ acetone stock. Protoplasts were viewed with a Leica DMIL fluorescence microscope equipped with an excitation filter (450 - $490 \mathrm{~nm})$ and suppression filter (515 nm).

Protoplasts were counted with a Neubauer ultra plane counting chamber (Hausser Scientific) under a Leica DMIL microscope. These data were used to relate expression values obtained through qPCR experiments to protoplast number.

\subsubsection{Calculation of size and surface of the protoplast}

The diameter of protoplasts was measured on micrographs taken with a Leica DMIL microscope with the help of Scion Image for Windows 4.0.3.2 software. From the diameter (d), the protoplast volume, $\left((\pi / 6) \mathrm{d}^{3}\right)$ and surface $\left(\pi \mathrm{d}^{2}\right)$ could be calculated,due to the almost perfectly spherical shape of protoplasts.

\subsection{Statistical analysis}

Statistical analysis was carried out with Origin ${ }^{\circledR} 6.1$ (OriginLab Corporation) software, using paired and independent Student's t test and one-way ANOVA. 


\section{$3 \quad$ Results}

\subsection{Apoplastic $\mathrm{pH}$ measurements}

Apoplast $\mathrm{pH}$ was measured through three independent approaches: in-vitro gel system, electrophysiology and confocal microscopy. The in-vitro gel system involved incubating leaf segments in agarose containing a $\mathrm{pH}$ indicator that made it possible to directly relate changes in apoplast acidity to changes in growth. With $\mathrm{pH}$ microelectrodes precise values of apoplast $\mathrm{pH}$ in growing and non-growing leaf regions could be obtained. Finally, confocal microscopy involved loading plants with $\mathrm{pH}$ fluorescence probes and had the advantage that intact plants could be studied.

\subsubsection{In-vitro agarose gel system}

The base $70 \mathrm{~mm}$ of leaf three was placed in agarose gel medium containing the $\mathrm{pH}$ indicator bromocresol purple. Growth was monitored parallel to acidification of the medium. The basic assumption underlying this experiment was that any changes in the extent of acidity of the medium adjacent to leaf tissue reflected similar changes in the net $\mathrm{H}^{+}$production rate (due to $\mathrm{PM}-\mathrm{H}^{+}$-ATPase activity) in the tissue's apoplast. 'Extent' of acidity can refer to either or both, changes in $\mathrm{pH}$ and changes in the area of medium which was acidic. Gel images of a typical set of experiments, involving application of fusicoccin and vanadate, are shown in Fig. 3.1 A-C.

There was a non-specific acidification of medium with a maximum acidification at the first hour following the placement of unpeeled leaf segments into the agarose. This acidification, which most likely reflected changes in apoplast $\mathrm{pH}$ caused by the unpeeling and which was not restricted to the base $40 \mathrm{~mm}$ (leaf elongation zone), disappeared within 4 - $5 \mathrm{~h}$ and then reappeared in a growth-dependent manner (Fig. 3.2 A and B). Growth dependency of acidification was also tested by applying an initial $(0-24 \mathrm{~h})$ cold treatment. There was no acidification of medium and no growth either during the cold treatment (Fig. 3.3). As soon as the cold treatment finished, growth resumed parallel to the acidification of medium (Fig. 3.3). 
A
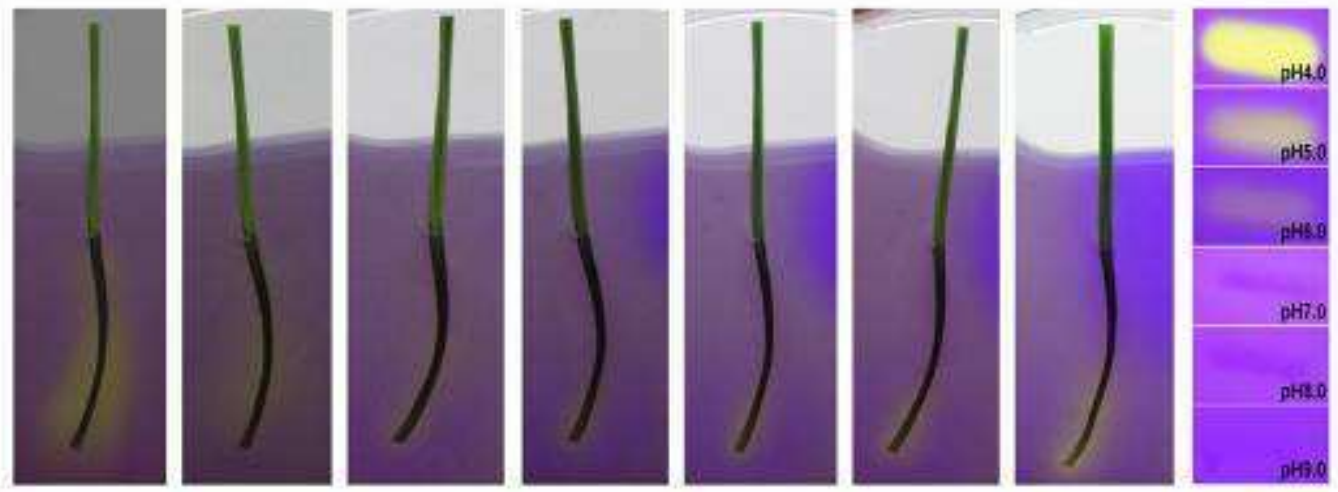

B
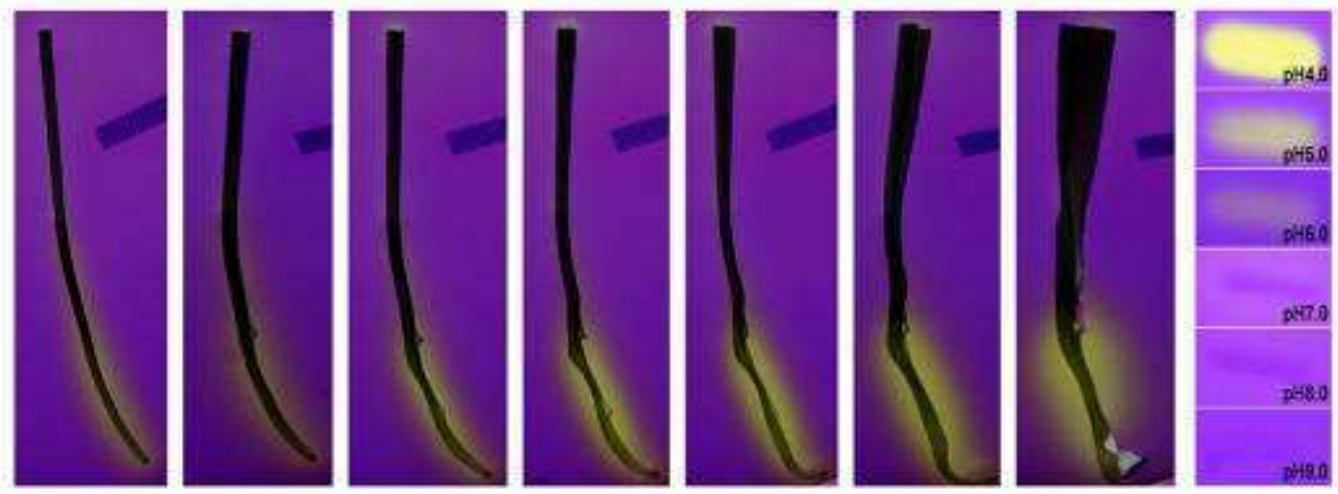

C
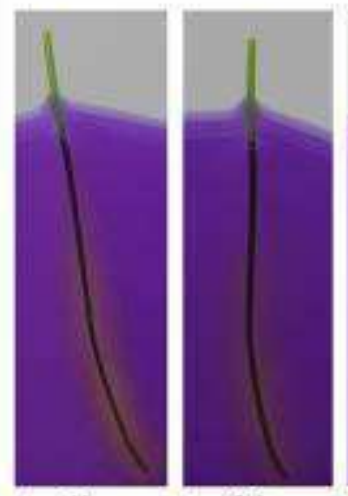

$2 \mathrm{~h}$

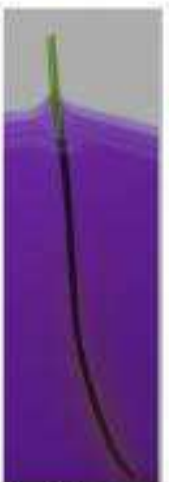

$4 \mathrm{~h}$

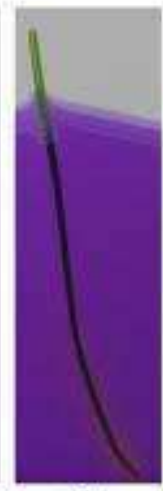

$6 \mathrm{~h}$

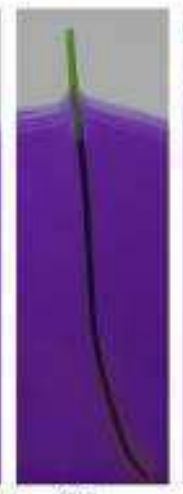

$8 \mathrm{~h}$

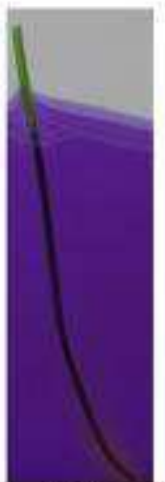

$10 \mathrm{~h}$
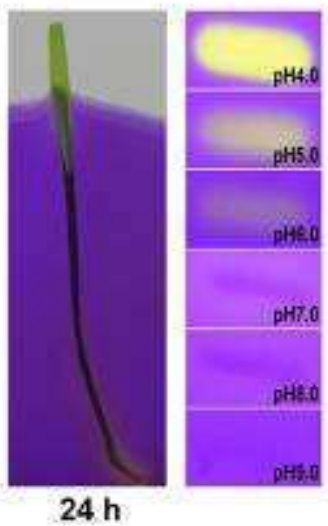

$24 \mathrm{~h}$

Figure 3.1 Leaf growth and apoplast acidification as analysed through the

\section{agarose gel system}

Typical images of an experiment involving control leaves $(A)$ and leaves which were placed in agarose containing $5 \mu \mathrm{M}$ fusicoccin (B) and $500 \mu \mathrm{M}$ vanadate (C). Scale bar is $1 \mathrm{~cm}$ long. 
A

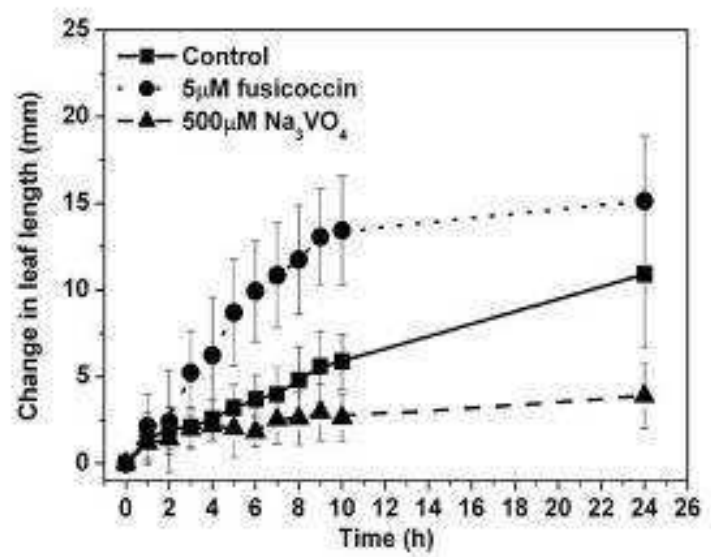

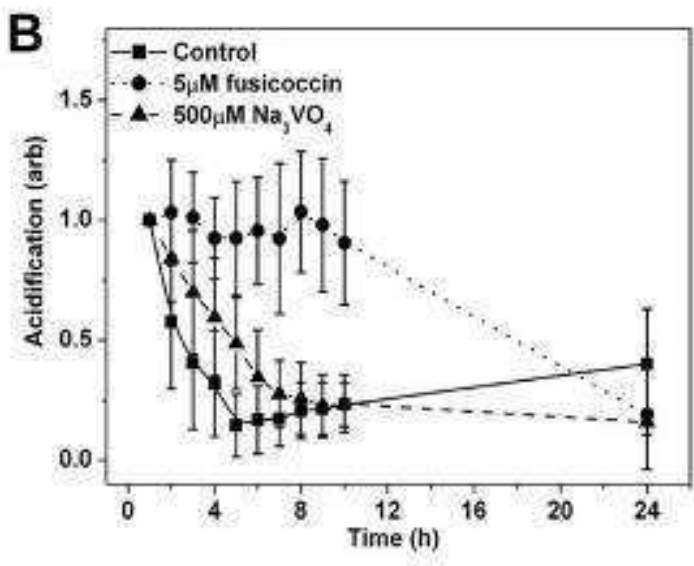

Figure 3.2 Time course of growth and acidification of in-vitro gel experiments

Typical time course of changes in leaf length (A) and medium acidification (B) in response to treatments are shown. Values are averages and standard deviations (error bars) of 27 (control) and 10 (treatments) plants.

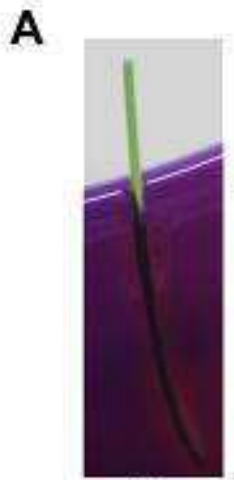

$1 \mathrm{~h}$

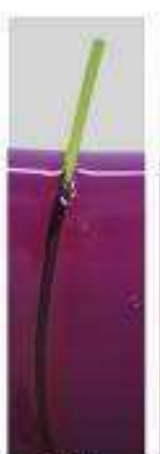

$3 \mathrm{~h}$

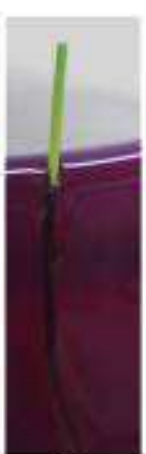

$6 \mathrm{~h}$

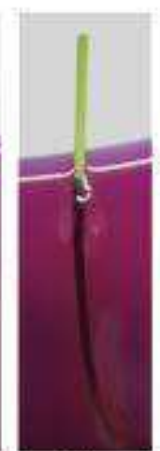

$9 \mathrm{~h}$

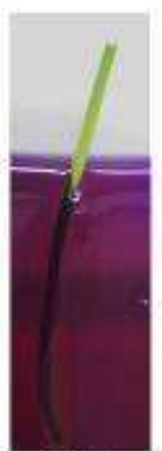

$24 \mathrm{~h}$

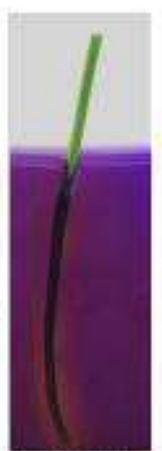

$25 \mathrm{~h}$

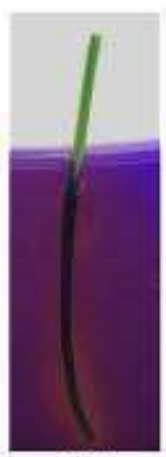

$28 \mathrm{~h}$

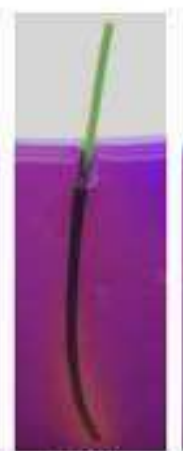

$30 \mathrm{~h}$

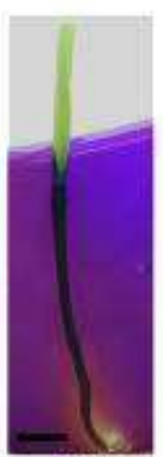

$48 \mathrm{~h}$

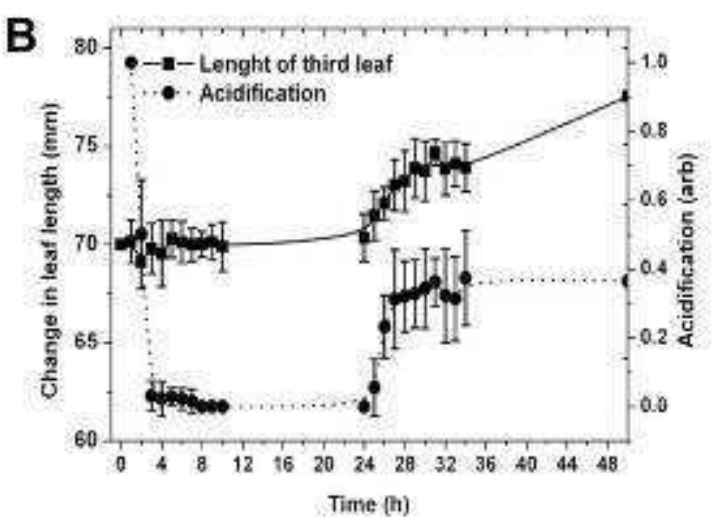

Figure 3.3 Leaf growth and acidification in agarose gel under cold treatment

Typical images of an experiment involving cold treated leaves $0-24 \mathrm{~h}$ and under control condition $24-48 \mathrm{~h}(\mathrm{~A})$. Scale bar represents $1 \mathrm{~cm}$. Response of medium acidification and change in leaf length (growth) to cold treatment and subsequent incubation in the growth chamber (B); values are averages and standard deviations (error bars) of 10 plants. 
A range of treatments was tested for their effect on medium acidification and leaf growth (Fig. 3.4). Fusicoccin increased significantly leaf elongation rate and medium acidity. Vanadate caused the opposite effect, as did caesium, which inhibits $\mathrm{K}^{+}$channels (Szczerba et al., 2009; Volkov et al., 2009).
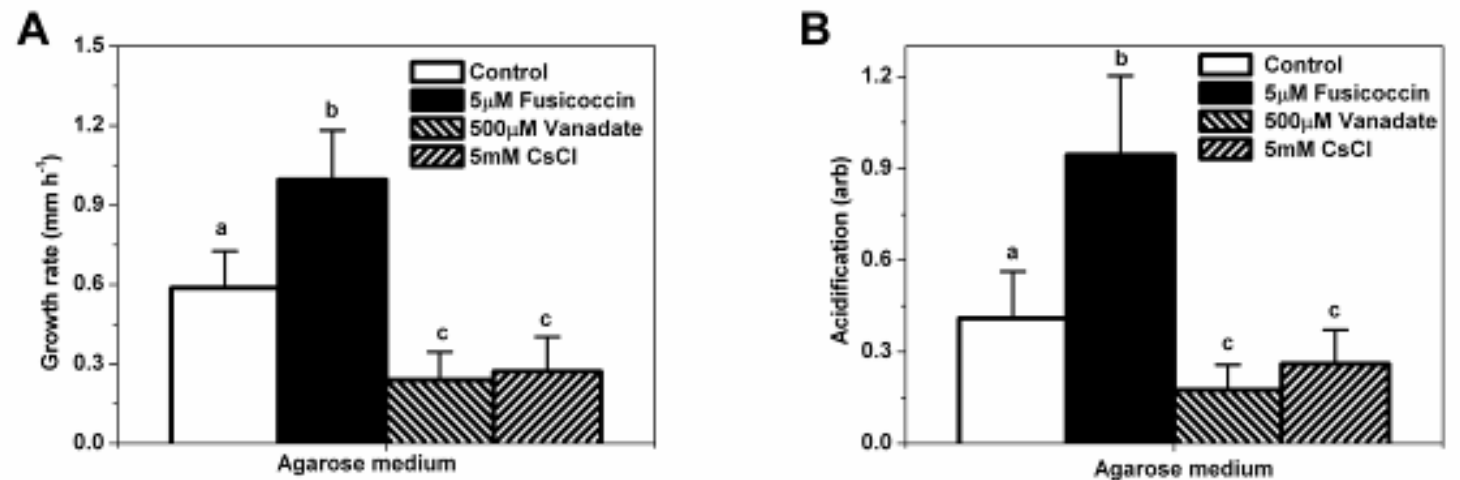

Figure 3.4 Average rate of leaf elongation (A) and medium acidification (B) in

leaves exposed to fusicoccin, vanadate and caesium treatments as tested through the agarose gel system

All media contained $10 \mathrm{mM} \mathrm{KCl}$ and test reagents were applied at $5 \mu \mathrm{M}$ (fusicoccin), $500 \mu \mathrm{M}$ (vandate) or $5 \mathrm{mM}(\mathrm{CsCl})$. Values are averages and standard deviations of 20 (control), 9 (fusicoccin), 7 (vanadate) and 14 (CsCl) plants. Different letters show a statistically significant difference at $p<0.05$ (Student's t-test and ANOVA).

Although auxin-induced growth is often related to cell wall acidification and referred to as 'acid growth', no such stimulation of either growth or acidification was observed in the present study. Using in-vitro gel system and applying the artificial auxin, $\alpha$-Naphthaleneacetic acid (NAA), growth did not change and acidification was similar to control. If anything, acidification of NAA treated plants continuously decreased whereas control plants started to slightly decrease after $5 \mathrm{~h}$ (Fig. 3.5).

Auxin-induced growth was not detected either when the experiment was carried out in liquid medium $\left(10 \mathrm{mM} \mathrm{KCl}\right.$ and $1 \mathrm{mM} \mathrm{CaCl}_{2}$ without agarose and bromocresol purple) to check whether the absence of any auxin effect was due to conditions associated with the agarose gel. To check whether it was possible to induce any auxin-specific effects, coleoptiles were tested since these represent the classical 'acid growth' system. A significant increase in growth was measured (Fig. 3.6). 

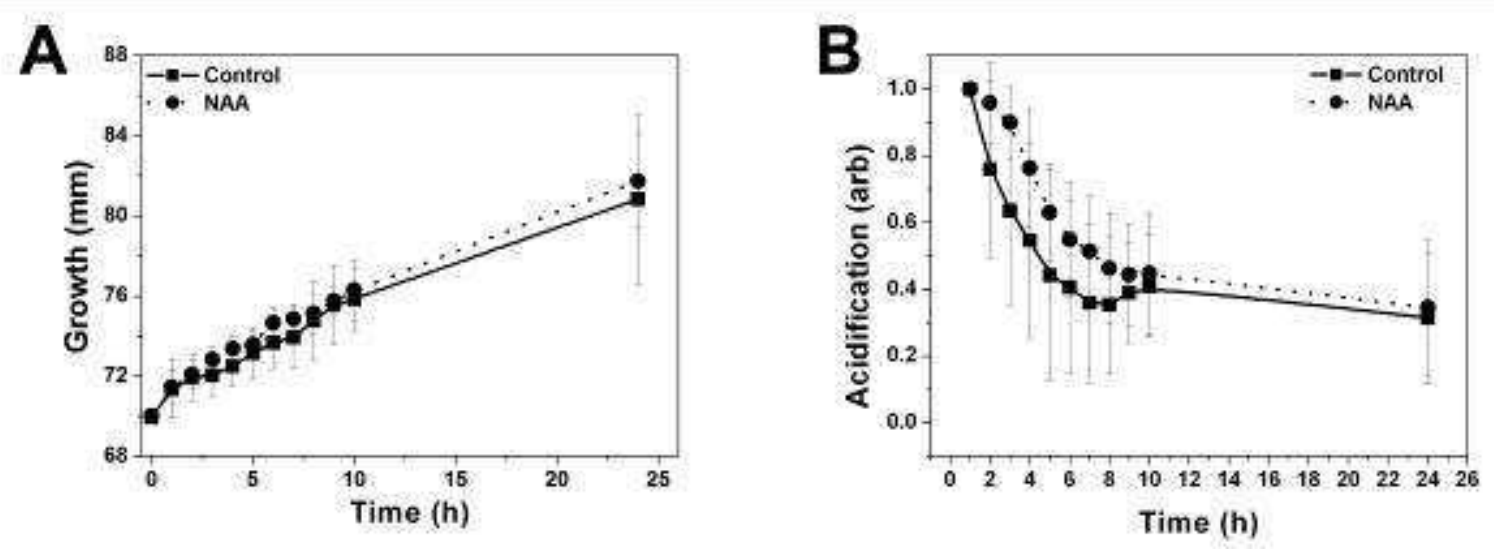

Figure 3.5 Effect of auxin on leaf growth and medium acidification using the in-vitro gel system

Difference in growth $(\mathrm{A})$ was not found between $5 \mu \mathrm{M}$ NAA treated and control plants. Medium acidification was similar in auxin-treated and non-treated (control) leaves (B). Traces are average of 10 - 27 plants, error bars represent standard errors.
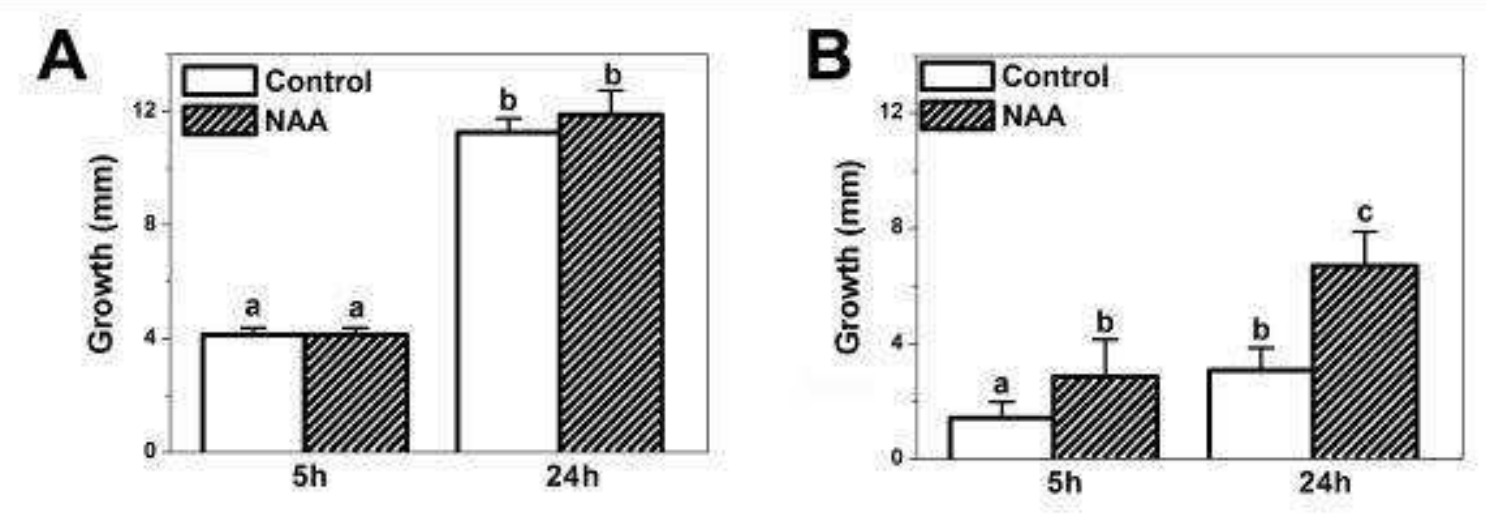

Figure 3.6 Growth effect of auxin when applied in liquid medium

NAA $(5 \mu \mathrm{M})$ effect on growth was tested in liquid medium on leaf $(A)$ and coleoptile pieces (B). Measurements were carried out at $5 \mathrm{~h}$ and $24 \mathrm{~h}$ of incubation. Values are averages and standard deviations (error bars) of 4 leaf pieces and 40 coleoptile segments. Different letters show a statistically significant difference at $p<0.05$ using Student's t-test and ANOVA.

\subsubsection{Microelectrode measurements}

Microelectrode measurements of apoplastic $\mathrm{pH}$ in the growing leaf three showed that the $\mathrm{pH}$ in the elongation zone was by up to one $\mathrm{pH}$ unit lower than the $\mathrm{pH}$ in the emerged blade (Fig. 3.7 A). Apoplastic pH in the elongation zone depended on the $\mathrm{K}^{+}$concentration in the bathing medium which was in direct contact with the leaf surface during measurements. At the lowest $\mathrm{K}^{+}$concentration tested $(0.1 \mathrm{mM})$, apoplast $\mathrm{pH}$ was 4.8. Apoplast $\mathrm{pH}$ increased with the $\mathrm{K}^{+}$concentration of the medium. At $10 \mathrm{mM} \mathrm{K}$, apoplast $\mathrm{pH}$ in the elongation zone was 5.8 and 
indistinguishable from the value in the emerged blade. In contrast to apoplast $\mathrm{pH}$ in the elongation zone, apoplast $\mathrm{pH}$ of the emerged blade did not change with bathing medium $\mathrm{K}^{+}$. When the $\mathrm{pH}$ of the bathing medium was adjusted to $\mathrm{pH} 7.0$ using $\mathrm{KOH}$ (final $\mathrm{K}$ concentration of $0.3-0.5 \mathrm{mM}$ ) apoplastic $\mathrm{pH}$ in the elongation zone was between 4.8 and 5.2. This proved that the lower apoplastic $\mathrm{pH}$ measured in the elongation zone was independent from the $\mathrm{pH}$ of the bulk (bathing) solution which was in direct contact with the apoplast, when the solution did not contain any buffer component. When the $\mathrm{pH}$ of the bathing solution was adjusted to $\mathrm{pH} 7.0$ using 100 $\mathrm{mM}$ TRIS- $\mathrm{HCl}$, including $0.1 \mathrm{mM} \mathrm{KCl}$, the $\mathrm{pH}$ of the apoplast was $6.1-6.2$ in both elongation zone and emerged blade (Fig. 3.7 B). Although this $\mathrm{pH}$ was lower by almost one $\mathrm{pH}$ unit than the $\mathrm{pH}$ of the bathing medium, this experiment showed that apoplast $\mathrm{pH}$ of the emerged blade was responsive to changes in the composition of the bathing medium and that the two were in direct contact. Bathing medium must have bypassed the cuticle and entered leaves through stomata. Growth of leaves on the microelectrode stage was not affected by $\mathrm{K}^{+}$treatments, despite the $\mathrm{K}^{+}$dependency of apoplast pH (Fig. 3.8).
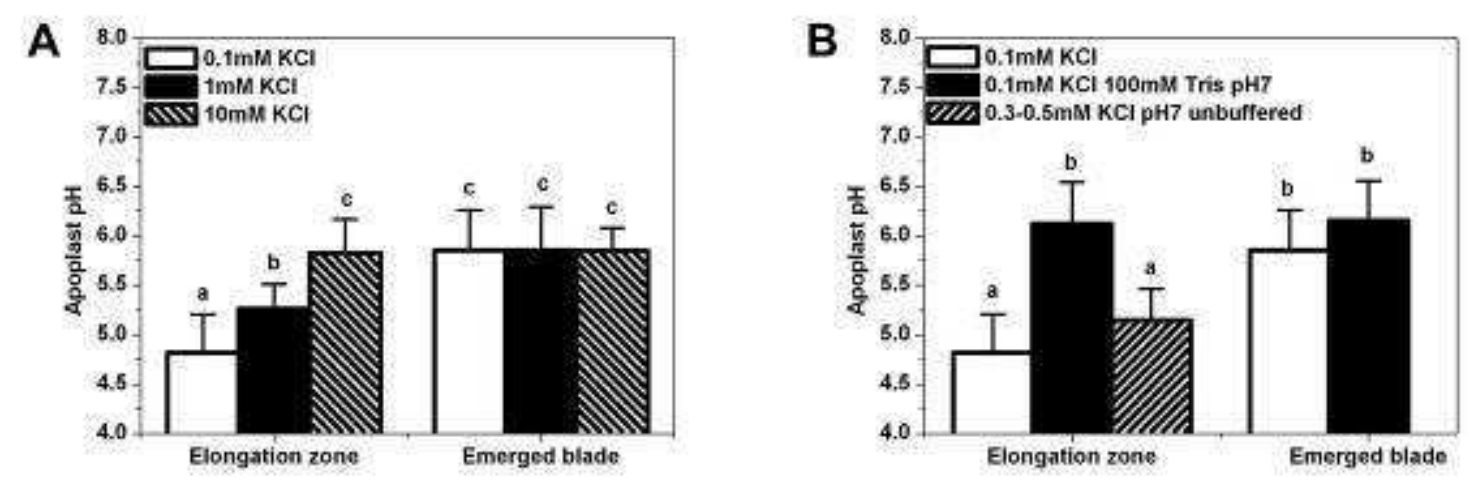

Figure 3.7 Microelectrode analyses of apoplast $\mathrm{pH}$ in the elongation zone and emerged blade-portion of leaf three of barley.

Apoplast $\mathrm{pH}$ was measured in dependence of the $\mathrm{K}^{+}$concentration (added as $\mathrm{KCl}$ ) of the electrode bathing medium which was in direct contact with the leaf tissue analysed (A). Apoplast $\mathrm{pH}$ measured when buffered solutions were applied as bathing medium (B). Values are averages \pm SD of $7-15$ measurements obtained on 3 - 6 plants of each treatment. Different letters show a statistically significant difference at $p<0.05$ (Student's t-test and ANOVA). 


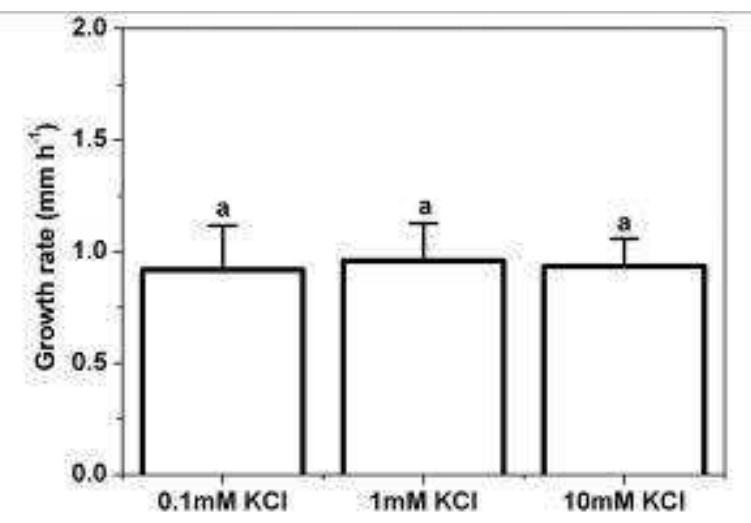

Figure 3.8 Growth rate of leaf three in response to $\mathrm{K}^{+}$-treatments during micro $\mathrm{pH}$ measurements.

Values are averages \pm SD of 7 - 15 measurements obtained on 3 - 6 plants of each treatment. Different letters show a statistically significant difference at $p<0.05$ (ANOVA).

Vanadate $\left(\mathrm{Na}_{3} \mathrm{VO}_{4}\right)$ and fusicoccin were added to the bathing medium to test whether the lower $\mathrm{pH}$ in the apoplast of the elongation zone was dependent on the activity of the PM- $\mathrm{H}^{+}$-ATPase. Vanadate, which inhibits the $\mathrm{PM}-\mathrm{H}^{+}$-ATPase, was tested at a concentration of $500 \mu \mathrm{M}$ in presence of $0.1 \mathrm{mM} \mathrm{KCl}$. Apoplast $\mathrm{pH}$ in the elongation zone increased from $\mathrm{pH} 4.8$ to $\mathrm{pH} 5.8$, precisely the $\mathrm{pH}$ value observed in the emerged blade (Fig. 3.9). Fusicoccin, which stimulates the PM- $\mathrm{H}^{+}-\mathrm{ATPase}$ (Marré, 1979; Würtele et al., 2003), was tested at a concentration of $5 \mu \mathrm{M}$ in presence of $1 \mathrm{mM} \mathrm{KCl}$. Apoplast $\mathrm{pH}$ was 5.2 and identical to the $\mathrm{pH}$ measured in absence of fusiccocin at $1 \mathrm{mM} \mathrm{KCl}$ in the bathing medium (Fig. 3.9). The rate of leaf elongation decreased in response to vanadate and increased in response to fusicoccin treatments (Fig. 3.10). This was observed for all experimental setups (Fig. 3.10). 


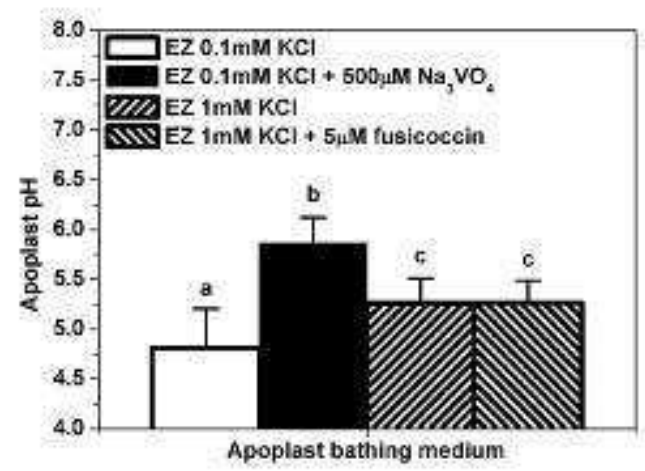

Figure 3.9 Microelectrode $\mathrm{pH}$ analyses in the leaf elongation zone of barley in response to sodium orthovanadate and fusicoccin treatments

The $\mathrm{KCl}$ concentration in the bathing medium was as indicated. Values are averages and standard deviations (error bars) of 12 (controls of $0.1 \mathrm{mM}$ and $1 \mathrm{mM} \mathrm{KCl}$ ), 4 (500 $\mu \mathrm{M}$ vanadate) and 4 (5 $\mu \mathrm{M}$ fusicoccin) datasets of between $3-6$ different plants each. Different letters show a statistically significant difference at $p<0.05$ (Student's t-test and ANOVA).

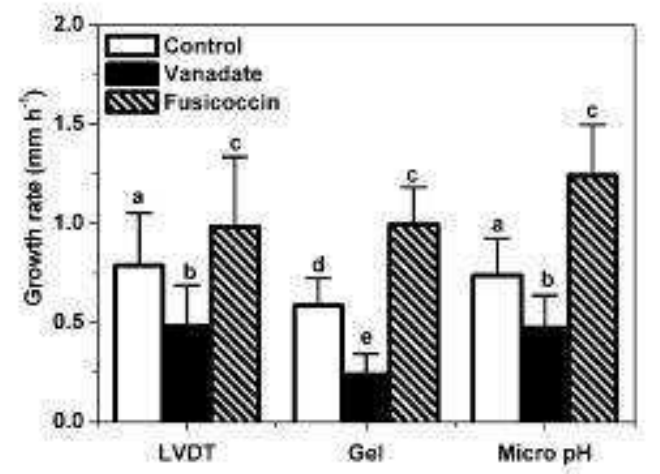

Figure 3.10 Growth rate of leaf three of barley in response to vanadate and fusicoccin treatments as analysed through different approaches

Values are averages and standard deviations (error bars) of 13 - 60 (control), 3 - 8 (vanadate) and 3 - 10 (fusicoccin) replicates. Different letters show a statistically significant difference at $p<0.05$ (Student's t-test and ANOVA).

\subsubsection{Confocal microscopy}

Acridine orange and 5(6)carboxyfluorescein are $\mathrm{pH}$ sensitive fluorescence dyes. They were used to test whether the apoplastic $\mathrm{pH}$ was lower in the elongation zone compared with emerged blade in intact barley plants. First, the system had to be calibrated. This was achieved by peeling epidermal strips from plants which had been grown for $24 \mathrm{~h}$ in the presence of 5(6)carboxyfluorescein and $48 \mathrm{~h}$ in presence 
of acridine orange in the root medium to allow sufficient uptake of dye into leaf tissue. Exposure of epidermal strips to solutions of different $\mathrm{pH}$ showed (i) that dye had been taken up into the leaf apoplast and (ii) that the fluorescence intensity of dye in the apoplast changed in the physiological $\mathrm{pH}$ range, in the same manner as observed for dye in free solution (Fig. 3.11 A, B for acridine orange and Fig. 3.12 A, B for carboxyfluorescein). Fluorescence decreased with $\mathrm{pH}$. Optical sections from the epidermis of intact third leaves showed that the fluorescence intensity, and by implication $\mathrm{pH}$, were considerably lower in the apoplast of the elongation zone than in the apoplast of the emerged blade (Fig. 3.11 C-F for acridine orange and Fig. 3.12 CF for carboxyfluorescein).

It is possible that the difference in fluorescence intensity between leaf regions resulted not from differences in apoplast $\mathrm{pH}$ but from differences in the concentration of dye accumulated during the uptake period. This was tested by peeling epidermis strips from the elongation zone and emerged blade (leaf three) of dye-loaded plants and incubating the peels in $\mathrm{pH} 7.5$ buffer solution. Peels were examined after a 30 min incubation period using a Leica epifluorescence microscope. The fluorescence intensity and by implication carboxyfluorescein and acridine orange concentration was similar in the epidermis of the two leaf regions; if anything, it was higher in the elongation zone (Fig. 3.13). This experiment showed that the lower apoplast $\mathrm{pH}$ in the epidermis of the elongation zone of intact, dye-loaded plants, was not the result of a lower fluorochrome concentration but reflected most likely a true difference in apoplast $\mathrm{pH}$ between the two leaf regions. Uptake of dyes through roots and accumulation in leaf tissue did not cause changes in leaf growth (Fig. 3.14 A, B). 

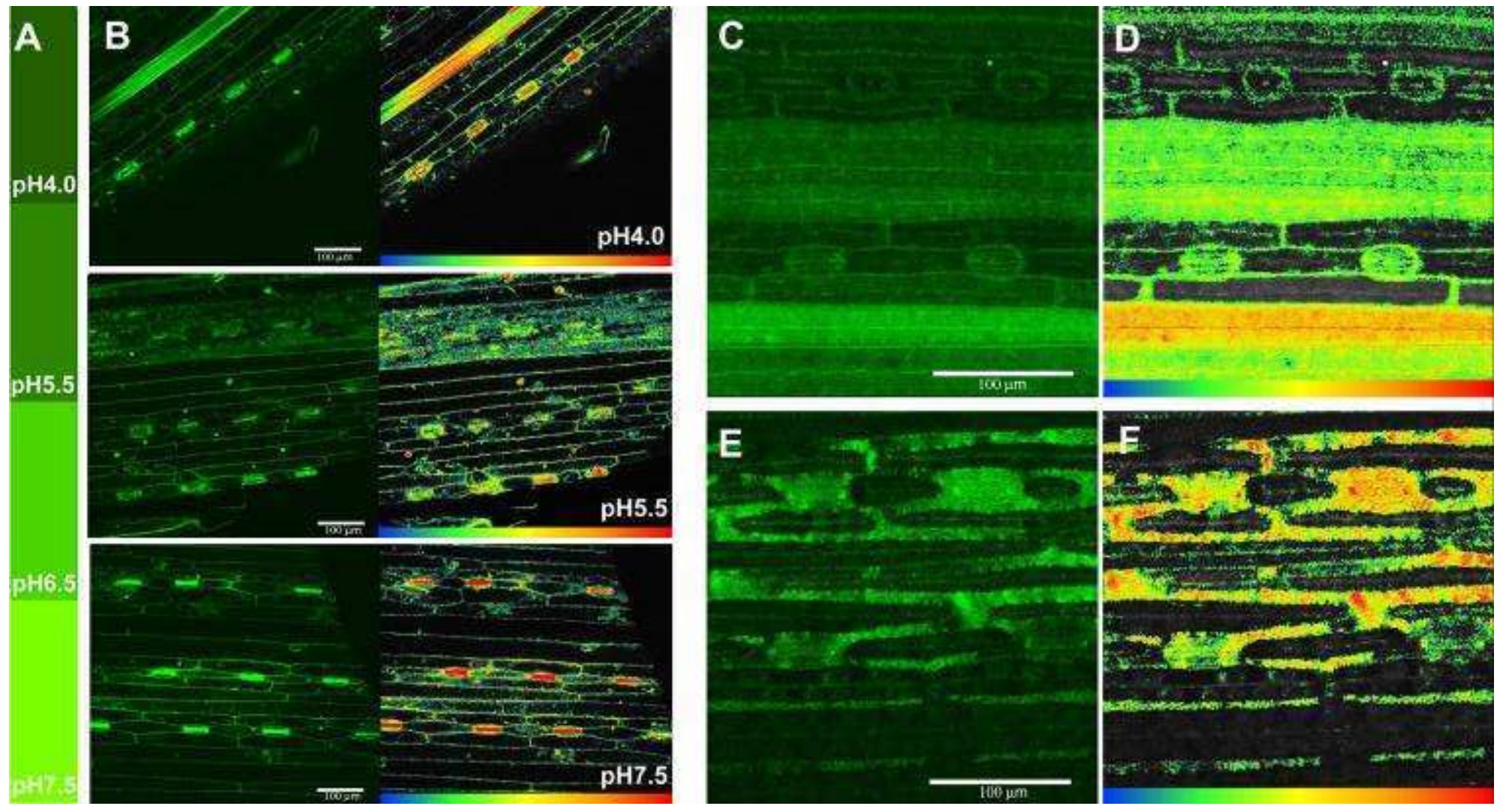

Figure 3.11 Confocal microscopic analysis of apoplastic pH using acridine orange fluoresce $\mathrm{pH}$ sensitive fluorescence dye

The $\mathrm{pH}$ sensitivity of fluorescence of dye as tested on sample droplets which contained $2.5 \mu \mathrm{M}$ acridine orange and were buffered at the $\mathrm{pH}$ indicated $(\mathrm{A})$. Confocal images of epidermal peels of the mature leaf one; following incubation of peels for $30 \mathrm{~min}$ in the solutions as shown in (B). Typical confocal images (C, $E)$ and their heat map $(D, F)$. Elongation $(C, D)$ and emerged $(E, F)$ region of leaf three of intact plants. Images containing scale bars show the original fluorescence image, while corresponding images without scale bars represent heat maps of images. 

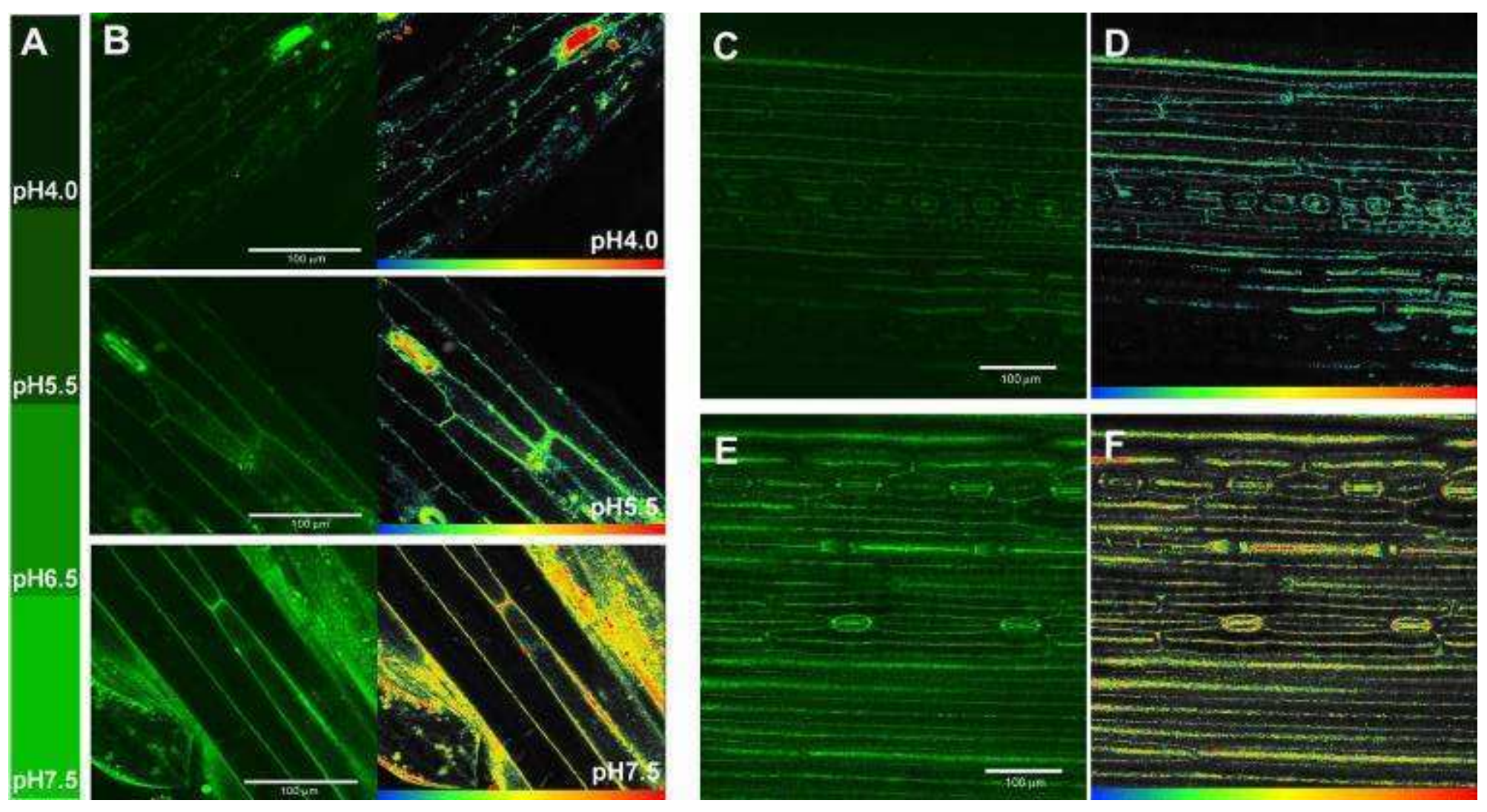

Figure 3.12 Confocal microscopic analysis of apoplastic pH using 5(6)carboxyfluorescein fluoresce $\mathrm{pH}$ sensitive fluorescence dye

The $\mathrm{pH}$ sensitivity of fluorescence of dye as tested on sample droplets which contained $10 \mu \mathrm{M}$ carboxyfluorescein and were buffered at the $\mathrm{pH}$ indicated $(\mathrm{A})$. Confocal images of epidermal peels of the mature leaf one; following incubation of peels for $30 \mathrm{~min}$ in the solutions as shown in (B). Typical confocal images $(C, E)$ and their heat map $(D, F)$. Elongation $(C, D)$ and emerged $(E, F)$ region of leaf three of intact plants. Images containing scale bars show the original fluorescence image, while corresponding images without scale bars represent heat maps of images. 

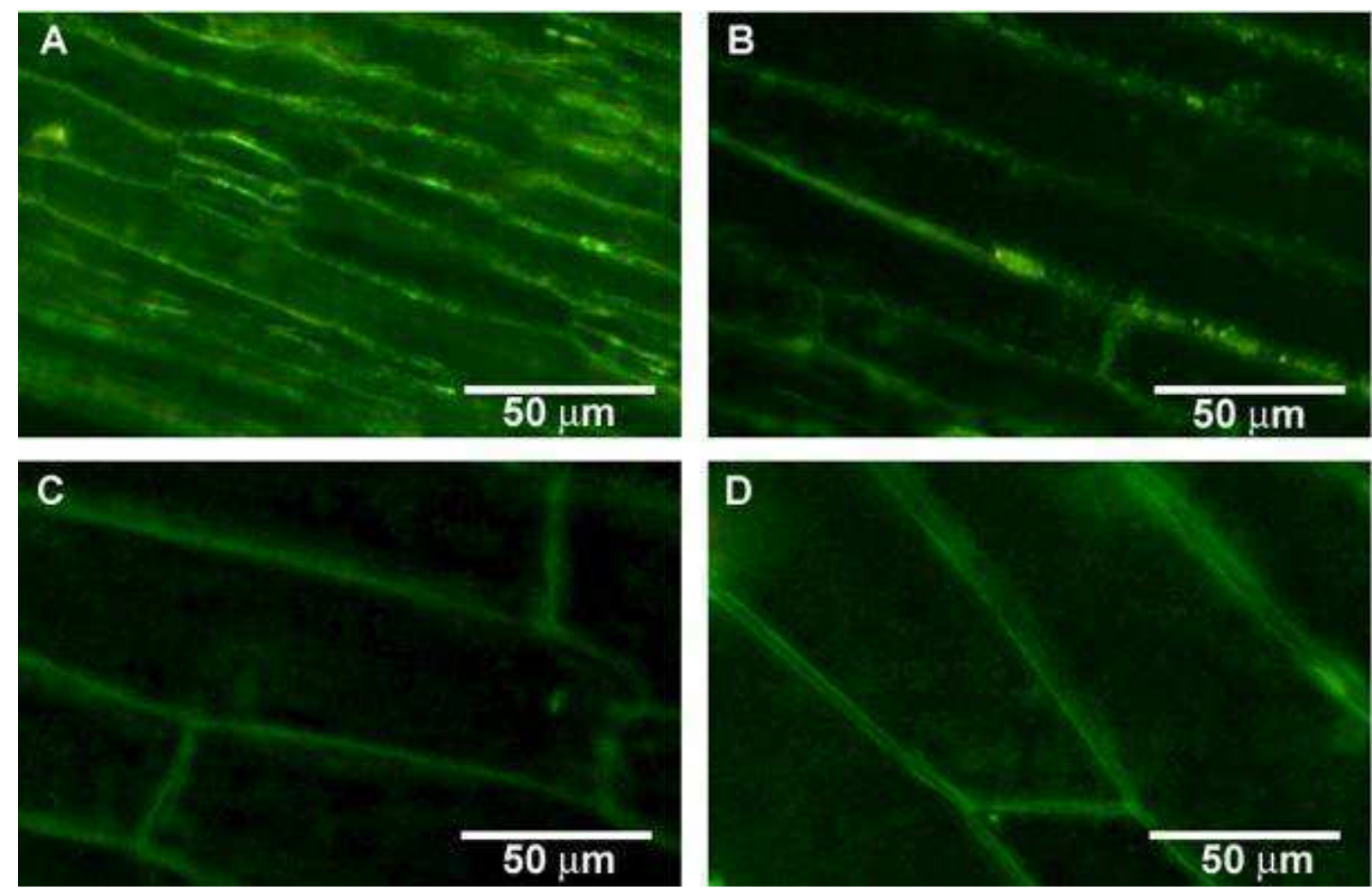

Figure 3.13 Carboxyfluorescein and acridine orange accumulation pattern in elongation zone and emerged blade

The distribution of the $\mathrm{pH}$ sensitive probes (5(6)carboxyfluorecein, $\mathrm{A}, \mathrm{C}$ and acridine orange, $B, D)$ appears to be similar in the elongation zone $(A, C)$ and emerged leaf blade $(B, D)$. The dye was taken up through the roots of intact plants and the epidermal strips of leaf three were incubated $(30 \mathrm{~min})$ in $\mathrm{pH} 7.5$ buffer prior to be viewed under the microscope (Leica DMIL; 450 - $490 \mathrm{~nm}$ excitation filter and $515 \mathrm{~nm}$ suppression filter).
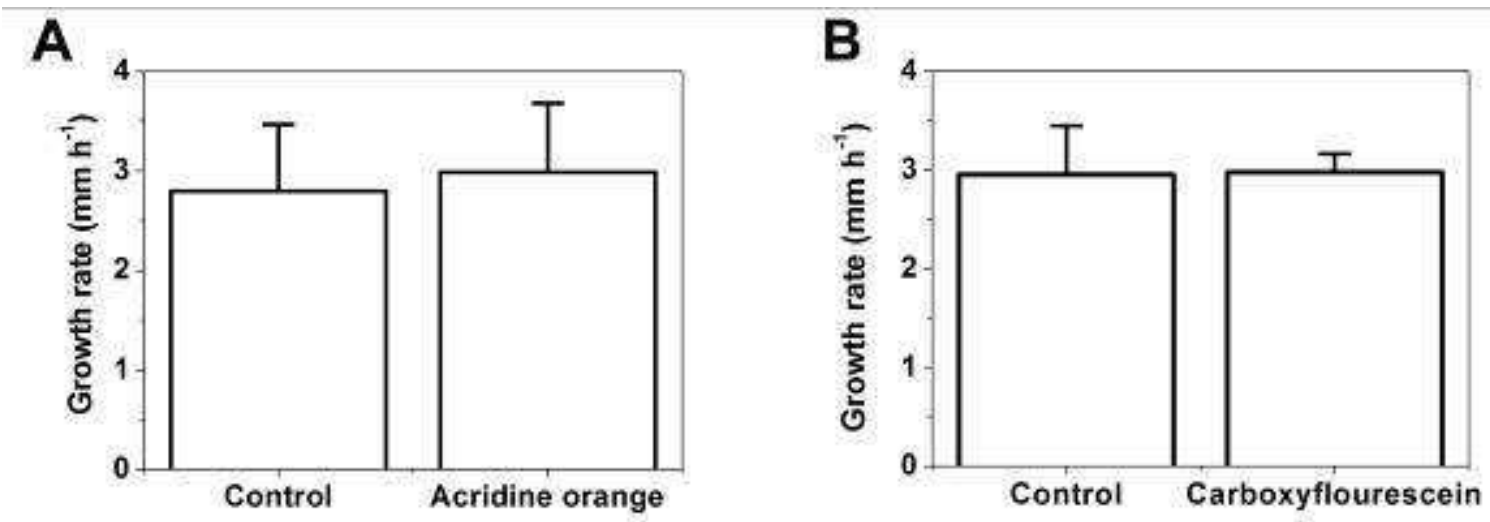

Figure 3.14 Effect of pH sensitive dyes on leaf growth rate

Growth, as measured with the LVDT on intact plants (unpeeled leaf three) did not change after $48 \mathrm{~h}$ incubation of plants in nutrient solution containing $2.5 \mu \mathrm{M}$ acridine orange (A); the same was observed for plants after $24 \mathrm{~h}$ incubation in nutrient solution containing $10 \mu \mathrm{M}$ carboxyfluorescein. Values are averages of 3 replicates, and error bars represent standard errors. 
The $\mathrm{pH}$ sensitivity of fluorochrome 5(6)carboxyfluorescein and acridine orange was determined by fluorescence spectroscopy. Both fluorescein probes showed $\mathrm{pH}$-sensitivity in the physiological $\mathrm{pH}$ range and had single peak spectra. Carboxyfluorescein showed a larger $\mathrm{pH}$ sensitivity in the $\mathrm{pH}$ range of interest compared with acridine orange (Fig. 3.15).
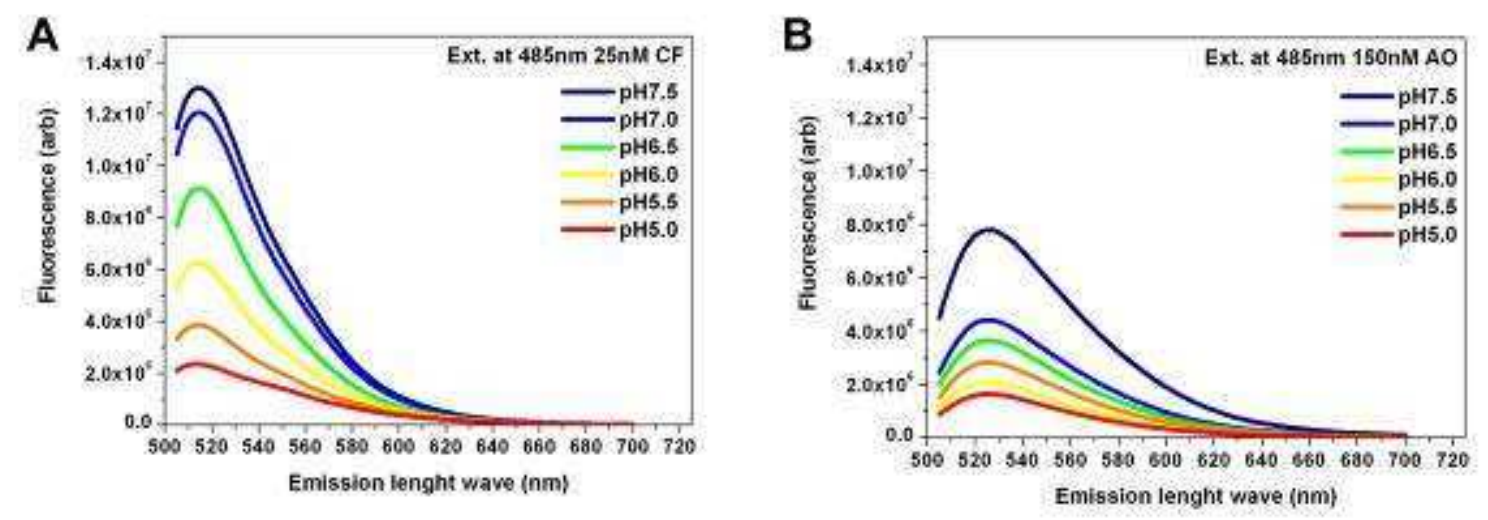

Figure $3.15 \mathrm{pH}$ sensitivity of fluorochromes

Fluorescence spectra and $\mathrm{pH}$ sensitivity of $5(6)$ carboxyfluorescein $(\mathrm{A})$ and acridine orange (B) was recorded. Both fluorochromes had $\mathrm{pH}$ sensitivity although carboxyfluorescein gave more explicit signal and better $\mathrm{pH}$ fidelity in the physiological $\mathrm{pH}$ range.

\subsection{LVDT analyses of growth responses to treatments}

\subsubsection{Leaf elongation under different treatments}

The basic assumption underlying LVDT experiments was that the wet tissue paper which was soaked in test solution and in direct contact with the surface of the elongation zone of leaf three allowed the test solution to diffuse into the apoplast. The responsiveness of setup to treatments was tested through two types of experiment, one designed to increase $\left(37^{\circ} \mathrm{C}\right)$ and on e designed to reduce growth (1 $\mathrm{M} \mathrm{NaCl}$ ). Elongation growth of grass leaves responds little to changes in ambient temperature but to the temperature close to the basal meristem (Stoddart \& Lloyd, 1986). Therefore, parts of a potato which had been heated to $37^{\circ} \mathrm{C}$ in an incubator were placed round the leaf elongation zone without any direct contact between the potato and the barley seedling. Growth started to increase within minutes (Fig. 3.16 A, B). With time, the potato cooled down and leaf elongation rate decreased. When finally $1 \mathrm{M} \mathrm{NaCl}$ was added to impose a severe osmotic stress, growth stopped instantly and remained zero or close to zero (Fig. 3.16 A, B). 


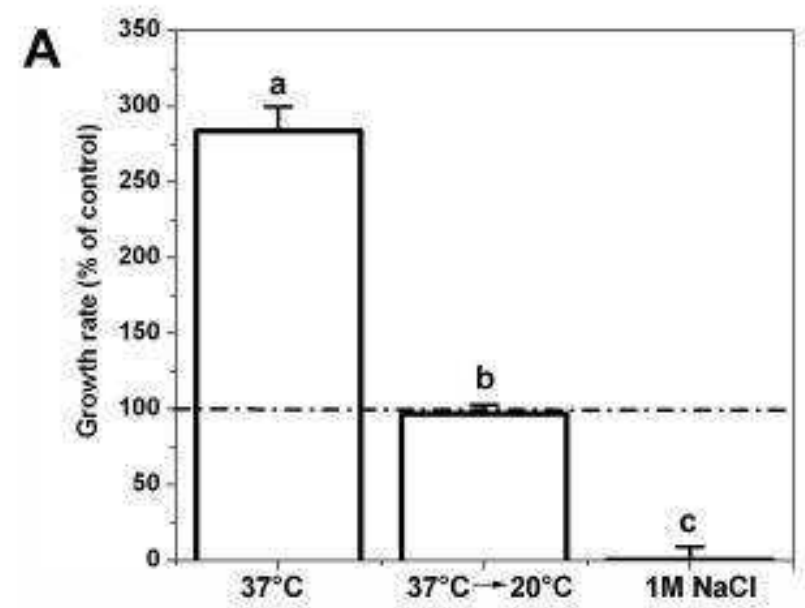

B

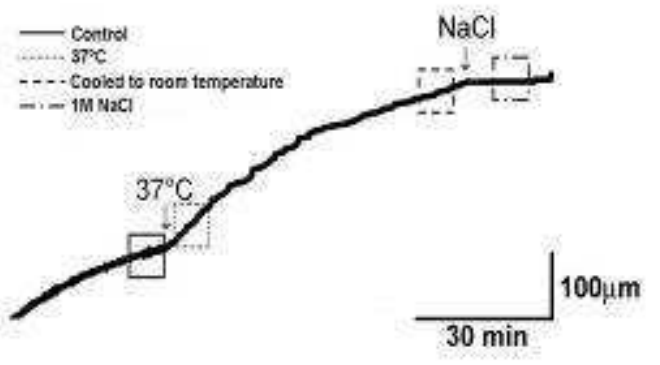

Figure 3.16 Testing the responsiveness of the LVDT setup to treatments which were expected to increase $\left(37^{\mathrm{C}} \mathrm{C}\right)$ or stop growth $(1 \mathrm{M} \mathrm{NaCl})$

Average values (three plants) and standard deviations (error bars) (A) and a typical trace (B) are shown. The apoplastic bathing medium always contained $1 \mathrm{mM} \mathrm{KCl}$. Different letters show a statistically significant difference at $p<0.001$ (Student's $t$ test).

Having tested the responsiveness of the LVDT setup, treatments were applied. In presence of $1 \mathrm{mM} \mathrm{KCl}$ in the test solution fusicoccin $(5 \mu \mathrm{M})$ increased leaf elongation rate to $160 \%$ the rate observed in control plants. Vanadate, $\mathrm{CsCl}$ and $\mathrm{CsCl}-$ vanadate double treatments caused a $50 \%$ decrease in growth rate (Fig. 3.17). The same was observed for the $\mathrm{K}^{+}$channel blocker tetraethylammonium (TEA) and ammonium, which blocks high-affinity $\mathrm{K}^{+}$transporters $\left(\mathrm{NH}_{4}{ }^{+}\right.$; HAK-type transporters (Kronzucker et al., 2003; Rodriguez-Navarro \& Rubio, 2006; Szczerba et al., 2006). 

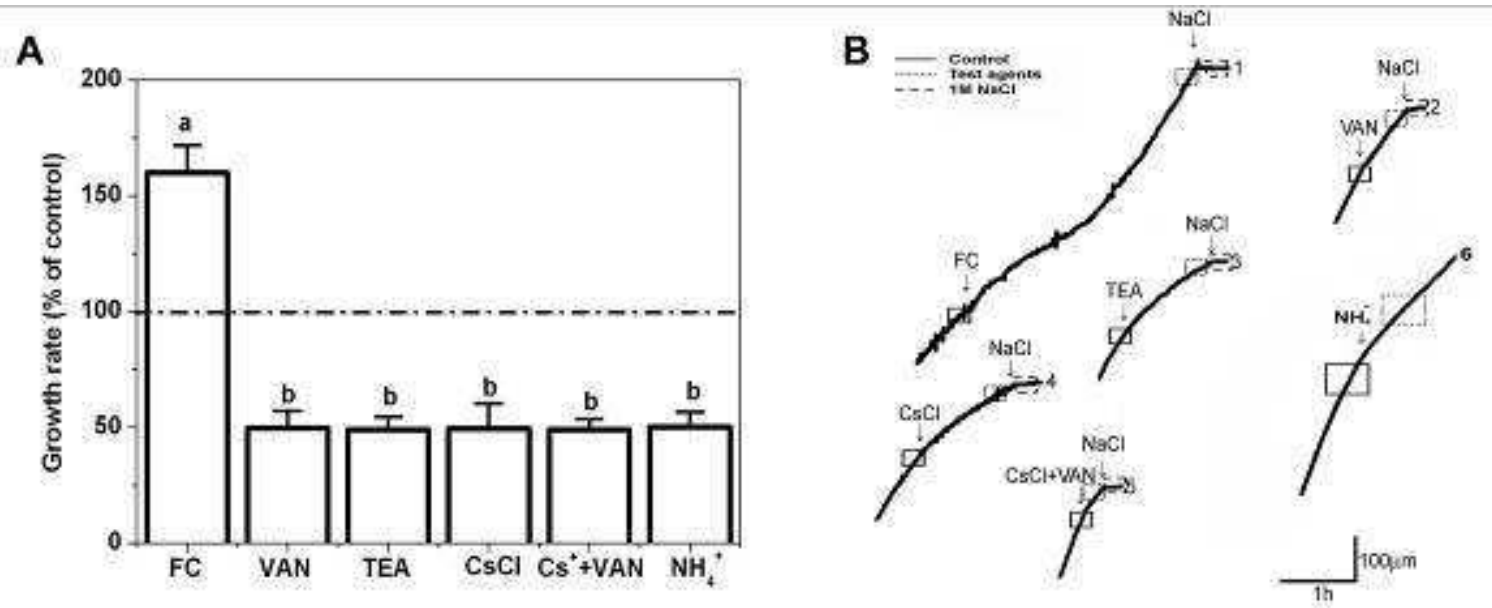

Figure 3.17 The effect of test reagents in the apoplastic bathing medium on leaf growth as measured with the LVDT setup

Average values and standard deviations of experiments $(A)$ involving application of test reagents are shown (fusicoccin $(5 \mu \mathrm{M}, \mathrm{n}=3$ plants), vanadate (VAN, $500 \mu \mathrm{M}, 6$ plants), tetraethylammonium chloride (TEA, $50 \mathrm{mM}, 6$ plants), $\mathrm{CsCl}(40 \mathrm{mM}, 4$ plants), CsCl+VAN double-treatment $\left(40 \mathrm{mM} / 500 \mu \mathrm{M}\right.$, 3 plants), and $\left(\mathrm{NH}_{4}\right)_{2} \mathrm{SO}_{4}(20$ $\mathrm{mM}, 3$ plants)). Media always contained $1 \mathrm{mM} \mathrm{KCl}$. Typical traces of experiments (B). Growth rates are expressed as percent of the respective $\mathrm{KCl}$ control, which contained only $\mathrm{KCl}$ but no test reagents in the apoplastic bathing medium. Different letters show a statistically significant difference at $p<0.05$ (Student's t-test and ANOVA).

The effect of fusicoccin on elongation growth was dependent on the $\mathrm{K}^{+}$ concentration in the bathing medium which was in direct contact with the leaf elongation zone (Fig. 3.18). The higher the $\mathrm{K}^{+}$concentration was, the larger was the stimulation of growth. In contrast, the inhibitory effect of vanadate on leaf elongation growth did not depend on the $\mathrm{K}^{+}$concentration in the bathing medium (Fig. 3.18). This experiment showed that changes in the $\mathrm{K}^{+}$concentration per se did not affect growth but required a functional PM- $\mathrm{H}^{+}$-ATPase to affect growth. 


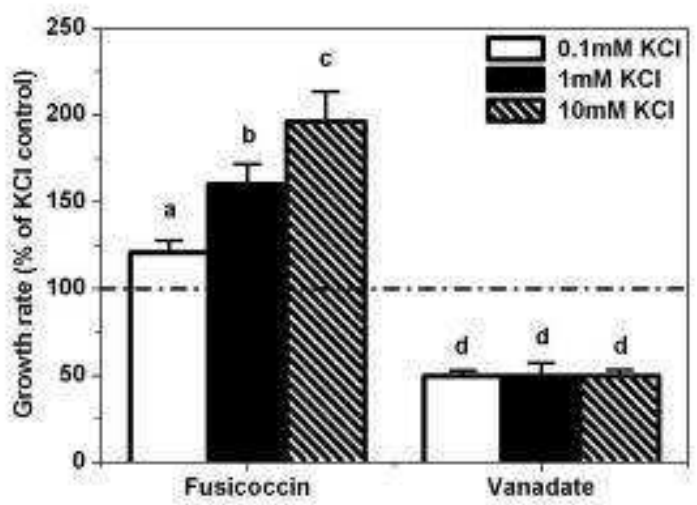

Figure 3.18 Potassium dependency of the leaf growth response to fusicoccin (5 $\mu \mathrm{M})$ and vanadate $(500 \mu \mathrm{M})$

Values are averages and standard deviations (error bars) of $3-6$ plants, and the $\mathrm{K}^{+}$ concentration of apoplastic bathing medium was as indicated. Growth rates are expressed as percent of the respective $\mathrm{KCl}$ control, which contained only $\mathrm{KCl}$ and no test reagents in the apoplastic bathing medium. Different letters show a statistically significant difference at $p<0.05$ (Student's t-test and ANOVA).

Short term (1 - 4 h) auxin-induced leaf growth was measured with the same LVDT set up. Treatments ( $5 \mu \mathrm{M}$ NAA with $1 \mathrm{mM} \mathrm{KCl})$ did not caused any significant increase in growth rate, moreover the leaf elongation rate slightly (but not significantly) decreased rather than increased (Fig. 3.19). These results suggested that leaf elongation can not be further increased by auxin treatments.

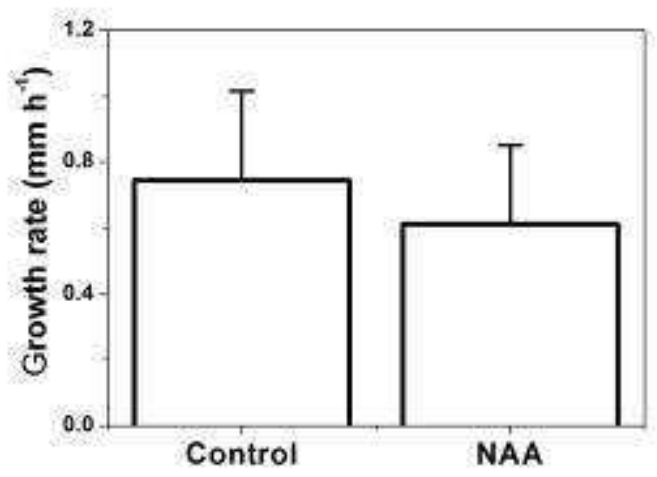

Figure 3.19 Auxin effect on leaf elongation growth

Elongation growth was monitored using the LVDT system. Growth in control (1 mM $\mathrm{KCl})$ and NAA treated plants $(1 \mathrm{mM} \mathrm{KCl}$ and $5 \mu \mathrm{M} \mathrm{NAA})$ did not significantly differ from each other. Values are averages and standard deviations (error bars) of 3 replicates. The difference in growth between control and NAA treatment is statistically not significant (Student's t-test). 


\subsubsection{Cell wall changes in response to treatments}

Changes in cell wall properties were tested for $500 \mu \mathrm{M}$ vanadate, $40 \mathrm{mM} \mathrm{CsCl}$ and 5 $\mu \mathrm{M}$ fusicoccin treatments by applying an additional $3 \mathrm{~g}$ counterweight on the LVDT system. Control plants had $1 \mathrm{mM} \mathrm{KCl}$ in the apoplast bathing medium of the elongation zone. The elastic growth component significantly changed only in response to the fusicoccin treatment, whereas plasticity was affected significantly in response to $\mathrm{CsCl}$ (Fig. 3.20 A). Additional stress $(0.03 \mathrm{~N}$ ) on the cell wall did not change the relative growth rate compared with control (1 $\mathrm{mM} \mathrm{KCl}, \Delta \Delta \mathrm{v})$, except in fusicoccin-treated leaves. Fusicoccin treatment caused a $50 \%$ increase in $\Delta \Delta \mathrm{v}$ compared with all other treatments and the control (Fig. 3.20 B).
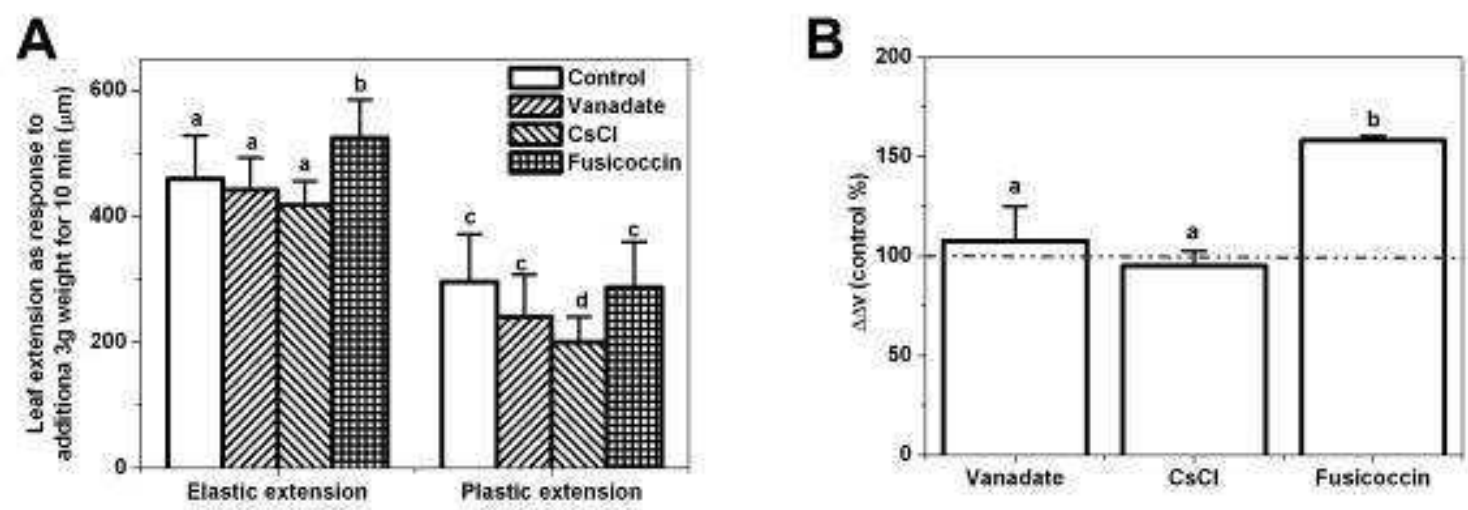

Figure 3.20 Cell wall changes under different treatments

Elastic and plastic growth (A) and $0.03 \mathrm{~N}$ stress caused growth rate (B) was measured on 3 independent plants in two replicates each. $\Delta \Delta \mathrm{v}$ means the difference between $\Delta v_{\text {control }}$ and $\Delta v_{\text {treatment }}$ where $\Delta v$ is the difference in growth rate before and under the applied additional stress $\left(\mathrm{V}_{2}-\mathrm{v}_{1}\right.$ on Fig. 3.2). Different letters show statistically different values at $p<0.05$ level with Student's t-test and ANOVA.

Growth rate before $\left(\mathrm{v}_{1}\right)$ and under $\left(\mathrm{v}_{2}\right)$ applied $0.03 \mathrm{~N}$ force was in agreement with previous effect of test reagents on growth (compare Fig. 3.17 and Fig. 3.21). The fusicoccin treatment caused a large increase in growth, although the increase was statistically not significant. 


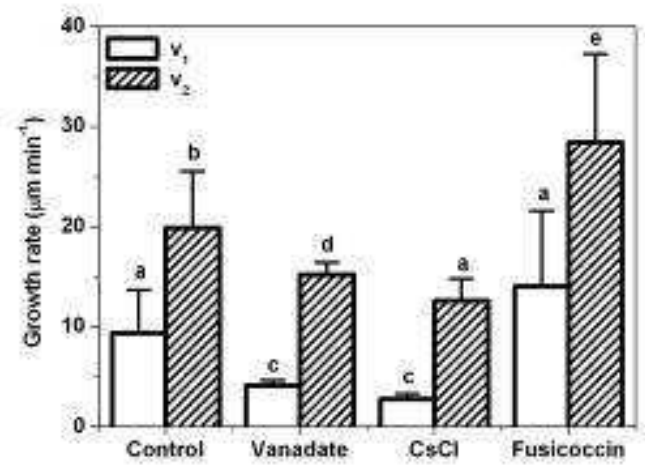

Figure 3.21 Growth rate before and in response to an additional applied force $(0.03 \mathrm{~N})$

Growth rate before $\left(\mathrm{v}_{1}\right)$ and under $\left(\mathrm{v}_{2}\right)$ applied force $(3 \mathrm{~g})$ using different treatments as vanadate $(500 \mu \mathrm{M}), \mathrm{CsCl}(40 \mathrm{mM})$ or fusicoccin $(5 \mu \mathrm{M})$. Bath medium of control plants contained $1 \mathrm{mM} \mathrm{KCl}$. Values are averages of $3-3$ replicates. Different letters shows statistically different values at $p<0.05$ level with Student's t-test and ANOVA.

\subsection{Expression analysis of PM- $\mathrm{H}^{+}$-ATPase using $\mathrm{qPCR}$}

$\mathrm{PM}-\mathrm{H}^{+}$-ATPase expression was analysed using $\mathrm{qPCR}$. Altogether five reference genes (GADPH, cyclophilin, ubiquitin, HSP70 and PM- $\mathrm{H}^{+}$-ATPase) were tested in the experimental system. Only ubiquitin and the two PM- $\mathrm{H}^{+}$-ATPase (Ha1 and ATPase) primer pairs showed similar expression in the elongation zone and emerged blade (Fig. 3.22 A). Other, commonly used reference genes such as actin, tubulin, EF1, LHC were not suited because growing and non-growing leaf regions had to be compared (see Besse et al., 2011; Volkov et al., 2009). Ubiquitin could not be used as reference gene because the PCR product was not homogenous but produced more than one band as agarose gel analysis showed (Fig. 3.22 B). Applying Genevestigator bioinformatics application (www.genevestigator.com) could not solve the problem. Therefore, it was decided to carry out absolute qPCR quantification to determine $\mathrm{PM}-\mathrm{H}^{+}$-ATPase expression levels in the leaf elongation zone and emerged blade. 
A

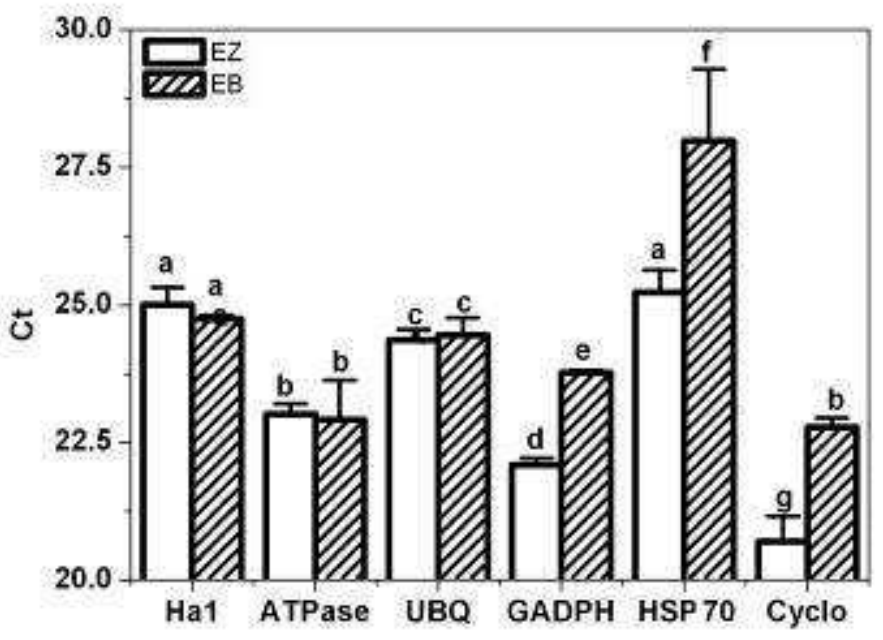

B

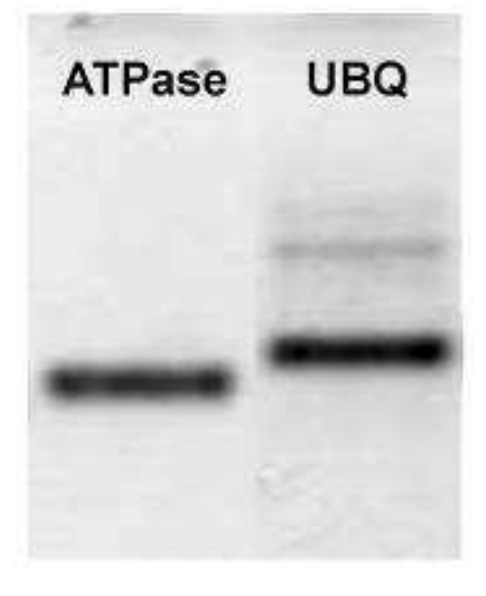

\section{Figure 3.22 reference genes for qPCR experiments}

$500 \mathrm{pg}$ total RNA-equivalent cDNA was used in each reaction well to check the qPCR profile of candidate reference genes. Expression, as shown as Ct-value, of the two PM- $\mathrm{H}^{+}$-ATPase PCR primer pair (Ha1 and ATPase) and ubiquitin (UBQ) was similar between the two leaf regions, effectively qualifying them as reference genes of expression. In contrast, expression of glyceraldehyde-3-phosphate dehydrogenase (GADPH), heat shock protein $70 \mathrm{kDa}$ (HSP70) and cyclophylin (Cyclo) differed significantly between leaf regions (A). Values are averages of 3 replicates and error bars represent SD. Different letters show significantly different values at $p<0.05$ level using Student's t-test and ANOVA. Agarose gel picture of PM- $\mathrm{H}^{+}$-ATPase (ATPase) and ubiquitin (UBQ) show that that ubiquitin shows more than one PCR product $(\mathrm{B})$.

\subsubsection{Quality control of the standard required for absolute qPCR}

Quality of reference DNA (purified PM-H ${ }^{+}$-ATPase PCR fragments) was validated using end point detection digital PCR technique (Vogelstein \& Kinzler, 1999). The concentration of fragments was calculated as 0.5 copy $\mu l^{-1}$ based on Nanodrop ${ }^{\circledR}$ measurements. From 40 PCR reactions 21 were PCR positive and 19 negative (Fig. 3.23). This suggested a concentration of 0.525 DNA copy $\mu l^{-1}$ in the external standard and was just $2.5 \%$ higher compared with the calculated copy concentration $\left(0.5\right.$ copy $\left.\mu l^{-1}\right)$. 
Figure 3.23 Digital PCR pattern of external standard DNA

Using digital PCR technique the concentration of the external standard for $\mathrm{PM}-\mathrm{H}^{+}-$ ATPase expression was verified. The PCR positive / negative ratio was $21 / 19$, which suggests a concentration of 0.525 copy of ATPase DNA in $1 \mu$ l of standard compared with the calculated 0.5 . Therefore, the reliability of the standard was higher than $95 \%$.

\subsubsection{Calculation of cell number and membrane surface}

Total cell volume of the leaf regions was calculated for the two barley cultivars using the water content of the plant material, cell dimensions and contribution of each tissue to total leaf symplast volume (Table 3.1). The water content differed significantly between the two leaf regions but not between the two cultivars.

Table 3.1 Water content of two different regions of leaf three in two cultivars of barley

\begin{tabular}{l|l|l|l|l} 
Cultivar & Leaf part & No replicates & Water content (\%) & SD \\
\hline \hline \multirow{2}{*}{ Golf } & Elongation zone & 3 & 92.06 & 1.57 \\
\cline { 2 - 5 } & Emerge blade & 3 & 86.78 & 2.25 \\
\hline \multirow{2}{*}{ Jersey } & Elongation zone & 7 & 93.78 & 3.12 \\
\cline { 2 - 5 } & Emerge blade & 7 & 87.78 & 1.07
\end{tabular}

The tissue volume ratio was measured on cross sections using light microscopy (Table 3..2 and Fig. 3.24) and average cell size was estimated from the present protoplast measurements and data published for Golf (Fricke \& Flowers, 1998; Volkov et al., 2007; Volkov et al., 2009, Kavanagh, 2010) (Table 3.3). Mesophyll and epidermis cell size and surface area was calculated separately and the total number of cells and surface area was calculated from data on the contribution of each tissue to total leaf symplastic volume (not considering intercellular air space). Mesophyll cell size differed between growing and mature, emerged tissues around 2.2-fold and epidermis cells differed 4.6-fold, in each case being larger in emerged tissue. The surface was about 2.6-fold and 1.9-fold higher in the emerged blade for epidermis and mesophyll, respectively. 
Table 3.2 The contribution of different tissues to total leaf volume in the elongation zone (EZ) and emerged blade (EB) of leaf three of barley. Values are given as $\%$ of the total leaf volume and are either not corrected or corrected for intercellular air space, effectively giving a contribution to total leaf symplastic volume.

\begin{tabular}{l|l|l|l|l} 
& \multicolumn{2}{|c|}{ EZ } & \multicolumn{2}{c}{ EB } \\
\hline \hline Epidermis (\%) & 24.85 & \pm 1.54 & 23.37 & \pm 2.94 \\
\hline Mesophyll (\%) & 61.75 & \pm 1.93 & 51.61 & \pm 4.36 \\
\hline Vascular bundle (\%) & 8.99 & \pm 1.97 & 4.01 & \pm 0.93 \\
\hline Intercellular air space (\%) & 4.40 & \pm 1.32 & 21.01 & \pm 4.29 \\
\hline Epidermis corrected (\%) & 26.00 & \pm 1.28 & 29.59 & \pm 3.72 \\
\hline Mesophyll corrected (\%) & 64.60 & \pm 1.96 & 65.34 & \pm 5.52 \\
\hline Vascular bundle corrected (\%) & 9.41 & \pm 1.80 & 5.08 & \pm 1.18
\end{tabular}
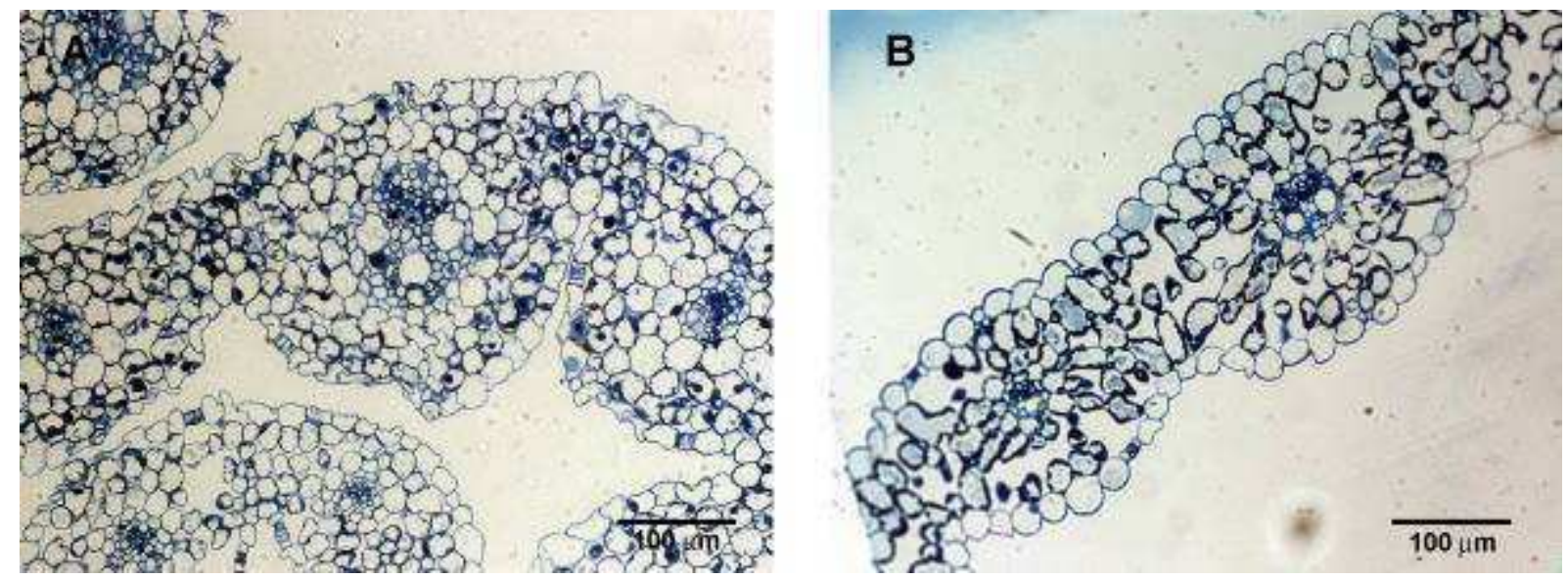

Figure 3.24 Representative cross sections used for determination of the contribution of different tissues and air space to total leaf volume

Toluidine blue stained cross sections were used to calculate the percentage of different tissues to total leaf and symplastic volume in the elongation zone (A) and emerged blade (B) of leaf three of barley. 
Table 3.3 Cell size calculation based on the present and literature data. Values shown in bold were used for to relate ATPase expression and activity data to cell volume and surface area

\begin{tabular}{|c|c|c|c|c|}
\hline & \multicolumn{2}{|c|}{ EZ } & \multicolumn{2}{|c|}{ EB } \\
\hline Cell volume & Average & SD & Average & SD \\
\hline $\begin{array}{l}\text { Epidermis cell size (Fricke \& Flowers, } \\
1998 \text { ) }\end{array}$ & 99.4 & & 461 & \\
\hline Epidermis cell size average (pl) & 99.4 & & 461 & \\
\hline Mesophyll cell size (my protoplast results) & 3.7 & & 9.4 & \\
\hline Mesophyll cell size (Volkov et al., 2007) & 8.9 & & 24.4 & \\
\hline Mesophyll cell size (Volkov et al., 2009) & 11.8 & & 17.4 & \\
\hline Mesophyll cell size (Kavanagh, 2010) & 2.08 & & 8.11 & \\
\hline Mesophyll cell size average (pl) & 6.62 & \pm 4.52 & 14.83 & \pm 7.59 \\
\hline Cell surface & & & & \\
\hline $\begin{array}{l}\text { Surface of epidermis cell (Fricke \& } \\
\text { Flowers, 1998) }\end{array}$ & 27100 & & 65200 & \\
\hline $\begin{array}{l}\text { Surface of epidermis cell (Kavanagh, } \\
\text { 2010) }\end{array}$ & 12308 & & 34809 & \\
\hline Surface of epidermis cell average $\left(\mu m^{2}\right)$ & 19,707 & $\pm 10,459$ & 50,004 & $\pm 21,490$ \\
\hline Mesophyll cell size (my protoplast results) & 1,157 & & 2,154 & \\
\hline Mesophyll cell size (Volkov et al., 2007) & 2,077 & & 4,068 & \\
\hline Mesophyll cell size (Volkov et al., 2009) & 2,506 & & 3,247 & \\
\hline Mesophyll cell size (Kavanagh, 2010) & 788 & & 1,952 & \\
\hline Surface of mesophyll cell $\left(\mu \mathrm{m}^{2}\right)$ & 1,632 & \pm 796 & 2,855 & \pm 988 \\
\hline
\end{tabular}

\subsubsection{Gene expression data based on absolute qPCR method}

Using the absolute qPCR method, together with cell size and tissue volume contributions it was found that $\mathrm{PM}-\mathrm{H}^{+}$-ATPase had a constant expression pattern in both elongation zone and emerged leaf blade; it was deemed to be a perfect reference gene in both Golf and Jersey cultivars (Fig. 3.25 and Table 3.4). The total RNA content was similar in the elongating zone and emerge leaf blade. This applied to both Golf and Jersey cultivars (Table 3.4).

Results expessed per plasma membrane surface unit were significant, being around 2 times higher $\mathrm{PM}-\mathrm{H}^{+}$-ATPase protein concentration as might be presumed in elongation zone compare with emerge blade in both barley cultivars. Absolute expression was 3 times higher in Golf compare to Jersey cultivar (Fig. 3.26). The calculation here presumed that protein translation from mRNA was linear and had equal probability in elongation zone and emerge blade. More details of the calculation can be found in the Appendix. 

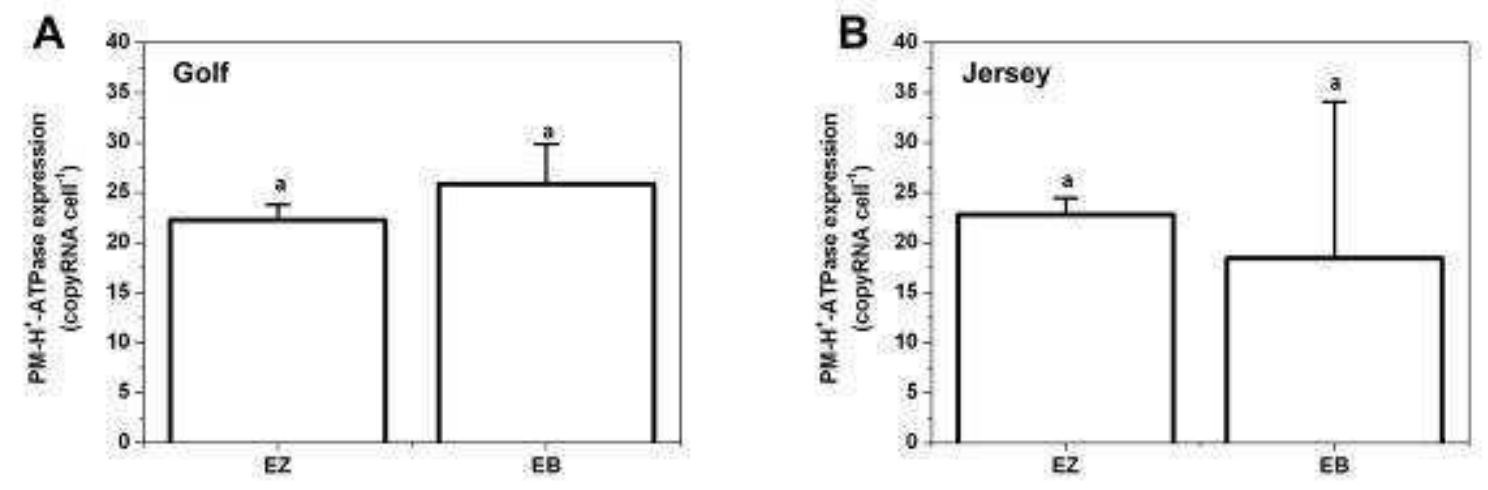

Figure 3.25 Expression of PM-H $\mathrm{H}^{+}$-ATPase using absolute qPCR

Using absolute $\mathrm{PPCR}$, the total number of mRNA transcripts was determined for each cDNA sample. The amount of cDNA obtained from a given amount of leaf region (elongation zone, EZ; emerged blade, EB) was known, as was the number of cells for each region. This made it possible to express QPCR data as mRNA copy number per cell. Results are shown for the barley cultivars Golf $(A)$ and Jersey (B) and represent averages and standard deviation (error bars) of three independent experiments (batches of plants). PM- $\mathrm{H}^{+}$-ATPase expression (copyRNA cell ${ }^{-1}$ ) did not differ significantly between elongation zone (EZ) and emerged blade (EB) in either Golf or Jersey (Student's t-test).

Table 3.4 Ct values of PM- $\mathrm{H}^{+}$-ATPase expression together with RNA content per cell in the elongation zone (EZ) and emerged blade (EB) of leaf three of barley.

Two barley cultivars were studied, Golf and Jersey, and three independent experiments were carried out.

\begin{tabular}{l|c|c|c|c} 
& Ct & SD & RNA content $\left(\right.$ pg cell $^{-1}$ ) & SD \\
\hline EZ (Golf) & 23.8 & 0.2 & 22.3 & 1.5 \\
\hline EB (Golf) & 24.2 & 0.5 & 25.9 & 4.0 \\
\hline EZ (Jersey) & 22.7 & 0.2 & 22.8 & 1.7 \\
\hline EB (Jersey) & 22.8 & 0.2 & 18.5 & 15.6
\end{tabular}

Since the determination of cell number in a given leaf region involved large errors, an additional control experiment was conducted in which RNA was extracted from protoplast suspension of the Jersey cultivar. The number of protoplasts could easily be calculated. RNA yield of $300-1000 \mu$ protoplast suspension (about 0.5 - 7

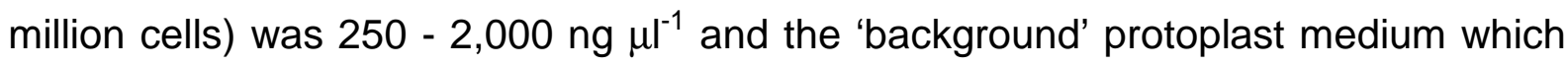
was taken as supernatant folowed gentle centrifugation of protoplasts, yielded virtually no extractable RNA (less than $1-10 \mathrm{ng}^{-1} \mathrm{l}^{-1}$, which was below the measuring range of the Nanodrop ${ }^{\circledR}$ equipment). Results for protoplasts were expressed in copy number of $\mathrm{PM}-\mathrm{H}^{+}$-ATPase transcript protoplast ${ }^{-1}$ and in copy number of $\mathrm{PM}-\mathrm{H}^{+}$ATPase transcript $\mathrm{mm}^{-2}$ protoplast plasma membrane surface area. These figures 
were in the same range as results obtained for the Jersey cultivar when calculated cell number was used as reference system (see Fig. 2.25).
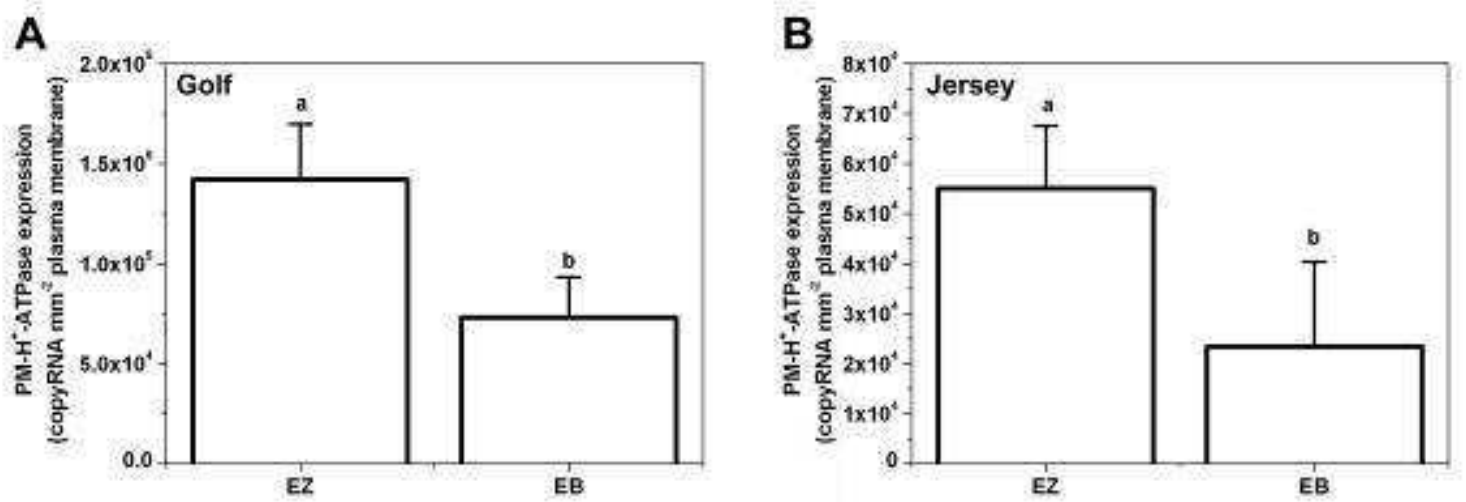

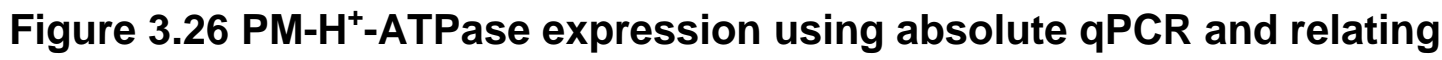
expression data to total plasma membrane surface area

PM- $\mathrm{H}^{+}$-ATPase gene shows significantly (around 2 times) higher expression in the elongation zone (EZ) compared with emerged leaf blade (EB). Values for the Golf barley cultivar (A) were 3 fold higher than values for the Jersey barley cultivar (B). Results are averages and standard deviations (error bars) of three 3 independent experiments. Different letters shows statistically different values between leaf regions (student's t-test, $\mathrm{p}<0.05$ ).

Table 3.5 RNA content and PM- $\mathrm{H}^{+}$-ATPase expression in the elongation zone (EZ) and emerged blade (EB) of leaf three of barley (Golf, Jersey). Different reference systems were used. Results are averages and SD of $3-6$ independent experiments. Protoplasts were isolated only from the Jersey barley cultivar. PM, plasma membrane; protopl., protoplast.

\begin{tabular}{|c|c|c|c|c|c|c|}
\hline & \multicolumn{2}{|c|}{ RNA (pg cell ${ }^{-1}$ ) } & \multicolumn{2}{|c|}{ ATPase copy cell ${ }^{-1}$} & \multicolumn{2}{|c|}{$\begin{array}{l}\text { ATPase copy } \mathrm{mm}^{-2} \\
\text { PM }\left(\times 10^{3}\right)\end{array}$} \\
\hline EZ (Golf) & 22.3 & \pm 1.5 & 300 & \pm 60 & 142 & \pm 28 \\
\hline EB (Golf) & 25.9 & \pm 4.0 & 260 & \pm 70 & 73 & \pm 20 \\
\hline EZ (Jersey) & 22.8 & \pm 1.7 & 120 & \pm 30 & 55 & \pm 12 \\
\hline EB (Jersey & 18.5 & \pm 15.6 & 80 & \pm 60 & 23 & \pm 17 \\
\hline EZ protopl. & 18.7 & \pm 17.5 & 50 & \pm 30 & 38 & \pm 23 \\
\hline EB protopl. & 20.7 & \pm 19.2 & 50 & \pm 40 & 12 & \pm 7 \\
\hline
\end{tabular}



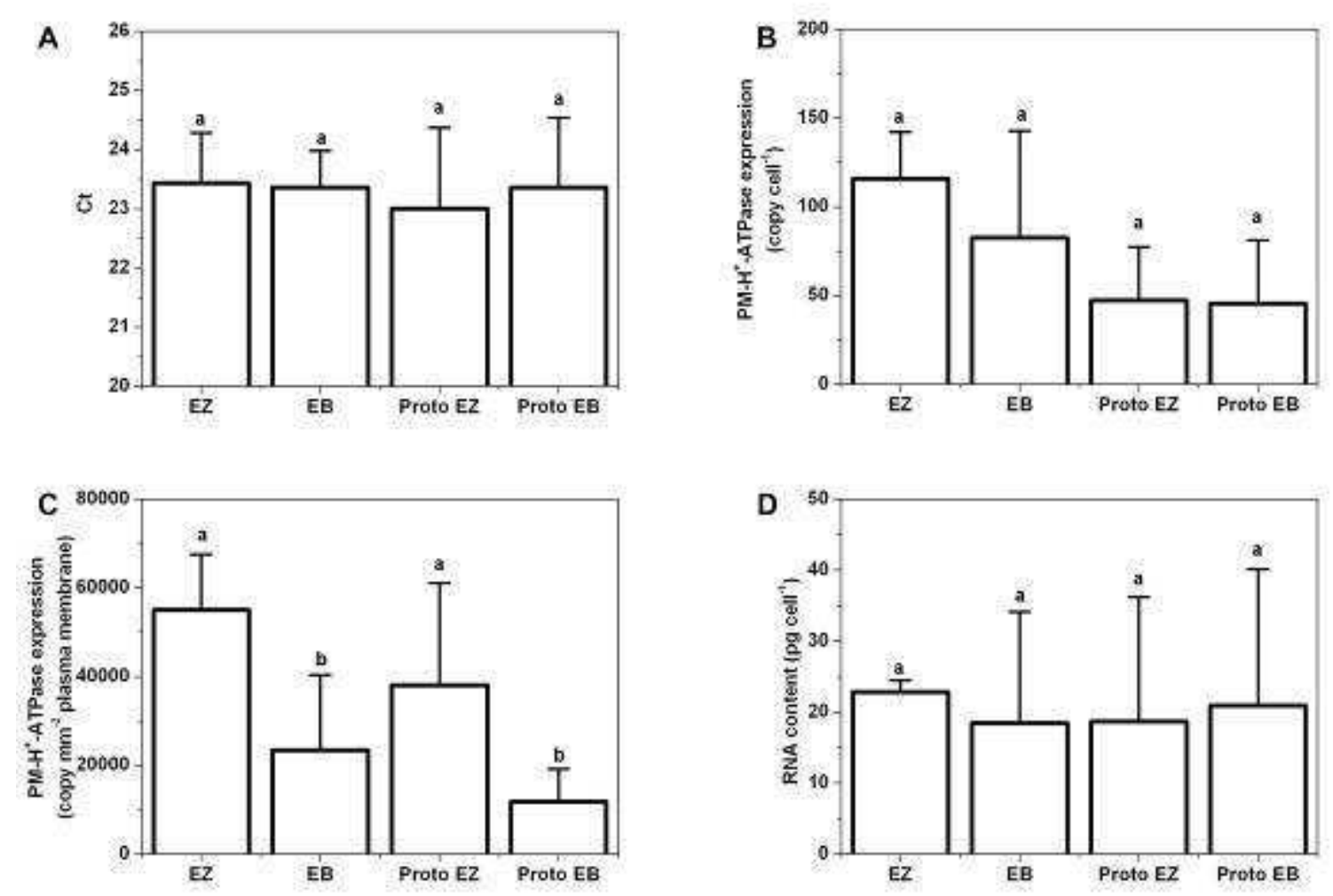

Figure 3.27 Comparison of molecular biological data using leaf tissues or mesophyll protoplasts

Ct values (A), PM- $\mathrm{H}^{+}$-ATPase copy in a cell (B), per $\mathrm{mm}^{2}$ plasma membrane $(\mathrm{C})$ and total RNA content in a cell (D) was compared between experiments where RNA was isolated from whole leaf segments of the elongation zone (EZ) and emerged blade (EB) and from isolated mesophyll protoplasts of the elongation zone (Proto EZ) and emerged blade (Proto EB). Values are averages of $3-6$ batches of plants. Different letters show statistically significant differences at $p<0.05$ using Student's t-test and ANOVA. All experiments were conducted on the barley cultivar Jersey

\section{$3.4 P M-H^{+}$-ATPase activity and expression at protein level}

Data from qPCR experiments showed that the copy number of PM- $\mathrm{H}^{+}-\mathrm{ATPase}$ transcripts per unit plasma membrane surface area was significantly higher in growing compared with non-growing leaf tissue. This could partially explain the lower apoplast $\mathrm{pH}$ in elongating tissue. To test to which degree changes in the activity of the $\mathrm{PM}-\mathrm{H}^{+}$-ATPase protein also contributed to the lower $\mathrm{pH}$, plasma membrane fractions were isolated from growing and non-growing part of barley leaves and used to determine the activity of $\mathrm{PM}-\mathrm{H}^{+}$-ATPase. Due to the lack of availability of Golf seeds towards the end of this project, these experiments were carried out on the spring barley cultivar Jersey. 


\subsubsection{Optimization of membrane isolation and ATPase assay}

Membrane isolation and ATPase assay had to be optimized. The original method had been described for a large amount of plant tissue (125 g) (Kjellbom \& Larsson, 1984) however previous studies showed that with the method plasma membrane fraction might be purified from lower amout of plant material (Wei et al., 2007). The $P_{i}$ determination assay had been designed originally for animal membranes (Sarkadi et al., 1992), with animal cells notably lacking any vacuolar ATPases.

\subsubsection{Plasma membrane isolation}

It was impossible to harvest more than $6 \mathrm{~g}$ leaf material from the elongation zone and emerged blade portion of leaf three, given the growth constraints (growth chamber, laboratory space) since this required already between $200-400$ barley seedlings. Preliminary experiments were carried out to find the minimum amount of leaf tissue which was required for a two-phase separation system with $12 \mathrm{~g}$ final separation weight. These experiments showed that below $1 \mathrm{~g}$ initial leaf tissue virtually no membrane fraction could be obtained and above $10 \mathrm{~g}$ the plasma membrane fraction could not be separated from chloroplast membranes using 5 - 6 purification steps.

One washing step of the membrane fraction as recommended by Pitann et al. (2009b) was not enough to fully eliminate the rest of the polymers (dextran and PEG) from the purified membrane fraction. In the presence of one or both of these polymers PAGE could not be carried out properly and protein bands appeared blurred on the gel (Fig. 3.28).

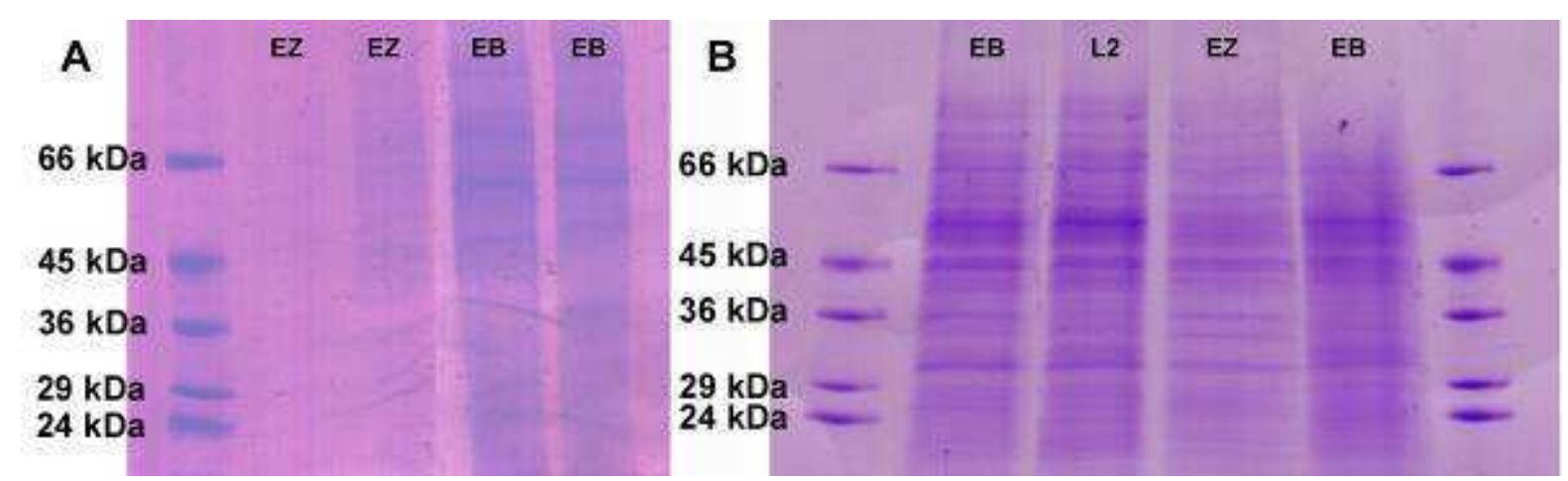

Figure 3.28 Impact on the quality of PAGE separation of washing steps during plasma membrane isolation

Residues of the polymers in plasma membrane fractions caused proteins to appear blurred on the polyacrylamide gel. One washing step was not enough to completely eliminate the polymers (A) while applying two steps (B) the blurring effect was not found on Coomassie stained gels. EZ - elongation zone, EB - emerged leaf blade and L2 - leaf blade of second leaf. 
3.4.1.2 Determination of total protein content in plasma membrane vesicles

In studies where plasma membranes have been isolated, protein concentration has typically been quantified with the Bradford method or a modification of it (Yan et al., 1998; Yan et al., 2002; Zörb et al., 2005; Pitann et al., 2009b; Zhu et al., 2009; Hatzig et al., 2010; Wakeel et al., 2010). Using this approach, it was found in the present study that protein concentration was grossly underestimated, compared to quantification of proteins through densitometry by Phoretix 4.01 software (Phoretix International) on Coomassie stained PAGE gels and calibration with protein standards (Sigma) of known protein content. (Fig. 3.29).

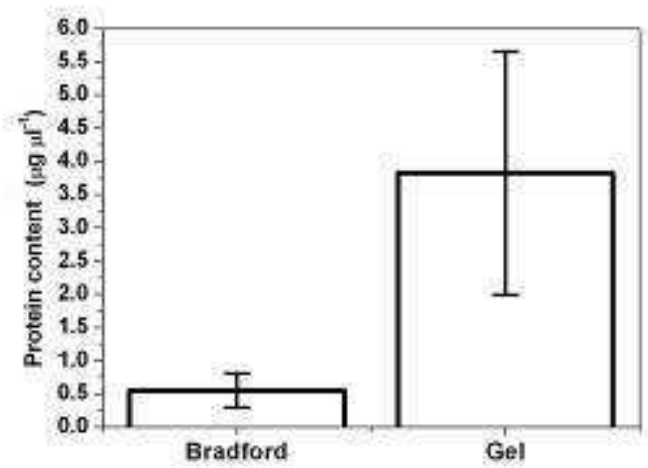

Figure 3.29 Protein measurement in plasma membrane vesicles using two different methods

The protein concentration of the plasma membrane vesicles was significantly lower when determined with the Bradford method than when determined through densitometry of samples run on PAGE gels. The difference in protein concentration between the two methods was statistically significant at $p<0.05$ (Student's t-test).

\subsubsection{ATPase assay}

Optimization of ATPase assay was carried out to find the optimal reaction volume, detection method and membrane protein amount for the assay. Preliminary experiments showed that colour development was more reproducible in $1750 \mu \mathrm{l}$ compared with $200 \mu \mathrm{l}$ (microtiter plate). The optical density of the samples had to be measured within a minute of completion of colour development, together with the calibration curve. If this was not considered, the absorbance changed rapidly (Fig. 3.31). When $3 \mu \mathrm{g}$ total membrane protein were used and the assay was run for 60 min at $28{ }^{\circ} \mathrm{C}$ reproducible and easy to measure amount of released (from ATP) amount of $P_{i}$ could be measured A typical ATPase assay is shown in Fig. 3. 30. 


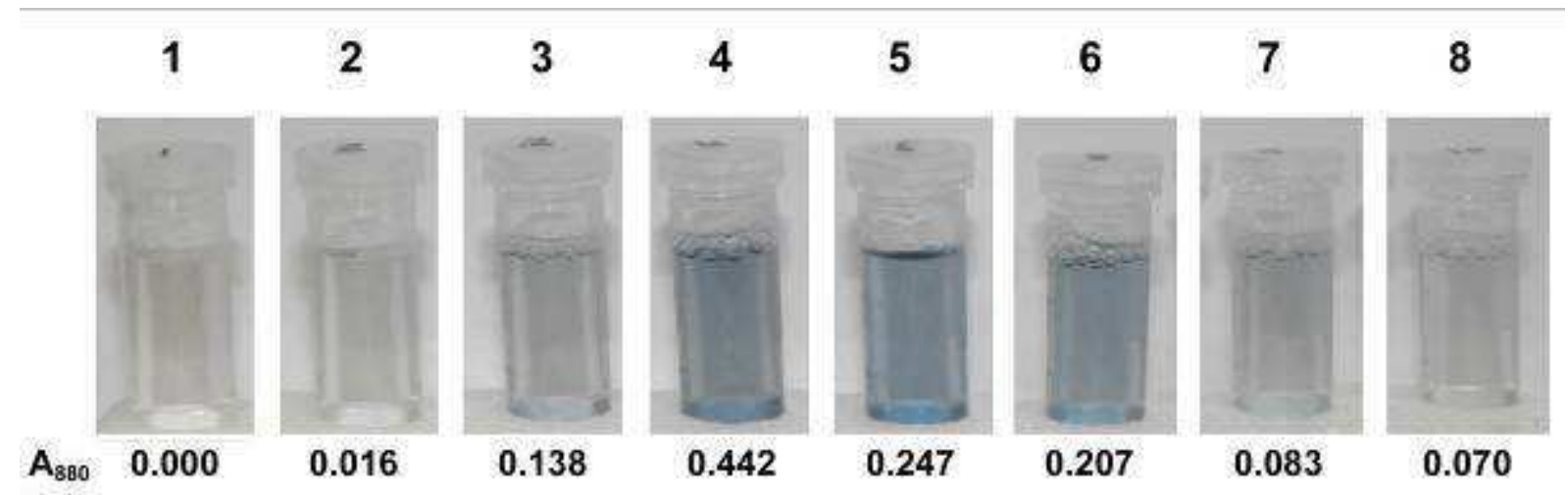

Figure 3.30 Typical ATPase assay

The concentration of $P_{i}$ was determined by a blue colour reaction (detecting the absorbance at $880 \mathrm{~nm}$ ) using calibration curve standards (1 - 4; with 0, 10, 30 and 60 $\mathrm{nmol} \mathrm{P}_{\mathrm{i}}$ per reaction. Without blocking bacterial and vacuolar type of ATPases (5) slightly more $\mathrm{P}_{\mathrm{i}}$ could be measured compared with a reaction where these ATPase were blocked with $10 \mathrm{mM} \mathrm{NaN}_{3}$ and $100 \mathrm{mM} \mathrm{KNO}_{3}$ (6); $500 \mu \mathrm{M}$ vanadate (7) blocked ATPase activity almost to the same extent as when total protein was denatured using SDS (8). Values below the tubes show the absorbance at $880 \mathrm{~nm}$.

To determine the optimal detection time of the colour development reaction kinetics was recorded (Fig. 3.31). Between 20 - 30 min the absorbance was between 0.1 - 0.6 (arbitrary units) and could be measured with high reproducibility. In addition, the calibration curve was linear in this time range.
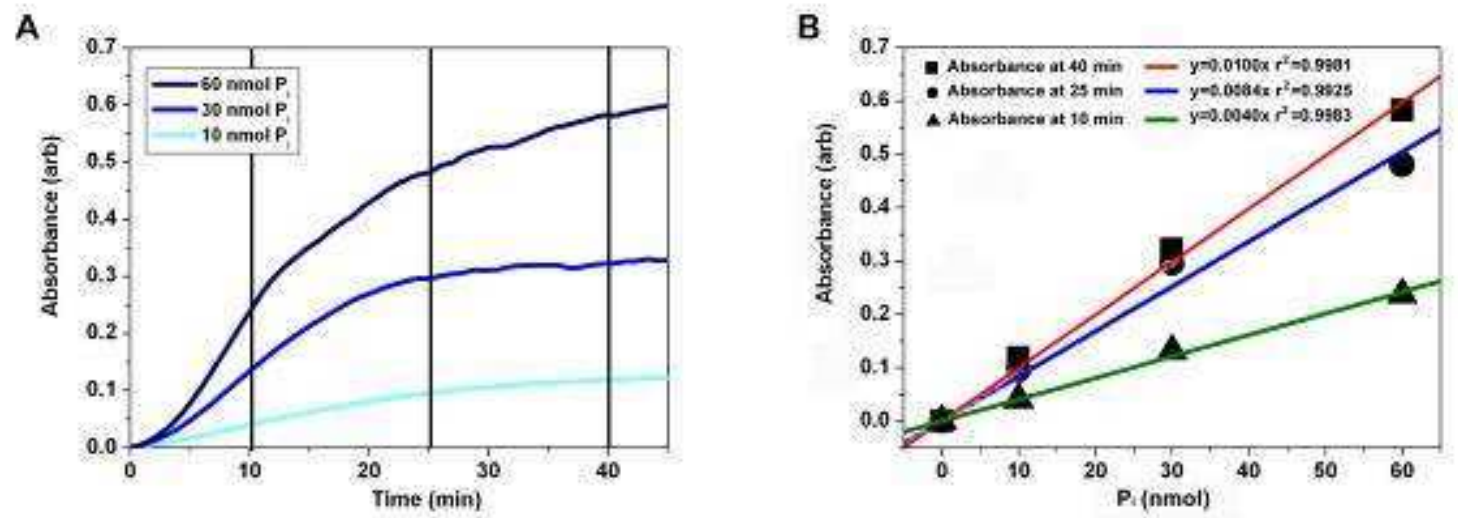

Figure 3.31 Kinetics of $\mathbf{P}_{\mathbf{i}}$ detection assay

Kinetics of the $P_{i}$ detection assay was recorded at 10, 30 and $60 \mathrm{nmol} \mathrm{P}_{\mathrm{i}}$ concentration (A) and calibration curve at the time point 10, 25 and 40 min (B). Before $20 \mathrm{~min}$ the absorbance values were too low to be use reliably for measurements and the absorbance changed quickly. Between 20 to $30 \mathrm{~min}$ the reaction was slower and the values ideal for measurements whereas past $40 \mathrm{~min}$ of colour development absorbance values became too high and higher $\mathrm{P}_{\mathrm{i}}$ concentrations resulted in errors. 


\subsubsection{Quality of plasma membrane fractions}

The quality of plasma membrane fractions was checked on SDS PAGE gradient gels stained with Coomassie Brilliant Blue and on Western blots. Based on SDS gels the plasma membrane protein pattern of the emerged leaf blade (leaf three) and fully expanded blade (leaf two) was comparable whereas the elongation zone of leaf three and microsomal fraction (no plasma membrane purification) of emerged blade of leaf three differ from the other two (Figure $3.32 \mathrm{~A}$ ). Western blot analysis confirmed the presence of PM- $\mathrm{H}^{+}$-ATPase in the isolates (Figure $3.32 \mathrm{~B}$ ), although based on these Western blots quantitative analysis of $\mathrm{PM}-\mathrm{H}^{+}$-ATPase density in the plasma membrane of different leaf regions could not be achieved. Subsequently, a more sensitive Western blot system (at UCD) was used to compare $\mathrm{PM}^{-\mathrm{H}^{+}-\mathrm{ATPase}}$ content of plasma membranes between elongation zone and emerged blade.
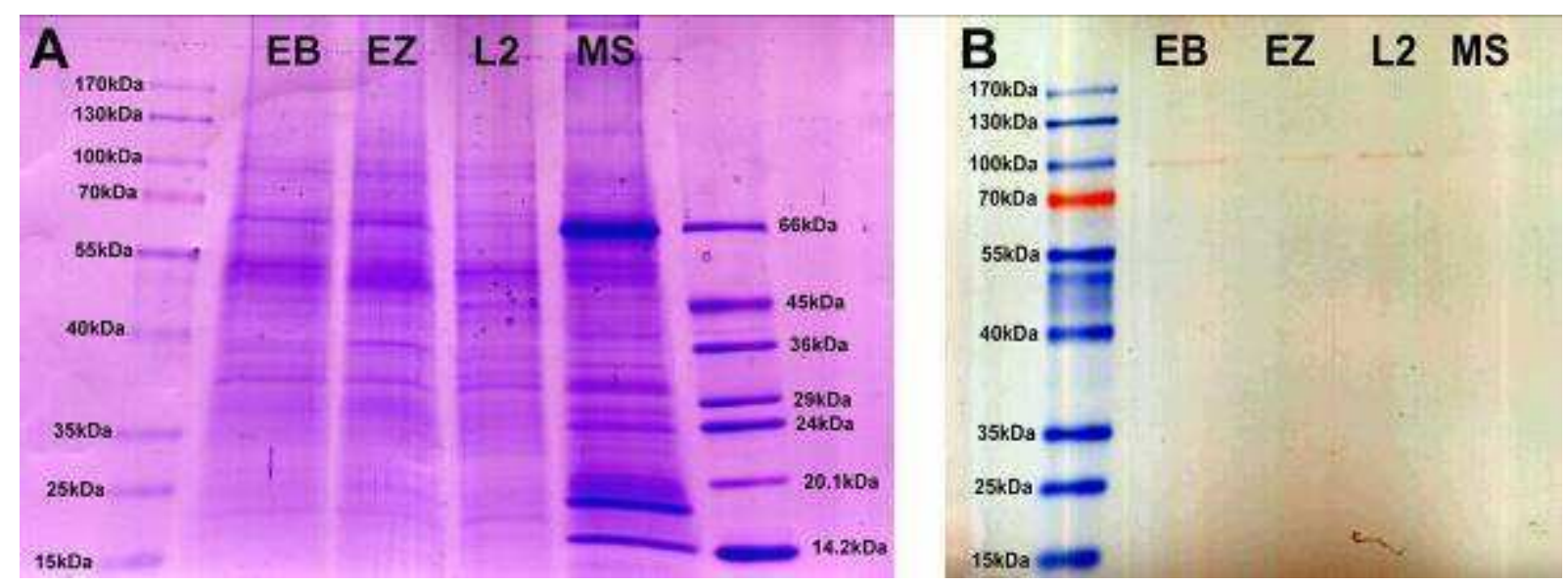

Figure 3.32 Coomassie stained SDS polyacrylamide gel and Western blot of plasma membrane proteins from different leaf regions

Gradient SDS polyacrylamide gel stained Coomassie Brilliant Blue R250 (A) shows the difference or similarity in membrane protein pattern of emerged leaf blade three (EB), elongation zone of leaf three (EZ), fully expanded leaf blade from leaf two (L2) and microsomal fraction from emerged leaf blade two (MS). Western blot (B) analysis demonstrated the presence of PM- $\mathrm{H}^{+}$-ATPase in the isolates and also that the commercially available antibody recognised barley $\mathrm{PM}^{-} \mathrm{H}^{+}$-ATPase (expected molecular weight of about $105 \mathrm{kDa}$ ). The band intensity was too weak to allow densitometric analyses of bands. This had to be done subsequently using a more sensitive detection system for the secondary antibody employed 


\subsubsection{Quantitative analysis of $P M-H^{+}$-ATPase protein}

Sensitivity of the Western blot detection system at Eötvös University, where plasma membrane isolations and ATPase enzyme assays were carried out, was not enough to perform quantitative analysis on blots. Using the same samples in Dublin (having transported the samples on dry ice from Budapest) on thinner gels and chemiluminescence detection the proportion of $\mathrm{PM}-\mathrm{H}^{+}$-ATPase in total membrane protein was measured using a densitometric approach. The same amount of total membrane protein $(5 \mu \mathrm{g})$ from the elongation zone contained 2.33 times higher concentration of PM- $\mathrm{H}^{+}$-ATPase protein than non-growing leaf blade (Fig. 3.33 A). Densitometry of Coomassie stained gradient gels supported Western blot data. A higher $\mathrm{PM}-\mathrm{H}^{+}$-ATPase protein expression was measured in the elongation zone (Fig. $3.33 \mathrm{~B})$ although the difference using the $\mathrm{PM}-\mathrm{H}^{+}-\mathrm{ATPase}$ band on SDS gels (identified based on molecular weight and Western blots) was lower with the ratio between the two leaf regions being 1.5 fold compared with 2.33-fold above.

The higher sensitivity of the second Western blot approach made it possible to detect a second band on the blot, at around $70 \mathrm{kDa}$. This might represents a fragment of the PM- $\mathrm{H}^{+}$-ATPase enzyme (Fig. $3.33 \mathrm{C}$ )
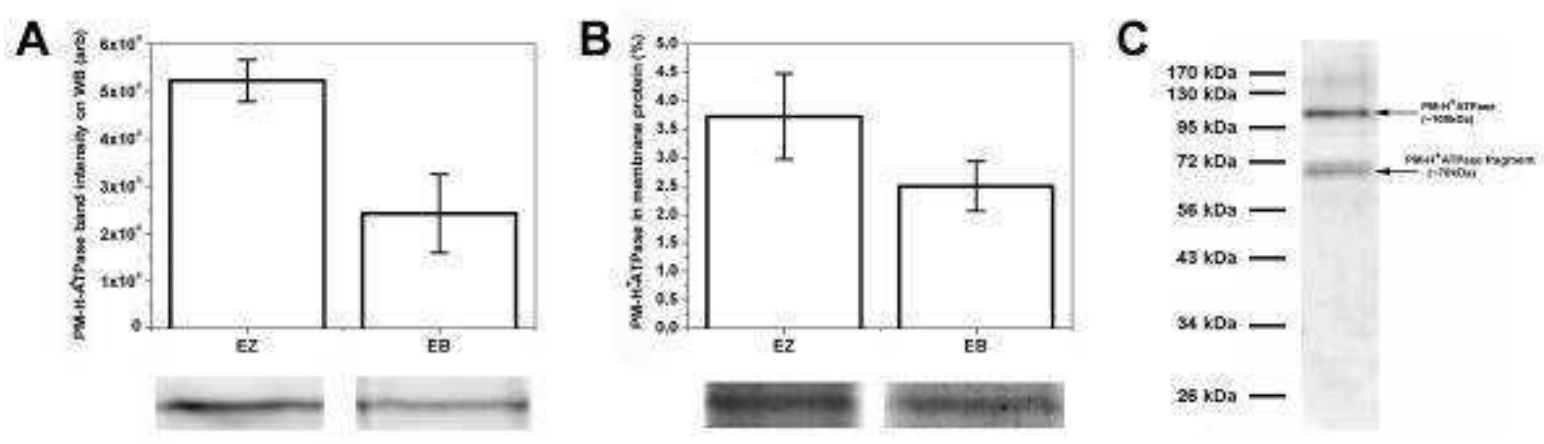

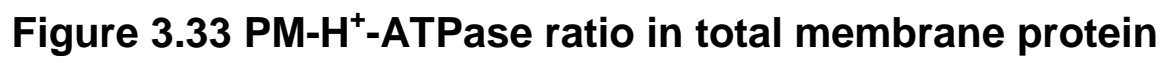

$\mathrm{PM}-\mathrm{H}^{+}$-ATPase protein, expressed on the basis of total plasma membrane protein applied onto gels (and entered into Western blots) was significantly higher in the elongation zone (EZ) compare with emerged blade (EB) (A); the same applied to densitometric analyses of Coomassie Brilliant Blue stained polyacrylamide gels (B). Results are significant using Student's t-test $(p<0.05)$. Using higher sensitivity on Western blots a second band was found which respresents most likely a $70 \mathrm{kDa}$ fragment of the PM- $\mathrm{H}^{+}$-ATPase (C). 


\subsubsection{Activity of PM- $H^{+}$-ATPase}

Vandate-sensitive ATPase activity of membrane fractions was measured using inside-out plasma membrane vesicles and an ATP hydrolysis assay. Results were expressed in nmolP $\mathrm{h}^{-1} \mu \mathrm{g}^{-1}$ total membrane protein at $28^{\circ} \mathrm{C}$. As Fig. 3.34 show $\mathrm{s}$ plasma membrane vesicles of the elongation zone had more than 2 times higher vanadate-sensitive ATPase activity compared with vesicles prepared from the emerged blade. Vacuolar and prokaryotic types of ATPases were blocked using high azide and nitrate concentration in the reaction mixture, and data were validated with vanadate sensitivity. The resulting enzyme activity represented $\mathrm{PM}-\mathrm{H}^{+}$-ATPase activity and this was two fold higher in the plasma membrane of the elongation zone compare with membranes prepared from the emerged leaf blade.

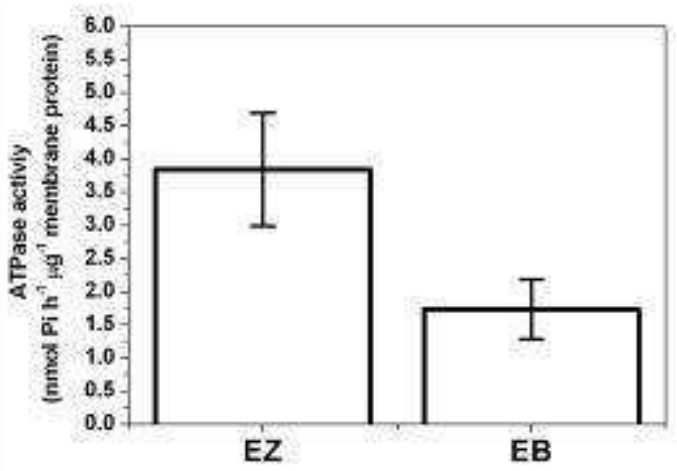

Figure 3.34 ATPase activity of inside-out plasma membrane vesicles

Vanadate-sensitive ATP hydrolysis activity of inside-out plasma membrane vesicles of the elongation zone (EZ) was more than two times higher than activity in the emerged blade of leaf three of barley (EB). Results are averages of four independent batches of membranes and $9-10$ replicate activity determinations. Differences were statistically significant $(p<0.05)$ using Student's t-test.

\subsubsection{Immunolocalisation of PM- $H^{+}$-ATPase}

Paraffin-embedded sections were used to localise the tissue-specific distribution of $\mathrm{PM}-\mathrm{H}^{+}$-ATPase protein. Alkaline phosphatase-labelled secondary antibody with fast red detection was used. Reddish colour showed the location of PM- $\mathrm{H}^{+}$-ATPase protein. There was no difference in $\mathrm{PM}^{-} \mathrm{H}^{+}$-ATPase distribution between the elongation zone (Fig. 3.35 A) and emerged blade (Fig. 3.35 B). Higher expression of $\mathrm{PM}^{-\mathrm{H}^{+}-\mathrm{ATPa} e}$ was found in guard cells (Fig. $3.35 \mathrm{E}$ ), phloem, and xylem parenchyma. $\mathrm{PM}-\mathrm{H}^{+}$-ATPase was detected virtually on the plasma membrane of every living cell. Longitudinal sections of the elongation zone (Fig. 3.35 D) provided 
further detail. Guard cells were easily identifiable. Dead parts of xylem tubes were free from red colour, whereas phloem and xylem parenchyma cells contained large amount of PM- $\mathrm{H}^{+}$-ATPase. Negative control (Fig. 3.35 C), where primary PM- $\mathrm{H}^{+}-$ ATPase specific antibody was not applied, verified the selectivity of the assay as immunospecific staining was not present.
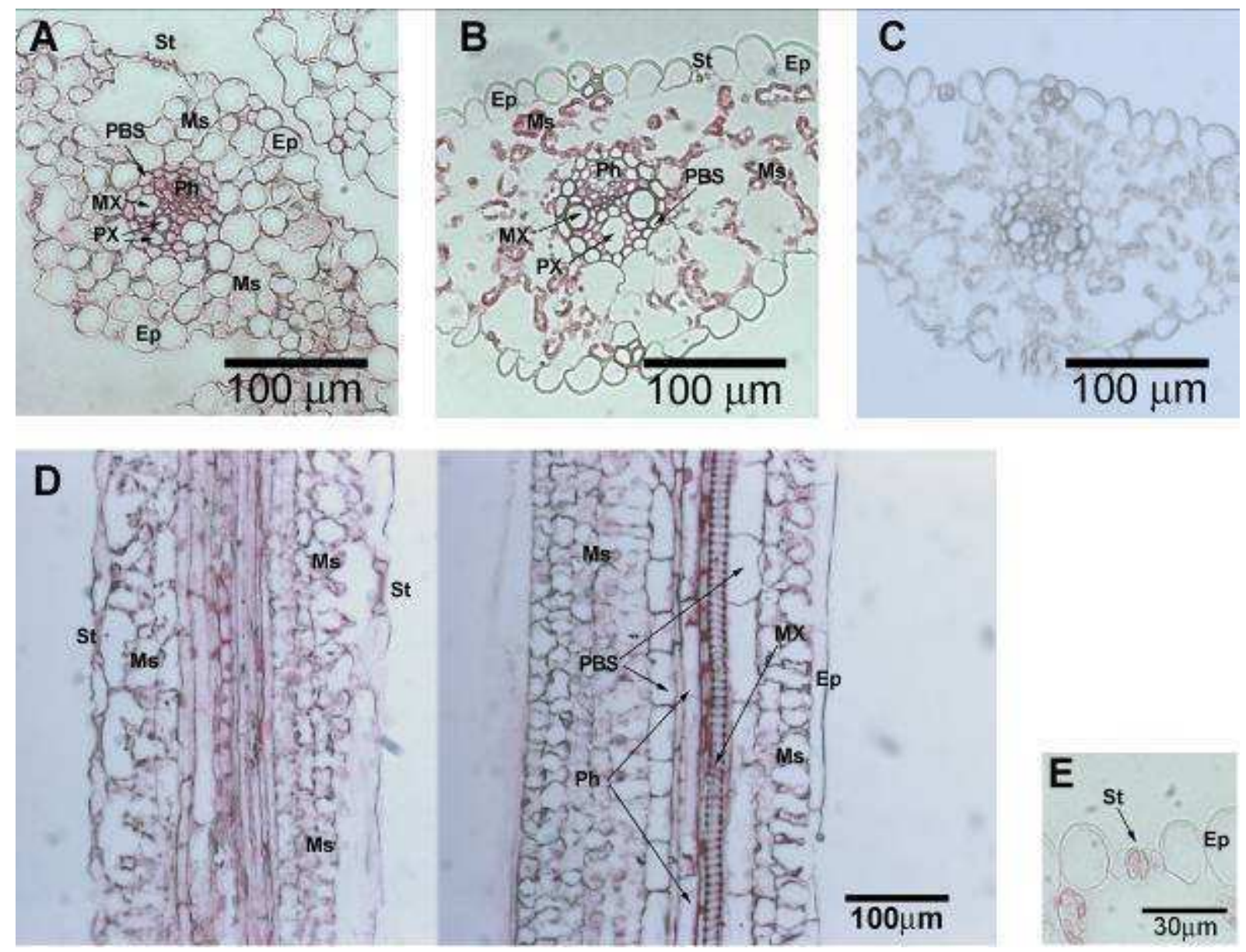

Figure 3.35 PM- $\mathrm{H}^{+}$-ATPase immunolocalisation on leaf cross and longitudinal sections

PM- $\mathrm{H}^{+}$-ATPase expression was detectable on all plasma membranes, both in the elongation zone (A) and emerged blade (B). Higher expression was present in guard cells $(E)$, phloem and xylem and phloem subsidiary cells. Differences between elongation zone and emerged blade were not visible. Negative control (primary antibody was not applied) was free from immunolabelling (C). Longitudinal sections of elongation zones (D) were supporting observations from cross sections, stomata guard cells and vascular elements and subsidiary cells being heavily stained. Ep: epidermis; St: stomata; MX: metaxylem; PX: protoxylem; Ph: phloem; Ms: mesophyll cells; PBD: parenchymateous bundle sheath. 


\section{Discussion}

\subsection{Growth-associated apoplast acidification}

Using different methods to measure or visualise apoplastic $\mathrm{pH}$ or $\mathrm{H}^{+}$transport activity into the intercellular space, a lower $\mathrm{pH}$ was recorded in the elongation zone compared with emerged blade of barley leaves. This observation is in agreement with the 'acid growth theory' which would predict a more acid apoplast $\mathrm{pH}$ in growing tissue.

\subsubsection{Apoplast $\mathrm{pH}$ difference between growing and non-growing leaf} tissue

Three independent approaches were used to analyse apoplast $\mathrm{pH}$. Microelectrode $\mathrm{pH}$ measurements provided the most quantitative data. Also, similar to confocal analyses and contrary to the in-vitro gel system, microelectrode analyses measured $\mathrm{pH}$ in the actual wall or apoplast space. These measurements showed that the $\mathrm{pH}$ in the apoplast was by up to $1 \mathrm{pH}$ unit lower and, therefore, the $\mathrm{H}^{+}$concentration up to 10 -fold higher in elongating tissue. There do not exist any directly comparable studies on other grass leaves, although slightly different approaches have been taken for some species. When $\mathrm{pH}$ was measured in droplets placed on the exposed elongation zone of maize leaves a lower apoplastic $\mathrm{pH}$ compared with the emerged blade or elongation zone under non-growing conditions was measured; the absolute $\mathrm{pH}$ values in these droplets were significantly higher than the ones measured here, and the $\mathrm{pH}$ reading was not stable but drifted during recordings (Van Volkenburgh \& Boyer, 1985; Neves-Piestun \& Bernstein, 2001). Using $0.5 \mathrm{~g}$ of growing maize leaf segments in $2 \mathrm{ml}$ unbuffered bathing medium, Neves-Piestun \& Bernstein (2001) measured a pH of 4.8 , a value which is very similar to the value recorded here for barley leaves.

\subsubsection{Reliability of $\mathrm{pH}$ values measured in elongation zone and}

\section{emerged blade}

Microelectrode measurements revealed that apoplast $\mathrm{pH}$ in the leaf elongation zone depended on the bathing medium concentration of $\mathrm{K}^{+}$. At the lowest $\mathrm{K}^{+}$concentration tested $(0.1 \mathrm{mM})$ apoplast $\mathrm{pH}$ was 4.8 , yet at $10 \mathrm{mM} \mathrm{K}^{+}$, apoplast $\mathrm{pH}$ increased to 5.8 
and was identical to the value in emerged tissue (Fig. 3.7). Since the emerged leaf contains at its surface a major permeance barrier (cuticle) to externally applied solution, this could mean that the difference in $\mathrm{pH}$ observed between leaf regions was an artefact and reflected differences in the access of bath solution between leaf regions. If, by chance, the $\mathrm{K}^{+}$concentration in the apoplast of the emerged blade of intact plants had been $10 \mathrm{mM}$, or at least higher than $1 \mathrm{mM}$, and if none of the external bathing solution had reached the apoplast, one would have predicted an apoplast $\mathrm{pH}$ of 5.8 based on measurements for elongating tissue at $10 \mathrm{mM} \mathrm{K}^{+}$. Felle (2006) measured an apoplastic $\mathrm{K}^{+}$concentration of $2.6 \mathrm{mM}$ in mature barley leaves. Also, if the apoplast $\mathrm{K}^{+}$concentration in the leaf elongation zone in-planta was close to $10 \mathrm{mM}$, one would not expect to find a difference in apoplast $\mathrm{pH}$ between the two leaf regions in intact, undisturbed plants. Recently, Ehlert et al. (2011) reported apoplast $\mathrm{pH}$ between 4.1 and 5.9 with average mean of 5.1 for elongating maize leaf tissue as analysed through $\mathrm{pH}$ microelectrodes.

Felle (2006) inserted pH microelectrodes through stomatal pores of mature barley leaves and measured a $\mathrm{pH}$ of 4.88 . This $\mathrm{pH}$ is significantly lower than the $\mathrm{pH}$ reported here $(\mathrm{pH}$ 5.8) for emerged blade tissue. Possibly, the difference in results is due to use of $2 \mathrm{mM}$ MES / TRIS buffer ( $\mathrm{pH}$ 5.0) in the bathing medium in the study by Felle (2006). Also, measurements by Felle (2006) were carried out under illumination, stimulating PM-H ${ }^{+}$-ATPase pump activity (Stahlberg \& Van Volkenburgh, 1999), whereas the present measurements were carried out in the dark. In a natural setting, the mature blade is exposed to full, ambient light whereas the elongation zone receives less light, and this light is green-filtered due to subtending sheaths. Therefore, it is possible that the difference in apoplast $\mathrm{pH}$ between leaf regions in field-grown and -analysed plants is considerably smaller than the difference measured here with the microelectrode setup in a darkened laboratory environment or through confocal analyses on intact leaves. Vanadate experiments on detached leaves clearly showed that the lower apoplast $\mathrm{pH}$ in the barley leaf elongation zone depended on the activity of the PM- $\mathrm{H}^{+}-$ATPase.

\subsubsection{Relation between apoplast acidification and leaf growth}

Acidification of the apoplast in the elongation zone of barley leaves generally coincided with growth, but there were notable exceptions. A positive relation was best visualised by cold treatment in the in-vitro gel system (Fig. 3.3). In the same system vanadate and fusicoccin treatments caused parallel changes in the growth 
rate of leaves and acidification of medium adjacent to leaf apoplast (Fig. 3.1). Also, vanadate treatment in the microelectrode setup reduced growth and increased apoplast $\mathrm{pH}$ in the elongation zone to a value usually observed for mature tissue. However, when fusicoccin was applied in the $\mathrm{pH}$ microelectrode setup, growth increased while apoplast $\mathrm{pH}$ remained unchanged (Fig. 3.9 and 3.10). Also, changing the apoplast $\mathrm{K}^{+}$concentration from 0.1 to 1 or $10 \mathrm{mM}$ significantly increased apoplast $\mathrm{pH}$ in the elongation zone, yet growth did not change (Fig. 3.7 and 3.8). Irrespective of the underlying mechanisms, these data show that there does not exist a simple, single relation of how apoplast $\mathrm{pH}$ relates to growth in the leaf elongation zone. The seemingly contradictory fusicoccin data obtained through the microelectrode and in-vitro gel setup could be explained through differences in what these two setups measured. The in-vitro gel system measured bulk effects on $\mathrm{pH}$ further away from the leaf surface and showed an increase in the acidified area and corresponding net production rate of $\mathrm{H}^{+}$, and $\mathrm{H}^{+}$was titrated by the $\mathrm{pH}$ indicator bromocresol purple. In contrast, the microelectrode setup provided a point measurement of $\mathrm{pH}$ closer to the cell surface, irrespective of the rate at which $\mathrm{H}^{+}$diffused into surrounding bathing medium or was consumed through transport processes involving $\mathrm{K}^{+}$. Thus, while fusicoccin will have stimulated $\mathrm{H}^{+}$pumping in both setups and led to increased diffusion, apoplast $\mathrm{pH}$ may not have changed in either setup.

\section{2 $K^{+}$and apoplast acidification}

Potassium uptake coupled to $\mathrm{H}^{+}$uptake (symport) has been discussed as an alternative explanation for some of the effects associated with the 'acid growth' theory. For example, $\mathrm{K}^{+}$uptake and apoplast acidification were linked to growth in roots (Glass et al., 1981; Ullrich \& Novacky, 1990; Amtmann et al., 1999) and coleoptiles (Claussen et al., 1997; Tode \& Lüthen, 2001; Christian et al., 2006). The present data also suggest that $\mathrm{K}^{+}$transport and apoplast acidification are linked with each other in some way during elongation of barley leaf cells.

\subsubsection{Potassium uptake and leaf growth}

A previous patch-clamp study on $\mathrm{K}^{+}$transport in barley concluded that apoplast $\mathrm{K}^{+}$ must exceed 3 - $5 \mathrm{mM}$ to allow growing leaf cells to take up $\mathrm{K}^{+}$through channels (Boscari et al., 2009; Volkov et al., 2009). Calculations showed that at $10 \mathrm{mM}$ apoplast $\mathrm{K}^{+}$, about $50 \%$ of $\mathrm{K}^{+}$uptake was facilitated by time-dependent inwardrectifying currents typical of Shaker $\mathrm{K}^{+}$channels such as AKT1 or AKT2. The 
remaining $50 \%$ was facilitated by instantaneous currents, which includes either or both, $\mathrm{K}^{+}$high-affinity transporters such as HAK / KUP / KT type $\mathrm{K}^{+} / \mathrm{H}^{+}$symporters (for historical reasons, these three abbreviations denote the same type of symporters; for details see e.g. Ashley et al. (2006) and Szczerba et al. (2009)) or non-selective cation channels. At apoplast concentrations below 3 - $5 \mathrm{mM}$, uptake of $\mathrm{K}^{+}$would have to occur through high-affinity uptake mechanisms. The $\mathrm{K}^{+}$ concentrations tested in the present study covered the range 0.1 to $10 \mathrm{mM}$. Therefore, it is possible that different $\mathrm{K}^{+}$uptake mechanisms contributed to the growth and $\mathrm{pH}$ response of leaves depending on the $\mathrm{K}^{+}$concentration of bathing medium. When $\mathrm{K}^{+}$uptake was blocked through application of inhibitors $\left(\mathrm{Cs}^{+}, \mathrm{TEA}\right)$ of $\mathrm{K}^{+}$inward-rectifying Shaker-type channels, or at least reduced significantly, growth was reduced by $50 \%$. A similar reduction in growth was observed in response to vanadate and $\mathrm{CsCl}$-vanadate double treatments (applied at $10 \mathrm{mM}$ bathing medium $\mathrm{K}^{+}$; Fig. 3.17). The latter observation excludes the possibility that $\mathrm{Cs}^{+}\left(\mathrm{K}^{+}\right.$channels) and vanadate (PM- $\mathrm{H}^{+}$-ATPase) inhibited 'different' $50 \%$ of growth and were additive. Instead, growth was reduced through some common mechanism. Membrane potential was not measured in response to the above treatments, but the most likely scenario is that inhibition of $\mathrm{PM}-\mathrm{H}^{+}$-ATPase through vanadate depolarised membrane potential to such an extent that uptake of $\mathrm{K}^{+}$through channels was thermodynamically not possible. This would explain why direct blockage of channels through $\mathrm{Cs}^{+}$caused the same growth reduction as blockage of $\mathrm{PM}-\mathrm{H}^{+}-\mathrm{ATPase}$. Similarly, Tode \& Lüthen (2001) concluded from experiments involving TEA that the acid-growth type response of maize coleoptiles required the activity of inwardrectifying $\mathrm{K}^{+}$channels. Linkage of $\mathrm{K}^{+}$transport, leaf growth and cell wall acidification was found in light-induced growth of tobacco leaves (Stiles et al., 2003), yet $\mathrm{K}^{+}$ uptake was required for $\mathrm{H}^{+}$efflux and growth without any noticeable accumulation of solutes (Stiles \& Van Volkenburgh, 2004). This would exclude a primarily osmotic requirement for $\mathrm{K}^{+}$.

\subsubsection{High affinity potassium transporters and leaf growth}

High affinity $\mathrm{K}^{+}$transporters, but not $\mathrm{K}^{+}$selective channels, are reduced in transport activity by ammonium (Kronzucker et al., 2003; Rodriguez-Navarro \& Rubio, 2006; Szczerba et al., 2009; Hoopen et al., 2010). Application of $20 \mathrm{mM} \mathrm{NH}_{4}{ }^{+}$during LVDT experiments reduced growth by as much as $\mathrm{Cs}^{+}$, TEA and vanadate treatments did. This shows that high affinity $\mathrm{K}^{+}$uptake systems were involved in $\mathrm{K}^{+}$uptake and 
growth response of elongating barley leaf cells. The results also show that the three components, apoplast $\mathrm{pH}$, high-affinity and channel-mediated $\mathrm{K}^{+}$uptake were related to each other in some way that prevented inhibition of each component from being additive.

Boscari et al. (2009) observed that HvHAK4 was expressed particularly in the elongation zone of barley leaves. It is not known whether HvHAK4 functions as $\mathrm{K}^{+} / \mathrm{H}^{+}$symporter as thought for other HAK family members (Britto \& Kronzucker, 2008; Szczerba et al., 2009). If it does, HvHAK4 may not only provide a major route for $\mathrm{K}^{+}$entry into growing barley leaf cells, but also present a key mechanism through which the pump activity of the PM- $\mathrm{H}^{+}$-ATPase can be linked to osmotically-driven water uptake and apoplast acidification in growing leaf tissues. This needs to be studied further.

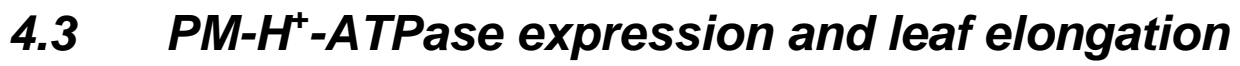

Using four independent techniques (qPCR, ATPase assay and densitometry on SDS PAGE and Western blot) it was found that the expression, activity and protein level of PM- $\mathrm{H}^{+}$-ATPase when related to the surface area of plasma membrane, was between 1.5 - 3.5 times higher in the elongation zone compared with the emerged blade (Table 4.1). The similarity in results for expression, protein level and activity may be a coincidence, but more likely reflects a true difference between growing and nongrowing barley leaf tissues.

Table 4.1 Summary of data for PM- $\mathrm{H}^{+}$-ATPase when related to surface area of plasma membrane. Ratio and standard deviation (SD) was calculated in two ways (a: averages of elongation zone (EZ) were divided by averages of emerged blade (EB) or i: average of ratio of paired EZ and EB). SDs in bracket are estimated SDs.

\begin{tabular}{l|l|l} 
Experiment type & Ratio EZ : EB & SD \\
\hline qPCR (Golf, a) & 1.96 & $\pm(0.47)$ \\
\hline qPCR (Golf, i) & 1.99 & \pm 0.28 \\
\hline qPCR (Jersey, a) & 2.36 & $\pm(0.91)$ \\
\hline qPCR (Jersey, i) & 3.53 & \pm 2.88 \\
\hline qPCR (Jersey protoplasts, a) & 2.13 & $\pm(0.70)$ \\
\hline qPCR (Jersey protoplasts, i) & 2.35 & \pm 0.49 \\
\hline Vanadate sensitive ATPase activity (Jersey, a) & 2.22 & $\pm(0.55)$ \\
\hline Coomassie stained SDS PAGE (Jersey, a) & 1.50 & $\pm(0.35)$ \\
\hline Western Blot (Jersey, a) & 2.33 & $\pm(0.72)$
\end{tabular}


Quantification of $\mathrm{PM}-\mathrm{H}^{+}$-ATPase protein level using Coomassie stained PAGE gels gave the lowest difference between elongation zone and emerged blade. This may result from individual bands, such as the band of the PM- $\mathrm{H}^{+}$-ATPase, containing numerous different proteins. For example, Hynek et al. (2006) concluded from MS / MS analyses of the PM- $\mathrm{H}^{+}$-ATPase band of plasma membrane vesicles prepared from barley aleurone layer that the band contained 22 different peptides. Together, the data suggest that the density at which functional PM- $\mathrm{H}^{+}-\mathrm{ATPase}$ is localised in the plasma membrane, or at which $\mathrm{PM}-\mathrm{H}^{+}-\mathrm{ATPase}$ is expressed per unit plasma membrane surface area of cells is about twice as high in growing as in nongrowing leaf regions. Also, expression and protein data suggest that the efficiency of translation of PM- $\mathrm{H}^{+}$-ATPase mRNA is similar in the two leaf regions.

\subsubsection{PM- $H^{+}$-ATPase density in plasma membrane and leaf growth}

The higher plasma membrane density of $\mathrm{PM}-\mathrm{H}^{+}$-ATPase in the elongation zone will aid the energisation required for continuous solute uptake, in particular uptake of $\mathrm{K}^{+}$, in growing leaf cells. It will also aid acidification of the apoplast as measured through $\mathrm{pH}$ microlelectrodes in the barley leaf elongation zone. Depending on the apoplast $\mathrm{K}^{+}$ concentration, the $\mathrm{pH}$ in the elongation zone was by up to $1.0 \mathrm{pH}$ unit lower $(\mathrm{pH}$ micro electrode measurements; Fig. 3.7) in the elongation zone compared with emerged blade. This corresponds to a 10 -fold difference in apoplast $\mathrm{H}^{+}$concentration and suggests that there exist post-translational modifications which further increase the PM- $\mathrm{H}^{+}$ATPase pump activity in growing barley leaf cells. Having said this, the wall space of growing cells is smaller (thinner walls) and this will aid apoplast acidification for a given pump activity. Apoplast acidification also depends on factors which are not related directly to the protein level and activity of PM- $\mathrm{H}^{+}$-ATPase such as apoplast $\mathrm{K}^{+}$concentration (Claussen et al., 1997;Tode \& Lüthen, 2001), temperature (Stoddart \& Lloyd, 1986; Pollock et al., 1990) hormones (especially auxin, e.g.: Rayle \& Cleland, 1970; Hager et al., 1971; Rayle \& Cleland, 1992; Claussen et al., 1997; Tode \& Lüthen, 2001; Hager, 2003; Grebe, 2005; Kutschera, 2006) and light (Van Volkenburgh \& Cleland, 1980; Stahlberg \& Van Volkenburgh, 1999). 


\subsection{2 qPCR data}

Determination of cell size and cell number can involve comparably large errors, due to the variation in size between populations and types of cell and due to small difference in cell radius (protoplasts) causing large differences in calculated cell volumes. Despite these intrinsic uncertainties, the present calculations showed that the PM- $\mathrm{H}^{+}$-ATPase expression per cell is very similar in growing and non-growing leaf tissue. Due to the lower surface area of the plasma membrane in growing cells (always assuming that there are no major invaginations of the plasma membrane, or that these would not differ between leaf regions), the density of PM- $\mathrm{H}^{+}$-ATPase is higher than the density in non-growing cells. As growing cells reach their full size, plasma membrane surface area increases leading to a continuous 'dilution' of PM$\mathrm{H}^{+}$-ATPase molecules. In such a scenario, the amount of $\mathrm{PM}-\mathrm{H}^{+}$-ATPase per cell seems to be a fixed size, and cessation of growth seems to coincide with a continuous dilution of $\mathrm{PM}-\mathrm{H}^{+}$-ATPas activity, resulting in decreasing rates of apoplast acidification (see also Fig. 3.25, Fig. 3.26 and Fig. 3.27). qPCR analysis of mesophyll protoplasts isolated from the elongation zone and emerged blade of the barley cultivar Jersey further supported the reliability of the calculated cell numbers of qPCR samples. Total RNA content of Golf and Jersey tissues per cell was very similar to total RNA content per protoplast. $\mathrm{PM}-\mathrm{H}^{+}$-ATPase expression data obtained for protoplasts, when expressed per protoplast number or total plasma membrane surface were lower but not significantly different to the other qPCR data for Jersey where expression was related to the calculated cell number or total membrane surface (see Table 3.5 and Fig. 3.27). The lower expression values are in agreement with immuno localisation results on leaf cross-sections which showed that mesophyll cells have a comparatively (to other leaf tissues) lower $\mathrm{PM}-\mathrm{H}^{+}-\mathrm{ATPase}$ expression. For RNA extraction from leaf segments, all types of cells were homogenised and accordingly averaged. In contrast, protoplasts were islolated only from mesophyll.

qPCR expression analyses also showed that the $\mathrm{Ct}$ value of $\mathrm{PM}-\mathrm{H}^{+}$-ATPase expression was almost identical in growing and non-growing leaf regions using the same amount of total RNA (250 - $500 \mathrm{pg}$ ). Therefore, when expression data are related to unit of extracted RNA, PM-H+-ATPase (Ha1 AY136627; Gl:23306665) is an ideal reference gene for expression analysis when comparing growing and nongrowing leaf regions, in agreement with Boscari et al. (2009) and Besse et al. (2011) (see Table 3.5 and Fig. 3.27). The same applies to the $\mathrm{PM}-\mathrm{H}^{+}$-ATPase isoforms AHA1 and AHA2 in Arabidopsis (Gaxiola et al., 2007). 


\subsubsection{Immunolocalisation of PM- $H^{+}$-ATPase}

Immunohistological analyses provided results which are in agreement with previous studies on the tissue localisation of PM- $\mathrm{H}^{+}$-ATPase protein (Villalba et al., 1991; Bouche-Pillon et al., 1994; Michelet \& Boutry, 1995; Morsomme \& Boutry, 2000; Palmgren, 2001; Gaxiola et al., 2007). Most staining, and by implication, $\mathrm{PM}-\mathrm{H}^{+}-$ ATPase protein, was observed in those leaf tissues which are characterised by high rates of solute exchange across the plasma membrane (guard cells) or high rates of solute loading / unloading associated with long-distance transport pathways (phloem; xylem parenchyma). Interestingly, but in agreement with previous studies, epidermis cells were not enriched in PM- $\mathrm{H}^{+}$-ATPase (Villalba et al., 1991). This was observed in elongation zone and emerged blade and shows that there exists a cell-type-specific control of PM- $\mathrm{H}^{+}$-ATPase protein level which is superimposed on any developmental gradient.

\subsection{Leaf growth and changes in cell wall properties}

The effect of chemical treatments (vanadate, $\mathrm{CsCl}$, fusicoccin) on cell wall properties was followed with the LVDT system. Fusicoccin increased the elasticity without affecting the plasticity of walls. In contrast, $\mathrm{CsCl}$ decreased the plastic component yet did not alter the elastic component of cell wall. Vanadate did not modify either component. From these results it can be concluded that PM- $\mathrm{H}^{+}$-ATPase activity, which is inhibited by vandate, is not required to maintain wall elasticity or plasticity. The fusicoccin treatment did not cause changes in the plastic component of the cell wall. Since plasticity is the relevant size for growth (irreversible expansion), and since plasticity is thought to change with apoplast $\mathrm{pH}$ through action of expansions (Cosgrove, 1996), fusicoccin probably did not decrease the apoplast pH (in agreement with the microelectrode measurements where fusicoccin failed to cause apoplast acidification) or it facilitated leaf elongation through a mechanism other than 'acid growth'. The increased $\Delta \Delta v$ suggests that in the background of fusicoccinrelated growth facilitated $\mathrm{K}^{+}$uptake may be found (both $\mathrm{v}_{1}$ and $\mathrm{v}_{2}$ were higher than in the control). The increased elasticity of the cell wall may be caused by a cell wall modifying protein or enzyme activated by increased $\mathrm{H}^{+}$transport acrosss the plasma membrane into the cell wall space as the experiments with the agarose gel system showed. If fusicoccin increased the $\mathrm{H}^{+}$excretion through plasma membrane and the $\mathrm{H}^{+}$returned into the cell through $\mathrm{H}^{+} / \mathrm{K}^{+}$symport, then micro $\mathrm{pH}$ measurements, 
in-vitro gel records and cell wall property data would support each other. However, this would require that the change in $\mathrm{H}^{+}$concentration close to the site where proteins act in the wall was either so small or so inaccessible that it could not be measured with the microelectrodes.

\section{5 'Acid growth' in barley leaves?}

Auxin is one of the most important hormones in plants and its involvement in growth is unquestionable, at least in coleoptiles (Rayle \& Cleland, 1970; Lüthen et al., 1990; Rayle \& Cleland, 1992; Kutschera, 1994) or roots (Christian et al., 2006; Kutschera, 2006).

Surprisingly, in the present study the artificial auxin NAA did not cause any effect on leaf growth or apoplast acidification as tested through the in-vitro gel system (Fig. 3.6) or LVDT measurements (Fig. 3.19). In a related study on the barley cultivar investigated here, the elongation zone was not exposed by peeling back the sheath of leaves one and two but, instead, a small window was cut into these sheaths, causing less physical damage to the plant. Even in this system, application of 5 and $10 \mu \mathrm{M}$ indole acetic acid (IAA) to the apoplast of the elongation zone did not increase the growth rate of leaves (Touati et al., unpublished). For some reason, the barley leaves tested here seem not to be sensitive to externally-applied auxin. A possible interpretation could be that the third leaf, when measured in this project was in the development stage of maximum growth, and the internal auxin concentration might have been so high that any auxin-dependent growth mechanisms was saturated and externally applied auxin could not cause any further increase in growth. The elongation zone of leaf one of wheat has been reported to contain IAA at 500 - $600 \mathrm{ng} \mathrm{g}^{-1}$ fresh weight (Vysotskaya et al., 2003) and this would mean that IAA oocurs naturally in the $\mu \mathrm{M}$ range.

\subsection{Model of leaf growth in barley}

Under different treatments the role of $\mathrm{PM}-\mathrm{H}^{+}$-ATPase and high or low affinity $\mathrm{K}^{+}$ uptake system was tested in relation to elongation growth and apoplast acidification in leaf three of barley. The predicted effects of test reagents on growth and acidification are summarised in Fig. 4.1. The results partly support the classical 'acid growth' theory and partly the 'facilitated solute uptake' theory. PM- $\mathrm{H}^{+}$-ATPase dependent $\mathrm{H}^{+}$excretion is essential for at least $50 \%$ of leaf growth. However, the equilibrium $\mathrm{pH}$ is not necessarily reflecting changes in transmembrane $\mathrm{H}^{+}$pumping 
because $\mathrm{H}^{+} / \mathrm{K}^{+}$symport might transport protons back into the cell as Fig. 4.1 shows. Treatments with different $\mathrm{K}^{+}$transport blockers (TEA, $\mathrm{CsCl}, \mathrm{NH}_{4}^{+}$) and their double treatments with sodium-orthovanadate, the $\mathrm{PM}-\mathrm{H}^{+}$-ATPase blocker, suggested that in the background of the 'acid growth' of barley leaves an active HAK type $\mathrm{K}^{+}$uptake system might play a key role in facilitating a $\mathrm{H}^{+} / \mathrm{K}^{+}$symport mechanism (Bañuelos et al., 2002; Bucker et al., 2006; Britto \& Kronzucker, 2008; Szczerba et al., 2009). Acidification of the cell wall or protonation of some enzymes in the cell wall might have additional important role in growth as cell wall property measurements showed. HvHAK4, a member of the family of $\mathrm{K}^{+}$transporters, is mainly present in barley shoots (Rubio et al., 2000) and it has significantly higher expression in the leaf elongation zone (Boscari et al., 2009), further supporting the idea of a combined 'acid growth' and 'facilitated solute uptake'.

Based on qPCR, enzyme activity and Western blot result, PM- $\mathrm{H}^{+}$-ATPase expression in the plasma membrane might be controlled by a simple mechanism. The enzyme density in the plasma membrane can be diluted by cell growth; its density in the plasma membrane changes with cell size. The total number of $\mathrm{PM}-\mathrm{H}^{+}-$ ATPase molecules was constant at cellular level while the total membrane surface increasing more than two-fold during cell development (Fig. 3.25 and Fig. 3.26). Taking into consideration all of the present results (expression analysis and physiological measurements with $\mathrm{pH}, \mathrm{H}^{+}$transport activity and $\mathrm{K}^{+}$uptake during the leaf development) and published information about expression of HvHAK4 (Rubio et al., 2000; Boscari et al., 2009) leads to the model shown on Fig. 4.2. The $50 \%$ of leaf growth that was sensitive to inhibition of $\mathrm{PM}-\mathrm{H}^{+}$-ATPase requires high expression of HvHAK4 in the elongation zone (Boscari et al., 2009) and a high plasma membrane density of PM- $\mathrm{H}^{+}$-ATPase molecules. 

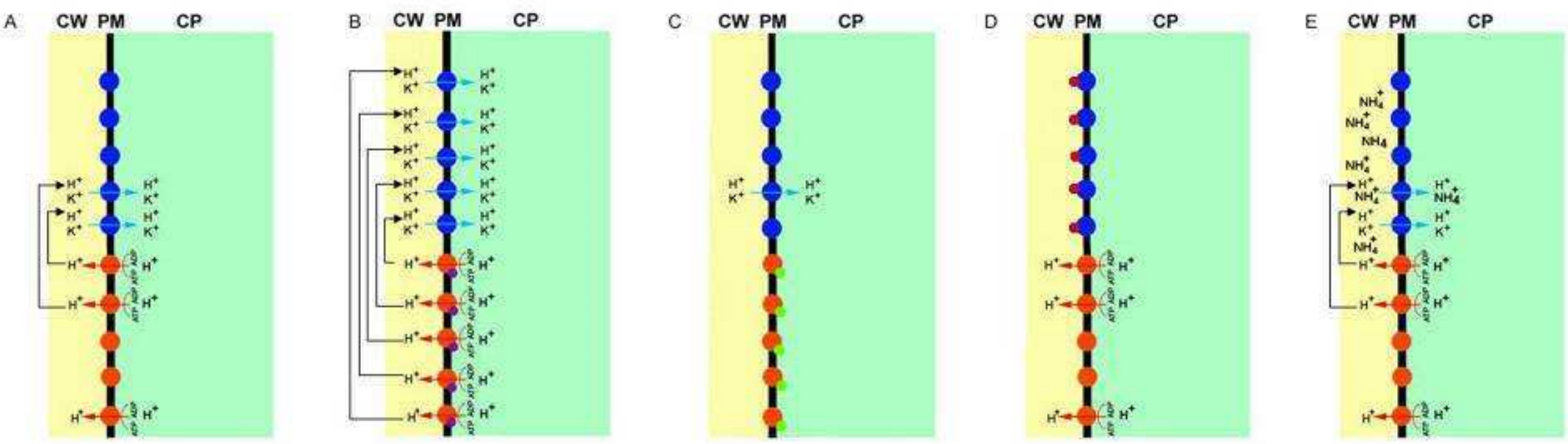

\section{Figure 4.1 Supposed effect of the treatments on barley leaf cells}

On the sketches cell wall (apoplast, $\mathrm{CW}$ ) is labelled with yellow colour, cytoplasm (CP) is green and black lines refer to plasma membrane (PM). Orange balls symbolise PM- $\mathrm{H}^{+}$-ATPase and blue balls are high affinity $\mathrm{H}^{+} / \mathrm{K}^{+}$symporters. Under control conditions $\mathrm{PM}-\mathrm{H}^{+}-$ ATPases pump out the $\mathrm{H}^{+}$and $\mathrm{K}^{+}$are taken up into the cell through high affinity $\mathrm{K}^{+}$transporters (A). Fusicoccin (purple dots) permanently activate all the proton pumps and this massive $\mathrm{H}^{+}$efflux is short cut by $\mathrm{K}^{+}$transporter activity, causing higher turgor pressure in the cells and accelerates leaf growth (B). Vanadate (green dots) permanently blocks PM- $\mathrm{H}^{+}$-ATPase and without $\mathrm{H}^{+}$transport $\mathrm{K}^{+}$uptake and growth are inhibited $(\mathrm{C})$. Caesium ions blocks (deep red dots) $\mathrm{K}^{+}$transporters and reduce leaf growth (D) and ammonium ions (NH ${ }_{4}^{+}$) reduce active $\mathrm{K}^{+}$accumulation through a competitive way and reduce growth (E). 


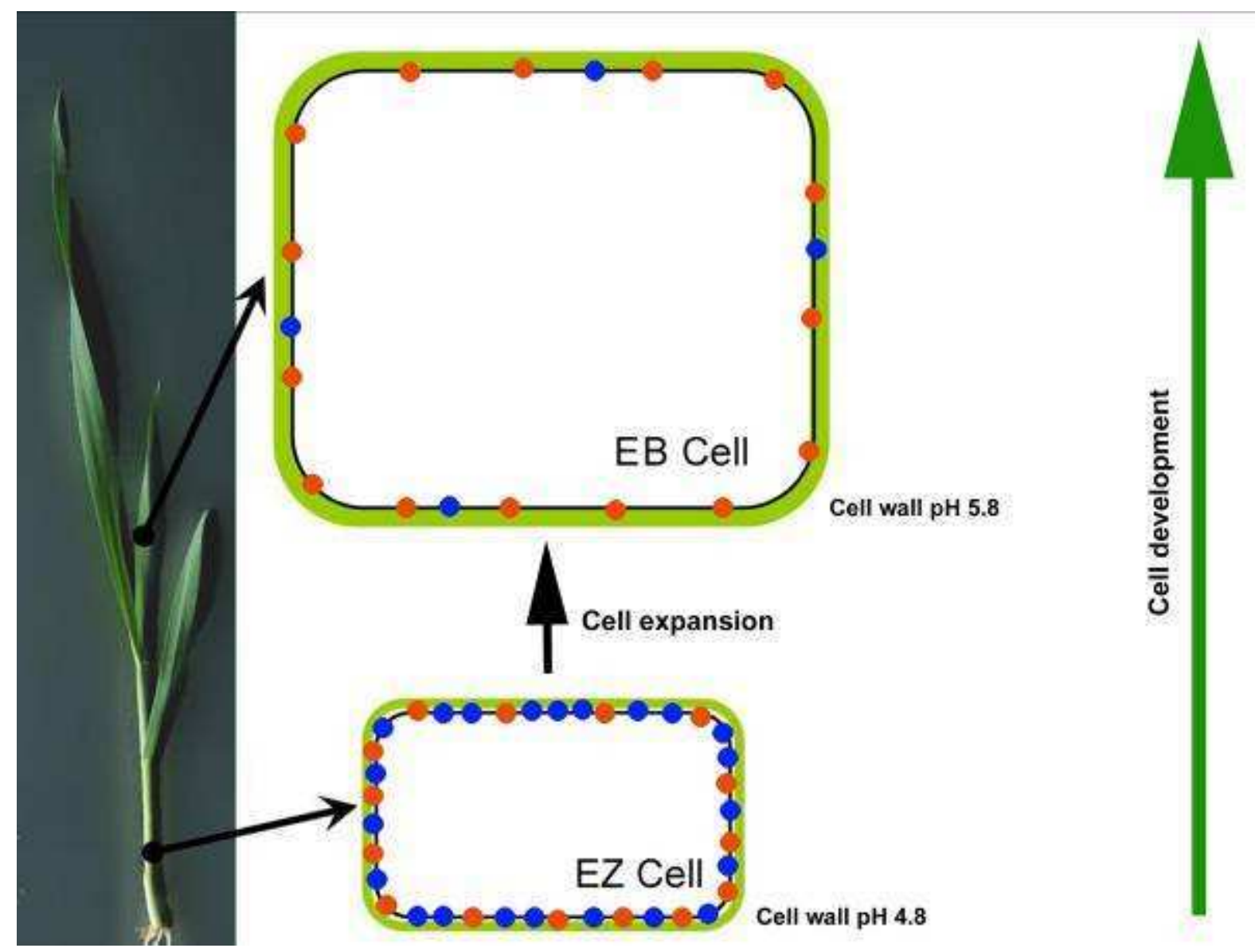

Figure 4.2 Model of leaf elongation in barley leaves

Cell size and membrane surface are increased 2 - 3 fold during cell development, as cells expand in the elongation zone (EZ) and finally reach full maturity in the emerged blade (EB). The number of PM- $\mathrm{H}^{+}$-ATPase molecules (orange balls) per cell is constant where as HvHAK4 (blue balls) expression (and presumably protein level) per cell decreases significantly during cell development. Therefore, both the maximum proton transport and $\mathrm{K}^{+}$accumulation capacity are significantly higher in the elongation zone than in the emerged blade cell and can facilitate elongation growth through 'acid growth' and 'solute accumulation'. On the figure light green colour represents the cell wall and the black line the plasma membrane. 


\section{$5 \quad$ Conclusions and future work}

\subsection{Conclusions}

(i) In this study the $\mathrm{pH}$ and $\mathrm{H}^{+}$transport activity were examined in the elongation zone and the non-growing emerged blade portion of leaf three of barley, using three independent approaches - an in-vitro gel system with bromochresol purple as $\mathrm{pH}$ indicator, confocal microscopy combined with $\mathrm{pH}$ sensitive fluoresceince probes and microelectrode technique. All techniques show a lower $\mathrm{pH} /$ higher proton efflux in the elongation zone compared with emerged blade and support the classical 'acid growth' theory for the elongation growth of plant organs.

(ii) Experiments with $\mathrm{K}^{+}$channel and transporter blockers, and with $\mathrm{PM}-\mathrm{H}^{+}-$ ATPase activator and blocker point to new aspects of the acid growth theory when applied to barley leaves. LVDT measurements, analyses of cell wall property and microelectrode $\mathrm{pH}$ results suggest that a lower or higher $\mathrm{H}^{+}$transport activity is not linked directly to leaf growth, but linked through a $\mathrm{H}^{+} / \mathrm{K}^{+}$symport system which facilitates solute (especially $\mathrm{K}^{+}$) uptake into growing cells. Changes in cell wall properties suggest that elongation of barley leaves can be described with a combination of the classical 'acid growth' and the 'facilitated solute uptake' theory.

(iii) In expression studies, both at the gene and protein level, a two fold higher $\mathrm{PM}-\mathrm{H}^{+}$-ATPase density per unit plasma membrane surface area is found in growing compared with non-growing leaf tissue. $\mathrm{PM}-\mathrm{H}^{+}$-ATPase seems an ideal reference gene in studies where growing and non-growing barley leaf tissues need to be compared. The copy number of the enzyme in the plasma membrane might be controlled by a simple mechanism of growth-dilution: the total amount of $\mathrm{PM}-\mathrm{H}^{+}$ATPase is constant in the cells and the plasma membrane surface increases during cell and tissue development.

(iv) Immunohistological analyses show that $\mathrm{PM}-\mathrm{H}^{+}-\mathrm{ATPase}$ protein is present mainly in those leaf tissues which are characterised by high rates of solute exchange across the plasma membrane (guard cells) or high rates of solute loading / unloading associated with long-distance transport pathways (phloem; xylem parenchyma). This applies to both elongation zone and emerged blade and shows that there exists a cell-type-specific control of $\mathrm{PM}-\mathrm{H}^{+}$-ATPase protein level which is superimposed on any developmental gradient. 


\section{$5.2 \quad$ Future works}

(i) Due to limited financial resources only some $\mathrm{pH}$ micro electrode measurements could be carried out. It would be interesting to further study the relation between apoplastic $\mathrm{K}^{+}$concentration and cell wall acidification applying 10 $\mathrm{mM} \mathrm{KCl}$ treatment togheter with $5 \mu \mathrm{M}$ fucicoccin and $\mathrm{K}^{+}$transporter blockers e.g. $\mathrm{CsCl}$, TEA or $\mathrm{NH}_{4}^{+}$.

(ii) Using inside-out plasma membrane vesicles and fluorimetric approach proton pumping activity could be monitored. Within this project preliminary experiments were carried out and 5(6)carboxyfluorescein seem a good candidate for these probes (better for this purpose than acridine orange that was used by many previous studies e.g. Yan et al. (1998); Yan et al. (2002); Zörb et al. (2005); Pitann et al. (2009b); Zhu et al. (2009); Wakeel et al. (2010). Due to time constraints, these experiments could not be finished. Results of these vesicular transport assays could further support PM- $\mathrm{H}^{+}$-ATPase activity data.

(iii) Most of the present data point to HvHAK4 playing a key role in leaf cell elongation growth in barley. HvHAK4 is a putative $\mathrm{K}^{+} / \mathrm{H}^{+}$symporter, yet the precise function and characteristics of this transporter remain unknown. It would be good to carry out functionality tests of HvHAK4 and its regulation through test reagents which also impact on growth and PM- $\mathrm{H}^{+}$-ATPase. 


\section{$6 \quad$ Literature}

Amtmann A, Jelitto TC, Sanders D. 1999. $\mathrm{K}^{+}$-selective inward-rectifying channels and apoplastic $\mathrm{pH}$ in barley roots. Plant Physiol. 120: 331-338.

Arif I, Newman I. 1993. Proton efflux from oat coleoptile cells and exchange with wall calcium after IAA or fusicoccin treatment. Planta 189: 377-383.

Ashley MK, Grant M, Grabov A. 2006. Plant responses to potassium deficiencies: A role for potassium transport proteins. J. Exp. Bot. 57: 425-436.

Babcock DF. 1983. Examination of the intracellular ionic environment and of ionophore action by null point measurements employing the fluorescein chromophore. J. Biol. Chem. 258: 6380-6389.

Bañuelos MA, Garciadeblas B, Cubero B, Rodríguez-Navarro A. 2002. Inventory and functional characterization of the HAK potassium transporters of rice. Plant Physiol. 130: 784-795.

Besse M, Knipfer T, Miller AJ, Verdeil J-L, Jahn TP, Fricke W. 2011. Developmental pattern of aquaporin expression in barley (Hordeum vulgare L.) leaves. J. Exp. Bot. 62: 4127-4142.

Boscari A, Clément M, Volkov V, Golldack D, Hybiak J, Miller AJ, Amtmann A, Fricke W. 2009. Potassium channels in barley: Cloning, functional characterization and expression analyses in relation to leaf growth and development. Plant, Cell Environ. 32: 1761-1777.

Bouche-Pillon S, Fleurat-Lessard P, Fromont JC, Serrano R, Bonnemain JL. 1994. Immunolocalization of the plasma membrane $\mathrm{H}^{+}$-ATPase in minor veins of Vicia faba in relation to phloem loading. Plant Physiol. 105: 691-697.

Boyer JS. 2001. Growth-induced water potentials originate from wall yielding during growth. J. Exp. Bot. 52: 1483-1488.

Britto DT, Ebrahimi-Ardebili S, Hamam AM, Coskun D, Kronzucker HJ. 2010. ${ }^{42} \mathrm{~K}$ analysis of sodium-induced potassium efflux in barley: Mechanism and relevance to salt tolerance. New Phytol. 186: 373-384.

Britto DT, Kronzucker HJ. 2008. Cellular mechanisms of potassium transport in plants. Physiol. Plant. 133: 637-650.

Brummer B, Felle H, Parish RW. 1984. Evidence that acid solutions induce plant cell elongation by acidifying the cytosol and stimulating the proton pump. FEBS Letters 174: 223-227.

Bucker CA, de Souza SR, Fernandes MS. 2006. Effects of fusicoccin and vanadate on proton extrusion and potassium uptake by rice. J. Plant Nutr. 29: 485-496.

Chazen O, Neumann PM. 1994. Hydraulic signals from the roots and rapid cell-wall hardening in growing maize (Zea mays L.) leaves are primary responses to polyethylene glycol-induced water deficits. Plant Physiol. 104: 1385-1392.

Christian M, Steffens B, Schenck D, Burmester S, Böttger M, Lüthen H 2006. How does auxin enhance cell elongation? Roles of auxin-binding proteins and potassium channels in growth control. Plant Biol. 346-352.

Claussen M, Lüthen H, Blatt M, Bottger M. 1997. Auxin-induced growth and its linkage to potassium channels. Planta 201: 227-234.

Clerc S, Barenholz Y. 1998. A quantitative model for using acridine orange as a transmembrane pH gradient probe. Anal. Biochem. 259: 104-111. 
Collins D, Walpole C, Ryan E, Winter D, Baird A, Stewart G. 2011. UT-B1 mediates transepithelial urea flux in the rat gastrointestinal tract. J. Membr. Biol. 239: 123-130.

Conway EJ, O'Malley E. 1946. The nature of the cation exchanges during yeast fermentation, with formation of 0.02N-H ion. Biochem. J. 40: 59-67.

Cosgrove DJ. 1993. Wall extensibility - its nature, measurement and relationship to plant-cell growth. New Phytol. 124: 1-23.

Cosgrove DJ 1996. Plant cell enlargement and the action of expansins. BioEssays 18: $533-540$.

Cosgrove DJ. 1998. Cell wall loosening by expansins. Plant Physiol. 118: 333-339.

Csiszár J, Erdei L, Pécsváradi A, Szabó M, Tari I. 2004. Növényélettan, növekedés- és fejlődésélettan (Plant physiology, growth and developing physiology). Szeged, JATEPress.

Darwin C. 1880. The power of movement in plants, chapter ix sensitiveness of plants to light: Its transmitted effects. London, John Murray.

Dennis PG, Hirsch PR, Smith SJ, Taylor RG, Valsami-Jones E, Miller AJ. 2009. Linking rhizoplane $\mathrm{pH}$ and bacterial density at the microhabitat scale. J. Microbiol. Methods 76: 101-104

Döring O, Busch M, Lüthje S, Lüthen H, Hilgendorf F, Böttger M. 1996. lonostats. Protoplasma 194: 1-10.

Duby G, Boutry M. 2009. The plant plasma membrane proton pump ATPase: A highly regulated P-type ATPase with multiple physiological roles. European $\mathrm{J}$. Physiol. 457: 645-655.

DuPont FM. 1989. Effect of temperature on the plasma membrane and tonoplast ATPases of barley roots : Comparison of results obtained with acridine orange and quinacrine. Plant Physiol. 89: 1401-1412.

Ehlert C, Plassard C, Cookson SJ, Tardieu F, Simonneau T. 2011. Do pH changes in the leaf apoplast contribute to rapid inhibition of leaf elongation rate by water stress? Comparison of stress responses induced by polyethylene glycol and down-regulation of root hydraulic conductivity. Plant Cell Environ. 34: 1258-1266.

Epstein E, Rains DW, Elzam OE. 1963. Resolution of dual mechanisms of potassium absorption by barley roots. PNAS 49: 684-692.

Felle HH. 2005. pH regulation in anoxic plants. Annals Bot. 96: 519-532.

Felle HH. 2006. Apoplastic pH during low-oxygen stress in barley. Annals Bot. 98: 1085-1093.

Felle HH, Herrmann A, Huckelhoven R, Kogel KH. 2005. Root-to-shoot signalling: Apoplastic alkalinization, a general stress response and defence factor in barley (Hordeum vulgare). Protoplasma 227: 17-24.

Fleurat-Lessard P, Bouche-Pillon S, Leloup C, Bonnemain JL. 1997. Distribution and activity of the plasma membrane $\mathrm{H}^{+}$-ATPase in Mimosa pudica $\mathrm{L}$ in relation to ionic fluxes and leaf movements. Plant Physiol. 113: 747-754.

Frensch J. 1997. Primary responses of root and leaf elongation to water deficits in the atmosphere and soil solution. J. Exp. Bot. 48: 985-999.

Fricke W. 2002a. Biophysical limitation of cell elongation in cereal leaves. Annals Bot. 90: 157-167.

Fricke W. 2002b. Biophysical limitation of leaf cell elongation in source-reduced barley. Planta 215: 327-338. 
Fricke W. 2004. Rapid and tissue-specific accumulation of solutes in the growth zone of barley leaves in response to salinity. Planta 219: 515.

Fricke W, Akhiyarova G, Veselov D, Kudoyarova G. 2004. Rapid and tissuespecific changes in $A B A$ and in growth rate in response to salinity in barley leaves. J. Exp. Bot. 55: 1115-1123.

Fricke W, Flowers TJ. 1998. Control of leaf cell elongation in barley. Generation rates of osmotic pressure and turgor, and growth-associated water potential gradients. Planta 206: 53-65.

Fricke W, Leigh RA, Tomos AD. 1994. Concentrations of inorganic and organic solutes in extracts from invidual epidermal, mesophyll and bundle-sheath cells of barley leaves. Planta 192: 310-316.

Fricke W, McDonald AJS, Mattson-Djos L. 1997. Why do leaves and leaf cells of $\mathrm{N}$-limited barley elongate at reduced rates? Planta 202: 522-530.

Fricke W, Peters WS. 2002. The biophysics of leaf growth in salt-stressed barley. A study at the cell level. Plant Physiol. 129: 374-388.

Gaxiola RA, Palmgren MG, Schumacher K. 2007. Plant proton pumps. FEBS Letters 581: 2204-2214.

Glass ADM, Siddiqi MY, Giles KI. 1981. Correlations between potassium uptake and hydrogen efflux in barley varieties: A potential screening method for the isolation of nutrient efficient lines. Plant Physiol. 68: 457-459.

Graber ML, DiLillo DC, Friedman BL, Pastoriza-Munoz E. 1986. Characteristics of fluoroprobes for measuring intracellular pH. Anal. Biochem. 156: 202-212.

Grebe M. 2005. Growth by auxin: When a weed needs acid. Science 310: 60-61.

Green PB, Erickson RO, Buggy J. 1971. Metabolic and physical control of cell elongation rate: In vivo studies in nitella. Plant Physiol. 47: 423-430.

Grignon C, Sentenac H. 1991. pH and ionic conditions in the apoplast. Ann. Rev. Plant Physiol. Plant Mol. Biol. 42: 103-128.

Hachez C, Heinen RB, Draye X, Chaumont F. 2008. The expression pattern of plasma membrane aquaporins in maize leaf highlights their role in hydraulic regulation. Plant Mol. Biol. 68: 337-353.

Hager A. 2003. Role of the plasma membrane $\mathrm{H}^{+}$-ATPase in auxin-induced elongation growth: Historical and new aspects. J. Plant Res. 116: 483-505.

Hager A, Debus G, Edel HG, Stransky H, Serrano R. 1991. Auxin induces exocytosis and the rapid synthesis of a high-turnover pool of plasmamembrane $\mathrm{H}^{+}$-ATPase. Planta 185: 527-537.

Hager A, Menzel H, Krauss A. 1971. Experiments and hypothesis concerning primary action of auxin in elongation growth. Planta 100: 47-71.

Hatzig S, Hanstein S, Schubert S. 2010. Apoplast acidification is not a necessary determinant for the resistance of maize in the first phase of salt stress. J. Plant Nut. Soil Sci. 173: 559-562.

Hohl M, Hong YN, Schopfer P. 1991. Acid- and enzyme-mediated solubilization of cell-wall $\beta-1.3, \beta-1.4-D-g l u c a n$ in maize coleoptiles : Implications for auxinmediated growth. Plant Physiol. 95: 1012-1018.

Hoopen FT, Cuin TA, Pedas P, Hegelund JN, Shabala S, Schjoerring JK, Jahn TP. 2010. Competition between uptake of ammonium and potassium in barley and Arabidopsis roots: Molecular mechanisms and physiological consequences. J. Exp. Bot. 61: 2303-2315. 
Hruz T, Wyss M, Docquier M, Pfaffl M, Masanetz S, Borghi L, Verbrugghe P, Kalaydjieva L, Bleuler S, Laule O, Descombes P, Gruissem W, Zimmermann P. 2011. Refgenes: Identification of reliable and condition specific reference genes for RT-qPCR data normalization. BMC Genomics 12: 156.

Hsiao TC, Frensch J, Rojas-Lara BA. 1998. The pressure-jump technique shows maize leaf growth to be enhanced by increases in turgor only when water status is not too high. Plant, Cell Environ. 21: 33-42.

Hsiao TC, Xu LK. 2000. Sensitivity of growth of roots versus leaves to water stress: Biophysical analysis and relation to water transport. J. Exp. Bot. 51: 15951616.

Hynek R, Svensson B, Jensen ONr, Barkholt V, Finnie C. 2006. Enrichment and identification of integral membrane proteins from barley aleurone layers by reversed-phase chromatography, SDS-PAGE, and LC-MS/MS. J. Proteome Res. 5: 3105-3113.

Johansson F, Sommarin M, Larsson C. 1993. Fusicoccin activates the plasmamembrane $\mathrm{H}^{+}$-ATPase by a mechanism involving the c-terminal inhibitory domain. Plant Cell 5: 321-327.

Katsumi M. 2007. Studies on plant growth substances in japan before 1945. Plant Biotech. 24: 155-163.

Kavanagh CA. 2010. Changes in cell ultrastructure during leaf development in barley (Hordeum vulgare L.) and in response to salinity. MSc Thesis, University College Dublin, Dublin.

Keller CP, Van Volkenburgh E. 1998. Evidence that auxin-induced growth of tobacco leaf tissues does not involve cell wall acidification. Plant Physiol. 118: 557-564.

Kim S, Dale BE. 2004. Global potential bioethanol production from wasted crops and crop residues. Biomass and Bioenergy 26: 361-375.

Kjellbom P, Larsson C. 1984. Preparation and polypeptide composition of chlorophyll-free plasma-membranes from leaves of light-grown spinach and barley. Physiol. Plant. 62: 501-509.

Knipfer T, Fricke W. 2011. Water uptake by seminal and adventitious roots in relation to whole-plant water flow in barley (Hordeum vulgare L.). J. Exp. Bot. 62: 717-733.

Kronzucker HJ, Szczerba MW, Britto DT. 2003. Cytosolic potassium homeostasis revisited: ${ }^{42} \mathrm{~K}$-tracer analysis in Hordeum vulgare L. Reveals set-point variations in $\mathrm{K}^{+}$. Planta 217: 540-546.

Kruger $\mathbf{N}$ 2002. The Bradford method for protein quantitation. The protein protocols handbook, 15: (4) 15-21.

Kutschera U. 1994. Tansley review no. 66. The current status of the acid-growth hypothesis. New Phytol. 126: 549-569.

Kutschera U. 2006. Acid growth and plant development. Science 311: 952-954.

Kutschera U, Bergfeld R, Schopfer P. 1987. Cooperation of epidermis and inner tissues in auxin-mediated growth of maize coleoptiles. Planta 170: 168-180.

Kutschera U, Schopfer P. 1985a. Evidence against the acid-growth theory of auxin action. Planta 163: 483-493.

Kutschera U, Schopfer P. 1985b. Evidence for the acid-growth theory of fusicoccin action. Planta 163: 494-499. 
Laemmli UK. 1970. Cleavage of structural proteins during the assembly of the head of bacteriophage T4. Nature 227: 680-685.

Larkin PJ. 1976. Purification and viability determinations of plant protoplasts. Planta 128: 213-216.

Lenaeus MJ, Vamvouka M, Focia PJ, Gross A. 2005. Structural basis of TEA blockade in a model potassium channel. Nature Struct. Mol. Biol. 12: 454-459.

Li L, Li S-M, Sun J-H, Zhou L-L, Bao X-G, Zhang H-G, Zhang F-S. 2007. Diversity enhances agricultural productivity via rhizosphere phosphorus facilitation on phosphorus-deficient soils. PNAS 104: 11192-11196.

Lockhart JA. 1965. An analysis of irreversible plant cell elongation. J Theor. Biol. 8: 264-275.

Lüthen H, Bigdon M, Böttger M. 1990. Reexamination of the acid growth theory of auxin action. Plant Physiol. 93: 931-939.

Lüthen H, Böttger M. 1988. Kinetics of proton secretion and growth in maize roots action of various plant-growth effectors. Plant Sci. 54: 37-43.

Maathuis FJM, Filatov V, Herzyk P, C. Krijger G, B. Axelsen K, Chen S, Green BJ, Li Y, Madagan KL, Sánchez-Fernández R, Forde BG, Palmgren MG, Rea PA, Williams LE, Sanders D, Amtmann A. 2003. Transcriptome analysis of root transporters reveals participation of multiple gene families in the response to cation stress. Plant J. 35: 675-692.

Malnic G, Geibel JP. 2000. Cell $\mathrm{pH}$ and $\mathrm{H}^{+}$secretion by $\mathrm{S} 3$ segment of mammalian kidney: Role of H+-ATPase and $\mathrm{Cl}^{-}$. .J. Membr. Biol. 178: 115-125.

Manente S, Pieri SD, lero A, Rigo C, Bragadin M. 2008. A comparison between the responses of neutral red and acridine orange: Acridine orange should be preferential and alternative to neutral red as a dye for the monitoring of contaminants by means of biological sensors. Anal. Biochem. 383: 316-319.

Marré E. 1979. Fusicoccin - tool in plant physiology. Ann. Rev. Plant Physiol. Plant Mol. Biol. 30: 273-288.

Martre P, Bogeat-Triboulot M-B, Durand J-L. 1999. Measurement of a growthinduced water potential gradient in tall fescue leaves. New Phytol. 142: 435439.

McQueen-Mason S, Durachko DM, Cosgrove DJ. 1992. Two endogenous proteins that induce cell wall extension in plants. Plant Cell 4: 1425-1433.

McQueen-Mason SJ. 1995. Expansins and cell wall expansion. J. Exp. Bot. 46: 1639-1650.

Michelet B, Boutry M. 1995. The plasma membrane $\mathrm{H}^{+}$-ATPase: A highly regulated enzyme with multiple physiological functions. Plant Physiol. 108: 1-6.

Miller AJ, Smith SJ. 1992. The mechanism of nitrate transport across the tonoplast of barley root cells. Planta 187: 554-557.

Mito N, Wimmers LE, Bennett AB. 1996. Sugar regulates mrna abundance of $\mathrm{h}^{+}-$ atpase gene family members in tomato. Plant Physiol. 112: 1229-1236.

Moloney MM, Elliott MC, Cleland RE. 1981. Acid growth effects in maize roots evidence for a link between auxin-economy and proton extrusion in the control of root-growth. Planta 152: 285-291.

Moran N. 2007. Osmoregulation of leaf motor cells. FEBS Letters 581: 2337-2347.

Morsomme P, Boutry M. 2000. The plant plasma membrane $\mathrm{H}^{+}$-ATPase: Structure, function and regulation. BBA - Biomembr. 1465: 1-16. 
Morth JP, Pedersen BP, Buch-Pedersen MJ, Andersen JP, Vilsen B, Palmgren MG, Nissen P. 2011. A structural overview of the plasma membrane $\mathrm{Na}^{+}, \mathrm{K}^{+}$ATPase and $\mathrm{H}^{+}$-ATPase ion pumps. Nature Rev. Mol. Cell. Biol. 12: 60-70.

Neumann PM. 1993. Rapid and reversible modifications of extension capacity of cell walls in elongating maize leaf tissues responding to root addition and removal of $\mathrm{NaCl}$. Plant, Cell Environ. 16: 1107-1114.

Neves-Piestun BG, Bernstein N. 2001. Salinity-induced inhibition of leaf elongation in maize is not mediated by changes in cell wall acidification capacity. Plant Physiol. 125: 1419-1428.

O'Neal ME, Landis DA, Isaacs R. 2002. An inexpensive, accurate method for measuring leaf area and defoliation through digital image analysis. J. Econ. Entom. 95: 1190-1194.

Oecking C, Eckerskorn C, Weiler EW. 1994. The fusicoccin receptor of plants is a member of the 14-3-3-superfamily of eukaryotic regulatory proteins. FEBS Letters 352: 163-166.

Olivari C, Meanti C, De Michelis MI, Rasi-Caldogno F. 1998. Fusicoccin binding to its plasma membrane receptor and the activation of the plasma membrane $\mathrm{H}^{+}$ATPase. IV. Fusicoccin induces the association between the plasma membrane $\mathrm{H}^{+}$-ATPase and the fusicoccin receptor. Plant Physiol. 116: 529537.

Paál Á. 1918. Über phototropsche Reizleitungen. Jehrb. wiss. Bot. 58: 406-458.

Palmgren MG. 1991. Acridine-orange as a probe for measuring $\mathrm{pH}$ gradients across membranes - mechanism and limitations. Anal. Biochem. 192: 316-321.

Palmgren MG. 2001. Plant plasma membrane $\mathrm{H}^{+}$-ATPases: Powerhouses for nutrient uptake. Ann. Rev. Plant Physiol. Plant Mol. Biol. 52: 817-845.

Palmgren MG, Sommarin M, Serrano R, Larsson C. 1991. Identification of an autoinhibitory domain in the C-terminal region of the plant plasma membrane $\mathrm{H}^{+}$-ATPase. J. Biol. Chem. 266: 20470-20475.

Pedersen BP, Buch-Pedersen MJ, Morth JP, Palmgren MG, Nissen P. 2007. Crystal structure of the plasma membrane proton pump. Nature 450: 11111119.

Perrot-Rechenmann C. 2010. Cellular responses to auxin: Division versus expansion. Cold Spring Harbor Persp. Biol. 2: a001446; 1-15.

Peters WS. 2004. Growth rate gradients and extracellular pH in roots: How to control an explosion. New Phytol. 162: 571-574.

Peters WS, Felle HH. 1999. The correlation of profiles of surface $\mathrm{pH}$ and elongation growth in maize roots. Plant Physiol. 121: 905-912.

Peters WS, Luthen H, Bottger M, Felle H. 1998. The temporal correlation of changes in apoplast $\mathrm{pH}$ and growth rate in maize coleoptile segments. Austr. J. Plant Physiol. 25: 21-25.

Peters WS, Richter U, Felle HH. 1992. Auxin-induced $\mathrm{H}^{+}$-pump stimulation does not depend on the presence of epidermal-cells in corn coleoptiles. Planta 186: 313-316.

Pfaffl MW. 2001. A new mathematical model for relative quantification in real-time RT-PCR. Nucl. Acids Res. 29: e45.

Philippar K, Büchsenschütz K, Edwards D, Löffler J, Lüthen H, Kranz E, Edwards K, Hedrich R. 2006. The auxin-induced $\mathrm{k}^{+}$channel gene ZMK1 in maize functions in coleoptile growth and is required for embryo development. Plant Mol. Biol. 61: 757-768. 
Philippar K, Fuchs I, Lüthen H, Hoth S, Bauer CS, Haga K, Thiel G, Ljung K, Sandberg G, Böttger M, Becker D, Hedrich R. 1999. Auxin-induced $\mathrm{K}^{+}$ channel expression represents an essential step in coleoptile growth and gravitropism. PNAS 96: 12186-12191.

Philippar K, Ivashikina N, Ache P, Christian M, Lüthen H, Palme K, Hedrich R. 2004. Auxin activates KAT1 and KAT2, two $\mathrm{K}^{+}$-channel genes expressed in seedlings of Arabidopsis thaliana. Plant J. 37: 815-827.

Pitann B, Kranz T, Muhling KH. 2009a. The apoplastic pH and its significance in adaptation to salinity in maize (Zea mays L.): Comparison of fluorescence microscopy and ph-sensitive microelectrodes. Plant Sci. 176: 497-504.

Pitann B, Schubert S, Muhling KH. 2009b. Decline in leaf growth under salt stress is due to an inhibition of $\mathrm{H}$--pumping activity and increase in apoplastic $\mathrm{pH}$ of maize leaves. J. Plant Nutr. Soil Sci. 172: 535-543.

Pollock CJ, Tomos AD, Thomas A, Smith CJ, Lloyd EJ, Stoddart JL. 1990. Extension growth in a barley mutant with reduced sensitivity to lowtemperature. New Phytol. 115: 617-623.

Pope AJ, Leigh RA. 1988. Dissipation of ph gradients in tonoplast vesicles and liposomes by mixtures of acridine orange and anions: Implications for the use of acridine orange as a pH probe. Plant Physiol. 86: 1315-1322.

Pritchard J. 1994. The control of cell expansion in roots. New Phytol. 127: 3-26.

Rayle DL. 1973. Auxin-induced hydrogen-ion secretion in avena coleoptiles and its implications. Planta 114: 63-73.

Rayle DL, Cleland R. 1970. Enhancement of wall loosening and elongation by acid solutions. Plant Physiol. 46: 250-253.

Rayle DL, Cleland RE. 1992. The acid growth theory of auxin-induced cell elongation is alive and well. Plant Physiol. 99: 1271-1274.

Reidy B, McQueen-Mason S, Nösberger J, Fleming A. 2001. Differential expression of $\alpha$ - and $\beta$-expansin genes in the elongating leaf of festuca pratensis. Plant Mol. Biol. 46: 491-504.

Richardson A, Wojciechowski T, Franke R, Schreiber L, Kerstiens G, Jarvis M, Fricke W. 2007. Cuticular permeance in relation to wax and cutin development along the growing barley (Hordeum vulgare) leaf. Planta 225: 1471-1481.

Rodriguez-Navarro A, Rubio F. 2006. High-affinity potassium and sodium transport systems in plants. J. Exp. Bot. 57: 1149-1160.

Rubio F, Santa-María GE, Rodríguez-Navarro A. 2000. Cloning of Arabidopsis and barley cDNAs encoding HAK potassium transporters in root and shoot cells. Physiol. Plant. 109: 34-43.

Sabirzhanova IB, Sabirzhanov BE, Chemeris AV, Veselov DS, Kudoyarova GR. 2005. Fast changes in expression of expansin gene and leaf extensibility in osmotically stressed maize plants. Plant Physiol. Biochem. 43: 419-422.

Sakurai N, Masuda Y. 1978. Auxin-induced changes in barley coleoptile cell-wall composition. Plant Cell Physiol. 19: 1217-1223.

Santi S, Cesco S, Varanini Z, Pinton R. 2005. Two plasma membrane $\mathrm{H}^{+}$-ATPase genes are differentially expressed in iron-deficient cucumber plants. Plant Physiol. Biochem. 43: 287-292. 
Sarkadi B, Price EM, Boucher RC, Germann UA, Scarborough GA. 1992. Expression of the human multidrug resistance cdna in insect cells generates a high-activity drug-stimulated membrane ATPase. J. Biol. Chem. 267: 48544858.

Schopfer P. 1989. pH-dependence of extension growth in Avena-coleopiles and its implications for the mechanism of auxin action. Plant Physiol. 90: 202-207.

Schulte D, Close TJ, Graner A, Langridge P, Matsumoto T, Muehlbauer G, Sato K, Schulman AH, Waugh R, Wise RP, Stein N. 2009. The international barley sequencing consortium - At the threshold of efficient access to the barley genome. Plant Physiol. 149: 142-147.

Senn ME, Rubio F, Bañuelos MA, Rodríguez-Navarro A. 2001. Comparative functional features of plant potassium hvhak1 and hvhak2 transporters. J. Biol. Chem. 276: 44563-44569.

Shen H, He LF, Sasaki T, Yamamoto Y, Zheng SJ, Ligaba A, Yan XL, Ahn SJ, Yamaguchi M, Sasakawa H, Matsumoto H. 2005. Citrate secretion coupled with the modulation of soybean root tip under aluminum stress. Up-regulation of transcription, translation, and threonine-oriented phosphorylation of plasma membrane $\mathrm{H}^{+}$-ATPase. Plant Physiol. 138: 287-296.

Slayman CL. 1965. Electrical properties of Neurospora crassa. J. General Physiol. 49: 69-92.

Spalding EP, Hirsch RE, Lewis DR, Qi Z, Sussman MR, Lewis BD. 1999. Potassium uptake supporting plant growth in the absence of AKT1 channel activity: Inhibition by ammonium and stimulation by sodium. J. Gen. Physiol. 113: 909-918.

Speth C, Jaspert N, Marcon C, Oecking C. 2010. Regulation of the plant plasma membrane $\mathrm{H}^{+}$-ATPase by its c-terminal domain: What do we know for sure? European J. Cell Biol. 89: 145-151.

Stahlberg R, Van Volkenburgh E. 1999. The effect of light on membrane potential, apoplastic $\mathrm{pH}$ and cell expansion in leaves of Pisum sativum L. var. Argenteum. - role of the plasma-membrane $\mathrm{H}^{+}$-ATPase and photosynthesis. Planta 208: 188-195.

Steudle E. 2000. Water uptake by roots: Effects of water deficit. J. Exp. Bot. 51: 1531-1542.

Stiles K, McClintick A, Volkenburgh E. 2003. A developmental gradient in the mechanism of $\mathrm{K}^{+}$uptake during light-stimulated leaf growth in Nicotiana tabacum L. Planta 217: 587-596.

Stiles KA, Van Volkenburgh E 2004. Role of $\mathrm{K}^{+}$in leaf growth: $\mathrm{K}^{+}$uptake is required for light-stimulated $\mathrm{H}^{+}$efflux but not solute accumulation. Plant, Cell Environ. 27: 315-325.

Stoddart JL, Lloyd EJ. 1986. Modification by gibberellin of the growth-temperature relationship in mutant and normal genotypes of several cereals. Planta 167: 364-368.

Szczerba MW, Britto DT, Kronzucker HJ. 2006. Rapid, futile $\mathrm{K}^{+}$cycling and poolsize dynamics define low-affinity potassium transport in barley. Plant Physiol. 141: 1494-1507.

Szczerba MW, Britto DT, Kronzucker HJ. 2009. $\mathrm{K}^{+}$transport in plants: Physiology and molecular biology. J. Plant Physiol. 166: 447-466.

Sze H, Li X, Palmgren MG. 1999. Energization of plant cell membranes by $\mathrm{H}_{+-}$ pumping ATPases: Regulation and biosynthesis. Plant Cell 11: 677-690. 
Tang AC, Boyer JS. 2008. Xylem tension affects growth-induced water potential and daily elongation of maize leaves. J. Exp. Bot. 59: 753-764.

Tang C, Drevon JJ, Jaillard B, Souche G, Hinsinger P. 2004. Proton release of two genotypes of bean (Phaseolus vulgaris L.) as affected by $N$ nutrition and $P$ deficiency. Plant Soil 260: 59-68.

Taylor G, Davies WJ. 1985. The control of leaf growth of betula and acer by photoenvironment. New Phytol. 101: 259-268.

Tode K, Lüthen H. 2001. Fusicoccin- and IAA-induced elongation growth share the same pattern of $\mathrm{K}^{+}$dependence. J. Exp. Bot. 52: 251-255.

Ullrich Cl, Novacky AJ. 1990. Extracellular and intracellular ph and membranepotential changes induced by $\mathrm{K}^{+}, \mathrm{Cl}^{-}, \mathrm{H}_{2} \mathrm{PO}_{4}^{-}$, and $\mathrm{NO}_{3}{ }^{-}$uptake and fusicoccin in root hairs of limnobium-stoloniferum. Plant Physiol. 94: 1561-1567.

Van Volkenburgh E, Boyer JS. 1985. Inhibitory effects of water deficit on maize leaf elongation. Plant Physiol. 77: 190-194.

Van Volkenburgh E, Cleland RE. 1980. Proton excretion and cell expansion in bean Phaseolus vulgaris leaves. Planta 148: 273-278.

Vera-Estrella R, Barkla BJ, Higgins VJ, Blumwald E. 1994. Plant defense response to fungal pathogens (activation of host-plasma membrane $\mathrm{H}^{+}$ATPase by elicitor-induced enzyme dephosphorylation). Plant Physiol. 104: 209-215.

Vesper MJ, Evans ML. 1979. Nonhormonal induction of $\mathrm{H}^{+}$efflux from plant tissues and its correlation with growth. PNAS 76: 6366-6370.

Villalba JM, Lützelschwab M, Serrano R. 1991. Immunocytolocalization of plasmamembrane $\mathrm{H}^{+}$-ATPase in maize coleoptiles and enclosed leaves. Planta 185: 458-461.

Vogelstein B, Kinzler KW. 1999. Digital PCR. PNAS 96: 9236-9241.

Volkov V, Boscari A, Clément M, Miller AJ, Amtmann A, Fricke W. 2009. Electrophysiological characterization of pathways for $\mathrm{K}^{+}$uptake into growing and non-growing leaf cells of barley. Plant, Cell Environ. 32: 1778-1790.

Volkov V, Hachez C, Moshelion M, Draye X, Chaumont F, Fricke W. 2007. Water permeability differs between growing and non-growing barley leaf tissues. .J. Exp. Bot. 58: 377-390.

Vysotskaya LB, Arkhipova TN, Timergalina LN, Veselov SY, Dedov AV, Kudoyarova GR. 2003. Effect of partial root excision on shoot water relations. J. Plant Physiol. 160: 1011-1015.

Wakeel A, Hanstein S, Pitann B, Schubert S. 2010. Hydrolytic and pumping activity of $\mathrm{H}+-$ ATPase from leaves of sugar beet (Beta vulgaris L.) as affected by salt stress. J. Plant Physiol. 167: 725-731.

Wei WX, Alexandersson E, Golldack D, Miller AJ, Kjellborn PO, Fricke W. 2007. HvPIP1;6, a barley (Hordeum vulgare L.) plasma membrane water channel particularly expressed in growing compared with non-growing leaf tissues. Plant Cell Physiol. 48: 1132-1147.

Wieczorek H, Putzenlechner M, Zeiske W, Klein U. 1991. A vacuolar-type proton pump energizes $\mathrm{K}^{+} / \mathrm{H}^{+}$antiport in an animal plasma-membrane. J. Biol. Chem. 266: 15340-15347.

Würtele M, Jelich-Ottmann C, Wittinghofer A, Oecking C. 2003. Structural view of a fungal toxin acting on a 14-3-3 regulatory complex. EMBO J. 22: 987-994. 
Yan F, Feuerle R, Schaffer S, Fortmeier H, Schubert S. 1998. Adaptation of active proton pumping and plasmalemma ATPase activity of corn roots to low root medium pH. Plant Physiol. 117: 311-319.

Yan F, Zhu Y, Muller C, Zorb C, Schubert S. 2002. Adaptation of $\mathrm{H}^{+}$-pumping and plasma membrane $\mathrm{H}^{+}$ATPase activity in proteoid roots of white lupin under phosphate deficiency. Plant Physiol. 129: 50-63.

Zhu Y, Tingjun DI, Guohua XU, Xi C, Houqing Z, Feng YAN, Qirong S. 2009. Adaptation of plasma membrane $\mathrm{H}^{+}$-ATPase of rice roots to low $\mathrm{pH}$ as related to ammonium nutrition. Plant, Cell Environ. 32: 1428-1440.

Zoccarato F, Cavallini L, Alexandre A. 1999. The pH-sensitive dye acridine orange as a tool to monitorexocytosis/endocytosis in synaptosomes. J. Neurochem. 72: 625-633.

Zörb C, Stracke B, Tramnitz B, Denter D, Sümer A, Mühling KH, Yan F, Schubert S. 2005. Does $\mathrm{H}^{+}$pumping by plasmalemma ATPase limit leaf growth of maize Zea mays during the first phase of salt stress? J. Plant Nutr. Soil Sci. 168: 550-557. 


\section{$7 \quad$ Appendix}

\subsection{Processing of $q P C R$ data}

(i) Total cell volume was considered to equal the total water content of plant tissue (neglecting any water in intercellular space). The water content was calculated from the fresh weight of the samples:

$$
\begin{aligned}
m_{w} & =m_{F W} \cdot w_{\%}[\mathrm{~g}] \\
V_{\text {cell }} & =m_{w} \cdot 10^{12}\left[\mu \mathrm{m}^{3}\right]
\end{aligned}
$$

where: $m_{w}$ : amount of water in the tissue $(\mathrm{g}) ; m_{F W}$ : fresh weight of tissue $(\mathrm{g})$ and $w_{\%}$ : percentage water content of the tissue, $100 \cdot\left(\frac{m_{F W}-m_{D W}}{m_{F W}}\right) ; m_{D W}$, dry weight); $V_{\text {cell }}$ : total cell volume $\left(\mu \mathrm{m}^{3}\right)$.

(ii) From water content, from the proportion of leaf volume occupied by epidermis (0.26) and mesophyll (0.646) and from the cell sizes $\left(99,372 \mu \mathrm{m}^{3}\right.$ for epidermis cells in elongation zone; $461,552 \mu \mathrm{m}^{3}$ for epidermis cells in emerged blade; $6,620 \mu \mathrm{m}^{3}$ for mesophyll cells in elongation zone and 14,830 for mesophyll cells in emerged leaf blade) the number of epidermal cells, mesophyll cells and total number of the cells were calculated:

Elongation zone:

$$
N_{\text {Epcell }}=\frac{V_{\text {cell }} \cdot 0.260}{99,372} ; N_{\text {Mcell }}=\frac{V_{\text {cell }} \cdot 0.646}{6,620} \text { [piece] }
$$

Emerged Blade:

$$
N_{\text {Epcell }}=\frac{V_{\text {cell }} 0.296}{461,552} ; N_{\text {Mcell }}=\frac{V_{\text {cell }} 0.653}{14,830} \text { [piece] }
$$

Total cell number:

$$
N_{\text {cell }}=N_{\text {Epcell }}+N_{\text {Mcell }} \text { [piece] }
$$

where: $N_{\text {Epcell: }}$ number of epidermal cells; $N_{\text {Mcell }}$ : number of mesophyll cells and $N_{\text {cell }}$ : total cell number.

(iii) Plasma membrane surface was calculated as:

$$
\begin{array}{ll}
\text { Elongation zone: } & A=N_{\text {Epcell }} \cdot 19,704+N_{\text {Mcell }} \cdot 1,632\left[\mu \mathrm{m}^{2}\right] \\
\text { Emerge blade: } & A=N_{\text {Epcell }} \cdot 50,004+N_{\text {Mcell }} \cdot 2,855\left[\mu \mathrm{m}^{2}\right]
\end{array}
$$

where: $A$ : plasma membrane surface of the sample $\left(\mu \mathrm{m}^{2}\right)$. 
(iv) Calculation of the PM- $\mathrm{H}^{+}$-ATPase copy number in the sample was carried out with the help of calibration curve using $\mathrm{PM}-\mathrm{H}^{+}$-ATPase DNA standard. This calibration curve was different for each qPCR measurement. An example of this calculation may be found in Fig. 7.1.

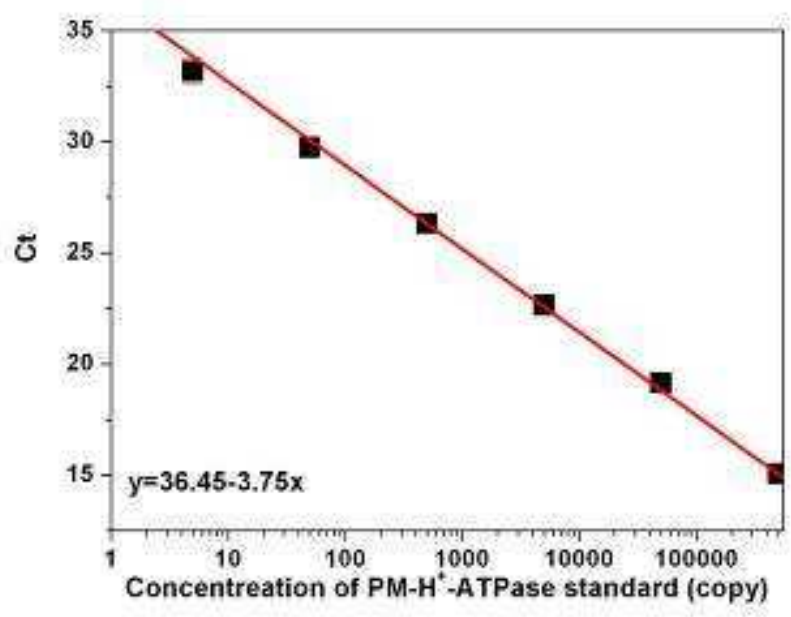

Figure 7.1 Typical calibration curve for converting Ct values into transcript copy number

For calibration three replicates were used and $r^{2}$ of the fitted line was always higher than 0.98 .

From the calibration curve $\mathrm{Ct}$ values were converted into copy number of $\mathrm{PM}-\mathrm{H}^{+}$ATPase transcript. For example, using the above calibration curve resulted in the following:

$$
N_{P M-H^{+}-\text {ATPase }}=10^{\frac{36.45-\overline{C_{t}}}{3.75}} \text { [copy] }
$$

where: $N_{P M-H^{+}-A T P a s e}$ : copy number of PM- $\mathrm{H}^{+}$-ATPase in the PCR sample (typically $250 \mathrm{pg}) ; \overline{C t}$ : average $\mathrm{Ct}$ values of 3 technical replicates.

(v) From the copy number of PCR reaction the total copy number in $1 \mu \mathrm{g}$ RNA could easily be calculated through multiplying the results with respective dilution factors; these were typically 4,000 using $250 \mathrm{pg}$ template in each reaction:

$$
N_{\text {copy } 1 \mu \mathrm{g}}=N_{P M-H^{+}-\text {ATPase }} \cdot 4,000 \text { [copy] }
$$

where: $N_{\text {copyl } 1 \mu g}$ is the PM- $\mathrm{H}^{+}$-ATPase copy number in $1 \mu \mathrm{g}$ RNA 
(vi) The copy number of transcript in $1 \mu \mathrm{g}$ RNA could then be multiplied by the total RNA content of the leaf sample used for extraction of RNA:

$$
N_{\text {totalcopy }}=N_{\text {copy } 1 \mu \mathrm{g}} \cdot m_{R N A}[\mathrm{copy}]
$$

where: $N_{\text {totalcopy }}$ : the total PM- $\mathrm{H}^{+}$-ATPase mRNA copy in the sample; $m_{R N A}$ is amount of total RNA $(\mu \mathrm{g})$ in the sample.

(vii) Finally, this total copy number of $\mathrm{PM}-\mathrm{H}^{+}$-ATPase transcripts could then be realted to the total number of cells or the total plasma membrane surface area in the leaf sample:

$$
\begin{gathered}
c_{\text {copy.cell }}=\frac{N_{\text {totalcopy }}}{N_{\text {cell }}} \text { [copy cell }{ }^{-1} \text { ] } \\
c_{\text {copy } \cdot A^{-1}}=\frac{N_{\text {totalcopy }}}{A} \cdot 10^{6} \text { [copy } \mathrm{mm}^{-2} \text { ] }
\end{gathered}
$$

where: $c_{\text {copy.cell }}$ : PM- $\mathrm{H}^{+}$-ATPase copy number in a single cell; $c_{\text {copy } \cdot A^{-1}}: \mathrm{PM}-\mathrm{H}^{+}-\mathrm{ATPase}$ copy number in $1 \mathrm{~mm}^{2}$ plasma membrane.

Example for these calculations can be found on Table 7.1 for Golf and Table 7.2 for Jersey barley cultivar. 
Table 7.1 Example for qPCR calculation of Golf cultivar. S1 - 3 label different batches

\begin{tabular}{|c|c|c|c|c|c|c|}
\hline & \multicolumn{3}{|c|}{ Elongation zone } & \multicolumn{3}{|c|}{ Emerged blade } \\
\hline & S1 & $\mathbf{S 2}$ & S3 & S1 & S2 & S3 \\
\hline Fresh weight (mg) & 56.6 & 57.7 & 50.0 & 53.5 & 50.7 & 48.7 \\
\hline Water content (mg) & 52.1 & 51.3 & 46.0 & 46.4 & 44.0 & 42.3 \\
\hline Number of epidermis cells $\left(\times 10^{4}\right)$ & 13.6 & 13.4 & 12.0 & 2.98 & 2.82 & 2.71 \\
\hline Number of mesophyll cells $\left(\times 10^{6}\right)$ & 5.08 & 5.00 & 4.49 & 2.04 & 1.94 & 1.86 \\
\hline Total number of cells $\left(\times 10^{6}\right)$ & 5.22 & 5.14 & 4.61 & 2.07 & 1.97 & 1.87 \\
\hline $\begin{array}{l}\text { Total membrane surface of } \\
\text { epidermis cells }\left(\mathrm{mm}^{2} \times 10^{3}\right)\end{array}$ & 2.69 & 2.64 & 2.37 & 1.49 & 1.41 & 1.36 \\
\hline $\begin{array}{l}\text { Total membrane surface of } \\
\text { mesophyll cells }\left(\mathrm{mm}^{2} \times 10^{3}\right)\end{array}$ & 8.30 & 8.17 & 7.33 & 5.84 & 5.53 & 5.31 \\
\hline $\begin{array}{l}\text { Total membrane surface of the } \\
\text { sample }\left(\mathrm{mm}^{2} \times 10^{3}\right)\end{array}$ & 10.9 & 10.8 & 9.70 & 7.32 & 6.94 & 6.67 \\
\hline Total RNA in the sample $(\mu \mathrm{g})$ & 123 & 106 & 105 & 61.3 & 51.9 & 40.9 \\
\hline $\begin{array}{l}\text { PM- } H^{+} \text {-ATPase copy in } 1 \mu \mathrm{g} \text { RNA } \\
\left(\times 10^{6}\right)\end{array}$ & 14.8 & 11.5 & 13.7 & 9.91 & 6.63 & 14.1 \\
\hline $\begin{array}{l}\text { PM- } \mathrm{H}^{+}-\text {ATPase copy in the } \\
\text { sample }\left(\times 10^{9}\right)\end{array}$ & 1.83 & 1.21 & 1.43 & 0.607 & 0.344 & 0.577 \\
\hline PM-H ${ }^{+}$-ATPase copy in a cell & 350 & 236 & 312 & 293 & 175 & 306 \\
\hline 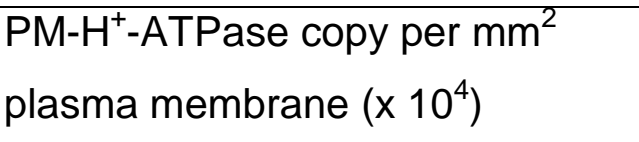 & 166 & 112 & 148 & 83.0 & 49.6 & 86.6 \\
\hline
\end{tabular}


Table 7.2 Example for qPCR calculation of Jersey cultivar. S1 - 3 label different batches

\begin{tabular}{|c|c|c|c|c|c|c|}
\hline & \multicolumn{3}{|c|}{ Elongation zone } & \multicolumn{3}{|c|}{ Emerged blade } \\
\hline & S1 & $\mathbf{S 2}$ & S3 & S1 & S2 & S3 \\
\hline Fresh weight (mg) & 69.2 & 57.6 & 58.7 & 77.1 & 74.9 & 62.2 \\
\hline Water content $(\mathrm{mg})$ & 64.9 & 54.0 & 55.1 & 68.5 & 66.5 & 55.2 \\
\hline Number of epidermis cells $\left(\times 10^{4}\right)$ & 17.0 & 14.1 & 14.4 & 4.39 & 4.27 & 3.54 \\
\hline Number of mesophyll cells $\left(\times 10^{6}\right)$ & 6.33 & 5.27 & 5.37 & 3.01 & 2.93 & 2.43 \\
\hline Total number of cells $\left(\times 10^{6}\right)$ & 6.50 & 5.41 & 5.52 & 3.06 & 2.97 & 2.47 \\
\hline $\begin{array}{l}\text { Total membrane surface of } \\
\text { epidermis cells }\left(\mathrm{mm}^{2} \times 10^{3}\right)\end{array}$ & 3.35 & 2.79 & 2.84 & 2.20 & 2.13 & 1.77 \\
\hline $\begin{array}{l}\text { Total membrane surface of } \\
\text { mesophyll cells }\left(\mathrm{mm}^{2} \times 10^{3}\right)\end{array}$ & 10.3 & 8.60 & 8.77 & 8.61 & 8.36 & 6.94 \\
\hline $\begin{array}{l}\text { Total membrane surface of the } \\
\text { sample }\left(\mathrm{mm}^{2} \times 10^{3}\right)\end{array}$ & 13.7 & 11.4 & 11.6 & 10.8 & 10.5 & 8.71 \\
\hline Total RNA in the sample $(\mu \mathrm{g})$ & 161 & 119 & 121 & 24.7 & 108 & 26.8 \\
\hline $\begin{array}{l}\text { PM- }{ }^{+} \text {-ATPase copy in } 1 \mu \mathrm{g} \text { RNA } \\
\left(\times 10^{6}\right)\end{array}$ & 5.90 & 4.76 & 4.45 & 4.52 & 4.13 & 5.56 \\
\hline $\begin{array}{l}\text { PM- } \mathrm{H}^{+} \text {-ATPase copy in the } \\
\text { sample }\left(\times 10^{9}\right)\end{array}$ & 9.49 & 5.65 & 5.34 & 1.11 & 4.47 & 1.49 \\
\hline PM-H ${ }^{+}$-ATPase copy in a cell & 146 & 104 & 97 & 36 & 150 & 60 \\
\hline $\begin{array}{l}\text { PM- } \mathrm{H}^{+} \text {-ATPase copy per } \mathrm{mm}^{2} \\
\text { plasma membrane }\left(\times 10^{4}\right)\end{array}$ & 6.94 & 4.97 & 4.60 & 1.03 & 4.26 & 1.71 \\
\hline
\end{tabular}


Table 7.3 Example for qPCR calculation of Jersey protoplasts. S1 - 3 label different batches

\begin{tabular}{|c|c|c|c|c|c|c|}
\hline & \multicolumn{3}{|c|}{ Elongation zone } & \multicolumn{3}{|c|}{ Emerged blade } \\
\hline & S1 & S2 & S3 & S1 & S2 & S3 \\
\hline Protoplast No $\left(\times 10^{6}\right)$ & 5.13 & 5.05 & 5.51 & 5.57 & 3.84 & 7.85 \\
\hline Surface $\left(\mathrm{mm}^{2} \times 10^{10}\right)$ & 8.37 & 8.24 & 9.00 & 1.59 & 1.10 & 2.24 \\
\hline Total RNA( $\square \mathrm{g})$ & 26.5 & 28.2 & 37.9 & 31.6 & 29.2 & 65.3 \\
\hline $\begin{array}{l}\text { PM- } H^{+} \text {-ATPase copy in } 1 \mu \mathrm{g} \text { RNA } \\
\left(\times 10^{6}\right)\end{array}$ & 5.34 & 3.95 & 7.02 & 3.09 & 2.06 & 5.60 \\
\hline $\begin{array}{l}\text { PM- } H^{+} \text {-ATPase copy in the } \\
\text { sample } \\
\left(\times 10^{7}\right)\end{array}$ & 14.1 & 11.1 & 26.6 & 9.75 & 6.00 & 36.6 \\
\hline PM-H $\mathrm{H}^{+}$-ATPase copy in a cell & 27.6 & 22.0 & 48.3 & 17.5 & 15.6 & 46.6 \\
\hline $\begin{array}{l}\text { PM- }{ }^{+} \text {-ATPase copy in } 1 \mathrm{~mm}^{2} \\
\text { plasma membrane }\left(\times 10^{4}\right)\end{array}$ & 1.69 & 1.35 & 2.96 & 0.613 & 0.548 & 1.63 \\
\hline
\end{tabular}




\subsection{List of chemicals}

$\left(\mathrm{NH}_{4}\right)_{2} \mathrm{HPO}_{4}$

M\&B

5(6)carboxyfluorescein

Sigma

Acetic acid

Reanal, BDH

Acridine orange

$\mathrm{BDH}$

Acylamide $\left(\mathrm{C}_{3} \mathrm{H}_{5} \mathrm{NO}\right)$

Sigma-Aldrich

Agarose

Bioline

Ammonium molibdate

$M \& B$

APS (ammonium persulfate; $\left(\mathrm{NH}_{4}\right)_{2} \mathrm{~S}_{2} \mathrm{O}_{8}$ )

Sigma-Aldrich

APTES (3-aminopropyltriethoxysilane)

Sigma-Aldrich

Ascorbic acid

Szkarabeusz

ATP (adenosine 5'-triphosphate disodium salt hydrate)

Sigma

Bis acrylamide (N,N'-methylenebis(acrylamide), $\mathrm{C}_{7} \mathrm{H}_{10} \mathrm{~N}_{2} \mathrm{O}_{2}$ ) Sigma

BIS-TRIS propane $\left(\mathrm{CH}_{2}\left[\mathrm{CH}_{2} \mathrm{NHC}\left(\mathrm{CH}_{2} \mathrm{OH}\right)_{3}\right]_{2}\right)$

Sigma

Boric acid

$\mathrm{BDH}$

$\mathrm{Brij}^{\mathrm{TM}} 58$

Sigma

Bromocresol purple

DIFCO

Bromophenol blue $\left(\mathrm{C}_{19} \mathrm{H}_{10} \mathrm{Br}_{4} \mathrm{O}_{5} \mathrm{~S}\right)$

Reanal

BSA (bovine serum albumin fraction $\mathrm{V}$ )

Sigma-Aldrich

$\mathrm{Ca}\left(\mathrm{NO}_{3}\right)_{2} \times 4 \mathrm{H}_{2} \mathrm{O}$

Reanal, BDH

$\mathrm{CaCl}_{2}$

Reanal, BDH

$\mathrm{CaSO}_{4}$

$\mathrm{BDH}$

Cellulase

Worthington

Coomassie brilliant blue R-250 $\left(\mathrm{C}_{45} \mathrm{H}_{44} \mathrm{~N}_{3} \mathrm{NaO}_{7} \mathrm{~S}_{2}\right)$

Reanal

$\mathrm{CsCl}$

Gibco BLR

$\mathrm{CuSO}_{4} \times 5 \mathrm{H}_{2} \mathrm{O}$

$\mathrm{BDH}$

Dextran T-500

Sigma-Aldrich

Driselase

Sigma

DTT (dithiothreitol, $\mathrm{C}_{4} \mathrm{H}_{10} \mathrm{O}_{2} \mathrm{~S}_{2}$ )

Sigma, Fluka

EDTA

Reanal, BDH

Entellan ${ }^{\circledR}$

Merck

Ethanol

Merck

Ethidium bromide

Sigma

Fe ${ }^{\text {IIINaEDTA }}$

$\mathrm{BDH}$

Formalin

$\mathrm{BDH}$ 
Fusicoccin

Glycerol

Glycine

$\mathrm{H}_{2} \mathrm{SO}_{4}$

$\mathrm{H}_{3} \mathrm{BO}_{3}$

$\mathrm{HCl}$

HEPES $\left(\mathrm{C}_{8} \mathrm{H}_{18} \mathrm{~N}_{2} \mathrm{O}_{4} \mathrm{~S}\right)$

Hydrogen lonophore II Cocktail A

$\mathrm{K}_{2} \mathrm{HPO}_{4}$

$\mathrm{KCl}$

$\mathrm{KH}_{2} \mathrm{PO}_{4}$

$\mathrm{KNO}_{3}$

$\mathrm{KOH}$

MES (2-[N-morpholino]ethanesulfonic acid, $\mathrm{C}_{6} \mathrm{H}_{13} \mathrm{NO}_{4} \mathrm{~S}$ )

Methanol

$\mathrm{MgSO}_{4} \times 7 \mathrm{H}_{2} \mathrm{O}$

$\mathrm{MnSO}_{4} \times \mathrm{H}_{2} \mathrm{O}$

MOPS (3-[N-morpholino]propanesulfonic acid, $\mathrm{C}_{7} \mathrm{H}_{15} \mathrm{NO}_{4} \mathrm{~S}$ )

$\mathrm{Na}_{2} \mathrm{HPO}_{4} \times 2 \mathrm{H}_{2} \mathrm{O}$

$\mathrm{Na}_{2} \mathrm{MoO}_{4} \times 2 \mathrm{H}_{2} \mathrm{O}$

$\mathrm{Na}_{3} \mathrm{VO}_{4}$

NAA (1-naphthaleneacetic acid, $\mathrm{C}_{12} \mathrm{H}_{10} \mathrm{O}_{2}$ )

Na-ascorbate

$\mathrm{NaCl}$

$\mathrm{NaH}_{2} \mathrm{PO}_{4} \times 2 \mathrm{H}_{2} \mathrm{O}$

$\mathrm{NaN}_{3}$

$\mathrm{NaOH}$

Neo-clear ${ }^{\circledR}$

$\mathrm{NH}_{4} \mathrm{H}_{2} \mathrm{PO}_{4}$

Nitrocellulose

Non soluble PVP (polyvinylpyrrolidone)

Paraffin wax

Pectolyase

PEG-3350

Phtalate buffer
Sigma

Reanal, Fluka

Reanal

Molar

$\mathrm{BDH}$

$\mathrm{BDH}$

Sigma

Fluka

Reanal, BDH

Reanal, BDH

Reanal, BDH

Reanal, BDH

Reanal, BDH

Sigma

Reanal, BDH

Reanal, BDH

$\mathrm{BDH}$

Sigma

$\mathrm{BDH}$

$\mathrm{BDH}$

Sigma

Sigma

Fluka

$\mathrm{BDH}$

$\mathrm{BDH}$

Sigma

$\mathrm{BDH}$

Merck

M\&B

Sigma

Serva

$\mathrm{BDH}$

Sigma

Sigma

Sigma 
PMSF (phenylmethylsulfonyl fluoride, $\mathrm{C}_{7} \mathrm{H}_{7} \mathrm{FO}_{2} \mathrm{~S}$ )

Sigma

Potassium antimony (III) oxid tartrate

$\mathrm{BDH}$

Potassium hydrogen phthalate $\left(\mathrm{KHC}_{8} \mathrm{H}_{4} \mathrm{O}_{4}\right)$

Sigma-Aldrich

PVC (high molecular weight polyvinyl chloride)

Fluka

PVP K30 (polyvinylpyrrolidone)

Sigma

SDS (Sodium dodecyl sulfate, $\mathrm{CH}_{3}\left(\mathrm{CH}_{2}\right){ }_{11} \mathrm{OSO}_{3} \mathrm{Na}$ )

Sigma

Sorbitol

Sigma

Sucrose $\left(\mathrm{C}_{12} \mathrm{H}_{22} \mathrm{O}_{11}\right)$

Reanal, Sigma

TAPS (N-tris[Hydroxymethyl]methyl-3-amino-propanesulfonic acis) Sigma

TEMED ( $N, N, N^{\prime}, N^{\prime}$-tetramethylethylenediamine, $\left.\mathrm{C}_{6} \mathrm{H}_{16} \mathrm{~N}_{2}\right) \quad$ Fluka

THF (tetrahydrofuran, $\mathrm{C}_{4} \mathrm{H}_{8} \mathrm{O}$ )

Sigma-Aldrich

Toluidine blue

Sigma

TRIS (tris(hydroxymethyl)aminomethane, $\mathrm{NH}_{2} \mathrm{C}\left(\mathrm{CH}_{2} \mathrm{OH}\right)_{3}$ )

Reanal, |B|

Triton ${ }^{\circledR} \mathrm{X}-100$

Reanal, Sigma

Tween ${ }^{\circledR} 20$

Sigma

$\mathrm{ZnCl}_{2}$

$\mathrm{BDH}$

$\beta$-mercapto ethanol $\left(\mathrm{HSCH}_{2} \mathrm{CH}_{2} \mathrm{OH}\right)$

Sigma

$\alpha$-Naphthaleneacetic acid (NAA)

Sigma 